1.5

If

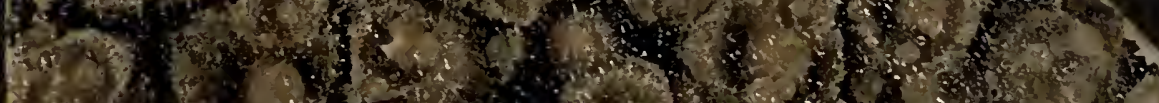

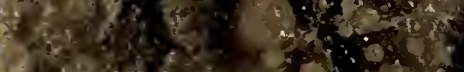

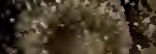

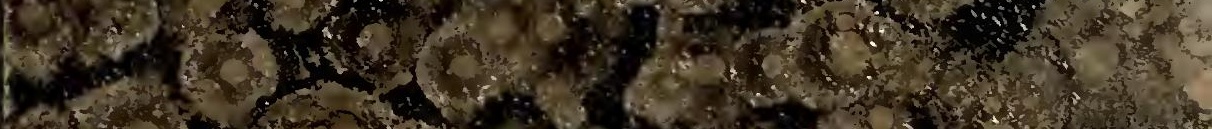

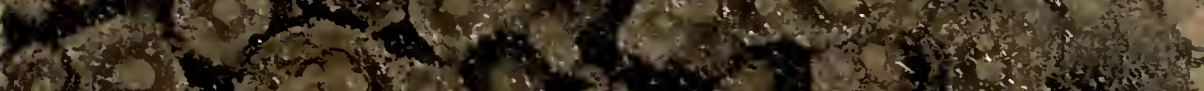

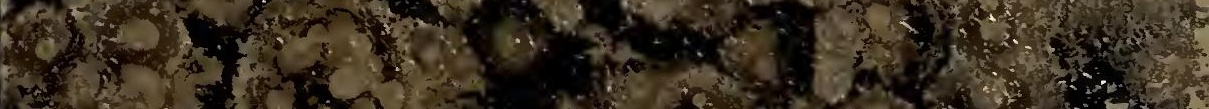

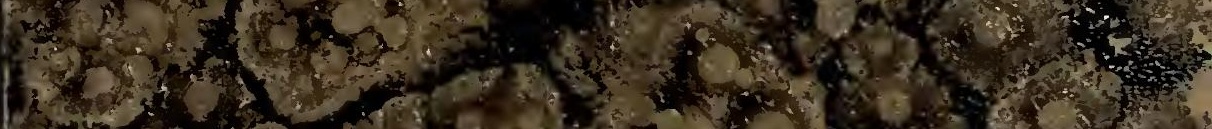

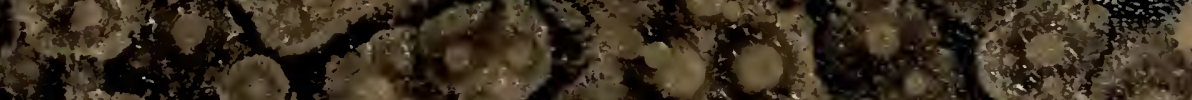

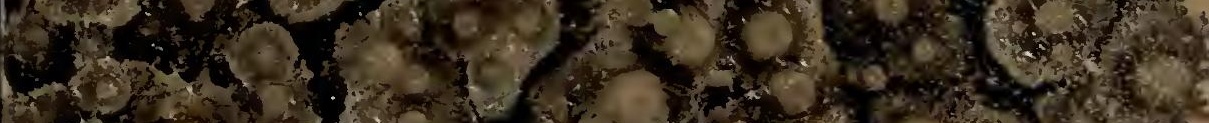

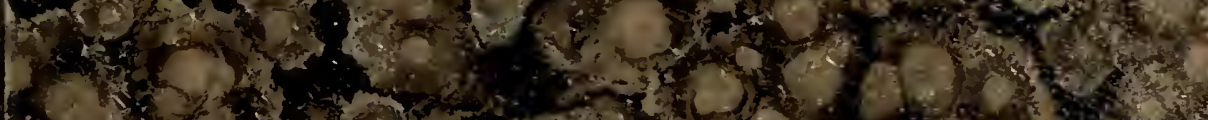

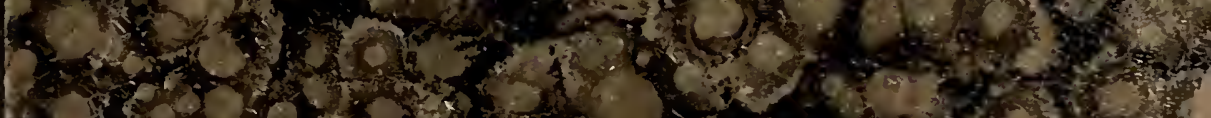

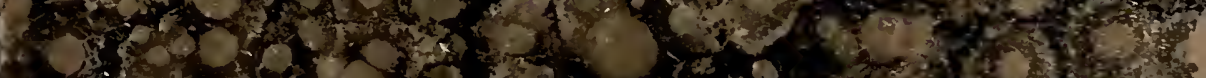

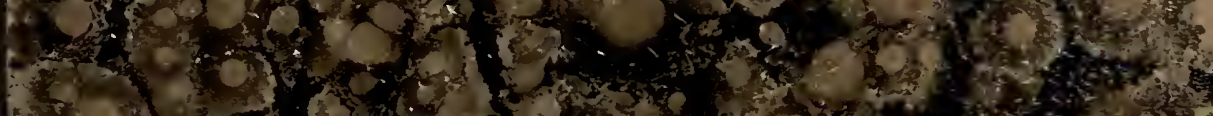

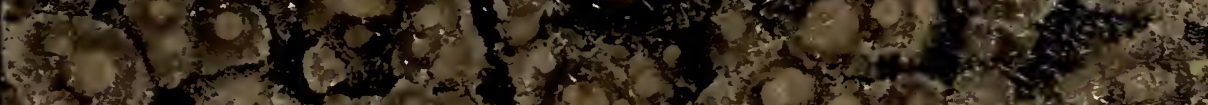
(v)

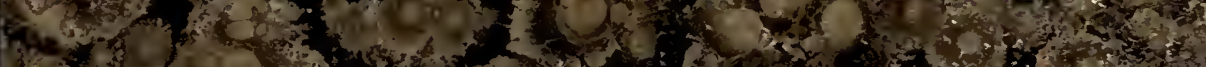

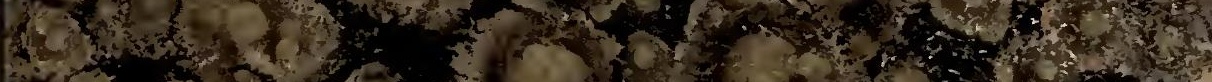

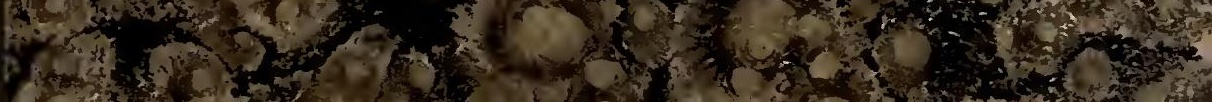

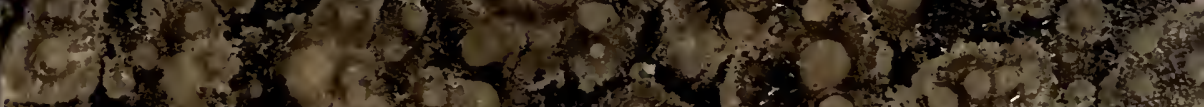

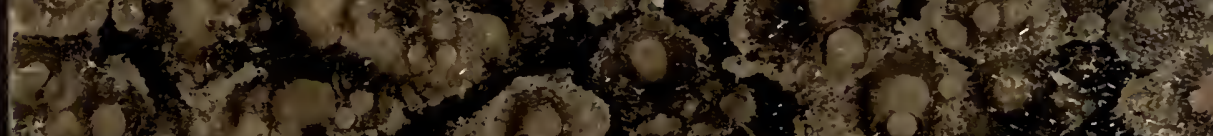

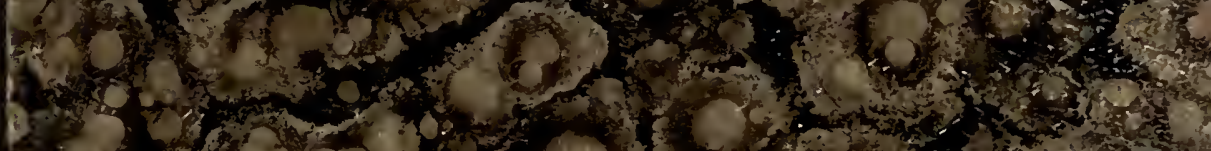

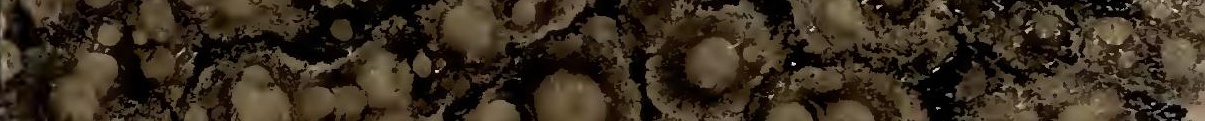

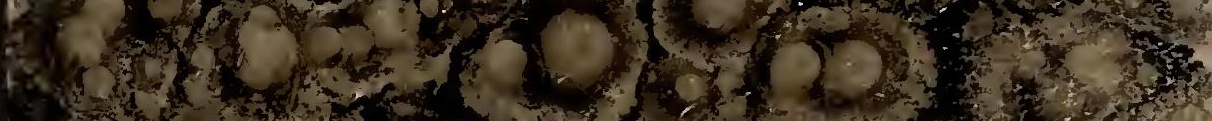

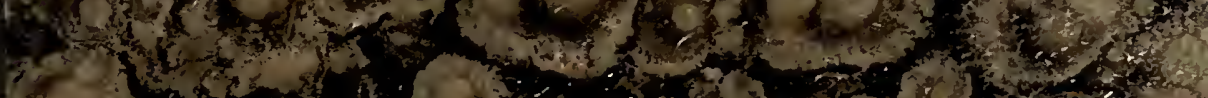

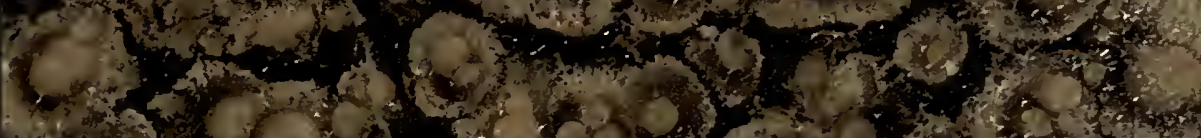

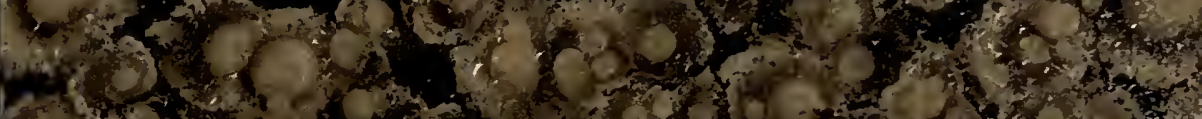

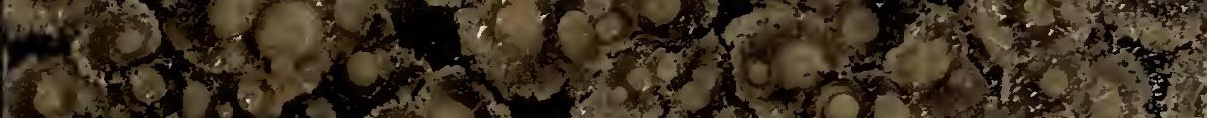

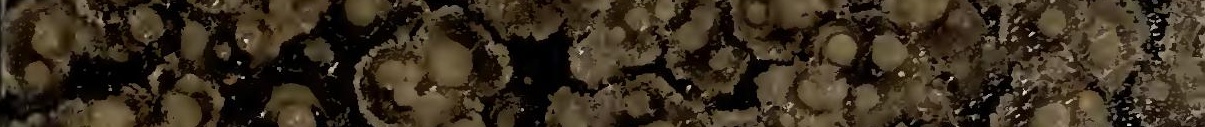

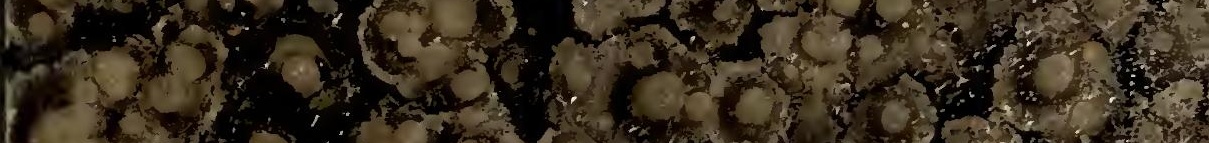

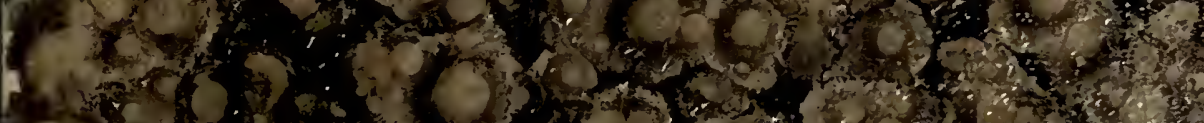

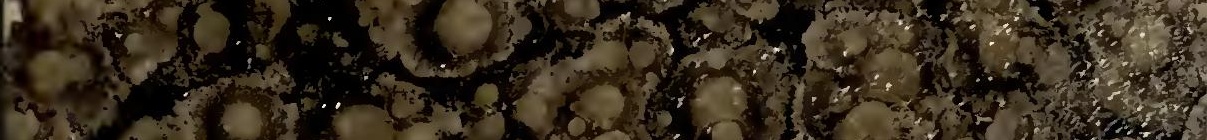

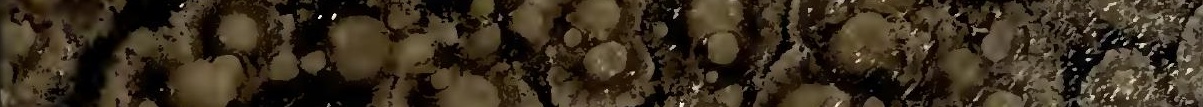

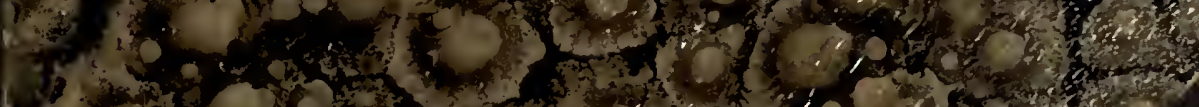

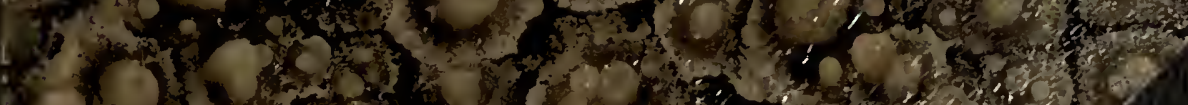
I L H

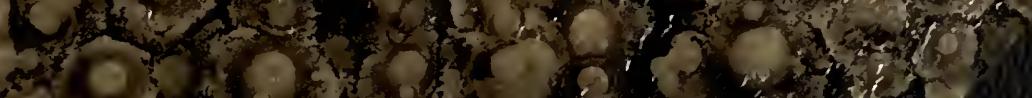


Protozos:

arucar

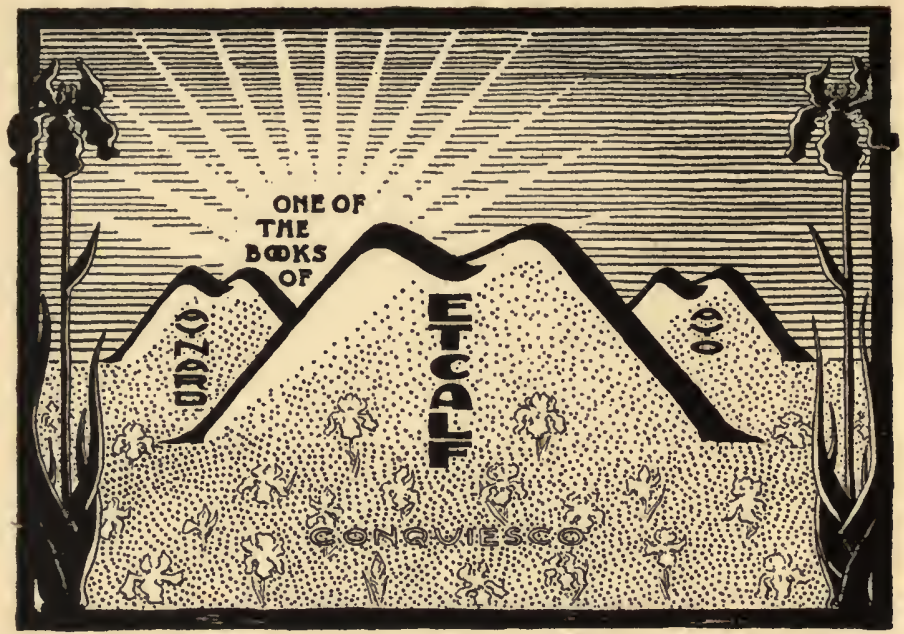




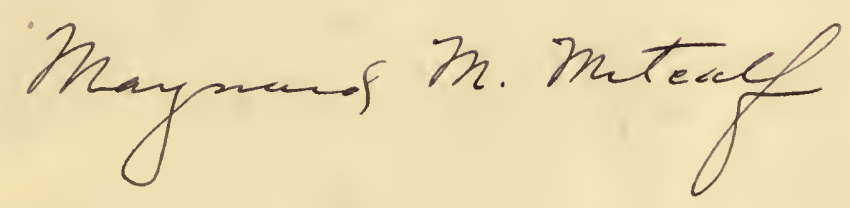

Unuzburg 1907 



\section{B. Eyferth's}

\section{Einfachste Lebensformen des}

Tier- und Pflanzenreiches

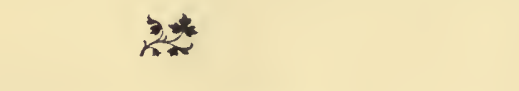

Naturgeschichte

der

mikroskopischen Süsswasșerbewohner

\section{(3)}

Dritte, vollständig neubearbeitete und vermehrte Auflage von

Dr. Walther Schönichen und Dr. Alfred Kalberlah

Mit über 700 Abbildungen auf 16 Tafeln in Lichtdruck

nach Zeichnungen von Dr. A. Kalberlah,

Assistenten am Kgl. bot. Garten zu Halle a. d. S.

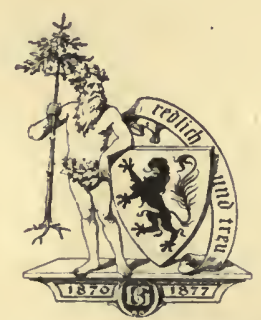

Braunschweig 1900

Verlag von Benno Goeritz. 
Alle Rechte,

auch das der Uebersetzung in fremde Sprachen, vorbehalten.

Gesetz vom I1. Juni 1870 . 


\section{Vorwort.}

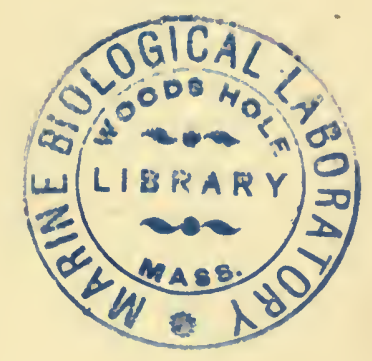

Es war im Jahre 1877 , als im Verlage von Haering ein Büchlein von B. Eyferth erschien unter dem Titel: „Die mikroskopischen Süsswasserbewohner in gedrängter Uebersicht vorgeführt. Mit einer Lichtdrucktafel“. Der überaus günstige Erfolg, den das Werkchen erzielte, ermutigte den Autor bereits im nächsten Jahre (1878) eine Erweiterung seines Buches vorzunehmen. So entstand die erste Auflage des vorliegenden Buches; sie war mit fünf Lichtdrucktafeln ausgestattet und trug den Titel: „Die einfachsten Lebensformen. Systematische Naturgeschichte der mikroskopischen Süsswasserbewohner.“ I 879 erschien hierzu noch ein Supplementheft, das die Schizophyten und Flagellaten behandelte und zwei Tafeln Abbildungen in Lichtdruck enthielt. Beide Werke fanden wiederum eine ausserordentlich wohlwollende Aufnahme, so dass bereits im Jahre 1886 im Verlage von Benno Goeritz in Braunschweig eine zweite Auflage erscheinen konnte. (Die einfachsten Lebensformen des Tier-und Pflanzenreiches. Naturgeschichte der mikroskopischen Süsswasserbewohner bearbeitet von B. Eyferth. Mit 7 Lichtdrucktafeln.) Nachdem auch diese Auflage seit längerer Zeit völlig vergriffen und der Verfasser inzwischen verstorben war, wurde den unterzeichneten Herausgebern im Februar des Jahres 1899 der Auftrag einer Neubearbeitung des Eyferth'schen Werkes zu Teil.

In dem Zeitraume, der seit dem Erscheinen der zweiten Auflage des Eyferth verstrichen ist, ist sowoh1 in ihrem Verhältnis zur Wissenschaft selbst als auch in ihrer Stellung in der wissenschaftlichen Litteratur manches anders geworden. 
Bei den gewaltigen Fortschritten, die gerade die Naturwissenschaften in unserer Zeit $z u$ verzeichnen haben, ist es nur natürlich, dass der Umfang des von Eyferth behandelten Stoffes eine Erweiterung, die angewandte Gliederung eine tiefgreifende Umgestaltung erfahren mussten. Und in der That, es ist seit jener Zeit einerseits eine Fülle von neuen Arten und Gattungen bekannt geworden, während andrerseits durch die Arbeit zahlreicher hervorragender Forscher der Stoff von neuen Gesichtspunkten aus beleuchtet wurde, so dass die Systematik der behandelten Mikroorganismen heute vielfach ein gänzlich verändertes Gepräge zeigt. Diesen Fortschritten haben die Herausgeber der vorliegenden dritten Auflage Rechnung zu tragen' versucht. Gute Floren und Faunen, sowie vortreffliche Monographien haben bei dieser Arbeit eine wertvolle Hülfe geleistet; es sei hier nur hingewiesen auf die unübertroffenen floristischen Forschungen von Hansgirg und O. Kirchner in Böhmen und Schlesien, auf Weber's Rädertier-Fauna des Genfer Sees, auf Bütschli's Bearbeitung der Protozoen, auf die Klebs'schen Flagellaten-Studien. Daneben hat jedoch auch die übrige wissenschaftliche Litteratur volle Berücksichtigung gefunden; überall wurde der Anschluss an die neuesten wissenschaftlichen Ergebnisse angestrebt. So hat sich die Aufnahme einer grossen Anzahl neuer Spezies in das Buch notwendig gemacht. Auf die Aufführung aller bekannten Arten wurde verzichtet, da sonst der Umfang desWerkes ins.Ungemessene gewachsen wäre, während die Gattungen fast sämtlich aufgenommen wurden. Unsichere Gattungen und Arten sind in der Mehrzahl der Fälle einfach gestrichen worden; nur einige wenige wurden beibehalten. Es sind dies meist solche, deren Zugehörigkeit zu dem Entwicklungskreise anderer Formen zwar vermutet wird, aber hier und da noch nicht sicher nachgewiesen wurde. Durch die Beibehaltung derartiger Spezies wird dem Benutzer unseres Buches jedenfalls die Ben ennung des von ihm untersuchten Naturobjektes ermöglicht; wir glauben daher in dieser Frage den richtigen Weg eingeschlagen $\mathrm{zu}$ haben, zumal ein Hinweis auf die systematische Stellung der zweifelhaften Form wohl niemals unterlassen ist. Drei bis vier Spezies, die Eyferth selbst aufgestellt hat, wurden ausschliesslich aus Gründen der Pietät für diese Auflage noch festgehalten.

Die Beschreibung der Gattungs- und Artcharaktere, die in der zweiten Auflage oft so kurz und unzulänglich war, dass ein 
sicheres Bestimmen unmöglich wurde, ist von uns mit Vorliebe den Originalen z. T. wörtlich entnommen, wenigstens aber in Anlehnung an gute Floren, Faunen und Monographien gegeben worden. Nur bei den Rädertieren konnte eine Anzahl von Artbeschreibungen aus der zweiten Auflage einfach übernommen werden. Es schien uns dies um so eher statthaft, als ja dem Verfasser der früheren Auflagen, obwohl er auf den von ihm bearbeiteten Gebieten Autodidakt war, eine so bedeutende Artkenntnis aus der Praxis zur Seite stand.

Die Nomenklatur im pflanzlichen Teile lehnt sich meist an Engler-Prantls „Natürliche Pflanzenfamilien“ an. Die neuesten Aenderungen nach $\mathrm{O}$. Kuntze sind in den Text nicht mit aufgenommen worden; doch wurden sie wenigstens im Register berücksichtigt.

Von den Bakterien sind vor allem solche Arten aufgeführt worden, die sich direkt ohne umständliche Kultur bestimmen lassen, z. B. die Winogradski'schen Schwefelbakterien, sofern diese überhaupt reine Arten sind. Von Formen, die nur durch Kultur bestimmbar sind, haben namentlich solche, die allgemeines Interesse erwecken, Aufnahme gefunden.

Die Bearbeitung der Pilze musste sich auf einen kurzen Ueberblick beschränken, da der dem Buche gesteckte Raum ohnehin bei weitem überschritten ist, und anscheinend auch das Interesse weiterer Kreise sich mehr den Algen als den Pilzen zuwendet.

Vor allem wurde bei unserer Neubearbeitung darnach gestrebt, das Bestimmen zu vereinfachen und $z u$ erleichtern. Von diesem Gesichtspunkte aus haben wir die Mühe nicht gescheut, für Familien, Gattungen, Arten und Varietäten dichotomische Bestimmungstabellen anzulegen, die, wie wir hoffen, die Brauchbarkeit des Buches wesentlich erhöhen werden. Diejenigen Charaktere, die in diesen Tabellen bereits benutzt wurden, sind aus Raumrücksichten' bei der Artdiagnose fortgelassen. Als Unterscheidungsmerkmale sind in den Bestimmungstabellen nach Möglichkeit ganz äusserliche, auch für den Laien leicht auffindbare Charaktere benutzt worden.

Bei einigen wenigen Formen, die wegen ihrer Durchsichtigkeit oder aus anderen Gründen eine besondere Aufmerksamkeit der Mikroskopiker beanspruchen können, wurde die Artbeschreibung etwas weiter ausgedehnt. Ueberhaupt ist AllgemeinInteressantes nach Möglichkeit mit eingeflochten worden. 
Was die Litteratur anlangt, so sind des beschränkten Raumes wegen nur die Hauptwerke angeführt worden, in denen man ja meistens die Einzelabhandlungen verzeichnet findet.

Zur raschen Orientierung über die im Texte beschriebenen Arten wurde ein ausführliches Register angefügt, in das auch die Hinweise auf die Abbildungen aufgenommen sind.

Auch in der Anordnung der einzelnen Organismengruppen unterscheidet sich die neue Auflage von ihrer Vorgängerin. Namentlich bei den Pflanzen war die Eyferth'sche Anordnung nicht mehr ganz wissenschaftlich. Wir haben im Pflanzen- wie im Tierreiche konsequent eine vom Niedern zum Höheren aufsteigende Ordnung durchgeführt.

Schliesslich sind auch die Abbildungen völlig erneuert und erheblich vermehrt worden. Zwar waren die von Eyferth entworfenen Bilder zum grössten Teile richtig und gut; doch war die Wiedergabe seiner Bleistiftskizzen nicht besonders glücklich und liess feinere Details zu sehr verschwinden. Die von der Firma Gebr. Plettner, Halle ausgeführten Lichtdrucktafeln sind erheblich schöner und klarer ausgefallen. Dargestellt finden sich fast sämtliche im Texte aufgeführte Gattungen, nur in wenigen Fällen wurden einige Genera familienweise zusammengezogen. Dabei war der Zeichner bestrebt, wenn möglich Habitusbilder $\mathrm{zu}$ geben und gleichzeitig Fortpflanzungsgeschichtliches und Biologisches in der Zeichnung darzustellen. Eine grọsssere Anzahl der Abbildungen sind Originale, die übrigen sind den besten Vorlagen nachgezeichnet.

Die Herausgabe des pflanzlichen Teiles sowie die Zeichnung sämtlicher Tafeln übernahm Dr. Kalberlah, die einleitenden Abschnitte und den tierischen Teil behandelte Dr. Schoenichen; die Mastigophoren wurden gemeinschaftlich bearbeitet.

Alles in Allem ist ein Buch entstanden, das vom alten Eyferth eigentlich nur noch den Namen führt. Die Anzahl der beschriebenen Formen ist erheblich vermehrt, die Anordnung vielfach geändert, die Tafeln sind völlig neu. In dieser neuen Gestalt übergeben wir das Buch der Oeffentlichkeit und halten sein Erscheinen um so mehr für berechtigt, als an ähnlichen Werken immer noch Mangel herrscht. Nur das vorzügliche Buch von Kirchner und Blochmann „Die mikroskopische Pflanzen- und Tierwelt des Süsswassers. Hamburg 1891 und 1895" kann in gleicher Weise zum Bestimmen der mikroskopischen Lebewesen 
benutzt werden. Manchem freilich ist der Preis dieses mit lithographierten Tafeln ausgestatteten Buches zu hoch; und zudem ist die zweite Auflage bisher noch nicht vollständig. erschienen.

Als Werke, die die Lebewelt des Süsswassers mehr vom biologischen Gesichtspunkte aus bearbeiten, zum Bestimmen aber weniger brauchbar sind, seien genannt und empfohlen: O. Zacharias, Die Tier- und Pflanzenwelt des Süsswassers. 2 Bände. Leipzig ı891.

K. Lampert, Das Leben der Binnengewässer. Leipzig 1898.

Endlich sei noch auf das Buch von C. Mez, „Mikroskopische Wasseranalyse. Berlin $1898^{\prime \prime}$ hingewiesen, das freilich hauptsächlich für den hygienischen Wasseruntersucher Interesse hat.

Derjenige, der die früheren Auflagen des Eyferth kennt, wird vielleicht die gemütliche Freude an dem Formenreichtum der Mikroorganismen, die dem verstorbenen Autor eigen war, vermissen. 'Sie war es, die das Buch auch für so manchen Laien anregend machte. Auch wir haben namentlich in den einleitenden Abschnitten dieser Seite ein wenig gerecht zu werden versucht; im systematischen Teile dagegen erwählten wir den wissenschaftlichen Gesichtspunkt $\mathrm{zu}$. dem vorherrschenden. Mancherlei Mängel mögen sich vor allem vielleicht wegen der relativ kurzen Zeit, die den Herausgebern zur Verfügung stand, eingeschlichen haben; auch einige Zeichnungen sind wohl verbesserungsfähig. Wir bitten ihretwegen um eine nachsichtige Beurteilung; andererseits aber werden wir jedem Wunsche der Rezensenten und Benutzer des Buches Rechnung zu tragen suchen und nach Kräften bestrebt sein, vorhandene Mängel völlig auszutilgen in einer vierten Auflage; deren Erscheinen wir weniger in unserem Interesse erhoffen, als wir es dem Herrn Verleger wünschen, der weder Mühe noch Mittel gespart hat, um dem Buche eine vornehme Ausstattung zu verleihen.

Schliesslich ist es uns eine angenehme Pflicht, dem Herrn Privatdozenten Dr. Brandes sowie den Herren Prof. Dr. Grenacher und Prof. Dr. Klebs unseren Dank auszusprechen für die liebenswürdige Erlaubnis zur Benutzung der Bibliothek ihrer Institute und für die mannigfachen Ratschläge, womit sie unsere Arbeit unterstützten.

Halle, im März 1900

Dr. Walther Schönichen.

Dr. Alfred Kalberlah. 


\section{Druckfehler-Verzeichnis}

Bedauerlicher Weise sind folgende Druckfehler, die wir zu entschuldigen bitten, stehen geblieben:

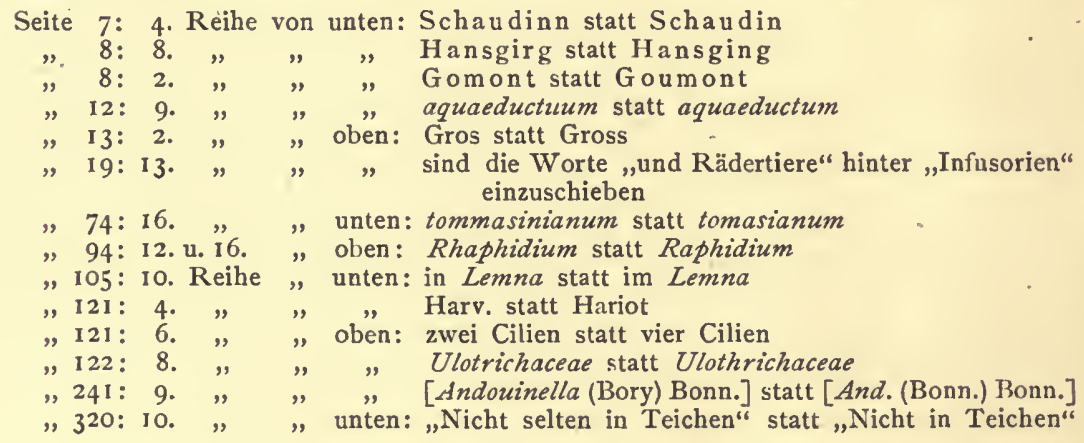




\section{Einleitung.}

Will man den Abschnitt in der Geschichte der biologischen Wissenschaften, in dem wir augenblicklich stehen, durch eine kurze Überschrift charakterisieren, so dürfte der Titel „Periode der Zellforschung“ gewiss der passendste sein. Freilich hatte bereits im Jahre 1672 Nehemias Grew gezeigt, dass zahlreiche pflanzliche Organe aus Bienenzellen ähnlichen Gebilden sich zusammensetzen, es war ferner Unger im Jahre 1826 gelungen, den schleimigen Inhalt solcher Zellen zu entdecken, und $\mathrm{Sch}$ wan $\mathrm{n}$ hatte 1839 die Neuerungen der Botaniker auf das Gebiet der Zoologie übertragen und auch hier die Zelle als das Differential aller Organismen erkannt; doch ist das Studium des feineren Aufbaues von Protoplasma und Kern, sowie der mannigfachen Verrichtungen, welche die Zelle zu leisten vermag, erst ein Kind der letzten Jahrzehnte. Der mächtigste Hebel zur Erkenntnis des eigentlich Wesentlichen an der Zelle ist die Erforschung der niedrigsten, nur aus einer einzigen Zelle bestehenden Geschöpfe gewesen, und wird es auch wohl für lange Zeit noch bleiben: denn hier präsentieren sich die Lebensphänomene am einfachsten und klarsten; es ist hier die Quelle, woraus alle schöpfen müssen, die Licht verbreiten wollen über das Problem des Lebens.

Der Mikroskopiker, der die Geheimnisse der Welt im Wassertropfen erforscht, findet bei seinen Untersuchungen hin und wieder vielleicht ein klcines ziegelrot gefärbtes Geschöpfchen. Auf langen, stachelartigen Fortsätzen des jeglicher Differenzierung entbehrenden Protoplasmakörpers rollt sich das winzige Wesen gleichsam planlos durch das Wasser. Es gerät zufällig in

Eyferths Einfachste Lebeformen. 3. Aufl. 
die Nähe einer Spirogyra, einer Alge, deren Zellen durch den Besitz spiralig gewundener Chlorophyllbänder ausgezeichnet sind, und mit einem Male ändert es seine Richtung, um zielbewusst auf den Algenfaden loszusteuern. Welches Wunder! das kleine Protoplasmaklümpchen ist, obgleich es keine Spur eines Sinnesorganes besitzt, nicht allein im stande unter den zahlreichen Algenarten seiner Umgebung die ihm allein zusagende Spirogyra heraus $\mathrm{zu}$ erkennen, sondern es verrät auch, indem es diese sich zum Ziele wählt, einen Willen: den Schimmer einer Seele. Hat das Liliput-Wunderkind nun sein Ziel erreicht, so zieht es gewöhnlich seine stachelartigen Fortsätze ein und lässt sich auf einer der Zellen des Algenfadens als ein unregelmässig geformtes Klümpchen nieder. Nicht lange währt es, so ist die Wand jener Algenzelle, ohne dass unser ziegelroter Geselle irgend ein mechanisches Werkzeug hierzu besässe, offenbar durch chemische Einwirkungen durchbohrt; und nun schlüpft das rote Plasma des Eindringlings zum Teile in das Innere der Algenzelle und resorbiert, gleichsam ein kleiner Vampyr, deren lebendigen Inhalt. Nicht mit Unrecht hat der kleine Räuber daher den Namen Vampyrella spirogyrae erhalten. Hat nach beendigter Nahrungsaufnahme die Vampyrella die Alge wieder verlassen, so ist sie zu weiteren Exkursionen häufig zu phlegmatisch; sie nimmt eine kugelige Gestalt an und scheidet an ihrer ganzen Oberfläche ein widerstandsfähiges Häutchen ab: sie encystiert sich. Lange Zeit kann solch eine Cyste, ohne das geringste Lebenszeichen zu äussern, lagern. Allmählich aber wird es in ihrem Inneren lebendig: der protoplasmatische Inhalt zerfällt in zahlreiche Teile, welche durch die geborstene Hülle ins Freie gelangen und hicr den geschilderten Lebenslauf der Vampyrclla wiederholen. Die Cyste ist also hier nichts anderes als eine Wiege für die Nachkommenschaft.

Ueberschaut man den Lebenslauf der Vampyrclla, so ergiebt sich, dass die Fähigkeit zur Bewegung, Ernährung, Fortpflanzung und zum Wollen in ihm sich offenbart. Mehr Funktionen aber vermag im Princip das höchst stehende Tier ebensowenig $\mathrm{zu}$ vollziehen wie die höchstentwickelte Pflanze, sodass also zwischen den vollkommensten Lebewesen und den niedrigsten nicht ein qualitativer Unterschied, sondern nur ein quantitativer bestehen kann. Im vielzelligen Organismus verläuft der Lebensprozess natürlich viel komplizierter und gross- 
artiger als beim einzelligen; denn in ihm kann das überaus wichtige Princip der Arbeitsteilung verwirklicht werden: ein Teil der Zellen dient im Gehirn der Funktion des Wollens, ein anderer besorgt im Darme die Ernährung, die Muskelzellen setzen dic Bewegungen ins Werk, die Zellen des Eierstockes und des Hodens dienen der Fortpflanzung. Entsprechend diesen verschiedenartigen Verrichtungen müssen aber auch die Formverhältnisse der Zellen der höheren Lebewesen eine wunderbare Mannigfaltigkeit aufweisen; und so ergiebt sich, dass morphologisch die Differenzierung, physiologisch die Arbeitsteilung den mehrzelligen Organismus von dem einzelligen unterscheidet. Der letztere gleicht dem Urmenschen, der alleine umherschweifend die sämtlichen Funktionen des Menschenlebens noch alleine vollzichen konnte. Der erstere hingegen gleicht unserem modernen Staate, wo das Princip der Arbeitsteilung die Differenzierung der einzelnen Stände in fast erschreckender Weise geschaffen hat. Wie aber die Kulturgeschichte nur verständlich wird, wenn sie die Qualitäten des Urmenschen zum Ausgangspunkte nimmt, so muss auch eine gesunde Zellforschung stets sich stützen auf das Studium der einzelligen Organismenwelt.

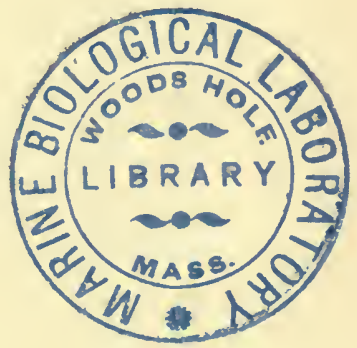




\section{Geschichtlicher Rückblick.}

Es war im Monate September des Jahres 1675 , als der holländische Naturforscher Anton von Leeuwenhoek (sprich Lëuwenhuk) zu Delft eines Tages auf den Gedanken kam, ein irisierendes Häutchen, welches er in einem Gefässe mit Regenwasser auf der Oberfläche schwimmen sah, mikroskopisch zu untersuchen. $\mathrm{Zu}$ seinem grössten Erstaunen löste sich die scheinbar unbelebte, weissliche Substanz unter dem Vergrösserungsglase auf zu einem Gewimmel zahlloser, winziger Elemente. Diese Entdeckung war zu überraschend und unerhört, als dass sic sogleich die richtige Deutung hätte finden können; und so glaubte denn Leeuwenhoek zunächst, die lebendigen Atome der Welt vor Augen zu haben, bis ihn die Beobachtung, dass jene kleinen Wesen sich ganz willkürlich bewegten, in ihnen winzige Tiere (animalcula) erkennen lehrte.

Ueber diese Entdeckung Lecuwenhocks schüttelten die Zeitgenossen ungläubig die Köpfe, bis der Engländer R. Hooke die Angaben des holländischen Naturforschers bestätigen und der Königlichen Gesellschaft zu London derartige kleine Lebewesen vorzeigen konnte. Jetzt wurde die Beschäftigung mit den animalcula mit einem Schlage populär. Es gehörte bald zum guten Tone, sie nach allen Richtungen zu studieren, und alle möglichen Flüssigkeiten wurden mit dem Mikroskop darnach durchforscht. Wie sehr diese Bestrebungen jedoch meist aus rein sportlichen Interessen hervorgingen, zeigt der Titel des im Jahre 1763 von M. F. Ledermüller verfassten Buches: „Mikroskopische Augen-und Gemiütsergötzungen". In dieser Schrift werden die kleinen Organismen des Wassertropfens zum ersten Male 
animalcula infusoria (Aufgusstierchen) genannt, ein Name, der 1765 durch Wrisberg wissenschaftlich sanktioniert wurde, und der-zuerst nur für die in Aufgüssen erzeugten Mikroorganismen, später auch für die im Freien, in stehenden und fliessenden Gewässern vorkommenden Gültigkeit hatte.

Erklärte noch Linné das Reich der Infusorien für ein unentwirrbares Chaos wechselnder Gestalten, so schaffte der bedeutende dänische Zoologe O. F. Mü1ler' (1786), nachdem wertvolle Vorarbeiten von Gleichen-Russwurm, Trembley und Roesel von Rosenhof geliefert waren, endlich Wandel, indem er zum ersten Male eine systematische Einteilung versuchte. Die Rädertiere wurden im Jahre 1812 von Dutrochet zuerst als selbständige Klasse abgesondert mit der Begründung, dass in ihnen eine Differenzierung. verschiedener Organe deutlich erkennbar sei, während die übrigen Infusorien nur belebte Schleimklümpchen seien. Diese Unterscheidung hatte Bestand bis in die dreissiger Jahre unseres Jahrhunderts, obwohl bereits Spallanzani die kontraktilen Vakuolen der Infusorien entdeckt hatte.

Erst Chr. Fr. Ehrenberg trat dieser Ansicht entgegen und machte so von neuem die Infusorienkunde zum Centrum des wissenschaftlichen Interesses. $\mathrm{Er}$ sah in den Infusorien Miniatur-Ausgaben der höheren Tiere und schrieb ihnen einen vollständigen Verdauungs - A pparat, wohl ausgebildete Geschlechtswerkzeuge und Sinnesorgane, kurz die ganze komplizierte Organisation der höheren Tiere zu. Natürlich beruhten diese Angaben sämtlich auf Beobachtungsfehlern, die bei der damaligen Mangelhaftigkeit der optischen Instrumente sehr wohl unterlaufen konnten. So hielt er die mit Nahrungstoffen erfüllten Vakuolen im Protoplasma der Infusorien für Mägen, die wie die Beeren einer Traube an einem gemeinschaftlichen Darme sitzen sollten. Die kontraktilen Blasen und die Kerne galten ihm für Samenblasen und Keimdrüsen, die im Protoplasma zerstreuten Körnchen für Eier. Ja, selbst Blutgefässe, Nerven und Muskeln glaubte der rührige Mikroskopiker zu erkennen. Wie sehr diese Auffassung Ehrenbergs Anklang fand, wird in trefflicher Weise illustriert durch die Behauptung des schwedischen Gelehrten Agardh (1827), der den Infusorien sogar Zauberkraft zuschrieb. Er beobachtete eine Vorticelle unter dem Mikroskope und fand, dass zahllose kleine Algen mit unwiderstehlicher Gewalt in die Mundöffnung des 
Tieres hineingestrudelt wurden. Da cr jedoch dic Erreger jenes Strudels, die Wimpern des Infusores, nicht wahrnehmen konnte, glaubte er, das Gesçhöpf vermöge durch magische Kräfte Nahrungstoffe an sich heranzuzaubern. Niedergelegt hat Ehrenberg seine Ansichten in zahlreichen Abhandlungen sowie in seinem 1838 erschienenen Prachtwerke: „Die Infusionstiere als vollkommne Organismen", das wegen seiner naturgetreuen Abbildungen seine Bedeutung heute noch nicht verloren hat; obgleich die Behauptungen des Verfassers über den morphologischen Wert des Infusorienkörpers längst widerlegt sind.

Die ersten Angriffe auf die Ehrenberg'schen Theoreme gingen von Dujardin aus, dessen weiteres Verdienst dic $\mathrm{Ab}$ trennung der Rhizopoden als besondere Klasse ist. Doch schoss diese Reaktion weit über ihr Ziel hinaus insofern, als Dujardin auch die kompliziert organisierten Rädertierchen in der Einfachheit des Baues den Rhizopoden gleichstellte. Jetzt wurde auch die von den Infusorien so abweichende Natur der Bacillarien und Closterien erkannt, und beide Gruppen wurden dem Pflanzenreiche einverleibt.

Endlich wurde auch durch die Untersuchungen v. Siebolds, Steins, M. Schultzes und Haeckels die Einzelligkeit der Rhizopoden und Infusorien nachgewiesen, und damit ihre systematische Stellung unter den Protozoen endgültig gesichert. Die in ihrem Baue von allen übrigen vielzelligen Tieren stark abweichenden Rädertiere stellte man in die zoologische Rumpelkammer, d. i. in das Reich der Würmer. Gegenwärtig ist wohl nur die systematische Stellung zahlreicher Flagellaten noch unsicher, indem Zoologe und Botaniker gleichberechtigte Ansprüche auf sie geltend machen. Es ist dies ein interessanter Beleg für die Thatsache, dass Pflanzen und Tiere, so divergent ihre Charaktere bei ihren höher entwickelten Formen sind, in den niedrigsten Formen nicht mehr zu scheiden sind, dass also beide Reiche aus gemeinsamer Wurzel sich entwickelt haben.

Lange Zeit hindurch waren die Mikroorganismen für spekulative Naturforscher so recht die Geschöpfe, die aus einer Urzeugung (generatio aequivoca) hervorgehen konnten. Hatte Aristoteles geglaubt, Frösche und Aale könnten aus anorganischen Substanzen oder aus faulenden organischen Resten entstehen, und hatte man sich bis tief in unser Jahrhundert hinein die Entstehung von entoparasitischen Würmern nicht anders zu er- 
klären gewusst, so war hier doch von der exakten Forschung, namentlich durch die Bemühungen des grossen Helminthologen R. Leuckart Wandel geschaffen worden. Von Mikroorganismen hingegen behauptete noch im Jahre 1878 Sédillot eine Entstehung durch Urzeugung. Vor ihm hatte F. A. Pouchet die Lehre von der Urzeugung krampfhaft verteidigt, bis er nach einem Jahrzehnte lang dauernden wissenschaftlichen Duell mit dem ausgezeichneten französischen Gelehrten Pasteur abgeführt wurde. Pasteur liess es sich nicht verdriessen, Wasser und Luft aus allen Gegenden der Welt, von den höchsten Gipfeln der Alpen und Pyrenäen, wie von den Mitten der Oceane zu untersuchen, und die Allgegenwärtigkeit der Mikroorganismen, in erster Linie der Bakterien und ihrer Keime, nachzuweisen. Auf diesem ausserordentlich mühevollen Wege hat es ihm zwar nicht an Vorgängern gefehlt: genannt seien Spallanzani (circa 1760), Franz Schulze (1836) und Schwann (1839), doch bleibt es das dauernde Verdienst Pasteurs, dass er durch Anwendung seiner Forschungsresultate auf die Praxis der Vater unserer ganzen modernen Asepsis und Antisepsis geworden ist.

Für eine Anzahl der niedrigsten Organismen aus den Klassen der Schleimpilze und Sarcodinen war der Nachweis eines Kernes lange Zeit hindurch nicht. geglückt. Häckel hatte daher diese Geschöpfe zu einer besonderen Gruppe, die er Moneren nennt, vereinigt. Nachdem aber durch Anwendung feinerer Färbemethoden bei der Mehrzahl der Moneren ein Kern aufgefunden wurde, hat man den Häckel'schen Gedanken wieder aufgegeben, zumal nach dem jetzigen Stande der Zellwissenschaft die Anwesenheit eines Kernes oder wenigstens der specifischen Kernsubstanz für jede Zelle unentbehrlich scheint.

Die neuere Zeit hat für alle Zweige der mikroskopischen Lebewelt eine gewaltige Litteratur geschaffen, aus der nur die wertvollsten Arbeiten hier erwähnt werden können. Für die Protozoen hat das Bütschli'sche Protozoenwerk eine überaus bedeutungsvolle und eingehende Uebersicht gebracht. Die Kenntnis der Sarcodinen ist durch Fr. E. Schulze, Hertwig, Greeff, Gruber, Blochmann und Schewiakoff wesentlich erweitert worden. Schaudin hat eine Uebersicht der Heliozoen gegeben. Für die Erforschung der Infusorien sind das Werk von Fr. Stein „Der Organismus der Infusionstiere (Leipzig 1859-83)", sowie die Arbeiten von Claparède und Lachmann 
und Maupas grundlegend geworden. Die Flagellaten sind von Kent, Stokes und namentlich von Klebs gründlich revidiert worden. Bei den meisten dieser neueren Erscheinungen tritt der systematische Gesichtspunkt mehr oder weniger in den Hintergrund; die Morphologie und Physiologie stehen jetzt durchaus im Vordergrunde des wissenschaftlichen Interesses.

Die Rädertiere haben durch C. T. Hudson eine gründliche Behandlung erfahren. Wertvolle Beiträge haben Leydig, Cohn, Gosse, Eckstein und Zelinka geliefert. Neuerdings hat E. F. Weber die Rädertierfauna des Genfer Sees einer geradezu klassischen Ueberarbeitung unterzogen.

Wie auf tierischem so gilt auch auf pflanzlichem Gebiete Ehrenberg als der Begründer der Mikrographie. Die meisten Formen hingegen haben Kützing und Rabenhorst beschrieben, während $\mathrm{zu}$ gleicher Zeit und späterhin besonders Cohn, Pringsheim und De Bary auf physiologischem und entwickelungsgeschichtlichem Gebiete thätig waren. In neuerer und neuester Zeit haben in systematischer Richtung Reinsch, de Toni, Schmitz, Möbius, Schmidle, Lemmermann, Kirchner und Hansging gearbeitet.

Das Special-Gebiet der Bakterienkunde ist von Cohn, De Bary, Zopf, Migula und Alfred Fischer in systematischer Hinsicht bearbeitet worden, während Namen wie Pasteur, R. Koch, Roux, Günther und Behring auf praktischem Gebiete hervorleuchten. Dic Schizophyceen haben in Zopf, Bornet, Flahaut, Goumont und Kirchner bedeutende Bearbeiter gefunden. 


\section{Einführung.}

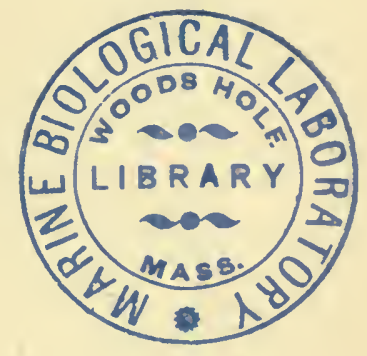

Die mikroskopische Lebewelt ist allgegenwärtig. Ueberall in stehenden und fliessenden Gewässern, selbst in den Abwässern der Fabriken, wo nur irgend genügend Feuchtigkeit ist, um den winzigen Lebenskeimen ein Gedeihen zu gestatten, dort findet sich eine Fauna und Flora von grosser Reichhaltigkeit zusammen. So hängen an den schilfumkränzten Ufern der Teiche und Seen an Stengeln und Blättern der Wasserpflanzen, an dürren Reisern und Steinen bewegliche, flutende, schlüpfrige Flocken aus Tausenden von grünen Algenfäden zusammengewebt und stellen einen mikroskopischen Urwald dar, worin ticrische Formen sich tummeln und jagen. An dürren Blättern, an Heu, an trockenem Moos, am Torf haften Millionen und aber Millionen von Keimen, dem belebenden, aus dem Scheintode sie weckenden Nass entgegenharrend. Es ist nichts weiter nötig, als Aufgüsse auf solche Substanzen zu machen, und bald werden Legionen von "Infusionstieren", wie durch ein Zauberwort gerufen, sich einstellen. Wer also die winzigen Wesen, die dem unbewaffneten Auge unsichtbar in jedem Tröpflein sich tummeln, kennen lernen will, der kann um Material nicht verlegen sein. Jede Regenpfütze, jeder Graben, jeder Tümpel bietet eine unendliche Fülle des Interessanten; namentlich an lauen Frühlingstagen, wenn ein warmer Regenguss herniedergegangen ist, und die Oberfläche der stehenden Gewässer sich mit einem grünlichen oder bräunlichen Schaume bedeckt, und der Landmann sagt: „das Wasser blüht", dann ist es so recht die Zeit, von der Wasserblüte zu schöpfen. Der unangenehme, spermatische oder moderige Geruch des geschöpften Reichtumes 
darf uns dabei nicht stören, wir nehmen eine Probe unter das Mikroskop und werden für die kleine Belästigung durch den Anblick, der hier sich uns bietet, reich entschädigt. Wie in einem Ballsaale, so tummelt sich und wimmelt hier alles durcheinander. da präsentieren sich in grüner Robe zahlreiche Algenzellen, meist in langen Ketten nebeneinander gereiht; die reizenden Diatomeen stehen still in einer Ecke zusammen, gleichsam plaudernd, und tragen ihr wunderbar zierliches, wic mit lauter Plissé-Fältchen garniertes Galakleid zur Schau; dazwischen führen seltsam gestaltete Infusorien einen protozoischen Tanz auf; und die Rädertier-Weibchen werden nicht müde, mit ihrem Fächer, dem Räderorgane, immer neue Nahrung sich in den Mund zu wedeln. Kurz es ist ein fesselnder Anblick, dieses Bild von dem Treiben der Kleinsten der Kleinen; es ist in der That eine wahrhaftige "Augen - und Gemütsergötzung“.

Haben wir uns nach dem ersten Eindrucke gesammelt, so gilt es das Detail des Bildes zu studieren. Eine grosse Anzahl von Gebilden erweist sich sogleich als unbelebt und des weiteren Interesses unwürdig. Beine, Fühler, Kiefer und alle möglichen Körperteile von Gliedertieren, vielfach nur noch als Chitinskelett erhalten, Schuppen von Schmetterlingsflügeln und Mückenfühlern, Daunenstrahlen von Gänse - und Entenfedern, Mäuse - und Rattenhaare, Hakenborsten von Würmern, Baumwollen- und Leinenfasern, Bastzellen und Zellenreste von Land- und Wasserpflanzen, Stärkekörner, Pollenkörner, letztere namentlich von Nadelhölzern, Körner von kohlensaurem Kalke, Gypskryställchen, Quarzsplitter und tausend andere Dinge gehören in die Kategorie der „unbelebten Wasserbewohner".

Meist haust zwischen dem Wirrwarr der Algen auch eine Anzahl grösserer Tiere, die schon mit blossem Auge wahrnehmbar sind. So dürften nurselten kleine Rundwürmer(Nematoden) fehlen. Unablässig sind diese Wesen geschäftig, ihren aalglatten Körper unruhig hin und her zu schlängeln. Gewöhnliche Species sind Dorylaimus stagnalis und Trilobus gracilis. Andere Vertreter des Würmerreiches sind die mit Borsten bewehrten Oligochaeten: da finden sich vielfach das mit orangeroten Oel-Punkten gezierte Acolosoma quatcrnarium, die an ihrem langen Rüssel kenntliche Nais proboscidea und die rüssellose $N$. clinguis. Auch winzige Strudelwürmer (Planarien) sind häufig und täuschen dem unbewaffneten Auge das Bild eines grossen Infusionstieres vor, 
bis das Vergrösserungsglas ihre höhere Organisation und ihre meist gelbroten Augenpunkte enthüllt. Leicht kenntlich sind des weiteren die meist zahlreich vorhandenen Insektenlarven an den hornigen Kiefern und an dem in der Mittellinie des Rückens befindlichen, pulsierenden Blutgefässe. An den bekrallten Fussstummeln und an der Trägheit der Bewegungen erkennen wir das Bärtierchen (Macrobiotus macrony'x), jenen Scheintods-Künstler, der mehrere Jahrzehnte lang in Trockenstarre liegen kann, ohne die Lebenskraft zu verlieren. Er gehört mit den zahlreichen Wassermilben, die an Hässlichkeit der Gestaltung ihren grösseren Verwandten auf dem Lande um nichts nachstehen, zu den Spinnentieren. Am stärksten sind die Krebstiere vertreten, namentlich durch die Ordnungen der Blattfüsser (Phyllopoda), der Spaltfüsser (Copepoda) und der Muschelkrebschen (Ostracodd). Der häufigste Repräsentant der ersten Ordnung ist der mohnkorngrosse Wasserfloh (Daphnia pulex). Seine langen, schlagbaumartigen Fühler, sein grosses, mit zahlreichen Krystallkörpern versehenes, stets zitterndes Stirnauge und das kräftig pulsierende, etwa oval gestaltete Rückenherz machen ihn zum reizvollen mikroskopischen Objekte. Von anderen Phyllopoden ist noch Lynceus sphaericus erwähnenswert. Unter den Ostracoden sind gewisse Cypridinen, die Cypris fusca und C. ovum, die gewöhnlichsten Erscheinungen. Sie gleichen kleinen zweischaligen Muscheln, aus deren klaffender Spalte Fühler und Ruderfüsse vortreten. Durch prachtvolle bunte Färbung fallen die langgeschwänzten Copepoden auf, deren Weibchen am Hinterleibe meist zwei mächtige Eiersäcke tragen. In erster Linie sind es die Gattungen Cyclops und Canthocamptus, deren Angehörige oft scharenweise in Tümpeln und Teichen sich tummeln. Kolonienweise beisammen hausen die Moostierchen (Bryozoen), die zierliche Tentakelkränze entfalten, wenn sie ungestört sind. In ihrem Körper liegen häufig grosse, mit einem Luftringe und mit Häkchen versehene Eier, sogenannte Statoblasten. An Wasserpflanzen festgeheftet findet sich hin und wieder der Süsswasserpolyp (Hydra viridis und H. fusca), dessen lange, mit zahlreichen, glashellen Nesselkapseln armierte Fangarme unablässig nach Beute sich ausstrecken. Die Hauptvertreter der grösseren Tiere, die als Beigabe zu der mikroskopischen Lebewelt häufig genug dem Beobachter begegnen, dürften damit aufgezäh1t sein.

Nach Abzug dieser Formen verbleibt immer noch ein 
gewaltiges Heer von Organismen, das aus den Klassen der Algen, Pilze und Bakterien, sowie der Wurzelfüsser, Sonnentierchen, Infusorien und Rädertiere sich rekrutiert. Im allgemeinen dürfte die Ermittelung der systematischen Stellung bei den einzelnen

- mikroskopischen Objekten auf keinerlei Schwierigkeiten stossen; doch ist dem Anfänger vielleicht die der „Einfülırung“ folgende Tabelle willkommen.

Entsprechend ihrer weiten Verbreitung sind die Mikroorganismen den verschiedenartigsten Lebensbedingungen angepasst. Wo tierische und pflanzliche Substanz mit Wasser unter Luftzutritt ruhig steht, wie dies bei den Gläsern in den Laboratorien häufig der Fall ist, pflegt schon nach wenigen Tagen eine wolkige Trübung in der Flüssigkeit aufzutreten, die bald die Bildung eines zarten, weisslichen Häutchens an der Oberfläche des Wassers zur Folge hat. Beide Gebilde erscheinen unter dem Mikroskope meist als eine lappige oder wolkige Gallerte, in der zahllose bewegliche oder unbewegliche Bakterien durcheinander wimmeln oder eingebettet sind. Zwischen diesen Spaltpilzen leben gewöhnlich einige auf ihre Vertilgung angewiesene InfusorienArten, so Cercomonas termo, Monas gutulla, Glancoma scintillans, Colpidium colpoda, Paramaccium aurelia und P.putrinum, Euplotes charon, Vorticclla microstoma, alles Formen, die ein Uebermass von im Wasser gelösten organischen Substanzen lieben und überall dort auftreten, wo faulige Gärung herrscht.

Ist die Menge der gelösten organischen Stoffe etwas geringer, so sind es neben Bakteriaceen namentlich Pilze, die an den im Wasser schwimmenden Reisern grosse, weissliche oder bräunliche, flottierende Flocken zusammensetzen, die unter Umständen ein ganzes Flussbett auskleiden können. Gewöhnlich sind es weit verzweigte Saprolegnien (Leptomitus lactcus), dünne Fäden von Spaltpilzen (Clodothrix, Sphacrotiluis, Beggiatoa) oder Mycelien höherer Pilze (Sclcnosporium aquacductum), die hier ihr Elysium finden. Zwischen diesen Pilzflocken leben oft noch zahlreiche, schöne Diatomeen, besonders aber viele Vorticellen, namentlich baumförmige (Epistylis), Stentoren und Rotiferen, ferner Traubenmonaden (Anthophysa vegetans), deren braune, verăstelte Stielgerüste zuweilen die ganze Oberfläche des Wassers als kupferbrauner Schaum bedecken.

Die chlorophyllgrünen Algen kommen zu üppiger Entwicklung meist nur in Wasser, das arm ist an organischen Sub- 
stanzen und genügende Beleuchtung hat; das Gleiche gilt vielleicht von dem Gross der Diatomeen. Je üppiger und reichhaltiger diese assimilierende Flora ist, desto mannigfaltiger ist auch die Entwicklung der mikroskopischen Tierwelt. Grössere Infusorien (z. B. Paramaecium bursaria) und Rädertiere (Euchlanis dilatata) sind die gewöhnlichsten Bewohner derartiger Wässer. Sie alle gehen in kurzer Zeit zu Grunde, sobald Fäulnisprozesse auftreten. In Wasser, das zahlreiche, in langsamer Zersetzung begriffene organische Reste enthält, treten die Chlorophyceen und Diatomeen schon etwas zurück, um zahlreichen (Desmidiaceen und) Bakteriaceen Raum zu geben. Abgestorbene Algenfäden, Grashalme u. dgl. sind dann stets dicht mit Schizomycetenfäden besetzt. Daneben erscheinen meist spangrüne Spaltalgen, besonders Oscillarien, die dem .Wasser einen unangenehmen Modergeruch erteilen. In solchem Wasser (Sumpfwasser) können die meisten Infusorien-Arten leben. Von Algen sind besonders die Volvocineen (Pandorina monum, Gonium pectorale) und Peridineen vertreten.

Im Allgemeinen hängt es also von der Menge der im Wasser gelösten organischen Substanzen ab, welche Tier- und Pflanzenformen darin vorherrschen; und da in Folge der nie rastenden Thätigkeit der allgegenwärtigen Bakterien derChemismus eines Wassers einem steten Wechsel unterworfen ist, so werden im Laufe der Zeit die verschiedenartigsten Faunen und Floren in der mannigfaltigsten Folge einander Platz machen. Ist eine bestimmte Spezies zu üppiger Entwicklung gelangt, so werden auch diejenigen Formen, die von der ersteren sich nähren, in Kürze in grosser Anzahl erstehen, bis ihre Reihen durch die Scharen einer neu erstehenden dritten Art dezimiert oder gänzlich vernichtet werden; und so wird der Wassertropfen zu einem Schlachtfelde, wo der Kampf um das Dasein gerade so unerbittlich und wütend tobt, wie auf allen übrigen Gebieten des Lebens.

Im einzelnen Falle hängt naturgemäss das Auftreten bestimmter Organismen vielfach von Zufälligkeiten ab. Wenn gewisse Bakterien und Monaden in jeder fauligen Infusion sich einstellen, und wir ihre Erzeugung völlig in der Hand haben, so lässt das Erscheinen der meisten übrigen Formen keineswegs mit mathematischer Bestimmtheit sich voraussagen. So ist z. B. das Infusor Colpoda cucullus häufig ein Bewohner von Infusionen, doch ist es durchaus kein regelmässiger Gast. Häufig kommt 
es vor, dass manche Formen an Orten, wo man Jahre lang keine Spur von ihnen zu entdecken vermochte, plötzlich massenhaft auftreten. Besonders gewisse Algen (z. B. Hydrodictyon utriculare) und Rädertiere (z. B. Hydatina scnta) zeigen dieses auffallende Verhalten. Vielfach ist die Folge des scharenweisen Erscheinens bestimmter Arten eine fast plötzliche Verfärbung des Wassers. So wird durch Volvocineen, Cryptomonadinen und Protococcaceen das Wasser grün gefärbt; die massenhafte Entwicklung von Rädertieren zieht eine milchige Trübung des Wassers nach sich. Ein auffälliges und aufregendes Phänomen ist von alters her die blutige Verfärbung des Wassers gewesen, wie sie durch Eaglena sanguinea, Astasia haematodes und Sphaerella pluvvialis verursacht wird. Zur Erklärung eines solchen plötzlichen Auftretens von nie zuvor an dem betreffenden Orte gefundenen Species muss man sich daran erinnern, dass die Fortpflanzungskörper der mikroskopischen Lebewelt gegen äussere Einflüsse, wie Hitze, Kälte und Trockenheit, meist in erstaunlichem Masse widerstandsfähig sind, dass der Wind aus weit entfernten Gegenden solche Lebenskeime herbeitragen kann, und dass an den Füssen der Wasservögel Eier und Cysten über Erdteile und Oceane verschleppt werden. Gleichzeitig sind dies auch die Faktoren, denen zum grössten Teile die mikroskopische Lebewelt ihren Kosmopolitismus verdankt.

In grösseren Wasserbecken bedingt der Unterschied zwischen den Lebensbedingungen der Uferregion und des offenen Wassers gewöhnlich die Ausbildung zweier verschiedener Lebeweltszonen, einer littoralen und einer pelagischen. Der pelagischen Organismenwelt oder dem Plankton verleiht die grosse Monotonie der Existenzbedingungen des offenen Wassers eine Anzahl ganz spezifischer Charaktere. Zunächst verbietet der fast völlige Mangel von Gegenständen, die zum Festheften dienen könnten, im Plankton das Vorkommen sessiler Formen. Vielmehr ist grösste Beweglichkeit und unablässige Unruhe eines der Kennzeichen pelagischer Species. Da jedoch eine ununterbrochene Bewegung in kurzer Zeit zur Erschöpfung führen müsste, so ist durch geeignete Schwebe-Vorrichtungen Sorge getragen, dass die Planktongeschöpfe auch im Zustande der Ruhe an der Oberfläche des Wassers verbleiben. In diesem Sinne wirkt hauptsächlich eine Vergrösserung der Körperoberfläche, die bis zur Ausbildung zahlreicher, die Körperlänge weit überragender, 
stachelartiger Fortsätze gesteigert sein kann. Namentlich gewisse Peridineen und Diatomeen liefern hierfür die besten Belege. Andererseits aber kann auch durch eine wässerige Aufquellung der Gewebe eine recht bedeutende Ausgleichung des Gewichtes zwischen Wasser und Körpersubstanz angestrebt sein, wodurch gleichzeitig die glashelle Durchsichtigkeit vieler Planktontiere bedingt sein dürfte. Da derartige Glastiere im Wasser nur ausserordentlich schwer sichtbar sind, so darf man in ihrer Durchsichtigkeit wohl eine Schutzfärbung sehen. In grösseren Landseen giebt es ausserdem auch eine besondere Tiefsecfauna.

Die Erbeutung pelagischer Tiere geschieht am einfachsten in der Art, dass ein möglichst engmaschiges Netz einige Male in der Kreuz und Quere durch das Wasser gezogen, und der Inhalt nach dem Ablaufen der Flüssigkeit in ein bereit gehaltenes, mit Wasser gefülltes Gefäss gegeben wird. Eine ungezählte Menge von Copepoden dürfte zumeist der augenfälligste Bestandteil der Beute sein. Jetzt gilt es die Mikroorganismen zu isolieren. $\mathrm{Zu}$ diesem Zwecke dient eine Anzahl von kleinen Bechergläsern, die an Stelle des Bodens Netze von verschiedener Maschenweite tragen. Zuerst giesst man die Beute rlurch das mit dem weitmaschigsten Gaze-Netze versehene Gefäss, wodurch die gröbsten Bestandteile zurückgehalten werden. Nach mehrmaligen derartigen Durchsiebungen durch immer engmaschigere Netze werden schliesslich fast nur noch mikroskopische Lebewesen im Wasser vorhanden sein.

Zur Untersuchung der einzelnen Tierformen eines Gewässers entnehme man der mitgebrachten Probe zunächst mit Hülfe einer Pipette einige Tropfen und breite sie auf einem Objektträger aus, um bei einer schwachen Vergrösserung eine kurze Revue über die erbeuteten Species abzuhalten. Am leichtesten gestaltet sich die Einzeluntersuchung bei unbeweglichen, oder nahezu unbeweglichen Lebewesen, wie z. B. bei Fadenalgen, Fadenbakterien, Sonnentierchen, festsitzenden Rotatorien und Aehnlichem. Störende Fremdkörper werden sich bei schwacher Vergrösserung mittelst einer feinen Präpariernadel meist leicht zur Seite schieben und ganz entfernen lassen, so dass nach vorsichtiger Auflegung eines Deckgläschens und Absaugung von eventuell vorhandenem überschüssigem Wasser durch ein sorgfältig angenähertes Stückchen Fliesspapier die Beobachtung mit stärkeren Linsen vor sich gehen kann. Soll das Objekt aufbewahrt werden, 
so stelle man es in eine feuchte Kammer, die man sich mit Leichtigkeit selbst herstellen kann. Ueber einen tiefen, mit Wasser gefüllten Teller, stülpe man eine Glasglocke (Käseglocke) so, dass ihr unterer Rand vom Wasser überdeckt wird. Unter dieser Glocke werden die Objektträger mit ihren Präparaten auf einem aus Draht zusammengebogenen Gestelle sich längere Zeit völlig frisch erhalten.

Viel komplizierter gestaltet sich die Isolierung beweglicher Objekte. Man bedient sich hierzu kleiner Pipetten, die am einen Ende in eine äusserst feine, mit einer winzigen Oeffnung versehene Spitze ausgezogen sind, während über das andere Ende ein zum Ansaugen und Ausspritzen dienender Gummihut (Gumminutsch) gestülpt ist. Nachdem ein solches Instrument durch Eintauchen in kcchendes Wasser sterilisiert ist, sauge man bei schwacher-Vergrösserung die zu untersuchende Form aus der Wasserprobe $a b$ und übertrage sie in einen Tropfen reinen Wassers, wo das kleine Wesen gleichsam eine Waschgelegenheit findet. Nach abermaliger Sterilisierung der Pipette wird, nachdem man sich bei einer mässigen Vergrösserung überzeugt hat, dass das gewünschte Individuum unversehrt übertragen ist, das letztere aus seinem Bade wiederum abgesogen und übergeführt in einen Tropfen reinen Wassers, der auf ein Deckgläschen aufgetupft wurde. Hier hat das Geschöpf seine Endstation erreicht. Handelt es sich um eine Bakterien fressende Species, so kann man aus einer bakterienhaltigen Erbsen-Infusion ein Tröpfchen hinzuthun und den kleinen Gefangenen auf diesem Wege mit Nahrung versehen. Das Deckgläschen, an dem der Wassertropfen haftet, wird nun über ein mit kreisförmiger Durchlochung ausgestattetes, einer Schraubenmutter ähnliches Pappestück gedeckt, in der Art, dass der Tropfen in das Lumen des Untersatzes hineinhängt. Das ganze wird schliesslich auf einen Objektträger gestellt, und jetzt kann die Beobachtung des Objektes im ,hängenden 'Tropfen" bei starker Vergrösserung erfolgen.1) Diese Methode arbeitet bei weitem eleganter als ein anderes Verfahren, welches darin besteht, dass das Objekt auf dem Objektträger verbleibt und hier mit einem Deckgläschen bedeckt wird. Wenn man auch durch Einschieben einiger Haare oder Papierstreifen zwischen

1) Bedient man sich hohl geschliffener Objektträger, so kann man das Deckglas mit dem hängenden Tropfen auf diese direkt auflegen. 
Deckglas und Objektträger den zwischen beiden Gläsern herrschenden Druck herabsetzen kann, so läuft man doch bei dieser Methode stets Gefahr, zartere Formen zu zerquetschen. Für zahlreiche Geschöpfe gestaltet sich die Untersuchung im hängenden Tropfen übrigens etwas einfacher, als oben angegeben ist, indem nicht immer die Ausführung der sämtlichen Cautelen notwendig ist. So kann für die Mehrzahl der Rotatorien und grösseren Infusionstiere die Sterilisierung der Pipette und vielfach auch die Uebertragung in einen ",waschenden Tropfen" in Wegfall kommen. Ja, man kann, wenn es sich nicht um eine Züchtung, sondern nur um die Bestimmung derartiger grösserer Mikroorganismen handelt, die Isolierung überhaupt vollkommen fortlassen. Für eine andere Reihe von Mikroorganismen ist hingegen die sorgfältigste Beobachtung aller oben angegebenen Vorschriften durchaus unentbehrlich. Namentlich gilt dies für eine ganze Reihe von Algen, die man erst durch Beobachtung des ganzen Entwicklungsganges sicher identifizieren kann; nur eine strenge Isolation kann hier genügende Sicherheit bieten.

Die Isolierung der einzelnen, näher zu untersuchenden Formen einer frischen Wasserprobe darf übrigens nicht zu lange verzögert werden, da die im frischen Wasser lebenden Arten selbst bei der grössten Vorsicht nach kurzer Zeit zu Grunde gehen. Am ehesten gelingt noch die Aufbewahrung, wenn man einige Algen oder andere Pflänzchen hinzugiebt. Unter dem Deckgläschen kann man dagegen die Mehrzahl der Frischwasserformen viele Tage, ja Wochen lang am Leben erhalten, wenn man nur das während der Beobachtungszeit verdunstete Wasser durch lufthaltiges reines Wasser wieder ersetzt und während des Nichtgebrauches das Objekt in der feuchten Kammer aufbewahrt. Bei Aufbewahrung von Material in grösseren Gefässen besteht überdies stets die Gefahr, dass Raubtiere vorhanden sind, die binnen kurzem die kleine Menagerie entvölkern. Solche gefährliche Räuber sind besonders einige grössere Iufusorien (Urostyla grandis, gewisse Amphileptus-Arten), Naidinen und Planarien. Für Pilz- und Algenkulturen kann man die lästigen Räuber durch Ersticken töten, indem man die Kulturen einige Tage in einem luftdicht verschlossenen Glase stehen lässt.

Zum Studium von Amoeben empfiehlt sich folgendes sehr einfache Verfahren. In die amoebenhaltige Infusion lege man einige Deckgläschen ein. Nach einiger Zeit wird aut diesen 
eine Anzahl der gewünschten Objekte sich eingefunden haben. Es bedarf jetzt nur noch der vorsichtigen Uebertragung der Deckgläschen auf Objektträger, um die Amoeben, die ihre Pseudopodien meist noch ungeniert entfalten, beobachten $z u$ können.

Zahlreiche Mikroorganismen erschweren durch ihre ausserordentlich lebhafte Beweglichkeit in hohem Masse die Beobachtung. Selbst bei Verwendung eines Revolvertubus ist es unmöglich, viele Formen länger als einen Augenblick im Gesichtsfelde $\mathrm{zu}$ behalten. Um solche unruhigen Geister bewegungslos zu machen, erwärme man sie auf dem Objektträger an der Sonne oder an einer Flamme bis höchstens $50^{\circ} \mathrm{C}$. Dabei erfolgt die Erstarrung des Plasmas. Die wärmestarren Infusorien lassen einige Zeit die Wimpern und die inneren Organe sehr gut erkennen, später aber zerfliessen sie. Bessere Resultate noch erzielt man, wenn das Objekt Dämpfen von Osmiumsäure oder Cocain ausgesetzt wird, die meist eine blitzartig schnelle Fixierung bewirken. Natürlich muss wegen der Giftigkeit der genannten Substanzen stets die nötige Vorsicht beobachtet werden. Durch Behandlung mit Osmiumsäure wird gleichzeitig auch eine Schwärzung etwa vorhandener Fett- und Oeltröpfçhen erreicht.

Vielfach aber ist es durchaus erwünscht, die Tiere lebend zu untersuchen; vor allem gilt dies von zahlreichen Infusorien, wenn es sich z. B. um die Beobachtung der pulsierenden Vakuole handelt. In solchen Fällen setze man auf den Objektträger vier kleine Füsschen aus einem Gemisch von Wachs und venetianischem Terpentin auf und lege auf diese das Deckglas. Letzteres presse man durch sanften Druck so weit gegen den Objektträger, bis das lebhafte Geschöpf gerade festgeklemmt ist. Natürlich muss man bei dem Aufdrücken auf das Deckglas mit cler grössten Vorsicht verfahren, damit die zu untersuchende Form nicht zerquetscht werde.

Das Studium der Mundverhältnisse von Infusorien wird häufig durch die Karminfütterung erleichtert. Man gebe zu dem Wassertropfen auf dem Objektträger ein wenig sehr feinkörnigen Karminpulvers zu. Durch die Strudelorgane der Tiere werden dann die winzigen Körnchen nach dem Schlunde geführt.

Zur Konservierung in Dauerpräparaten sind am ehesten die zierlichen Kieselpanzer der Diatomeen geeignet. Einen diatomeenhaltigen Wassertropfen gebe man auf ein Platinblech und giesse 
ein wenig konzentrierte Schwefelsäure zu; das Gemisch halte man alsdann auf dem Metallbleche über eine Flamme und erhitze solange, bis alle Feuchtigkeit verschwunden und ein kaum sichtbarer weisser Staub zurückgeblieben ist. Diesen übertrage man auf einen Objektträger, lege ein Deckglas auf, umziehe dessen Ränder mit Paraffin und verkitte zum Schluss ringsherum mit Canadabalsam. Bei dieser Aufbewahrung in Luft sind die Skulpturverhältnisse des Diatomeenpanzers am deutlichsten sichtbar.

Zur Fixierung und Färbung von Algen empfiehlt sich Jod-Eosinlösung nach Palla; namentlich tritt der Kern nach Anwendung dieses Reagenzes deutlich hervor. Für manche Infusorien sind auch Sublimat-Alkohol und Pikrinessigsäure und Räclertiere geeignete Fixierungsmittel.

Von der grössten Bedeutung ist die Kenntnis der mikroskopischen Lebewelt für die Prüfung eines Wassers auf seine Verwendbarkeit. Derartige Untersuchungen haben damit zu beginnen, dass man ein sorgfältig gereinigtes Gefäss mit weiter Oeffnung mit dem Wasser füllt und es zunächst mit blossem Auge besichtigt. Zeigt es sich vollkommen klar, farblos und geruchlos, so wird es sich in den meisten Fällen auch bei der weiteren Untersuchung als genügend rein erweisen. Ist es zwar klar, aber gelblich schillernd, so ist auf einen Gehalt an Eisen zu schliessen, das sich beim Stehen an der Luft als rostfarbener Niederschlag ausscheidet. Zeigt das Wasser aber irgend eine nennenswerte Trübung, so enthält es sicher auch erhebliche Mengen fremder Stoffe. Um diese für die mikroskopische Untersuchung $\mathrm{zu}$ gewinnen, lässt man das Gefäss gut bedeckt mindestens eine Stunde ruhig stehen. Nach Verlauf dieser Zeit haben sich die im Wasser schwebenden Teilchen entweder alle am Boden abgelagert oder auch teilweise an der Oberfläche zu einem Häutchen angesammelt. Um diese Ausscheidung zu befördern, kann man ein paar Tropfen Gelatinelösung zugiessen. Zur Ueberführung des Häutchens auf den Objektträger hebt man es mit einem Glasstabe ab. Meist entpuppt es sich unter dem Mikroskope als Aggregat lebender oder abgestorbener Organismen; seltener besteht es nur aus Körnern von kohlensaurem Kalke.

Einen, wenn auch nur geringen, Bodensatz wird auch das beste Wasser stets ablagern. Einzelne Fasern von Wolle, Baum- 
wolle und Leinen, die ja überall auch in der Luft schweben, vermodernde Pflanzenteilchen, Korkzellen vom Verschluss der Probeflaschen fehlen kaum jemals. An und zwischen diesen aber sammelt sich, was an Spaltpilzen, Monaden und sonstigen mikroskopischen Lebewesen vorhanden ist. Grössere Tiere (Cypris, Cyclops, Daphnia) sind selten und dann schon mit blossem Auge sichtbar. Jetzt giesst man das Wasser bis auf einen geringen Rest vorsichtig ab oder zieht es besser ab mit einem Heber, der unten etwa einen Centimeter aufwärts gebogen ist.

Von dem Bodensatze wird mittels einer Pipette etwas auf einen Objektträger übergeführt und nach Auflegen eines Deckglases untersucht.

Ist der Bodensatz pulverig, so wird er meist aus mineralischen Stoffen, Quarzsplittern, Körnern von kohlensaurem Kalk, auch wohl Gypskrystallen bestehen. Thonerde bildet feinkörnige Niederschläge, sehr feinpulverig sind auch die rostfarbenen Eisenniederschläge. Schwarze Niederschläge enthalten Schwefeleisen.

Ist der Bodensatz flockig, so wird man ausser den schon erwähnten Gespinnstfasern selbst in gutem Brunnenwasser, sofern, wie gewöhnlich, Röhren und Gestänge der Pumpe aus Holz bestehen, abgeriebene Holzteilchen finden, an und zwischen diesen gewöhnlich auch Mycelfäden und Conidien (Sporen) von Pilzen, die das faule Holz bewohnen, oder auch von Schimmelpilzen. Besonders häufig sieht man grosse, sichelförmig gebogene, septierte, farblose oder braun gefärbte Sporen, meist mit grossen Oeltropfen, die von solchen Holzpilzen abstammen. Auch kleine Conidien (Spermatien), die man mit Vibrionen und Bakterien verwechseln könnte, kommen öfter vor. In den meisten Fällen werden sich aber auch mindestens Sporen von wirklichen Spaltpilzen, besonders kleine Zoogloca-Ballen finden lassen, gewöhnlich auch einzelne Flocken oder doch Fäden von Cladothrix oder Crenothrix und deren Scheiden. Letztere sehen oft den gleichfalls häufigen Stielgerüsten der Traubenmonaden sehr ähnlich, sind aber mehr cylindrisch und lassen stets eine centrale Höhlung erkennen, während die Monadenstiele meist stark nach der Spitze verjüngt sind und wie geflochten aussehen. Zwischen diesen Fäden findet man fast immer, oft sehr zahlreich, kleinere und grössere, weissliche oder glashelle Kügelchen. Es können das Hefezellen, Conidien und Sporen von Saprolegnien und anderen Pilzen, eingekapselte Infusorien, ferner Monaden 
und manches andere sein. Zur genaueren Bestimmung ist es nötig, diese Gebilde auf dem Objektträger zu kultivieren und ihre Entwicklung zu beobachten. Farblose Schläuche können Saprolegnien, Mucorinen oder auch Stiele von Vorticellinen, besonders Epistylis, sein. Letztere enthalten dann meist noch Reste des Stielfadens, jene Pilzschläuche hingegen grobkörniges Plasma. Sind freie Bakterien vorhanden, so sitzen diese in grösserer oder geringerer Anzahl sicher an den stärkeren Fasern. Wenn letztere ganz reinlich aussehen, so wird man das betreffende Wasser unbedenklich für tadellos erklären können, sofern damit die chemische Untersuchung übereinstimmt.

In schlechtem Brunnenwasser finden sich neben den bereits aufgezählten Stoffen und Geschöpfen häufig Oscillatorien und selbst Beggiatoen, manchmal sogar Spirochaete und Sarcina. Dazu gesellen sich die Infusorien und Flagellaten: Vorticella microstoma, Cyclidium glaucoma, Glaucoma scintillans, Colpidium colpoda, Paramaecium aurelia, Urostyla multipes, Euplotes charon, mehrere Bodo-Arten, Monas guttula und $M$. vivipara u. s. w.

Ferner finden sich Amöben und beschalte Rhizopoden, Rotatorien (Rotifer vulgaris, Colurus bicuspidatus, Philodina), Naisund Rhabdonema-Arten, Milben, Cyclops, Cypris und DaphniaArten, alles Tiere, die nach Vejdovský zum Teile eine besondere Dunkel-Fauna repräsentieren. Rattenhaare, Stärkekörner, ganze Zellen von gekochten Kartoffeln und Getreideresten, Fleischfasern, Epithelzellen und andere Dinge, die auf Zuflüsse von Spülwasser oder Kloaken hindeuten, kommen ebenfalls nicht selten vor. Findet man Diatomeen, grüne Algen oder grüne Euglenen, die sonst nur reines Wasser bewohnen, im Brunnen, so deutet ihr Vorhandensein darauf hin, dass entweder Licht in den Brunnen einfällt, oder wenn nicht, dass diese Organismen vor kurzem auf irgend eine Weise in das Wasser gelangten. Auf jeden Fall steht der Brunnen also mit der Aussenwelt in offener Verbindung, so dass die Gefahr einer Infektion mit schädlichen Organismen nicht ausgeschlossen erscheint. Die chemische Untersuchung derartigen Wassers wird in den meisten Fällen ein ähnlich schlechtes Resultat ergeben und einen bedeutenden Gehalt an organischen Stoffen, sowie an Salpetersäure aufdecken.

Die zur Untersuchung des Wassers und seiner Lebewesen nötigen Reagenzien sind zum grossen Teile in jeder Apotheke erhältlich; wenn nicht, so wende man sich an die Firma Grübler in Leipzig oder an die Engelapotheke in Halle. 


\section{Schlüssel.}

I. Bewegliche Formen . . . . . . . . . . . . . 2

2. Grün gefärbt . . . . . . . . . . . . . 3

3. Durch lange Geisseln oder kürzere Cilien beweglich 4

4. Durch Geisseln beweglich . . . . . . . . 5

5. Zellen zu Kolonien verbunden Volvocaceen

5*. Zellen einzeln . . . . . . . . . . . . 6

6. Mit Plasmamembran, mit einer Geissel, Körper langgestreckt . . . . Euglenoidinen

6*. Ohne Plasmamembran, mit zwei Geisseln . . 7

7. Geisseln von verschiedener Länge; träge, meist vereinzelt lebende Formen Chloromonadinen

$7 *$. Geisseln von gleicher Länge, lebhaft bewegliche, etwa ovale Formen '). Chlamydomonadinon

$4^{*}$. Durch Cilien beweglich . . . . . . . . . 8

8. Cilien in einem Kreise am farblosen Vorderende Schwärmer von Oedogonium

$8^{*}$. Cilienkleid gleichmässig oder mit besonderen Differenzierungen . . . . . grüne Infusorien.

$3^{*}$. Bewegungsorgane unsichtbar, Bewegung sehr langsam, ruckweise . . . . . . . . . . Dcsmidiaccen

$2^{*}$. Nicht grün gefärbte Formen . . . . . . . . . . 9

9. Gelbe oder braune Formen . . . . . . . I

Io. Braune Färbung . . . . . . . . . . . . 1 I

II. Ohne sichtbare Bewegungsorgane, mit Kieselskelett Bacillariaccen

I I*. Mit Geisseln und Celluloseskelett

Pcridinecn

IO*. Gelbe Formen mit Geisseln . . Chromomonadincn

$9^{*}$. Anders gefärbte oder farblose Formen . . . . . I 2

1) Hierher gehören auch die vielen Sclıwärmsporen und Gameten höherer Algen. 
12. Farbe rosa oder blaugrün . . . . . . . . . . 13

13. Rosa gefärbt, in Sumpfwasser. Schwcfelbakterien

I3*. Blaugrüne Fäden . . . . . Oscillarien

12*. Farblose Organismen. . . . . . . . . . . . 14

14. Fäden mit schwarzen Körnern in Innern . . . . . Beggiatoen

14 *. Ohne schwarze Körner, meist keine Fäden . . 15

15. Schleimklümpchen mit meist unregelmässigen, fingerartigen Fortsätzen, ohne Geisseln, langsam auf dem Substrate sich bewegend . . Sarkodinen

I 5 * Körperform bestimmter, Geisseln oder Wimpern meist sichtbar . . . . . . . . . . . . . 16

16. Kleine Stäbchen der Kokken, Bewegungsorgane unsichtbar, lebhaft beweglich Bacteriaceen

16*. Grössere Formen, Bewegungsorgane mindestens bei durch Jod getöteten Exemplaren sichtbar $\quad 17$

17. Die Bewegungsorgane sind meist wenige längere Geisseln . . . . . Mastigophoren

$\mathbf{1} 7$. Die Bewegungsorgane sind zahlreiche kleinere Cilien . . . . . . . . . . . . . 18 ı. Niedere, einzellige Formen . . . . . .

Infusorien

I8*. Höher differenzierte Formen . . . 19

19. Bewegungsorgane sind zwei bauchständige Wimperbänder . . Gastrotrichen

$19 *$. Bewimperung ist auf das Vorderende beschränkt . . . Rotatorien

I*. Unbeweglich (meist) . . . . . . . . . . . 20

20. Ungefärbte Formen . . . . . . . . . . . . 2 I

21. Mit deutlicher Membran versehene Organismen, parasitisch in Algen oder frei im Wasser Fäden bildend .

Pitze

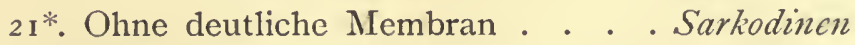

20*. Grüngefärbte Formen

siehe Tabelle für Pfanzen (S. 24). 


\section{A. Pflanzliche Organismen.}

I. Die Zellen sind farblos oder blaugrün und pflanzen sich nur durch einfache Zweiteilung fort, selten kommt noch eine einfache Konidienbildung hinzu; Kern meist nicht deutlich entwickelt .`. . . . . . . . . . . I. Schizophytae

$1^{*}$. Die Zellen entweder farblos oder grün (braun, rot) gefärbt und höher entwickelt . . . . . . . . . . . . . . 2

2. Die Zellen sind grün (braun oder rot) und assimilieren . II. Euphyceae

$2^{*}$. Dic Zellen sind farblos, Lebensweise saprophytisch oder parasitisch . . . . . . . . III. Fungi 


\section{Schizophytae}

(Spaltpflanzen).

Die niedrigsten Formen der Spaltpflanzen sind einzellige Organismen von kugeliger oder länglicher Gestalt. Fäden, die sich aus Zellenreihen zusammensetzen, sind nur bei den höheren Schizophyten entwickelt. Die Organisationsstufe sämtlicher Spaltpflanzen ist so niedrig, dass nicht einmal eine Differenzierung in Kern und Protoplasma vorhanden ist. Rudimentäre Andeutungen eines Kernes sind wohl in dem sogenannten Centralkörper der Bakterien und Spaltalgen zu sehen. Auch die Art der Fortpflanzung, die der ganzen Gruppe den Namen gegeben hat, verharrt auf der tiefsten Entwicklungsstufe; sie erfolgt durch einfache Zweiteilung. Jede Andeutung einer geschlechtlichen Fortpflanzung fehlt; hingegen ist die Bildung von Dauersporen nicht selten. Einer grossen Anzahl von Formen kommt Bewegungsfähigkeit $z u$.

Die Spaltpflanzen bilden eine ziemlich natürliche Gruppe, die sich in zwei Klassen zerlegen lässt. Die Vertreter der ersten Klasse, die Bakterien, erinnern in manchen Punkten an die Tiere. Die Spaltalgen hingegen müssen bereits als typische Pflanzen angesprochen werden.

I. Zellinhalt farblos oder rosa (selten chlorophyll-grün)

I. K1. Bacteriaceae

I*. Zellinhalt mehr oder weniger blaugrün gefärbt

II. K1. Schizophyceae

\section{Bacteriaceae, Schizomycetes}

(Bakterien, Spaltpilze).

Litteratur:

Cohn, F., Untersuchungen über Bakterien. (In den Beiträgen zur Biologie der Pflanzen. Breslau 1870-1876). 
Koch, R., Die Aetiologie der Milzbrandkrankheit, begründet auf die

Entwicklungsgeschichte des Bacillus anthracis. (Ebenda 1876).

Zopf, W., Die Spaltpilze, III. Aufl. 1885.

De Bary, A., Vorlcsungen über Bakterien, II. Aufl. 1887.

Von modernen Schriften seien nur einige allgemeineren Charakters genannt:

Flügge, Die Mikroorganismen, II. Auf. 1886.

Fraenkel, Grundriss der Bakterienkunde. Berlin 1887.

Günther, Einführung in das Studium der Bakteriologie. V.Aufl. Lpzg. 1898. Macé, Traité pratique de Bactériologie, II. Ed. Paris 1891.

Hueppe, Naturwissenschaftliche Einführung in das Studium der Bakterien.

Wiesbaden 1896.

MIigula, A., Schizomycetes in Engler-Prantls Natürl. Pflanzenfamilien. Leipzig $\mathbf{1} 895$.

Migula, A., System der Bakterien. Handbuch der Morphologie, Entwicklungsgeschichte und Systematik der Bakterien. I. Allg. Teil. Jena I 897.

Lafar, Fr., Technische Mykologie. Ein Handbuch der Gärungsphysiologie. I. Schizomyceten-Gärungen. Jena 1897.

Fischer, A., Vorlesungen über Bakterien. Jena 1897.

Winzige Tyrannen und Titanen der Schöpfung sind die Bakterien. Ueberall sind sie vorhanden, in Luft und Erde und Wasser; namentlich aber sammeln sie sich in gewaltigen Heerscharen überall, wo organische Reste der Fäulnis anheimfallen. Jeder Wassertropfen, den man mit dem Mikroskope durchforscht, zeigt eine Fülle von Bakterien, die teils vollkommen unbeweglich zwischen toten wie lebenden Algen lagern, teils mit lebhaften Bewegungen im Wasser umherschiessen oder unter schraubenartigen Windungen sich vorwärts schlängeln. Und wer gar leichtfaulende Substanzen, wie Fleisch oder Erbsen, mit Wasser übergiesst, und dann das Gefäss einige Tage sich selbst überlässt, bis eine Trübung der Flüssigkeit eine reichliche Bildung von Bakterien anzeigt, der wird mit Bewunderung das Gewimmel und Getümmel dieser Liliput-Organismen betrachten. Ja, wenn die Bakterien in solchen Kulturen nicht einzeln im Wasser umherschwärmen, sondern zu Tausenden und aber Tausenden in eine Gallerthülle als sog. "Zoogloca" eingebettet still beisammen liegen, so kann man schon mit unbewaffnetem Auge ihre Ansammlungen wahrnehmen. (Vgl. Taf. I, 25).

Reich wie die Individuenzahl ist auch die Speziesanzahl der Bakterien. Alle diese verschiedenen Formen hier zu charakterisieren, würde eine ausserhalb des Rahmens dieses Buches liegende Aufgabe sein, schon aus dem Grunde, weil eine grosse 
Menge von Arten ohne langwierige Reinkulturen sich gar nicht bestimmen lässt. Von derartigen Formen sind nur einige wenige hier aufgeführt, um einen Einblick zu gewähren in die Fülle der subtilen Manöver und Cautelen, die der Bakteriologe auf Schritt und Tritt zu beachten hat. Dagegen fehlt es auch nicht an Spezies, die dem Bestimmer mehr Freude bereiten und ihren „werten Namen" leichter feststellen lassen.

Bei der ausserordentlichen Kleinheit der meisten Bakterien - die kleinsten mögen sich zum Menschen verhalten wie ein Sandkorn zum Montblanc (Cohn) - ist es von vornherein verständlich, dass erst die neueste Zeit, wo die Mikroskope und die mikroskopische Technik eine so gewaltige Vervollkommnung erfahren haben, einiges Licht über die Naturgeschichte der Bakterien verbreitet hat. Seit ihrer Entdeckung durch Leeuwenhoek hat man die Bakterien lange Zeit für Tiere gehalten, bis es Perty im Jahre $185^{2}$ gelang, Sporen dieser Organismen aufzufinden. Endlich hat Cohn im Jahre 1876 den endgültigen Beweis für die Pflanzennatur der Bakterien erbracht.

Trotz ihrer Winzigkeit spielen die Bakterien im Haushalte der Natur eine überaus wichtige Rolle. Die einen gehören als Erreger der gefährlichsten Krankheiten zu den furchtbarsten Geisseln der Menschheit; die andern erweisen sich in Flur und Feld als schätzenswerte Bundesgenossen des Menschen.

Die morphologischen Verhältnisse der Bakterien sind ausserordentlich einfach. Im grossen und ganzen giebt es nur drei Formen des Bakterienkörpers: Kugel, Stab bezw. Faden und Schraube. Die meisten Formen sind so klein, dass erst die stärksten Vergrösserungen ihren Körper plastisch hervortreten lassen. Die meisten Bakterien sind einzellige Pflanzen, doch bilden manche höher entwickelten Formen auch mehr oder weniger lange Fäden aus. Wie den Pilzen, so fehlt auch den Bakterien das Chlorophyll, mithin die Fähigkeit, den Kohlenstoff der Luft zu assimilieren. Ein deutlicher Kern ist ähnlich wie bei den Spaltalgen (Schizophyceen) in der Bakterienzelle nicht nachweisbar. Doch kann nach neueren Untersuchungen für einzelne Vertreter beider Pflanzengruppen das Vorhandensein eines Kernes oder kernähnlichen Organes nicht wohl bezweifelt werden. Die Anwesenheit einer Membran konnte A. Fischer nachweisen.

Ein Teil der Bakterien ist gänzlich bewegungslos und starr; die übrigen dagegen zeigen, wenigstens in bestimmten Lebens- 
perioden, eine sehr lebhafte Beweglichkeit. Als Bewegungsorgane dienen Geisseln, die entweder einzeln an einem Körperende oder zu Büscheln an beiden Polen stehen oder endlich über den ganzen Zellkörper verteilt sind. Die Geisseln selbst zu sehen, gelingt einem geübten Auge nur bei einigen grösseren Formen, wie Spirillum undula und Chromatium okcni, namentlich wenn man die Bakterien führende Flüssigkeit langsam auf dem Objektträger ohne Auflegen eines Deckglases eintrocknen lässt; bei allen übrigen bedarf es zur Sichtbarmachung der Bewegungsorgane einer komplizierten Präparation und Färbung.

Die Vermehrungsfähigkeit der Bakterien ist ganz ungeheuer. Die Fortpflanzung geschieht durch eine einfache Zweiteilung, was $\mathrm{zu}$ der Bezeichnung Schizomyceten Veranlassung wurde. Bei ungünstigen Ernährungsbedingungen tritt bei vielen Formen eine Sporenbildung auf, indem das Protoplasma sich unter Wasserverlust stark zusammenzieht und sich mit einer meist stark lichtbrechenđen Membran umgiebt. In neuen Nährlösungen keimen solche Sporen in kurzer Zeit wieder aus. Ausserdem sind bei den Fadenbakterien noch Conidien beobachtet worden. Es sind dies kleine Zellen, die aus dem Verbande gelöst und vom Wasser fortgeschwemmt die Stammväter never Fäden werden. In grellem Lichte erscheint das riesenhafte Fortpflanzungsvermögen der Bakterien durch Berechnungen Cohn's. Er geht aus von einem Bakterium und nimmt an, dass dieses in einer Stunde nur einmal sich teile. Nach 24 Stunden würde dann die Nachkommenschaft bereits $163_{14}$ Millionen betragen. Und schon nach $4 \frac{1}{2}$ Tagen würde der Ocean, d. h. ein Volum von 1350 Millionen Cubikkilometern, von der Nachkommenschaft dieses einen Bakteriums ausgefüllt sein. Natürlich kann in der Natur eine derartige Vermehrung niemals stattfinden, da die bald erfolgende Erschöpfung der Nährlösungen stets nur eine beschränkte Anzahl von Teilungen gestattet.

Die physiologischen Leistungen der Bakterien sind, ausserordentlich vielseitig. Manche Formen (chromogene Bakterien) scheiden Farbstoffe ab. Bekannt ist unter diesen namentlich der Bacillus prodigiosiss, der auf gekochten Kartoffeln und ähnlichen Substanzen in Form von blutroten Tröpfchen sich ansammelt und so zu der Sage von dem Hostien- oder Heiligenblute Anlass geben konnte. Das Blauwerden von Milch, die Grünfärbung des Eiters sind ebenfalls Wirkungen chromogener 
Bakterien. Andere Spezies leuchten des Nachts wie Phosphor, man nennt diese Arten photogen. Sie finden sich hin und wieder auf toten Fischen, an Fleisch und dergleichen. Einige davon sind neben gewissen Geisselinfusorien (Noctiluca miliaris) und kleinen Medusen Ursache des Mcerleuchtens. Wieder andere Formen erzeugen durch ihr lebhaftes Wachstum und ihre Atmung eine erhebliche, deutlich messbare Erwärmung ihrer Umgebung (thermogene Bakterien). Namentlich in feuchtem Heu sind solche Formen zu Hause, und hier kann die durch sie veranlasste Temperaturerhöhung so bedeutend werden, dass eine Selbstentzündung des Heues eintritt. Auch bei der Tabaksgärung und beim Flachsrösten spielen derartige Bakterien eine Rolle.

Und auch sonst begegnet man den Wirkungen der Bakterien auf Schritt und Tritt. Das Sauerwerden der Milch, die Umwandlung von Bier und anderen alkoholischen Flüssigkeiten in Essig sind Werke der Bakterien. Ferner sind sie als Fäulniserreger thätig und verrichten damit für die Pflanzenwelt einen überaus wichtigen Dienst, indem sie die für die Pflanzen unbrauchbaren Eiweissstoffe in assimilierbare Verbindungen überführen. Eine ähnliche wertvolle Leistung geht von den Erregern der Harnstoffgärung aus. Sie führen nämlich die stickstoffhaltigen Verbindungen des tierischen Harnes in Ammoniumkarbonat über, das alsdann, wiederum durch Bakterien (Nitritbakterien), in salpetrige Säure und schliesslich durch die sogenannten Nitratbakterien in Salpetersäure umgewandelt wird. So ist Gelegenheit zur Bildung von salpetersauren Salzen geboten, die dann von den Pflanzen aufgenommen werden können. Noch andere Formen besitzen das Vermögen, den elementaren Stickstoff der Luft zu assimilieren. Diese Spezies leben in den Wurzelknöllchen der Hülsengewächse und führen diesen die nötige Stickstoffnahrung zu. Selbst bei der Bereitung von Butter und Käse helfen Bakterien mit und werden so dem Landwirte zur unentbehrlichen Hülfskraft.

Freilich fehlt es auch nicht an schädlichen Formen. Wenn in Zuckerfabriken plötzlich über Nacht ganze Bottiche voll Rübensaftes in eine unbrauchbare Gallerte umgewandelt sind, so ist hierfür ein Bakterium, der Froschlaichpilz (Streptococcus mesenterioides) verantwortlich zu machen. Andere Spezies machen in Brauereien das Bier schleimig und fadenziehend, oder verderben im Haushalte Speisen und Getränke. Bei weitem schäd- 
licher noch sind die Wirkungen zahlreicher Bakterien, die als Krankheitserreger thätig sind. Es war im Jahre 1855, als zwei deutsche Aerzte im Blute milzbrandkranker'Tiere zuerst Bakterien entdeckten. 1868 geschah das Gleiche bei Diphtherie und beim Rückfalltyphus. Aber erst 1876 gelang es Robert Koch den unzweifelhaften Beweis zu erbringen, dass die gefundenen Bakterien in der That die Ursache jener Krankheiten waren. Die Folgezeit lehrte dann fast bei allen Infektionskrankheiten Bakterien als Erreger ausfindig machen. Den schädlichen Einfluss der Bakterien erklärt man sich durch die Annahme, dass deren Exkretstoffe, Toxine genannt, furchtbare Gifte für den Körper sind. Zahlreiche Forscher wie Koch, Pasteur, Roux, Behring haben sich mit der Bekämpfung der Bakterien beschäftigt und die Serumtherapie ausgebaut, die auf dem Gedanken fusst, durch spezifisch wirkende Antitoxine den Einfluss der Toxine zu paralysieren.

Die Ernährung der Bakterien ist bei den niedrigsten Formen (Fischers prototrophen Bakterien) ausserordentlich einfach. Diese Arten nehmen nicht das geringste Quantum organischer Nahrung auf. Es gehören hierher die Salpeterbakterien sowie die Stickstoffbakterien der Leguminosen. Nur ganz geringe Mengen organischer Nahrung verbrauchen die Schwefel- und Eisenbakterien. Eine zweite Gruppe, die metatrophen Bakterien, besteht aus echten Fäulnisbewohnern (Saprophyten). In Flüssigkeiten mit reichlichem organischen Materiale, so z. B. in den Darmhöhlungen der Tiere, sind derartige Formen zu Hause. Manche von ihnen, so der Cholera- und Milzbrandbazillus, können auch sekundär als Parasiten auftreten und erinnern hierdurch an die dritte Gruppe, an die paratrophen Bakterien, die ausschliesslich als Parasiten leben und von den Körpersäften ihrer Wirte sich nähren. Nach ihrem Verhältnisse zum Sauerstoff teilt man die Bakterien ein in ärobe und anaërobe, je nachdem ihr Wachstum durch die Anwesenheit von Sauerstoff begünstigt oder gehemmt wird.

Von besonderem Interesse ist der Stoffwechsel der Schwefelbakterien, der Beggiatoen und der zahlreichen anderen jener Formen, die auch ohne Anlegung von Kulturen leicht zu bestimmen sind. Sie finden sich überall, wo organische Reste in Zersetzung begriffen sind, so an stillen Buchten von Teichen, in toten Meeresarmen, in den Versuchsschalen des Laboratoriums, in denen absterbende Algen, Rhizome und Aehnliches einige Wochen 
unter Wasser stehen. Der Boden solcher Gefässe ist bedeckt mit schwarzem Schwefeleisen, dem Endprodukte der Eiweisszersetzung einiger Bakterien. Auf den faulenden Stoffen lagert ein Häutchen, wie Spinnengewebe so zart, von meist weisser, selten rosaer bis weinroter Färbung. Gleichzeitig macht sich der charakteristische, an faule Eier erinnernde Geruch des Schwefelwasserstoffes bemerkbar.

Dieser Schwefelwasserstoff ist keineswegs ein Ausscheidungsprodukt der Bakterien,' sondern er dient ihnen als Nahrung. Wie nämlich die grünen Pflanzen mit Hülfe des Sonnenlichtes aus der Kohlensäure der Luft den Kohlenstoff zu gewinnen vermögen, um ihn zum Aufbau,der Kohlehydrate, d. h. der zum Veratmen dienenden Substanzen zu verwerten, so gewinnen die Schwefelbakterien aus dem Schwefelwasserstoff den Schwefel, speichern ihn in Form von dunkeln, stark lichtbrechenden Kügelchen von ölartiger Konsistenz im Innern ihrer Zellen auf, um ihn dann oxydiert als Schwefelsäure wieder abzugeben. Eine ganze Anzahl dieser Schwefel-Bakterien ist rot gefärbt durch einen Farbstoff, den Ray Lankester Bacteriopurpurin getauft hat, und dessen Spektrum mit dem des Chlorophylles gewisse Aehnlichkeit besitzt. Die Behauptung Engelmanns, jener Farbstoff diene unter Beihülfe der Energie des Sonnenlichtes der Kohlensäure-Assimilation, ist daher überaus wahrscheinlich und wird auch durch das biologische Verhalten dieser Formen unterstützt

Eine andere Gruppe, die ebenfalls einen anorganischen Stoff als Energiequelle benutzt, bilden die Eisenbakterien, für die Leptothrix ochracea als Prototyp genannt sei. Diese Formen sammeln in ihren Scheiden reichlich Eisenhydroxyd, das sie aus dem Ferrokarbonat des Wassers gewinnen. Infolge dieses Eisengehaltes zeigen die Eisenbakterien meist eine gelbe Färbung.

Die meisten Bakterien vermögen in Flüssigkeiten einer Temperatur von $100^{\circ} \mathrm{C}$. nicht $\mathrm{zu}$ widerstehen. Hierauf beruht die Anwendung der Siedehitze zur Sterilisierung von Operationsinstrumenten, sowie der Milch und zahlreicher Konserven. Bei Anwendung von trockener Hitze jedoch ist eine Temperatur von $160^{\circ}$ zur Abtötung der Bakterien erforderlich. Die Sporen einiger Formen sind noch widerstandsfähiger." Oft genügt $\mathrm{zu}$ deren Vernichtung nicht einmal ein einstündiges Kochen. $\mathrm{Zu}$ diesen Arten gehört z. B. der Heubazillus (Bacillus 
subtilis), von dem man sich auf Grund dieser Eigenschaft sehr leicht eine Reinkultur anlegen kann. Man nehme eine Hand voll trockenes Heu und lasse es in cinem Gefässe etwa 4 Stunden lang mit cin wenig Wasser stehen. Die dann abgegossene bräunliche Flüssigkeit enthält neben zahlreichen anderen Spezies auch Sporen des Hcubazillus. Alle diese Begleiter lassen sich leicht abtöten, wenn man die Flüssigkeit in einem mit Deckel versehenen Gefässe etwa eine halbe Stunde lang kochen lässt. Dann bleibe das Gefäss, ohne geöffnet $z u$ werden, bei einer Temperatur von $20-36^{\circ} \mathrm{C}$. mehrere Tage lang stehen, bis sich auf der Oberfläche der Flüssigkeit die „Kahmhaut" bildet, die aus sporenbildenden Zellen und Schwärmern des Bacillus subtilis besteht.

Das System der Bakterien endlich ist keineswegs schon genügend erforscht. Dies hat seinen Grund vor allem darin, dass eine ganze Reihe von Bakterienspezies pleomorph ist, d. h. die verschiedensten Formen annehmen kann. So können z. B. kugelige Arten unter bestimmten Kulturbedingungen $\mathrm{zu}$ fadenbildenden werden. Diesen Verhältnissen tragen die Einteilungsversuche der Bakterien mehr oder weniger Rechnung. Das beste System ist wohl das von Fischer, jedoch ist es von einer gewissen Schwerfälligkeit nicht ganz freizusprechen. Dem folgenden liegt die von Migula im Jahre 1897 gegebene Einteilung zu Grunde.

I. Nicht fadenförmig.

2. Körper völlig kugelrund, höchstens eiförmig; Teilung nach einer oder mehreren (zwei bis drei) Richtungen des Raumes; Sporenbildung selten

I. Fam. Coccacéae (S. 33)

2*. Körper viel länger als breit; Teilung nur nach einer Richtung des Raumes . . . . . . . . . . . 3

3. Zellen mehr oder weniger cylindrisch, gerade. . II. Fam. Bacteriaceae (S. 36)

$3^{*}$. Zellen schraubig gewunden

III. Fam. Spirillaceae (S. 40)

I*. Fadenförmig (Desmobacteriaceae)

4. Mit fester Hülle und Scheide

IV. Fam. Chlamydobacteriaceae (S. 43)

$4^{*}$. Ohne Scheide, unverzweigt

V. Fam. Beggiatoaceae (S. 47) 


\section{Fam. Coccaceae}

(Kugelbakterien).

I. Zellfamilien in eine feste, deutlich abgegrenzte Gallertkapsel eingeschlossen . . . . . . . . . I. Ascococculs (S. 33)

$1^{*}$. Zellfamilien nicht in solche Gallerte eingeschlossen . . . 2

2. Zellteilung nur nach einer Richtung des Raumes (es entstehen rosenkranzförmige Ketten) 2. Streptococcus (S. 34)

$2^{*}$. Zellteilung nach mehr als einer Richtung des Raumes 3

3. Zellteilung nach zwei Richtungen (es entstehen Zellflächen) . . . . . 3. Lampropedia (S. 35)

$3^{*}$ : Zellteilung nach drei Richtungen (es entstehen Zellhaufen) . . . . . . . . . . . . 4

4. Die Zellen liegen stets regelmässig in Paketform . . . . . 4. Sarcina (S. 35)

$4 *$ Die Zellen bilden unregelmässige Zellhaufen 5

5. Die Zellhaufen bilden kompakte Massen

5. Micrococcus (S. 36)

$5^{*}$. Die Zellhaufen stellen (im Alter) zerrissene, gallertige Hohlkugeln dar, Färbung rosa .

6. Lamprocystis (S. 36).

\section{Ascococcus Billroth (Gallertkokken).}

Die meist kleinen Zellen in kompakten Haufen zusammengelagert, von einer meist hornigen Gallertmasse umschlossen.

ı. Zellen rosa gefärbt (Schwefelbakterien) . . . . . . . . 2

2. Teilung nach einer Richtung des Raumes

2*. Teilung nach drei Richtungen . . . . . . . . . 3

I. A. gelatinoszes

3. Zellen schwärmfähig; Familien klein, einzeln oder $\mathrm{zu}$ mehreren von einer Gallertcyste umgeben . . 4

4. Kokken $2,7-5,2 \mu$ gross 2. A. violaceus

$4^{*}$. Kokken nicht über i $\mu$ 3. A. nufus

$3^{*}$. Zellen nicht schwärmfähig; Familien auf dem Substrate flach ausgebreitet, aus kugeligen, in gemeinsamer Gallerte locker ausgebreiteten Zellen

4. A. roseo-persicinus

I*. Zellen nicht rosa, nicht schwefelhaltig 5. A. billrothi 
I. Asc. gelatinosus (Win.) Kirchn. (= Thiothece gel. Win.). Entspricht in der Art des Wachstums der Alge Aphanothece (S. 54) Färbung der Zellen, die auch in den Schwärmzustand übergehen können, grauviolett; kleine Schwefelkörner.

2. Asc. violaceus (Win.) Kirchn. (= Thiocystis viol. Win.).

Bei dieser und der folgenden Art quillt die ziemlich dicke Gallerte stark auf, ehe sie die schwärmenden Zellen entlässt; Farbe hellrosa bis rötlichviolett.

3. Asc. rufus (Win.) (= Thiocystis ruf. Win.).

Der vorigen ähnlich, doch kleiner und von intensiverer Farbe, violettrot, selbst braunrot, bei Schwefelreichtum selbst schwarz erscheinend.

4. Asc. roseo-persicinus (Win.) (= Thiocapsa r.-p. Win.).

Entspricht der Alge Aphanocapsa (S. 53).

5. Asc. billrothi Cohn (Taf. I, I).

Die ungefärbten Familien, meist mehr oder weniger kugelig, bis $200 \mu$ im Durchmesser gross, bilden auf faulenden Flüssigkeiten rahmartige, gelblichweisse Ueberzüge, die einen intensiven Käsegeruch verbreiten.

\section{Streptococcus Billroth (Kettenkokken).}

Die Zellen hängen nach der Teilung längere oder kürzere Zcit zusammen, so dass oft lange, rosenkranzförmige Reihen entstehen (Taf. I, 3), doch können auch nur 2 vereint bleiben (Diplococcusform) oder die Zellen sich sofort trennen. Einige haben dicke Gallerthüllen.

I. Zellen rosa gefärbt . . . . . . . . . . . . . . 2

2. Zellen $2,8-3,4 \mu$ gross. . . . . . . 1. Str. roseus

$2^{*}$. Zellen kaum $0,5 \mu$ gross . . . . . . 2. Str. granula

I*. Zellen ungefärbt: viele Formen, wie Str. lacteus Schroeter, der im Wasser gebogene Ketten von 3-25 Zellen bildet, Str. cincreus Zimmermann und Str. margaritaccus Schroeter; sie sind ohne Kultur kaum zu unterscheiden.

1. Str. roseus (Win.) (= Amoebobacter ros. Win.) (Taf. I, 2).

Diese und die folgende Art bilden hellilafarbene, bewegliche Familien, die wie Amoeben auf dem Substrate kriechen. Die Zellen sind kurz vor der Teilung $6 \mu$ lang. 
2. Str. gramula (Win.) (= Am. granula Win.).

Ausserordentlich klein, je ein Schwefelkorn.

Von einer gewissen Bedeutung war besonders früher der Str. (Lenconostoc) mesenterioides (Van Tiegh.) Mig., der durch die sog. Dextrangärung in den Zuckerfabriken schädlich wird (vgl. S. 29).

\section{Lampropedia Schroeter (Tafelkokken).}

Entspricht im allgemeinen der Gattung Merismopedia (S. 55) unter den Schizophyceen. Leicht mit der folgenden Gattung zu verwechseln.

I. Zellen mit Eisenhydroxydhülle . . . . I. L. ochracea I*. Zellen ohne Eisen . . . . . . . . . . . . . . . . 2

2. Zellen farblos . . . . . . . 2. L. hyalina

$2^{*}$. Zellen rosa gefärbt . . . . . 3. L. rosea

I. L. ochracea Mettenheimer.

Eisenbakterium, mit Leptothrix ochracea und Gallionella ferruginea zusammen, selten.

2. L. hyalina Schroeter.

In bis $18 \mu$ breiten Tafeln $z u 4-16$ Zellen vereinigt. In Sumpfwasser.

3. L. rosea (Win.) (= Thiopedia ros. Win.) (Taf. I, 4).

Schwefelhaltig, schwärmfähig. Unter andern Schwefelbakterien.

\section{Sarcina Goodsir (Paketkokken).}

Bildet ganz regelmässige Pakete, wie Warenballen (Taf. I, 5).

I. Zellen $2 \mu$ dick . . . . . . . . . . . . . . . . 2

2. Zellen farblos . . . . . . . I. S. paludosa

$2^{*}$. Zellen rosenrot . . . . . . . 2. S. rosea

I*. Zellen höchstens $\mathrm{r} \mu$ dick . . . . . . . . . . . . . 3

3. Zellen mit Eigenbewegung. . . . S. mobilis

3*. Ohne Eigenbewegung: hierher gehören Formen wie S. Alava De By., S. lutea Schroeter etc., die ohne Kultur nicht zu unterscheiden sind. 
I. S. paludosa Schroeter.

Besonders in Zucker- und Stärkefabrikabwässern, bis zu 64 Zellen im Pakete.

2. S. rosea Schroeter (= Thiosarcina ros. Win.) gehört zu den Schwefelbakterien.

Die bekannteste Art dieser Gattung, S. ventriculi Goodsir, die vielleicht eine Sammelspezies ist, lebt im Magen von Kranken, wahrscheinlich jedoch, ohne schädlich zu sein.

5. Micrococcus Cohn (Kokken).

Sehr häufig im Wasser anzutreffen, doch wird höchstens die eine, rosagefärbte Art, $M$. ruber zu bestimmen sein; die zahlreichen andern, wie M. agilis Ali-Cohen, M. luteus Cohn etc. sind nur durch Kultur zu unterscheiden.

1. M. ruber (Win.) Mig. (= Thiopolycoccus rub. Win.) (Taf. I, 6) Zellen $\mathrm{I}-2 \|$ gross, Schwefelbakterium.

Interessant ist noch der $M$. aureus Aut. (= M. pyogenes aurcus Schroeter), der in Wundeiter, doch auch in Kanalwasser zu finden ist, desgl. der $M$. ureae Leube, der mit mindestens noch zwei anderen Bakterien die ammoniakalische Harnstoffgärung verursacht.

6. Lamprocystis Schroeter (Rote Wasserblüte).

L. roseo-persicina (Cohn) Schroeter (Taf. I, 7).

Ein interessantes Schwefelbakterium, das in der Jugend rosafarbene, solide Kugeln, im Alter grosse Hohlkugeln darstellt, die zuletzt zerreissen, so dass netzartig durchlöcherte Lappen entstehen; Zellen bis ca. $2 \mu$ gross. In Sümpfen und Abzugsgräben, bildet häufig mit Algen und Oscillatorien etc. die sog. Wasserblüte. (Vgl. dazu Clathrocy'stis S. 55).

\section{Fam. Bacteriaceae (Stäbchenbakterien).}

Die Zellen sind immer länger oder kürzer stäbchenförmig, können jedoch auch zu längeren Fäden auswachsen. Beweglich oder unbeweglich, häufig mit Sporenbildung. 
I. Zellfamilien in fest abgegrenzter Gallerthülle; rosa gefärbt . I. Cystobacter (S.37)

I*. Ohne feste Gallerthülle . . . . . . . . . . . . . . 2

2. Zellen rot gefärbt . . . . . . . . . . . 3

3. $\mathrm{Zu}$ Familien vereinigt . 2. Thiodictyon (S. 37)

$3^{*}$. Zellen immer einzeln . . . . . . . . . . . 4 4. Zellen cylindrisch-elliptisch . . . . . .

3. Chromatium (S. 38)

$4^{*}$. Zellen stab- bis spindelförmig

4. Rhabdochromatium (S. 38)

2.* Zellen nicht rosa gefärbt. . 5. Bacillus (S. 39).

1. Cystobacter Schroeter (Gallertbakterien).

Die Gallerthülle mit fester, hornartiger Aussenhaut; die Zellen sclber stellen kurze, dünne Stäbchen dar, die später zu längeren Fäden zusammenhängen. Fleischrot, meist in schwefelwasserstoffhaltigem Wasser.

I. Zoogloeen kugelig, stellenweise darmartig gewunden . . . I. C. fuscus

I*. Zoogloeen cylindrisch-keulenförmig, nach unten verdünnt. .

2. C. erectus

1. C. fuscus Schroeter

Die Kolonie wird zuletzt zu einer $30-60 \mu$ langen und 20 bis $30 \mu$ breiten, kastanienbraunen . Cyste.

2. C. erectus Schroeter

Gleicht der vorigen, bildet bis $80 \mu$ lange Gallertklümpchen.

\section{Thiodictyon Win.}

Umfasst nur rote Schwefelbakterien.

1. Zellen mindestens $5 \mu$ lang .. I. Th. elegans

I*. Zellen höchstens $2,4 \mu$ lang . . 2. Th. bacillosum

1. Th. elegans Win. (rotes. Wassernetz) (Taf. I, 8).

Gleicht einem verkleinerten Hydrodictyon-Netze, da die Zellen sich mit ihren Enden netzartig zusammenlegen. Zellen $5 \mu$ lang, I,7 $\mu$ dick, vor der Teilung doppelt so lang. Häufig.

2. Th. bacillosum (Win.) (= Amoebobacter bac. Win.).

Zellen gleichen der vorigen Art, sind nur kleiner $(\mathrm{I}, 7 \mu$ dick und 2,4 $\mu$ lang); die Familien amoeboid beweglich. Hier und da. 


\section{Chromatium Perty.}

Verhältnismässig sehr grosse, rosa gefärbte Formen, die infolgedessen schon oft zum Studium der Plasmastruktur der Bakterienzelle herangezogen sind. Wegen ihrer Grösse und Aehnlichkeit mit einigen Flagellaten (Monas) werden sie vielfach diesen zugerechnet, unterscheiden sich von ihnen aber durch das Fehlen einer kontraktilen Vakuole, leiten aber jedenfalls zu ihnen über. Die meisten tragen eine Geissel am einen Ende (ob alle?). Alle fünf Formen sind Schwefelbakterien, kommen also nur in schwefelwasserstoffhaltigem Wasser vor.

I. Dicke der Zellen über $5 \mu$. . . . . I. Ch. okeni

${ }^{*}$. Dicke der Zellen unter $5 \mu$. . . . . . . . . . . . 2

2. Zellen $4,2 \mu$ dick . . . . . 2. Ch. weissi

$2^{*}$. Zellen $3 \mu$ dick . . . . . . . 3. Ch. minus

$2^{* *}$. Zellen 2, $1 \mu$ dick . . . . . . 4. Ch. vinosum

$2^{* * *}$. Zellen $\mathrm{I}-\mathrm{I}, 2 \mu$ dick . . . . . 5. Ch.minutissimum

I. Chr. okeni (Ehrbg.) Perty (Schwefeltönnchen) (Taf. I, 9).

Das interessanteste, weil grösste, Bakterium; es wird $8 \mu$, vor der Teilung bis $15,3 \mu$ lang und $6-6,3 \mu$ dick. Seine Vorwärtsbewegung ist ziemlich schnell, aber gleichmässig. Es zeigt, die Erscheinung der "Schreckbewegung“: bei plötzlicher Verdunkelung des Gesichtsfeldes - durch ein Stückchen Papier oder einen vorgehaltenen Finger - unterbricht es seine Vorwärtsbewegung momentan, um sich erst einige Zeit im Kreise zu drehen, ehe es in gerader Richtung weitereilt (vgl. S. 28).

Mit den folgenden Arten ist es eine gewöhnliche Erscheinung unter den roten Schwefelbakterien.

2. Chr. weissi Perty.

Etwa $5,7-5,9 \mu$, vor der Teilung $1 \mathrm{I}-11,5$ lang.

3. Chr. minus Win.

3,5-7 $\mu$ lang.

4. Chr. vinosum (Cohn) Win.

$5 \mu$ lang.

5. Chr.minutissimum Win. Zellen elliptisch, sehr klein. Häufig in schwefelwasserstoffhaltigem Wasser.

\section{Rhabdochromatium Win.}

Gleicht der Gattung Chromatium, doch mehr stab- und spindelförmig, rosagefärbt und schwefelhaltig. 
I. Dicke der Zellen 2,5-7 $\mu$. . . . . . . . . . . . 2

2. Länge der Zellen $15-30 \mu$. . . I. Rh. roseum

$2^{*}$. Länge der Zellen 5-10 $\mu$. . . 2. Rh. minus I*. Dicke der Zellen 8,5 . . . . . . 3. Rh. fusiforme

I. Rh. roseum (Cohn) Win. ('Taf. I, Io).

Bildet unter bestimmten Kulturbedingungen kürzere oder längere Fäden; reich an Schwefelkörnern.

2. Rh. minus Win. ist arm an Schwefel.

3. Rh. fusiforme Win.

Reich an Schwefel. Der Körper geht ganz allmählich in die Geissel über; 25-50 $\mu$ lang, also das längste bekannte, einzellige Bakterium.

\section{Bacillus Cohn (incl. Bacterium) (Stäbchenbakterien).}

Mehr oder weniger stäbchenförmig, mit oder ohne Sporenbildung. Sehr zahlreiche, ohne weiteres kaum zu unterscheidende Arten. Die alten, ohne Kultur aufgestellten Spezies wie B. termo (Ehrbg.), das „Fäulnisbakterium“, B. lineola (O. F. Müller), u. a. lassen sich heute kaum wiedererkennen und umfassen jedenfalls mehrere Arten.

Den B. subtilis Cohn („Heubazillus“) (Taf. I, I I) kann der Anfänger sich leicht in Reinkultur züchten (vgl. Seite 3I); er ist ungefähr $6 \mu$ lang und $I-I, 5 \mu$ breit; durch die über den ganzen Zellkörper verteilten zahlreichen Geisseln lebhaft bewegt. Vor der Sporenbildung in lange Fäden auswachsend, die sich an der Oberfläche der Flüssigkeit als sog. Kahmhaut sammeln. Nachdem die Fäden sich durch Querwände gegliedert haben, scheiden sie in jeder Zelle eine $1,2 \mu$ lange und $0,6 \mu$ breite Spore $\mathrm{ab}$; diese keimt, indem sie einen seitenständigen Schlauch bildet, der zum Schwärmer wird.

Eine andere grosse Form kommt dem Beobachter bei der Wasseruntersuchung vielfach vor Augen:

B. megatherium De By.; Zellen bis 1о $\mu$ lang, $2,5 \mu$ dick, beweglich, oft in kürzeren oder längeren Ketten, durch das Gesichtsfeld „wackelnd“.

Die übrigen z. T. im Wasser sehr häufigen Arten wie B. subtiliformis, vulgatus, fuorescens, vulgaris, coli etc. müssen hier unberücksichtigt bleiben. Interessant ist eine ganze Reihe 
pathogener und sonstiger Formen, von denen hier unter den chromogenen Formen der Bac. prodigiosus (vgl. S. 28), unter den Krankheitserregern der B. anthracis (Milzbrand), B. tctani (Starrkrampf), B. typhi (Unterleibstyphus) genannt seien.

\section{Fam. Spirillaceae}

(Schraubenbakterien).

Durch ihre mehr oder weniger ausgeprägte Schraubengestalt sind die Spirillaceen wohl die auffälligsten und interessantesten Wasserbakterien. Die meisten stellen deutlich ausgebildete Schrauben oder Teile einer Schraube, die keine volle Umdrehung zeigen, dar. Ihre Vorwärtsbewegung geschieht durch Bewegen der polaren Geisseln, wodurch sie sich oft ziemlich schnell vorwärts schrauben. Dadurch, dass sie bald vor-, bald rückwärts eilen, beleben sie das mikroskopische Bild ausserordentlich, zumal wenn zahlreiche Formen, wie dies in Faulfüssigkeit der Fall ist, vorhanden sind.

I. Zellen in scharf abgegrenzter Gallerthülle

I. Myconostoc (S. 40)

1*. Zellen nicht in Gallerte. . . . . . . . . . . . . . 2

2. Zellen kurz, nur halbkreisförmig gekrümmt (,kommaförmig"); selten (in Kultur!) längere, biegsame Schrauben; unbeweglich oder mit einer polaren Geissel . . . . .

2. Microspira (S. 41 )

2*. Zellen länger, schraubenförmig gewuinden . . . . 3

3. Schrauben starr, verhältnismässig kurz; mit polaren Geisselbüscheln . . . . . . 3. Spirillum (S.41)

$3^{*}$. Zellen mit vielen (über 100) Schraubengängen, rasch beweglich . . . . . 4. Spirochacte (S.42).

I. Myconostoc Cohn (Gallertschraubel).

Eine Art M. gregarium Cohn (Taf. I, 12).

Es bildet $10-17 \mu$ grosse Gallertkugeln, in denen die farblosen, durcheinander geschlungenen, etwa $2 \mu$ breiten Fäden. eingeschlossen sind. Ist vielleicht die Entwicklungsform eines Fadenbakteriums. In Sumpfwasser, verpesteten Bachläufen, auch in Wasser, worin Algen faulen, besonders im Winter. 
2. Microspira Schroeter (Kommabazillus).

Einige sehr schwer unterscheidbare Formen, unter denen auch der aus Indien stammende Cholerabazillus Micr. comma Schroeter (Taf. I, I3) sich befindet. Erst die peinlichsten Reaktionen und Beobachtungen können diesen Krankheitserreger von den zahlreichen anderen wasserbewohnenden „Vibrionen“ unterscheiden. Wir dürfen sie hier füglich übergehen.

3. Spirillum Ehrbg. (Wasserschraubel).

Alle mehr oder weniger stark schraubenförmig gekrümmt, doch starr und nicht biegsam.

Die rotgefärbten Arten und Spir. volutans gehören zu den Schwefelbakterien, halten sich also in Flüssigkeiten mit Schwefelwasserstoffgehalt auf, doch kommen auch die anderen Spirillen in meist stark verpestetem Wasser vor, also besonders in Abwässern der Zuckerfabriken und in andern organische Substanzen führenden Flüssigkeiten.

I. Zellen rotgefärbt

2. Höhe der Schraubengänge 9-12 2 1. Sp. sanguineum

$2 *$. Höhe der Schraubengänge $5 \mu$. . 2. Sp. rufum

1*. Zellen nicht rot gefärbt . . . . . . . . . . . . . 3

3. Mit stark lichtbrechenden (Schwefel)-Körnchen . . .

$3^{*}$. Ohne solche Körnchen

3. Sp. volutans

4. Nur bogenförmig gekrümmt (oder nur ein Schraubengang; auch in Ketten) . . . 4. Sp. rugula

4*. Mehrere Schraubengänge. . . . . . . . 5

5. Zellen weniger als I $\mu$ dick . . . . . . 6

6. Kaum messbar dicke Zellen

6*. Zellen $0,5 \mu$ und dicker

5. Sp. tenerrimum

7 Zellen $0,8-1 \mu$ dick 6. Sp. scrpens

$7^{*}$. Zellen dünner . . 7. Sp. temue

$5^{*}$. Zellen $1-\mathrm{I}, 5 \mu$ dick . . 8. Sp. undula

1. Sp. sanguincum (Ehrbg.) Cohn. (Taf, I, 14).

Schrauben etwa Io - $30 \mu$ lang und bis $3 \mu$ dick; die Schraubengänge 9-1 $2 \mu$ dick und 6- iо $\mu$ breit; schwach rosa. Ziemlich selten. 
2. Sp. rufum Perty.

8- $16 \mu$ lange Schrauben mit $\mathrm{I}-4$ Windungen von circa $5 \mu$ Höhe; Dicke der Zelle ${ }^{1}-I-2 \mu$; an den Polen Geisselbüschel von $6-18$ wellig gebogenen Geisseln.

Es tritt auf als blutrote Wolken oder als Schleimüberzug zwischen Algen. Häufiger als vorige Art.

3. Sp. volutans Ehrbg.

. Eine der grössten Formen; 30-50 $\mu$ lange, $2-2,5 \mu$ dicke Schrauben; die $3-5$ Umgänge haben eine Höhe von $10-15 \mu$. Mit kräftigen Geisselbüscheln an den Polen.

Wie die übrigen, in Wasser mit faulenden organischen Resten, besonders zwischen Beggiatoa.

4. Sp. mugula Winter. (Taf. I, I5).

Zellen $0,5-2,5 \mu$ dick, kurz halbkreisförmig, bilden Sporen an dem einen Pol, daher "Trommelschlägerform“. In Abwässern häufig.

5. Sp. tenerrimum Lehmann und Neumann.

Die kleinste Form, mit 3-4 sehr feinen Windungen.

6. Sp. serpens (O. F. Müller) Winter.

Die ı- $-30 \mu$ langen Schrauben haben $3-4$ sehr weite, fast wellenförmige Windungen. Vielfach in Sumpfwasser.

7. Sp. tenue Ehrbg.

Gleicht der folgenden Art, doch kleiner und zierlicher. Schraubenlänge $4-15 \mu$, I -5 Windungen von $2-3 \mu$ Höhe; Zellen o,8 $\mu$ dick. Nicht selten.

8. Sp. undula Ehrbg.

Häufig in Faulflüssigkeiten. Die $1,0-1,5 \mu$ dicken Zellen bilden Schrauben von $1 / 2-6$ Umgängen von $5 \mu$ Höhe. Auch hier ist Sporenbildung bekannt (vgl. S. 28).

(Sp. sputigenum ist ein Mundspirillum).

\section{Spirochaete Ehrbg. (Spiralfädchen).}

Der vorigen Gattung schr ähnlich, nur bedeutend länger (bis über $200 \mu$ ) und sehr biegsam und beweglich.

Sp. plicatilis Ehrbg. (Taf. I, 16).

Höchstens $0,5 \mu$ dicke Fäden mit sehr zahlreichen Windungen. In Sumpfwasser, doch immer vereinzelt. Es ist eine der unter- 
haltendsten Formen, da die blitzschneli sich bewegenden Fäden bald vor-, bald rückwärts sich schlängeln, Schlingen bilden und wieder lösen, kurz ein immer lebendiges mikroskopisches Bild darbieten.

$(S p$. obermeieri Cohn lebt während des Fiebers im Blute der am Rückfallfieber Erkrankten, $S p$. dcntium in der Mundhöhle von Gesunden).

IV. Fam. Chlamydobacteriaceae (Scheidenbakterien).

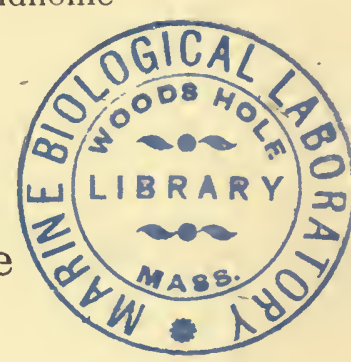

Die höchststehenden Bakterien, die mit der folgenden Familie zu den Schizophyccen (Cyanophycecn) überleiten und jedenfalls nahe verwandt mit ihnen sind. Die meist stäbchenförmigen Zellen bilden Fäden mit mehr oder weniger deutlichen Scheiden. Die Teilung geschieht gewöhnlich senkrecht zur Längsachse, also in einer Richtung, nach 3 Richtungen nur bei Crenothrix während der Konidienbildung. Letztere ist bei mehreren Formen beobachtet und besteht in der Ausbildung kleiner, des Umherschwärmens oder des Kriechens fähiger Zellen, die später zu neuen Pflanzen heranwachsen. Fäden unverzweigt, nur tritt bei einigen Formen eine unechte Verzweigung auf, insofern eine Zelle im Verbande an der folgenden vorbeiwächst und so zur Bildung eines scheinbaren Astes Veranlassung giebt. Ueberall, besonders zwischen faulenden Algen.

I. Fäden unecht verzweigt . . . . . . . . . . . . . 2

2. Fäden ziemlich dick, in schleimigen, weisslichen (selten rötlichen) Rasen . . . . . . I. Sphaerotilus (S. 44)

2*. Fäden zart, einzeln . . . . . . . . . . . . . 3

3. Mit kaum sichtbarer Scheide (Färbung mit Jod!) . 2. Cladothrix (S. 44)

3*. Mit zarter, aber deutlicher Scheide

3. Glaucothrix (S. 45)

I*. Fäden unverzweigt . . . . . . . . . . . . . 4

4. Mit Schwefelkörnern . . . 4. Thiothrix (S.45)

$4^{*}$. Ohne Schwefelkörner . . . . . . . . . . . . 5 
5. Zellfäden gleichmässig dick . . . . . . . . . 6

6. Fäden gerade, nicht schraubig gedreht .

\section{Leptothrix (S. 45)}

6*. Fäden meist um einander gewunden, bei schwacher Vergrösserung wie gegliedert aussehend .

6. Gallionella (S. 46)

5*. Fäden gegen die Spitze dicker . . 6. Crenothrix (S. 47).

\section{Sphaerotilus Kg. Sumpfbakterien.}

Sph. natans Kg. (Taf. I, I 7).

Die $(7-9 \mu$ langen) Zellen bilden etwa $2-3 \mu$ dicke Fäden in farblosen, ziemlich dicken Scheiden. Die immer in Büscheln zusammenhängenden Fäden bilden lange, weisse - auch rötliche - schlüpfrige, oft flutende Rasen in sehr stark verunreinigtem Wasser und sollen nach $\mathrm{Mez}$ widerlich süsslich riechen. Die Vermehrung geschieht durch Abgliederung von Fadenstücken. Sind sie makroskopisch dem Apodya-Rasen sehr ähnlich, so gleichen sie mikroskopisch der Cladothrix und Leptothrix, unterscheiden sich aber leicht durch die Verfilzung und die Verzweigung von diesen.

\section{Cladothrix Cohn (Wasserfaden).}

\section{Cl. dichotoma Cohn (Taf. I, I8).}

Viel zarter als vorige, nicht zu dicken Strängen verbunden, wenigstens nicht verflochten und in schleimigen Flocken. In weiten Abständen wiederholt gabelig geteilt, die Seitenäste laufen an der Basis eine zeitlang neben den Hauptfäden her. An der Spitze der Fäden bilden sich die Konidien, die dicht unterhalb des einen Pols ein Büschel Geisseln tragen, mittels deren sie umherschwärmen. Einige Zellen, die in den leeren Scheiden zurückbleiben, sind nach Migula vielleicht als Dauerzellen aufzufassen. Vielleicht umfasst diese Form mehrere Arten. Wohl überall; wenn auch nicht in grosser Anzahl in der freien Natur. Entwickelt sich aber in jeder, längere Zeit stehenden Wasserprobe reichlich.

Cl. bovis (= Actinomyces bovis Harz) kommt in Geschwüren des Rindes und auch des Menschen vor. 
3. Glaucothrix Kirchn. (Brunnenfaden).

Gl. putealis Kirchn. (Taf. I, I9).

Zarte Fäden, die nur wenig verzweigt sind; Zellen $2-4 \mu$ dick, $4-15 \mu$ lang. Die $3-8 \mu$ dicken Scheiden anfangs farblos, später dunkel braungelb gefärbt. Selten, in Brunnen.

4. Thiothrix Win. (Weisser Schwefelfaden).

Der Beggiatoa (siehe S. 47) sehr ähnlich, doch mit Scheide, und unbeweglich; reichlich mit Schwefelkörnern gefüllt. Fortpflanzung durch Stäbchenkonidien, die nach der Loslösung umherkriechen, ehe sie, in ein Gallertpolster festgeheftet, zu einem neuen Faden auswachsen.

I. Basis verdickt, $2-2,5 \mu$ dick, Spitze $1,4-1,5 \mu$ Th. nivea I*. Fäden gleichmässig dick . . . . . . . . . . . . 2

2. Ueber $1 \mu$ dick . . . . . . . . . Th. temuis

2*. $0,4-0,5 \mu$ dick . . . . . . . . . Th. tenuïsima

Alle 3 Formen:

Th. nivea Win. (Taf. I, 20),

Th. tenuis Win. und

Th. tenuissima Win.

wohl ebenso häufig wie Beggiatoa und an denselben Orten.

\section{Leptothrix $\mathrm{Kg}$.}

Dünnbescheidete, zarte Fäden, die festsitzen und durch Zerfall in Einzelzellen sich fortpflanzen.

1. Zellen anfangs farblos, zuletzt durch Eisen gelbbraun gefärbt I*. Zellscheiden immer farblos

I. L. ochracea

2. Zellen mit sehr dicker, gallertiger Scheide . . . . .

2. L. epiphytica

2*. Zellen mit zarter Scheide . . . . . . . . . . . 3

3. Fortpflanzung durch Zerfall der Fäden; auf Algen etc. festsitzend . . . . . . . 3. L. parasitica

$3 *$ Fortpflanzung durch hervortretende Konidien .. . 4 4. Festsitzend .. . . . . . 4. L. fuitans

$4^{*}$. $\mathrm{Zu}$ watteartigen Räschen verfilzt, frei zwischen Algen . . . . . . . 5. L. hyalina 
1. Lept. ochracea Kg. (Eisenbakterium).

Eins der Eisenbakterien, ausgezeichnet durch dic Ablagerung von Eisenhydroxyd in die Scheiden, die dadurch eine braune Farbe annehmen (vgl. S. 31 ).

Die sehr leicht zerbrechlichen Fäden etwa $2 \mu$ dick, anfangs farblos, später ockergelbe Schleimmassen bildend; die Zellen selbst farblos und häufig gebogen. In eisenhaltigen Quellen hin und wieder; wenn vorhanden, sehr zahlreich. (Hierher gehört vielleicht auch Gallionella ferruginea Ehrbg.).

2. L. epiphytica (Mig.).

Bildet kurze farblose Zellfäden in dicker Scheide, die auf Algen etc. festgeheftet sind.

3. L. parasitica Kg. (Taf. I, 21).

Wohl die häufigste Form, die man überall bei der Untersuchung frischen Wassers an Algen festgeheftet finden wird; Fäden sehr dünn, etwa I $\mu$ dick, mit langen, cylindrischen Zellen, farblose oder wenig gelbliche, ganz lockere Räschen bildend.

4. L. fuitans (Mig.).

Ebenfalls sehr dünne, bis $1 \mathrm{~cm}$ lange Fäden, die an Algen etc. festsitzen. Die fast kugeligen Konidien keimen gerne schon am Mutterfaden aus.

5. L. hyalina (Mig.).

Noch feiner wie vorige, kaum o,6 $\mu$ dick, nicht festgewachsen, sondern zu „wattenartigen Räschen" verflochten, frei zwischen Algen schwimmend.

Die sogenannte "Lept. buccalis" umfasste alle im Munde vorkommenden Bakterien und ist jetzt in eine ganze Reihe von Arten aufgelöst: in eine Lept. innominata, einen Bacillus, ein Spirillum sputigenum etc.

\section{Gallionella Ehrbg.}

G. ferruginea Ehrbg. (Taf. I, 22).

Zweifelhafte Gattung und Art, die in letzter Zeit zu Leptothrix ochracea gestellt wurde, nach Migula jedoch ein selbständiges Genus darstellt. Die Fäden sind meist, wie es auch bei Spirulina hin und wieder geschieht, umeinander geschlungen, jedoch unbeweglich. In eisenhaltigem Wasser, jedoch viel seltener als Lept. ochracea. 


\section{Crenothrix Cohn.}

Cr. polyspora Cohn (Grundwasserbakterium) (Taf. I, 23).

Hochentwickeltes Eisenbakterium. Die einzelnen, deutlich gegliederten Fäden sitzen mit der verdünnten Basis fest (Dicke der Fäden unten $1,5-5 \mu$, oben $6-9 \mu$ ). Bei der Vermehrung treten entweder einfach die Zellen des Fadens aus den Scheiden heraus, oder diese zerfallen vorher noch (durch Teilungen nach 3 Richtungen!) in grössere oder kleinere, unbewegliche Kügelchen, die - häufig schon auf der Mutterpflanze - zu neuen Individuen auswachsen. In eisenhaltigem Grundwasser, häufig bis $20 \mathrm{~m}$ tief in der Erde. Vermehrt sich besonders in Brunnen und Wasserleitungen, zuweilen mit Lept. ochracea zusammen, oft sehr bedeutend und ist dadurch schon Ursache von Wasserkalamitäten geworden, wie in den siebenziger Jahren in Berlin.

\section{Fam. Beggiatoaceae (Schwefelbakterien).}

Bilden wie die Vertreter der vorigen Familie Fäden, haben es aber noch nicht zur Ausbildung von Konidien gebracht und besitzen keine Scheiden. Den Oscillatorien der folgenden Klasse so nahe verwandt, dass man beide nur künstlich trennen kann.

\section{Beggiatoa Trev. (Schwefelbakterium).}

Häufigstes Schwefelbakterium; von den übrigen Formen, z. B. von Thiothrix durch die an die Oscillatorien erinnernde, gleitende und pendelnde Bewegung sofort zu unterscheiden. Die Beggiatoen bilden festgeheftete, lange, flutende oder freibewegliche, auf dem Substrate umherkriechende, weissliche Fäden. Die weisse Farbe rührt von dem reichen Inhalte an Schwefelkörnern her, die die Zellen ausfüllen.

Die trennenden Zellwände zwischen den einzelnen Zellen sind im frischen Zustande meist unsichtbar. Erst wenn in schwefelwasserstofffreiem Wasser Schwefelhunger eintritt, wodurch die Schwefelkörner verschwinden, oder bei Färbung treten die Zellwände bei allen Arten deutlich hervor (vgl. S. 30). Vermehrung durch Abtrennung einzelner Glieder. 
Sie kommen alle in stark verunreinigtem. Wasser, besonders Abzugsgräben aus Häusern und Fabriken vor, in denen sie oft den Grund mit ihren flutenden Rasen bekleiden. Treten in grösserer Anzahl meist nur im Winter auf. $\mathrm{Ob}$ die unten aufgeführten Arten alle aufrecht zu erhalten sind, ist fraglich, da Uebergänge zwischen ihnen nicht selten sind.

I. Dicke der Fäden $5-7 \mu$. . . . . I. B. arachnoidea

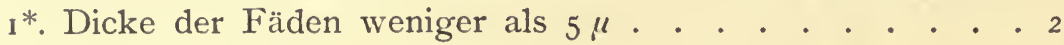

2. $3-4 \mu$ dick . . . . . 2. B. alba

$2^{*} .1-2,5 \mu$ dick . . . . . . . . 3. B. leptomitiformis

I. B. arachnoidea Ag.

Die dickste Form, soll die Zellwände auch im frischen Zustande deutlich erkennen lassen. Glieder $1 / 2-1$ Mal so lang als dick, Enden leicht gekrümmt.

2. B. alba (Vauch.) Trev. (Taf. I, 24).

Die gewöhnlichste, überall verbreitete Form.

3. B. leptomitiformis Trev.

Der vorigen ähnlich, nur dünner. Querwände ebenfalls undeutlich.

\section{Schizophyceae}

(Myxophyceae, Phycochromaceae, Cyanophyceae)

Spaltalgen, Blaualgen.

Litteratur:

Naegeli, C., Gattungen einzelliger Algen. Zürich 1849 .

Zopf, W., Morphologie der Spaltpflanzen. Lpzg. 1882.

Bornet, E. et Ch, Flahaut, Revision des Nostocacées hétérocystées

(Annales d. sc. nat. sér. VII. tomes III-VII), Paris 1886-1888.

Gomont, M., Monographie des Oscillariées. (Ebenda, tomes XV u. XVI), Paris 1892 .

Fischer, A., Untersuchungen über den Bau der Cyanophyceen und Bakterien. Jena 1897 .

Kirchner, O., Schizophyceae in Engler-Prantls Natürl. Pflanzenfam. I. I. Lpzg. 1898.

Die Schizophyceen bilden mit den Bacteriaceen die niederste Gruppe im Pflanzenreiche; sie unterscheiden sich von ersteren 
besonders durch den Mangel der Schwärmerbildung und durch Vorhandensein des "Phykochrom" genannten, blaugrünen Farbstoffes. Dieser stellt eine Mischung von Chlorophyll und „Phykocyan"“ dar und macht eine Assimilation der Kohlensäure der Luft möglich.

Die einfachsten Formen sind einzellige, einzeln lebende Organismen, während in den höheren Gruppen eine wenigstens lockere Zusammenlagerung in Gallerte statt hat, bis ein engerer Zusammenschluss in Fäden bei den differenziertesten Formen erreicht wird. Einige von diesen fadenförmigen Gattungen zeigen eine eigenartige, auch bei den Beggiatoen bekannte Ortsbewegung: sie gleiten, bei gleichzeitiger Drehung um ihre Längsachse, auf dem Substrate hin, dem sie durch eine Gallertscheide angeheftet sind.

Im Verlaufe dieser Fäden findet man bei einigen Familien grössere, gelbliche Zellen mit verdickter Membran und zwei Knötchen im Innern, „Grenzzellen“, „Heterocysten“, die mit der Fortpflanzung nur insofern zusammenhängen, als hier eine Trennung der Fäden statthaben kann.

Die Fortpflanzung verläuft immer ungeschlechtlich, lediglich durch Zweiteilung der Zellen. Bei den Fadenalgen verlässt meist ein aktiv bewegliches Fadenstückchen („Hormogonium“) die Scheide, um an anderer Stelle weiter zu wachsen. Bei einzelligen Formen können auch Konidien vorkommen, die in meist etwas vergrösserten Zellen, den "Konidangien“, entstehen und unmittelbar keimen. Auch Sporen- (Dauerzellen-) bildung ist bei vielen Familien die Regel.

Die Blaualgen kommen auf feuchter Erde oder im Wasser vor. $\mathrm{Da}$ sie meistens etwas sumpfiges Wasser lieben, so liegt der Gedanke nahe, dass sie trotz ihrer Assimilationsthätigkeit noch organische Nahrung aufzunehmen vermögen. Das Folgende ist vielfach eng an Kirchners Bearbeitung angeschlossen.

I. Vermehrung durch einfache Zellteilung oder durch Konidien ( 4 in einer Mutterzelle gebildet). Fflanzen einzellig, meist zu Familien vereinigt . . . . I. Coccogoneae (S. 50)

I*. Vermehrung durch fadenförmige, aktiv bewegliche Hormogonien; mehrzellige (ausgen.: Spirulina), einfache oder verzweigte, oft bescheidete Fäden . . II. Hormogoneae (S. 59). 


\section{Coccogoneae Thuret.}

I. Vermehrung geschieht nur durch vegetative Zellteilung 1. Chroococcaccae (S.50)

I*. Vermehrung durch Konidien, die sich in einer Mutterzelle bilden; Pflanzen epiphytisch auf Algen, meist in Spitze und Basis differenziert. . . . . 2. Chamaesiphonaceae (S. 57)

\section{Fam. Chroococcaceae.}

Einzellige, blaugrüne Algen; freilebend oder in Gallerte eingebettet. Zellteilung nach einer bis drei Richtungen des Raumes. Schwärmsporenbildung noch nicht sicher erwiesen, jedenfalls aber wegen der nahen Verwandtschaft zu Bakterien nicht unwahrscheinlich. ${ }^{1}$ )

I. Zellen einzeln lebend, d. h. ohne durch Gallerte zusammengehalten $\mathrm{zu}$ sein

2. Zellen kugelig . . . . I. Chroococcus (S. 5I)

2*. Zellen länglich . . ... . . . . . . . . . 3

3. Zellen cylindrisch, nicht spindelförmig. . . . . 4

4. Zellen dünnwandig, ohne differenziertes Chromatophor

2. Synechococcus (S. 52)

4*. Zellen dickwandig, mit meist sternförmigem Chromatophor . . . 3. Chroothece (S. 52)

3*. Zellen spindelförmig . . 4. Dactylococcopsis (S. 53)

$1^{*}$. Zellen zahlreich in Gallerte eingebettet. . . . . . . 5

5. Familien und Gallerte ohne bestimmte Gestalt . . 6

6. Zellen erscheinen in mehrere Hüllen eingekapselt, da die alten Hüllen lange erhalten bleiben . . . . 7

7. Zellen kugelig, in formlosen Gallertklumpen

5. Glococapsa (S. 53)

$7 *$. Zellen länglich bis cylindrisch

8. Zellen ohne bestimmt geformtes Chromatophor 6. Glocothece (S. 53)

8*. Zellen mit sternförmigem Chromatophor 7. Zachariasia (S. 53)

1) Ueber die von vielen Forschern hierher gestelten Gattungen Porphyridium, Glaucocystis, Gloeochaete, Allogonium und Asterothrix siehe unter den Rhodophyceen. 
6*. Zellen einzeln in Gallerte, da die Hüllen bald gallertig zerfliessen

9. Zellen kugelig

ı. Zellen rötlich . . . siche Porphyridium

10*. Zellen blaugrün . 8. Aphanocapsa (S. 53)

9*. Zellen länglich . . . 9. Aphanothece (S. 54)

$5^{*}$. Zellen in bestimmt geformter Gallerte . . . . . II

I I. Familien freischwimmend . . . . . . . . . I2

I2. Zellen mit Teilung nach 3 Richtungen des Raumes, (es entstehen Zellhaufen) . . . . . . . . I 3

13. Zellen kugelig. . . . . . . . . . . . I4

14. Familien mehr oder weniger kugelig oder traubig. . . . 10. Microcystis (S. 54)

14*. Familie nur in der Jugend kugelig, im Alter netzartig zerreissend

I I. Clathrocystis (S. 55)

13*. Zellen meist keilförmig, Familien kugelig . . .

12. Gomphosphaera (S. 55)

12*. Teilungen nur nach 2 Richtungen des Raumes: (es entstehen Zellflächen) . . . . . . . 15 15. Familien hohlkugelig. . . . . . .

13. Coelosphaerium (S. 55).

15*. Familien tafelförmig oder häutig . . . . 16

16. Zellen etwa isodiametrisch, nicht flach . I7

17. Zellen kugelig, regelmässig angeordnet . 14. Merismopedia (S. 55)

$17^{*}$. Zellen cylindrisch, palissadenförmig nebeneinander stehend

15. Holopedium (S. 56)

16*. Zellen ganz flach, tafelförmig . . .

16. Tetrapedia (S. 56)

I I*. Familien an der Unterlage als kleine Erhebungen festgewachsen . . . 17. Oncobyrsa (S. 57)

\section{Chroococcus Naeg.}

Die etwa kugeligen Zellen selten längere Zeit zusammenhängend; blaugrün, violett, bräunlich oder gelb; selten in Gallerthülle. 
I. Zellhaut dünn, nicht aus Schichten zusammengesetzt . 2 2. Zellen bis $4 \mu$ dick . . . . . . . I. Chr. minor

$2 *$. Zellen über $4 \mu$ dick . . . . . . . . . . . . 3

3. Membran sehr deutlich . . 2. Chr. minutus

$3^{*}$. Membran undeutlich, schleimig 3 . Chr. helveticus

I*. Zellhaut mehr oder weniger dick, geschichtet

4. Inhalt spangrün bis blaugrün . . 4. Chr. turgidus

$4^{*}$. Inhalt gelb, ockerfarben bis braun . 5. Chr. macrococcus

1. Chr. minor (Kg.) Naeg.

Zellen meist isoliert, blass spangrün, Dicke 3,25-3,75 $\mu$; auf Steinen festsitzend.

2. Chr. mimutus (Kg.) Naeg.

Liegen meist zu zweien zusammen, dick 6-9, lang 10-13 4 ; wie vorige.

3. Chr. helveticus Naeg.

Dicke $4,5-7,5 \mu$, blass spangrün, zu 2, 4 oder 8 zusammen. In Torfgewässern und sonst, häufig.

4. Chr. turgidhıs (Kg.) Naeg. (Taf. I, 26).

Zellen einzeln oder zu 2-4 vereint, Zellhaut gelblich, dünn [var. tenax Kirchn.] oder dick, farblos [var. chalybeus (Rabh.) Kirchn.]. Dicke 1 2-25 (-35) $\mu$. Häufig unter anderen Algen, Oscillarien, auch an nassen Felsen.

5. Chr. macrococcus ('Trev.) Rabh.

Mit sehr dicker, farbloser Membran, bis $90 \mu$ dick. An nassen Mauern und auf feuchter Erde.

\section{Synechococcus Naeg.}

Blaugrün oder gelblich, einzeln oder zu mehreren vereinigt; Zellteilung senkrecht zur Längsachse.

Syn. aeruginosus Naeg. (Taf. I, 27).

Blaugrün, Zellen $7-16 \mu$, einzeln oder zu zweien. An feuchten Felsen häufig, auch im Wasser.

\section{Chroothece Hansg.}

Elliptische Zellen mit dicker, deutlich geschichteter Membran, oft auf Stiel. Blaugrünes oder gelbes Chromatophor. Teilung senkrecht zur Längsachse (vgl. Bangiaceen). 
Chr. richteriana Hansg. (Taf. I, 28),

Lager $2-5 \mathrm{~mm}$ dick, meist orangegelb. Zellen $18-24 \mu$ breit und $24-33 \mu$ lang (Zelllumen $6-10$ und $15-18 \mu$ ), mit Pyrenoid. In und an salzhaltigen Sümpfen.

\section{Dactylococcopsis Hansg.}

Einzeln oder in Haufen, S-förmig oder Rhaphidium-ähnlich, blau- oder olivengrün, Teilung nur nach einer Richtung.

D. rhaphidioides Hansg. (Taf. I, 29).

Zellen I- $3 \mu$ dick, 5-6 Mal so lang, blass blaugrün. Auf feuchtem Boden.

\section{Gloeocapsa (Kg.) Naeg.}

Zellen kugelig, einzeln oder zu mehreren, von gemeinsamer, deutlich geschichteter Membran umgeben. Teilung nach drei Richtungen. Dauerzellen sind beobachtet. Meist an feuchten Mauern, Felsen, auf feuchter Erde etc.

Gl. polydermatica $\mathrm{Kg}$. (Taf. I, 30).

Mit farblosen Membranen.

Gl. magma $\mathrm{Kg}$. mit roten Hüllmembranen.

\section{Gloeothece Naeg.}

Glococapsa-ähnlich, doch mit länglicheren Zellen, meist zu Familien vereinigt. Meist auf feuchtem Boden, so Gl. monococca (Kg.) Rabh. mit amethystfarbenen und Gl.confluens Naeg. mit farblosen Hüllmembranen. Im Wasser und an nassen Felsen ist häufig:

Gl. lincaris Naeg. (Taf, I, 31).

Zellen (ohne Gallerte) I, $5-2 \mu$ dick.

\section{Zachariasia Lemmerm.}

Bis 4 in gemeinsamer, deutlicher Hülle.

Z. endophytica Lemmerm. (Taf. I, 32).

Endophytisch im Gallertlager einer Rivularia.

\section{Aphanocapsa Naeg.}

In strukturlose Gallerte eingelagert. Teilung nach drei Richtungen, 
I. Zellen über $7 \mu$ dick, gelblich, Lager gelbbraun

1. Aph. testacea

$1^{*}$. Zellen bis $4,5 \mu$ dick, blaugrün . . . . . . . . . . 2

2. Zellen 3,5-4,5 $\mu$ dick . . . . . 2. Aph. pulchra

2*. Zellen $2-3,5 \mu$ dick . . . . . 3. Aph. castagnei

Aph. testacea (A. Br.) Naeg. auf feuchter Erde etc., dagegen kommen Aph. pulchra (Kg.) Rabh. (Taf. I, 33) und Aph. castagner (Kg.) Rabh. auch im Süsswasser vor.

\section{Aphanothece Naeg.}

Zellen wie bei Aphanocapsa, doch länglich. Teilung senkrecht zur Längsachse.

1. Familien in rundlichem, gallertigem Lager [Coccochloris (Spr.)] . . . . . . . . . . . . . . I. Aph. stagnina I*. Lager formlos, schleimig [Aphanothcce (Naeg.)] . . . . 2

2. Zellen $4,5 \mu$ dick . . . . . . 2. Aph. microscopica 2*. Zellen 2,5-4 $\mu$ dick . . . . . 3. Aph. castagnci

I: Aph. stagnina (Spr.) A. Br. (Taf. I, 34).

Lager bleich spangrün, erbsen- bis kirschgross, lang $5-8 \mu$, dick $3-5 \mu$. Zwischen Algen freischwimmend. Ebenso:

2. Aph. microscopica Naeg. (Taf. I, 35).

Lager bis $1 \mathrm{~mm}$ gross; Zellen $4,5 \mu$ dick, bis 2 Mal so lang. 3. Aph. castagnci (Bréb.) Rabh.

\section{Microcystis $\mathrm{Kg}$.}

Zellen klein und kugelig, zu soliden, rundlichen Familien vereint. Teilung nach 3 Richtungen.

1. Familien etwa kugelig (Microcystis $\mathrm{Kg}$.) . . . . . . . 2

2. Zellen mit dicker geschichteter Hülle I. M. marginata

2*. Zellen mit ganz dünner Hülle. . . 2. M. olivacea

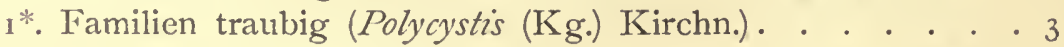

3. Lager gelblich bis spangrün . . 3. M. flos aquae

$3^{*}$. Lager blau bis olivengrün . . . 4. M. elabens

I. M. marginata (Menegh.) $\mathrm{Kg}$.

Lager blaugrün, Hülle farblos. Dicke der Zellen $3-4 \mu$; In sumpfigem Wasser. 
2. M. olivacea $\mathrm{Kg}$.

Lager olivengrün, Zellen $\mathrm{I}, 5-3 \mu$ dick. Bildet ein dünnes, häutiges Lager.

3. M. flos aquae (Wittrock) Kirchn. (Tafel I, 36).

Zellen $4-6,5 \mu$ dick, ist mit der folgenden:

4. M. elabens (Bréb.) Kg.

(Zellen $3-4,5 \mu$, Familien bis $80 \mu$ dick) hier und da an der Bildung der Wasserblüte beteiligt.

\section{xx. Clathrocystis Henfrey (vgl. Lamprocystis S. 36).}

Zellen kugelig, Familien zuerst auch kugelig, dann zerrissen, in gemeinsamer Gallerte. Teilungen nach 3 Richtungen.

Cl. aeruginosa (Kg.) Henfr. (Taf. I, 37).

Zellen blaugrün, Dicke der Zellen $3-4 \mu$. Bildet häufig auf der Oberfläche des Wassers dicke Häute als Wasserblüte.

\section{Gomphosphaera $\mathrm{Kg}$.}

Solide, kugelige Familien; die Zellen im Innern kugelig, aussen keilförmig mit der Spitze nach innen.

G. aponina Kg. (Taf. I, 38).

Zellen zu vier bis vielen in einer Familie, mit blaugrünem bis orangenem Inhalte. Dicke $4 \mu$, Länge (der äussern) bis $10 \mu$. In stehendem Wasser freischwimmend, hin und wieder in der Wasserblüte.

\section{Coelosphaerium Naeg.}

Die etwa kugeligen Zellen in kleinen Gallertkugeln in einschichtiger Lage. Vermehrung durch einzelne Zellen oder Teilung der Familie.

C. kützingianum Naeg. (Taf. I, 39).

Die $30-60 \mu$ grossen Familien enthalten $2-5 \mu$ dicke Zellen. Nicht selten in Teichen, kann ebenfalls eine Wasserblüte bilden.

\section{I4. Merismopedia (Meyen) Lagerh.}

Zellinhalt blaugrün, gelblich oder violett; Zellen in Längsund Querreihen. Teilung nur in zwei Richtungen. 
ı. Familien regelmässig viereckig . . . . . . . . . . . 2

2. Zellen schön blaugrün . . . 1. M. elegans

$2^{*}$. Zellen blass blaugrün . . . . . . . . . . . . . 3

3. Zellen einander genähert, $3-6 \mu$ dick .

2. M. glauca

$3^{*}$. Zellen von einander entfernt, $3 \mu$ dick .

3. M. punctata

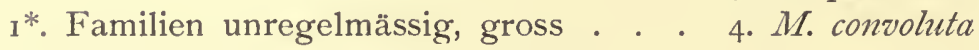

I. M. clegans A. Br.

Zellen $6-9 \mu$ dick; Familie regelmässig; bildet hier und da eine Wasserblüte, nicht selten.

2. M. glauca (Ehrbg.) Naeg. (Taf. I, 40),

3. M. punctata Meyen und

4. M. convoluta Bréb.

Zellen bis $8 \mu$ lang; alle in stehendem Wasser.

\section{Holopedium Lagerh.}

Mit blaugrünem Inhalte, in einschichtigen Familien ohne regelmässige Anordnung der Elemente. Teilung parallel zur Längsachse.

I. Zellen $6 \mu$ dick . . . . . . . . . . I. II. gcminatum 1*. Zellen $2-3 \mu$ dick : . . . . . 2. H. irregulare

I. H. gcminatum Lagerh.

Zellen i $2 \mu$ hoch, $6 \mu$ dick. In Süsswasser.

2. H. irregulare Lagerh. (Taf. I, 4I).

Hier und da in Süsswasser.

\section{I6. Tetrapedia Reinsch.}

Zellen flach, quadratisch, blaugrün, mit dünner Membran, einzeln oder $\mathrm{zu} 2-\mathrm{I} 6$ zusammenhängend. Vermehrung durch Einschnürungen vom Rande her.

r. Zellteilung geschieht durch Einschnürung in der Mitte der Zellen . . . . . . . . . . I. T. gothica I*. Zellteilung von den Ecken aus... 2. T. cmarginata

I. T. gothica Reinsch (Taf. I, 42).

Ränder mehr oder weniger gewellt, Ecken abgerundet, $6-8 \mu$ breit. In Tümpeln und Weihern, nicht häufig. 
2. T. emarginata B. Schröd. (Taf. I, 43).

Cönobien aus 4 Zellen; jede ein rechtwinkliges Dreieck mit konkaver Hypotenuse darstellend; an den Katheten sind die Dreiecke vereinigt. Im Plankton von Flüssen.

\section{I7. Oncobyrsa C. A. Ag.}

Zellen in dicken, zusammenfliessenden Gallerthüllen, mit blaugrünem Inhalte, in radialen Reihen in festsitzenden Familien.

1. Die Zellen sind $2-6 \mu$ dick . . . O. rivularis

I*. Die Zellen sind I I- I3 $\mu$ dick . . . O. lacustris

I. O. rizularis (Kg.) Menegh. (Taf. I, 44).

Zellen $2-6 \mu$ dick, bis $2 \mathrm{Mal}$ so lang, zu 2-4 genähert. In Bächen höherer Gebirge meist verbreitet.

2. O. lacustris Kirchn.

Zellen I I- I $3 \mu$ dick, I5-25 $\mu$ lang. In Seen.

\section{Fam. Chamaesiphonaceae.}

Etwas höher organisiert als vorige Familie, schon mit Konidienbildung in einzelnen vegetativen Zellen (Konidangien), meist mit Basis und Spitze. Einzeln oder in kleinen Familien.

I. Neben der Konidienbildung ist noch vegetative Vermehrung vorhanden, in Familien . . . . . . . . . . . . . . 2

2. Familien scheibenförmig, meist einschichtig . . . .

$$
\text { I. Xenococcus (S. 58) }
$$

$2^{*}$. Familie mehr oder weniger kugelig

$$
\text { 2. Pleurocapsa (S. } \left.5^{8}\right)
$$

I*. Nur Konidienbildung bekannt, meist einzeln . . . . . 3

3. Die ganze Zelle bildet sich zu gleicher Zeit zu Konidien um, Konidien reihenförmig . . 3. Clastidizım (S. 58)

$3^{*}$. Konidienabschnürung beginnt an der Spitze und setzt sich gegen die Basis fort . . . . . . . . . . . . . 4 4. Die Konidangien eiförmig-cylindrisch . . . . . . 4. Chamaesiphon (S. 58) 4*. Die Konidangien flaschenförmig . 


\section{Xenococcus Thuret.}

Zellen dicht zusammengedrängt, eckig, Familie scheibenförmig und festsitzend. Konidien kugelig, 32 in randständigen Konidangien.

$X$. kemeri Hansg. (Taf. I, 45).

Zellen $4-6 \mu$ dick, bis $9 \mu$ lang, zu einem höckerförmigen, bis $30 \mu$ dicken Lager vereint. Konidien kugelig, bis $3 \mu$ breit, zu 32 in einer Zelle. In schnellfliessendem Wasser, an Mühlenschleusen etc., selten.

\section{Pleurocapsa Thuret.}

Mit blaugrünem bis gelblichem Inhalte. Teilung nach 3 Richtungen. Vermehrung durch sich ablösende Zellen und Konidien.

I. Zellen blaugrün . . . . . . . I. Pl. Aluviatilis

I*. Zellen kupferrot . . . . . . . 2. Pl. cuprea

1. Pl. Anviatilis Lagerh.

Lager klein; Zellen meist strahlig $4-10(-26) \mu$ dick, ebenso lang; Konidangien endständig, I4-25 $\mu$ dick, mit I6-32 Konidien. An untergetauchten Wasserpflanzen.

2. Pl. cuprea Hansg. (Taf. I, 46).

Lager krustenförmig; Vegetative Zellen $3-6 \mu$ breit, meist einreihig. Bildet kupferrote Ueberzüge an Steinen in schnellfliessenden Bächen.

\section{Clastidium Kirchn.}

Zellen mehr oder weniger lang, eiförmig, an der Basis festgewachsen mit langer Spitze. Dünne, scheidenlose Membran. 8- 12 Konidien in einer Zelle.

Cl. setigenum Kirchn. (Taf. I, 47).

Zellen cylindrisch bis spindelförmig, $2,5-4 \mu$ dick, bis $38 \mu$ lang, Borste bis $50 \mu$ lang. Zerstreut in Bächen.

\section{Chamaesiphon A. Br. und Grun.}

Zellen mehr oder weniger cylindrisch, mit blaugrünem bis gelblichem Inhalte, festsitzend, meist gesellig. Zahlreiche Konidien. 
I. Konidangien ei-oder keulenförmig [Sectio I: Sphaerogonium (Rost.) Hansg.]

2. Scheide farblos . . . . . I. Ch. incrustans

2*. Scheide gefärbt . . . . . . 2. Ch. fuscus

1*. Konidangien cylindrisch, später mehrzellig [Sectio II: Brachythrix (A. Br.) Hansg.] . . . . . 3. Ch. confervicola

1. Ch. incrustans Grun.

Die kurzen Zellen sitzen mit einem Stiele an Fadenalgen an, bis $17 \mu$ lang, an der Spitze bis $4 \mu$ dick. Häufig.

2. Ch. fuscus (Rost.) Hansg.

Zellen 2,5-4 $\mu$ dick, 5-7 (-21) $\mu$ lang, mit braungefärbter, oben offenerScheide und meist olivengelbem Inhalte An Steinen etc.

3. Ch. confervicola A. Br. (Taf. I, 48).

Zellen $3-4 \mu$ breit, bis $38 \mu$ lang, unten stielartig verdünnt; Scheiden dünn, farblos. An den verschiedensten Wasserpflanzen häufig.

\section{Godlewskia Jancz.}

Mit gallertiger Membran, meist zu unregelmässigen Familien vereint.

G. aggregata Jancz. (Taf. I, 49).

Die Konidien keimen an der Mutterpflanze gleich wieder aus. Epiphytisch auf Batrachospermum, nicht häufig.

\section{Hormogoneae Thuret.}

Mehrzellig (cf. Spirulina), bildet Fäden in Scheiden (beides zusammen $=$ Filament). Vermehrung durch bewegliche Fadenstücke [„Hormogonien“] und durch Dauerzellen.

1. Fäden enden nicht haarartig dünn (I. Psilonematcae) . . 2

2. Fäden einfach, nicht verzweigt . . . . . . . . 3

3. Zellen des Fadens ganz gleichartig, ohne Grenzzellen etc. . . . . . . . 1. Oscillatoriaccae (S. 60)

$3^{*}$. Fäden von anders gebauten Zellen unterbrochen. 2. Nostocaceae (S. 68)

2*. Fäden verzweigt . 
4. Verzweigung unecht, durch Vorüberwachsen einer Zelle im Verbande an der folgenden. Fäden mit einer Zellreihe . . . . 3. Scytoncmaceac (S. 73)

4*. Verzweigung echt, Abzweigung durch Längsteilung einer Zelle entstanden. Fäden auch mit mehreren Zellreihen . . . . . 4. Stigoncmataceae (S. 77) 1*. Fäden mit verdünnten, haarartigen Enden (II. Trichophorcac) 5. Rivulariaceae (S. 78).

\section{Fam. Oscillatoriaceae.}

Fäden meistens in einer Scheide, oft zusammenlebend. Vermehrung durch Hormogonien. Vielfach beweglich.

I. Fäden ohne Scheide, frei . . . . . . . . . . . 2

2. Fäden mehrzellig . . . . . . . . . . . . . 3

3. Fäden nicht spiralig . . . 1. Oscillatoria (S. 61)

3*. Fäden spiralig. . . . . 2. Arthrospira (S. 63)

$2^{* \cdot}$ Fäden einzellig, spiralig . . . 3. Spirulina (S. 63)

I*. Fäden bescheidet . . . . . . . . . . . . . . . 4

4. Nur ein Faden in jeder meist gleichmässig dicken Scheide 5

5. Die dicken, schleimigen Scheiden zu Lagern verklebt, Fäden oft gekrümmt . . . 4. Phormidium (S. 64)

$5 *$. Scheiden fest, nicht schleimig. . . . . . . . 6

6. Filamente nicht zu Bündeln verwachsen. . . . 7

7. Filamente $z u$ Rasen und Flocken vereint, nie gekrümmt . . . . . 5. Lyngbya (S. 65)

$7^{*}$. Filamente $z u$ häutigen Lagern verfilzt .

$$
\text { 6. Hypheothrix (S. 65) }
$$

6*. Filamente zu aufgerichteten oder niederliegenden Bündeln verwachsen . . 7. Symploca (S. 66)

4*. Meist mehrere Fäden in den oft ungleichmässig dicken Scheiden . . . . . . . . . . . . 8

8. In den stärksten Filamenten zwei bis mehrere Fäden 9 9. Die schleimigen Scheiden miteinander verklebt. Endzelle haubenförmig verdickt 8. Hydrocoleum (S.66)

9*. Die Scheiden nicht verklebt. Endzelle einfach . 10 ı. Scheiden farblos. . . . . . . . . . II 
11. Filamente $z u$ aufrechten, nicht pinselförmigen Büscheln verwachsen . 9. Symplocastrum (S. 66) 1 I*. Filamente $z u$ pinselförmigen Büscheln vereint. 10. Inactis (S. 67)

I0*. Scheiden gefärbt, Filamente verzweigt

11. Schizothrix (S. 67)

8*. Zahlreiche Fäden in den Filamenten, die schleimigen Scheiden mit cinander verklebt 12. Microcoleus (S. 67)

\section{Oscillatoria Vauch.}

Zellen kurz cylindrisch, .Fäden meist frei, kriechen lebhaft unter Längsdrehung umher. Leben gewöhnlich in Wasser mit organischen Substanzen, selbst in Abwässern, z. B. O. limosa. Viele der früher aufgestellten Arten sind jetzt in wenige zusammengefasst.

I. Fäden am Ende zugespitzt, gerade, nicht gekrümmt oder spiralig, mit stumpfer, etwas kopfförmiger Endzelle, Zellen etwa so lang als breit, oder etwas kürzer, nicht über $8 \mu$ dick. (Sect. I: Prolificae Gom.) . . . . . I. O. mbescens I*. Fäden anders gebaut

2. Fäden am Ende mehr oder weniger verdünnt . . . . 3

3. Fadenzellen nur $1 / 3-1 / 10$ Mal so lang als dick, Endzelle stumpf . . . . . . . . . . . . . . . . . . 4

4. Fäden zwischen den Zellen nicht eingeschnürt, Ende meist kaum verdünnt, Zellen $1 / 2-1 / 10$ Mal so lang als dick (Sect. II: Principes Gom.) . . . . . . . . 5

5. Zellwände niemals granuliert, meist über $25 \mu$ stark 2. O. princeps

$5^{*}$. Zellwände meist granuliert, meist nur bis $16 \mu$ stark 3. O. limosa

$4^{*}$. Fäden $z$ wischen den Zellen schwach eingeschnürt, Zellen $1 / \tau-1 / 3$ Mal so lang als breit (Sect. III: Margaritiferae Gom.) . . . . . 4. O. margaritifera

3*. Fadenzellen $1 / 3$ bis mehrmals so lang als dick, Enden deutlich verdünnt . . . . . . . . . . 6

6. Fäden am Ende gebogen, Zellen $1 / 3-4$ mal so lang als dick (Sect. V: Attcnuatac Gom.) . . . . . . 7

7. Endzelle kopfförmig verdickt, $2-3 \mu$ dick . . .

6. O. splendida

$7 *$ Endzelle nicht so 
8. Zellfaden 4-6 $\mu$ dick . 7. O. formosa

8*. Zellfaden 8-13 $\mu$ dick . . 8. O. chalybea

6*. Fäden am Ende spiralig gedreht, Zellen $1 / 3-11 / 2$ Mal so lang als dick (Sect. VI: Tercbriformes Gom.).

\section{O. terebriformis}

$2^{*}$. Fäden am Ende nicht verdünnt, ohne Einschnürungen . 9

9. Zellen $1 / 2-1 / 10$ Mal so lang als dick, über I I $\mu$ dick (siehe Sectio II).

9*. Zellen $1 / 3-2$ Mal so lang als dick, nicht über II $\mu$ dick. (Verg1. auch Sectio III). (Sect. IV: Aequales Gom.) . . 5. O. tenuis

I. Prolificae Gom.

1. O. rubescens D. C.

Fäden violettrot, trocken lila, steif und zerbrechlich, leicht gekopft, $6-8 \mu$ stark, $2-4 \mu$ lang. In Seen, bildet eine Wasserblüte, selten.

\section{Principes Gom.}

2. O. princeps Vauch. em. Gom.

Fäden satt blaugrün, starr, Zellen $16-60$, meist $25-50 \mu$ dick, $3-5 \mu$ lang, festgeheftet oder freischwimmend, in stehendem Wasser häufig.

3. O. limosa Ag. em. Gom. (Taf. II, I).

Zellen I $1-20$, meist I $_{3}-\mathrm{i} 6 \mu$ dick und $2-5 \mu$ lang, mit gerader Spitze, nicht gekopft. Wie vorige, sehr häufig, besonders in Abwässern.

III. Margaritiferae Gom.

4. O. margaritifera $\mathrm{Kg}$.

Olivengrün in schwarzem Lager, $17-20 \mu$ dick, lang und deutlich zugespitzt, Zellen $3-6 \mu$ lang, Querwände an den Seiten granuliert, mit etwas konvexer Zellhaube. In etwas salzigem Wasser, hier und da.

IV. Aequales Gom.

5. O. tenuis Ag. (Taf. II, 3).

Faden 4-10 $\mu$ dick, Spitze gerade oder gebogen, nicht gekopft. Zellen 2,6-5 $\mu$ lang; mit var. natans (Kg.) Gom. (6- o $\mu$ dick) und var. tergestina Rabh. (4-6 $\mu$ dick). In Gräben, Sümpfen etc.; sehr häufig. 
V. Attenuatae Gom.

6. O. splendida Grev. (Taf. II, 2).

Blass blaugrün, lang zugespitzt, deutlich kugelig gekopft; Zelle $2-3 \mu$ dick, $3-9 \mu$ lang. Wie vorige, auch auf feuchter Erde.

7. O. formosa Bory

Schön blaugrün, Ende etwas gebogen, abgerundet, Zellen $2,5-5 \mu$ lang. Nicht selten.

8. O. chalybea Mertens

Dunkelblaugrün, gerade oder etwas spiralig, zwischen den Zellen wenig eingeschnürt, zugespitzt, Zellen $3,6-8 \mu$ lang. Ueberall häufig.

VI. Terebriformes Gom.

9. O. terebriformis Ag.

Lager stahlblau, spiralig oder gekrümmt, $4-6,5 \mu$ dick, Zellen 2,5-6 $\mu$ lang, leicht zugespitzt, Endzelle abgerundet. In Schwefelquellen.

\section{Arthrospira Stizenberger.}

Scheidenlose, schraubig gedrehte Fäden, die sich langsam schraubend vorwärts bewegen.

A. jenneri Stizenberger (Taf. II, 4).

Satt blaugrün, $5-8 \mu$ dick; $9-15 \mu$ grosse, 2 I -3 I $\mu$ weite Schrauben bildend, Zellen $4-5 \mu$ lang. In Sümpfen und Teichen häufig.

\section{Spirulina Turpin.}

Einzellig, schraubig gedreht.

I. Windungen unregelmässig . . . I. Sp. meneghiniana I*. Windungen regelmässig . . . . 2. Sp. major

I. Sp. meneghiniana Zan.

Durchmesser der Windungen $3,2-5 \mu$, ihre Weite $3-5 \mu$ und mehr; Dicke der Fäden $1,2-\mathbf{r}, 8 \mu$. In salzigem Wasser.

2. Sp. major Kg. (Taf. II, 5).

Durchmesser der Windungen 2,5-4 $\mu$, Weite 2,7--5 $\mu$; Dicke der Fäden $1,2-1,7 \mu$. In stehendem Wasser häufig. 


\section{Phormidium $\mathrm{Kg}$.}

Einzeln in dünne, verklebte Scheiden eingeschlossen. Dünnes, häutiges Lager. In Thermen z. T. noch bei $85^{\circ} \mathrm{C}$. wachsend.

I. Fäden kaum $3 \mu$ dick

2. Bildet lederige, braunviolette Ueberzüge i. Ph.purpurascens $2^{*}$. Blau- oder olivengrüne Ueberzüge . . . . . . . . 3

3. Dicke, lederige Ueberzüge, oben schmutziggrün, innen entfärbt, Spitze gerade . . . . 2. Ph. valderianum

$3^{*}$. Dünne, häutige Lager, Spitze gekrümmt . . . . .

3. Ph. tenue

1*. Fäden über $3 \mu$ dick . . . . . . . . . . . . 4

4. Lager mit Kalk inkrustiert . . . 4. Ph. incrustatum

4*. Lager frei von Kalk . . . . . . . . . . . . . . 5

5. Fäden nicht gekopft . . . . 5. Ph. corium

5 *. Fäden gekopft . . . . . . . . . . . 6

6. Fadenspitze gerade . . . . .6. Ph. subfuscum

6*. Fadenspitze mehr oder weniger gebogen . . . .
7. Pl. uncinatum

I. Ph. purpurascens (Kg.) Gom.

Fäden stark gekrümmt, I,5-2 $\mu$ dick, Zellen $2-4,5 \mu$ lang, Endzelle rund. Zelle mit 4 Protoplasma-Körnchen. An Wasserfällen, hier und da.

2. Ph. valderianum Gom.

Fäden glatt, $2-2,5 \mu$ dick, mit gerader, stumpfer Spitze. Zellen $3,3-6,7 \mu$ lang, mit 2-4 Protoplasma-Körnern. Häufig. 3. Ph. tenue (Menegh.) Gom.

Fäden $1-z \mu$ dick, $z$ wischen den Zellen etwas eingezogen, zugespitzt und gekrümmt. Zellen 2,5-5 $\mu$ lang. Häufig, auch auf feuchter Erde.

4. Ph. incrustatum (Naeg.) Gom.

Hartes, mit Kalk inkrustiertes Lager. Scheiden dünn, Fäden 4-5 $\mu$ dick, Zellen 3,5-5,2 $\mu$ lang. Querwände deutlich. An Wasserfällen.

5. Ph. corium (Ag.) Gom.

Die gebogenen Fäden $3-4,5 \mu$ dick, in lederigem, ausgebreitetem Lager. Zellen $3,4-8 \mu$ lang. An Bachrändern, Wasserfällen etc., nicht selten. 
6. Ph. subfuscum (Ag.) Kg. (Taf. II, 6)

Die geraden, glatten, zerbrechlichen, 5,5-1 i $\mu$ dicken Fäden kurz zugespitzt. Zellen $2-4 \mu$ lang. Gekopfte Spitze rund oder konisch. An Wasserfällen, an Bächen etc., gemein.

7. Ph. uncinatum (Ag.) Gom.

Die gekrümmten Fäden $6-9 \mu$ dick, kurz zugespitzt. Zellen 2-6 $\mu$ dick. Wie vorige, sehr häufig.

\section{Lyngbya Ag.}

In festen, häutigen, meist farblosen Scheiden. Die Polster oder Rasen meist im Meere. Im Süsswasser nur zwei Arten:

I. Fäden frei, spiralig gedreht . . . . . I. L. contorta I*. Fäden epiphytisch, Fadenalgen spiralig umschlingend

2. L. epiphytica

I. L. contorta Lemmerm.

Fäden $1-I, 5 \mu$ dick, mit niedrigen, kreisförmigen Windungen. In Seen, selten.

2. L. epiphytica Hieron. auf Oedogonium und Tolypothrix, selten.

\section{Hypheothrix $\mathrm{Kg}$.}

Fäden vielzellig, dünn, in farbloser Scheide, Endzelle nicht mit verdickter Membran. Filamente wenig verzweigt, niederliegend, Scheiden nicht verklebt; Lager häutig.

I. Filamente kurz, wenig biegsam, dicht zusammengewirrt, Lager ohne Kalk . . . . . . . . . . 1. H. Lateritia

I*. Filamente lang, biegsam, nicht so dicht . . . . . . . 2

2. Lager mit Kalk inkrustiert. . . . 2. H. coriacea

2*. Lager nicht inkrustiert . . . . . 3. H. lardacea

1. H. lateritia $\mathrm{Kg}$. (Taf. II, 7)

Fäden bleichgrün, zahlreich in einer Scheide, undeutlich gegliedert; Zelle $2-5 \mu$ lang, $1,3-\mathbf{I}, 6 \mu$ dick. Endzelle abgerundet. An feuchten Ufersteinen.

2. H. coriacea $\mathrm{Kg}$.

In lederigem Lager. Zellen $\mathrm{I}-\mathrm{I}, 7 \mu$ dick, $3-6 \mu$ lang. Endzelle spitz konisch. An Wasserfällen etc. 
3. H. lardacea (Ces.) Rabh.

In olivengrünem oder rötlichem Lager. Fäden bleichblaugrün, $1,5-2 \mu$ dick, Zellen 2-3 $\mu$ lang. An Mauern und vom Wasser benetzten Felsen.

\section{Symploca Kg.}

Fäden einzeln in farbloser, dünner Scheide; Filamente zu aufsteigenden oder niederliegenden Bündeln verwachsen.

I. Fäden $3 \mu$ und dicker . . . . . . . . . . . . . . 2

2. Fäden 5-8 $\mu$ dick. Bündel lang. . 1. S. muscorum.

$2^{*}$. İäden $3,4-4 \mu$ dick, Bündel kurz . 2. S. muralis I*. Fäden $\mathrm{I}-3 \mu$ dick .

3. Bündel anastomosieren nicht . . 3. S. dubia

$3^{*}$. Bündel anastomosieren, Fäden 1,8-3 $\mu$ dick

\section{S. parietina}

Die Arten 1. S. muscorum (Ag.) Gom., 2. S. muralis Kg. (Taf. II, 8) und 4. S. parietina meist nur an feuchten Mauern, Uferrändern etc.

3. S. dubia (Naeg.) Gom.

Fäden $1,5-2,5 \mu$ dick, Zellen 3-8 $\mu$ lang, Lager bleich. An Wasserfällen und feuchten Moosen.

\section{Hydrocoleum $\mathrm{Kg}$.}

Fäden mit haubenartig verdickter Endzelle, zu mehreren in verklebten Scheiden.

1. Lager nicht mit Kalk inkrustiert, Fäden $6-8 \mu$ dick, deutlich gekopft, Zellen $4-5,5 \mu$ lang. . . . . 1. H. homoeotrichum 1*. Lager mit Kalk inkrustiert, Fäden $6 \mu$ dick, Zellen 3-9 $\mu$ lang 2. H. oligotrichum

1. H. homoeotrichum Kg. (Taf. II, 9) und 2. H. oligotrichum A. Br. in schnell fliessenden Bächen und an Wasserfällen, selten.

\section{Symplocastrum (Gom.) Kirchn.}

$\mathrm{Zu}$ mehreren in farbloser Scheide, zu dichten Büscheln verwachsen.

S. friesi (Ag.) Kirchn. (Taf. II, Io)

Lager schwarz bis olivengrün, mit $3 \mathrm{~cm}$ hohen Büscheln. Fäden 3-6 $\mu$ dick, Zellen 4-11 $\mu$ lang. An von Wasser befeuchteten Felsen, auf feuchter Erde etc. 
I0. Inactis $\mathrm{Kg}$. em. Thuret.

$\mathrm{Zu}$ mehreren in meist farbloser Scheide eingeschlossen, Endzelle ohne verdickte Membran. In rasigen, verfilzten Büscheln.

I. Fäden dünn und aufrecht, krustenbildend . . . . . . . 2

2. Filamente meist unverzweigt . . . I. I. pulvinata

$2^{*}$. Filamente reich verzweigt : . . . 2. I. fasciculata

I*. Die I,5-2,5 $\mu$ dicken Fäden fluten als pinselförmige Büschel im Wasser. . . . . . . . . 3. I. tinctoria.

I. I. pulvinata $\mathrm{Kg}$.

Bildet wie die folgende Art harte, krustige, kalkige Lager, die aussen mit Erhebungen versehen, innen gezont sind. Fäden $\mathrm{I}-2 \mu$ dick. An Holzwerk etc. in frischem Wasser.

2. I. fasciculata Grun. (Taf. II, i i)

Fäden $1,4-3 \mu$ dick, Zellen $\mathrm{I}, 2-3,5 \mu$ lang, Endzelle spitz konisch. Ebenda.

3. I. tinctoria (Ag.) Thuret.

Fäden mit runder Endzelle. Zellen $1,4-3 \mu$ lang. In Bächen.

\section{Ir. Schizothrix (Kg. u. Gom.) Kirchn.}

Fäden zu mehreren in gefärbten Scheiden, die oben spitz auslaufen. Filamente verzweigt.

I. Zellen so lang oder kürzer als breit . . I. Sch. muelleri

1*. Zellen länger als breit . . . . . . 2. Sch. brauni

1. Sch. muelleri Naeg. (Taf. II, I 2)

Scheiden goldgelb, Fäden 7-13 $\mu$ dick, Zellen $4-9 \mu$ lang, Endzelle stumpf konisch. An überfluteten Stellen, selten.

2. Sch. brauni Gom.

Scheiden dunkelblau. Ende lang zugespitzt, Fäden etwas eingeschnürt, 1,7 $\mu$ dick, Zellen $2-5 \mu$ dick. An untergetauchten Steinen.

\section{Microcoleus Desmaz.}

Fäden langzellig, mit verdünnten Enden, in grosser Anzahl zusammenliegend, in verklebten Scheiden.

I. Fäden zwischen den Zellen eingezogen, 4-5 $\mu$ dick.

I. M. lacustris

I*. Fäden nicht eingezogen, $5-7 \mu$ dick . . 2. M. paludosus 
1. M. lacustris (Rabh.) Farlow

Scheiden schleimig zerfliessend, Zellen 6-12 $\mu$ lang, Endzelle stumpf konisch.

2. M. paludosus (Kg.) Gom. (Taf. II, i 3)

Scheiden kaum schleimig, nicht zerfliessend. Zellen 4-13 $\mu$ lang. Endzelle nicht kopfig. Beide in Teichen und an nassen Felsen.

[M. vaginatus (Vauch.) Gom., (Taf. II, 14): 3,5-7 $\mu$ dick, auf feuchtem Boden, allgemein verbreitet.]

\section{Fam. Nostocaceae.}

Unverzweigte Fäden, aus gleichartigen Zellen meist mit nur einzelnen inhaltsarmen, anders gefärbten sog. Grenzzellen dazwischen, frei oder in Gallerte. Hormogonien und Dauerzellen.

1. Fäden ohne Grenzzellen (I. Isocystideae).

I*. Fäden mit Grenzzellen

$$
\text { I. Isocystis (S. 69) }
$$

2. Fäden ohne Scheide, oder diese zerfliessend (II. Anabacncac) 3 3. Lager gallertig, bestimmt abgegrenzt .

$$
\text { 2. Nostoc (S. 69) }
$$

$3^{*}$. Fäden einzeln oder in unregelmässigen Schleimklumpen 4

4. Grenzzellen mitten im Faden . . . . . . . . . 5

5. Vegetative Zellen kurz, scheibenförmig

$$
\text { 3. Nodularia (S. 7 I) }
$$

5*. Vegetative Zellen, so lang oder länger als dick . 6

6. Fäden einzeln oder in formlosen Massen .

$$
\text { 4. Anabacna (S. } 71 \text { ) }
$$

6*. Fäden in kleinen, schüppchenförmigen Flocken

$$
\text { 5. Aphanizomenon (S. } 72 \text { ) }
$$

4*. Grenzzellen am Ende des Fadens

$$
\text { 6. Cylindrospermum (S. 72) }
$$

$2^{*}$. Fäden in deutlichen Scheiden (III. Aulosircae) . . . . 7

7. Fäden in der Scheide einzeln. . . . . . . . 8

8. Grenzzellen nur mitten im Faden

$$
\text { 7. Aulosira (S. 73) }
$$

8*. Grenzzellen am Ende und mitten im Faden

$$
\text { 8. Microchaete (S. 73) }
$$

$7^{*}$. Fäden meist $z u$ mehreren in einer Scheide

9. Desmonema (S. 73) 


\section{Isocystis Borzi.}

Fäden einzeln oder in kleinen Lagern, mit kugeligen Zellen. Ohne Grenzzellen, aber mit bräunlichen Dauerzellen.

Is. infusionum (Kg.) Borzì (Taf. II, 15)

Die runden Zellen etwa $1-1,5 \mu$ dick, unregelmässig zusammenhängend. In Teichen, verbreitet.

\section{Nostoc Vauch.}

Das gallertige Lager zuerst mehr oder weniger kugelig, später verschieden gestaltet, selbst hohl, frei oder festsitzend, mit oder ohne dichtere Hautschicht. Zellen tonnenförmig oder cylindrisch. Dauerzellen reihenweise entstehend.

I. Familien freischwimmend . . . . . . . . . . . . 2

2. Familien ohne deutliche äussere Hautschicht . . . 3

3. Familien mikroskopisch klein . . . . . . . . . 4

4. Fäden dicht verwirrt, Scheiden hyalin, schleimig (Sect.: Amorpha). . . . . . . . . 1. N. punctiforme

$4^{*}$. Fäden nicht so dicht, Scheiden deutlich (Sect.: Palıdosa)

2. N.pahudosum

$3^{*}$. Lager grösser, mit blossem Auge deutlich sichtbar, gallertig, anfangs kugelig, später zerrissen und unregelmässig (Sect.: Intricata) . . . . . . . . . . . . 5

5. Fäden dicht gedrängt, eng verflochten' . . . . .

3. N. linckia

$5^{*}$. Die leicht gekrümmten Fäden locker verschlungen 6

6. Zellen mehr als doppelt so lang wie dick . . . .

4. N. spongiaeforme

6*. Zellen nicht oder kaum länger als dick . . . . 7

7. Fäden ohne besonders sichtbare Scheiden . . .

5. N. carneum

$7 *$ Scheiden besonders an der Peripherie deutlich erkennbar, öfters bräunlich gefärbt . . . . . .

6. N. piscinale

$2^{*}$. Lager mit fester Hautschicht umgeben . . . . . . 8

8. Grenzzellen $6-7 \mu$ dick . . . . 7. N.priniforme

8*. Grenzzellen 8-10 $\mu$ dick. . . . . 8. N. coeruleum

I*. Familien bilden ein kugeliges, später hohles, festsitzendes

Lager. (Sect.: Verrucosa) . . . . . . 9. N. verrucosum 
I. N.punctiforme (Kg.) Hariot.

Fäden $3-4 \mu$ dick, mit engen, farblosen Gallertscheiden, meist frei, auch an Wasserpflanzen festsitzend. Ist auch durch seine endophytische Lebensweise im Stamme von Gunnera und in Cycadeenwurzeln interessant.

2. $N$. paludosum $\mathrm{Kg}$. (Taf. II, I6)

Dauerzellen oblong, $4 \mu$ dick, $6-8 \mu$ lang, Lager ziemlich konsistent. In stehendem Wasser.

3. N. linckia (Roth) Bornet

Im Alter unregelmässig zerrissene Lappen bildend. Fäden 3,5-4 $\mu$ dick. Grenzzellen $5-6 \mu$ dick, fast rund. Sporen $6-7 \mu$ breit und 7-8 $\mu$ lang. In Gräben und Teichen.

4. N. spongiaeforme Ag.

Scheiden gewöhnlich an der Peripherie gelbbräunlich. Fäden 3,5-4,5 $\mu$ dick, kugelig bis lang $(7 \mu)$ cylindrisch, Grenzzellen $7-8 \mu$ dick; Sporen $6-7 \mu$ dick, $10-12 \mu$ lang. Wic vorige Art.

5. N. carneum Ag.

Lager weich und schlüpfrig, grünlich oder rötlich, vegetative Zellen 3,5-4 $\mu$ dick; doppelt so lang, Grenzzelle $6 \mu$ lang, Spore $6 \mu$ dick, 8 - - $о \mu$ lang. Nicht selten.

6. N.piscinale $\mathrm{Kg}$.

Lager bräunlichgrün; vegetative Zellen $4 \mu$, Grenzzellen $4,5-6 \mu$, die kugeligen Sporen $6-7 \mu$ dick. Häufig.

7. N. pruniforme $\mathrm{Ag}$.

Lager sehr gross, mehr oder weniger kugelig, olivenfarbig und dunkler, Fäden von der Mitte strahlig ausgehend. Vegetative Zellen $4-6 \mu$ dick. In stehendem Wasser, hier und da.

8. N. coenuleum Lyngbye

Lager kleiner, erbsengross, bläulich, Zellen $5-7 \mu$ dick, meist etwas niedergedrückt. Zerstreut.

9. N. verrucosum Vauch.

Lager bis $10 \mathrm{~cm}$ gross, zuerst solid, später blasig, schwärzlich; die flachkugeligen vegetativen Zellen $3-3,5$, die kugeligen Grenzzellen $6 \mu$, die $7 \mu$ langen Sporen $5 \mu$ dick. In schnell fliessenden Bächen, häufig.

Zahlreiche Arten, wie $N$. commune Vauch., und andere sind an feuchten Stellen überall häufig. 


\section{Nodularia Mertens.}

Fäden mit dünner Scheide und fast scheibenförmigen Zellen. Grenzzellen zusammengedrückt, Dauerzellen kugelig, in Reihen, Grenzzellen nicht direkt berührend, mit glatter Aussenmembran.

N. major (Kg) Kirchn. (Taf. II, I7)

Fäden 12-I $8 \mu$ dick, Sporen 14-I5 $\mu$ breit und $6-7 \mu$ lang. Nicht häufig.

\section{Anabaena Bory.}

Meist zu schleimigen Massen vereint.

I. Dauerzellen nicht regelmässig zu beiden Seiten einer Grenzzelle, unregelmässig gelagert . . . . . . . . . . . 2

2. Dauerzellen oval oder kugelig [Sect.: Trichormus (Rabh.) Born. et F1.] . . . . . . . . . . . A. variabilis

.2*. Dauerzellen cylindrisch, [Sect.: Dolichospermum (Ralfs) Born. et F1.] . . . . . . . . . . . . . . . . 3 3. Fäden und Dauerzellen gekrümmt . . . . . 4 4. Dauerzellen 7 - $13 \mu$ dick, bis $50 \mu$ lang. . . 2. A. flos aquae $4^{*}$. Dauerzellen $16-18 \mu$ dick, bis $30 \mu$ lang . . 3. A. circinalis

$3^{*}$ Fäden und Dauerzellen gerade; letztere meist von den Grenzzellen entfernt . . 4. A. catenula

I*. Die cylindrischen Dauerzellen zu beiden Seiten einer Grenzzelle [Sect.: Sphaerozyga (Ag.) Born. et F1.] . . . . . . .

5. A. oscillarioides

I. A. variabilis $\mathrm{Kg}$.

Zellfäden gekrümmt, 4-6 $\mu$ dick, Zellen fassförmig $2,5-6 \mu$ lang, Grenzzellen $6 \mu$ breit, $8 \mu$ lang, Dauerzellen oval, $7-9 \mu$ dick, 8 - $4 \mu$ lang, von den Grenzzellen entfernt, mit glatter Aussenhaut. In stehendem Wasser.

Bei der nahe verwandten $A$. hallensis Jancz., die in Halle gefunden wurde, ist die Sporenaussenhaut mit Papillen besetzt.

2. Ȧ. flos aquae Bréb. (Taf. II, I 8)

Fäden $4-8$ (meist 5,5) $\mu$ dick, Zellen $6-8 \mu$ lang, Sporen gekrümmt, $7-13$ (meist 9) $\mu$ dick, 20-35 (-50) $\mu$ lang. Bildet eine häufige Wasserblüte auf Teichen und Seen. 
Eine nahe Verwandte ist A. spiroides Kleb. mit spiraligen Windungen, kommt mit voriger gemischt vor.

\section{A. circinalis (Harvey) Rabh.}

Fäden gekrümmt, selten gerade, $8-14 \mu$ dick, Grenzzellen $8-10 \mu$ dick. Wie vorige, mit Gasvakuolen im Innern und daher Planktonalge.

4. A. catcnula (Kg.) Born. et F1.

Die gekrümmten Fäden 5-8 $\mu$ dick. Grenzzellen etwas grösser als die vegetativen Zellen, $6-9 \mu$ dick, $9-13 \mu$ lang, Dauerzellen 7-10 $\mu$ dick, $16-30 \mu$ lang, bräunlich. In Gräben und Teichen.

5. A. oscillarioides Bory (Taf. II, 19)

Fäden 4,2-6 $\mu$ dick, Endzelle rund, Zellen sonst tonnenförmig. Grenzzellen $6-8 \mu$ dick und lang, oder $6 \mu$ dick und $10 \mu$ lang. Dauerzellen zuletzt ganz cylindrisch, 8-10 $\mu$ dick, 20-40 $\mu$ lang. In Teichen und Sümpfen, häufig.

\section{Aphanizomenon Morren.}

Fäden gerade, etwas gegen das Ende verdünnt, Dauerzellen aussen glatt.

Aph. flos aquac (L.) Ralfs (Taf. II, 20)

Fäden starr, 5-6(3) $\mu$ dick, beiderseits deutlich zugespitzt; Zellen etwa cylindrisch, meist $3-6(-22) \mu$ lang; Grenzzellen $4-7 \mu$ dick, 9-20 $\mu$ lang; Dauerzellen 4,5-5 (7-8) $\mu$ dick und $22-40(60-80) \mu$ lang. Mit Gasvakuolen, in der Wasserblüte.

\section{Cylindrospermum $\mathrm{Kg}$.}

Die kurzen, scheidenlosen Fäden in ausgebreitetem Gallertlager. Dauerzellen meist einzeln.

I. Dauerzellen cylindrisch . . . . . . . I. C. stagnale

${ }^{*}$. Dauerzellen elliptisch. . . . . . . . 2. C. majus

1. C. stagnale ( $\mathrm{Kg}$.) Born. et $\mathrm{F} 1$.

Das ausgebreitete Lager festgeheftet oder freischwimmend, Fäden 3,8-4,5 $\mu$ dick, Zellen 3-4 Mal so lang. Grenzzellen $6-7 \mu$ dick, $16 \mu$ lang. Dauerzellen mit abgerundeten Ecken, 10-16 $\mu$ breit, 32-40 $\mu$ lang, gelbbraun. In Sümpfen und Teichen. 
2. C. majus $\mathrm{Kg}$. (Taf. II, 21)

Zellen $4-5 \mu$ dick, 5-6 $\mu$ lang. Dauersporen Io-I5 (I 2) $\mu$ dick, 20-30 (38) $\mu$ lang. Aussenhaut rauh-papillös. Gemein, in stehendem Wasser und auf feuchter Erde.

\section{Aulosira Kirchn.}

Mit deutlicher Scheide, Filamente einzeln oder zu Bündeln. A. laxa Kirchn. (Taf. II, 22)

Fäden 5-8 $\mu$ dick, Grenzzellen 5-8 $\mu$ dick; Dauersporen 5-7 $\mu$ dick, $20-24 \mu$ lang. In Gräben, selten.

\section{Microchaete Thuret.}

Mit deutlicher Scheide, einzeln oder zu aufrechten Räschen vereinigt.

M. goeppertiana Kirchn. (Taf. II, 23)

Fäden einzeln, Zellen unten 2-3 Mal, oben nur $1 / 3-1 / 2 \mathrm{Mal}$ so lang als dick, 5-6 $\mu$ dick; Grenzzelle etwa kugelig $6 \mu$ dick, $6-8,5 \mu$ lang; Dauerzellen einzeln oder zu zweien, $6-7,5 \mu$ dick, $13-17 \mu$ lang. Hin und wieder.

\section{Desmonema Berk. et Thur.}

Fäden meist an beiden Enden verdünnt. Dauerzellen eiförmig, einzeln oder zu zweien. Filament in strahligen Bündeln.

D. wrangeli (Ag.) Born. et Fl. (Taf. II, 24)

Lager schwarzgrün, $5-6 \mathrm{~mm}$ hoch, mehrmals pseudodichotom verzweigt. Fäden $9-10 \mu$ dick mit Einschnürungen. 1-2 Grenzzellen, oder diese fehlen. In schnell fliessenden Bächen und an Wasserfällen.

\section{Fam. Scytonemaceae.}

Fäden mit Gegensatz zwischen Basis und Spitze, in büschelförmigen Rasen vereint. Hormogonien und Dauerzellen.

I. Grenzzellen und Dauerzellen fehlen . . I. Plectonema (S. 74)

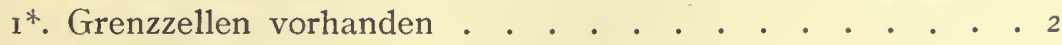

2. Fäden einzeln in den Scheiden . . . . . . . . 3 
3. Fäden einzeln oder zu zweien beisammen, die Verzweigung entsteht in der Regel zwischen zwei Grenzzellen

4. Scheiden dünner als der Faden

$$
\text { 2. Scytoncma (S. 74) }
$$

$4^{*}$. Scheiden oben dick, trichterförmig geschichtet

$$
\text { 3. Petalonema (S. 75) }
$$

$3^{*}$. Fäden einzeln, Verzweigung entsteht unmittelbar unter einer Grenzzelle . . 4. Tolypothrix (S. 75)

2*. Fäden zu mehreren in einer Scheide . . . . . . . 5

5. Fäden gerade nebeneinander liegend . . . . .

5*. Fäden gekrümmt, Nostoc-ähnlich durcheinander gewirrt . . . . . . 6. Diplocolon (S. 76)

\section{Plectonema Thuret.}

Einzeln in festen, farblosen oder gefärbten Schläuchen. Verzweigung einzeln oder zu zweien. Diese Gattung leitet zu den Oscillatorien über.

1. Grössere Pflanzen, rasig, Dicke der Fäden $3 \mu$ und stärker .

1. Pl. tomasinianum

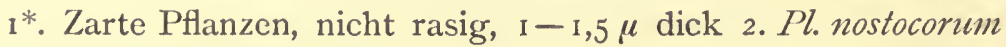

1. Pl. tomasinianum (Kg.) Bornet (Taf. II, 25)

Lager meist bleichgrün, häufig (falsch) verzweigt, Scheiden im Alter gelblich, bis $3 \mu$ dick. Fäden I I- $22 \mu$ dick, Zellen 3-9 $\mu$ lang, Endzelle rund. Auf untergetauchten Wasserpflanzen. Hier und da.

2. Pl. nostoconum Bornet

Zellen 2-2,5 $\mu$ lang. Querwände nicht granuliert. Endzelle rund. Zwischen andern Schleimalgen, häufig.

\section{Scytonema Ag.}

Einzeln in einer Scheide, verzweigt. Scheiden geschichtet oder ungeschichtet, aussen nicht mit besonderer Hautschicht. Dauerzellen (bei einigen) mehr oder weniger kugelig.

I. Scheiden ungeschichtet oder aus parallelen Schichten gebildet [Euscytonema (Borzi) Born. et F1.] . . . 1. Sc. crispum I*. Scheiden mit divergierenden Schichten [Myochrotes Bornet et Fl.] . . . . . . . . . . 2. Sc. mirabile 
I. Sc. crispum (Ag.) Bornet (Taf. II, 26)

Wenig verzweigt, Fäden $16-36 \mu$ dick, $3 \mathrm{~cm}$ und länger, kraus. Fäden 14-30 $\mu$.dick, grün oder bleich-violett. Grenzzellen mehr oder weniger quadratisch.

2. Sc. mirabile (Dillw.) Bornet

Lager etwa schwarz-grün, $2-4 \mathrm{~mm}$ hoch, Filamente I $5-2$ I $\mu$ dick, die letzten Zellen an der Spitze dünn. Fäden 6-12 $\mu$ dick, hellgrün; Zellen unten cylindrisch, oben scheibenförmig. Grenzzellen mehr oder weniger quadratisch. In stehendem Wasser an Pflanzen und an feuchten Felsen.

(Auf feuchtem Boden wachsen Sc. ocellatum Lyngbye und andere).

\section{Petalonema Berkeley.}

Die schief geschichtete Scheide von fester Randschicht umgeben, sonst wie Scytonema.

I. Filamente $0,5-2 \mathrm{~mm}$ hoch, $\mathrm{I}_{5}-30 \mu$ dick, das rasig-krustige

Lager schwarz . . . . . . . . . . I. P. crustaceum

I*. Filamente $4-8 \mathrm{~mm}$ hoch, $24-66 \mu$ dick, reich geschichtet, meist einzeln oder genähert . . . . 2. P. alatum

I. P. crustaceum (Ag.) Kirchn.

Scheiden hellgelb, Fäden $6-8 \mu$ dick, blaugrün, Zellen ctwa quadratisch. Grenzzellen oblong. An von Wasser benetzten Felsen.

2 P. alatum Berkeley (Taf. II, 27)

Zellen blaugrün, Schichten stark dichotom, Zellen 9-15 dick. Grenzzellen gelblich, rund. An Wasserfällen, feuchten Felsen und in Sümpfen.

\section{Tolypothrix Kg. em. Thuret.}

Dauerzellen (bei einigen Arten) kugelig bis elliptisch. Filamente zu einem krustenförmigen oder rasigen Lager vereint.

I. Rasig, häufig schwimmend, Zweige ausgebreitet, oft mehrere Grenzzellen am Grunde, in stillstehendem Wasser : . . 2

2. Filamente 10-15 $\mu$ dick, Zellen kurz, die jungen tönnchenförmig . . . . . . . . . . . I. T. distorta

$2^{*}$. Filamente $9-12,5 \mu$ dick, Zellen mehr oder weniger isodiametrisch oder länger. . . . 2. T. lanata

$2^{* *}$. Filamente 8 - $10 \mu$ dick, Zellen wie bei voriger Art. , 
$I^{*}$. Rasig, flutend, regelmässig verzweigt, Filamente $12-17 \mu$ dick, in stark fliessendem Wasser... . 4. T. penicillata

I. T. distorta $\mathrm{Kg}$.

Filamente $\mathrm{I}-3 \mathrm{~cm}$ lang, häufig verzweigt, gekrümmt, Scheide fest, durchsichtig, selten gelb. Fäden 9- I $2 \mu$ dick, blaugrün, Zellen etwa so lang als breit. Grenzzellen meist einzeln. An Pflanzen und Steinen festgeheftet, in Sümpfen, ruhig fliessenden Bächen etc., häufig.

2. T. lanata (Desv.) Wartmann (Taf. II, 28)

Filamente $2 \mathrm{~cm}$ hoch, cylindrisch; Zellen ca. Io $\mu$ dick, I-4 Grenzzellen. An untergetauchten Pflanzen in stehendem Wasser.

3. T. tenuis $\mathrm{Kg}$.

Filamente $2 \mathrm{~cm}$ hoch; Zellen $6-8 \mu$ dick, blaugrün, $1-5$ Grenzzellen. Vorkommen wie bei voriger Art.

4. T. penicillata (Ag.) Thuret

Filamente bis $2 \mathrm{~cm}$ lang, Scheiden im Alter gelblich, Fäden etwa $10 \mu$ dick, blaugrün. Zellen 4-i $2 \mu$ lang; die gelben Grenzzellen meist einzeln. An Pflanzen, Steinen etc., in schnell fliessenden Bächen.

T. (Hassallia) byssoidea (Berk.) Kirchn. kommt nur ausserhalb des Wassers vor.

\section{Hydrocoryne Schwabe.}

Zweige sehr lang. Zellen kugelig oder elliptisch. Dauerzellen unbekannt. In formlosen Lagern.

H. spongiosa Schwabe (Taf. II, 29)

Filamente $4-6 \mu$ dick, wenig verzweigt; Fäden $3-4 \mu$ dick, bleich blaugrün. Die oblongen Grenzzellen inmitten der Fäden. An untergetauchten Pflanzen.

\section{Diplocolon Naeg.}

[Diplocolon heppi Naeg. bildet krumige, braunschwarze Räschen an Kalkfelsen.] 


\section{Fam. Stigonemataceae.}

Filamente kriechend und rasenförmig, oder mit den Scheiden zusammengewachsen. Hormogonien und Dauerzellen.

I. Filamente frei, einzeln oder in Räschen . . . . . . . 2

2. Fäden aus einer Zellreihe gebildet . . . . . . . . 3

3. Seitenzweige in der Dicke teils gleichbleibend, teils verdünnt auslaufend . 1. Mastigocladus (S. 77)

3*. Seitenzweige mit unverdünntem Ende . . . . . 2. Hapalosiphon (S. 77)

2*. Fäden meist aus zwei bis mehreren Zellreihen bestehend 3. Stigonema (S. 77)

1*. Filamente in einem gallertigen Lager vereint . . . . . 4 4. Scheiden dünn, aber deutlich. . 4. Capsosira (S. 78)

$4 *$ Scheiden dick, zu einer Gallerte zusammenfliessend 5. Nostochopsis (S. 78)

\section{Mastigocladus Cohn.}

Fäden meist mit einer Zellreihe, mit Grenzzellen im Verlaufe des Fadens, in hautartigem, geschichtetem Lager. Zellen cylindrisch bis kugelig.

M. laminosus Cohn (Taf. II, 30)

Filamente $6 \mu$ dick, jung Anabaena-Fäden ähnelnd, mit oder ohne Scheide, nach beiden Enden zugespitzt. Grenzzellen intercalar und häufig dicker als die übrigen Zellen, mehr oder weniger rund. In kälteren Thermen.

\section{Hapalosiphon Naeg.}

Zweige unverzweigt; Fäden meist einreihig mit intercalaren Grenzzellen.

II. pumilus (Kg.) Kirchn. (Taf. II, 31)

Lager spangrün bis bräunlich, $1-3 \mathrm{~mm}$ hoch, Filament $18-24 \mu$ dick, Aestchen 5, meist 8-12 $\mu$ dick; Zellen noch einmal so lang als breit; Scheiden farblos bis gelbbraun. Hormogonien etwa $6 \mu$ dick, $100-300 \mu$ lang.

\section{Stigonema (Ag.).}

Filamente frei, verzweigt, oft in rasigen Lagern. Scheiden meist gelb bis bräunlich gefärbt. Hormogonien und bei einigen Arten Dauerzellen. 
St. ocellatum (Dillw.) Thuret (Taf. II, 32)

Lager rasig, bleich. Filamente aufsteigend, $3-8 \mathrm{~mm}$ hoch, unregelmässig verzweigt, $35-45 \mu$ dick, können sich alle in Hormogonien umwandeln. Zellen verschieden gross, $20-30 \mu$ dick, in farbloser oder gefärbter Scheide. Hormogonien $15 \mu$ breit und $50-65(150) \mu$ lang. In torfigem Wasser, doch auch auf feuchtem Boden.

[Andere Arten wie St. hormoides (Kg.) Bornet, St. panniforme ( $A g$.) Hieron. u. s. w. leben nur auf feuchten Boden].

\section{Capsosira Kg.}

Nur eine Zellreihe in jeder Scheide, Grenzzellen einzeln, seitlich. Filamente verzweigt und aufrecht, verwachsen.

C. brebissoni Kg. (Taf. II, 33)

In kleinen, $\mathbf{I}-3 \mu$ hohen, schwarzgrünen Lagern an untergetauchten Gegenständen. Die Lager innen grün und gelb gezont. Filamente $7,5 \mu$ dick, Zellen rund, $4-5 \mu$ breit, blaugrün. Die nicht geschichtete Scheide farblos oder gelb. Selten.

\section{Nostochopsis Wood.}

Fäden mit einer Reihe von Zellen, meist seitlichen, gestielten Grenzzellen. Filamente verzweigt.

$N$. lobata Wood (Taf. II, 34)

Bildet $1 \mathrm{~mm}$ hohe, bis $2 \mathrm{~cm}$ breite, gallertige Lager. Filamente 4- $9 \mu$ breit, hellblaugrün, Zellen etwa quadratisch. An untergetauchten Pflanzen oder freischwimmend.

\section{Fam. Rivulariaceae.}

Fäden mit einer Zellreihe und Gegensatz zwischen Basis und Spitze, meist mit Grenzzelle und in Scheide. Filamente einfach und verzweigt, meist zu Lagern vereint. Hormogonien und Dauerzellen, auch Konidien.

1. Fäden ohne Grenzzellen . . . . . . . . . . . . . 2

2. Am Grunde der Fäden mit kugeligen Konidien . . . $2^{*}$. Keine Konidienbildung vorhanden 1. Leptochaete (S. 79) 
3. Die Filamente von einer horizontal ausgebreiteten Unterlage aufwärts wachsend 2. Amphithrix (S. 79) $3^{*}$. Filamente ohne solche Unterlage . . . . . . .

3. Homoeothrix (S. 79) I*. Fäden mit Grenzzelle . . . . . . . . . . . . 4

4. Filamente frei oder in verzweigten Büscheln, nicht in gallertigen Lagern . . . . . . . . . . . . 5

5. Fäden und Verzweigungen einzeln in deutlichen Scheiden . . . . . 4. Calothrix (S. 80)

$5^{*}$. Verzweigungen $2-6$ in einer und derselben Scheide 5. Dichothrix (S. 80)

4*. Filamente in einem gallertigen Lager 6. Rivularia (S. 8 I)

\section{Leptochaete Borzi.}

Filamente dünn und unverzweigt, aufrecht, in krustenartigem Lager.

1. Scheiden farblos . . . . . . 1. L. stagnalis

1*. Scheiden goldgelb bis braun. . . 2. L. nidulans

I. L. stagnalis Hansg.

Filamente $3-4,5 \mu$ dick, bis $50 \mu$ lang, bildet spangrüne Ueberzüge auf Steinen.

2. L. nidulans Hansg. (Taf. II, 35)

Fäden zu 5- 100 in kleinen Häufchen vereinigt, an der Basis $2-4,5 \mu$ dick, bis $45 \mu$ lang; Fadenspitze aus den Filamenten hervorragend. Im Lager von Clathrocystis aeniginosa (siehe S. 55) und Polycystis.

\section{Amphithrix $\mathrm{Kg}$.}

Die dünnen, unverzweigten Fäden in ein dünnes Haar ausgehend, mit dünnen und engen Scheiden.

A. ianthina (Mont.) Born. et Fl. (Taf. II, 36)

Lager dünn, amethystfarben; Fäden $0,3-0,5 \mathrm{~mm}$ lang, 1,50-2,25 $\mu$ dick; Scheiden rötlich, Zellen mehr oder weniger isodiametrisch; Hormogonien $20 \mu$ lang. An untergetauchten Steinen in Quellen.

\section{Homoeothrix Thuret.}

Filamente einfach oder verzweigt mit farblosen Scheiden; in polsterförmigem Lager. 
I1. juliana (Menegh.) Kirchn. (Taf. II, 37)

Filamente einzeln oder in olivengrünem Lager, $2 \mathrm{~mm}$ hoch, 10 - 15 $\mu$ dick. Scheide farblos, ungeschichtet. Fäden 9-12,5 $\mu$ dick, in eine lange Spitze ausgezogen. Zellen $1 / 3$ Mal so lang als breit. Hormogonien 4-5 Mal so lang. An Steinen und Wasserpflanzen.

\section{Calothrix Ag.}

Einzeln oder zu Lagern vereinigt. Grenzzellen intercalar oder basal. Dauerzellen (bei einigen), einzeln oder gereiht.

I. Lager sitzen an lebenden Wasserpflanzen . . . . . . 2

2. Endophytisch im Lager schleimiger Algen

$$
\text { I. C. fusca }
$$

2*. Epiphytisch, auf Wassermoosen u. S. w. festsitzend .

$$
{ }_{1 *} \text {. Lager sitzen an Holz und Steinen . 3. C. parietina }
$$

1. C. fusca (Kg.) Born. et Fl. (Taf. II, 38)

Filamente $0,2-0,3 \mathrm{~mm}$ lang, $10-12 \mu$ dick, unten verdickt (bis $15 \mu$ ). Scheiden dick, farblos. Fäden $7-8 \mu$ dick, mit langem Haar. I -2 basale Grenzzellen. Im Lager von Batrachospermum, Chaetophora, Palmellaceen etc., häufig.

2. C. ascendens (Naeg.) Born. et F1.

Filamente I $\mathrm{mm}$ hoch, $18-24 \mu$ dick, von der Basis zur Spitze verdünnt. Scheide geschichtet. Fäden in der Mitte I $2 \mu$ dick. In Sümpfen.

3. C. parietina (Naeg.) Thuret

1/4 - I mm hohe Filamente, 10-I $2 \mu$ dick, gelbbraun; Fäden 5- Io $\mu$ dick, in I $\mu$ starke Spitzen ausgezogen. Hormogonien 3 Mal solang als breit. An von Wasser überrieselten Steinen u.s.w.

[Die seltene $C$. thermalis (Schwabe) Hansg. mit farblosen Scheiden, in Thermen.]

\section{Dichothrix Zanardini.}

Fäden regelmässig dichotom verzweigt, Grenzzellen basal oder intercalar. In polsterförmigen Lagern.

I. Scheiden dünn, Filamente $10-12 \mu$ dick 1 . D. orsiniana 1.* Scheiden geschichtet, Filamente $16-24 \mu$ dick . 
I. D. orsiniana ( $\mathrm{Kg}$.) Born. et $\mathrm{Fl}$.

Das schleimige Lager braun-grün, 2-3 $\mathrm{mm}$ hoch, Zweige eng zusammengedrückt in derselben gelben Scheide eingeschlossen. Fäden $6-7,5 \mu$ dick, olivengrün, zugespitzt. Basale Grenzzellen. An Felsen und Steinen, besonders bei Wasserfällen.

2. D. sypsophila (Kg) Born. et F1. (Taf. II, 39)

Häufig mit Kalk inkrustiert, Filamente bis $2 \mathrm{~mm}$ hoch, 15-18 $\mu$ dick, aufrecht. Scheide dick, geschichtet, gelbbraun; Fäden olivengrün, $6-8 \mu$ dick. An bewässerten Mauern und Kalkfelsen.

\section{Rivularia (Rok.) Ag. (Gallerthaaralge).}

In einem mehr oder weniger kugeligen Lager verzweigte Fäden in gallertiger Scheide. Basale Grenzzellen. Dauerzellen (bei Gloeotrichia) unmittelbar über der Grenzzelle. Hormogonien und (bei einer Art) Konidien.

I. Dauerzellen vorhanden, die schlanken Fäden nur ganz allmählich verdünnt. [Sect: Gloeotrichia (Ag.) Kirchn.] . . 2

2. Lager klein, mit lang ausstrahlenden, peitschenförmigen Enden . . . . . . . . 1. R. echimulata

2*. Lager nicht so, mit glatter Oberfläche . . . . . . 3

3. Lager hart. Sporenaussenhaut aus einer Schichte. 2. R. pisum

$3^{*}$. Lager weich. Sporenaussenmembran doppelt . . . 3.'R. natans

1*. Dauerzellen fehlen. Fäden vom Grunde an verdünnt [Sect.: Eurivularia Kirchn.] . . . . . . . . . . . . . 4 4. Die mit Kalk inkrustierten Lager nur im Centrum hart, nicht gezont . . . . . . . 4. R. mimutula 4*. Die Lager bis zur Peripherie erhärtet, konzentrisch gezont 5. R. haematites

I. R. (Gloetr.) echinulata Engl. Bot. (Taf. II, 40)

Bildet gelbgrüne Kügelchen von 0,3-I mm Durchmesser; die Haare brechen leicht ab. Basale Grenzelle to $\mu$ dick. Bildet hin und wieder eine Wasserblüte.

2. R. (Gloetr.) pisum Ag.

Fäden $4-7 \mu$ dick, olivengrün, Zellen etwa quadratisch. Sporen o, I-0,4 mm lang, 9- I5 $\mu$ dick; Grenzzellen 7,5- I $4 \mu$ dick. In Teichen häufig. 
3. R. (Gloctr.) natans (Hedwig) Welw.

Lager zuletzt hohl, bis $10 \mathrm{~cm}$ gross, olivengrün, Fäden $7-9 \mu$ dick, in eine dicke Spitze ausgezogen; Sporen $40-250 \mu$ lang, ohne Scheide $10-18 \mu$ dick, äussere Hülle weit, bis $40 \mu$ dick. In Gräben und 'Teichen, festsitzend oder freischwimmend.

4. R. minutula (Kg.) Born. et Fl. (Taf. II, 41)

Lager bis $8 \mathrm{~mm}$ breit, mit Kalk inkrusticrt, Scheide weit, $27 \mu$ dick, geschichtet, farblos oder gelblich; Fäden unten 9- I 2,5 $\mu$ dick, in farblose Spitzen verdünnt. Grenzzellen oblong. An Pflanzen, auf Erde und an Steinen in Bächen, häufig.

5. R. hacmatites (DC.) Ag.

Bildet steinharte, oft sehr grosse (bis $30 \mathrm{~cm}$ ) olivengrüne Lager. Scheiden ziemlich eng, zerbrechlich. Fäden $4-7,5 \mu$ dick; Zelle am Grunde noch einmal so lang als dick, an der Spitze halb so lang. An Wasserfällen der Gebirge, nicht selten. 


\title{
II. Euphyceae
}

\author{
(Echte Algen).
}

\section{Litteratur:}

Cooke, M. C., British fresh-water Algae excl. Desmid. and Diatom. London $1883-1884$.

Falkenberg, P., Die Algen im weitessten Sinne in Schenks Handbuche der Botanik. Breslau $188 \mathrm{r}$.

Hansgirg, Ant., Prodromus der Algenflora von Böhmen I. u. II. Prag 1888/93. (Im Archiv für die naturwissenschaftliche Landesdurchforschung von Böhmen V, VI, VII).

Kirchner, Osc., Algen in Cohns Kryptogamenflora von Schlesien. Breslau 1878.

Kirchner, Osc., Die mikroskopische Pflanzenwelt des Süsswassers. Hamburg 189 I.

Kützing, F. T., Phycologia germanica. Nordhausen 1845 .

Kützing, F. T., Tabulae phycologicae oder Abbildungen der Tange mit 1900 Tafeln. Nordhausen $18+5 / 7 \mathrm{t}$.

Rabenhorst, M., Flora europaea algarum aquae dulcis et submarinae. Lpzg. 1864-1868.

de Toni, Sylloge Algarum Iff. Patavii $1889 \mathrm{ff}$.

de Wildeman, Flore des Algues de Belgique. Bruxelles et Paris 1896.

Wolle, Fr., Fresh-water Algae of the United States. Betleh. 1887.

Wille, N., Kjellman, F. R., und Schmitz, Fr., in Engler und Prantls Natürlichen Pflanzenfamilien. 1890-1897.

Die grosse Gruppe der Euphyceen umschliesst niedrige und hochentwickelte Formen. Das Vorhandensein eines deutlichen Zellkẹnes und scharf begrenzter, grüner Chromatophoren ist das Hauptkriterium, das die echten Algen von den Schizophyten scheidet. Allerdings fehlt es nicht an Uebergangsformen zwischen beiden Gruppen. So kann man bei den winzigen StichococcusFormen zweifelhaft sein, ob sie nicht wohl den Bakterien zuzuzählen sind; dieser Zweifel ist umsomehr berechtigt, als man 
in neuester Zeit unter den letzteren einige chlorophyllgrǘne Spezies nachgewiesen zu haben glaubt. Dieser Fall lässt also nur die Grösse als Unterscheidungșmerkmal bestehen und liefert für die nahe Verwandtschaft zwischen Euphyceen und Schizophyceen den sichersten Beweis.

In ihrem Stoffwechsel verraten die Euphyceen sich als echte Pflanzen. Ihr Chlorophyllgehalt befähigt sie, die Kohlensäure der Luft zu organischen Substanzen zu verarbeiten. Das crste Produkt der Assimilation ist entweder Stärke, die frei im Chromatophoren oder an bestimmten eiweisshaltigen Körpern, den Pyrenoiden, abgelagert wird, oder Oel. Hierin ist gegenüber den Schizophyten ein wesentlicher Fortschritt zu sehen.

Wie aus niederen Formen höher organisierte sich entwickeln können, veranschaulichen die Stichococcus-Arten. Die Stichococcus-Zellen bleiben nämlich in Kulturen nach der Teilung vielfach im Zusammenhange, setzen längere oder kürzere Fäden zusammen, und erläutern so aufs klarste die Entstehung von Fadenbildungen. Schliessen sich nun bei höheren Formen noch mehr Zellen noch fester zusammen, so ist ein vielzelliger Organismus entstanden, in dem morphologisch Differenzierung und physiologisch Arbeitsteilung sich notwendig machen (vgl. S. 3). So findet sich dic Ausbildung von Wurzel, Stengel und Blatt und die ganze wunderbare Organisation der höheren Pflanze bereits bei den Euphyceen embryonenhaft angedeutet und vorbereitet.

Vor allem ist es das Gebiet der Fortpflanzungserscheinungen, worauf die Algen sich als Vorläufer höherer Organisationsstufen erweisen. Im einfachsten Falle ist allerdings auch bei den Euphyceen die Fortpflanzung ungeschlechtlich und verläuft als cine einfache Querteilung. Zwei Modi sind hierbei möglich: erstens können beide Teilprodukte der Zelle an Volumen gleich sein, wobei beide Tochterindividuen am Leben bleiben, und der Lebensprozess kontinuierlich ist; zweitens aber - und das trifft für höhere Formen $z \mathrm{u}-$ können die Teilprodukte ungleich sein, wobei die Mutterzelle nach längerer oder kürzerer Zeit abstirbt. Im letzteren Falle sind die Tochterzellen vielfach beweglich und schwärmen mittels zweier oder mehr Geisseln umher, um an einer andern Stelle auszukeimen und eine neue Pflanze entstehen zu lassen. (Schwärmsporen, Zoosporen).

Diese Wege der ungeschlechtlichen Fortpflanzung kommen schon den Bacteriaceen zu, sie finden sich auch bei allen Formen 
der Euphyceen, treten aber bei deren höheren Gruppen mehr und mehr in den Hintergrund; dagegen gewinnt die geschlechtliche Fortpflanzung immer mehr an Bedeutung. Schon bei den Protococcoideen tritt sie auf: die mit Geisseln herumschwärmenden Zellen, die den ungeschlechtlichen Schwärmsporen mehr oder weniger gleichen, kopulieren, d. h. zwei dieser Schwärmer (Gameten) legen sich zusammen, ihr Plasma vereinigt sich zu einer einzigen Zelle, der Zygospore, aus der dann mittelbar oder unmittelbar die neue Pflanze entsteht. Im einfachsten Falle sind die Gameten noch einander gleich, so dass eine Unterscheidung in männliche und weibliche Gameten nicht möglich ist (Isogameten). Vielfach jedoch ist die Grösse der Gameten verschieden (A nisogameten), wobei man mit mehr oder weniger Recht den kleineren als den beweglicheren für den männlichen Teil halten kann. Durchgreifender ist die Differenzierung bei der Eibildung. Hier verharrt der weibliche Teil, das Ei, gänzlich unbeweglich und wird von der männlichen Zelle, dem Spermatozoid, das meist bedeutend kleiner und beweglicher ist, aufgesucht und befruchtet. Diese Art der geschlechtlichen Fortpflanzung kommt allen höheren Pflanzen (und Thieren) zu, natürlich in den verschiedensten Modifikationen und Komplikationen.

Schon bei den Algen sind die mannigfachsten Verschiedenheiten zu finden. Bald ist der männliche Teil eine unbewegliche, kleine Zelle, die passiv vom Wasserstrome dem Eie zugeführt wird, bald sind die Zellen aktiv beweglich und haben zwei gleiche, oder zwei ungleiche Geisseln etc.; bald bildet sich nur ein $\mathrm{Ei}$ in der Eimutterzelle, dem Oogonium, bald eine ganze Anzahl. In ähnlicher Weise erzeugt die Samenmutterzelle (Antheridium), bald nur wenige, bald sehr zahlreiche Spermatozoiden. Das Resultat dieser Befruchtung ist überall eine einzige Zelle, die Oospore.

Verwandt mit den Kopulationserscheinungen ist die Konjugation, die hauptsächlich den Konjugaten zukommt. So iegen sich vielfach zwei Individuen der einzelligen Desmidiaceen aneinander, ihre Schalen öfnen sich, und durch Zusammentreten der beiderseitigen Inhalte wird wieder eine $Z$ ygospore gebildet. Dasselbe findet bei den fädigen Formen, den Zygnemeen, statt, wo die einzelnen Zellen desselben Fadens unter sich oder mit solchen fremder Fäden eine Konjugation eingehen. Das Resultat 
sowohl der Konjugation wie der Eibefruchtung und der Kopulation ist das gleiche: die Mischung des Plasmas zweier Individuen zu einer neuen Zelle, die das Ausgangsmaterial für eine neue Pflanze bildet.

Die Einteilung ist im grossen und ganzen nach der in „Engler-Prant1s natürlichen Pflanzenfamilien“ eingehaltenen vorgenommen.

I. Organismen rein chlorophyllgrün oder gelblich (oder rötlich, dann aber einzellig; braun nur bei Phacothamnion) . . . 2

2. Organismen nicht ansehnlich, nicht wirtelig verzweigt 3

3. Zellinhalt gleichmässig grün oder mit der Zellwand anliegenden Chlorophyllplatten; mit oder ohne Schwärmerbildung . . . I. Chlorophyccae (S. 86)

$3^{*}$. Zellinhalt mit spiraligem, sternförmigem oder sonstigem Chromatophor. Vermehrung durch Konjugation vorhanden, keine Schwärmsporen .

\section{Conjugatac.}

$2 *$. Organismen ansehnlich, wirtelig verzweigt, oft durch Kalkinkrustation brüchig . . V. Characcae

1*. Organismen braun, rot bis violett oder bläulich . . . . 4 4. Mit Kieselpanzer, beweglich oder unbeweglich . . . . III. Bacillariaceac

4*. Ohne Kieselpanzer . . . . . . . . . . . . . . 5

5. Einzellig, beweglich durch zwei Geisseln, mit Cellulosepanzer ... . . . IV. Peridiniaceae

5*. Hochentwickelte Pflanzen, unbeweglich . . . 6

6. Zellinhalt braun, Schwärmsporenbildung . . VI. Phacophyceac

6*. Zellinhalt rot, rosa oder bläulich, Geschlechtliche Vermehrung . . . VII. Rhodophyceae

\section{Chlorophyceae}

(Grünalgen)••

1. Zellen nicht schlauchförmig, meist mit einem Zellkerne . 2

2. Ohne Spitzenwachstum, einzeln lebend oder in Familien vereint, aber nicht zu engverbundenen Fäden oder Zellkörpern vereint . . . . I. Protococcoideae (S. 87) 
$2^{*}$. Mit Spitzenwachstum; Zellen in einfachen oder verzweigten Zellfäden, auch zu Flächen vereint.....

II. Confervoideae

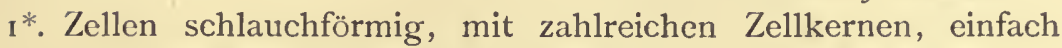
oder verzweigt, aber ohne Querwände III. Siphoncae

\section{Protococcoideae.}

Die einfachsten Formen, die sich zum Teil vielleicht direkt an die Bakterien anschliessen. Entweder einzeln lebende oder in Menge zusammenliegende Zellen. Im letzteren Falle entweder regellos in Familien (Tetraspora) oder in sog. "Coenobien", in bestimmt angeordneten, Zeit ihres Lebens unverändert bleibenden Kolonieen (Scenedesmus, Pediastrum etc.). Eine Anzahl von Formen ist stets unbeweglich, andere dagegen sind entweder nur zu Zeiten, oder immer beweglich. Die Vermehrung geschieht durch einfache Querteilung oder durch Ausbildung von ungeschlechtlichen Schwärmsporen oder geschlechtlichen Gameten.

I. Vegetative Zustände unbeweglich . . . . . . . . . . 2

2. Vegetative Zellteilung vorhanden, führt zur Vergrösserung der Kolonieen. . . . . . . . . . . . . . . . 3

3. Ohne Schwärmsporen'). . I. Pleurococcaceac (S. 87)

3*. Mit Schwärmsporenbildung II. Tetrasporaceae (S. 97)

$2^{*}$. Vegetative Zellteilungen fehlen ganz; nur Schwärmsporenbildung . . . . . . . III. Protococcaceae (S. 103)

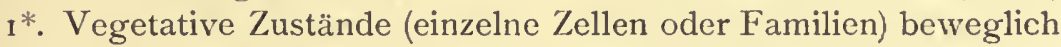
IV. Volvocaceae (S. 109)

\section{Fam. Pleurococcaceae.}

Zellen einzeln, in Familien oder in Coenobien. Vermehrung nur durch (meist successive) Zellteilung.

I. Die Zellen in Gallerte ${ }^{2}$ ) eingelagert oder an Gallertstielen sitzend . . . . . . . . . . . . . . . . 2

1) Hierher gehört auch die mit verschiedenen Tieren symbiotisch lebende Gattung Chlorella Beyerinck [Chl.prologenitum (Beyer.) in Spongilla fluviatilis, dem Süsswasserschwamme, und Chl. infusionum (Schrank) Beyer. in Hydra, bei Stentor, Paramaecium] etc.

$\left.{ }^{2}\right)$ Die Gallerte ist vielfach erst durch Färbemittel wie Safranin und Vesuvin nachweisbar. 
2. In Gallerte eingelagert . . . . . . . . . . . . . 3

3. Zellen in der Gallerte einzeln oder zahlreich, aber keine regelmässige Kolonie bildend. . . . . . . . . . 4

4. Zellen nicht einreihig in langen Gallertschläuchen - 5

5. Zellen nicht mondsichelförmig . . . . . . . 6

6. Zellen länglich-cylindrisch, nur Querteilung

$$
\text { I. Dactylothece (S.90) }
$$

6*. Zellen mehr oder weniger rund

7. Zellen nach der Teilung in Tetraden verbunden bleibend . . . 2. Tetracoccus (S. 9o)

$7^{*}$. Zellen trennen sich sofort. . . . . . . 8

8. Die Muttermembran wird bei der Teilung nicht zersprengt . . 3. Palmodictyon (S. 9o)

8*. Die Muttermembran wird zersprengt . . .

4. Schizochlamy's (S. 9o)

5*. Zellen halbmondförmig . 5. Kirchneriella (S. 91)

$4^{*}$. Zellen einreihig in Gallertschläuchen

6. Geminella (S.91)

$3^{*}$. Zellen bilden regelmässige vierteilige Kolonien .

$2^{*}$ Zellen an Gallertstielen befestigt

7. Staurogenia (S. 91)

8. Dimorphococcus (S.91)

I*. Die Zellen sind ohne Gallerte

9. Ohne lange, dünne Stacheln (höchstens mit kurzen, dicken Stacheln)

ı. Zellen einzeln oder in unbestimmter Anzahl mit einander verbunden .

II. Zellen mehr oder weniger rundlich . . . . . I2

I 2. Mit dicker, geschichteter, gelatinöser Hüllmembran

9. Urococcus (S. 91)

12*. Membran mehr oder weniger dünn . . . . I3

I3. Zellen mit kurzen Stacheln besetzt.

10. Acanthococcus (S. 92)

13*. Zellen ohne Stacheln . . . . . . . . 14

14. Die Zellen gross, trennen sich sofort nach der Teilung . . . . I1. Ercmosphaera (S. 92)

$I_{4}^{*}$. Die Zellen klein, hängen längere Zeit zusammen 1 2. Pleurococcus (S. 92)

I I*. Zellen oval, scharf-eckig bis spindelförmig . . I5

I5. Zellen oval bis cylindrisch. . . . . . . I6 
16. Die cylindrischen Zellen liegen nicht zu mehreren in der alten Muttermembran

\section{Stichococcus (S. 92)}

I6*. Die ovalen Zellen liegen meist zu mehreren in der Muttermembran . . . . . . . I7

17. Zellen mit Pyrenoiden .

I 7 *. Zellen ohne Pyrenoide .

$$
\text { 14. Nephrocytium (S. 93) }
$$

I 5. Oocystis (S. 93)

15*. Zellen nicht oval . . . . . . . . . . . 18

18. Zellen vieleckig, in mehr oder weniger lange Spitzchen auslaufend i6. Polyedrium (S. 93)

18*. Zellen spindelförmig oder halbmondförmig . 19

19. Zellen sehr dünn, spindelförmig, gerade oder gekrümmt, einzeln, oder in unregelmässigen Haufen . . . . . . . . . 20

20. Zellen mit Pyrenoid, Enden in lange Borsten ausgezogen, einzeln .

I 7. Schroederia (S. 94)

20*. Zellen ohne Pyrenoid, oft in Haufen, Enden nicht so . . I8. Rhaphidium (S.94)

I9*. Zellen dick, stark halbmondförmig gekrümmt, meist regelmässig gelagert . . . . . . . I9: Selenastrum (S. 94)

10*. Zellen in bestimmter Anzahl, koloniebildend 21

21. Die Zellen in der Kolonie sind deutlich in einer Ebene gelagert. . . . . . . . . . . . 22

22. Die Kolonie bildet ein solides, viereckiges Täfelchen mit bestacheltem Rande.

20. Cohniella (S. 94)

22*. Kolonien nicht so . . . . . . . . . . . 23

23. Die Zellen liegen parallel nebeneinander, Zellteilung nach einer Richtung

21. Scenedesmus (S. 94)

23*. Die Zellen schliessen nicht eng aneinander, Zellteilung nach zwei Richtungen

22. Crucigenia (S. 95)

21 *. Die Zellen kugelförmig oder anders gelagert . 24

24. Die einzelnen Zellen mehr oder weniger rund 25

25. An der Peripherie der kugelförmigen Kolonie angeordnet . . . 23. Coelastrum (S. 95) 
25*. Kolonic nicht hohl . 24. Sorastrum (S. 96)

$24^{*}$. Die Zellen länger als dick . . . . . . . 26

26. Zellen halbmondförmig gebogen . 19. Sclenastrum (S. 94)

26*. Zellen langgestreckt 25. Actinastrum (S. 96)

$9^{*}$. Zellen mit langen, dünnen Stacheln . . . . . . 27

27. Stacheln am Grunde nicht deutlich verdickt . . . .

[Golenkinia siche folgende Familic (S. 99)]

$27 *$. Stacheln verdickt . . . . . . . . . . . . 28

28. Stacheln sitzen auf Knötchen . . . . . . . .

[Lagerheimia siehe folgende Familie (S. 99)]

$28 *$. Stacheln nicht so . . . . . . . . . . 29

20. Zellen einzeln, oder $2-8$ in gemeinsamer Hülle . 26. Chodatclla (S. 96)

29*. Zellen immer in Kolonien, niemals in gemeinsamer Hülle . . . . . 27. Richtcriclla (S. 97)

\section{Dactylothece Naeg.}

D. branni (A. Br.) Lagerh. (Taf. III, 1)

Zellen ohne Hülle $3-5 \mu$ dick, $6-9 \mu$ lang. Familien bis $24 \mu$ lang. Ausgebreitetes, gelblichgrünes schleimiges Lager. Wohl nur an feuchten Mauern.

\section{Tetracoccus West.}

Zellen bleiben in Familientetraden beisammen, Muttermembran überdauert die Teilung. Plattenförmiges Chromatophor.

T. nimbatus DeW.

Zellen $8-15 \mu$ gross. Ein Pyrenoid. An von Wasser befeuchteten Steinen.

\section{Palmodictyon $\mathrm{Kg}$.}

Zellen rund oder elliptisch, bis zu vier in einer Gallerthülle, die mit benachbarten ein anastomosierendes Netzwerk bilden. Teilung in zwei Richtungen.

$P$. viride $\mathrm{Kg}$. (Taf. III, 2)

In haardicken Schleimfäden eingeschlossen; Zellen $28-40 \mu$ dick, mit starker Membran. An Steinen in Teichen.

\section{Schizochlamys A. Br.}

Die Zellen sind unregelmässig in Gallerte eingelagert. Chromatophor kegelförmig mit einem Ausschnitte. Die zersprengten Mutterzellenmembranen bleiben in der Gallerte erhalten. 
Sch. gelatinosa A. Br. (Taf: III, 3)

Bildet bis faustgrosse Lager, festsitzend oder frei schwimmend. Zellen I I- I4 $\mu$ dick, meist vier genähert. In stehenden Gewässern, Sümpfen etc., nicht selten.

\section{Kirchneriella Schmidle.}

Die halbmondförmigen Zellen liegen meist regellos in der Gallerte zerstreut, meist vier genähert.

K. hinata Schmidle (Taf. III, 4)

Zellen $3-5 \mu$ breit, zwei Mal so lang, an den Enden mehr oder weniger zugespitzt. Gallertlager bis $1 / 2 \mathrm{~mm}$ gross. In Tümpeln.

\section{Geminella (Turp.) Lagerh.}

Die Gallertfäden bilden freischwimmende, mikroskopisch kleine Familien. Dauerzellen vorhanden. Gehört vielleicht zu Ulothrix.

G. intermpta (Turp.) Lagerh. (Taf. III, 5)

Zellen 5-6 (8) $\mu$ dick, 8-12 (15) $\mu$ lang, einzeln und getrennt in $16-18 \mu$ dicken Gallertröhren. Dauerzellen $9-10 \mu$ dick, bis I $5 \mu$ lang, mit brauner Membran. In Sümpfen und Teichen.

\section{Staurogenia $\mathrm{Kg}$.}

Die in Gallerte eingeschlossenen Familien bestehen aus 4-16 vierzelligen Coenobien. Zellen mit einem wandständigen Chromatophor und einem Pyrenoid.

St. lauterborni Schmidle (Taf. III, 6)

Länge der Zellen 6,8-12, Breite 6,8-8,5 $\mu$; 16 -zellige Familien können bis $50 \mu$ im Durchmesser haben. Im Plankton von Seen.

\section{Dimorphococcus A. Br.}

Die Zellen sitzen in den freischwimnenden Kolonien an den Enden von Gallertstielen zu 2-8 zusammen. Enden der Zellen bleiben frei vom Chromatophor.

D. lunatus A. Br. (Taf. III, 7)

Zellen $10-20 \mu$ lang. In Teichen.

\section{Urococcus (Hass.) Kg.}

Zellinhalt zuletzt bräunlich oder blutrot. Die Hüllmembran meist stielartig verlängert, können auch Palmella-artig verschleimen. Zweifelhafte Gattung! 
U. insignis (Hass.) $\mathrm{Kg}$.

Zellen kugelig, 23-53 $\mu$ dick, mit den kurzgestielten Hüllmembranen bis $75 \mu$ dick. Mit dem verwandten:

U. hookerianus (Berk. et Hass.) (Taf. III, 8), der durch langgestielte Membran ausgezeichnet ist, an feuchten Felsen und in Torfsümpfen.

\section{ro. Acanthococcus Lagerheim.}

Eine etwas unsichere Gattung, von deren zahlreichen Arten eine grössere Anzahl sicher Ruhesporen von Desmidiaceen ist. Oberfläche der Zellen mit Stacheln oder sonstigen Hervorragungen besetzt.

A. hirtus Reinsch (Taf. III, 9)

Zellen einzeln oder in kleinen Familien vereint, rund. Membran $1 / 8-1 / 9$ des Zelldurchmessers dick, homogen, mit ungleichen Stacheln dicht besetzt.

\section{Eremosphaera De By.}

Die Zellen einzeln lebend, freischwimmend, gross, mit centralem Zellkern. Mit zahlreichen Chlorophyllkörnern. Teilung in 2 (4) Tochterzellen.

E. viridis De By. (Taf. III, 10)

Zellen kugelrund, I00- I $45 \mu$ (selten $30-80 \mu$ ) im Durchmesser, meist vereinzelt. In Sümpfen und Moorgräben, zerstreut.

\section{Pleurococcus Menegh.}

Zellen mehr oder weniger rund, mit dünnen Wänden; meist mehrere Chlorophyllkörner. Mit oder ohne Pyrenoid. Dauerzellen vorhanden. Meist nur an Bäumen, Brettern etc., wo sie den grünen Ueberzug bilden, so Pl. vulgaris (Grev.) Menegh. (Taf. III, I I) u. and.

\section{Stichococcus Naeg.}

Die cylindrischen Zellen mit dünner Membran und wandständigem Chromatophor und Pyrenoid, einzeln oder reihenweise in kleinen Familien. Zellteilung nur in der Quere. Hierher sind manche Formen von Ulothrix zu rechnen, die an der Luft nur in der Kokkenform wachsen, im Wasser dagegen Fäden bilden.

St. bacillaris Naeg. (Taf. III, 12 )

Die Kokkenform (Durchmesser 2,1 $\mu$, Länge 3,4 $\mu$ ) überall an feuchten Brettern, in ausgehöhlten Baumstämmen etc. 
Der St. flaccidus (Kg.), als Kokkenform ebenda wachsend, ist jedenfalls die Luftform für die bisher Ulothrix faccida $\mathrm{Kg}$. genannte Fadenalge.

\section{Nephrocytium Naeg.}

Die ovalen, gekrümmten Zellen $\mathrm{zu} 2-\mathbf{1 6}$ in der freischwimmenden Membran der Mutterzelle. Teilung nach drei Richtungen. (Schwärmsporen?).

N. agardhianum Naeg. (Taf. III, I3)

Familien $34-60 \mu$ lang, $1 / 2-2 / 3$ Mal so dick, Zellen $2-7 \mu$ dick, und bis 4 Mal so lang. Zerstreut in stehenden Gewässern. Die verwandte

N. naegelii Grun. ist grösser (Zellen I I- $22 \mu$ dick und 2 Mal so lang). Ebenda.

\section{I5. Oocystis Naeg.}

Die ovalen Zellen einzeln oder zu 2-8 in der Muttermembran. Mehrere wandständige Chromatophoren, kein Pyrenoid.

I. Zellen rundlich, eiförmig, 15-2 I $\mu$ dick I. O. naegelii ${ }^{*}$. Zellen elliptisch, $6-18 \mu$ dick . . . 2. O. solitaria

I. O. naegelii A. Br.

Familien $2-8$ zellig; vor der Teilung bis $40 \mu$ lang. Zellhaut dick. In Teichen, Tümpeln etc.

2. O. solitaria Wittr. (Taf. III, 14)

Familien $2-4$ zellig; Zellen bis $25 \mu$ lang. Membran an den Polen verdickt. Ebenda.

3. O. marssoni Lemmerm.

Wie vorige, doch mit zugespitzten, kleineren Zellen.

\section{Polyedrium Naeg.}

Einige Spezies sind wahrscheinlich Entwicklungsstadien anderer Algen. Sie zeigen ein sehr verschiedenes Aussehen. Mit zugespitzten Enden oder mit drei oder mehr langen Spitzen. I. Die Zellen laufen an den Ecken in breite, weisse, gespaltene Lappen aus . . . . . . . . . . 1. P. enorme I*. Die Zellen mit abgerundeten Ecken, aber aufgesetztem Stachel 2. P. trigonum

I. P. enorme (Ralfs) De By. (Taf. III, 15)

Zellen $27-40 \mu$ breit. In Teichen und Sümpfen. 
2. P. trigomum Naeg. (Taf. III, 16)

Die 3 [oder 4: var. tetragonum (Naeg.) Rabh.] Ecken liegen in derselben Ebene, Seiten leicht konkav. Zellen to-30 $\mu$ breit. In Teichen und Sümpfen, zerstreut.

\section{I7. Schroederia Lemmerm.}

Zellen freischwimmend, einzeln, lang, spindelförmig, gerade oder gekrümmt, in lange Spitzen ausgezogen. Ein wandständiges Chromatophor, mit zentralem Pyrenoid.

Schr. setigera (Schroeder) Lemmerm. (Taf. III, I 7 )

Zellen $3-6 \mu$ breit, 60-85 $\mu$ lang, Spitzen $13-27 \mu$ lang. Im Plankton von Flüssen.

\section{Raphidium $\mathrm{Kg}$.}

Zellen nadel- oder spindelförmig, gerade oder gekrümmt, auch spiralig gebogen, oft zu bündelförmigen Eamilien vereint. Teilung durch sehr schiefe Querwände.

R. polymorphum Fresen. (Taf. III, I 8 ) .

Eine, wie der Name auch sagt, sehr veränderliche Art. Zellen $1,5-3,6 \mu$ dick, bis $30 \mathrm{Mal}$ so lang. Ueberall in stehenden Gewässern.

Eine $300 \mu$ lange Art, Rh. longissimum B. Schroeder lebt im Plankton.

\section{I9. Selenastrum Reinsch.}

Zellen meist $z u{ }_{4}$ oder 8 familienweise vereint. Längs- und Querteilung.

S. bibraianum Reinsch ('Taf. III, 19)

Zellen in der Mitte des konvexen Teiles aneinander geheftet. Familien $38-61 \mu, 33-38 \mu$ dick. In stehendem Wasser, hier und da.

\section{Cohniella B. Schroeder.}

Je 4 Zellen in jedem Coenobium, die lückenlos zusammenstossen. Teilung in zwei Richtungen.

C. staurogeniacformis B. Schroeder (Taf. III, 20)

Zellen $5-6 \mu$ breit. Im Plankton von Flüssen gefunden.

\section{Scenedesmus Meyen.}

Coenobien aus 2-I6 ei- oder spindelförmigen Zellen, die in der Natur wohl kaum isoliert gefunden werden. Längs-Teilung. 
I. Zellen an beiden Enden stumpf abgerundet, nicht zugespitzt 2

2. Coenobien stachellos . . . . . I. Sc. bijugatus

$2^{*}$. Coenobien mindestens an den letzten Zellen mit je zwei Hörnern . . . . . . . . . 2. Sc. quadricauda

$1^{*}$. Zellen zugespitzt, fast spindelförmig . 3. Sc. obliquus

I. Sc. bijugatus (Turp.) Kg.

Zellen mehr oder weniger oblong, stachellos, 4- - $\mu$ dick, 7-18 $\mu$ lang, ihrer ganzen Länge nach verwachsen. In stehenden Gewässern, zerstreut.

2. Sc. quadricauda (Turp.) Bréb. (Taf. III, 21)

Wie vorige Art, doch mit vier Seitenhörnern und grösser (Zellen $3-15 \mu$ dick, und $8-38 \mu$ lang). Variiert sehr. In Teichen etc., ziemlich verbreitet.

3. Sc. obliquus (Turp.) Kg. (Taf. III. 22)

Zellen an den zugespitzten Enden nicht verbunden; die zwei äusseren Zellen gewöhnlich nach aussen gebogen, $3-9 \mu$ dick und $5-27 \mu$ lang. Wie vorige Art, zerstreut.

\section{Crucigenia Morren.}

Die freischwimmenden Kolonien aus $48-64$ in einer Ebene liegenden Zellen. Die 4 Tochter-Zellen weichen bei der Teilung der Mutterzelle in der Mitte auseinander.

C. rectangularis Naeg. (Taf. III, 23)

Zellen länglich-elliptisch, $4-6 \mu$ dick, $5-7 \mu$ lang, in 13-55 $\mu$ breiten Familien vereint. In stehendem Wasser, ziemlich selten.

\section{Coelastrum Naeg.}

Die freischwimmenden Familien im Alter hohlkugelartig mit durchbrochener Peripherie. Zellen polygonal bis rund, häufig mit centrifugalem Fortsatze und gitterförmig durchbrochenem, glockenförmigem Chromatophoren und einem Pyrenoide. Jede Zelle kann eine neue' Kolonie bilden.

I. Interzellularräume ziemlich gross, grösser als der halbe Zel1durchmesser, Zellen mehr oder weniger polygonal durch gegenseitigen Druck. . . . . . . . . I. C. sphaericum 1*. Interzellularräume klein, Zellen rund . 2. C. microporum

I. C. sphaericum Naeg. (Taf. III, 24)

Zellen eiförmig, abgeplattet. Coenobien kugelig oder würfelförmig [var. cubicum (Naeg.) Rabh.], bis $90 \mu$ im Durchmesser, 
aus 8-50 Zellen bestehend. Zellen nach aussen vorgezogen, auch mit polarer Gallertverdickung [var. (?) proboscideum (Bohlin)]. In Teichen und Torfsümpfen, hin und wieder.

2. C. microporum Naeg.

Coenobien kugelig, 40-55 $\mu$ im Durchmesser, aus 8-32 runden, $6-16 \mu$ dicken Zellen bestehend. Wie vorige Art, seltener.

\section{Sorastrum $\mathrm{Kg}$.}

Etwa 8-32 keil- oder herzförmige Zellen sind um einen Punkt strahlig angeordnet und bilden eine solide, nach aussen mit kurzen Stacheln besetzte Kugel. Jede Zelle der sich auflösenden Kolonie kann durch Teilung eine neue Kolonie bilden.

S. spinulosum Naeg. (Taf. III, 25)

Coenobien 25-60 $\mu$ im Durchmesser, aus fast herzförmigen, mit je 4 Stacheln besetzten Zellen. Zellen etwa $15 \mu$ lang und ebenso breit. In Sümpfen und Torfmooren, meist vereinzelt.

\section{Actinastrum Lagerh.}

Zellen etwa kegelförmig, zu 4 oder 8 (16) in freischwimmenden Familien.

Act. hantzschi Lagerh. (Taf. III, 26)

Zellen $3-6 \mu$ dick, $10-24 \mu$ lang, gerade, allmählich verdünnt, strahlenförmig angeordnet. Im Plankton stehender Gewässer.

\section{Chodatella Lemmerm.}

Zellen freischwimmend, einzeln oder zu $2-8$ in gemeinsamer Membran, mit zwei bis zahlreichen Stacheln. Ein wandständiges Chromatophor mit Pyrenoid. Planktonorganismus.

I. An jedem Zellende 2 Stacheln . . . I. Ch. quadriseta I*. An jedem Zellende mehr als 2 Stacheln . . . . . . . 2

2. Zellen $8 \mu$ breit und $12 \mu$ lang . 2. Ch. Longiscta $2^{*}$. Zellen $9-18 \mu$ breit und 12-21 $\mu$.lang . 3. Ch. ciliata

1. Ch. quadriseta Lemmerm.

Zellen etwa eiförmig, $4 \mu$ breit und $5,5 \mu$ lang, Stacheln $15 \mu$ lang.

2. Ch. longiseta Lemmerm. (Taf. III, 27)

Zellen elliptisch, mit je 4-io langen Stacheln. Länge der Stacheln beträgt $44-55 \mu$. 
3. Ch. ciliata (Lagerh.) Lemmerm.

Zellen einzeln oder $\mathrm{zu} 2-8$ vereint, oval, mit $3-7$, meist sechs $18-20 \mu$ langen Stacheln. Vierzellige Familien $18 \mu$ dick und $30 \mu$ lang.

Alle drei im Plankton von Teichen und Seen.

\section{Richteriella Lemmerm.}

Zellen immer in Coenobien vereint, freischwimmend, ohne Gallertmantel, mit am Grunde verdickten Stacheln. Ein wandständiges Chromatophor mit einem Pyrenoid. Teilung nach drei Richtungen. Gehört mit Chodatella vielleicht zur folgenden Familie.

R. botryoides (Schmidle) Lemmerm. (Taf. III, 28)

Die runden Zellen $3--7 \mu$ dick, mit $\mathrm{I}-3$ langen $(60 \mu)$ Stacheln, die am Grunde etwa I,5 $\mu$ dick sind. Zellen unregelmässig oder regelmässig [var. fenestrata (Schröder)] gelagert. Im Plankton.

\section{Fam. Tetrasporaceae.}

Einzellige oder zusammenlebende, unbewegliche Zellen, meist mit Gallertbildungen. Geschlechtslose Fortpflanzung durch zweicilige Schwärmsporen, die direkt zu der Mutterzelle ähnlichen Zellen werden. Auch geschlechtliche Fortpflanzung durch Gameten ist bekannt.

1. Die Zellen besitzen keine Gallertbildungen . . . . . . 2

2. Die Zellen ohne lange Stacheln . . . . . . . . . 3

3. Die Membran sehr dünn . . I. Dactylococcus (S. 98)

3*. Die Membran dick, mit seitlichem Ansatze . . . .

2. Kentrosphaera (S. 99)

2*. Die Zellen mit langen Stacheln . 3. Lagerheimia (S. 99) I*. Die Zellen mit Gallertbildungen . . . . . . . . . . 4

4. Zellen mit langen Stacheln und einem Schleimhofe . .

$4^{*}$. Zellen ohne lange Stacheln . . . . . . . . . 5

4. Golenkinia (S. 99)

5. Viele Zellen in Gallerte ohne bestimmte Form eingelagert 6 6. Die Zellen Gloeocapsa-ähnlich, indem im Gallertlager die resistenten Hüllmembranen deutlich sichtbar bleiben und 2-32 Zellen umschliessen

5. Gloeocystis (S. 99) 
6*. Hüllmembranen zerfliessend oder nicht Gloeocapsaähnlich . . . . . . . . . . . . . 7

7. Zellen länglich-cylindrisch

6. Inoderma (S. 100)

$7^{*}$. Zellen rund .

8. Die Gallerte bildet ein meist einschichtiges, haut-artiges Lager, das zuletzt netzförmig zerreisst, Zellen meist 2 oder 4 genähert

$$
\text { 7. Tetraspora (S. 100) }
$$

8*. Die Gallerte bildet unregelmässige Lager . . 9 9. Membran dick und deutlich . . . . . . .

8. Chlorosphaera (S. IOI)

9*. Membran dick, aber bald gänzlich verschleimend 9. Palmella (S. IOI)

5*. Gallertmasse bestimmt geformt, oder Gallertstiele vorhanden . . . . . . . . . . . . . . . . . Io

10. Die Gallertmasse kugelig oder länglich, keine Gallertstiele . . . . . . . . . . . . . . . . . I I

II. Die Gallertmasse freischwimmend . . . . . I2

I2. Die Gallertmasse etwa kugelig, Zellen sehr dichtstehend, grün bis bräunlich .

$$
\text { Iо. Botryococcus (S. IоI) }
$$

12*. Die Gallertmasse etwa cylindrisch, mit deutlichen Zellen . . . . . 11. Palmodactylon (S. 102)

11*. Die Gallertmasse birnförmig, mit kurzem Stiele befestigt . . . . 12. Apiocystis (S. 102)

Iо*. Zellen an Gallertstielen festsitzend, oder durch solche verbunden . . . . . . . . . . . . 13

13. Ohne gemeinsame Gallerthülle .... . I4 14: Zellen durch Gallertstiele reihenweise verbunden 13. Hormotila (S. 1C2)

$14^{*}$. Zellen auf dichotom verzweigten Stielen 14. Mischococcus (S. 103) 13*. Mit gemeinsamer Gallerthülle

15. Dictyosphaerium (S. 103)

\section{Dactylococcus Naeg.}

Zellen einzeln oder zu mehreren zusammenhängend, oval bis spiral-förmig. Mehrere Chlorophyllplatten mit einem (oder 2) Pyrenoiden. Membran dünn. Schiefe Längsteilungen. 
D. infusionum Naeg. (Taf. III, 29)

Zellen spindelförmig, $3-6 \mu$ dick, $6-18 \mu$ lang, meist mit abgerundeten Enden. Die 2-8 Schwärmer +-5 Mal so lang als dick. In stehenden Gewässern.

D. caudatus (Reinsch) Hansg. in ein farbloses Stielchen auslaufend, an von Wasser benetzten Brettern, Steinen etc.

\section{Kentrosphaera Borzi.}

Zellen kugelig oder elliptisch oder unregelmässig, mit strahlig angeordnetem, deutlichem grünem Chlorophyllbande oder orange-rötlichem, feingekörntem Inhalte. Membran an der Aussenseite mit hornartigem Fortsatze, ab und $z u$ mit Verdickungen im Innern. Vielleicht Entwicklungszustand einer andern Alge.

K. facciolae Borzi (Taf. III, 3o)

Zellen vor der Schwärmerbildung bis $80 \mu$ dick, mit $2-3,5 \mu$ dicker Zellschicht. Bis 300 Schwärmer, die eiförmig und $2-3 \mu$ breit sind. In Teichen, an feuchten Wänden, unter LyngbyaArten, Bacillariaceen etc. Selten.

\section{Lagerheimia Chodat.}

Zellen einzeln oder $z u 2-8$ in gemeinsamer Hüllmembran, elliptisch, mit zwei vielfach auf Erhöhungen sitzenden Stacheln. 4-8 zweiteilige Zoosporen.

L. wratislaviense B. Schroeder (Taf. III, 3 1).

Zellen elliptisch mit $4(24-27 \mu)$ langen Stacheln, $8 \mu$ breit und 1 i $\mu$ lang. Planktonalge.

\section{Golenkinia Chodat.}

Zellen meist einzeln, freischwimmend, meist mit Gallerthof, mit feinen, am Grunde nicht verdeckten Stacheln. Ein Chromatophor. Zellen oft ölhaltig. Teilung in einer oder zwei Richtungen; Zoosporen viercilig.

G. radiata Chodat (Taf. III, 32)

Zellen rund, 10-1 $5 \mu$ dick, Stacheln $25-45 \mu$ lang. Planktonalge in Teichen.

\section{Gloeocystis Naeg.}

Zellen mehr oder weniger rund, mit dicken, blasenförmigen Hüllmembranen, einzeln oder zu $2-32$ in Glococapsa-ähnlichen Familien. $\mathrm{Ab}$ und $\mathrm{zu}$ rotgefärbt. Zellteilung nach allen Richtungen. 
G. gigas (Kg.) Lagerh. (Taf. III, 33)

Zellen kugelig, $9-12 \mu$ dick, einzeln oder zu $2-8$ in $46-99 \mu$ dicken Familien. Zellmembran dick, farblos. In stehenden Gewässern, verbreitet.

G. vesiculosa Naeg. und G. rupestris (Lyngb.) Rabh. an feuchten Felsen etc., häufig.

\section{Inoderma $\mathrm{Kg}$.}

Die Zellen sind meist. reihenweise in gallertigen Familien vereint; Vegetative Teilung nur der Quere nach.

1. Zellen 2,5-3,5 $\mu$ dick . . . . . . . 1. I. lamellosum ${ }^{*}$. Zellen $6-8 \mu$ dick . . . . . . . . . 2. I. majus

I. I. lamellosum $\mathrm{Kg}$.

Zellen meist reihenweise geordnet in hautartig-gelatinösem Lager von etwa olivengrüner Farbe; Dauerzellen etwas grösser als die vegetativen. An von Wasser berieselten Steinen, an Brunnen etc.

2. I. majus Hansg. (Taf. III, 34)

Lager hellgrün. Pyrenoid kugelig. Wie vorige Art, beide nicht häufig.

\section{Tetraspora Link.}

Teilungen in zwei Richtungen. Die Schwärmer entstehen direkt aus den vegetativen Zellen und haben zwei Cilien und eine Vakuole. Die Gameten entstehen $\mathrm{zu}$ acht in einer Zclle und kopulieren.

I. Farbe des Lagers bleich schmutziggrün, Gestalt unregelmässig ausgebreitet und zerschlitzt . . . . . I. T. gelatinosa

I*. Farbe gelbgrün; Gestalt röhrig, schlauchförmig, auch wellig gelappt . . . . . . . . . .2. T. lubrica

I. T. gelatinosa (Vauch.) Desv. (Taf. III, 35)

Lager zuerst festgewachsen, dann freischwimmend. Zellen 2-I $4 \mu$ dick, zerstreut, oder $\mathrm{zu} 2-4$ genähert; Dauersporen 15-24 $\mu$ dick. In Wassergräben, Teichen etc., nicht selten. .

2. T. lubrica (Roth) Ag.

Lager zuerst meist festgewachsen und vom Boden aufsteigend, später freischwimmend, bis $2 \mathrm{dm}$ lang, Zellen 7- I $\mu$ dick, $z u 2-4$ genähert. 
Bei T. explanata Ag. sind nur je zwei Zellen genähert. Beide in stehendem Wasser, Teichen etc.

\section{Chlorosphaera Klebs.}

Die Zellen liegen einzeln oder lose vereint in strukturloser Gallerte. Acht oder mehr Schwärmsporen mit zwei Cilien entstehen in einer Mutterzelle; Gameten unbekannt.

Chl. angulosa (Corda) Klebs (Taf. III, 36)

Zellen kugelig, 7-i 2,5 $\mu$ dick; mit dicker farbloser Membran; zu 2-64 in einem schleimigen, grünen Lager. An untergetauchten Gegenständen, wie Blättern, doch auch freischwimmend, hier und da verbreitet.

Die andern Chlorosphaera-Arten wie Chl. endophyta Klebs und $C h l$. alismatis Klebs leben raumparasitisch in Geweben von Lemna bezw. Alisma.

\section{Palmella Lyngb.}

Eine unsichere Gattung, jedenfalls gehören viele der hier beschriebenen Arten zu höheren (Faden)-Algen, die in ihrem Entwicklungsgange häufig ein sog. Palmclla-Stadium durchmachen.

I. Lager gelblichgrün . . . . . . I. P. stigeoclonii I*. Lager olivengrün . . . . . . . 2. P. mucosa

I. P. stigcoclonii Cienk.

Zellen $4,5-13 \mu$ dick, einzeln oder zu 2-4 von leicht zerfliessenden Membranen eng umschlossen. Lager bis $2 \mathrm{~cm}$ lang. $2-8$ Zoosporen in einer Zelle. In stehenden Gewässern.

2. P. mucosa $\mathrm{Kg}$.

Zellen 4-i4 $\mu$ dick, in formlosem, schlüpfrigem Lager. In Bächen, an Quellen und nassen Steinen, nicht selten.

( $P$. botryoides $\mathrm{Kg}$. häufig auf feuchter Erde in Wäldern).

\section{I0. Botryococcus $\mathrm{Kg}$.}

Zellen ei- bis keilförmig, zu traubenförmigen Haufen vereint, die meist frei schwimmen. Zellen im Alter durch eine braune Gallerte auseinander gehalten, die viel Oel enthält. Das mantelförmige Chromatophor ohne Pyrenoid. Die Schwärmsporen (bei $B$. terricola) setzen sich fest und teilen sich stark, bis kopulierende 
Gameten entstehen, aus deren Zygospore dann erst die ursprüngliche Pflanze wieder hervorgeht.

B. brauni Kg. (Taf. III, 37)

Zellen etwa $6 \mu$ dick, bis $13 \mu$ lang, in olivengrünen, gelbroten, oder rotbraunen, kugeligen Familien, die auf dem Wasserspiegel liegen sollen. Hier Vermehrung unbekannt. In stehenden Gewässern, hin und wieder eine bräunliche Wasserblüte bildend.

(B. terricola Klebs auf feuchter Erde).

\section{Ix. Palmodactylon Naeg.}

Die kugeligen Zellen in langen Schläuchen eingeschlossen, die mikroskopische, frei schwimmende Gallertmassen bilden. Teilung in einer, dann in 3 Richtungen. Die Schwärmsporen wachsen unmittelbar zu neuen Pflanzen heran.

P. varium Naeg. (Taf. III, 38)

Familien aus vielen, bis 50 Schläuchen bestehend; Zellen 4,5-7 (9) $\mu$ dick [bei der var. subramosum (Naeg.) Hansg. 8-12 $\iota$ dick]. In stehendem Wasser, zerstreut.

\section{Apiocystis Naeg.}

Zellen regellos in mikroskopischen, birnförmigen Blasen vereint. Vermehrung durch 2 wimperige Schwärmsporen, die an der Seite der Blase ausschwärmen und später keimen.

A. branniana Naeg. (Taf. III, 39)

Blase $20-100 \mu$ breit und etwa 2 Mal so lang. Die kugeligen. Zellen $6-8 \mu$ dick, oft bis 300 in einer Blase. In Sümpfen an Cladophora etc., hin und wieder.

\section{r3. Hormotila Borzi.}

Zellen mit mehreren Chlorophyllkörnern, aber keinem Pyrenoid. In jeder Zelle können 8-64 Schwärmsporen entstehen, die mit zwei Cïlien und einem rotem Augenfleck versehen sind und unmittelbar eine neue Pflanze erzeugen oder zuerst ein Uebergangs- (das „Palmella-") stadium durchmachen.

H. mucigena Borzì (Taf. III, 40)

Zellen 4 - I $2 \mu$, kurz vor der Schwärmerbildung bis $30 \mu$ dick, meist kugelig, mit wandständigem Chromatophor und dicker Zellhaut. Zoosporen $\mathrm{I}-2,5 \mu$ dick, $3-5 \mu$ lang. An Steinen und Felsen, die von Quellen bespült werden, etc., selten. 
14. Mischococcus Naeg.

Die Zellen sitzen zu je 2 oder 4 auf dichotom verästelten, keuligen Gallertstielen. $2-4$ Chromatophoren ohne Pyrenoid. Die Gameten kopulieren entweder oder keimen sofort. Aus den Zellen der keimenden Zygospore entstehen $\mathrm{I}-4$ Schwärmer, die erst die baumförmigen Kolonien erzeugen.

M. confervicola Naeg. (Taf. III, 4 I)

Zellen rund, hellgrün, fein granuliert. An Cladophora, Oedogonium und anderen Algen in Wassergräben und Sümpfen.

\section{Dictyosphaerium Naeg.}

Die mehr oder weniger runden Zellen liegen hohlkegelförmig in rundlicher Gallerte. Die einzelnen auf Fäden, den Resten der Muttermembran. Mantelförmiges Chromatophor mit einem Pyrenoid. Die zur Ruhe gekommenen Schwärmsporen bilden direkt neue Kolonien.

1. Zellen elliptisch oder eiförmig . . 1. D. ehrenbergianum ${ }_{1 *}^{*}$ Zellen kugelig . . . . . . . 2. D. pulchellum

I. D. ehrenbergianum Naeg.

Zellen $4-7 \mu$ dick, $11 / 3$ Mal so lang. Familien kugelig oder oval, bis $80 \mu \mathrm{im}$ Durchmesser. In stehendem Wasser, Teichen etc., selten.

2. D. pulchellum Wood (Taf. III, 42)

Zellen $3-8 \mu$ dick; Familien kugelrund, $26-45 \mu$ im Durchmesser. Ebenda.

\section{Fam. Protococcaceae.}

Die Zellen leben einzeln oder in ungeordneten Haufen oder in bestimmt gebauten Coenobien bei einander. Da vegetative Zellteilung fehlt, findet eine Vermehrung nur durch Schwärmsporen statt. Die geschlecchtliche Fortpflanzung geschieht, soweit sie bekannt ist, durch kopulierende Gameten.

I. Die Zellen einzeln lebend oder nur zu mehr oder weniger regelmässigen Kolonien vereint (I. Protococceae) . . . . 2 
2. Die Zellen ohne dünne, stielförmige Verlängerung, höchstens mit langer Borste oder durch ein schlauchförmiges Würzelchen im Boden befestigt. Die Zellen sind meist Raumparasiten im Gewebe höherer Pflanzen, doch auch frei (A. Endosphaereae) . . . . . . . . . . . . 3

3. Zellen nicht Botrydium-ähnlich, ohne langen wurzelähnlichen Stiel

4. Das Chromatophor beinahe hohlkugelförmig; freilebende Zellen . . . 1. Protococcus (S. 104)

4*. Das Chromatophor nicht so . . . . . . . 5 5. Zellen mit langen, dichotom verzweigten Borsten . . . 2. Dicranochaete (S.105) $5^{*}$. Zellen ohne Borsten, im Gewebe höherer Pflanzen lebend: Chlorochytrium (S. 105 und andere Formen.

$3^{*}$. Zellen kugelig, zuletzt Botrydium-artig, mit langem, wurzelähnlichen Fortsatze im Boden sitzend . . .

3. Protosiphon (S. 105)

2*. Die Zellen haben einen mehr oder weniger langen, dünnen Stiel, an dem sie festsitzen, oder, wenn frei schwimmend, einen Stachel (B. Characieae) . . . . 6

6. Die Zellen der jüngeren Generation sitzen niemals an ihren Mutterzellen . . . . . . . . 7 7. Die Zellen kugelig, mit sehr zartem Stiele . . 4. Peroniella (S. I05) $7^{*}$. Die Zellen eiförmig, mit dickem Stiele

5. Characium (S. 106)

6*. Die Zellen sitzen entweder an der Muttermembran fest und bilden „Bäumchen“, oder die Zellen schwimmen frei . . . . . . 6. Ophiocytium (S. 106)

I*. Die Zellen bilden regelmässige Coenobien (II. Hydrodictycac) 8

8. Die Coenobien sind tafelförmig 7. Pediastrum (S. 107) 8*. Die Coenobien bilden hohle Netze .

\section{Hydrodictyon (S. 109)}

Siehe auch Coelastrum und Sorastrum in voriger Familie.

\section{Protococcus Ag.}

Zellen kugelig, mit dünner Membran, oft mit roten Schleimkugeln, einzeln oder in Haufen. Vermehrung meist nur durch Zoosporen. 
Pr. infusionum (Schrank) Kirchn.

Zellen I $5-45(-$ IOO) $\mu$ dick, enthalten später meist einen roten Farbstoff; Membran dick, geschichtet. Frei schwimmend. In stehenden Gewässern, hier und da häufig.

Zahlreiche andere Arten, wie Pr.viridis Ag. leben an alten Baumstämmen, an Zäunen, Steinen etc., einige sind sicher nur Entwicklungsformen von höheren Algen.

\section{Dicranochaete Hieron.}

Die nierenförmigen, festsitzenden Zellen mit einer langen, verzweigten Borste aus Gallerte. Mehrere kugelige Chromatophoren mit Pyrenoiden. 8-24 Schwärmsporen entstchen in einer Zelle, deren Protoplasma sich vorher zusammengezogen hat.

D. reniformis Hieron. (Taf. IV, I)

Zellen bis $35 \mu$ dick, Borsten $80-160 \mu$ lang. In Quellen und Sümpfen, an Moosen und feuchtem Holze, in höheren Gebirgen.

\section{Protosiphon Klebs.}

Zelle zuletzt Botrydium-artig und vielfach mit dieser Alge verwechselt. Wandständiges, netzförmiges Chromatophor mit Amylonkern; zahlreiche Kerne. Vegetative Teilung nur, um die Mutterzellen für die Schwärmer zủ bilden. Dauerzellen rot. Die Schwärmer können kopulieren oder sofort keimen (parthenogenetisch?)

Pr. botryoides (Kg.) Klebs (Taf. IV, 2)

Länge bis $\mathrm{I}, 4 \mathrm{~mm}$. Unter Botrydium am Rande von Teichen grüne Ueberzüge bildend.

Chlorochytrium lemnae Cohn lebt raumparasitisch im Lemna trisulca, Scotinosphaera paradoxa Klebs ebenda und in Hypnum und Endosphacra biennis Klebs in Potamogeton lucens.

\section{Peroniella Gobi.}

Die etwa runden Zellen sitzen auf langen, sehr dünnen Stielen, die mit einer kleinen Scheibe befestigt sind. Zellinhalt zuerst goldgelb, dann grün. $7-8$ eincilige Schwärmsporen aus einer Zelle. Dauersporen.

$P$. hyalothecae Gobi (Taf. IV, 3)

In der Schleimhülle von Hyalotheca mucosa, selten. 


\section{Characium A. Br.}

Dic Zellen mehr oder weniger länglich, mit einem Stiele an Algen etc. befestigt. Grosse und kleine Schwärmsporen. Dauerzellen.

1. Stielchen undeutlich, sehr kurz (Subsessiles Rabh.)

I. Ch. subulatum

1*. Stielchen deutlich, oft lang (Stipitatac Rabh.) . . . . . 2

2. Zelle ohne Stachel . . . . . 2. Ch. naegelii

2*. Zelle mit Stachel am Scheitel . 3. Ch. longipes

r. Ch. subulatum A. Br.

Zellen schräg-lanzettlich, gerade oder, gekrümmt, Centrum chlorophyllgrün, Membran braun, $4-5 \mu$ dick, $\mathrm{i} 2-20 \mu$ lang. In Teichen und Tümpeln.

2. Ch. nacgclii A. Br. (Taf. IV, 4)

Zellen gerade, eiförmig bis elliptisch, mit rundem Scheitel, $7-18 \mu$ dick, $20-42 \mu$ lang, der $4 \mu$ lange Stiel am Grunde nicht verbreitert. An Cladophora, Oedogonium etc.

3. Ch. longipes Rabh.

Zellen lanzettlich, 6,5-10 $\mu$ dick, mit dem Stielchen 20 bis 25 (45) $\mu$ lang, am Scheitel mit aufrechtem oder schiefem Stachel. Stiel am Grunde mit gelblichem Knötchen. An Fadenalgen in Teichen, selten.

\section{Ophiocytium Naeg. em. Lemmerm.}

Zellen frei oder festgeheftet, cylindrisch oder keilförmig, gerade oder gebogen; einzeln oder zu Familien verbunden. Mehrere wandständige Chromatophoren ohne Pyrenoide. Inhalt oft mit Oel. Vermehrung durch unbewegliche Schwärmer und zweicilige Zoosporen.

1. Zellen leben nicht frei, sondern sind an einem Stiele befestigt (Sect.: Stipitatac) .. . . . . . . . . . . . . . . 2

2. Stiele 5-19 $\mu$ lang, Familion in meist einfacher Dolde I. Oph. gracilipes

$2^{*}$. Stiele $2-3,5 \mu$ lang, Familie mit mehrfachen Dolden

2. Oph. arbuscula

I*. Zellen leben frei im Wasser........... . 3

3. Zellen an einem Pole mit gekopftem Stachel

3. Oph. majus 
$3^{*}$. Zellen nicht so

4. Zellen an einem Pole mit einfachem Stachel

4. Oph. cochleare

$4^{*}$. Zellen an beiden Polen gleich . . . . . . . 5

5. Zellen an beiden Polen mit Stacheln

5. Oph. capitatum

$5^{*}$. Zellen an beiden Polen ohne Stacheln . .

7. Oph. parvulum

1. Oph. (Sciadium) gracilipes (A. Br.) Lemmerm.

Zellen in einfachen Familien, $5-7 \mu$ breit, am scheibenförmigen Grunde festgeheftet. Stiele 10-14 $\mu$ lang. Ohne Oel im Zellinhalte. In Teichen und Sümpfen, zerstreut.

2. Oph. (Sc.) arbuscula (A. Br.) Lemmerm. (Taf. IV, 5)

Zellen gerade, $3-5 \mu$ breit. Stiel wie bei voriger Art, aber nur $2-3,5 \mu$ lang. Ohne Oel. Vorkommen wie bei voriger Art.

3. Oph. majus Naeg. (Taf. IV, 6)

Zellen $8-17 \mu$ breit, S-förmig gebogen oder gekrümmt, mit gekopftem Stiele. Mit Oeltröpfchen im Innern. In Sümpfen und Teichen.

4. Oph. cochleare (Eichwald) A. Br.

Zellen $5-8 \mu$ breit, gekrümmt, an einem Pole ein $\mathrm{I}-12 \mu$ langer Stachel. Ohne Oel. Vorkommen wie bei voriger Art.

5. Oph. capitatum Wolle (Taf. IV, 7)

Zellen 5- 1о $\mu$ breit, S-förmig gebogen oder gekrümmt, an jedem Pole mit $5-7 \mu$ langen Stacheln. Ohne Oel. Vorkommen wie bei Oph. majus.

6. Oph. parvulum (Perty) A. Br.

Zellen $3-9 \mu$ breit, gerade oder gekrümmt, an beiden Polen abgerundet. Ohne Oel. Vorkommen wie bei Oph. majus.

\section{Pediastrum Meyen.}

Die Coenobien schwimmen frei umher, sind rund und tafelförmig, aus polyedrischen Zellen zusammengesetzt. Die Randzellen anders gestaltet (ausgebuchtet etc.) als die innern, beide mit mehreren Zellkernen. Das wandständige Chromatophor mit Pyrenoid. Neue Kolonien entstehen durch Schwärmer, die aus einer Zelle austreten und in einer Gallertblase sich zu einem neuen Coenobium zusammenlegen. 
1. Die Randzellen ganzrandig, jede in eine einfache Spitze ausgezogen [I. Monactinium (Corda) A. Br.] 1. P. simplex

1*. Dic Randzellen anders gestaltet . . . . . . . . . . 2

2. Die Randzellen mit je 2 aufgesetzten Spitzen (II. Anomopedium Naeg.) . . . . . . . 2. P. integrum

2*. Die Randzellen lappig oder getcilt . . . . . . . 3

3. Die zwei Randlappen nicht wieder geteilt (III. Diactinium A. Br.).

4. Die Zellen schliessen lückenlos aneinander

3. P. boryanum

4*. Die Zellen lassen Zwischenräume im Innern .

4. P. duplex

3*. Die zwei Randlappen noch einmal zweizähnig oder eingeschnitten (IV. Tetractinium A. Br.) . . . . 5 5. Ohne Lücken im Innern des Coenobiums. . 5. P. tetras

$5^{*}$. Ziemlich grosse Lücken im Innern

6. P. biradiatum

1. P. simplex Meyen (Taf. IV, 8)

Coenobien 5-32-teilig, 6-76 $\mu$ im Durchmesser; Randzellen etwa eiförmig, nur an der Basis verwachsen. Im Innern centrale Lücke oder ohne solche. In Teichen, Sümpfen etc., zerstreut.

2. P. integrum Naeg.

Coenobien 4-64-zellig, etwa $120 \mu$ lang und $100 \mu$ breit. Zellen unregelmässig. Alle Zellen ganzrandig und mehr oder weniger gleichgestaltet, $20-28 \mu$ dick. Randzellen mit (meist) 2 einfachen Stacheln. In Sümpfen, an nassen Felsen, oft zahlreich.

3. P. boryanum (Turp.) Menegh.

Coenobium 8-128-zellig. Randzellen tief ausgerandet oder zweilappig. Lappen zugespitzt oder in einen Fortsatz auslaufend. Variiert sehr. In stehendem Wasser, wie Teichen, Sümpfen etc., ziemlich verbreitet.

4. P. duplex Meyen (Taf. IV, 9)

Coenobien 8-32-zellig. Die Mittelzelle meist ausgerandet, wodurch Lücken entstehen. Randzellen zweilappig. Vorkommen wie bei voriger Art, doch häufiger.

5. P. tetras (Ehrbg.) Ralfs.

Coenobien 4-16-zellig, Randzellen 8-27 $\mu$ dick, seitlich ganz mit einander verwachsen, durch einen schmalen Einschnitt 
geteilt. Jede innere Zelle mit einem Einschnitte. In sumpfigen Teichen, Moorgräben verbreitet, doch vereinzelt.

\section{P. biradiatum Meyen}

Coenobien 8-32-zellig; Randzellen 9-21 $\mu$ dick, nur an der Basis verwachsen. Randzellen lang, zweispaltig, Lappen zweizähnig. In Teichen, Tümpeln etc., nicht häufig.

\section{Hydrodictyon $\mathrm{Kg}$. (Wassernetz).}

Bildet ein freischwimmendes Netz aus cylindrischen Zellen, von denen je 3 (oder 4) mit den Enden zusammenhängen. Zellen bis I cm lang, mit zahlreichen Zellkernen. Ein wandständiges Chromatophor mit Pyrenoiden. Geschlechtslose Fortpflanzung durch Schwärmsporen, die zu $7-20000$ in einer Zelle entstehen. Diese bewegen sich in der Muttermembran und ordnen sich hier zu einem neuen, kleinen Netze an. Die geschlechtliche Fortpflanzung geschieht so, dass in der Zelle 30-100000 Gameten gebildet werden, die in das Wasser austreten und hier kopulieren oder sich ohne solche Vereinigung entwickeln. In der Zygospore solcher kopulierenden Schwärmer entstehen $2-5$ grössere Schwärmer, die zu den sogenannten "Polyedern" heranwachsen; erst in diesen bilden sich neue Schwärmer, die sich zum neuen Netze zusammenlegen.

\section{H. utriculatum (L.) Lagerh. (Taf. IV, , o)}

Thallus oft 6 und mehr dm lang. Zellen an jungen Exemplaren $\mathrm{I}-2$, an älteren 4 - io $\mathrm{mm}$ lang, $0,1-0,2 \mathrm{~mm}$ dick. Dic grossen Schwärmer $8 \mu$ dick, Io $\mu$ lang; die kleinen $3-6 \mu$ dick und 5-8 $\mu$ lang. In stehendem, reinem Wasser, in Teichen etc. meist zahlreich auftretend, hier und da.

\section{Fam. Volvocaceae.}

Die Volvocaceen stehen an der Grenze zwischen Tier- und Pflanzenreich. Während sie früher unter die Flagellaten gerechnet wurden, zieht man sie jetzt, wenn auch etwas willkürlich, zum Pflanzenreiche. Es sind eben trotz der Verwandschaft mit den Flagellaten auch unverkennbare Beziehungen zu den Protococcoideen vorhanden. 
Die Organisationshöhe der Volvocaceen lässt sich sehr verschieden beurteilen. Einerseits kann man in ihnen niedere Formen sehen, da sie auf der Stufe freier Beweglichkeit, die bei den höheren Pflanzen nur ein Durchgangsstadium ist, verharren. Andererseits jedoch erinnern manche Organisationszüge, so namentlich die Fortpflanzungsverhältnisse, so lebhaft an höhere Pflanzen und Tiere, dass man den Volvocaceen den Rang einer Uebergangsform von den Einzelligen zu den differenzierten Vielzelligen nicht wohl streitig machen kann.

Die Volvocaceenzellen leben einzeln oder in Kolonien und schwärmen die längste Zeit des Lebens umher. Jede Zelle ist entweder mit einem oder mehreren Chromatophoren versehen oder bleibt farblos. Die vegetative Vermehrung findet durch Längsund Querteilung der Zellen statt. Dauerzellenbildung ist bekannt. Die geschlechtliche Vermehung findet sich in verschiedener Weise entwickelt. Bei einigen Formen gleichen sich die kopulierenden Gameten noch vollständig (Pandorina, Sphaerella etc.), bei andern (Eudorina und Volvox) ist nur der männliche Teil beweglich, während der weibliche als typisches $\mathrm{Ei}$, wie bei allen höheren Pflanzen, unbeweglich ist. Das Produkt der Kopulation ist im ersten Falle die Zygospore, im zweiten die Oospore.

I. Die Zellen einzeln, nicht Kolonie bildend . . . . . . . 2

2. Die Zellen sind nur von einer dünnen, meist zweiklappigen Hülle umgeben . . . . . . . . . . . . . . . . 3

3. Nur Längsteilung vorhanden; Cystenbildung ohne Kopulation (I. Polyblepharideae) . . . . . . . . . 4 4. Die freien Zellen mit 4 Geisseln . . . . . . . . .

I. Pyramidomonas (S. 112 )

$4^{*}$. Die Zellen mit 5 oder mehr Geisseln . . . . . . 5

5. Mit 5 Geisseln. . . 2. Chloraster (S. I 1 2)

5*. Mit 6-8 Geisseln . . 3. Polyblepharides (S. 1 1 2)

$3^{*}$. Längs - und Querteilung vorhanden. Kopulation von

Makro- und Mikrozoosporen, oder nur letzteren (II. Chlamydomonadeae)

6. Die Zellen sind grün gefärbt . . . . . . . . 7 7. Mit 4 Geisseln . . . . 4. Carteria (S. 112)

7*. Mit 2 Geisseln (vgl. auch die eingeisselige Cylindromonas S. I13) . . . . . . . . . . . . . . 8

8. Die Hülle deutlich sichtbar . . . . . . . 9 
9. Die Hülle mindestens an einer Seite anliegend 5. Chlamydomonas (S. I I 3) 9*. Die Hülle überall weit abstehend, Zelle oft rot 6. Sphaerclla (S. I I4)

8*. Hülle fein, oft kaum sichtbar . . . . . Io ı. Zelle spindelförmig . . . . . . . . . I I

I1. Zwei bandförmige Chromatophoren, zwei Vakuolen an der Geisselbasis . . . . .

7. Chlorangium (S. I i 5 )

I I*. Zelle gleichmässig grün; zahlreiche Vakuolen unter der Oberfläche

8. Chlorogonium (S. I I 5 )

IO*. Zellen bohnenförmig, plattgedrückt, mit grossem centralem Augenfleck 9. Mesostigma (S. I 15)

6* Die Zellen sind farblos. . 10. Polytoma (S. I 15)

$2^{*}$. Die Zellen mit dicker, deutlich zweiklappiger, oder wenigstens in zwei Teilen aufspringender Hülle (III. Phacoteae) I 2 I2. Die zwei Klappen sind nur lose miteinander verbunden .

I I. Phacotus (S. п 16)

I2*. Die Hülle muss bei der Teilung in zwei Klappen zersprengt werden

13. Die Hülle ist ohne Flügelkante

12. Coccomonas (S. I 16)

I3*. Die Hülle mit Flügelkante 13. Pteromonas (S. 1 16)

I*. Die Zellen bilden Kolonien (IV. Volvoceae) . . . . . I $I_{4}$

I4. Die vereinigten Zellen ohne gemeinsame Gallerthülle .

I4*. Die Kolonie mit gemeinsamer Gallerthülle . . . I 5 14. Spondylomorum (S. 1 16)

I 5. Die Kolonien sind tafelförmig 15. Gonium (S. I 1 7)

$15^{*}$. Die Kolonien sind kugelig . . . . . . . . . 16

16. Die Zellen sind tafelförmig (im Aequator) angeordnet 16. Stephanosphaera $($ S. 1 1 7$)$

16*. Die Zellen kugelförmig angeordnet . . . . . I 17

17. Die Kolonien aus wenigen (bis 32 ) grossen Zellen 18 18. Die i6 Zellen der Kolonie stossen im Centrum zusammen . . . I 7. Pandorina (S. I I 7 )

I8*. Die 32 Zellen stehen von einander ab

18. Eudorina (S. 118)

17*. Die Kolonien aus zahlreichen, kleinen Zellen zusammengesetzt . . 19. Volvox (S. I I 8) 


\section{Polyblepharideae.}

\section{Pyramidomonas Schmarda.}

Körper kegelförmig, durch 4 Längsfurchen vierrippig, mit 4 schr langen. Geisseln; am Grunde der letzteren zwei kontractile Vakuolen. Chromatophor achtlappig, kelchförmig, mit Pyrenoid. Etwas metabolisch.

P. tetrarhynchus (Schmarda) (Taf. IV, i 1)

Individuen etwa $25-30 \mu$ lang, vorn etwa $15-20 \mu$ breit (nach Dangeard halb so gross). Geisseln bis fast $50 \mu$ lang. Ohne Membran, nur mit protoplasmatischer Hautschicht. In Sümpfen und Tümpeln.

\section{Chloraster Ehrbg.}

Körper etwa spindelförmig, mit 4 starken, gelappten Vorsprüngen und 5 Geisseln und einem Augenfleck. Sehr wenig bekannt.

Chl. gyrans Ehrbg. (Taf. IV, I 2)

Bis $40 \mu$ lang. Selten, in stehendem Wasser.

\section{Polyblepharis Dangeard.}

Zellen etwa keilförrnig, vorn flach, mit dünner Cellulosemembran; Chromatophor mit Pyrenoid und Stigma. Cysten kugelig, mit dicker Membran.

\section{$P$. singularis Dangeard (Taf. IV, 13 )}

Zellen 10-I $4 \mu$ lang, $8-9 \mu$ breit. Die $6-8$ Geisseln kaum von Körperlänge. In Sümpfen.

\section{Chlamydomonadeae.}

\section{Carteria Diesing.}

Individuen elliptisch, rund oder herzförmig mit zwei kontractilen Vakuolen; Chromatophor einfach muldenförmig, mit einem Pyrenoid. Der folgenden Gattung ähnlich.
I. Körper kugelig
I. C. multifilis
$1^{*}$. Körper herzförmig
2. C. cordiformis

I. C. multifilis (Fres.) Dill.

Membran mit flachen Hautwärzchen. Pyrenoid kugelig. Gameten mit Membran. In Weihern und Sümpfen, nicht häufig. 
2. C. cordiformis Carter (Taf. IV, 14)

Individuen breit, etwa herzförmig. Membran fein, Augenfleck gross und rund, Pyrenoid gross. Ebenda, verbreitet.

$\mathrm{Ob}$ die von $\mathrm{Hans}$ girg beschriebene Cylindromonas fontinalis Hansg. (Taf. IV, 15) hierher gehört, ist noch fraglich. Mit einer Geissel, zwei sternförmigen Chromatophoren und ohne Augenfleck. Vermehrung im Ruhezustande innerhalb einer Schleimhülle zu $2-4$ Tochterzellen.

\section{Chlamydomonas Ehrbg.}

Körper mehr oder weniger kugelig bis cylindrisch; zarte, anliegende Membran; zwei ineist seitlich von einem Hautwärzchen ausstrahlende Geisseln. Chromatophor meist einfach. Ein bis mehrere kugelige, seltener bandförmige Pyrenoide. Zwei kontraktile Vakuolen. Augenfleck. Längs- und Querteilung, meist in Ruhe. Produkt der Kopulation rotgelbe Zygosporen. Schwer zu unterscheidende Arten; viele alte Spezies, wie Chl. pulvisculus Ehrbg. und Chl. grandis Stein umfassen mehrere scharf zu trennende Arten. Die einzelnen Arten häufig zahlreich zusammen, so dass sie oft eine Grünfärbung des Wassers in Tümpeln etc. hervorrufen.

I. Mit Längsteilung; die Gameten mit Membran . . . . . 2

2. Körper oval, ohne Pyrenoid . . 1. Chl. reticulata

2*. Körper rund, mit Pyrenoid . . 2. Chl. ehrenbergi

I*. Querteilung oder keine reine Längsteilung . . . . . . 3

3. Längsteilung nur angelegt, vollendet als Querteilung; Gameten mit Membran, Pyrenoid hufeisenförmig . . 3. Chl. brauni

3*. Mit Querteilung, Gameten nackt . . . . . . . 4 4. Körper rund, ohne Hautwärzchen . . . . . . 4. Chl. reinhardi

$4 *$ Körper cylindrisch 5 5. Mit einem Pyrenoid. . 5. Chl. steini 5*. Mit zwei Pyrenoiden. . 6. Chl. kleini

1. Chl. reticulata Gorosch.

Chromatophor netzförmig; Hautwärzchen eckig; die zwei Geisseln von Körperlänge (bis $36 \mu$ ). Zygosporenmembran einfach, mit punktiertem Rande. In Wassertümpeln. 
2. Chl. ehrenbergi Gorosch.

Individuen von eiförmiger Gestalt. Geisseln zwei Mal so lang als der Körper, der $14-24 \mu$ lang ist. I (-3?) Pyrenoide. Ziemlich häufig, in Regenpfützen etc.

3. Chl. brauni Gorosch. (Taf. IV, I6)

Ellipsoidisch; ein kleiner Membrankegel zwischen den Geisseln. Stäbchenförmiges Stigma. Länge ${ }^{1}{ }_{4}-26 \mu$. Wie vorige.

4. Chl. reinhardi Dang.

Die zwei Geisseln länger als der Körper. Das eine Pyrenoid rund; Stigma scheibenförmig, im vorderen Drittel des Körpers. Zygosporenmembran einfach.

5. Chl. steini Gorosch. (Taf. IV, i7)

Körper cylindrisch, I $8-30 \mu$ lang, mit kurzen Geisseln (kürzer als die Körperlänge); auf der Membran zart längsgestreift. Sehr häufige Form.

6. Chl. klerni Schmidle

Membran fein und ohne Wärzchen; mit stäbchenförmigem Stigma und 15-20 an den Enden verwachsenen Chromatophorstreifen. Ein Pyrenoid vor, eins hinter dem centralen Kerne. Gameten cylindrisch.

\section{Sphaerella Sommerf. (Blutalge).}

Die Hülle steht vom Protoplasmakörper meist weit ab, doch ist sie mit ihm oft durch Plasmafäden verbunden; Plasma häufig rot gefärbt durch „Haematochrom“, einen Carotinfarbstoff. Mit oder ohne Augenpunkt. Ruhezellen mit dicker Membran. Vermchrung I. durch einfache Querteilung; 2. durch Makrozoosporen, die nach Ausscheidung einer Celluloschaut mit zwei Geisseln umherschwärmen und nach Eintrocknung 2-8 Schwärmzcllen entlassen; 3. durch rote Mikrozoosporen, die ohne Cellulosehaut vielleicht nach einer Kopulation zur Ruhe kommen.

Sph. pluvialis (Flot.) Wittr. (Taf. IV, I8)

Makrozoosporen 8-30 $\mu$ dick; ruhende Zellen 25 - $80 \mu$ dick. Färben kleine Wasscrtümpel oft intensiv blutrot, meist plötzlich erscheinend und eben so schnell verschwindend. Hin und wieder.

(Eine andere Art, Sph. nivalis Sommerf., bildet den „roten Schnee" der Hochgebirge.) 


\section{Chlorangium Stein.}

Im festsitzenden Zustande auf Gallertstielen; hier Vermehrung durch Querteilung und Aneinandervorbeiwachsen in 2-4 Tochterzellen, die sofort wieder Gallertstiele ausscheiden und so buschige Kolonieen bilden. Die Zellen mit 1-2 langen Chlorophyllbändern und zwei kontraktilen Vakuolen. Die Zellen können unmittelbar zu Schwärmern mit zwei Cilien und Augenfleck werden, die sich unter Verlust der Geisseln wieder mit dem Vorderende festsetzen und einen neuen Stiel bilden können.

Chl. stentorinum (Ehrbg.) Stein (Taf. IV, 19)

Länge als Schwärmer 30 ". Kommt epiphytisch auf kleinen Wasserkrebschen vor, nicht häufig.

\section{Chlorogonium (Ehrbg.)}

Spindelförmig, mit lang ausgezogenem, Geissel tragendem Ende; mit Chlorophyllkörnern, Pyrenoiden und zahlreichen Vakuolen. Teilung in 4-8 Tochterzellen (als Querteilung angelegt!); in jeder Zelle $16-32$ Gameten, die kopulieren und 8 runde, rote Sporen bilden.

Chl. euchlorum Ehrbg. (Taf. IV, 20)

Bis I $20 \mu$ lang. Hier und da, in Sümpfen etc.

Das ähnliche Cercidium elongatum Dang. ist gleichmässig grün und hat nur zwei Vakuolen.

\section{Mesostigma Lauterb.}

Die Hülle ist zart und etwas punktiert. Mit zwei Geisseln auf der Bauchseite, darunter zwei Vakuolen.

$M$. viride Lauterb.

I $8 \mu$ lang, I $4 \mu$ breit. Im Sumpfwasser.

\section{Polytoma Ehrbg.}

Mit zarter, meist vom Plasmakörper abstehender Hülle, farblos, mit oder ohne Stigma. Zwei kontraktile Vakuolen an der Geisselbasis. Mit zahlreichen Stärkekörnern am hinteren Ende. Vermehrung durch Teilung bis zu 8 Zellen, die in gemeinsamer Hülle noch kürzere Zeit umherschwimmen. Kopulation und Encystierung beobachtet.

P. wvella Ehrbg. (Taf. IV, 2 I)

Zelle mehr oder weniger eiförmig, etwa $25 \mu$ lang. Nicht selten, in Sumpfwasser. Häufiger in Aufgüssen. 


\section{Phacoteae.}

\section{Phacotus Perty.}

Linsenförmige Zellen mit zwei an der Peripherie locker vereinten, wenig skulpturierten Schalen, die von dem Plasma nicht ganz ausgefüllt werden. Ein Pyrenoid. Mit Augenfleck. Kontraktile Vakuolen.

Vier- oder Achtteilung in brauner Hülle. Kopulation von Makro- und Mikrozoosporen beobachtet.

I. Schale stark, skulpturiert, genau linsenförmig

I. Ph. lenticularis

I*. Schale zarter, vorn etwas ausgerandet, oft unregelmässig.

2. Ph. angulosus

I. Ph. lenticularis (Ehrbg.) Stein

Etwa $20 \|$ breite Individuen.

2. Ph. angulosus (Carter) Stein (Taf. IV, 22)

Entfernt Sphaerella pluvialis ähnlich; dreht sich sehr schnell durch das Wasser. Wie vorige Art, in stehendem Wasser.

\section{I2. Coccomonas Stein.}

Die dicke, spröde, ovale oder fast viereckige Hülle mit einer Geisselöffnung. Ein Pyrenoid und Augenfleck. Vermehrung durch Teilung innerhalb der Schale.

C. orbicularis Stein (Taf. IV, 23)

Individuen etwa $25 \mu$ lang. In Teichen etc.

\section{Pteromonas Seligo.}

Schalen dichtanliegend, etwa herzförmig, mit breiter, farbloser Kante (von der Seite gesehen S-förmig gebogen); Gameten oval, vorn mit Chromatophor. Ohne Stigma.

Pt. alata (Cohn) Seligo (Taf. IV. 24)

Länge des Plasmakörpers 12-14 $\mu$, Breite 8-9 $\mu$. Die Hülle ist $18-23 \mu$ lang und ${ }_{15}-20 \mu$ breit.

\section{Volvoceae.}

14. Spondylomorum Ehrbg.

Ein etwas ausserhalb des Formenkreises der Volvoceen stehendes Genus, da die zusammenhängenden Zellen noch nicht 
von einer gemeinsamen Hülle umgeben sind. Jede Zelle mit vier Cilien. Chromatophor mit Pyrenoid und Augenfleck. In jeder Zelle entstehen 16 Tochterzellen, die ebensovielen Kolonien den Ursprung geben können. Zoosporen sind nicht bekannt.

Sp. quaternarium Ehrbg. ('Taf. IV, 25)

Jede Zelle mit zugespitztem Hinterende, $18 \mu$ lang; ganze Kolonie $50 \mu$. Selten.

\section{Gonium Mill.}

Niedrigst stehende Volvoceen-Kolonie, Zellen tafelförmig angeordnet, indem sie neben einander liegen. Die Cilien tragenden Enden nach derselben Seite gekehrt. Die Gallerte ist ungefärbt kaum sichtbar, dagegen sind die Membranverbindungen $z$ wischen den Zellen stets deutlich, wenn auch schwach, zu sehen. Mit Pyrenoid und Augenfleck. Jede Zelle teilt sich. Rote Zygosporen.

I. Familien 16-zellig. . . . . . . . . G. pectorale I*. Familien 4-zellig . . . . . . . . 2. G. tetras

I. G. pectorale (O. Fr. Müll.) (Taf. IV, 26)

Seitenlänge der Kolonie 6o-70 $\mu$, jede Zelle 5-15 4 breit. In Teichen, Pfützen etc., häufig.

2. G. tetras A. Br.

Zellen 'kugelig, 8-12 $\mu$ breit, im Quadrat angeordnet. Vorkommen wie bei voriger Art.

\section{Stephanosphaera Cohn.}

Acht mit Protoplasmafortsätzen veŕsehene Zellen im Innern einer hohlen Gallertkugel, an deren Aequator die Geisseln hervorsehen; je mit 2-5 Pyrenoiden. Vermehrung ungeschlechtlich oder durch in der Hülle stattfindende Gametenkopulation.

St. phuvialis Cohn (Taf. IV, 27)

Kolonie $20-60 \mu$ gross, Zellen spindelförmig. In ausgehöhlten Steinen, Regenpfützen, selten.

\section{Pandorina Bory.}

Vermehrung: ז. durch Teilung jeder Zelle in Tochterzellen; 2. geschlechtlich durch Kopulation der in jeder Zelle gebildeten 
Gameten. Aus der roten Zygospore entsteht eine (oder 2-3) Schwärmspore, die nach einiger Zeit sich in 16 tafelförmig angeordnete Zellen teilt [,Goniumstadium"]; daraus entsteht dann die neue Kolonie durch Umlagerung.

P. morum (O. F. Müll.) Bory (Taf. IV, 28)

Zellen mehr oder weniger herzförmig, $9,5-$ I $5 \mu$ breit; Kolonic bis $70 \mu$ gross. In Teichen und Gräben, häufig.

\section{Eudorina Ehrbg.}

Der vorigen Gattung ähnlich, doch schon höher differenziert, indem sich bei der geschlechtlichen Vermehrung bewegliche Spermatozoiden entwickeln, welche die weiblichen, ruhenden, von den vegetativen Zellen sich kaum unterscheidenden Eier befruchten. Auch rein männliche und rein weibliche Kolonien sind beobachtet. In den Zellen entstehen auf einmal 64 schmale, birnförmige, gelbe Spermatozoiden. Oospore rot, rund.

Eu. elegans Ehrbg. (Taf. IV, 29)

Zellen $18-24 \mu$ breit. Wie vorige Art, nicht selten.

\section{Volvox L.}

Höchst entwickeltes Genus dieser Gruppe. Starke Differenzierung: es sind nur mehr einige (meist 8) Zellen der bis 22000 Zellen enthaltenden Kolonie zur ungeschlechtlichen Vermehrung geeignet („Parthenogonidien“). Was die geschlechtliche Vermehrung anlangt, so ist die Verteilung der beiden Geschlechter auf verschiedene Individuen häufig. Die männlichen Geschlechtszellen (in den rein männlichen Kolonien bis über 1000) bilden $8-256$ keulenförmige, gelbliche Spermatozoiden. Oospore rund, rot.

1. Zellen durch deutliche, dicke Plasmastränge verbunden

$$
\text { I. } V \text {. globator }
$$

1*. Zellen nur durch feine Fäden verbunden 2. $V$. aureus

I. $V$. globator L. (Taf. IV, 3o)

Die einzelnen Zellen mehr oder weniger ungleichmässig, nicht scharf umgrenzt. Mit meist 8 Parthenogonidien. Oospore stachelig; Kolonie bis $800 \mu$ gross. In Teichen und Gräben, häufig.

2. $V$. aurcus Ehrbg. (Taf. IV, 3I)

Meist 4-7 Parthenogonidien. Die einzelnen Zellen mehr oder weniger rund, Oospore glatt. Kolonie meist kleiner als bei voriger Art. Vorkommen wie bei letzterer, oft mit ihr zusammen. 


\section{Confervoideae.}

Die Gruppe umfasst Formen, die nicht mehr einzellig sind, sondern schon im mehrzelligen Thallus eine höhere Differenzierung aufweisen. Der Thallus kann einen Faden oder eine Fläche darstellen. Sind bei niedrigen Formen (Ulvaceen) noch alle Tallusteile zur Fortpflanzung, Bildung von Schwärmsporen etc. geeignet, so sind bei höheren nur bestimmte Zellen dazu fähig. Sowohl die Bildung von ungeschlechtlichen Schwärmsporen wie von geschlechtlichen Gameten kommt vor. Bald sind die Geschlechtszellen gleich (Gameten), bald ist die eine, die weibliche, zum ruhenden Eie geworden, das von der schwärmenden männlichen Zelle befruchtet wird. Durch die Ulvaceen schliessen die Confervoideen sich an die vorige Gruppe, genauer an die Tetrasporaceen, durch Conferva an die Chloromonadina unter den Mastigophoren an, während nach oben wahrscheinlich die Moose ihren Ursprung in Formen dieser Gruppe genommen haben.

Die Familien sind sich habituell vielfach recht ähnlich, und eine Bestimmung ist, wenn nicht die Fruktifikationsorgane der Algen vorliegen, schwierig. Nach einiger Uebung wird man jedoch die Familie, die Gattung sofort erkennen, da doch natürlich gewisse Unterschiede, die aber schwer in Worten festzulegen sind, bestehen; ausserdem werden die Abbildungen die Auffindung nicht unwesentlich erleichtern. Die Einteilung wieder nach Wille.

I. Die vegetativen Zellen haben nur je einen (selten zwei) Zellkern .

2. Geschlechtliche Fortpflanzung durch Konjugation schwärmender Gameten

3. Der Thallus ist eine ein- oder zweischichtige Fläche 4 4. Thallus flach oder röhrenförmig, freischwimmend oder an der Basis angewachsen, zum Teil makroskopisch .

I. Ulvaceae (S. 1 20)

4*. Thallus epiphytisch, in der Mitte oder ganz festgewachsen, mikroskopisch klein .

IV. Mycoideae (S. 132)

$3^{*}$. Der Thallus bildet einen (meist einreihigen) Faden 5

5. Fäden unverzweigt . . . II. Ulothrichaceae (S. 122)

$5^{*}$. Fäden verzweigt, Chromatophor selten braun . . . .

III. Chaetophoraceae (S. 1 26) 
2*. Geschlechtliche Fortpflanzung durch Eibefruchtung; die Oogonien, d. h. die das Ei bergenden Zellen, kugelig angeschwollen . . . . . . . . . . . . . . . . 6

6. Die Oospore unberindet, der Thallus besteht aus Fäden 7 7. Schwärmsporen mit zwei Cilien; Zellen meist mit dicker, geschichteter Membran, nach aussen glatt . . . .

V. Cylindrocapsaceae (S. 132)

$7^{*}$. Schwärmsporen mit Cilienkranz am Vorderende, Zellhaut mit eigenartigen, ringförmigen Verdickungen („Kappen“)

VI. Oedogoniaceae (S. 132)

6*. Oospore berindet; Fäden unregelmässig, oder Thallus scheibenförmig . . . . VII. Coleochactaceae (S. 135)

I*. Die vegetativen Zellen mit mehreren Zellkernen; die Zweige den Hauptfäden gleichgebaut . . . . . . . . . 8

8. Geschlechtliche Fortpflanzung durch Konjugation schwärmender Gameten; Fäden meist verzweigt, mit Basis und Spitze . . . . . . . . VIII. Cladophoraceae (S. I 36)

8*. Geschlechtliche Fortpflanzung durch Eibefruchtung; unverzweigte, freischwimmende Fäden ohne Gegensatz zwischen Basis und Spitze. IX. Sphacropleaceac (S. 138)

\section{Fam. Ulvaceae.}

Gelappter, ein- oder mehrschichtiger Thallus. Ungeschlechtliche Vermehrung durch vier- (zwei-) cilige Schwärmsporen, auch durch abgerissene Thallusstücke; geschlechtliche durch kopulierende Gameten.

I. Thallus als ein- (oder mehr-) schichtige Haut ausgebreitet 2 2. Zellen durch Schleim mehr oder weniger von einander getrennt, Lager Tetraspora-artig I. Monostroma (S. 12 I) $2^{*}$. Zellen eng aneinanderliegend . . . . . . . . . . 3

3. Thallus am Rande mehr oder weniger glatt, nur mit einem Stiele befestigt .2. Prasiola (S. 121)

$3^{*}$. Thallus am Rande in Fäden auslaufend, ganz festgewachsen . . . . . 3. Protoderma (S. I 2 I)

I* Thallus röhrenförmig, schlauchartig 4. Entcromorpha(S.121)

$1^{* *}$ Thallus ein solider Strang: . . . . Schizomeris (S. 122) 


\section{Monostroma (Thur.) Wittr.}

Thallus Tetraspora-ähnlich; Zellen im oberen Teile mehr oder weniger rund, im unteren lang keulenförmig, als wurzelähnliche Organe dienend. Das wandständige Chromatophor mit Pyrenoid. 4-16 Gameten in einer Zelle; Schwärmsporen mit vier Cilien.

M. bullosum (Roth) Thuret (Taf. V, 1)

Das schlüpfrige, grüne Lager ist anfangs festgewachsen, blasig, später zerrissen und ausgebreitet. Zellen $8-$ I $2 \mu$ dick. In Teichen und Sümpfen.

\section{Prasiola (Ag.) Menegh.}

Einschichtiger Thallus, an einem Ende zu einem Faden verschmälert, am Rande mehr oder weniger gekräuselt; Zellen rundlich und am Grunde verlängert. Etwas unsichere Gattung; zeigt verwandtschaftliche Beziehungen zu einigen Rhodophyceen (Bangia etc.).

Pr. sauteri Menegh.

Thallus linealisch oder keilförmig mit stumpfer Spitze; Zellen in Tetraden; bis $1 \mathrm{I} \mathrm{cm}$ lang. In kalten Quellen höherer Gebirge.

Pr. cripsa (Lightf.) Kg. (Taf. V, 2) bildet bis $6 \mathrm{~cm}$ lange Häutchen auf feuchter Erde, besonders an Aborten etc.

Pr. calopliylla (Carm.) Kg. an feuchten Felsen. (Pr. cripsa ist allerdings vielleicht nur eine Wuchsform von Hormidium parietinum $\mathrm{Kg}$. oder umgekehrt).

\section{Protoderma $\mathrm{Kg}$.}

Thallus krustenförmig, in der Mitte mit mehreren Zellschichten. Zellen im Innern mehr oder weniger kantig.

Pr. viride $\mathrm{Kg}$. (Taf. $\mathrm{V}, 3$ )

Zellen $3-7 \mu$ dick, bis $20 \mu$ lang. Auf Blättern von Wasserpflanzen etc. festgewachsen. In Sümpfen.

\section{Enteromorpha (Linck) Hariot.}

Thallus sack- oder schlauchförmig, verzweigt; Zellen oft in Längsreihen geordnet, mehr oder weniger rund. Schwärmsporen und Gameten. Fast nur marine Formen; bei uns nur: 
E. intestinalis (L.) Linck (Taf. V, 4 )

Der röhrige Thallus kann eine Länge von $1 \mathrm{~m}$ erreichen. Sammelt sich oft in grosser Menge an der Oberfläche des Wassers an. Kommt gern in etwas salzigem Wasser vor.

Die früher hierher gestellte Gattung Schizomeris (leibleini $\mathrm{Kg}$.) ist wahrscheinlich eine reichlich verflochtene Fadenmasse von Ulothrix.

\section{Fam. Ulothrichaceae.}

Ungeschlechtliche Fortpflanzung durch Schwärmsporen mit 2-4 Geisseln oder durch Dauerzellen, oder durch „A planosporen“, (unbewegliche Schwärmer); Geschlechtliche durch kopulierende zweicilige Gameten.

1. Die Zellen des Fadens in gleicher Entfernung von einander 2

2. Mit einem oder mehreren wandständigen Chromatophoren 3 3. Chromatophoren bestehen nicht aus Bändern. . . 4 4. Nur ein Chromatophor . . . . . . . . . . 5 5. Fäden ohne besondere Basalzelle. . . . . . . I. Hormidium (S. 123)

5*. Fäden mit besonderer Basalzelle . . . . . . 6

6. Fäden lang, Endzelle nicht zugespitzt . . . . 2. Ulothrix (S. 123)

6*. Fäden kurz, Endzelle zugespitzt . . . . .

3. Uroncma (S. 124)

4*. Mit mehreren Chromatophoren . . . . . . . 7

7. Fäden ohne basale Zelle; Membran einfach. . 4. Bumilleria (S. 1 24)

7*. Fäden mit basaler Zelle; Membran aus H-förmigen Stücken zusammengesetzt. . 5. Conferva (S. 124)

$3^{*}$. Chromatophoren sind bandförmig und wellig ausgebuchtet 6. Microspora (S. 125)

$2^{*}$. Mit centralem, sternförmigem Chromatophor .

7. Schizogonium (S. 125) 1*. Die Querwände zwischen den Zellen sehr ungleich

8. Binuclearia (S. 126) 


\section{Hormidium $\mathrm{Kg}$.}

Chromatophor mit centralem Pyrenoid; Fäden einzeln oder verwachsen.

\section{H. flaccidum (Kg.)}

Bildet ein dünnhäutiges, weiches, gelbgrünes Lager, oft gewebeartig verflochten; Zellen $3-10 \mu$ dick, $\mathrm{I}-3$ Mal so lang. Chromatophoren bloss der einen Seite der Zellwand anliegend. An feuchten Mauern, am Rande von Teichen, sehr häufig; selten im Wasser.

[H. parietinum Kg. (vgl. auch Prasiola crispa S. I2 I) und H. varium $\mathrm{Kg}$., die starre Fäden besitzen, wohl nur ausserhalb des Wassers].

2. Ulothrix $\mathrm{Kg}$. (Kraushaaralge).

Die Schichten der Zellmembran laufen konzentrisch um jede Zelle; Chromatophor ein wandständiger, mehr oder weniger vollständiger Cylinder mit Pyrenoiden. Zoosporen mit vier, Mikrozoosporen mit vier oder zwei zweiciligen Gameten.

I. Fäden $12-75 \mu$ dick . . . . . . . . 1. U. zonata $\mathrm{I}^{*}$. Fäden 5 - 10 (1 12$) \mu$ dick .

2. Fäden ohne kopuliercnde Seitenäste 2. U. subtilis $2^{*}$. Fäden mit scheinbar kopulierenden Seitenästchen . .

3. U. mirabilis

I. U. zonata (Web. et Mohr) Kg. (Taf. V, 5)

Sehr veränderlich, umfasst jedenfalls viele der früher beschriebenen Spezies. Fäden mehr oder weniger schleimig, $1 / 2-3 \mathrm{dm}$ lang, flutend, büschelig verworren. Vegetative Zellen $12-40 \mu$ $(-75)$ dick, $1 / 4-4$ Mal so lang. In langsam und schnell fliessendem Wasser, besonders in Bächen, Springbrunnenbecken, auf feuchten Steinen etc.; ziemlich verbreitet.

2. U. subtilis ( $\mathrm{Kg}$.)

Bildet freischwimmende Flocken; Zellen $1 / 2-2$ Mal so lang als dick; Zellhaut dünn und ungeschichtet. Das bandförmige, wandständige Chromatophor füllt das ganze Zellumen aus. Wie vorige Art, doch auch in stehendem Wasser, eben so häufig.

3. U. mirabilis (Kg.) Hansg.

Zellen 7-10 $\mu$ dick, mehr oder weniger quadratisch; in Bächen höherer Gebirge, nicht häufig. 


\section{Uronema Lagerh.}

Die Fäden sitzen mit einer Haftscheibe fest; Chromatophor wandständig mit zwei (einem) Pyrenoiden; Schwärmsporen viercilig. Dauersporen.

$U$. conforvicolum Lagerh. (Taf. V, 6)

Zellen $4-6 \mu$ breit, 10-18 $\mu$ lang; Basalzelle meist 18-32 $\mu$, Scheitelzelle bis $26 \mu$ lang. In stehenden Gewässern, an Fadenalgen festsitzend.

\section{Bumilleria Borzi.}

Ohne Pyrenoid, ohne Stärke. Fäden leicht in kurze Stücke zerfallend. Die eingeisseligen Zoosporen ohne Augenfleck und amöboid. Dauerzellen.

B. sicula Borzi (Taf. V, 7)

Der Zellendurchmesser $15-18 \mu$. Kommt am Rande von Teichen unter Botrydium, wie es scheint, selten vor.

\section{Conferva (L.) Lagerh.}

Unverzweigte, wurzellose Fäden, von Ulothrix durch anders gebautes Chromatophor, körnigen Zellinhalt und dickere Zellwände, die schachtelartig ineinander greifen, zu unterscheiden. Chromatophor ölbildend. Schwärmsporen mit einer langen (und einer kurzen?) Cilie. Aplanosporen.

I. Faden bis $15 \mu$ dick . . . . . . . . I. C. bombycina I*. Faden über $15 \mu$ dick . . . . . . . 2. C. utriculosa

I. C. bombycina (Ag.) Wille (Taf. V,8)

Die ziemlich ungleich dicken Fäden bilden gelblich- oder dunkelgrüne Flocken; Zellen 2-I 2 Mal so lang als dick (5-i $5 \mu$ ), Fäden an den Querwänden wenig eingeschnürt; die kugeligen sporenbildenden Zellen lösen sich später ab. Variiert sehr. In stehendem Wasser, Teichen, Bassins etc., gemein.

2. C. utriculosa $\mathrm{Kg}$.

Die gelblichgrünen, deutlich eingeschnürten Fäden $15-18 \mu$ dick, Zellen 2-6 Mal so lang, mit ziemlich dünner Zellhaut. Wie vorige Art, doch seltener. 


\section{Microspora (Thur.) Lagerh.}

Die Fäden schwinmen immer frei umher. Mehrere Chromatophoren in einer Zelle; Schwärmsporen ohne Augenfleck; zweierlei Art: grössere und kleinere, beide kopulieren nicht. Dauersporen und Aplanosporen.

I. Zellen bis $10 \mu$ dick .

2. Zellen an den Querwänden eingeschnürt r. M. Aloccosa

2*. Zellen nicht eingeschnürt. . . . . 2. M. stagnorum $1^{*}$. Zellen über $20 \mu$ dick . . . . . . . 3: M. amoena

I. M. Aloccosa (Vauch.) Thur.

Bildet gelblichgrüne Flocken im Wasser, Zellen 6-9 (selten bis 15$) \mu$ dick, bis $1 \frac{1}{2}$ Mal so lang. Zellhaut dünn. In stehendem Wasser und Bächen, nicht selten.

2. M. stagnorum (Kg.) Lagerh.

Flocken zuletzt ziemlich bleich; $3-5$ (nach anderen 5-9) $\mu$ dick, I-4 Mal so lang, mit sehr dicker Zellhaut; Dauerzellen elliptisch. In stehendem Wasser, nicht häufig.

3. M. amoena (Kg.) Rabh. (Taf. V, 9)

Faden ziemlich steif, lebhaft grün, 20-25 $\mu$ dick, I-2 Mal so lang, mit dicker Zellhaut. In Bächen, Brunnen etc., seltener auch in Sümpfen, verbreitet.

\section{Schizogonium $\mathrm{Kg}$.}

Thallus fadenförmig bis blattartig. Zoosporen unbekannt. Vermehrung durch sich loslösende Teile. $\mathrm{Ob}$ die Gattung aufrecht erhalten werden kann, ist fraglich; sie gehört vielleicht zu Prasiola crispa (S. $12 \mathrm{I})$.

Sch. murale (Kg.) auf feuchter Erde, nicht selten.

\section{Binuclearia Wittr.}

Fäden ohne Unterschied von Basis und Spitze; Chromatophor ringförmig, ohne Pyrenoid, aber mit Oel.

B. tatrana Wittr. (Taf. V, io). Nicht häufig. 


\section{Fam. Chaetophoraceae.}

Verzweigte, aufrechte oder kriechende 7ellreihen. Ungeschlechtliche Vermehrung durch mit 2-4 Geisseln versehene Schwärmsporen, Dauerzellen und Aplanosporen; geschlechtliche durch kopulierende, zweigeisselige Gameten. Die Familie schliesst sich durch Gloeoplax und Conochaete eng an die Protococcoideen an.

I. Chromatophor grün, zuweilen daneben "Haematochrom" . 2 2. Die Zellen mit Haaren besetzt, die Zoosporangien den vegetativen Zellen gleich (I. Chactophoreae) . . . . . 3 3. Der Thallus nicht epiphytisch, sondern aufrechtstehend, (selten kriechend oder in einer Schleimmasse eingebettet) 4 4. Ein meist farbloser Hauptstamm und grüne Nebenäste I. Draparnaldia (S. 127)

4*. Kein besonderer Unterschied zwischen Hauptstamm und Aesten . . . . . . . . . . . . . . . 5

5. Die Zellmassen in Schleim eingebettet . . . 6

6. Zellmasse halbkugelig

2. Chactophora (S. 127)

6*. Lager Tetraspora-artig, Zellen in einer Ebene. .

3. Gloeoplax (S. 1 27)

$5^{*}$. Zellen nicht (oder wenig) in Schleim eingebettet.

4. Stigeoclonium (S. I29)

3*. Der Tallus epi- oder endophytisch auf Pflanzen. . . 7

7. Endophytisch in der Schleimhülle anderer Algen .

5. Chactonema (S. I 29)

7*. Auf oder in der Membran anderer Pflanzen . . . 8

8. Die Zellen ohne Haarspitzen, nur die Endzelle in mehrzelliger Haarspitze endend

6. Endoctonium (S. 129)

8*. Zellen mit Haaren, Aeste ohne Haarspitze . . . 9 9. Haar der Zelle ohne Scheide am Grunde . . .

7. Aphanochacte (S. I 29)

$9^{*}$. Haar am Grunde von einer Scheide umgeben Io Io. Scheide schmal, sehr deutlich . . . . . .

8. Chactosphaeridium (S. 130)

IO*. Scheide als Membrankegel ausgebildet, mehr oder weniger deutlich .

9. Conochaete (S. 130) 
2*. Die Zellen ohne Haare, die Zoosporangien den vegetativen Zellen unähnlich (II. Chroolepideae) . . . . . . . 11

I I. Zellen immer grün, Wasserbewohner . . . . . I 2 12. Thallus in halbkugeliger Gallerte . . . . . . .

ı. Chlorotylizim (S. I 30)

I2*. Thallus ohne Gallertbildungen . . . . . . . I3

13. Thallus aufrecht mit nur einer Basalzelle . . . 11. Microthamnion (S. I3I)

13*. Thallus aufrecht, aus einer Basalschicht entstehend 12. Gongrosira (S. I3 I)

I I*. Zellen meist durch Haematochrom rotgefärbt, Luftbewohner...... 13. Trentepohlia (S. 131) I*. Zellen mit braunen Chromatophoren (III. Phaeothamnieae) . 14. Phaeothamnion (S. I 3 I)

\section{Chaetophoreae.}

\section{Draparnaldia Bory.}

Thallus durch Haftscheibe befestigt, bildet schlüpfrige Rasen. Aeste viel dünner als der Hauptstamm, oft in Spitzen auslaufend. Chromatophor in dem Hauptstamme klein, mit Pyrenoid. Schwärmsporen viercilig; Dauerzellen.

I. Zellen deutlich angeschwollen, Astbüschel vom Stamme abstehend, im Umrisse eiförmig . . . . . 1. D. glomerata I*. Zellen kaum angeschwollen, Astbüschel anliegend, lanzettlich 2. D. phumosa

I. D. glomerata (Vauch.) Ag.

Thallus bis $10 \mathrm{~cm}$ lang, meist freischwimmend. Hauptstamm 30-70 $\mu$ dick, Zellen bis fünf Mal so lang; Zellen der Aestchen 9-12 $\mu$ dick. In Sümpfen, Quellen, Bächen etc., verbreitet.

2. D. plumosa (Vauch.) Ag. (Taf. V, I I)

Bis $5 \mathrm{~cm}$ lang, Zellen des Hauptstammes $45-50 \mu$ dick, bis I $1 \frac{1}{2}$ Mal so lang, die der Aeste 10-12, oben 7-9 $\mu$ dick. Wie vorige Art, an den verschiedensten Wasserpflanzen.

\section{Chaetophora Schrank.}

Die reich verzweigten Fäden in mehr oder weniger kugeliger oder gelappter, elastischer, ziemlich fester Gallerte eingeschlossen. Chromatophor bandförmig. 
I. Lager kugelig, erbsen- bis kirschgross . . . . . . . . 2

2. Lager glatt, lebhaft grün . . . . . . . . . 3

3. Endzellen pfriemenförmig, ohne Haar

$3^{*}$. Endzellen in ein Haar auslaufend

1. Ch. pisiformis

2. Ch. elegans

$2^{*}$. Lager uneben, höckerig, bleichgrün

3. Ch. tuberculosa

I*. Lager gelappt oder ästig, langgestreck

4. Ch. endiviacfolia

1. Ch. pisiformis (Roth) Ag.

Aeste stark verzweigt, strahlig gestellt; ihre Zellen unmerklich eingeschnürt, die der Hauptäste $9(-15) \|$ dick, 2-5 Mal so lang. In Teichen, Tümpeln etc., verbreitet.

2. Ch. elegans (Roth) Ag. (Taf. V, I2)

Aeste meist locker und gelblich, gerade oder oben gekrümmt; Hauptstamm 9-12 $\mu$ dick, Zellen 3 Mal so lang. Vorkommen wie bei voriger Art.

3. Ch. tuberculosa (Roth) Ag.

Lager bis kirschengross, ziemlich fest; Zweige büschelig; ihre Zellen eingeschnürt, kurz cylindrisch (8-10 $\mu$ dick, bis 1 1 $1 / 2$ Mal so lang), ohne Haar endend; Zellen der Hauptfäden wie vorige, kürzer. Wie vorige Art, doch seltener.

4. Ch. endiviaefolia (Roth) Ag. (Taf. V, 13)

Lager bis $80 \mathrm{~mm}$ lang; Zweige lose büschelig, oben meist plötzlich gekrümmt; Enden oft mit Haar. Wie vorige Art, nicht häufig.

\section{Gloeoplax Schmidle.}

Eine Tetraspora-ähnliche, niedere Form von noch unsicherer Stellung. Ein oder mehrere parietale Chlorophyllplatten ohne Pyrenoide. Je eine Schwärmspore in jeder Zelle. Die zuerst gebildeten, länglichen Zellen in Fadenform gehen bald in kugelige über.

Gl. weberi Schmidle (Taf. V, 14)

Zellen in der Jugend $5 \mu$ dick und $2-4$ Mal so lang, im Alter rund und 8-10 $\mu$ dick. In Hochmooren. 


\section{Stigeoclonium (Kg.).}

Thallus meist durch Haftplatte festsitzend, mit einfacher Verzweigung, oft in Haarspitzen endend. Das bandförmige Chromatophor mit einem Pyrenoide.

1. Zweige pfriemenförmig zugespitzt . . 1. St. tenue

I*. Zweige lang peitschenförmig ausgezogen . . . . . . . .

2. St. Alagelliferum

I. St. tenue (Ag.) Kg. (Taf. V, 15)

Lager 4-40 $\mathrm{mm}$ lang, schlüpfrig. Hauptfäden nur oben reichlich verzweigt; Zellen 9-15 $\mu$ dick, bis drei Mal so lang; schmale, wandständige Chromatophoren. Aeste kurz. In Brunnen, Wasserbehältern etc., verbreitet.

2. St. Aagelliferum $\mathrm{Kg}$.

Die untern Aeste zu 2-5 genähert, die oberen einzeln oder zu zweien. Zellen der Hauptfäden $\mathrm{I}_{4}-2 \mathrm{O} \mu$ dick, bis $8 \mathrm{Mal}$ so lang, mit dicker Zellhaut. Wie vorige Art, nicht selten.

\section{Chaetonema Nowakowski.}

Thallus mit meist rechtwinklig abstehenden Aesten. Viele Zellen mit I-2 dünnen Borsten, oft etwas vorgewölbt; Schwärmsporen mit vier Cilien.

Ch. irregulare Nowak. (Taf. V, 16)

Zellen 9-15 (6-9) $\mu$ dick, 2-4 Mal so lang; Borsten am Grunde $4-5 \mu$ dick, haarförmig endigend. In der Gallerte von Schizochlamys, Tetraspora etc., selten.

\section{Endoclonium Szymanski.}

Diese Gattung lebt in den Intercellulargängen abgestorbener Wasserlinsen (Lemna) als stark eingeschnürte, haarspitzige, verzweigte Fäden.

E. chroolepiforme Szym. Scheint selten zu sein.

\section{Aphanochaete A. Br.}

Thallus nicht oder unregelmässig verzweigt, meist niederliegend. Die Zellen auf dem Rücken in eine lange, durchsichtige, einzellige, nicht oder kaum bescheidete Borste ausgezogen. Chromatophoren mit einem Pyrenoid. 
Aph. repens A. Br. (Taf. V, I 7 )

Zellen 8-18 $\mu$ lang, 5-10 $\mu$ breit; Borsten oben I $\mu$, unten 3-4 $\mu$ dick; Zoosporen viergeisselig. Auf andern Wasserpflanzen, häufig.

\section{Chaetosphaeridium Klebahn.}

Zellen des Thallus in eine einfach bescheidete, lange, persistente Borste ausgezogen. Zellen durch leere Schläuche mit einander verbunden. Chromatophoren mit einem Pyrenoid. Von den zwei durch eine Querteilung der Zelle entstandenen Tochterzellen wachsen die unteren zu den Schläuchen aus.

Ch. pringsheimi Kleb. (Taf. V, 18)

Zellen ohne eigenen Schleim; Zwischenzellschläuche ziemlich lang; Durchmesser der Zellen 9-12 $\mu$, Länge der Borsten bis 300 , der Scheide bis $18 \mu$. An Coleochaete-Pflanzen, selten.

\section{Conochaete Klebahn.}

Zellen nicht zu Fäden vereint, in halbkugeligem Schleimlager. Membran in mehrere lange, hinfällige, mit konischer Scheide umgebene Haare ausgezogen.

C. klebahni Schmidle (Taf. V, 19)

Kolonien $20-40 \mu$ breit, geringe Schleimbildung. Zellen 8 - I $2 \mu$ gross, mit dünner Zellhaut und fünf bis mehr sehr langen Haaren. Scheide 2-4 $\mu$ dick, 5-7 $\mu$ lang. Auf Sphagnumblättern, selten.

\section{Chroolepideae.}

\section{ı. Chlorotylium $\mathrm{Kg}$.}

Thallus oft von Kalk inkrustiert; Zonen chlorophyllreicher Zellen wechseln mit solchen chlorophyllarmer Zellen ab, dadurch entstehen helle und dunkle concentrische Ringe. Breites Chromatophor. Zweicilige Schwärmzellen; Dauerzellen; aus diesen ein Palmellastadium mit vierciligen Schwärmern.

Chl. cataractarum $\mathrm{Kg}$. (Taf. V, 20)

Lager lebhaft grün bis rötlich, meist stark inkrustiert, bis hanfkorngross. Fäden scheinbar dichotom verzweigt. Zellen $6-12 \mu$ dick, die matter gefärbten $2-6 \mathrm{Mal}$, die grünen bis $1 \frac{1}{2} \mathrm{Mal}$ so lang. Dauerzellen rötlich. In lebhaft fliessenden Bächen, an Wasserfällen etc., nicht selten. 


\section{Microthamnion Naeg.}

Thallus steif, aufrecht, di- oder trichotom verzweigt. Bei der Verzweigung ist die den Ast abtrennende Querwand ein Stück in diesem hochgerückt. Das bandförmige Chromatophor ohne Pyrenoid, aber mit Oel. Zoosporangien an den verdickten Enden.

1. Pfänzchen zuletzt äusserst reich und dicht verzweigt, Aestchen abstehend . . . . . . . . . . . I. M. kuetzingianum

$1^{*}$. Pflänzchen gerade, lockerer verzweigt, Aeste mehr oder weniger anliegend . . . . . . . . . . 2. M. strictissimum

1. M. kuetzingianum Naeg. (Taf. V, 21)

Zuletzt $100-200 \mu$ hoch, Zweige meist etwas gekrümmt, Zellen 3-5!" dick, nach oben etwas keulig verbreitet, meist 2-3 Mal so lang als breit; lebhaft grün. In stehenden Gewässern, ziemlich häufig.

2. M. strictissimum Rabh. (Taf. V, 22)

Zuletzt bis $2 / 3 \mathrm{~mm}$ gross; Aestchen aufrecht, gerade; Zellen cylindrisch, 3-4 $"$ breit, meist 5-6 Mal so lang; blaugrün. In stehenden Gewässern, Brunnen etc., häufig.

\section{Gongrosira $\mathrm{Kg}$.}

Chromatophor mit Pyrenoid; Zoosporangien endständig; Thallus cinfach oder verzweigt; Zellen so lang als breit.

G. debaryana Rabh. (Taf. V, 23)

Lebhaft grüner, dichotom verzweigter Thallus; Dauerzelle rot. An Steinen und Holz in Teichen, selten.

13. Trentepohlia Mart. (Chroolepus Ag.).

Der unregelmässig verzweigte, rotgefärbte Thallus bildet rot-braune Ueberzüge an Bäumen [Tr. uimbrina (Kg.) Born.], an feuchten Steinen [goldgelb: Tr. aurea (L.) Mart.] und an Felsen höherer Gebirge [wohlriechend: „Veilchenstein“: Tr. iolithus (L.) Wittr.].

\section{Phaeothamnion Lagerh.}

Zellen cylindrisch bis keulenförmig, Endzelle stumpf oder spitz. Schwärmsporen mit zwei gleichen Geisseln. Wird der braunen Chromatophoren wegen oft zu den Phaeophyceen gestellt.

Ph. confervicolum Lagerh. (Taf. V, 24). 


\section{Fam. Mycoideae.}

Der Thallus ist eine Zellscheibe; Schwärmsporen und Gameten; weder Dauerzellen noch Aplanosporen.

Ausser Chaetopeltis nur epiphytische Meeres- oder endophytische Luftbewohner.

\section{Chaetopeltis Berth.}

Thallus eine einschichtige Scheibe; mehrere Chromatophoren in jeder Zelle, ohne Pyrenoide.

Ch. orbicularis Berth. (Taf. V, 25)

Thallus Coleochaete-artig, scheibenförmig, bis I mm gross, auf andern Wasserpflanzen festsitzend. Schwärmsporen (und Gameten?). Selten.

\section{Fam. Cylindrocapsaceae.}

Der Thallus besteht aus Zellfäden. Die Oogonien werden von zweiciligen Spermatozoiden befruchtet.

\section{Cylindrocapsa Reinsch.}

Zellen $23-30 \mu$ breit, noch einmal so lang. In Gräben etc., selten.

Cy. involuta Reinsch (Taf. V, 26)

\section{Fam. Oedogoniaceae.}

Jede vegetative Zelle kann eine Schwärmspore bilden, die sofort keimt. Bei der geschlechtlichen Fortpflanzung bilden sich je zwei Spermatozoide, die durch eine Oeffnung in das Oogonium eintreten und das Ei befruchten. Zum Teil (z. B. bei Bulbochacte und einigen Oedogonium-Arten) werden kleine Schwärmsporen, sog. "Androsporen“ gebildet, die sich am Oogonium festsetzen und hier auskeimen; erst dic in diesen „Zwergmännchen“ entstehenden Spermatozoiden befruchten das Ei.

I. Fäden unverzweigt . . . . . . Oedogonium (S. 133) 1*. Fäden verzweigt . . . . . 2. Bulbochacte (S. 134) 


\section{Oedogonium Linck.}

Die $\dot{F}$ äden entweder monöcisch (Oogonien und Antheridien auf derselben Pflanze) oder diöcisch (die Geschlechtsorgane auf verschiedenen Pflanzen). Die zahlreichen Arten sind ohne Fruktifikationsorgane kaum zu bestimmen (Taf. V, 28).

1. Fäden monöcisch [I. Enoedogonium (Wood) Hansg.] . . 2

2. Fäden $12-18 \mu$ dick, Oogonien mit einem Deckel sich öffnend . . . . . . . . . . . . 1. Oe. crispum

$2^{*}$. Fäden 20-30 $\mu$ dick, Oogonien durch ein Loch sich öffnend

2. Oe. vaucheri

I*. Fäden diöcisch . . . . . . . . . . . . . . . . . 3

3. Das Ei wird durch Spermatozoiden befruchtet, die in rein männlichen Fäden entstehen [II. Pringsheimia (Wood) Hansg.] . . . . . . . . . . . . . . . . . . . 4

4. Fäden $10-20 \mu$ dick, Oogonium mit einem Deckel sich öffnend . . . . . . . . 3. Oe. pringsheimi

$4^{*}$. Fäden $35-55 \mu$ dick, Oogonium mit einem Loche sich öffnend . . . . . . . . . 4. Oe capillare

$3^{*}$. Die das Ei befruchtenden Spermatozoiden stammen aus Zwergmännchen [III. Androgynia (Wood) Hansg.] . . 5

5. Vegetative Zellen vier Mal wellig eingeschnürt. . .

\section{Oe. undulatum}

$5^{*}$. Vegetative Zellen nicht so gebaut . . . . . . . . 6

6. Oospore glatt . . . . . 6. Oe. rothi

6*. Oospore mit Stacheln . . . 7.Oe.echinospermum

I. Oe. crispum (Hass.) Wittr.

Oogonien einzeln; Antheridien 2-5-zellig über oder unter den Oogonien. Vegetative Zellen I $2-18 \mu$ dick, bis $4 \frac{1}{2}$ Mal so lang, Oogonien $37--49 \mu$ dick und bis $54 \mu$ lang. In stehendem Wasser, hier und da.

2. Oe. vaucheri (Lebl.) A. Br.

Antheridien 2-4-zellig, Vegetative Zellen $20-30 \mu$ dick, bis vier Mal so lang. Oogonien $20-30$, nach anderen $40-55 \mu$ dick, $40-65 \mu$ lang. Ebenso wie vorige Art.

3. Oe. pringsheimi Cram. (Taf. V, 27)

Oogonien einzeln oder zu 2-6 zusammen, mit engem, aber deutlichem Spalte. Vegetative Zellen des weiblichen Fadens bis vier Mal so lang als dick, die des männlichen nur I I-I6 $\mu$ dick. 
4. Oe. capillare (L.) $\mathrm{Kg}$.

Oogonien einzeln, cylindrisch, Oospore kugelig; männliche Pflanze so dick als die weibliche. Fadenzellen bis zwei Mal so lang als dick, Oogonien $35-55 \mu$ dick, bis $\mathrm{i} 1 / 2 \mathrm{Mal}$ so lang. Das ähnliche Oe. stagnale $\mathrm{Kg}$. hat kugelige Oosporen und dünnere, männliche Fäden.

5. Oe. undulatum (Bréb.) A. Br.

Oogonien öffnen sich durch ein Loch. Die einzelligen, umgekehrt kegelförmigen Zwergmännchen sitzen nicht auf den Oogonien. Vegetative Zellen $15-17 \mu$ dick, bis fünf Mal so lang; Oogonien $5 \mathrm{I}-56 \mu$ dick, bis $75 \mu$ lang.

6. Oe. rothi Pringsh.

Oogonien öffnen sich durch ein Loch; die einzelligen, verkehrt eiförmigen Zwergmännchen sitzen auf den Oogonien. Vegetative Zellen $6-8 \mu$ dick, bis acht Mal so lang, Oogonien $20-24 \mu$ dick, $16-19 \mu$ lang.

7. Oe. echinospermum A. Br.

Oogonien öffnen sich durch ein Loch. Zwergmännchen mehrzellig. Vegetative Zellen $18-30 \mu$ dick, bis $4 \frac{1}{2} \mathrm{Mal}$ so lang, Oogonien $40-50 \mu$ dick, bis $57 \mu$ lang.

\section{Bulbochaete Ag.}

Die verästelten Zellreihen in einer langen, farblosen, am Grunde angeschwollenen Borste endigend. Die Oogonien öffnen sich durch ein Loch in der Wand.

I. Oogonien kugelig (I. Eubulbochacte Hansg.)

$$
\text { I. B. setigera }
$$

I*. Oogonien ellipsoidisch (II. Ellipsospora Hansg.) 2. Zellen 12-15 $\mu$ dick . . . . . 2. B. pygmaea $2^{*}$. Zellen $19-23 \mu$ dick . . . . 3. B. rectangularis

I. B. sctigera (Roth) Ag.

Vegetative Zellen $25-28 \mu$ dick, $2-5 \mathrm{Mal}$ so lang. Oogonien kugelförmig - viereckig, $75-80 \mu$ dick, 60-65 $\mu$ lang. Zwergmännchen 1 2-14 $\mu$ dick, bis $36 \mu$ lang. In alten Teichen, in sumpfigen Gewässern, nicht selten. 
2. B. pygmaea Pringsh.

Zellen bis ein Mal so lang als dick; Oogonien $23-25 \mu$ dick, bis $40 \mu$ lang. Zwergmännchen bis $18 \mu$ lang. Wie vorige Art, häufig.

3. B. rectangularis Wittr. (Taf. $\mathrm{V}, 29$ )

Zellen bis zwei Mal so lang als breit; Oogonien 33-39 $\mu$ dick, bis $55 \mu$ lang; Zwergmännchen bis $27 \mu$ lang. Wie vorige Art, ziemlich verbreitet.

\section{Fam. Coleochaetaceae.}

Thallus festsitzend, polsterförmig, aus dichotom verzweigten, oft verwachsenen Zellreihen bestehend. Zweicilige Schwärmsporen, zweicilige Gameten. Die Oospore, während des Reifens von einem Gewebe umrindet, bildet eine kleine Zellscheibe, in der sich Schwärmsporen entwickeln. Aus letzteren entsteht die neue Pflanze.

\section{Coleochaete Bréb.}

Mit dem Familiencharakter.

1. Thallus polsterartig, mit aufstrebenden Zweigen [I. Eucoleochaete (Bréb.) Hansg.] . . . . . . . . . I. C. pulvinata

I*. Thallus scheibenartig festgewachsen, mit kriechenden Zweigen [II. Phyllactidium (Kg.) Hansg.] . . . . . . . . . . 2

2. Thallus ohne Borsten . . . 2. C. orbicularis $2^{*}$. Thallus mit Borsten . . . . 3. C. scutata

I. C. pulvinata A. Br. (Taf. V, 3o)

Bildet bis $2 \mathrm{~mm}$ hohe, kugelige Lager. Vegetative Zellen $20-43 \mu$ dick, kaum zwei Mal so lang. Oogonien zuerst flaschenförmig; berindet, bis $150 \mu$ dick; Antheridien $17 \mu$ dick. In stehenden Gewässern, nicht selten.

2. C. orbicularis Pringsh.

Vegetative Zellen 8-12 $\mu$ dick, zwei Mal so lang. Gern an der Unterseite von auf der Oberfläche des Wassers schwimmenden Blättern, auch an Holz, nicht häufig. 
3. C. scutata Bréb. (Taf. V, 31)

Vegetative Zellen $25-46 \mu$ breit und bis drei Mal so lang; Oosporen $140-160 \mu$ lang, $120 \mu$ breit. Vorkommen wie bei voriger Art.

\section{Fam. Cladophoraceae.}

Thallus ein verzweigter oder unverzweigter Faden. Jede Zelle mit zwei oder mehr Zellkernen. Zweicilige Gameten, Schwärmsporen zwei- bis viercilig. Dauerzellen.

1. Fäden unverzweigt . . . . . . . . . . . . . 2

2. Fäden ganz glatt . . . . I. Chaetomorpha (S. I36)

$2^{*}$. Fäden mit wurzelähnlichen Auswüchsen . . . . . .

2. Rhizoclonium (S. 136) 1*. Fäden verzweigt . . . . . 3. Cladophora (S. 137)

\section{Chaetomorpha $\mathrm{Kg}$.}

Die Fäden sitzen meist mittels einer korallenähnlichen Basalzelle fest. Das Chromatophor ist eine durchlöcherte Platte mit vielen Pyrenoiden. Schwärmsporen und Befruchtung unbekannt.

Ch. herbipolensis Lagerheim (Taf. V, 32)

Dunkelgrüne Rasen. Steife, in der Jugend cylindrische, im Alter fast tonnenförmige Zellen, Membran deutlich längs gestreift. Die Schwärmer keimen olıne Kopulation. Die Zellen sind $75-255 \mu$ lang und bis $130 \mu$ breit. Ist wohl selten.

Die anderen Arten, wie Ch. linum $\mathrm{Kg}$. und Ch. implexa $\mathrm{Kg}$. wohl nur im Salzwasser.

\section{Rhizoclonium $\mathrm{Kg}$.}

Thallus mehr oder weniger kriechend, zuletzt freischwimmend; netzförmiges Chromatophor mit vielen Pyrenoiden; nur Dauerzellen bekannt.

1. Mit ziemlich dicker Zellhaut . . . I. Rh.hieroglyphicum I*. Mit dünner Zellhaut . . . . . 2. Rh. fontinale

I. Rh. hicroglyphicum (Ag.) $\mathrm{Kg}$.

Bildet etwa gelbgrüne Rasen. Fäden mit kurzen, seitlichen Rhizoiden. Zellen $12-25$ « dick. Häufig, in Bächen, an Wehren, auch an feuchten Felsen. 
2. Rh. fontinale $\mathrm{Kg}$. (Taf. V, 33)

Fäden lebhaft grün bis dunkelgrün, oft mit gegliederten Wurzelästen. Zellen $\mathrm{I}_{3}-\mathrm{i} 7 \mu$ dick, bis vier Mal so lang. Zwischen Moosen, an Steinen etc., in Quellen.

\section{Cladophora $\mathrm{Kg}$.}

Reich verzweigte Zellfäden. Chromatophor wie bei voriger Gattung. Schwärmsporen mit vier oder zwei Cilien.

I. Thallus rasenartig, keine polsterförmigen, rundlichen Ballen bildend [I. Eucladophora (Kg.) Hauck] . . . . . . . . 2

2. Fäden (im Alter) freischwimmend, etwas verflochtene Watten bildend; Zoosporangien nicht an der Spitze der Zweige . . . . . . . . . . . . . . . . 3

3. Zellen mit gleichmässig verteiltem Chlorophyll und dicker Membran . . . . 1. Cl. fracta

$3^{*}$. Zellen mit spiraligem Chlorophyllbande, und dünner, oft längsgefalteter Zellhaut . 2. Ch. crispata

$2^{*}$. Auch im Alter festgewachsen; Zoosporangien an der Spitze der Zweige . . . . . . . . . . . . . . . . . 4

4. Zellen der Zweiglein 3-6 Mal, die der Hauptäste 6-7 Mal so lang als dick . 3. Cl. glomerata

4*. Zellen der Zweiglein 3-12 Mal, die der Hauptäste $\mathrm{I}_{1 / 2}{ }_{2}-2 \mathrm{Mal}$ so lang als dick 4. Cl. fuitans

$1^{*}$. Thallusfäden zu rundlichen, schwammigen, freischwimmenden Polstern verflochten (II. Aegagropila (Kg.)

5. Cl. aegagropila

I. Cl. fracta (Vahl) $\mathrm{Kg}$.

Zellen der Hauptäste $54-\mathrm{i} 20 \mu$ dick, bis drei Mal so lang, die der Zweiglein 15-40 $\mu$ dick, bis 6 Mal so lang, meist etwas angeschwollen. Sehr veränderliche Spezies. In stehenden Gewässern, in Tümpeln etc., verbreitet.

2. Cl. crispata (Roth) $\mathrm{Kg}$.

Zellen cylindrisch, die der Hauptäste $43-100 \mu$ dick, die der Zweiglein $24-27 \mu$ dick, bis i6 Mal so lang. Wie vorige Art, doch auch in Bächen.

3. Cl. glomerata (Ag.) Kg. (Taf. V, 34)

Fäden zu Büscheln gehäuft; Zellen der Hauptzweige 6o bis ıо० $\mu$ dick, bis $8 \mathrm{Mal}$ so lang, die der Zweiglein $30-50 \mu$ dick, 
bis 6 Mal so lang. Variiert ebenfalls sehr. In Bächen, Flüssen etc., überall verbreitet.

4. Cl. fuitans $\mathrm{Kg}$.

Die wenig verzweigten Fäden bilden bis $6 \mathrm{dm}$ lange Rasen, Zweige kurz, angedrückt. Zellen an den Hauptästen 120-135 $\mu$ dick, bis zwei Mal so lang, an den Zweiglein bis $86 \mu$ dick, bis I $2 \mathrm{Mal}$ so lang, mit dicker Membran. In schnellfliessenden Bächen, auf dem Grunde flutend, häufig.

5. Cl. aegagropila (L.) Rabh.

Die dicht verflochtenen Fäden mehr oder weniger radiär gestellt; die rundlichen Polster dunkelgrün; Zellen der Hauptfäden $60-80 \mu$ dick, die der Zweiglein $36-44 \mu$ dick, bis $8 \mathrm{Mal}$ so lang und länger. Kann Büschel von der Grösse eines Menschenkopfes bilden. In Seen, zwischen Algen.

\section{Fam. Sphaeropleaceae.}

Die Eizellen werden in grosser Anzahl in jedem Oogonium gebildet. Die zweiciligen Spermatozoiden lang gestreckt. Die keimende Oospore bringt $\mathrm{I}-8$ Schwärmsporen hervor, aus denen die neuen Pflanzen entstehen.

\section{Sphaeroplea Ag.}

Hat die Charaktere der Familie.

Sph. annulina Ag. (Taf. V, 35)

Die vegetativen Zellen $36-72 \mu$ dick, bis 20 Mal so lang; Oospore $17-36 \mu$ dick, meist rot gefärbt. Chromatophor ringförmig. In Tümpeln, flachen Gräben, die zeitweise austrocknen, und ähnlichen Oertlichkeiten zu Zeiten rostrote Ueberzüge bildend, nicht häufig.

\section{Siphoneae}

(Schlauchalgen).

Die mit zahlreichen Zellkernen versehenen Zellen sind schlauchförmig, d. h. verhältnismässig erweitert oder verlängert bis lang fadenförmig. Die ungeschlechtliche Vermehrung geschieht durch Schwärmsporen oder unbewegliche Schwärmer 
(Aplanosporen); auch Dauerzellen sind bekannt. Die geschlechtliche entweder durch Gametenkopulation oder durch Ei-. befruchtung.

I. Zellen kugelig oder keulenförmig; Fortpflanzung durch kopulierende Gameten . . . . . . . I. Botrydiaceae (S. 139) I*. Zellen schlauchförmig, Fortpflanzung durch Eibefruchtung . 2. Vaucheriaceae (S. 140)

\section{Fam. Botrydiaceae.}

Thallus mehr oder weniger kugelig, mit farblosem, wurzelähnlichem Stiele. Neben schwärmenden Gameten sind auch noch Schwärmsporen und Aplanosporen vorhanden; auch giebt es eine Vermehrung durch Sporen, die in den „Wurzeln" entstehen, die sog. Wurzelzellen.

\section{Botrydium Wallr.}

Ohne Pyrenoide.

B. gramulatum (L.) Grev. (Taf. V, 36)

Bildet bis $2 \mathrm{~mm}$ dicke Blasen auf feuchtem Lchme, besonders am Rande von Dorfteichen etc., häufig.

\section{Fam. Vaucheriaceae.}

Thallus lang schlauchförmig, oft (auch dichotom) verzweigt. Die Eier entstehen in abgegliederten Seitenzweigen (Oogonien), die Spermatozoiden ebenso (in Antheridien). Die Oospore wächst nach einer Ruhepause direkt zum neuen Schlauche aus. Zahlreiche kleine, pyrenoidlose Chromatophoren. Grosse Schwärmsporen mit vielen Cilien, Aplanosporen und Dauerzellen.

\section{Vaucheria DC.}

Die Gattung besitzt den Familiencharakter. Der Tallus ist ab und zu gallenartig aufgeschwollen infolge der Anwesenheit eines Rädertieres (Proales werneckl). Beschreibung nach Götz. 
1. Antheridien ohne seitliche Ausstülpungen. ... . . . . 2

2. Antheridien kaum oder nicht gekrümmt, länglich-cylindrisch zugespitzt, ungestielt (I. Tubuligerae Walz) . . . . . 3

3. Fäden starr, von bedeutender Breite (bis $200 \mu$ ) .

I. $V$. dichotoma

$3^{*}$. Fäden weich, von geringer Breite $(33-45 \mu)$.

2. V. ornithocephala

$2^{*}$. Antheridien horn- oder schneckenartig eingerollt, auf kurzen

Seitenästen des Thallusfadens (II. Comiculatae Walz) - 4

4. Die Antheridienspitzen neben oder zwischen den sitzenden oder kurzgestielten Oogonien . . . . . . . . . . 5

5. Fadendicke $39-50 \mu$, ein Oogonium und daneben ein Antheridium . . . . . 3. V. repens

$5^{*}$. Fadendicke $50-83 \mu$, ein Antheridium zwischen zwei Oogonien . . . . . . . 4. V. sessilis

$4^{*}$. Die Antheridien bilden das Ende eines Astes, unter ihnen die Oogonien . . . . . . . . . . . . . . . . 6

6. Fäden 49-66 $\mu$ dick, ein Oogonium

5. V. terrestris

6*. Fäden $66-83 \mu$ dick, 2-6 Oogonien

6. $V$. racemosa

I*. Antheridien mit seitlichen Ausstülpungen (III. Anomalae Hansg.) . . . . . . . . . . . . . . . . . . . . 7

7. Fadendicke $55-99 \mu$, Antheridien am hornartig gekrümmten Fadenende . . . . . . . . . 7. V. geminata

$7^{*}$. Fadendicke $22-55 \mu$, Antheridien meist aufrecht

8. $V$. de baryana

I. V. dichotoma (L.) Ag.

Eine diöcische Form, die bis $2 \mathrm{dm}$ lange Rasen bildet. Oogonien rundlich, bis I 1 $\mu$ dick, einzeln oder zu 2-6.genähert. Antheridien auf besonderen Fäden. In Tümpeln, Gräben etc.; scheint etwas salziges Wasser zu lieben.

2. $V$. ornithocephala $\mathrm{Ag}$.

Die $1-6$ Oogonien hintereinander auf derselben Seite, mehr oder weniger vogelkopfartig. Länge der Oospore 50-60 $\mu$. In fliessendem Wasser, nicht selten.

3. V. repens Hass. (Taf. V, 37)

Länge der Oospore $66-77 \mu$. Meist auf feuchtem Boden als feiner Ueberzug, doch auch in fliessendem Wasser in polsterförmigen Rasen. Nicht selten. 
4. V. sessilis (Vauch.) DC. (Taf. V, 38 )

Schnabel des Oogoniums schief aufgerichtet (bei voriger Art horizontal). Länge der Oospore $66-99 \mu$. Bildet in stehendem Wasser, in Teichen etc. freischwimmende Watten, findet sich auch in stark fliessendem Wasser, häufig.

5. V. terrestris Lyngb.

Das Oogonium sitzt direkt auf dem Fruchtaste; das Antheridium bis $\mathrm{I} 1 / 2 \mathrm{Mal}$ spiralig eingerollt. Länge der Oospore 83-121 $\mu$. Auf feuchtem Boden, oft halb unter Wasser, sehr häufig.

6. V. racemosa (Vauch.) DC.

Länge der Oospore $66-77 \mu$. In Gräben und Tümpeln.

7. V. geminata (Vauch.) DC.

Ein oder zwei aufrechte Oogonien. Länge der Oospore 99-1 $38 \mu$. An Ufern von Bächen etc.

8. $V$. de baryana Wor. (Taf. V, 39)

Antheridien mit I-4 Ausstülpungen. Länge der Oospore $60-72 \mu$. In Polstern an Brunnenrändern und in Bächen.

\section{Conjugatae.}

Chlorophyllgrüne, ein- oder mehrzellige Algen, die sich nur in einer Richtung teilen. Keine Schwärmzellen. Zygosporenbildung durch Konjugation zweier Zellinhalte. Hier und da auch Dauerzellen und Aplanosporen.

I. Individuen einzeln oder zu Fäden vereint, durch eine Einschnürung in der Mitte in zwei symmetrische Hälften geteilt . . . . . . . . . . . I. Desmidiaceae (S. 142) I*. Die cylindrischen Zellen ohne Einschnürung, zu Fäden vereint II. Zygnemaceae (S. I7I) 


\section{Fam. Desmidiaceae.}

\section{Litteratur:}

Ralfs, J., The British Desmidieae, Tafeln von Edw. Jenner. London 1848 . de Bary, A., Untersuchungen über die Familie der Conjugaten. Lpzg. 1858. Wolle, F., Desmids of the United States. Betlehem 1884. Cooke, British Desmids. London $1887 / 88$.

Die meisten Formen sind deutlich in zwei symmetrische Hälften geteilt. Die Cellulose-Membran ist in der Regel deutlich skulpturiert und in zwei Schalen gesondert. Die Zellen leben einzeln oder sind $z u$ langen Zellreihen vereint. Gallertbildung ist bei ihnen sehr häufig. Viele Formen zeigen eine. Diatomeen-ähnliche Bewegung, die jedenfalls mit der Gallertausscheidung im Zusammenhange steht. Bei der gewöhnlichen Zellteilung trennen sich die zwei Schalen von einander, indem der Zellinhalt aus jeder Hälfte hervorquillt und je wieder eine neue Hälfte ergänzt, so dass die zwei neuen Zellen je eine neue und je eine alte Zellhälfte erhalten (vgl. Taf. VI, 26). Bei der Konjugation können sich zwei ganze Zellen zu einer Zygospore vereinigen oder nur der Inhalt der Zellen, wobei dann die leeren Häute übrigbleiben. Die Zygospore ist meist mit Stacheln oder sonstigen Erhebungen versehen (vgl. Taf. VI, 27). Sie bildet beim Keimen eine Keimzelle, die ein bis acht neue Individuen hervorbringt. Die Desmidien sind mit den Diatomeen zusammen die schönsten mikroskopischen Süsswasserorganismen, die schon von jeher die Aufmerksamkeit, auch der Laien, auf sich gelenkt haben.

1. Zellen zu Zellreihen vereinigt, häufig in Gallerte eingebettet (Eudesmidieae Hansg.) . . . . . . . . . . . . . . 2

2. Zellen nicht oder nicht deutlich in zwei Hälften geschieden, also ohne oder mit schwacher Mitteleinschnürung . . . 3 3. Zellen viel länger als breit, stabförmig . . . . . 4

4. Chromatophor eine axile, mehr oder weniger verbogene Platte . . . . . . . 1. Gonatozygon (S. 145)

$4 *$. Chromatophor ein wandständiges, zuweilen unregelmässiges Spiralband . . 2. Genicularia (S. 145) 
3*. Zellen meist ebenso breit wie lang

$$
\text { 3. Hyalotheca (S. 146) }
$$

2*. Eine deutliche Mitteleinschnürung teilt die Zelle in zwei Hälften

5. Scheitelansicht rund oder elliptisch . . . . . . 6

6. Die einzelnen Zellen nicht durch auffällige Stacheln, Bänder oder Knötchen verbunden . . . . . . 7

7. Die Zellen länger als breit (dick) . . . . . 8

8. Scheitelansicht der Zellen rund, mit zwei einander entgegengesetzten, niedrigen Leisten

4. Gymmozyga (S. 146)

8*. Scheitelansicht elliptisch, ohne diese Leisten

5. Spondylosium (S. 146)

$7 *$ Die Zellen sind breiter (dicker) als lang .

6. Didymoprium (S. I 47)

6*. Die Zellen sind durch Stacheln etc. an einander befestigt

7. Sphaerozosma (S. 147)

$5 *$ Scheitelansicht drei- oder viereckig, seltener oval

8. Desmidium (S. 148)

I*. Zellen einzeln, trennen sich nach der Teilung, so dass selten mehr als zwei zusammen gefunden werden [Didymoidene (Reinsch) Hansg.] . . . . . . . . . . . . . . . . 9

9. Zellmembran cinheitlich, ohne Mittel-Einschnürung, Zellen cylindrisch, in der Scheitelansicht rund (Trib.: Spirotaenieae Hauptfl.) . . . . . . . . . . . . . . . . 10

Io. Chromatophor: eine einfache Chlorophyllplatte . .

9. Mesotaenium (S. 148)

10*. Chromatophor: ein oder mehrere wandständige Spiralbänder . . . . . . . 10. Spirotaenia (S. 149)

9*. Zellmembran zweiteilig, mit oder ohne Mitteleinschnürung I 2

I2. Zellen ohne jede mittlere Einschnürung [Trib.: Closterieae (Trev.) De Toni] . . . . . . . . . . I 3

13. Zellen halbmondförmig gekrümmt, selten fast gerade, in der Mitte meist wenig bauchig, Enden meist in eine Spitze verlängert . I 1. Closterium (S. I 49)

13*. Zellen gerade, cylindrisch, mit stumpf abgerundeten Enden . . . . . . . . . . . . . . 14

14. Chromatophor: mehrere in der Achse der Zelle zusammenstossende Platten (in der Scheitelansicht als Stern erscheinend) 12. Penium (S. 150) 
I4*. Je ein nach allen Seiten strahlenförmig verzweigtes Chromatophor in jeder Zellhälfte.

13. Cylindrocystis (S. 155)

I $2 *$ Zellen in der Mitte deutlich zusammengezogen ${ }_{15}$

15. Zellen mehrmals länger als breit, nur eine seichte Einschnürung in der Mitte (Trib.: Docidieae De Toni) . . . . . . . . . . . . . 16 16. Zellen an jedem Ende mit einem linienförmigen Einschnitte . . . 14. Tetmemorus (S. 156)

16*. Zellen ohne diese Einschnitte . . . . . 17

17. Chromatophor wandständig mit krystallführenden, hellen Endbläschen .

15. Pleurotaenium (S. I56)

17*. Chromatophor axil, ohne solche Endbläschen, aber mit tiefen Längsfurchen

16. Docidium (S. 157)

$15^{*}$. Zellen im grossen und ganzen so breit wie lang, durch einen mehr oder weniger tiefen Einschnitt in zwei Hälften geteilt [Trib.: Micrasterieae (Endl.) De Toni] . . . . . . . . . . . . . . 18

18. Scheitelansicht rund, oval oder elliptisch . 19

19. Chromatophoren wandständig . . . . 20 20. Zelle mit Stacheln . . . . . . 21

21. Stacheln einfach, unverzweigt ....

17. Holacanthum (S. 157)

$2 \mathrm{I}^{*}$. Stacheln verzweigt

18. Schizacanthum (S. 158 )

20*. Zelle ohne Stacheln

19. Pleurotaeniopsis (S. $\left.15^{8}\right)$

19*. Chromatophor axil . . . . . . . . 22

22. Zellen mit Stacheln . . . . . . .

20. Arthrodesmus (S. 150)

22*. Zellen ohne Stacheln . . . . . 23

23. Zellen schwach keilförmig, sitzen in Kalkröhren . . 21. Oocardium (S. 160)

23*. Zellen symmetrisch, nicht in Kalkröhren 24

24. Zellhälften mehr oder weniger rundlich, höchstens gebuchtet, aber nicht durch tiefe und schmale Einschnürungen zerteilt . . . . . . . . 25 
25. Zellen einzeln, frei. . . 22. Cosmarium (S. 160).

$25^{*}$. Zellen zu mehreren auf Gallertstielen . . . . . .

23. Cosmocladium (S. 163)

$24^{*}$. Zellhälften durch tiefe Einschnitte zerteilt. . . . . 26

26. Scheitelansicht breit elliptisch mit einer oder mehreren Ausbuchtungen an der Seite, Zellen nicht flach . . .

24. Euastrum (S. I63)

26*. Scheitelansicht schmal elliptisch, linear, oder schmal rhombisch, ohne Einbuchtungen, Zellen flach . . . .

25. Micrasterias (S. I65)

18*. Scheitelansicht 3-5-eckig oder mit auslaufenden Aesten 27

27. Chromatophor axil . . . 26. Staurastrum (S. 167)

27*. Chromatophor wandständig . 27. Pleurenterium (S. 17 I)

\section{Eudesmidieae Hansg.}

\section{Gonatozygon De By.}

Die langen Zellen setzen Fäden zusammen; ganz cylindrisch oder an den Enden wenig verdünnt. Membran mit Wärzchen besetzt. Chromatophor ist eine axile Platte mit Leisten und Pyrenoiden. Die Zellen trennen sich vor der Kopulation und biegen sich knieförmig. In dem Verbindungskanale bildet sich eine glatte Zygospore.

1. Zellen wenig spindelförmig . . . . . . G. brebissoni 1*. Zellen ganz cylindrisch . . . . . . . 2. G. asperum

1. G. brebissoni De By. (Taf. VI, I)

Die Zellen, die 10-16 Mal so lang als breit und an den Enden ein wenig gekopft sind, trennen sich leicht von einander. Dicke des Fadens $5-7 \mu$. Hier und da, nicht selten.

2. G. asperum (Ralfs) Rabh.

Die an den Enden wenig verbreiterten Zellen etwa 10-20 Mal so lang als breit. Wie bei der vorigen Art hat das Chromatophor eine Längsreihe von Pyrenoiden. Dicke $10-12 \mu$. Vorkommen wie bei voriger Art.

\section{Genicularia De By.}

Voriger Gattung ähnlich; doch besteht das Chromatophor aus wandständigen, mehr oder weniger regelmässigen, mit Pyrenoiden besetzten Spiralbändern. 
G. spirotaena De By. (Taf. VI, 2)

Zellen io-20 Mal länger als breit, mit wenig angeschwollenen Enden und feinwarziger Oberfläche. Dicke $17-23 \mu$. Selten.

\section{Hyalotheca Ehrbg.}

Zellen kurz cylindrisch, fadenbildend, mit Schleimmantel. Scheitelansicht kreisförmig. In jeder Zellhälfte zwei axile Chromatophoren mit radial ausstrahlenden Platten. Zygosporen glatt und rund.

I. Auf der Membran zwei ringförmige Erhebungen, anı Rande ohne mittlere Einschnürung . . . . . . 1. H. mucosa

I*. Membran glatt, doch mit schwacher Mitteleinschnürung

2. H. dissitiens

I. H. mucosa (Mert.) Ehrbg. (Taf. VI, 3)

Mit sehr starker Gallerthülle. Ungefähr so lang als breit. Zellen ohne Hülle $18-20 \mu$ breit. Häufig, in stehendem Wasser.

2. H. dissiliens (Smith) Bréb. (Taf. VI, 4)

Mit schwächerer Gallerthülle. Die Fäden zerfallen vor der Kopulation. Dicke $14-36 \mu$. Zygosporen etwa $25 \mu$ dick. Ebenda, sehr häufig.

\section{Gymnozyga Ehrbg. (= Bambusina Kg.).}

Die wie Tonnen im mittleren Teile mehr oder weniger verdickten Zellen bilden lange gewundene Fäden. Eine schwache, aber scharfe Einschnürung in der Mitte teilt jede Zelle in zwei Hälften. Chromatophoren bestehen aus $6-8$ radial gestellten Platten. Querschnitt rund, mit zwei kleinen Erhebungen. Zygospore rund und glatt.

G. brebissoni (Kg.) Nordst. (Taf. VI, 5)

Die mittlere Einschnürung wird begrenzt von je einem erhöhten Ringe, der den Fäden ein gezacktes Aussehen verleiht. Dicke $22-28 \mu$. Sehr verbreitet, in allen Torfwässern.

\section{Spondylosium (Bréb.) Arch.}

Die gegen das Ende zụ immer etwas verdünnten Zellen haben eine scharfe mittlere Einschnürung und hängen zu Fäden aneinander. Scheitelansicht dreieckig oder elliptisch. Membran glatt oder mit Erhebungen an den Enden. Ohne Gallertscheide. Axiles, radiärstrahliges Chromatophor. Zygospore unbekannt. 
I. Zellhälften von der Mitteleinschnürung nach den Enden zu gleichmässig verdünnt, trapezförmig . . I. Sp. pulchellum 1*. Zellhälften oblong . . . . . . . 2. Sp. depressum

I. Sp. pulchellum Arch.

Zellen etwa so lang wie breit, mit tiefer, schmaler Einschnürung. Die Chromatophoren haben in jeder Hälfte ein Pyrenoid. Keine oder wenig ausgebildete Gallerte. Dicke 9- I I $\mu$, Länge etwa IO-I $4 \mu$. Nicht selten.

2. Sp. depressum Arch. (Taf. VI, 6)

Zellen durch tiefe Einschnürung in zwei rund oblonge Hälften geteilt, mit Wärzchen. Etwa so lang $(8-$ Iо $\mu$ ) als breit (Iо- I $2 \mu$ ). Wie vorige Art, häufiger.

\section{Didymoprium $\mathrm{Kg}$.}

Zellen mit geraden Enden zu Fäden vereint, in der Mitte mit schwacher Einschnürung und jederseits davon ein Zahn; Scheitelansicht breit elliptisch, mit zugespitzten Enden. Membran glatt. Chromatophoren: acht wandständige Platten mit drei Amylumherden. Zygospore rund, in einer der kopulierenden Zellen.

D. grevillei Kg. (Taf. VI, 7)

Zellfäden in Gallerte eingelagert, Zellen zwei Mal so breit (dick) als lang. Gelbgrün gefärbt und in Gallerte eingebettet. $40-80 \mu$ breit. Verbreitet, in Torfgewässern.

\section{Sphaerozosma (Corda) Arch.}

Die Zellen sind durch zapfenförmige Fortsätze vereinigt. Scheitelansicht elliptisch oder dreieckig. Zygospore glatt.

1. Zellen in der Mitte mit scharfer, schmaler Einschnürung .

I. Sph. vertebratum

I*. Zellen mit ganz flacher Eindellung . . 2. Sph. excavatum

I. Sph. vertebratum (Bréb.) Ralfs (Taf. VI, 8)

Zellen $1 / 2$ bis etwa so lang wie breit, gegen die Nachbarzelle stark abgerundet, daher mehr oder weniger gegen die Mitte $\mathrm{zu}$ gekrümmt erscheinend; eine einzige einfache Klammer in der Mitte zwischen den Zellen. Zellen I 2-35 $\mu$, Zygospore 2 I $\mu$ dick. Mit oder ohne Gallerte. Hin und wieder. 
2. Sph. excavatum Ralfs (Taf. VI, 9)

Zellen (etwa zwei Mal) länger als breit, viereckig, klein, durch zwei Klammern an einander befestigt. Am Rande häufig mit drei Zähnen. Zygospore elliptisch. Dicke 9-12 $\mu$. Wie vorige Art, häufiger (?).

\section{Desmidium (Ag.) Ralfs.}

Zellen mit deutlicher, nach innen schmälerer Einschürung und jederseits davon mit einem scharfen Zahne. Scheitelansicht drei- oder viereckig. Selten mit Gallerte. Mit 6 oder 8 Chromatophorplatten. Zygospore elliptisch und glatt.

I. Zellen am Rande mit je zwei unregelmässigen, scharfen Zähnen; Fäden solide . . . . . . . . 1. D. swartzi

$I^{*}$. Zellen am Rande mit abgerundeten Buckeln; Fäden durchlöchert . . . . . . . . . 2. D. aptogonum

I. D. swartzi Ag. (Taf. VI, Io)

Zellen mit scharfer Mitteleinschnürung. Scheitelansicht dreieckig, mit stumpfen Ecken und konkaven Seiten. Dicke 25-50 $\mu$. Häufig.

2. D. aptogonum Bréb.

Zellen so breit oder breiter als lang, durch drei breite farblose Fortsätze mit einander verbunden, wodurch der Faden durchlöchert erscheint. Einschnürung nur schmal, Fädẹn ohne Gallerte. Scheitelansicht dreieckig. Breite $22-37 \mu$. Selten.

\section{Ii. Didymoideae (Reinsch) Hansg.}

\section{Mesotaenium Naeg.}

Gerade, kurz stabförmige Zellen mit abgerundeten Enden; in Gallerte eingebettet oder frei. Scheitelansicht mehr oder weniger rund. Chromatophor ist eine axilläre Platte. Niedrig stehende Form: bei der Kopulation verschmelzen die ganzen Zellen mit der Zellhaut zur Zygospore, die vor der Keimung erst in vier Tochterindividuen zerfällt.

1. Farbe der Zellen grün . . . . . . . M. endlicherianım I*. Farbe der Zellen violettfarben . . . 2. M. violascens 
I. M. endlicherianum Naeg.

Zellen cylindrisch, glatt, 3-4 Mal so lang als breit, 9-i I $\mu$ dick. Nicht häufig.

Das ähnliche, aber dickere $($ г6-20 $\mu$ ) M. branni De By. (Taf. VI, I 1) findet sich häufig, in Schleim eingebettet, an feuchten Felswänden etc., selten im Wasser.

2. M. violascens De By.

Nach den stumpf abgerundeten Ecken deutlich verdünnt; Chlorophyllplatte neben der Längsachse gelegen, innerhalb von meist violettgefärbtem Plasma. Dicke $15-25 \mu$. An feuchten Felswänden, wie in Wasser, zwischen Algen.

\section{Io. Spirotaenia Bréb.}

Zellen mehr oder weniger cylindrisch, mit abgerundeten Enden, bis spindelförmig, ohne Mittelẹinschnürung. Scheitelansicht rund, Membran glatt. Chromatophor: ein parietales Spiralband oder ein axiler Strang mit spiralig gedrehten, nach aussen verdickten Leisten, wodurch mehrere Spiralbänder vorgetäuscht werden. Runde oder sternförmige Zygospore.

I. Zellen mit einem Spiralbande . . . I. Sp. condensata I*. Zellen mit (scheinbar) mehreren Spiralbändern . . . . . . 2. Sp. obscura

I. Sp. condensata Bréb. (Taf. VI, 12)

Zellen cylindrisch, 5- io Mal so lang als breit. Spiralband mit zahlreichen (8-I 2) Umdrehungen. Dicke 18-25 und Länge I $80 \mu$. In Sümpfen, nicht selten.

2. Sp. obscura Ralfs

Zellen nach den Enden etwas verschmälert, bis spindelförmig, 5-8 Mal so lang als breit. Mit Endvakuolen, in denen sich ein Körnchen bewegt. Dicke 8-30 $\mu$; Länge $50-220 \mu$. Nicht so häufig wie vorige Art.

\section{Closterium Nitzsch.}

Die verlängerten, mehr oder weniger zugespitzten Zellen fast gerade oder gebogen bis sichelförmig, in der Mitte nicht oder wenig bauchig. Scheitelansicht rund. Im farblosen Plasma jeden Endes eine Vakuole mit Gypskryställchen, die durch 
Brownsche Molekularbewegung in tanzender Unruhe sind. Membran glatt oder längsgestreift. Chromatophor axil, mit zahlreichen, radiär ausstrahlenden Platten. Zygospore rund, oval und viereckig, oder viereckig mit vorspringenden Hörnern. Mit etwa 100 Arten.

I. Zellen wenig gebogen . . . . . . . . . . . . 2

.2. Zellen fast cylindrisch, konvexe und konkave Seite parallel; Zygospore rund oder viereckig . . . . . 3

3. Zellen 4-10 Mal so lang als breit . . . . . . . 4 4. Zellhaut glatt, Enden nicht verdünnt

\section{Cl. obtusum}

$4^{*}$. Zellhaut mit feinen Längsstreifen, Enden wenig, aber deutlich verdünnt. . . . 2. $\mathrm{Cl}$. didymotocum

$3^{*}$. Zellen mehr als 15 Mal so lang als breit . . . . . 5

5. Zellen fein längsgestreift, meist drei Querlinien

3. Cl. juncidum

$5^{*}$. Zellen glatt . . . . . . . . 4. Cl. gracile

$2^{*}$. Zellen allmählich von der Mitte nach den Enden zugespitzt, Rücken konvex, Bauchseite fast gerade; Zygospore glatt und rund . . . . . . . . . . . . . . . . 6

6. Zellenden plötzlich in eine verlängerte Spitze ausgezogen . . . . . . . . 5. Cl. attenuatum

6*. Zellenden einfach abgerundet. . . . . . . . 7

7. Zellhaut gestreift . . . . . . . . . . . 8

8. Zellenden nach dem Rücken zu wenig umgebogen

6. Cl. turgidum

8*. Zellenden gerade gerichtet (vgl. auch Nr. Io)

7. $\mathrm{Cl}$. acerosum

$7^{*}$. Zellhaut glatt, Enden kugelig abgerundet .

8. Cl. hinula

$1^{*}$. Zellen stärker gebogen, oft bis sichelförmig . . . . . . 9

9. Die Zellenden ohne lang ausgezogene, hyaline Enden Io 10. Rücken- und Bauchseite in derselben Richtung gekrümmt, Zygosporen rund oder eckig . . . . . I I

Ir. Zellen wenig gekrümmt . . . . . . . . . I 2

12. Grosse Formen, über $30 \mu$ breit . . . . . . I3

13. Zellen mit deutlichen (5-6) Längsrippen auf jeder Seite . . . . . . 9. Cl. costatum

I3*. Zellen mit zahlreichen feinen Längsstreifen

10. Cl. striolatum 
1 $2^{*}$. Kleine Formen, bis i $5 \mu$ breit . . . . . . I 4

14. Enden allmählich zugespitzt, über $9 \mu$ breit . I I. Cl. acutum

$14^{*}$. Enden mehr oder weniger stumpf, bis $6 \mu$ breit 12. $\mathrm{Cl}$. cormu

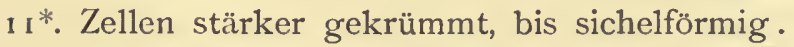
15

15. Zellen nach den Enden zu wenig verdünnt, etwa 14 "breit . . . . . . 13. Cl. jenneri

15*. Zellen nach den Enden zu deutlich verschmälert i6

I6. Endbläschen deutlich begrenzt, halbkreisförmig gekrümmt . . . . . I4. $\mathrm{Cl}$. venus

16*. Endbläschen undeutlich begrenzt, weniger stark gekrümmt . . . . . . . . . . . . . I7

${ }_{7}$. Zellhaut glatt und farblos, $12 \mu$ breit . . . 15. Cl. parvulum

17*. Zellhaut mit feinen Längsstreifen, über I6 $\mu$ breit . . . . . . I6. Cl. dianae

10*. Rückenseite konvex, Bauchseite mit einer Verdickung in der Mitte; Enden allmählich verdünnt, Zygosporen glatt . . . . . . . . . . . . . . . . 18

18. 5-6 Mal so lang als breit, schwach gekrümmt I9 19. Rücken sehr konvex, Mitte breit angeschwollen, Enden abgerundet . . . s7. Cl. ehrenbergi

19*. Rücken weniger konvex, Form schlanker; Enden weniger abgerundet . . I8. $\mathrm{Cl}$. moniliferum

18*. 6-8 Mal so lang als breit, stark gekrümmt; Enden ziemlich spitz . . . . . 19. Cl. leibleini

9*. Die Enden sind lang ausgezogen und hyalin . . . 20

20. Die Zellen sind leicht gekrümmt . . . . . . . . .

20. $\mathrm{Cl}$. rostratum

20*. Die Zellen, in der Mitte wenigstens, gerade . . . 21

21. Die hyalinen Enden halb so lang als die Zellhälften

2 I. Cl. kuetzingi

$2 I^{*}$. Die hyalinen Enden machen $2 / 3-3 / 4$ der Zellhälften aus

22. Cl. setaceum

I. Cl. obtusum Bréb.

Zellen fast gerade, mit stumpfen Enden. Eine Reihe Pyrenoide. Glatte und farblose Zellhaut. Zellen 5- I I $\mu$ dick und $50-150 \mu$ lang. Häufig. 
2. $\mathrm{Cl}$. didymotocum Corda

6-- ro Mal so lang als breit. Enden meist scharf abgestutzt mit deutlichen Endbläschen. Membran, besonders an den Enden, rötlich. In der Mitte deutliche Querlinie, meist auch noch zwei seitliche. Seltener.

3. Cl. juncidum Ralfs

Sehr langgestreckt-cylindrisch, 15-35 Mal so lang als breit, fast gerade, nur die Enden wenig gekrümmt, mit stumpfen Enden. Zellmembran fast farblos. Dicke $52-14 \mu$, Länge $220-400 \mu$. Nicht selten.

4. Cl. gracilc Bréb.

Sehr zarte Zellen, die 25-30 Mal so lang als breit sind, fast gerade wie bei voriger Art. Das schmale Chlorophyllband oft im Zickzack, wie spiralig erscheinend. Dicke 5-8 $\mu$, Länge 150-350 $\mu$. Runde Zygospore 22-30 $\mu$ dick. Hier und da.

5. Cl. attemuatum Ehrbg.

12-I5 Mal so lang als breit, nach den Enden wenig verdünnt bis auf die dünn ausgezogenen Spitzen. Mit deutlichen Längsstreifen, $34-42 \mu$ dick. Vorkommen wie bei voriger Art.

6. Cl. turgidum Ehrbg.

8-12 Mal so lang als breit. Wenig verdünnt gegen die Enden. Membran mit deutlichen Längsstreifen und scharfer mittlerer Querlinie. Dicke $64-80 \mu$, Länge $620-700 \mu$. Nicht häufig.

7. Cl. acerosum Ehrb.

Die linealich-lanzettlichen Zellen 6-15 Mal so lang als breit, Rücken wenig konvex, Bauch fast gerade. Enden konisch, Membran farblos, sehr fein gestreift und mit deutlicher Querlinie. Dicke $17-60 \mu$, Länge $50-420 \mu$. Ziemlich häufig.

8. Cl. hinula Ehrbg.

Die halbmondförmigen Zellen 5-6 Mal so lang als breit, Rücken stark konvex, Bauchseite fast gerade. Chromatophor mit vielen Pyrenoiden. Membran farblos, ohne Längsstreifen und ohne Mittellinie. Dicke 70-1 г $\mu$, Länge 400-550 $\mu$. Verbreitet.

9. $\mathrm{Cl}$. costatum Corda

Zellen gegen die abgerundeten Enden zugespitzt, 5-8 Mal so lang als breit, Membran gelbrot. Deutliche Querlinic, Zygo- 
spore $100-120 \mu$ dick. Zelle $63-75 \mu$ dick und $320-350 \mu$ lang.

Häufig.

10. Cl. striolatum Ehrbg.

Wenig gekrümmte, in der Mitte gewöhnlich ein wenig eingezogene Zellen, 6- Io Mal so lang als breit. Zahlreiche deutliche Längsstriche und gewöhnlich drei mittlere Querstreifen. [Die var. clongatum (Rabh.) ist ${ }_{1} 2-16 \mathrm{Mal}$ so lang als breit und hat stärkere Streifen]. Dicke $38-40 \mu$, Iänge $300-380 \mu$. Verbreitet.

I I. Cl. acutum Bréb.

Die leicht gekrümmten Zellen 6-2o Mal so lang als breit, schmal lanzettlich; mit feiner, abgestumpfter Spitze. Membran farblos und glatt. Zygospore viereckig, im Querschnitt elliptisch. Dicke 9-1 $2 \mu$, Länge I 10-140 $\mu$. Verbreitet.

I 2. Cl. cormu Ehrbg.

Zellen leicht gekrümmt und schlanker als bei voriger Art, 20-30 Mal so.lang als dick; Enden lang ausgezogen und abgestuzt. Farblose, nicht gestreifte Membran. Etiva $6 \mu$ dick. Verbreitet.

\section{I3. Cl. jonneri Ralfs}

Ziemlich stark gekrümmte, etwas plumpe Form. Entfernung der Zellenden von einander 6-7 Mal so gross als die Zellbreite. Gegen die Enden wenig verschmälert, Enden breit abgerundet, mit grossen Endbläschen. Membran nicht gestreift. Dicke $14 \mu$, Länge $90 \mu$. Häufig.

I4. ${ }^{\circ}$ l. venus $\mathrm{Kg}$.

8-12 Mal so lang als breit, allmählich in feine Spitzen verdünnt; Zellhaut farblos und glatt. Verwaschene Chlorophyllbänder. Dicke 8-10 $\mu$. Nicht selten.

15. Cl. parvulum Naeg.

Aehnlich der vorigen Art, doch mit deutlichen ChlorophyllBändern. Enden zugespitzt. Endbläschen gegen das Ende nicht begrenzt. Meist mit $2-4$ Pyrenoiden. Dicke $7-16 \mu, 7-8$ Mal so lang. Ueberall, nicht selten.

16. $\mathrm{Cl}$. dianae Ehrbg.

Die mondsichelförmigen Zellen 6-8 Mal so lang als breit, ziemlich spitz. Membran gelblich, gestreift (?) und mit Querbinde. Zygospore glatt, $60 \mu$ dick. Dicke $16-25 \mu$, Länge I $70-300 \mu$. Sehr häufig. 
17. Cl. ehrenbergi Menegh.

Zellen etwa 5-6 Mal so lang als breit, mit zahlreichen Pyrenoiden. Membran farblos und glatt, ohne Mittellinie. Zygospore wie bei voriger Art. Dicke 57-110, Länge 320-350 $\mu$. Verbreitet.

18. Cl. moniliferum Ehrbg. (Taf. VI, 13)

Schlanker und kleiner als vorige Art, 5-6 (-9) Mal so lang als breit, Zellhaut farblos, glatt oder gestreift (?). Dicke $45-70 \mu$, Länge $320-480 \mu$. Ueberall, sehr häufig.

19. Cl. leibleini $\mathrm{Kg}$.

Kleinere, stark gekrümmte, gegen die Enden verdünnte Form mit deutlicher Querlinie. Enden etwas spitz. Die glatte Membran kaum gelblich. Dicke $40-60 \mu$, Länge bis $360 \mu$. Sehr verbreitete Form.

20. Cl. rostratum Ehrbg.

Zellen Io-15 Mal so lang als breit, wenig gekrümmt, Seiten fast parallel. Membran gelb oder bräunlich, gestreift. Querlinie vorhanden. Zygospore kreuzförmig. Dicke 10-32. Dicke der Enden $5 \mu$, Iänge $210-500 \mu$. Sehr häufig.

21. Cl. kuetzingi Bréb. (Taf. VI, I4)

Wie die folgende Art in der Mitte gerade, nur die feinen, $2 \mu$ dicken Enden gebogen. Dicke $17 \mu, 30$ Mal so lang. Seltener als vorige Art.

22. Cl. setaceum Ehrbg.

20-25 Mal so lang als breit. Membran farblos, fein gestreift. Zygospore wie bei voriger Art. Dicke 10-18 8 (am Ende $2 \mu$ ), Länge $210-360 \mu$.

\section{Penium (Bréb.) De By.}

Zellen gerade und cylindrisch mit abgerundeten Enden, in der Mitte kaum eingeschnürt; Scheitelansicht rund oder oval. Das Chromatophor besteht aus strahlenförmig divergierenden Chlorophyllplatten, die am Rande gelappt sein können. Zygospore rund oder viereckig.

I. Zellmembran mit feinen Knötchen besetzt . . . . . . 2

2. Zellen über $100 \mu$ lang . . . . I. P. margaritaceum

2*. Zellen höchstens $60 \mu$ lang . . . 2. P. cylindrus

I*. Zellmembran glatt . 
3. Zellen höchstens $80 \mu$ lang . . 3. P. navicula

$3^{*}$. Zellen über $250 \mu$ lang

4. Zellen mit deutlicher Endvakuole und meist drei Querbinden . . . . 4. P. interruptum

4*. Zellen nicht so gebaut . . 5. P. digitus

I. P. margaritaceum (Ehrbg.) Bréb.

6-1o Mal so lang als breit. Wenig. verschmälert, in der Mitte kaum eingeschnürt, Enden fast abgestutzt, oft mit Vakuole. Membran bräunlich.' Dicke 22-28 $\mu$, Länge I $5-225 \mu$. Verbreitet.

2. P. cylindrus Bréb.

Membran rotgelb, 3-4 Mal so lang als breit, in der Mitte nicht verschmälert. Dicke $13-25 \mu$, Länge $50-57 \mu$. Nicht selten.

3. P. navicula Bréb.

Breit spindelförmig, $3-5$ Mal so lang als breit, an der Spitze abgestumpft. Chlorophyllplatten in der Mitte unterbrochen, mit I-2 Pyrenoiden. Mit Endvakuolen; Zygosporen fast quadratisch, mit spitzen Ecken. Dicke $12--17 \mu$, Breite $43-72 \mu$. Verbreitet.

4. P. interruptum Bréb. (Taf. VI, 15)

Zellen 3-4 Mal so lang als breit, an den Enden plötzlich keilförmig verschmälert. Spitzen abgerundet, mit Endvakuole; Zellen im Alter mit drei Querbinden. Dicke $35-60 \mu$, Länge $280-320 \mu$. Nicht selten.

5. P. digitus (Ehrbg.) Bréb.

Zellen elliptisch oder oblong, 3-5 Mal so lang als breit. Nit einer hellen Querbinde. Enden breit zugerundet. Dicke $60-100 \mu$, Länge $300-400 \mu$. Ziemlich häufig.

\section{Cylindrocystis (Menegh). De By.}

Voriger Gattung ähnlich, doch mit axilem, nach allen Richtungen ausstrahlendem Chromatophor; Zygospore viereckig. Vor ihrer Keimung werden erst $2-8$ Tochterindividuen in der Hülle gebildet.

C. brebissoni Menegh. (Taf. VI, 16)

Zèllen cylindrisch, $2 \frac{1}{2}-4 \frac{1}{2}$ Mal so lang als breit, an den Enden kaum verschmälert, plötzlich breit abgerundet. Membran glatt, Zygospore granuliert. Dicke $\mathrm{i} 5-\mathrm{i} 7 \mu$, Länge $36-56 \mu$ [var. turgida: Dicke $24-25 \mu$, Länge $30-47 \mu]$. In Torfstichen etc., sehr häufig. 


\section{Tetmemorus Ralfs.}

Zellen cylindrisch oder spindelförmig, mit mittlerer Einschnürung und tiefem, schmalem Endeinschnitte; sonst ganzrandig. Membran meist mit hervortretenden Körnern. Chromatophor axil, mit Pyrenoiden. Zygospore glatt, rund oder linsenförmig.

1. Zellmembran mit Punkten besetzt oder granuliert . . . 2

2. Zellen von vorn gesehen cylindrisch 1. T.brebissoni

$2^{*}$. Zellen von vorn und von der Seite spindelförmig.

I*. Zellmembran ganz glatt . . . . 3 T. laevis

I. T. brebissoni Ralfs '(Taf. VI, 17)

An den Enden der von der Seite spindelförmigen, mit Punktreihen besetzten Zellen befindet sich kein hyaliner Fleck, 5-6 Mal so lang als breit. Dicke $17-30 \mu$, Länge etwa $190 \mu$. Ziemlich häufig.

2. T. granulatus (Bréb.) Ralfs

Die granulierten Zellen mit farblosem, lippenförmigem Fortsatze an den Enden. Dicke $38-56 \mu$, Länge etwa $120 \mu$. Nicht selten.

3. T. laevis Ralfs

Zellenden wenig verdickt, Zellen von der Seite spindelförmig. Membran so gut wie glatt. Dicke $20-25 \mu$. Häufig.

\section{Pleurotaenium (Naeg.) Lund.}

Zellen gerade, cylindrisch, gegen die stumpf abgeschnittenen Enden hin etwas verschmälert, mit grossen Endvakuolen. Scheitelansicht rund. Mit wellenförmigen Anschwellungen jederseits der Mitteleinschnürung. Chromatophor: wandständige Bänder mit Pyrenoiden.

I. Zellhaut glatt . . . . . . . . 1. P. trabecula

I*. Zellhaut deutlich granuliert . . . . 2. nodulosum

1. Pl. trabccula (Ehrbg.) Naeg. (Taf. VI, i 8)

Zellen lang cylindrisch, 8-20 Mal so lang als breit. Zellhälften nach den Enden allmählich verdünnt oder etwas verdickt, brcit abgestutzt. Kugelige Zygospore mit Schleimhülle. Dicke $25-35 \mu$, Länge $180-450 \mu$. Nicht selten. 
2. Pl. nodulosum De By.

Wie vorige Art, doch plumper. Mitteleinschnürung von brauner Leiste umgeben; jede Zellhälfte mehrmals wellig eingeschnürt. Dicke $40-60 \mu$. Seltener als vorige Art.

\section{Docidium (Bréb.) Lund.}

Zellen gerade, meist cylindrisch, höchstens etwas verschmälert. Meist ohne Vakuolen. Jederseits der Mitteleinschnürung Querrippen, die meist längs gerillt sind. Axiales Chromatophor strahlig divergierend.

I. Zellwände ganz gerade, nicht gewellt . I. D. baculum I*. Zellwände gewellt . . . . . . . 2. D. dilatatum

I. D. baculum (Bréb.) (Taf. VI, 19)

Zellhälften nur an der Basis mit einer Erhöhung, wenig verdünnt, breit abgestutzt; 10-2o Mal so lang als breit. Membran glatt. Dicke $14-22 \mu$, Länge $45-60 \mu$. Nicht selten.

2. D. dilatatum (Cleve) Lund.

Wie vorige Art, doch mit gewellten Einschnürungen. Ende flach abgestutzt. Dicke ${ }_{15}-18,8 \mu$. Selten.

\section{Holacanthum (Lund.) Wille.}

Zellen gerade, mehr oder weniger rund, auch eckig, mit tiefem Einschnitt in der Mitte und zwei Reihen langer, unverzweigter Stacheln an den Enden. Scheitelansicht oval. Parietales Chromatophor: in jeder Halbzelle vier plattenförmige, mit je einem Pyrenoid versehene Teile. Zygospore rund, mit langen Stacheln.

I. Jede Zellhälfte hat in der Mitte der Breitseite eine kurze, cylindrische Ausbuchtung . . . . . I. H. aculeatum

I*. Die Zellen ohne solche Ausbuchtung, höchstens mit einer kleinen Anschwellung . . . . . . . . . . . . . . 2

2. Die Stacheln stehen immer paarweise bei einander . .

2. H. fasciculatuin

2*. Die der Mitteleinschnürung nächsten Stacheln einzeln, die andern paarweise. . . . . 3. H. cristatum

I. H. aculeatum (Ehrbg.) Lund.

Zellen etwa so lang wie breit, Zellhälften oblong bis nierenförmig. Membran granuliert mit vielen (meist $2 \times 18$ ) Stacheln 
besetzt. Vier Chlorophyll-Lamellen. Zellen (ohne Stacheln) 63-7 I $\mu$ dick; Zygospore 66-70 $\mu$ dick mit $33 \mu$ langen Stacheln. Nicht häufig.

2. H. fasciculatum (Ehrbg.) Lund.

Zellhälften nierenförmig. Zellhaut glatt, am Rande mit $6 \times 2$ Stacheln, Zelle 55-77 $\mu$ lang, 55-65 $\mu$ breit. Etwas häufiger als vorige Art.

3. H. cristatum (Bréb.) Lund. (Taf. VI, 20)

Zellhälften nierenförmig bis trapezoidisch, mit geraden oder gebogenen Stacheln. Zellhaut glatt oder fein granuliert. Zelle etwa $57 \mu$ lang, $50-55 \mu$ breit. Zygospore $50 \mu$ dick mit $16 \mu$ langen Stacheln.

\section{Schizacanthum (Lund.) Wille.}

Voriger Gattung ähnlich, aber verschieden durch die drei- bis vierspaltigen Stacheln, die grössere Anzahl der Pyrenoide in jedem Chromatophor und die Ausbildung der Zygosporen, die stachellos sind, aber Grübchen besitzen.

Sch. armatum (Bréb.) Lund. (Taf. VI, 21)

Von der Seite gesehen, etwa zwei Mal so lang als breit, mit zwei Reihen kurzer, dicker, gespaltener Stacheln. Membran granuliert. Zygosporen $100-140 \mu$ dick, Zellen 90-I $10 \mu$ breit, und $180-200 \mu$ lang. Nicht häufig.

\section{Pleurotaeniopsis Lund.}

Die Cosmarium-ähnlichen Zellen haben wandständige Chromatophoren und mehrere Pyrenoide. Mitteleinschnürung oft ganz unbedeutend. [Vgl. auch unter Cosmarium (S. 160)].

I. Zellen wenig, wenn auch deutlich, in der Mitte eingeschnürt 2

2. Chlorophyll-Längsbinden nicht gezackt

\section{r. Pl. turgidus}

2*. Chlorophyll-Längsbinden gezackt . 2. Pl. cosmarioides

$1^{*}$. Zellen durch eine tiefe Mitteleinschnürung in zwei Hälften geteilt . . . . . . . . . . . . . . . . . . 3

3. Zellumriss dick-cylindrisch mit abgerundeten Ecken.

3. Pl. cucumis

$3^{*}$. Zellumriss oblong, fast rund; die Zellhälften also von der Mitte an halbkreisförmig verschmälert . . . . . . . 
1. Pl. turgzdus (Bréb.) Lund.

Zellen 21:' Mal so lang als breit, Mitteleinschnürung stumpf, an den etwas verschmälerten Enden plötzlich breit abgerundet. Dicke etwa $100 \mu$. Nicht häufig.

2. Pl. cosmarioides (De By.)

Zellen fast cylindrisch, zwei Mal so lang als breit, mit scharf abgestutzten Enden. Zellhaut glatt oder punktiert. Breite 50 bis $56 \mu$, Länge $80-112 \mu$. Wie vorige Art.

3. Pl. cucumis (Corda) Lund. (Taf. VI, 22)

Aehnelt der vorigen Art, $\mathrm{I}^{1 / 3}-2$ Mal so lang als breit; Zellhälfte etwa so breit wie lang, mit breit abgerundeten Enden. Membran glatt. Durchmesser $36-56 \mu$, Länge $36-70 \mu$. Häufig.

4. Pl. ralfsi (Bréb.)

Zellen etwa $80 \mu$ lang, etwas schmäler. Nicht häufig.

\section{Arthrodesmus Ehrbg.}

Zellen Cosmarium-ähnlich in der Form, in der Gestalt des Chromatophors und der Zygospore, doch mit vier oder acht Stacheln bei sonst glatter Membran. Scheitelansicht oval.

1. Zellen mit insgesamt vier Stacheln . . . . . . . . . 2

2. Stacheln der Mitteleinschnürung zu gerichtet . . . .

I. A. convergens

2*. Stacheln nach aussen gerichtet . 2. A. incus I*. Zellen mit insgesamt acht Stacheln . . 3. A. octocornus

1. A. convergens (Bréb.) Ehrbg. (Taf. VI, 2j)

Zellen so lang als breit, Zellhälften elliptisch. Chromatophor mit kleinem Pyrenoide und grossem Stärkemantel. Zellhaut und Zygospore glatt. Zellen (44 $\mu$ dick), 33-93 $\mu$ lang, Verbindungsstück $44 \mu$ breit. Häufig.

2. A. incus Hass. (Taf. VI, 24)

Zellhälften viereckig, innere Ecken abgerundet, äussere mit je einem Stachel. Zygospore stachelig, $(22 \mu$ dick). Zellen $22 \mu$ lang; Isthmus $9 \mu$ breit. Nicht selten.

3. A. octocornis Ehrbg.

Mitteleinschnürung dreieckig, breit; Zellhälften trapezoidisch, jede freie Ecke mit Stachel. Zygospore stachelig. Breite $16 \mu$, Isthmus $5 \mu$ dick. Hier und da. 


\section{Oocardium Naeg.}

Die Zellen sitzen in Kalkröhren und sind durch diese Lebensweise etwas unsymmetrisch geworden. Chromatophor axil, mit radiären Platten; jede Hälfte mit einem Pyrenoid. Der Kern ist nach der schmalen Seite zu gerückt.

O. stratum Naeg. (Taf. VI, 25)

Bildet grünliche Krusten von kohlensaurem Kalke an von Wasser überrieselten Felsen. Die einzelnen Zellen, die etwa 22-24 $\mu$ lang und 19-20 (bezgl. 17) $\mu$ breit sind, sitzen im Eingange von selbstgebildeten Kalkröhren. Durch ins Innere der Röhren abgeschiedene Gallerte heben sich die Zellen zugleich mit dem Wachstume. Selten.

\section{Cosmarium (Corda) Lund.}

7ellen meist einzeln, oval oder rund; Scheitelansicht rund oder elliptisch. In der Mitte mehr oder weniger tief eingeschnürt, ganzrandig, gezahnt oder wellig. Membran glatt oder warzig oder mit Grübchen. Chromatophor: vier oder mehr vereinigte Platten mit je $1--2$ meist konstanten Pyrenoiden in jeder Hälfte. Zygospore meist rund und glatt oder stachelig. Mit sehr zahlreichen Arten. [Vgl. auch Pleurotaeniopsis (S. 158)].

I. Mittlere Einschnürung nicht tief, Isthmus viel breiter als die Hälfte der Zelle in ihrer grössten Breite . . . . . 2

2. Zellhälften fast kugelig, mit abgeflachter Basis, Zelle ${ }_{1} 1 / 2-2$ Mal so lang als breit . . . . I. C. connatum

$2^{*}$. Zellhälften oblong bis cylindrisch, $2-3$ Mal so lang als breit . . . . . . . . . . . . . 3

3. Zelle drei Mal so lang als breit . 2. C. palangula

$3^{*}$. Zelle zwei Mal so lang als breit. . 3. C. cucurbita I*. Mittlere Einschnürung sehr tief. . . . . . . . . . . 4

4. Scheitelansicht einfach rundlich, oval, ohne bauchig vortretende Mitte . . . . . . . . . . . . . 5

5. Zellhaut glatt oder punktiert, nicht mit Warzen besetzt . . . . . . . . . . . . . 6

6. Zellhälfte deutlich trapezförmig . . . . . . . 7 7. Zellen bis $30 \mu$ lang und $21 \mu$ breit

4. C. granatum $7^{*}$. Zellen über $50 \mu$ lang und über $60 \mu$ breit 
6*. Zellhälften nicht trapezförmig . . . . . . . . . 8

8. Zellhälften mehr oder weniger deutlich quadratisch, mit abgerundeten Ecken . . 6. C. quadratum

8*. Zellhälften im Umrisse halbkreisförmig, selten viereckig . . . . . . . . . . . . . . . . . 9

9. Mitteleinschnürung schmal linealisch. . . . . Io 10. Zellen mit gleichmässig gekerbtem Rande, in jeder Zellhälfte mit einem Pyrenoid.

\section{C. crenatum}

10*. Zellen nicht gekerbt, Rand nur gewellt oder glatt . . . . . . . . . . . . . . . II

I I. Zellhälfte mit zwei Pyrenoiden; Rand gewellt

8. C. undulatum

11*. Zellhälfte mit einem Pyrenoid, Scheitel flach oder abgeștutzt. . . 9. C. meneghinii

9*. Mitteleinschnürung wird nach aussen breiter, Zellhälften länglich oval . . 10. C. bioculatum

5*. Zellhaut mit Wärzchen besetzt . . . . . . 12

12. Zellhälften nierenförmig oder oval. . . . . . . . 11. C.margaritiferum

I2*. Zellhälften schwach trapezförmig

12. C. botrytis

4*. Scheitelansicht länglich, mit beiderseits bauchig hervorstehender Mitte, also etwa kreuzförmig . . . . . . I3

13. Zellhaut punktiert . . . . 13. C. phascolus

I $3^{*}$. Zellhaut mit Wärzchen besetzt . . . . . . . I4

14. Zellhälfte deutlich viereckig . I4. C. broomei

I 4 * Zellhälften nach der Mitte zu stark konvex ausgebaucht, nach aussen mit gerader Linie abschliessend.

I5. C. ornatum

1. C. connatum Bréb.

Zellen kurz und dick cylindrisch, Enden rund. Membran granuliert. Breite $45-75 \mu$; Länge $70-102 \mu$; Isthmus $35-50 \mu$ breit. Nicht selten.

2. C. palangula Bréb.

Zellen cylindrisch, an den Enden abgestutzt oder breit gerundet. Membran mit Punktreihen. Breite 12-15 4 . Nicht häufig.

3. C. cucurbita Bréb.

Zellen oblong, mit abgerundeten Enden; Membran punktiert. Breite $22-25 \mu$. Häufig. 
4. C. granatum Bréb.

Zellen wenig länger als breit; Zellhälften mit gerader Basis, abgerundeten unteren und spitzeren oberen Ecken und je einem Pyrenoid. Nicht selten.

\section{C. pyramidatum Bréb.}

Zellen etwa zwei Mal so lang als breit. Zellhälften pyramidenförmig, mit breit abgestutztem Scheitel und je zwei Pyrenoiden. Scheitelansicht breit elliptisch. Membran punktiert. Hier und da, häufig.

\section{C. quadratum Ralfs}

Zellen zwei Mal so lang als breit. Seiten der Zellhälften etwas konkav, diese mit je zwei Pyrenoiden. Membran glatt. Länge 44-49 $\mu$, Breite $25 \mu$ (die var. majus Lund. mit konvexen Seiten ist $60-64 \mu$ lang, $32-34 \mu$ breit). Häufig.

7. C. crenatum Ralfs

Zellen bis $\mathrm{I}^{1 / 2}$ Mal so lang als breit, Enden zugerundet; jede Zellhälfte mit i I - I4 Einkerbungen und einem Pyrenoid. Zellhaut fein punktiert. Länge $53-58 \mu$, Breite $38 \mu$. Nicht selten.

8. C. undulatum Corda

Zellen $11 / 2-2$ Mal so lang als breit, Mitteleinschnürung nach aussen erweitert. Membran am Rande punktiert. Zygospore wie bei der vorigen Art, mit zwei bis drei spitzigen Protuberanzen besetzt. Länge $54-60 \mu$, Breite $39-44 \mu$. Häufig.

9. C. meneghinii Bréb.

Zellen $1-\mathrm{I}^{1 / 2}$ Mal so lang als breit, Zellhälften oft fast viereckig, meist an den Seiten unduliert. Zygospore kugelig, mit kegelförmigen Erhebungen. Variiert sehr. Ueberall, häufig.

Iо. C. bioculatum Bréb.

Zellhälfte mit einem Pyrenoid. Zellhaut glatt oder fein punktiert. Zygospore wie bei voriger Art. Länge 12-36 , Breite $10-28 \mu$. Nicht selten.

\section{C. margaritiferum Menegh.}

Zellen so lang oder länger als breit. Zellhälften mit konvexen Seiten und breit abgerundetem Scheitel. Membran mit runden Wärzchen besetzt. Scheitelansicht oval. Zygospore mit gabeligen Spitzen. Länge $25-70 \mu$, Breite $25-60 \mu$; Isthmus 10-22 $\mu$ breit. Ueberall, häufig. 
12. C. botrytis Menegh. (Taf. VI, 26)

Zellen etwas länger als breit; Zellhälften nach aussen verschmälert, mit flach abgestutztem Scheitel. Membran warzig. Zygospore ähnlich wie bei voriger Art. Länge 22-30 (-70) $\mu$, Breite $20-30\left(-5^{8}\right) \mu$. Verbreitet.

13. C. phaseohis Bréb.

Zellen etwa so lang wie breit; Zellhälften etwa nierenförmig, Scheitel flach abgerundet. Membran granuliert. Länge $28-32 \mu$, Breite $24-36 \mu$; Isthmus $7 \mu$ breit. Hier und da.

14. C. broomei Thwaites

Zellen im Umfange fast quadratisch, Zellhälften mit stark abgerundeten, äusseren Ecken und kaum konvexen Seiten. Zygospore glatt. Länge $50-57 \mu$, Breite $30-50 \mu$. Nicht selten.

15. C. ornatum Ralfs (Taf. VI, 27)

Zellhälften nierenförmig; mit mittlerer, breiter, mit scharfen Ecken versehener Erhebung und je zwei Pyrenoiden. Die Ränder und die Erhebung mit Wärzchen besetzt. Zygospore mit vielen Ecken und langen Stacheln. Nicht häufig.

\section{Cosmocladium Bréb.}

Zellen Cosmarium-ähnlich, doch sind die Zellen durch je zwei Schleimfäden zu verzweigten Familien vereinigt. Freischwimmend oder festgeheftet.

I. Zellen festgeheftet, Familie in einer Ebene ausgebreitet . .

\section{C. pulchellum}

I*. Zellen im Schleime freischwimmend, nach zwei oder drei Richtungen verzweigt . . . . . 2. C. saxonicum

I. C. pulchellum Bréb.

Meist festgeheftet. Zellen nierenförmig, doppelt so lang als breit. Dicke $12,5 \mu$. In Teichen und Sümpfen, nicht häufig.

2. C. saxonicum De By. (Taf. VI, 28)

Zellen elliptisch-nierenförmig, hellgelb. Seltener.

\section{Euastrum (Ehrbg.) Ralfs.}

Zellen mehr oder weniger elliptisch, mit tiefer Einschnürung in der Mitte und eingebuchteten oder gespaltenen Enden. Am 
Rande symmetrisch gebuchtet oder gelappt. Scheitelansicht oval, mit seitlichen Buckeln. Membran mit Warzen. Axiles Chromatophor, mit radiären Platten und einem bis zwei Pyrenoiden in jeder Hälfte. Runde Zygospore mit Warzen oder Stacheln.

I. Der der Mitteleinschnürung parallele Aussenrand flach oder ausgerandet, nicht tief eingeschnitten . . . . . . . 2

2. Zelle bis $29 \mu \mathrm{lang}$, Seitenwände mit meist nur einer Einbuchtung . . . . . . . . . . . 1. Eu. binale

$2^{*}$. Zellen über $50 \mu$ lang, Seitenwände mit zwei Einbuchtungen . . . . . . . . . . . . . . . . . 3

3. Die der verbreiterten Mitteleinschnürung nächste Einbuchtung ist die breitere . . . 2. Eu. verrucosum

3*. Die äussere Einbuchtung ist die breiterc; Mitteleinschnürung linienförmig . . . . 3. Eu. pectinatum

I*. Die äusseren Enden durch einen schmalen Einschnitt geteilt . . . . . . . . . . . . . . . . . 4

4. Einschnitt nur ganz flach, Zellen fast quadratisch (1. Eu. binale)

4*. Einschnitt bedeutend tiefer, Zellhälften nach aussen mehr verschmälert . . . . . . . . . . . . . 5

5. Zellhälften durch zwei tiefe Einschnitte stark zerteilt, so dass $2 \times 2$ Seitenlappen und ein Endlappen enstehen 4. Eu. oblongum

$5^{*}$. Zellhälften an den Seiten nur mit seichten Ausbuchtungen . . . . . . . . . . . . . . . . . 6

6. Zellhälften mit je einer seichten Einbuchtung, und einem grossen Endlappen . . 5. Eu. ansatum

6*. Zellhälften mit je zwei Einbuchtungen . . . . . 7

7. Zellhälften nach aussen wenig verdünnt, ohne deutliche Endlappen . . . . 6. Eu. elegans

$7^{*}$. Zellhälften nach aussen stark verdünnt, mit deutlichen Endlappen . . . . . . 7. Eu. didelta

I. Eu. binale Ralfs

Kleine Form. Scheitel gerade abgestutzt, mit zugespitzten Ecken. Sehr veränderlich. Häufig, in Gräben und Teichen.

2. Eu. verrucosum Ehrbg.

Jede Zellhälfte mit zwei Seiten- und einem Endlappen, die aber ihrerseits wieder stark ausgebuchtet sind, sodass sie im 
ganzen sechs Lappen mit drei grossen, basalen Anschwellungen zeigt. Membran mit Warzen. Länge 75-100 $\mu$, Breite ebenso. Nicht selten.

3. Eu. pectinatum Bréb.

Zellen I $1 \frac{1}{2}-2 \mathrm{Mal}$ so lang als breit. Basis der Zellhälften gerade. Seitenlappen mit fast senkrechtem Rande aufsteigend, da die erste Einbuchtung klein ist. Scheitel fast gerade. Jede Zellhälfte mit drei Ausbuchtungen. Membran glatt oder punktiert Länge $58-78 \mu$, Breite $44-48 \mu$. Häufig.

4. Eu. oblongum Ralfs

Zellen im Umrisse oblong, $2-2 \frac{1}{2}$ Mal so lang als breit. Zellhälften mit gerader Basis. Endlappen verbreitert sich nach aussen bis auf das Doppelte. An der Basis und in jedem Lappen eine Anschwellung. Membran glatt oder granuliert. Länge etwa I $40-165 \mu$, Breite $70-86 \mu$; Isthmus $21-26 \mu$ breit. Ziemlich häufig.

5. Eu. ansatum (Ehrbg.) Ralfs

Zellen zwei Mal so lang als breit; die an der Basis meist stark konvexen Zellhälften in einen breiten Endlappen ausgezogen und mit je einer Ausbuchtung in der Mitte. Länge 75-88 $\mu$, Breite $37-4 \mathrm{I} \mu$. Hier und da, häufig.

6. Eu. elegans (Bréb.) Kg.

Etwa zwei Mal so lang als breit. Innere Ecken ziemlich spitz, Scheitel abgestutzt. Zellen mit schmalem Einschnitte. Eine Mittelausbuchtung. Membran punktiert. Sehr variabel. Verbreitet.

7. Eur. didelta Ralfs (Taf. VI, 29)

Zellen etwa zwei Mal so lang als breit. In jeder Zellhälfte im ganzen 11 Verdickungen. Membran punktiert. Länge 45 bis $140 \mu$, Breite $20-70 \mu$. Häufig.

\section{Micrasterias Ag.}

Zellen breit elliptisch oder rund, mit tiefer Mitteleinschnürung; Zellhälften tief dreilappig, Seitenlappen eventuell wieder mẹhr oder weniger tief geteilt, nicht aber der Endlappen. Scheitelansicht schmal elliptisch, mit scharfen Enden. Membran glatt oder warzig, am-Rande mit Zähnen. Chromatophor meist eine axile Platte mit Pyrenoiden. Zygospore kugelig mit vielfach verzweigten Stacheln. 
I. Die drei Lappen der Zellhälften nicht radiär, die zwei nach aussen stark erweiterten Einschnitte parallel der Mitteleinschnürung [Tetrachastrum (Dixon) Hansg.]

$$
\text { I. M. oscitans }
$$

1*. Mit drei (bis fünf) Lappen, die wie die Einschnitte radiär stehen (Eumicrasterias De Wild.) . . . . . . . . . . 2

2. Mittellappen mit zwei divergenten, hornförmigen Fortsätzen . . . . . . . . . 2. M. crux melitensis

2*. Mittellappen ohne solche Fortsätze. . . . . . . . 3

3. Mittellappen von der Basis bis zum Rande stark (bis auf das Doppelte) verbreitert, die kurzen Einschnitte nicht auf die Mitte zu gerichtet 3. M. truncata

$3^{*}$. Mittellappen mehr oder weniger verbreitert, Einschnitte mehr oder weniger auf die Mitte zu gerichtet 4 4. Die beiden Seitenlappen etwa gleich breit . 5 5. Die Mittellappen mit einer deutlichen, halbkugeligen Vertiefung .

4. M. jenneri

$5^{*}$. Mittellappen nur ausgebuchtet

5. M. papillifera

4*. Die inneren Seitenlappen doppelt so gross als die äusseren . . . . 6. M. rotata

1. M. oscitans (Hass.) Ralfs

Ebenso breit wie lang. Die inneren Lappen mit zwei Zähnen an der Spitze. Endlappen breit, mit zwei seitlichen Spitzen und meist stark konvexer Aussenseite. Membran punktirt. Breite etwa $120-160 \mu$. Selten.

2. M. crux melitensis Ralfs (Taf. VI, 30)

Die den Mittellappen begrenzenden Einschnitte tief und und verbreitert. Seitenlappen mehrfach wenig tief geteilt, Enden in zwei kurze Spitzen geteilt. [Bei der verwandten, zierlichen M. furcata Ag. sind die Enden zu langen, hornförmigen, zweispitzigen Fortsätzen ausgezogen]. Länge $107-130 \mu$, Breite $98-$ I $9 \mu$. Hier und da, nicht selten.

3. M. truncata Bréb.

Meist etwas breiter als lang. Einschnitte nicht tief. Endlappen sehr breit, halb so breit wie die ganze Zelle und ganzrandig, wenig konvex oder konkav. Membran glatt. Länge $94-105 \mu$, Breite $50-100 \mu$. Isthmus $18-22 \mu$ breit. Nicht selten. 
4. M. jenneri Ralfs

Zellen meist viel länger als breit. Zellhälften fünflappig Lappen nur wenig gebuchtet. Länge $25 \mathrm{c}-290 \mu$, Breite $108 \mu$. Hin und wieder.

\section{M. papillifera Bréb.}

Zellen im Umrisse fast kreisrund. Mittellappen mit stumpfen Zähnen. Seitenlappen gleichmässig zwei Mal dichotom eingeschnitten, letzte Enden in zwei stumpfe Zähne auslaufend. Membran punktiert, an den Haupteinschnitten mit Papillen besetzt. Zygospore rund, mit zwei bis drei Mal gegabelten Stacheln. Länge I $10-135 \mu$, Breite $100-125 \mu$. Nicht häufig.

\section{M. rotata Ralfs}

Mittellappen an den Ecken mit zwei Zähnen, letzte Segmente zweizahnig. Kugelige Zygosporen (108 $\mu$ dick), mit (25 $\mu$ ) langen, einfachen Stacheln. Länge bis $280 \mu$. Hier und da.

\section{Staurastrum (Meyen) Lund.}

Zellen einzeln oder $\mathrm{zu} 2-4$ verbunden, mit tiefer Mittelcinschnürung. Scheitelansicht drei-, vier- oder vieleckig, oft mit mehreren (zwei bis vielen) auslaufenden Armen. Membran glatt bis warzig oder stachelig. In jeder Zellhälfte ein axiles, aus radialen Platten bestehendes Chromatophor mit je einem Pyrenoid. Zygospore rund, stachelig oder viereckig. Mit zahlreichen Arten (Tabelle in engem Anschlusse an Kirchner).

I. Ecken unterscheiden sich in nichts von den Seiten (Scheitelansicht!), sind also nicht mit Punkten, Stacheln etc. versehen 2

2. Zellhaut glatt. . . . . . . . . . . . . 3

3. Mitteleinschnürung nach aussen wenig verbreitert, Zell-, hälften nach aussen ganz stumpf zugespitzt . . . .

1. St. orbiculare

$3^{*}$. Mitteleinschnürung stark erweitert, Zellhälften oval

2. St. muticum

2*. Zellhaut nicht glatt . . . . . . . . . . . . 4

4. Zellhaut mit Warzen oder Punkten . . . . . . 5

5. Mit runden, aber nicht verlängerten Enden

3. St. punctulatum

5*. Ecken mit Fortsätzen, Seiten konkav (Scheitelansicht!) 6 
6. Zellhälften um $60^{\circ}$ gegen einander um die Längsachse verschoben, so dass die $2 \times 3$ Enden, von der Scheitelseite gesehen, alternieren . . . 4. St. alternans

6*. Zellhälften nicht so verschoben, auf der Scheitclansicht sind nur drei Enden sichtbar . . . . 7

7. Zellhälften mit grünen Fortsätzen, schmal-oblong 5. St. dilatatum

7*. Zellhälften mit farblosen Fortsätzen . . . . . 8 8. Fortsätze mit breitem, rundem Ende. . . . .

6. St. margaritaceum 8*. Fortsätze spitzer, vorn abgestutzt

7. St. hexacerum

4*. Zellhaut mit Stacheln besetzt . . . . . . . . . . 9

9. Stacheln ganz fein und kurz, gleichmässig verteilt .

8. St. hirsutum

9*. Stacheln grob, Enden etwas ausgezógen. . .

9. St. aculcatum

I*. Ecken besonders ausgezeichnet (durch Punkte, Stacheln etc.) Io Io. Ecken mit langen, hornartigen Fortsätzen . . . . I I

II. Von der Schalenseite gesehen mit farblosen, zweistacheligen Protuberanzen auf den konkaven Seiten . 10. St. vestitum

11 *. Die konkaven Seiten ohne solche Dornen . . . 12

I2. Fortsätze mit zwei Stacheln . I I. St. furcigerum I $2 *$ Fortsätze mit mehr $(3-4)$ Stacheln . . . . . I 3

13. Fortsätze kurz und dick - I2. St. polymorphum

$13^{*}$. Fortsätze lang, der Mitteleinschnürung parallel. . 13. St. gracile

IO*. Enden ohne solche Fortsätze . . . . . . . . I4

14. Enden mit einem Stachel . . . . . . . . . 15

15. Isthmus lang und schmal, Zellhälften auseinander gerückt . . . . . . . . . 14. St. cuspidatum

I 5*. Isthmus kurz, Zellen elliptisch, Stachel gerade oder nach innen oder aussen gerichtet 15. St. dejectum

14*. Enden mit mehr als einem. Stachel . . . . . . I6

16. Ende mit drei Stacheln . . . 16. St. furcatum

16*. Enden mit vielen Stacheln . 17. St. teliferum

I. St. orbiculare Ralfs

Plumpe Form. Enden halbkreisförmig zugerundet. Länge $28-32 \mu$, Breite $22-50 \mu$. Häufig. 
2. St. muticum Bréb.

Zygospore mit gabelig geteilten Stacheln. Länge 35-40 $\mu$, Breite $33-40 \mu$. Wie vorige Art.

3. St. punctulatum Bréb.

Mitteleinschnürung nach aussen stark erweitert, Zellhälften stumpf zugespitzt. Scheitelansicht dreieckig, mit konkaven Seiten. Zygospore mit ( $14 \mu$ ) langen, zweigabeligen Stacheln. Länge $45-50 \mu$, Breite $28-45 \mu$. Sehr häufig.

4. St. alternans Bréb.

Zellhälften oblong oder elliptisch, infolge ihres Richtungsunterschiedes gewöhnlich ungleich aussehend. Enden abgerundet. Zygospore mit geteilten Stacheln. Länge und Breite $20-40 \mu$ Häufig.

5. St. dilatatum Ehrbg.

Mitteleinschnürung spitzwinklig. Enden in der Scheitelansicht meist abgestutzt. Länge $20-28 \mu$. Nicht selten.

6. St. margaritaceum (Ehrbg.) Menegh.

Mitteleinschnürung mit ganz stumpfem Winkel. Zellhälften mit stumpfen, abgerundeten Fortsätzen. Breite $33-44 \mu$. Kommt auch an feuchten Felsen vor.

7. St. hexacerum (Ehrbg.) Wittr.

Enden der Zellhälften zuweilen mit drei bis vier kleinen Zähnchen. Wärzchen in Parallelreihen. Zygospore bedornt. Länge $30-40 \mu$, Breite $36-45 \mu$. Hier und da.

8. St. hirsutum Bréb.

Mitteleinschnürung fast linear; Zellhälften fast halbkreisförmig. Länge $46 \mu$, Breite $36-62 \mu$. Sehr häufig.

9. St. aculeatum Menegh.

Gleichmässig mit langen Dornen besetzt, Mitteleinschnürung etwa im rechten Winkel erweitert. Zygospore mit langen, zweispitzigen Stacheln. Breite $34-50 \mu$. Selten.

10. St. vestitum Ralfs

Nur die Protuberanzen mit Warzen besetzt. Zellhälften elliptisch, die inneren Seiten viel stärker konvex. Länge $40-60 \mu$, Breite $62-90 \mu$. Hier und da. 
I I. St. furcigenum Bréb.

Mitteleinschnitt schmal linealisch, Zellhälften länglich, mit zweigabeligem, farblosem Fortsatze; $(2-4)$ ebensolche Fortsätze unter dem Scheitel. Scheitelansicht drei- bis neuneckig; die plötzlich zusammengezogenen Enden in zwei spitzige Fortsätze verlängert. Länge $77-83 \mu$, Breite $90 \mu$. Selten.

1 2. St. polymorphum Bréb.

Zellhälfte elliptisch, oft oblong, Ecken vorgezogen, in Scheitelansicht drei- bis siebeneckig. Zellhaut fein granuliert. Länge (25) $45-53 \mu$, Breite (20) $40 \mu$. Hier und da.

\section{St. gracile Ralfs (Taf. VI, 31)}

Scheitel gerade. Punkte auf den Fortsätzen in Querreihen. Länge $42-72 \mu$, Breite $50-60 \mu$. Einzige Planktondesmidiacee, in Teichen und Seen, nicht selten.

\section{St. cuspidatum Bréb. (Taf. VI, 32)}

Zellhälften mehr oder weniger dreieckig, mit Spitze nach innen und flachem Scheitel, in dessen Verlängerung zwei nach innen gerichtete Spitzen stehen. Membran glatt. Zygospore hat Buckel mit Stacheln. Länge $25-30 \mu$, Breite $25 \mu$. Hier und da.

\section{St. dejectum Bréb. (Taf. VI, 33)}

Zellhälfte mehr oder weniger elliptisch, Stachel kurz; in Scheitelansicht drei- bis vierlappig, Stacheln an den Enden. Zygospore mit (oder ohne?) Stacheln. Sehr veränderlich. Iänge $24-28 \mu$, Breite I $9-38 \mu$. Sehr häufig.

\section{St. furcatum Bréb.}

Zellhälften flachgedrückt, sechseckig, Scheitel flach; dessen Ecken mit je zwei, die mittleren Ecken mit je einem zweispitzigen Stachel. Ecken in Scheitelansicht spitz, mit drei starken, zweispitzigen Stacheln. I.änge $30 \mu$, Breite $37-40 \mu$.

\section{St. teliferum Ralfs}

Jedes runde Ende in Scheitelansicht mit mehreren starken Stacheln, die bei der Hauptansicht den Scheitel ganz besetzen. Runde, bestachelte Zygospore. Breite $36-50 \mu$. Häufig. 
27. Pleurenterium (Lund.).

Voriger Gattung äusserlich sehr ähnlich; doch besitzt es wandständige Chromatophoren mit mehreren Pyrenoiden.

Pl. sexcostatum (Bréb.) Lund. (Taf. VI, 34)

Enden der Zellhälften nicht in Fortsätze verlängert, kugelig oder fast sechseckig; in Scheitelansicht mit sechs gerade abgestutzten Ecken. Zellhaut mit Warzen besetzt. Länge $36-46 \mu$, Breite 26-4I $\mu$. Nicht häufig.

\section{Fam. Zygnemaceae.}

Die zu unverzweigten Fäden verbundenen Zellen sind gerade, cylindrisch, nicht eingeschnürt und ohne Wandskulptur, meist mit Gallertschicht. Die Chromatophoren sind axil oder wandständig, oft mit Oel- und Gerbstoffkügelchen versehen, verschieden gestaltet, zum Teil in Spiralbändern. Die Vermehrung erfolgt besonders durch Konjugation, d. h. durch Verschmelzen zweier Zellinhalte im Innern der Zellhäute oder neugebildeter Zellhautbrücken. Hierbei vereinigen sich entweder, was seltener geschieht, zwei neben einander liegende Zellen des gleichen Fadens durch seitliche Brücken („seitliche Konjugation“), oder es wird zwischen zwei verschiedenen Fäden eine Brücke gebildet, durch deren Vermittlung das Innere der beiden Zellen kommunizieren kann ["leiterförmige Konjugation“ (da die meisten Zellen eines Fadens zugleich zur Fortpflanzung schreiten, entsteht in der That ein leiterförmiges Gebilde)], oder endlich die konjugierenden Fäden biegen sich knieförmig gegen einander („knieförmige Konjugation"). Bei der Vereinigung der Zellen verschmelzen entweder beide Protoplasten vollständig, oder nur teilweise. Das Resultat ist eine Zy gospore mit verdickter Zellmembran, durch deren Keimung unmittelbar eine neue Pflanze entsteht. Auch Dauersporen können gebildet werden. (Einteilung nach Palla).

1. Chromatophor: ein wandständiges, meist spiralig gedrehtes Band (I. Spirogyreae) . . . . . . . I. Spirogyra (S. 172)

I*. Chromatophor axil, nicht bandförmig . . . . . . . . 2

2. Chromatophor in Einzahl, plattenförmig(II. Mongeotieae) 3 
3. Nur ein Teil der Zellinhalte verschmilzt zur Zygospore 2. Mougeotia (S. 175)

$3^{*}$. Der gesamte Inhalt der beiden Zellen verschmilzt zur Zygospore . . . . . . . . . . . . . . 4 4. Chromatophor mit Pyrenoiden

\section{Debarya (S. 176)}

4*. Ohne Pyrenoide. . . 4. Mougeotiopsis (S. 176)

$2^{*}$. Chromatophoren in der Zweizahl, mehr oder weniger sternförmig (III. Zygnemeae) . . . . . . . . . . 5

5. Die beiden konjugierenden Zellen vereinigen sich mit ihrer Gesamtmasse . . . 5. Zygnema (S. 177)

$5 *$. Vor der Konjugation wird der Zellinhalt durch eine Scheidewand in zwei Teile gesondert, von denen nur der eine in die Konjugation eintritt.

\section{Zygogonium (S. 177)}

\section{Spirogyra Linck.}

Ausgezeichnet vor allem durch das pyrenoidhaltige, bandförmige, gerade, meist aber spiralig gewundene Chromatophor, das die Alge zu einer der schönsten Fadenalgen des Süsswassers macht. Konjugation seitlich, leiterförmig oder knieförmig. Meist im Wasser, wo sie schleimige, lebhaft grüne Watten bildet. Sehr zahlreiche, schwer zu unterscheidende Arten. Einteilung nach Hansgirg und Kirchner.

I. Konjugation seitlich oder leiterförmig, meist spiralige Chlorophyllbänder [I. Euspirogyra (Linck) Hansg.] . . . . . 2

2. Zellen mit glatten Querwänden [a: Conjugata (Vauch.) Hansg.] . . . . . . . . . . . . . . . . 3

3. Zellen mit einem Chromatophor . . . . . . . . 4 4. Zygospore über $30 \mu$ dick, $1-2$ Mal so lang . . . 5 5. Zellen $11-12 \mu$ (nach Hansg. dagegen $27-39 \mu$ ) dick 1. Sp. affinis

$5^{*}$. Zellen $36-43 \mu$ (nach Hansg. $24-48 \mu$ ) dick

2. Sp.porticalis

$4^{*}$. Zygosporen nur bis $30 \mu$ dick . . . . . . . . . 6 6. Zellen $15-16,5 \mu$ (nach Hansg. 8-21 $\mu$ ) dick . . 3. Sp. gracilis

6*. Zellen 18 und mehr $\mu$ dick. 
7. Zellen $19,5-25 \mu$ (nach Hansg. $18-27 \mu$ ) dick . 4. Sp. communis

$7^{*}$. Zellen $18-28 \mu$ (nach Hansg. $22-36 \mu$ ) dick . 5. Sp. longata

$3^{*}$. Zellen mit mehreren Chlorophyllbändern . . . . 8

8. Zygospore oval . . . . . . . . . . . . . . 9

9. Zellen bis $40 \mu$ dick, Chlorophyllbänder kreuzen einander

IO

10. Die Chlorophyllbänder mit einem, höchstens zwei. Umgängen . . . . 6. 6p. decimina

IO*. Die Chlorophyllbänder mit $2 \frac{1}{2}-3 \frac{1}{2}$ Umgängen

7. Sp. rivularis

$9^{*}$. Zellen über $50 \mu$ dick . . . . . . . . . . I I

I I. Zellen $54-77 \mu$ dick, die Sporenzellen so lang als die vegetativen . . . 8. Sp. nitida

I ${ }^{*}$. Zellen 72-98 $\mu$ dick, die Sporenzellen kürzer als die vegetativen . . . 9. Sp.jugalis

8*. Zygospore linsenförmig abgeplattet. . . . . . I 2

1 2. Zellen bis $70 \mu$ dick . . . . . . . . . . 13

13. Zellen bis zwei Mal so lang als dick . . . . 10. Sp. bellis

I3*. Zellen 21/2-10 Mal so lang als dick

12*. Zellen I 20-I50 $\mu$ dick . . I2. Sp. crassa

$2^{*}$ Zellen mit gefalteten Querwänden [b: Salmacis (Bory) Hansg.] . . . . . . . . . . . . . . . . . . I4

14. Zellen 8-12 $\mu$ dick . . . . 13. Sp. tenuissima

14*. Zellen $16-34 \mu$ dick . . . . . 14. Sp. weberi

I*. Chlorophyllbänder der Längsachse parallel; Konjugation knieförmig [II. Sirogonium (Kg.) Wittr.] . I5. Sp. stictica

I. Sp.affinis (Hass.) Petit

Zellen I-3 (4) Mal so lang als dick; das eine Chlorophyllband mit $\mathrm{I}-3 \frac{1}{2}$ Umgängen. Konjugation meist seitlich. Fruktifizierende Zellen etwas angeschwollen. Zygospore 30-33 u dick. Häufig, in stehendem Wasser.

2. Sp.porticalis (Mül1.) Cleve (Taf. VI, 35)

Zellen bis sechs Mal so lang als breit. Fruktifizierende Zellen kaum angeschwollen. Chlorophyllband mit 2-4 $1 / 2$ Umgängen; Zygospore $30-42 \mu$ dick. Wie vorige Art, doch verbreitet. 
3. Sp. gracilis (Hass.) Kg.

Zellen 4-io Mal so lang als breit; Chlorophyllband mit $1 / 2-31 / 2$ Umgängen. Zygospore $20-30 \mu$ dick, bis 3 Mal so lang. Meist häufig.

4. Sp. communis (Hass.) Kg.

Das breite Chlorophyllband mit 2-8 Umgängen. Fruktifizierende Zellen kaum angeschwollen. Zygospore $19-23 \mu$ dick, 2-4 Mal so lang. Wie vorige Art.

5. Sp. longata (Vauch.) Kg.

Chlorophyllband mit 2-5 Umgängen; die fruktifizierenden Zellen nicht angeschwollen, kürzer als die anderen. Zygospore I $8-28 \mu$ dick, bis $2 \frac{1}{2}$ Mal so lang.

6. Sp. decimina (Müll.) $\mathrm{Kg}$.

Zellen $33-40 \mu$ dick, bis vier Mal so lang. Die zwei breiten Chlorophyllbänder mit je I- 2 Umgängen. Häufig.

7. Sp. rivularis Rabh.

Zellen $36-38 \mu$ dick, bis i I Mal so lang, mit 2-3 Chlorophyllbändern von je $2 \frac{1}{2}-3 \frac{1}{2}$ Umgängen. Fruktifizierende Zellen etwas angeschwollen. An Flussufern, Bächen etc., ziemlich verbreitet.

8. Sp. nitida (Dillw.) Linck

Zellen bis drei Mal so lang als dick, mit 3-5 eng aneinander liegenden Chlorophyllbändern von $\mathrm{I}-\mathrm{I} \frac{1}{2}$ Umgängen. Zygospore $60-90 \mu$ dick, bis zwei Mal so lang. Ziemlich verbreitet.

9. Sp.jugatis $\mathrm{Kg}$.

Mit $3-5$ parallelen, von einander entfernten Chlorophyllbändern. Hin und wieder.

10. Sp. bellis Petit

Zellen $60 \mu$ dick, etwas angeschwollen, mit 2-3 Chlorophyllbändern von $1-1 \frac{1}{2}$ Umgängen. Häufig.

I 1. Sp. orthospira Naeg.

Die 3-10 Chlorophyllbänder sehr steil gewunden. Zellkern deutlich sichtbar. Häufig.

12. Sp. crassa Kg.

Die 2-7 Chlorophyllbänder mit $1 / 2-1$ Umgange; Zellmembran dick. Zygospore $76-96 \mu$ dick, bis $14+\mu$ lang. Hin und wieder massenhaft auftretend. 
13. Sp. tenuissima (Hass.) $\mathrm{Kg}$.

Zellfäden meist einzeln, Zellen $4-28 \mathrm{Mal}$ so lang als breit. Das Chlorophyllband mit 3-51/2 Umgängen; fruktifizierende Zelle (bis $42 \mu$ ) angeschwollen. Zygospore elliptisch, $30 \mu$ dick, zwei Mal so lang.

14. Sp. weberi $\mathrm{Kg}$. (Taf. VI, 36)

Zellen 3-16 Mal so lang als dick, mit einem bis zwei Chlorophyllbändern von ein bis neun Umgängen. Fruktifizierende Zellen kaum angeschwollen. Zygospore bis $36 \mu$.dick. Häufig.

15. Sp. (Sirogonium) stictica (Eng1. Bot.) Wittr. (Taf. VI, 37)

Die gelblichgrünen Rasen nicht schlüpfrig. Zellen $40-57 \mu$ dick, bis fünf Mal so lang, mit zwei bis fünf Chlorophyllbändern. Fruktifizierende Zellen kürzer als die vegetativen. Zygospore bis $60 \mu$ dick, $1 \frac{1}{2}$ Mal so lang. Nicht häufig.

\section{Mougeotia (Ag.) Wittr.}

Das Chromatophor ist eine axile, linealische Chlorophyllplatte mit mehreren Pyrenoiden (Taf. VI, 38), die meist auf der Breitseite liegt; dreht man die Fäden absichtlich um $90^{\circ}$, so dass die Platten zunächst auf Hochkant stehen, so drehen sich letztere nach kurzer Zeit ebenfalls um $90^{0}$ und kehren zu der Lage auf der Breitseite zurück. Querwände linsenförmig. Konjugation leiter- oder knieförmig. Die Zygosporen werden durch zwei bis vier Querwände von den fruktifizierenden Zellen abgegrenzt. Zygospore mit zwei Membranen.

I. Die Zygospore von zwei seitlichen Zellen umgeben [I. Mesocarpus (Hass.) Wittr.] . . . . . . . . . . . . . . 2

2. Konjugation leiterförmig, Fäden frei [a: Eumesocarpus (Hass.) Hansg.] . . . . . . . . 1. M. parvula

2*. Konjugation nicht leiterförmig . . . . . . . . . 3

3. Konjugation seitlich, Fäden häufig vegetativ knieförmig an einander gewachsen [b: Pleurocarpus A.Br.]

2. M. genuflexa

$3^{*}$. Konjugation knieförmig [c: Craterospermum A. Br.] 3. M. laetevirens

1*. Die Zygospore von vier, den Ecken aufsitzenden Zellen umgeben [II. Staurospermum (Kg.) Wittr.] 4. M. viridis 
I. M. parvula Hass.

Zellen 6-10 $\mu$ dick, 5-12 Mal so lang; die kugeligen Zygosporen $8-24 \mu$ dick, mit glatter, gelbbrauner Mittelhaut. In Teichen und Gräben, nicht selten.

2. M. gemuflexa (Dillw.) Ag.

Zellen $25-33 \mu$ dick, $2-5$ Mal so lang. Die mehr oder weniger kugeligen Zygosporen $30 \mu$ dick, Mittelhaut wie bei voriger Art. In stehendem Wasser, überall verbreitet, aber selten konjugierend.

3. M. laetevirens (A. Br.) Wittr.

Zellen 22-40 $\mu$ dick, 3-8 Mal so lang; Zygospore kurz cylindrisch, $45-60 \mu$ dick, etwa $40 \mu$ lang. Vorkommen wie bei voriger Art, doch selten.

4. M. viridis (Kg.) Wittr. (Taf. VI, 39)

Zellen $6-8 \mu$ dick, 4-10 Mal so lang; Zygospore 22-31 $\mu$ dick, flach, mit farbloser, glatter, aber an den vier Ecken grubig vertiefter Mittelhaut. In Torfsümpfen und sonst, nicht häufig.

\section{Debarya Wittr.}

Zellen fünf Mal so lang als breit, mit geraden Querwänden. Chromatophor wie bei Mougeotia, Konjugation im Verbindungskanale. Die braungelbe Mittelmembran der Zygospore mit drei parallelen, durch Querstreifen verbundenen Längsleisten.

Deb. glyptosperma (De By.) Wittr. (Taf. VI, 40)

Zellen $10-12,5 \mu$ dick, 7-12 Mal so lang. Zygospore $40 \mu$ dick, $63 \mu$ lang. Ziemlich selten.

\section{Mougeotiopsis E. Palla.}

Der Mougcotia äusserst ähnlich, doch ohne Pyrenoide und mit anderer Art der (leiterförmigen) Konjugation, indem die Zygospore aus dem gesamten Zellinhalte entsteht.

M. calospora E. Palla (Taf. VI, 42)

Zelle mehr oder weniger rechteckig bis quadratisch, Chlorophyllplatte so dick wie $1 / 3$ des Zell-Iumens, mit zackiger Kontur. Scheint selten zu sein. 


\section{Zygnema $\mathrm{Kg}$.}

Zellen mehr oder weniger quadratisch, selten länglich; zwei strahlige (sternförmige) Chromatophoren mit je einem Pyrenoid; Zellkern dazwischen. Zygospore im Kanale oder in einer der Zellen gebildet.

I. Zygospore entsteht in einer der Zellen. . . . . . . 2

2. Zellen $35-54 \mu$ dick, bis zwei Mal so lang . . . . .

1. Z. cruciatum

$2^{*}$. Zellen $10(25)-36 \mu$ dick, bis $\mathrm{I}-6(3)$ Mal so lang .

2. Z. stellinum

$1^{*}$. Zygospore entsteht im blasig aufgetriebenen Kanale .

3. Z. pectinatum

I. Z. cruciatum (Vauch.) Ag.

Fruktifizierende Zellen nicht angeschwollen; die kugeligen Zygosporen mit fein punktierter Mittelhaut. In stehendem Wasser, zerstreut.

\section{Z. stellinum (Vauch.) Ag.}

Fruktifizierende Zellen wenig angeschwollen. Zygospore rund oder länglich. Wie vorige Art, doch verbreitet.

3. Z. pectinatum (Vauch.) Ag. (Taf. VI, 42)

Zellen $18-50 \mu$ dick, $1 / 2-5$ Mal so lang, mit dicker Membran. Dauerzellen den mehr oder weniger kugeligen Zygosporen ähnlich. In torfigen Gewässern und sonst, nicht überall.

\section{Zygogonium (Kg.) De By.}

Chromatophor etwa wie bei Zygnema; die im Konjugationskanale gebildete Zygospore mit glatter Membran.

Z. ericetorum (Kg.) Kirchn. (Taf. VI, 43)

Zellen $12-32 \mu$ dick, $3 / 4-4$ Mal so lang. Zellmembran oft sehr dick. Die kugelige oder längliche Zygospore mit glatter Mittelrnembran. In stehendem und fliessendem Wasser, nicht selten, auch auf feuchtem Torfboden. 


\section{Bacillariaceae (Diatomaceae)}

Diatomeen, Kieselalgen.

\section{Litteratur:}

Kützing, Fr. Tr., Die kieselschaligen Bacillarien oder Diatomeen. Nordhausen 1844 .

Rab enhorst, L., Die Süsswasser-Diatomaceen (Bacillarien). Lpzg. 1853. Smith, W., A Synopsis of the British Diatomaceae mit Tafeln von Tuffen West. 2 Bde. London 1853,56.

Pfitzer, E., Untersuchungen über Bau und Entwicklung der Bacillariaceen. (In Hansteins Bot. Abh. a. d. Geb. d. Morph. u. Phys.). 187 I. Pfitzer, E., Die Bacillariaceen (Diatomaceen). (In Schenks Handbuch der Botanik II). Breslau I 882 .

Schmidt, A., Atlas der Diatomaceenkunde. Heft I ff. Lpzg. $1874 \mathrm{ff}$. Schütt, F., Bacillariales (Diatomaceae) in Engler-Prantls Natürlichen Pflanzenfamilien I, I. Lpzg. 1896.

Die Diatomeen nehmen im System eine ziemlich isolierte Stellung ein. Ihre nächsten Verwandten sind die Desmidiaceen; an die Peridineen zeigen sie in ihrer Organisation einige Anklänge. Der Diatomeenkörper besitzt den morphologischen Wert einer Zelle. Seine starre Zellhaut besteht aus zwei mit imren Oeffnungen gegen einander gekehrten, in einander geschachtelten Hälften, die einem Kasten vergleichbar sind (vg1. Taf. VII, 29). Jedes dieser kastenförmigen Gebilde setzt sich aus wenigstens zwei fest verbundenen Teilen zusammen: erstens aus einem meist ringförmig gebogenen Gürtelbande (Pleura), das dem Rande des Kastens entsprechen würde, zweitens aus einer Schale (Valva), die dem Kastenboden vergleichbar wäre. Demnach lassen sich am Körper der Diatomeen Gürtel- und Schalenseiten unterscheiden und bei der Bestimmung der einzelnen Spezies verwerten. In die organische Grundsubstanz der Zellhaut ist in reichlicher Menge Kieselsäure eingelagert; es findet sich also eine weitgehende Verkieselung, die zu dem Namen "Kieselalgen" Veranlassung wurde. Durch Kochen mit Schwefelsäure oder durch Ausglühen lässt die organische Substanz sich leicht entfernen, und es bleibt nur das Kieselskelett erhalten (vgl. S. 18).

Die Kieselpanzer der Diatomeen gehören zu den anziehendsten mikroskopischen Objekten. Ihre Schalenseiten sind mit grösseren oder kleineren Kanälen, mit wunderbar zierlichen 
Rippen, Leisten, Knoten und mannigfaltigen, reizenden Skulpturen versehen, deren Feinheit und Regelmässigkeit eine wahre Augenweide bieten. In erster Linie sind die mit phantastisch gestalteten Schwebevorrichtungen armierten Planktonformen interessant (vgl. z. B. Taf. VII, 4, 5, 6).

Der Innenseite des Kieselpanzers liegt eng das Protoplasma an. Dieses umschliesst einen Hohlraum und führt einen oder mehrere braune Chromatophoren, die je nach den Arten Platten von verschiedener Gestalt oder Körner darstellen. Der braune Farbstoff der Chromatophoren heisst Diatomin; neben ihm ist auch Chlorophyll vorhanden. Das erste Assimilationsprodukt der Chromatophoren scheint Oel zu sein; doch finden sich auch Pyrenoide mit oder ohne Stärkeherd. Nur ein einziges Pyrenoid besitzen die Cymbelleen und Gomphonemeen; zwei Pyrenoide weisen einige Surirella-Arten auf. Der gewöhnlich in der Mitte der Zelle gelegene Kern ist von einem protoplasmatischen Mantel umgeben und vielfach ohne Anwendung von Färbemitteln deutlich sichtbar.

Viele Diatomeen neigen in hohem Masse zur Familienbildung und setzen oft in grosser Individuenzahl vereinigt Bänder, Fächer oder ähnliche Gebilde zusammen. Andere Formen sitzen vermittelst eines Gallertstieles einzeln oder zahlreich auf Fremdkörpern, wie z. B. auf Algen, fest und verharren in völliger Unbeweglichkeit. Die einzeln und frei lebenden Arten hingegen zeigen meist eine charakteristische, ungleichmässige, ruckweise, bald vorwärts bald rückwärts gerichtete Bewegung. Das $\mathrm{Zu}$ standekommen dieser Bewegung ist noch nicht genau ergründet. Nach Max Schultze tritt durch bestimmte Durchbohrungen, namentlich durch die sogenannte Rhaphe, die als Längsspalt auf der Schalenseite vieler Diatomeen sichtbar ist, ein dünner Protoplasmafaden aus, der auf der Schalenoberseite entlang gleitend die ganze Zelle in Bewegung setzt. Indessen ist trotz der Arbeiten O. Muellers der Vorgang keineswegs gänzlich aufgeklärt. Manche Forscher, so Buetschli, sehen in austretenden Gallertfäden die Bewegungsorgane der Diatomeen.

Während gewöhnlich die beiden starren Kieselschalen mit ihren umgebogenen Rändern vollständig in einander geschoben sind, werden sie vor der Fortpflanzung, die durch Zweiteilung erfolgt, so weit auseinander gerückt, dass sie einander nur eben noch berühren. In der Ebene, die von den äussersten, ein- 
ander noch berührenden Rändern der beiden Pleurae umgrenzt wird, wird alsdann eine Scheidewand angelegt, die bald einer der Richtung ihrer eigenen Ebene parallelen Zweispaltung unterliegt. Jede der beiden so entstandenen Grenzplatten bildet sich in der Folge zu einer neuen Schale aus; so dass die beiden Tochterdiatomeen je eine alte und je eine neue Schale besitzen. $\mathrm{Da}$ aber die eine der beiden alten Schalen um die doppelte Dicke der Gürtelbandwandung kleiner war als ihr Pendant, so muss diejenige Tochterzelle, die jene kleinere Schale mit bekam, um ebensoviel kleiner sein als die Mutterzelle. Diese Verkleinerung wird, je mehr Generationen auf diesem Wege erzeugt wurden, um so auffälliger; sie kann so weit gehen, dass die letzten Sprösslinge nur noch ein Drittel von der Grösse ihrer Ahnen erreichen.

Zur Wiederherstellung der ursprünglichen Grösse dient die Auxosporenbildung, die ungeschlechtlich oder geschlechtlich verlaufen kann. Im ersteren Falle bildet ein einziges Individuum, nachdem seine Gürtelbänder von einander gewichen sind, die Auxospore. Diese vergrössert und streckt sich, um alsdann eine Erstlingsschale auszuscheiden, die vielfach von der gewöhnlichen Schalenform etwas abweicht, nach einigen Teilungen jedoch die normale Struktur erhält. So spielt sich der Vorgang z. B. bei Melosira und Rhizosolenia ab. Bei der geschlechtlichen Auxosporenbildung vereinigen sich zwei Zellen und geben entweder einer (so bei Surirella) oder zwei Auxosporen (so bei Rhopalodia gibba, Taf. VII, 51) den Ursprung. Auch Bildung von Ruhesporen ist beobachtet.

Die Diatomeen sind ausserordentlich weit verbreitet; im Meere wie im Süsswasser sind sie zu Hause. In grosser Anzahl beisammenlagernd können sie im süssen Wasser braune Ueberzüge bilden, dem Meerwasser verleihen sie eine gelbbraune Färbung. In wie gewaltigen Scharen hin und wieder die Kieselalgen auftreten können, beweist eine im Herbste 1889 am Wasser der Sargasso-See angestellte Beobachtung, bei der in einem Kubikmeter Wasser 208000 Millionen Diatomeen gefunden wurden. Infolge dieser ungeheueren Anzahl, in der die Kieselalgen die Gewässer bevölkern können, sind diese winzigen Algen auch geologisch wichtig geworden. Aus ihren Kieselpanzern besteht z. B. die Infusorienerde und der Kieselguhr. Der Untergrund eines Teiles der Lüneburger Haide, der Stadt Berlin etc. 
setzt sich ausschliesslich aus den Kieselschalen von Diatomeen zusammen. Selbst im Guano finden sich ihre Skelette. Als Mageninhalt kleiner Krebschen gelangen sie in den Darm der Fische, dann in den Magen fischfressender Vögel, und ihre unverdaulichen Panzer werden mit dem Vogelkote in den Guano übergeführt.

Ein System, das allen verwandtschaftlichen Beziehungen gerecht würde, giebt es bislang noch nicht. Dem folgenden dient die ausgezeichnete Bearbeitung von Schütt als Vorbild, der I 896 das Pfitzersche System (I871) umgestaltete.

1. Schalenseite kreisförmig; Struktur nicht gefiedert, unregelmässig punktiert oder radiär gestreift. Ohne Rhaphe (A. Centricae) . . . . . . . . . . . . . . . . . 2

2. Zellen scheiben- oder büchsenförmig . . . . . . . 3 3. Zellen ohne Buckel oder Hörner, Querschnitt kreisförmig, meist zu Fäden zusammenhängend (I. Discoideae) . . 4

4. Zellen immer kettenbildend, kurz büchsenförmig, Gürtelseite mit Verzierungen. Ketten einer Fadenalge gleichend . . . . . . I. Melosirinae (S. 183)

4*. Zellen meist einzeln (oder zu zweien), scheibenförmig; Gürtelseite ohne Verzierungen

2. Coscinodiscinae (S. I84)

3*. Zellen an jedem Pole mit Ecke und Horn, länger als breit (III. Biddulphioideae) . . 4. Eucampiñae (S. 186)

$2^{*}$. Zellen stabförmig, mehrmals länger als dick, Querschnitt kreisförmig (II. Solenoideae) . . 3. Rhizosoleninae(S. I86)

I*. Schale unregelmässig, nicht kreisförmig; Struktur gefiedert. Mit oder ohne Rhaphe (B. Pennatae) . . . . . . . . 5

5. Schalenseite ohne Rhaphe, doch mit Mittellinie (Pseudorhaphe). Meist in Bändern (IV. Fragilarioideae) . . . 6

6. Die einzelnen Zellen mehr oder weniger tafelartig ausgezogen, Schalenseiten also schwach entwickelt. Zellen meist zu Bandketten vereint . 5. Tabellariinae (S. 187)

6*. Die Zellen meist stab- nicht tafelförmig . . . . . . 7

7. Zellen in Gürtel- und Schalenansicht keilartig zugespitzt

6. Meridioninae (S. 189)

7 . Zellen nicht keilförmig zugespitzt oder wenn, dann Längsachse dem einen Rande genähert . . . 8

8. Längsachse median . . . . . . . . . . . 9 
9. Schalen mit Querwänden im Inneren

7. Diatominae (S. 190)

9*. Schalen ohne Querwände 8. Fragilariinae (S. 19 I)

8*. Längsachse dem einen Rande genähert, Zellen in der Schalenansicht $\mathrm{C}$-förmig gekrümmt

9. Eunotiinae (S. 195)

$5^{*}$. Schalenseite mit echter Rhaphe.

10

10. Nur eine Schale mit echter Rhaphe, die andere mit

Pseudorhaphe;Zellen gekrümmt (V. Achnanthoideae) II

I1. Längsachse geknickt, (Zellen meist in gestielten Ketten) . . . . . . 10. Achnanthinae (S. 197)

I I*. Querachse geknickt, (Zellen meist epiphytisch auf Algen) . . . . . . . I1. Cocconeinae (S. 199)

IO*. Beide Schalenseiten mit echter Rhaphe . . . . 12

I 2. Rhaphe in der Mittellinie, Schalen nicht mit seitlichen Keilen (VI. Naviculoideae) . . . . . . . . . 13

13. Schalen mit deutlicher Rhaphe; ungekielt, oder wenn, der Kiel ohne Kielpunkte . . . . . 14 14. Zellen nicht keilförmig . . . . . . . . . 12. Naviculinae (S. 199)

14*. Zellen keilförmig zugespitzt . . . . . . 15

15. Zellen zugespitzt in der Richtung der Längsachse, Schalenansicht keilförmig, (Zellen auf Gallertstielen) . . 13. Gomphoneminac (S. 2 I I) 15*. Zellen zugespitzt in der Richtung der Querachse, Schalenansicht halbmondförmig .

14. Cymbellinae (S. 214)

13*. Schalen scheinbar ohne Rhaphe, jede Schale mit einem Längskiele (und Kielpunkten); Kiel randwärts nach derselben oder entgegengesetzten Seite verschoben; Querschnitt rhombisch

15. Nitsschinae (S. 219)

I 2*. Rhaphe in seitlichen Flügelkielen versteckt (VII.Surirelloideae) . . . . . 16. Surircllinae (S. 223)

\section{A. Centroicae.}

Der Grundtypus der Schale ist centrisch: der Querschnitt kreisförmig, mit oder ohne Ecken. Struktur: regellose Punkte oder Radien auf den Mittelpunkt als morphologisches Centrum orientiert. Eine Rhaphe fehlt. 


\section{Discoideae.}

\section{Fam. Melosirinae.}

Cylindrische Büchsen von kreisförmigem Querschnitt, ohne Rhaphe; Gürtelbandseite meist mit kräftiger Struktur. Zellen meist zu langen Ketten verbunden. Die Chromatophoren sind kleine, gelappte Plättchen. Ungeschlechtliche Auxosporenbildung (vgl. Taf. VII, I a).

\section{Melosira Ag.} bunden.

Zellen meist cylindrisch, zu Conferven-ähnlichen Eäden ver-

r. Zelle ohne scharfe Grenze zwischen Schalen- und Gürtelseiten; am Grenz-Rande keine Stacheln; Schalen meist gewölbt (Melosira i. eig. S.) . . . . . . . . . . . . . . . 2

2. Zellen in den Fäden eng verbunden, Schalen also nicht hoch gewölbt . . . . . . . . . . . . . . . 3

3. Schalenseite glatt, Gürtelseite kaum sichtbar punktiert 1. M. varians

$3^{*}$. Wenigstens die Schalenseite deutlich punktiert . . 2. $M$. distans

$2^{*}$. Zellen mit hochgewölbten, fast halbkugeligen Schalenseiten . . . . . . . . . . . 3. M. subflexilis

I*. Schalen- und Gürtelseite der Zellen scharf durch einen Kranz zahnförmiger Stacheln getrennt (Orthosira Thw.) . . . . 4 4. Schalenseite glatt, Gürtelseite ohne Wärzchen . . . 4. M. orichalcea

4*. Schalenseite radial gestreift, Gürtelseite mit einer Reihe starrer Warzen dicht vor dem Gürtelbande

\section{M. arenaria}

\section{M. varians Ag. (Taf. VII, I)}

Schalenseite glatt; Zellen 5-28 $\mu$ dick, ebenso oder noch einmal so lang. Einem Conferva-Faden sehr ähnlich. Sehr häufig, in stehendem oder fliessendem Wasser, auch in Abwässern.

2. M. distans $\mathrm{Kg}$.

Mit fast flachen Schalenseiten. Zellen $5-20 \mu$ dick, $1 / 2-3$ Mal so lang. Häufig, in Quellen und Teichen, besonders der Gebirge.

3. M. subflexilis $\mathrm{Kg}$.

Die $5-20 \mu$ dicken, ein bis zwei Mal so langen Zellen durch 
kurze Gallertstiele von einander getrennt. In schnell fliessenden Bächen. Seltener als die übrigen.

4. M. (Orthosira) orichalcea (Sm.) Kg.

Gürtelseite meist deutlich punktiert [bei der zar.crenulata $(\mathrm{Kg}$.) undeutlich punktiert oder glatt], auf der Schalenseite am Rande kurze (Länge $4-15 \mu$ ), radiale Streifen, mit deutlich gezähntem Rande. Zellen $7-30 \mu$ dick, 10-40 $\mu$ lang. In Gräben und Sümpfen.

5. M. (Orthosira) arenaria (Sm.) Moore (Taf. VII, 2)

Grosse Form. Die kurz cylindrischen Zellen an den ganz flachen, radialstreifigen Schalenseiten dicht verbunden. Gürtelseite punktiert. Durchmesser $80-$ I $20 \mu$, Grösse $25-35 \mu$. In Teichen.

\section{Fam. Coscinodiscinae.}

Zellen scheibenartig flach, bisweilen mit kürzeren oder längeren Stacheln; Gürtelband ohne auffällige Struktur. Zellen meist einzeln. Chromatophoren meist wie in voriger Familie.

1. Schalendeckel gewellt, mit zwei koncentrischen Abteilungen von verschiedener Struktur, einem breiten, peripherischen Ringe und einem centralen Kreise I. Cyclotella (S. 184)

I*. Schalenseite nicht so strukturiert . . . . . . . . . . 2

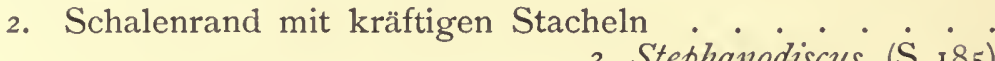
2. Stephanodiscus (S. 185) 2*. Schalenrand ohne kräftige Stacheln, oft mit kurzen Dornen 3. Coscinodiscus (S. 185)

\section{r. Cyclotella Kg.}

Der Ring auf der Schalenseite mit mehr oder weniger feinen, punktierten oder glatten Streifen, Centrum granuliert.

I. Schalenseite am Rande mit einer Reihe von feinen Stacheln I*. Schalenseite ohne solche Stacheln.

$$
\text { I. C. operculata }
$$

2. Streifen der Schalenseite bis zur Hälfte reichend 2. C. kuctzingiana 2*. Schalenseite nur mit kurzen, randständigen Streifen

I. C. operculata $\mathrm{Kg}$. 3. C. meneghiniana

Schalenseite ganz eben, mit abgestumpften Kanten, undeutlichen, radialen Randstreifen und punktiertem Centrum. 
Zellen i $2-30 \mu$ dick. In Quellen und Teichen, auch an nassen Felsen; verbreitet.

2. C. kuetzingiana Thw. (Taf. VII, 3)

Schalenseite meist wellig gebogen, Centrum meist glatt. Randstreifen stark, länger als bei voriger Art, bis zur Hälfte des Radius. Dicke $12-3^{8} \mu$. In Teichen und Flüssen, häufig.

3. C. meneghiniana Rabh.

Schalenseite immer eben, mit nur kurzen Randstreifen; sonst wie vorige Art, von der sie wohl nur eine Varietät bildet. Vorkommen wie bei C.operculata, doch seltener.

\section{Stephanodiscus Ehrbg.}

Schalendeckel wenig konvex, radial granuliert. Am Rande mit Stachelkranz.

St. hantzschianus Grun. (Taf. VII, 4)

Im Herbste bildet sich oft der in der Figur dargestellte Schwebeapparat dadurch aus, dass die Randstacheln sich unverhältnismässig stark entwickeln. Dicke $10-20 \mu$, Länge I 5 bis I $7 \mu$. Im Plankton von Teichen und Flüssen.

Der etwa halb so dicke St. astraea Grun. ist mehr tonnenförmig gebaut und scheint seltener zu sein.

\section{Coscinodiscus Ehrbg.}

Schalen kreisförmig oder elliptisch, ohne jedes Anhängsel, Oberfläche eben oder vertieft. Centralfeld hyalin, Struktur areoliert, granuliert.

C. subtilis Grun.

Eine marine Form, die nur in zwei kreisrunden Varietäten im Süsswasser vorkommt.

I. Mit deutlichen, genäherten Randstacheln und feinen, dichotom geteilten, in Bündeln gestellten Punktreihen . . . . . var. lacustris Grun.

I*. Mit kaum wahrnehmbaren Randstacheln. Die Reihen (am Rande I2, in der Mitte 10 auf Io $\mu$ ) sind zu I2-I4 radialen Bündeln vereinigt . . . . . . var. fluviatilis Lemmerm.

Beide Varietäten scheinen selten zu sein. Im Plankton von Teichen und Flüssen. 


\section{Solenoideae.}

\section{Fam. Rhizosoleniinae.}

Zellen sehr langgestreckt cylindrisch, Schale sehr hoch gewölbt und $z u$ einer Spitze vorgezogen. Plättchenförmige Chromatophoren. Eine ungeschlechtliche Auxospore bildet sich aus einer Zelle.

1. Das aufgesetzte Horn sehr lang, excentrisch

I. Rhizosolenia (S. I 86)

I*. Das Horn steht genau central . . 2. Cylindrotheca (S. 186)

\section{Rhizosolenia Ehrbg.}

Zellen lang cylindrisch, meist Ketten bildend. Mit einer oder zwei Ruhesporen. Meist marin.

Rh. longiseta Zach. (Taf. VII, 6)

Im Plankton von Seen und Flüssen, deshalb mit nur schwach verkieselter, beim Trocknen zusammenschrumpfender Schale. Ihrer Durchsichtigkeit halber sehr leicht zu übersehen und erst I 892 aufgefunden. Meist nur in aufgetrockneten Präparaten zu erkennen.

\section{Cylindrotheca Rabenh.}

Zellen mit spiralig sich kreuzenden Linien aus aufgesetzten Punkten. Kleine, körnige Chromatophoren.

C. gracilis (Bréb.) Grun. (Taf. VII, 7)

Ohne sonstige Skulptur; unvollkommen bekannt. In Teichen und Bächen.

\section{Biddulphioideae.}

\section{Fam. Eucampiinae.}

Die meist marinen Vertreter sind Plankton-Organismen, auch die wenigen, in den letzten Jahren im Süsswasser aufgefundenen Formen. Gürtel mit zahlreichen ringförmigen Zwischenbändern; plattenförmige Chromatophoren. 


\section{Attheya West.}

Atth. zachariasi J. Brun (Taf. VII, 5)

Eine sehr variable Form. Die vier Ecken in lange Spitzen ausgezogen. Dauersporenbildung beobachtet. Im Plankton verschiedener Seeen und Flüsse aufgefunden.

\section{B. Pennatae.}

Von den Centricae besonders durch den nicht auf einen Punkt, sondern auf eine Linie, die häufig als Rhaphe ausgebildet ist, als Centrum bezogenen Schalenbau verschieden; die Schalen sind also nicht kreisförmig im Querschnitt. Schalenverzierungen meist in bestimmtem Winkel zur Mittellinie orientiert, wie die Strahlen einer Feder, (daher Pennatae).

\section{Fragilarioideae.}

\section{Fam. Tabellariinae.}

Gürtelansicht rechtwinklig, die Schalenseite elliptisch, in der Mitte oft bauchig verdickt. Meist mit mehreren Querwänden im Innern. Körnige Chromatophoren.

I. Schalen nicht gekammert, nur mit der Schalenseite parallelen Querwänden . . . . . . . . . . . . . . . . 2

2. Die Scheidewände im Innern mit je drei Oeffnungen (Fenstern) . . . . . . . I. Diatomella (S. 187)

2*. Die Scheidewände mit je einem Fenster . . . . . 3

3. Schalenseiten ohne innere Rippen, nur gestreift; Fenster in der Mitte der Scheidewände . . . .

$$
\text { 2. Tabellaria (S. 188) }
$$

$3^{*}$. Schalenseiten mit starken Querrippen; die Fenster nicht gerade in der Mitte. . 3. Tetracyclus (S. 188)

I*. Schalen gekammert, d. h. durch die Scheidewände und durch auf letzteren senkrechte, mit den Schalenseiten in Verbindung stehende Wände in Kammern geteilt 4. Denticula (S. 189)

\section{Diatomella Grev.}

D. balfouriana Grev. (Taf. VII, 8)

Zellen mit zwei Querwänden; letztere mit je drei Fenstern; 
Enden fein quergestreift, abgerundet. Länge $12-55 \mu ; 19-22$ granulierte Streifen auf je $10 \mu$. Einzeln oder in Bändern. In Bächen hoher Gebirge (Alpen, Gesenke).

2. Tabellaria Ehrbg. (Zickzackbandalge).

Zellen tafelförmig (Gürtelseite); durch Gallerte meist zu zickzackförmigen Fäden verbunden, diese meist am Grunde durch Gallertpolster an Algen etc. befestigt. Zwei und mehr unregelmässige Querwände. Schalenseite lineal, in der Mitte und an den beiden Enden mehr oder weniger verdickt. Körnige Chromatophoren. Zwei Auxosporen bilden sich aus einer Mutterzelle.

1. Zellen mit zwei inneren Scheidewänden I. T. fenestrata I*. Zellen mit drei oder mehr Scheidewänden 2. T. flocculosa

I. T. fenestrata $\mathrm{Kg}$. (Taf. VII, Io)

Mittel- und Endanschwellung, von der Schalenseite gesehen, gleich dick; Gürtelbandseite $28-84 \mu$ lang und $5-16 \mu$ breit. Häufig in stehendem Wasser.

Bildet in Seen oft ganz allein das Plankton, und zwar hin und wieder so reichlich, dass das Wasser getrübt wird. In der kälteren Jahreszeit sind die Zellen zu kettenförmigen Verbänden, zwischen Juni und September nach Schröter zu Sternen und Spiralen (var. asterionelloïdes Grun.) verbunden.

2. T. flocculosa $\mathrm{Kg}$. (Taf. VII, 9)

Mittelanschwellung gewöhnlich grösser als die Endanschwellungen [bei der var. ventricosa $(\mathrm{Kg}$.) J. Brun ganz erheblich]; Zellen $\mathrm{zu}$ (breiteren) Bändern vereinigt, 25-45 $\mu$ lang. Meist häufiger als vorige Art, festsitzend.

\section{Tetracyclus Ralfs.}

Die einzeln oder in kurzen Bändern vorkommenden Zellen haben mehrere, je einmal durchbrochene Scheidewände; Fenster nicht in der Mitte. Schalenseite mit starken Rippen.

I. Zellen klein (bis $25 \mu$ ) . . . . . . . I. T. brauni

$1^{*}$. Zellen robust, in der Mitte bauchig, über $35 \mu$ gross

\section{T. lacustris}

1. T. brauni Grun. (Taf. VII, I I)

Schalenseite elliptisch-oval, mit 4-8 geraden Querrippen. Länge 10-25 . In Sümpfen der Gebirge, nicht häufig. 


\section{T. lacustris Ralfs}

35-65 $\mu$ lange, viel dickere Form mit 4-12 starken, gekrümmten, die konvexen Seiten dem Centrum zukehrenden Querrippen. Ebenda, selten.

\section{Denticula Kg.}

Schalen lanzettlich, ohne Rhaphe. Eine Reihe von Fensterchen stellt die Verbindung zwischen den Kammern und dem Zellinnern her. Mit Querriefen zwichen den Rippen.

I. Länge bis $15 \mu$, Gestalt lanzettlich . . . . I. D. frigida I*. Länge über $20 \mu$, Gestalt elliptisch-linealisch 2. D. elegans

I. D. frigida $\mathrm{Kg}$.

Sehr kleine, (8-i $5 \mu$ grosse) Form. Enden wenig vorgezogen; $60-80$ zarte Rippen auf je 100 $\mu$. Nicht selten, in Seen.

2. D. elegans $\mathrm{Kg}$. (Taf. VII, I 2)

20-30 $\mu$ gross, mit stumpf zugespitzten Enden; 40-45 starke Rippen und $160-200$ feine Streifen auf je $100 \mu$. Hier und da, besonders in höheren Gebirgen.

\section{Fam. Meridioninae.}

Schale und Gürtelansicht keilförmig; mit Quersepten; mit Psêudorhaphe; zahlreiche plattenförmige Chromatophoren; aus zwei Mutterzellen bilden sich zwei Auxosporen. Zellen wenigstens im Alter freischwimmend, (einzeln oder) in Ketten.

1. Meridion Ag. (Ringelalge).

Zwischen den durchgehenden Rippen mit Punktstreifen, die durch die sehr zarte Pseudorhaphe unterbrochen werden. Die Rippen erreichen fast die Gürtelbänder, desgleichen die feinen Streifen. Zellen meist zu kreisförmigen Bändern vereinigt.

I. Schalenseite an beiden Enden einfach abgerundet I. M. circulare

I*. Schalenseite am dickeren Ende mit halsartiger Einschnürung 2. M. constrictum

I. M. circulare Ag. (Taf. VII, I3)

Zelle in der Schalenansicht keulenförmig, mit meist zehn Querrippen (I 8-20 auf je Io $\mu$ ). [Selten mit infolge unvollkommener 
Teilung gebogenen Scheidewänden: var. zinkeni (Kg.) Grun.]. Länge $18-72 \mu$. Häufig, in stehendem Wasser.

2. M. constrictum Ralfs

Mit 8-10 Querrippen [die var. grunowi Kirchn. entspricht der var. zinkeni]. Länge ${ }_{15}-45 \mu$ und mehr. Wie vorige Art, doch seltener.

\section{Fam. Diatominae.}

Schalenansicht ähnlich wie bei voriger Familie, doch nicht keilförmig; mit starken Quersepten; Gürtelansicht rechteckig; körnige Chromatophoren.

\section{Diatoma D. C.}

Mit Pseudorhaphe, die aber die Querrippen nicht unterbricht.

I. Zellen zu Zickzackketten vereinigt, Rippen zart (Diatoma i. eig. S.)

2. Zellen in der Schalenseite mit kopfförmigen Verdickungen I. D. elongatum

2*. Zellen ohne solche Verdickungen 2. D. vulgare

$1^{*}$. Zellen zu breiten Bändern vereinigt oder einzeln; Rippen sehr kräftig (Odontidium Kg.) . . . . . . . . . . . . . 3

3. Zellen auf der Schalenseite mit kopfförmig abgeschnürten Enden . . . . . . . . . . . . 3. D. anceps $3^{*}$. Zellen nicht so gebaut, einfach stumpf abgerundet

1. D. elongatum Ag. 4. D. hicmale

Schalenseite ganz schmal. Sehr variable Form; Länge 7-1 10 $\mu ; 40-65$ Querrippen, 140 Streifen auf je $100 \mu$. Nicht selten.

2. D. vulgare Bory (Taf. VII, 14 )

Schalenseite breit lanzettlich bis linear, viel stärker als vorige Art. Länge 20-110 $\mu$; 45-95 Querrippen, 140 Streifen auf je $100 \mu$.

3. D. (Odontidium) anceps (Ehrbg.) Kirchn.

Meist mit Scheidewänden, die von unvollständiger Teilung herrühren und auf der Gürtelansicht als gebogene Rippen zu sehen sind. Gleich der folgenden Art, doch weit seltener. 
4. D. (Odontidium) hiemale Heib. (Kg.)

Eiförmig bis lanzettlich. Mit 2-12 starken Querrippen, die auf die rechteckige Gürtelseite wenig übergreifen. Länge I 2-35 . Häufig, besonders in Gebirgen, meist die forma mesodon (Ehrbg.) Grun. mit eiförmiger Schalenseite und nur zwei bis vier Rippen.

\section{Fam. Fragilari inae.}

Der vorigen Familie ähnlich, doch Schalenseite viel schmäler, stabähnlich; Querrippen fehlen oder sind wenigstens nicht durchgehend, Querstreifen sind vorhanden. Körnige oder plattenförmige Chromatophoren. Zellen oft zu Kolonien vereinigt.

I. Die beiden Enden der Zellen sind gleichgestaltet. . . . 2

2. Zellen in Ketten, ohne Lücken zwischen den Schalen

$2^{*}$. Zellen einzeln, festsitzend oder frei, stabförmig

$$
\text { I. Fragilaria (S. 19I) }
$$

$$
\text { 2. Synedra (S. 193) }
$$

1*. Die beiden Enden ungleich, mit dem dickeren Ende zu sternförmigen Kolonieen verbunden. . 3. Asterionella (S. 194)

\section{Fragilaria Lyngb.}

Zellen nach jeder Richtung symmetrisch, ohne oder mit kurzen Rippen, mit mehr oder weniger deutlich sichtbarer Pseudorhaphe. Gürtelansicht meist lineal-lanzettlich.

I. Pseudorhaphe schwer zu sehen, ganz schmal; Chromatophoren kleinkörnig (Sectio I: Fragilaria Ralfs) 1. Fr. virescens

1*. Pseudorhaphe breit; Chromatophor in Platten (Sectio II: Staurosira Ehrbg.) .

2. Zellen bei Schalenansicht in der Mitte plötzlich stark bauchig, dreieckig aufgetrieben . . 2. Fr.harrisoni

$2^{*}$. Zellen nicht so gebaut

3. Zellen berühren sich im Bande nur im Mittelstück, die Randpartien kammförmig, lang ausgezogen . . 3. Fr. crotonensis

$3^{*}$. Zellen berühren sich fast vollständig . . . . 4 4. Schalenseite mit in der Mitte unterbrochenen Querrippen . . . 4. Fr. mutabilis 
4*. Schalenseite nur mit punktierten Querstreifen 5

5. Schalenseite breit lanzettlich oder eiförmig 5. Fr. construens

$5^{*}$. Schalenseite schmal linear, mit zugespitzten Ecken . . . . . 6. Fr. capucina

I. Fr. virescens Ralfs (Taf. VII, 17)

Mittellinie fast unsichtbar. Gestalt schwankt von oval bis linear, Pole immer verlängert und abgerundet. In langen Bändern, selten zickzackförmig. Länge $12-70 \mu, 17,5$ Streifen auf je $10 \mu$. Ueberall, sehr verbreitet; auch in Schmutzwässern.

2. F. (Staurosira) harrisoni Grun.

Zellen in der Mitte sehr stark dreieckig aufgetrieben, ,fast kreuzförmig“, festsitzend, einzeln oder in kurzen Bändern. Länge I5-45 $\mu ; 3,3(6-8)$ Rippen auf je $10 \mu$. Selten.

3. Fr. (St.) crotonensis (Edw.) Kitton

Zellen von beiden Seiten spindelförmig, lang zugespitzt, auf der Gürtelbandseite von der Mitte bis gegen die Enden etwas eingeschweift. Rechts und links von dem das Chromatophor bergenden Mittelstück je ein Oeltropfen. Enden der Zellen farblos. Die langen, aus bis über 170 Einzelzellen bestehenden Bänder meist spiralig gedreht. Schöne Planktonalge.

4. Fr. (St., Odontidium) mutabilis (Sm.) Grun. (Taf. VII, I5)

Sehr veränderlich in Grösse und Form: Schalenseite eiförmig bis linear; Länge $5-65 \mu$. In stehendem, langsam fliessendem Wasser, nicht selten; auch im Plankton.

5. Fr. (St.) construens Grun.

Die oval-lanzettlichen Zellen häufig mit vorgezogenen Ecken, oder in der Mitte eingeschnürt. Zellen in Bändern oder Zickzackketten. Länge $10-45 \mu, 14-20$ Streifen auf je $10 \mu$. Nicht selten, in stehendem und langsam fliessendem, reinem Wasser.

6. Fr. (St.) capucina Desmar (Taf. VII, 16)

Ebenfalls häufig in der Mitte eingeschnürt (forma mesolcpta Rabh.), mit sehr zarten Querstreifen, häufig mit je zwei regelmässigen Oeltropfen. Zellen zu langen Bändern vereinigt. Meist 18-20 Streifen auf je $10 \mu$; Länge 1 I-100 $\mu$. Wie vorige Art, doch viel häufiger. 
2. Synedra Ehrbg. (Wasserelle).

Zellen frei oder (meist) an Algen angewachsen, häufig zu fächerförmigen Gebilden vereinigt, aber nicht in Bändern, immer mehr oder weniger stabförmig, manchmal wenig gekrümmt. Die Chromatophoren stellen zwei gelappte Platten dar.

1. Schalenseite immer bogig gekrümmt . I. S. hınaris I*. Schalenseite meist gerade, selten wenig gekrümmt

2. Schalenseite nicht kopfig verdickt, in der Mitte meist mit hellen, viereckigen Flecken

3. Zellen $70 \mu$ lang und länger . . . . . . . 4 4. Streifung kräftig; Schalenseite ganz linealisch, höchstens zugespitzt . . . 2. S. ulna

4*. Streifung zart und fein; Schalenseite meist von der Mitte gegen die Enden allmählich zugespitzt 3. S. oxyrhynchus

$3^{*}$. Zellen höchstens $50 \mu$ lang . . 4. S. radians

$2^{*}$. Schalenseite ohne solche Flecken und an den Enden rhombisch verdickt. . . . . 5. S. capitata

I. S. lunaris Ehrbg.

Schalenseite einfach oder doppelt [var. bilunaris (Ehrbg.)] gebogen, oft mit kopfförmig verdickten Enden. Festgewachsen. Länge 33-100 $\mu, 40-20$ Streifen auf je 10 $\mu$. Häufig, an Algen.

2. S. ulna (Nitzsch) Ehrbg. (Taf. VII, 18)

Sehr veränderliche Spezies; Zellen meist einzeln oder in Büscheln festgewachsen. Schalenseite linear. Es lassen sich folgende Formen unterscheiden:

r. Zellen meist einzeln

2. Der helle, streifenlose Fleck in der Mitte gross; Gürtelseite ganz linear, Länge 70-2 10 $\mu$, 95 Streifen auf je $100 \mu$. Häufigste Form a.: S. ulna im eigentlichen Sinne

$2^{*}$. Fleck fast verschwindend, Länge $220-280 \mu$. . . .

$I^{*}$. Zellen in Büscheln

b.: var. amphirhynchus (Ehrbg.) J. Brun

3. Zellenbüschel festgewachsen, Fleck mehr oder weniger deutlich; Schalenseite lang lanzettlich mit schwach kopfförmigen Enden; Gürtelseite in der Mitte etwas verengt; Länge $125-330 \mu$, Streifen wie bei a.

c.: var. splendens (Kg.) J. Brun

Eyferths Einfachste Lebeformen. 3. Aufl. 
3*. Zellenbüschel freischwimmend, Zellen zu 4-i6. Schalenseite mit allmählich verdünnten Enden; Länge 13-16 4 , Breite 7-8 $\mu$. Im Plankton von Flüssen

\section{d.: var. actinastroides Lemmerm.}

3. S. oxyrhynchus Kg. (erw.)

Der S. ulna ähnlich, doch mit feinerer Streifung: 1 20-160 Streifen auf je гоo $\mu$. Stark variabel:

1. Schalenseite schmal linealisch oder von der Mitte an nach den Enden gleichmässig verdünnt und mit lang zugespitzten Enden, Länge $90-150 \mu$

S. oxyrhynchus Kg. im eig. Sinne

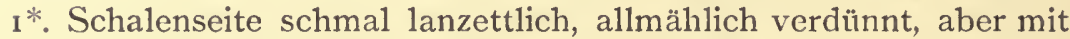
abgerundeten Ecken. Länge $120-230 \mu$. . . . . . . var. acus. Kg.

4. S. radians $\mathrm{Kg}$.

Zellen einzeln oder in Büscheln. Schalenseite schmal lineal, nach den Enden verschmälert. Streifung sehr fein. 20 Streifen auf je $10 \mu$. Länge $40-46 \mu$. Zicmlich häufig.

5. S. capitata (Ehrbg.) (Taf. VII, 19)

Mit deutlichen Endknoten. 9,5 Streifen auf ıo $\mu$. Länge bis $220 \%$. Nicht selten.

\section{Asterionella Hassall (Sternalge).}

Schöne, freischwimmende Alge mit linealischen Zellen und ungleich stark verdickten Pol-Enden. Schalenseite mit sehr feinen Querstreifen. Mit dem dickeren Ende meist zu sternförmigen Kolonien verwachsen.

1. Die Enden nur verdickt . . . . . . 1. A. formosa I*. Die verdickten Enden kopfförmig abgesetzt

\section{A. gracillina}

I. A. formosa Hassall (Taf. VII, 20)

Die Kolonien berühren sich an einer wenn auch kurzen Fläche des polygonal verdickten einen Endes. Länge 50-90 $\mu$. Im Plankton, wenn auch seltener wie folgende Art.

2. A. gracillima (Hantzsch) Heiberg (Taf. VII, 21)

Zierlicher als vorige Art, die Zellen der Kolonien berühren sich nur an einem Punkte. Länge $52-106 \mu, 4-17$ in cinem 
Sterne oder einer Spirale. Nicht selten, in Flüssen und Teichen, oft allein das Plankton bildend; wohl Varietät der vorigen Art.

\section{Fam. Eunotiinae.}

Gürtelseite rechteckig, Schalenseite C-förmig gebogen. Rhaphe oder Pseudorhaphe dem Rande der konkaven Seite genähert oder reduziert. Schalen mit Querstreifung. Die Chromatophoren sind zwei den Schalen anliegende Platten.

I. Mittel- und Endknoten deutlich, Pseudorhaphe dem konkaven Rande genähert . . . . . . . I. Ceratoneis (S. 195) I*. Schalenseite ganz quergestreift, ohne Längslinie

2. Eunotia (S. 195)

\section{Ceratoneis Ehrbg.}

Zellen frei. Mit deutlichen Polarknoten und ringförmigem Centralknoten.

C. arcus $\mathrm{Kg}$. (Taf. VII, 22.)

Von der Schalenseite gesehen in der Mitte des Bauches knopfförmig angeschwollen. Länge $13(45)-100 \mu, 14-18$ Querstreifen auf ıо $\mu$. Nicht selten, besonders im Gebirge.

\section{Eunotia Ehrbg.}

Ohne Querrippen, doch mit punktierten Querstreifen; ohne Mittel-, aber mit Endknoten; ohne Mittellinie. Gürtelseite rechteckig. Eine Auxospore aus zwei Mutterzellen gebildet.

1. Zellen in Bändern, konvexer Schalenrand nicht unduliert, in Schalenansicht schlank, bogenförmig [Sectio I: Fimantidium (Ehrbg.)]

2. Schalenseite mit heraufgezogenen, bekopften Enden . . 3 3. Rücken- und Bauchrand von der Schalenseite parallel . I. E. major

3*. Die beiden Ränder meist nicht parallel . . . . . 4

4. Schalenseite schlank, wenig gebogen . . . . .

$4^{*}$. Schalenseite plumper, Rücken gewölbt oder fast gerade . . . . . . . . . . . . 5 
5. Länge wenigstens $30 \mu . \cdot$. 3. E arcus

$5 *$. Länge höchstens $15 \mu$. . . . 4. E. exigrza

2*. Schalenseite ohne bekopfte oder heraufgebogene Enden .

5. E. pectinalis

I*. Zellen einzeln, selten zu Bändern vereinigt [Sectio II: Eunotia (Ehrbg.)] . . . . . . . . . . . . . . . 6

6. Polarknoten entwickelt, mit Buckeln auf dem Rücken (EuErnotia F. S.). . . . . . . . . . . . . . 7

7. Rücken mit zwei Wellen . . .6. E. diodon

$7^{*}$. Rücken mit drei Wellen . . . . 7. E. triodon

$7^{* *}$. Rücken mit vier Wellen . . . . 8. E. tetraodon

6*. Ohne Polarknoten (Pseudo-Eznotia Grun.) . . . .

(Vergleiche auch E. cxigua.) 9. E. lunaris Ehrbg.

I. E. (Himantidium) major (Sm.) Rabh.

Enden wenig kopfförmig verdickt, abgerundet. Länge 80 bis 190 $\mu$, Schalenseite $15 \mu$ breit, 10-1 2 Streifen auf $10 \mu$. Nicht häufig, mehr im Gebirge.

2. E. (Him.) gracilis (Ehrbg.) Rabh.

Schalenseite schmal; Enden nur wenig verdickt, doch stark heraufgebogen. Länge 90-I65 $\mu$ (nach anderen 25-75 $\mu$ ), halb so breit wie vorige Art. Streifung und Vorkommen wie bei voriger Art.

3. E. (Him.) arcus (Ehrbg.) Rabh. (Taf. VII, 23)

Hin und wieder mit zweibuckligem [var.bidens (Ehrbg.) Grun.], gewöhnlich mit einfach gewölbtem Rücken. Länge $25-80 \mu$, $10,5-15$ feine, kaum punktierte Streifen auf $10 \mu$. Verbreitet, in kalkhaltigem Wasser.

4. E. (Him.) exigua Rabh.

Der vorigen Art ähnlich, doch Zellen meist einzeln, Rücken gewölbt, oft mit zwei schwachen Wellen; Enden stark hinaufgebogen. Länge $7-13 \mu, 17,5-20$ Streifen auf $10 \mu$. Selten.

5. E. (Him.) pectinalis Dillw.

Abgerundete Enden leicht vorgezogen, plötzlich stark zusammengezogen. Rücken und Bauch fast parallel und gerade. Zellen in langen Bändern. Länge $18(55)-150 \mu, 10-16$ Streifen auf ıо $\mu$. Ueberall, häufig. 
6. E. diodon Ehrbg. (Taf. VII, 24)

Mit zwvei wellenförmigen, stumpfen Zähnen. Länge $25-40 \mu$, 12,5 Streifen auf $10 \mu$. Nicht häufig.

7. E. triodon Ehrbg.

Wie vorige Art, doch mit höher gewölbtem, dreibuckligem Rücken. Länge $38-64 \mu, 15$ Streifen auf $10 \mu$. Wie vorige Art.

8. E. tetraodon Ehrbg.

Mit vier Buckeln, sonst wie vorige Art. Länge $38-56 \mu$, 9,5 Streifen auf $10 \mu$. In Torfbrüchen, nicht selten.

Letztgenannte zwei Formen werden auch mit noch einigen andern gebuckelten zur Art E.polyodon (J. Brun) zusammengefasst.

9. E. lunaris Ehrbg.

Zellen an Algen festsitzend; Rippen zart ( 15 auf $10 \mu$ ). Länge $50-90 \mu$. In Gräben und Teichen.

\section{Achnanthoideae.}

\section{Fam. Achnanthinae.}

Zur Mittellinie der Gürtelseite nicht, sonst aber symmetrisch. Ungleichartige (obere und untere) Schale, die eine mit, die andere ohne Rhaphe. Zellen einzeln oder in Bändern.

\section{Achnanthes Bory.}

Wenig knieförmig gebogen; die konvexe Seite mit Pseudorhaphe, die konkave mit echter Rhaphe. Zu gestielten Ketten vereinigt oder einzeln, wie Hämmerchen aussehend. Chromatophor ist eine der konvexen Seite anliegende Platte. Zwei Auxosporen aus einer Mutterzelle.

I. Rhaphe und Pseudorhaphe gerade, nicht S-förmig gebogen; Zellen meist gestielt (Sectio I: Euachnanthes F.S.) . . . 2

2. Ohne langen Gallertstiel . . . . . A. subsessilis

2*. Meist mit mehr oder weniger langem Gallertstiele. . 3

3. Ohne riefenfreies Querband in der Mitte der Schalenseite. . . . . . . . . . . . . . . . 4

4. In der Mitte bauchig aufgetrieben

2. A. delicatula

$4^{*}$. In der Mitte nicht so beschaffen . . . . 5 
5. Mit deutlich vorgezogenen Enden

4. A. exilis

$5^{*}$. Nicht so gebaut . . 3. A. minutissima

3*. Mit solchem Querbande (einem „Kreuze“) . . . 6

6. Schalenseite in der Mitte und nahe den Polen eingeschnürt . . . . . . 5. A. coarctata

6*. Schalenseite nicht so eingeschnürt · · .

1*. Rhaphe S-förmig gebogen (Sectio II: Achnanthidium Kg.) 7. A. Alexella

1. A. subsessilis $\mathrm{Kg}$.

Stiel ganz rudimentär; Schalen wenig gekrümmt, oblong, mit abgerundeten Ecken. Länge $60-80 \mu$. An Algen, hin und wieder.

2. A. delicatula $\mathrm{Kg}$.

Auf der Schalenseite bauchig aufgetrieben, glatt, mit vorgezogenen, oft gekopften Spitzen. Länge 2- 12 $\mu$. Häufig, meist einzeln.

3. A. minutissima $\mathrm{Kg}$.

Wie vorige Art, doch schärfer geknickt, und mit einfach abgerundeten Ecken. Länge $15, u$ und mehr. Auf Gallertstielen. Vielleicht Varietät von der folgenden Art.

4. A. exilis $\mathrm{Kg}$. (Taf. VII, 25)

An sehr langem, dünnem Gallertfaden befestigt. Mit nur kleinem, rundem Centralknoten und sehr feiner Streifung. Nicht selten.

5. A. coarctata (Bréb.) Grun.

Enden kopfartig erweitert, Streifung deutlich, Zellen einzeln. Länge I $2-40 \mu$, I 6 Streifen auf $10 \mu$. Nicht selten.

6. A. lanceolata (Bréb.)

Mit deutlicher Querbinde (oft mit Stauroncis-ähnlichem Centralknoten) und undeutlicher Streifung, breit elliptisch, Enden breit gerundet. Länge $9-22 \mu$, г6 Streifen auf $10 \mu$. Häufig.

7. A. (Achnanthidium) Acxella (Kg.) Bréb. (Taf. VII, 26)

Die S-förmige Mittellinie seitlich auslaufend, Streifung sehr fein. länge $25-50 \mu$. Zellen einzeln und frei. Sehr verbreitet, aber nicht häufig. 


\section{Fam. Cocconeidinae.}

Obere Schale mit Pseudorhaphe, untere mit echter Rhaphe und Centralknoten. Zellen meist flach, in der Längsachse mehr oder weniger gebogen. Chromatophor wie in voriger Abteilung. Eine Mutterzelle bildet eine ungeschlechtliche Auxospore.

\section{Cocconeis Ehrbg.}

Mehr oder weniger gebogen, flach-blattartig oder gewölbt. In Menge neben einander auf Algen epiphytisch, nicht parasitisch.

C. communis Heib. (Taf. VII, 27)

Schalen mèr oder weniger rundlich-eiförmig, von verschiedener Grösse und Gestalt. Es sind zwei Hauptformen zu unterscheiden:

I. Schalen mehr oder weniger stark gekrümmt. Länge ${ }_{15}-25 \mu$.

a) f.pediculus (Ehrbg.).

1*. Schalen fast flach und mehr länglich. Länge $20-60 \mu$.

b) f. placentula (Ehrbg.).

Beide Formen, besonders aber forma a überall sehr häufig an Algen, diese, - - vor allem Cladophora-Arten - oft förmlich bedeckend.

\section{Naviculoideae.}

\section{Fam. Naviculinae.}

Beide Schalen mit echter Rhaphe, unter einander gleich, meist wenig konvex, mit einem Central- und zwei Polarknoten. Alle mit mehr oder weniger schiffähnlicher Schalenseite. Chromatophor: zwei grosse, den Gürtelbändern anliegende Platten.

1. Schalen ohne den Schalenseiten anliegende Kämmerchen 2

2. Schalen ohne Kiel (A. Naviculidae) . . . . . . . 3

3. Rhaphe fast gerade, Enden nach derselben Seite geknickt (I. Naviculae). . . . . . . . . . . 4

4. Rhaphehälften nicht zwischen Kieselrippen eingeschlossen; Knoten rund . . . . . . . . .

I. Navicula (S. 200)

4 *. Rhaphehälften zwischen zwei Kieselrippen eingeschlossen . . . . . . . . . . 5 
5. Centralknoten klein, nicht verlängert, Zellen frei . . . . . 2. Vanheurckia (S. 208)

$5^{*}$. Centralknoten in der Längsrichtung linienhaft verlängert . 3. Amphipleura (S. 209)

$3^{*}$. Rhaphe stark S-oder C-förmig gebogen (II. Pleurosigmae) . . . . . . . . . . . . . . 6

6. Zelle nicht um die Längsachse gedreht, Gürte]band gerade, Schale wenig gewölbt . . . . . 4. Pleurosigma (S. 209)

6*. Zelle um die mittlere Längsachse gedreht. Gürtel schief oder S-förmig. Schalen deutlich gewölbt

5. Scoliopleura (S. 2 10)

2*. Schale mit Kiel

(B. Amphiproridae)

6. Amphiprora (S. 210)

I*. Schalen mit Seitenkämmerchen, in Gallerte eingebettet

7. Mastogloia (S. 2 I I)

\section{Navicula Bory.}

Enthält eine sehr grosse Menge (900-1000) Arten; bei uns im Süsswasser wohl weit über 50 Arten. Rhaphe gerade oder wenig gebogen, an den Enden oft kurz umgeknickt. Oberfläche punktiert, gestreift oder gerippt. Zwei geschlechtliche Auxosporen entstehen in zwei Mutterzellen. Die zwei gürtelseitigen Chromatophoren rücken bei der Zellteilung auf die Schalenseite und werden hier durch schiefe Einschnitte geteilt (vgl. Taf. VII, 32).

Nach Van Heurck und Schütt gebe ich folgende Einteilung:

1. Ohne Kreuz (d. h. ohne verbreiterten Centralknoten) in der Mitte der Schalenseite. Rhaphe nach derselben Seite umgeknickt . . . . . . . I. Navicula Bory (S. 200) $1^{*}$. Mit Kreuz, d. h. mit verbreitertem Centralknoten .

II. Stauroneis Ehrbg. (S. 203)

I. Navicula Bory . . . . . . . . . . . . . . . . . I

I. Zellen frei, nicht in Gallerte eingeschlossen (Eu-Navicula) 2

2. Schalen ohne deutliche Punktierung, mit Rippen (höchstens bei starker Vergrösserung sind Perlenreihen vorhanden) 3

3. Linienförmige Rippen, nicht in Punkte auflösbar (Sect. I: Pinnulariae) 
4. Mit breitem, streifenlosem Mittelfelde (nicht zu verwechseln mit dem verbreiterten Centralknoten, siehe S. 203) (Stauroptera Ehrbg.) . . . . . . . . . 5

5. Schalenseite breit linealisch, am Ende nicht verschmälert . . . . . . . . I. N. cardinalis

$5^{*}$. Schalenseite mehr oder weniger elliptisch-lanzettlich 6

6. Rippen im mittleren Teile dem Mittelknoten zu gerichtet, an den Enden entgegengesetzt verlaufend

2. N. divergens

6*. Rippen nicht so . . . . . . . . . . . 7

7. Rippen kurz, sehr schief . 3. N. stauroptera

$7 *$. Rippen länger, in der Mitte konvergierend, an den Enden parallel . . 4. N. brebissoni

$4^{*}$. Schalenseite ohne Querzone . . . . . . . . 8

8. Schalen mit mehreren seitlichen Anschwellungen, kleine Form . . . . . . . 5. N. mesolepta

$8^{*}$. Schalenseiten ohne solche buckelförmigen Anschwellungen, höchstens in der Mitte und an den Enden wenig verdickt (Pinnularia Ehrbg.) . . 9

9. Zellen ohne jede Anschwellung . . . . Iо

ı. Mit wenig oder nicht verschmälerten Enden (kleine Form) . . . . . 6. N. borealis

$10^{*}$. Von der Mitte nach den spitz abgerundeten Enden allmählich verdünnt $7 . N$. viridis

9*. Zellen mit mittlerer Anschwellung . . . . I I

11. Nur mit mittlerer Anschwellung (grosse Form) 8. N. major

I I*. Mit Mittel- und Endanschwellungen

12. Grösse $200-400 \mu$. . 9. N. nobilis

12*. Grösse 50-100 $\mu$. . . 10. N. gibba

$3^{*}$. Die Rippen sind bei stärkerer Vergrösserung in Perlenreihen auflösbar. . . . . . . . . . . . . . ${ }_{1} 3$

13. Schalenseite lanzettlich, nach den Enden allmählich verschmälert . . . . . . . . . . . . . 14

14. Länge 1 1о $\mu$ und mehr, Körper in der Mitte wenig verdickt . . . . . . 11. $N$. oblonga

14*. Länge höchstens $75 \mu$, Körper spitzer auslaufend $\quad$ I 5

15. Mit fast parallelen Streifen und starker Mittellinie . . . . . . . . I2. N. gracilis

15*. Streifen nicht parallel . . . . . . 16 
I6. Schmal lanzettlich, nach den zugespitzten Enden geradlinig verschmälert . 13. N. lanccolata

16*. Breit lanzettlich, mit stumpfen Enden

\section{4. $N$. radiosa}

$13^{*}$. Schalenseiten nicht allmählich und gleichmässig verschmälert . . . . . . . . . . . . . . . 17

17. Querstreifen fein, (mindestens I 20 auf $100 \mu$, meist mehr), undeutlich punktiert . 15. N. cryptocephala

17*. Querstreifen deutlich punkticrt . . . . . . 18

18. Die fast parallelen Ränder vor den Enden plötzlich je in eine abgerundete Spitze verschmälert resp. vor dem Ende stark zusammengezogen .

I6. $N$. dicephala

18*. Nicht so gestaltet

19. Schmal lanzettlich, Enden stark ausgezogen oder kopfig . . . . . . 17.N.rhynchocephala

19*. Breit eiförmig, Enden zugespitzt .

18. $N$. gastrum

$2^{*}$. Schalen mit Punkten oder sehr feinen Streifen oder ohne deutliche Struktur . . . . . . . . . 20 20. Streifen deutlich punktiert . . . . . . . 2 I

2 I. Ohne sichtbare Längsfurchen . . . . . . 22 22. Querstreifen parallel, Mittelknoten klein

I9. N. cuspidata

$22^{*}$. Querstreifen konvergierend, Mittelknoten gross 23

23. Schalenseite breit lanzettlich und mit kopffớmigen Ecken . . . . . . . 20. N. tumida

$23^{*}$. Schalenseite elliptisch, vor den Enden nicht eingeschnürt . . . . . 21. N. inflata

$21^{*}$. Mit Längsfurchen und Strichen . . . . . 24

24. Mit deutlichen, durch zwei Längsbinden unterbrochenen Querstreifen . . . . . . . 25

25. Längslinien in der Nähe der Seiten-Bänder 26 26. Länge bis $80 \mu$, mit kopfförmig vorgezogenen Enden . . . . . . 22. N. amphisbacna 26*. Länge über ' гоо $\mu$, ohne solche Enden . 23. $N$. iridis

25*. Längslinien laufen in der Nähe der Mittellinie . 24. $N$. elliptica 24*. Die Querstreifen undeutlicher als die Längsstreifen 27 
27. Enden mehr oder weniger vorgezogen . 28 28. Vor den Enden eingeschnürt

28*. Vor den Enden nicht eingeschnürt . . . 29

29. Mittelrippe sehr stark, Mittelknoten in der Mitte eingeschnürt und mit der Mittelrippe verfliessend . . . . 26. $N$. crassincrvia

29*. Mittelrippe und Mittelknoten gewöhnlich 30

3o. Mit glattem, farblosem Saume längs der Mittellinie . . . . 27. N. firma

30*. Ohne solchen Saum . 28. N. affinis

$27^{*}$. Enden nicht vorgezogen .

31. Schalenseite in der Mitte mehr oder weniger bauchig, resp. Rand zwei Mal flach eingeschnürt 29. $N$. limosa

$3 I^{*}$. Schalenseite einfach elliptisch

27. N. firma

20*. Streifen mehr oder weniger undeutlich, nur bei starker Vergrösserung zu erkennen, klcine Formen . . . 32

32. Länge bis $17 \mu$; Körper oval; Streifen kaum sichtbar 30. $\mathrm{V}$. atomus

$32 *$. Länge mindestens $28 \mu$, Ränder fast parallel, Streifen fein . . . . . . . . 31. N. bacilhum

$1^{*}$. Zellen in Gallertröhren eingeschlossen, Kolonien rasenbildend (Schizonema Ag., resp. Colletonema Bréb.) 32. N. lacustris

II. Stauroncis Ehrbg.

33. Verbreiterter Mittelknoten den Rand nicht erreichend 34 34. Zellen mit weit vorgezogenen, deutlich abgeschnürten Enden . . . . . . . . . 33. N. anceps

$34^{*}$. Zellen mit höchstens unmerḳlich vorgezogenen Enden 35

35. Breit lanzettlich, Länge $60 \mu$, Streifen sehr stark . . 34. N. meniscus

$35^{*}$. Lanzettlich, Länge über $70 \mu$, Streifung zarter . . 36

36. Schalenseiten mit meist wenig vorgezogenen Enden, Mittelknoten gegen den Rand allmählich sich verflachend, Länge über $90 \mu$. $35 . N$. phoenicenteron

$36 *$ Schalenseiten einfach zugespitzt, Mittelknoten meist plötzlich abgegrenzt, Länge bis $90 \mu$ 
33*. Verbreiterter Mittelknoten erreicht den Rand. . . . 37

37. Mittelknoten nach dem Rande zu verbreitert . 37. N. acuta

37*. Mittelknoten nicht verbreitert . . . . . . . . 38

38. Mittelknoten flacht sich gegen den Rand hin ab. . 35. N. phoenicenteron

38*. Mittelknoten bleibt bis zum Rande ziemlich gleich stark 38. N. amphilepta

I. N. (Stanioptera Ehrbg.) cardinalis (Ehrbg.)

Enden abgerundet, fast unmerklich angeschwollen. Die Rippen (3,5-5 auf $10 \mu)$ nịcht bis zur Mittellinie reichend, in der Mitte wenig konvergierend. Länge $180-240$ (nach anderen bis 750) $\mu$ Breite $45-55 \mu$, grösste Form. Nicht häufig.

2. N. (Stpt.) divergens (W.Sm.)

Schalenseite linear-elliptisch, Endknoten schief, Rippen nicht bis zur Mittellinie reichend. Länge $60-170 \mu$, Breite $15-25 \mu$; 4,5-5 Rippen auf $10 \mu$. Selten.

3. $N$. (Stpt.) stauroptera Grun.

Schalen nach den (oft wenig angeschwollenen) Enden etwas verschmälert. Länge $40-100 \mu$, I0-I4 Rippen auf Io $\mu$. Nicht selten, in Teichen.

4. N. (Stpt.) brebissoni Kg. (Taf. VII, 3I)

Schalenseite elliptisch, mit abgerundeten Ecken; die deutlichen Rippen erreichen die Mittellinie nicht. Länge $25-65 \mu, 10-15$ Rippen auf го $\mu$. Ueberall häufig, auch in Schmutzwasser.

5. N. mesolepta (W. Sm.) (Taf. VII, 30)

Leicht kenntliche Form. Streifen $(9,5-13,5$ auf $10 \mu)$ bis fast zur Mittellinie reichend, im mittleren Teile stark konvergierend, hier auch hin und wieder fehlend (var. stauroneiformis Grun.). Länge $54-75 \mu$. Häufig.

6. N. (Pimularia) borcalis (Ehrbg.)

Die starken Rippen (5-7 auf 10 $\mu$ ) nicht konvergierend, Mittellinie bei weitem nicht erreichend, mit stumpfen Enden. Länge $20-70 \mu$. Ueberall häufig, auch ausserhalb des Wassers.

7. $N$. (P.) viridis (W. Sm.) (Taf. VII, 29)

Lang elliptisch, Streifen (6-8 auf го $\mu$ ) in der Mitte kon- 
vergierend, nicht die Mittellinie erreichend. Endknoten schief. Länge $55-125 \mu$. Ueberall, in stehendem und fliessendem Wasser, häufig.

8. $N$. (P.) major (W. Sm.) (Taf. VII, 28)

Länge 110-310 $\mu, 4-5$ Rippen auf Iо $\mu$; Vielleicht Varietät der folgenden Art. Vorkommen wie bei voriger Art.

9. $N$. (P.) nobilis (Ehrbg.)

Gleicht der vorigen Art, hat jedoch plumpere Enden; die starken Streifen $(4-5$ auf io $\mu$ ) im mittleren Teile nach dem Mittelknoten hin gerichtet. Länge $200-370 \mu$. Schöne Form, in stehendem Wasser.

10. $N .(P$.$) gibba (Ehrbg.)$

Endanschwellung oft kopfig, oft auch wenig ausgeprägt, schmäler jedenfalls als die bauchig verdickte Mitte; Streifung die Mittellinie nicht erreichend. Länge 55-100 $\mu, 8-12$ Streifen auf $10 \mu$. In stehendem Wasser und in Quellen.

i 1. $N$. (P.) oblonga (Rabh.) Kg.

Mit breit abgerundeten Ecken; Streifen (in der Mitte $4-8$ auf $10 \mu$ ) fast alle stark konvergierend, nahezu die Mittellinie erreichend und zart punktiert, Länge $85-190 \mu$. In stehendem Wasser.

\section{i 2. $N$. (P.) gracilis (Ehrbg.)}

Schalenseite lanzettlich, Enden abgerundet, auch die Gürtelseite nach den Enden zu ein wenig verschmälert. Länge $35-53 \mu$, 10-I I Streifen auf 1o $\mu$. Häufig, in fliessendem Wasser, weniger in Teichen und Gräben.

13. $N$. (P.) lanceolata $\mathrm{Kg}$.

Schalenseite schmal lanzettlich, zu den zugespitzten Enden geradlinig verschmälert. Die konvergierenden Streifen (in der Mitte etwa 12 auf $10 \mu$ ) undeutlich punktiert. Länge $40-50 \mu$. In stehendem Wasser.

\section{4. $N$. (P.) radiosa (W. Sm.)}

Streifen (in der Mitte 8-9,5 auf 1o $\mu$, am Ende viel enger) konvergierend. Gürtelseite nach den Enden verschmälert. Länge 35- $90 \mu$. Häufig, in stehendem und fliessendem Wasser, besonders an Mühlwehren. 
15. N. cryptocephala $\mathrm{Kg}$.

Veränderliche Form, so die Enden mehr oder weniger spitz, oft kopfförmig, Querstreifen zart. Folgende Formen:

I. Nur zugespitzt . . . . . var. lanceolata Grun.

I*. Mit kopfförmigen Enden . . . . . . . . . . . . . 2

2. Länglich-lanzettlich, Länge $25-50 \mu, 12-17$ Streifen auf го $\mu$. . . . . . . . . var. rhynchocephala Grun.

$2^{*}$. Kurz lanzettlich, Länge ${ }_{5}-20 \mu, 22$ Streifen auf Io $\mu$ var. minor Grun.

Ueberall, sehr häufig.

16. N. dicephala $\mathrm{Kg}$.

Schalenseite mehr oder weniger linear und geradlinig; die konvergierenden Streifen $\left(9,5^{-1} 13\right.$ auf Io $\mu$ ) erreichen die Mittellinie. Der grosse Mittelknoten fast viereckig. Länge $20-50 \mu$. Ueberall, doch nicht sehr häufig.

17. N. rhynchocephala $\mathrm{Kg}$.

Querstreifen (8,5-12 auf Io $\mu$ ) konvergierend, Längsstreifen fein. Die lanzettlichen Schalen meist lang zugespitzt oder wenig gekopft. Länge $25-55 \mu$. In Gräben und Teichen.

18. N. gastrum Ehrbg.

Die Streifen (8- Io auf Io $\mu$ ) konvergieren nach dem Mittelpunkte zu. Länge $25-45 \mu$. Wie vorige Art.

19. N. cuspidata $\mathrm{Kg}$. (Taf. VII, 33)

Schalenseite breit lanzettlich, Enden wenig vorgezogen; die Querstreifen (in der Mitte ca. I2 auf 10 $\mu$ ) erreichen die starke Mittellinie. Länge 60-I $40 \mu$. Ueberall, häufig.

20. N. tumida W. Sm.

Schalenseiten vor den Enden eingeschnürt, Streifen $(8,5$ bis I 3 auf Iо $\mu$ ) in deutliche Punkte auflösbar, bis zur Mittelrippe reichend. In Teichen und Flüssen.

\section{N. inflata $\mathrm{Kg}$.}

Schalenseite nach den länger vorgezogenen Enden zu verschmälert, ohne wie $N$. tumida eingeschnürt zu sein. Länge 28 bis 3 I $\mu$, I0- I 5 Streifen auf Io $\mu$. In stehendem und fliessendem Wasser. 
22. N. amphisbaena Bory

Schalenseite elliptisch, in der Mitte mit einer streifenlosen, glatten Stelle, Streifen ( $16-20$ auf $10 \mu$ ) konvergierend. Länge 40-90 $\mu$ : In Teichen.

23. N. iridis Ehrbg.

Lang linear-elliptisch, mit schmal gerundeten Enden. Etwa 16 Streifen auf $10 \mu$. Länge $100-350 \mu$. Wie vorige Art.

24. N. elliptica $\mathrm{Kg}$.

Schalenseite elliptisch bis oval; die konvergierenden Querstreifen (10-14 auf $10 \mu$ ), stark punktiert, lassen in der Mitte eine breite Stelle frei. Länge $25-75 \mu$. Wie vorige Art.

\section{N.producta (W. Sm.)}

Schalenseite elliptisch, Streifen (15-18 aut 1o $\mu$ ) erreichen die Mittellinie. Länge $60-120 \mu$. Nicht selten.

26. N. crassinervia Bréb.

Schalenseite lanzettlich, mit schwachen Längsstreifen (mehr als 40 auf $10 \mu)$. Länge $30-90 \mu$. Stellt, in grosser Menge in konsistente Gallerte eingelagert, die Frustulia torfacea A. Br. dar.

27. N. firma $\mathrm{Kg}$.

Schalenseite elliptisch, mit selten vorgezogenen Enden. Deutliche Längs-, aber schwache Querstreifen (15,0-16,5 auf $10 \mu$ ). Länge $65-115 \mu$.

28. N. affinis Ehrbg. (var. Taf. VII, 32)

Die länglich-lanzettliche Schalenseite mit deutlich vorgezogener, auch gekopfter Spitze. Feine Streifung (19-25 Querund 20 Längsstreifen auf 10 $\mu$ ). Länge 35-120 $\mu$.

Die var. amphirhynchus (Ehrbg.) Grun. hat stumpfe oder abgerundete Enden. Nicht selten, in Teichen und Gräben.

20. N. limosa Ag.

Schalenseite länglich, mit deutlichen Längs- und Querstreifen (17,5-ig auf Io $\mu$ ) und grossem Mittelknoten. Länge 35-140 $\mu$. In Flüssen und Teichen.

3o. N. atomus Grun.

Kleine, ovale Form mit gerundeten Enden. Mit feiner Mittellinie und kleinem Mittelknoten, Streifen (23-27 auf Io $\mu$ ) kaum sichtbar. Länge 14-17 $\mu$. Wie vorige Art. 
31. N. bacillum Ehrbg.

Mittellinie und Mittelknoten deutlich, die konvergierenden Querstreifen (14-21 auf $10 \mu$ ) sehr fein. In Teichen und Gräben.

32. N. (Colletonema) lacustris (Ag.) Kg.

Schalenstruktur etwas excentrisch, leitet deshalb zu Encyonema über. Die starken Streifen wenig konvergierend und an den Enden noch die vom Rande entfernten Endknoten strahlig umgebend. Schalenseite elliptisch. In grosser Anzahl in Gallerte eingebettet. In Seen.

33. N. (Stauroneis) anceps (Ehrbg.)

Starker, nicht verbreiterter Mittelknoten. Zarte, nicht (oder wenig) nach dem Mittelpunkt konvergierende Streifen [12-18(25) auf $10 \mu$ ]. Länge $40-70 \mu$. In stehendem Wasser, ziemlich häufig.

34. N. (St.) meniscus Schum.

Vor den abgestumpften oder abgerundeten Enden nicht (oder wenig) eingeschnürt. Schmaler, wenig breiter Mittelknoten. Die starken Streifen ( 7 auf $10 \mu$ ) konvergierend. Länge $50-60 \mu$. In Teichen und Flüssen.

\section{N. (St.) phocnicenteron (Nitzsch) - (Taf. VII, 34)}

Schalenseite lanzettlich, mit stumpfen Enden; Längs- und Querstreifen (14-18 auf $10 \mu$ ) deutlich. Mittelknoten nicht verbreitert. Länge 70-90(165) $\mu$. Häufig, in stehendem Wasser.

36. N. boryana Pont. (= St. gracilis $\mathrm{Sm}$.)

Schmal lanzettlich. Feine Streifen $(17-20$ auf $10 \mu)$. Länge $70-90 \mu$. Nicht häufig.

37. $N$. (St.) acuta (Sm.)

Schalenseitelanggezogen-rhombisch, Seitenränder fast gerade. Zellen $\mathrm{ab}$ und $\mathrm{zu}$ in Bändern. Länge 77-170 $\mu$. 12,5-14 Querstreifen auf $10 \mu$. In Teichen.

38. N. amphilepta Ehrbg. (= Stauroncis lanceolata Kg.)

Gleicht der $N$. phoenicenteron, nur erreicht der balkenartige Mittelknoten die Ränder. Länge 1 10-I60 $\mu, 14-18$ Querstreifen auf $10 \mu$. Hin und wieder.

\section{Vanheurckia Bréb.}

Zellen Navicula-ähnlich, doch zu beiden Seiten der Rhaphe je eine Kieselrippe. Centralknoten wenig vérlängert. In Gallertröhren. 
I. Alle Streifen parallel; Rhaphe setzt sich über die ganze Schale fort . . . . . . . . . . I. V. viridula

I*. Mittlere Streifen ein wenig strahlig; Rhaphe am Mittelknoten unterbrochen . . . . . . . . 2. V. vulgaris

1. V. viridula Bréb.

Nach den stumpfen Enden regelmässig zugespitzt; 28-30 Striche auf $10 \mu$, fein geperlt. Oft in Röhren eingeschlossen. Länge I00- I I0 $\mu$.

2. V. vulgaris (Thwaites) H. v. Heurck (Taf. VII, 35)

Enden ein wenig vorgezogen, Rhaphe doppelt; um den Mittelpunkt ein kleiner, heller Fleck; etwa 34 seitliche und 24 mittlere Streifen auf $10 \mu$. Etwa $50 \mu$ lang, Io $\mu$ breit. Beide hier und da.

\section{Amphipleura $\mathrm{Kg}$.}

Lang gestreckte Zellen mit stabförmig verlängertem Centralknoten, der an den Enden in je zwei die Rhaphehälften umgebende Rippen ausläuft. Mit zwei stumpfen Seitenkielen. Chromatophoren: zwei den Gürtelseiten anliegende Platten. Zwei Zellen bilden zwei geschlechtliche Auxosporen.

A. pellucida (Ehrbg.) Kg. (Taf. VII, 36)

Zellen einzeln, schmal (meist $15 \mu$ ) und lang (85-140 $\mu$ ). Mit ausserordentlich feiner Querstreifung. In Gräben und Teichen, scheint hier und da häufig zu sein.

\section{Pleurosigma W. Sm.}

Schalenseiten der Navicula sehr ähnlich, doch S-förmig gebogen; die gebogene Rhaphe am Ende nach den entgegengesetzten Seiten umgeknickt. Feine Quer- und Längsstreifen (das marine Pl. angulatum W.Sm. ist eins der gebräuchlichsten Testobjekte zur Prüfung der Güte von Mikroskopen). Zwei grosse, gelappte, den Gürtelseiten anliegende Chromatophoren. Meist marin.

I. Zellen frei, nicht in Gallertröhren eingeschlossen . . . . 2

2. Zellen an den Enden stumpf, bis auf $2 / 7$ der grössten Breite verschmälert, Streifung stark . . . I. P. attenuatum

$2^{*}$. Zellen bis auf $1 / 5$ verschmälert, Streifung zart . . . 3 3. Zellen bis $105 \mu$ lang . . . 2. P. spenceri

3*. Zellen über $130 \mu$ lang. . . . 3. P. acuminatum

$1^{*}$. Zellen meist in Gallertröhren eingeschlossen, wenig gebogen 
r. P. attenuatum (Kg.) W. Sm. (Taf: VII, 37)

Wenig gekrümmte Schale mit deutlichen Längs- (1 2-15) und weniger sichtbaren Querstreifen $(16-20$ auf $10 \mu$ ). Farbe der trockenen Schale purpurbraun. Länge I $40-300 \mu, 1 / 8$ so breit. Ueberall, vereinzelt.

2. P. spenceri W. Sm.

Leicht gebogene, schlanke Form. Streifung zart, Querstreifen $(20-24)$ deutlicher als Längsstreifen $(22-25$ auf $10 \mu)$; Farbe der trockenen Schale hellbraun bis farblos. Länge 50-105 $\mu, 1 / 8$ so breit. Wie vorige Art, seltener.

3. P. acuminatum Grun. (Taf. VII, 38)

Ziemlich stark gekrümmt, Streifung zart (17-20 Längsund 18-23 Querstreifen auf 10 $\mu$ ). Farbe der trockenen Schale gelblich. Länge $66-200 \mu, 1 /$ s so breit. Häufig, in reinem und unreinem Wasser.

4. P. scalproides Rabh.

Kleine, plumpe Form. Enden breit abgerundet, wenig (auf $2 / 3$ ) . verschmälert. Zarte Streifen (16,5-17,5 Längs- und 20 Querstreifen auf $10 \mu$ ). In Flusswasser.

\section{Scoliopleura Grun.}

Navicula-ähnliche Schalen, die aber um die Längsachse wenig gekrümmt sind, so dass das Gürtelband S-förmig gebogen erscheint, desgleichen die Rhaphe. Mit Querstreifen.

Sc. campylogramma Rabh.

Schalenseite stumpf abgerundet. Länge 18-27 $\mu$. In Bächen höherer Gebirge und in Flüssen.

\section{Amphiprora Ehrbg.}

Schiffchenförmig, doch um die mittlere Längsachse gedreht, in Gürtelansicht in der Mitte zusammengezogen. Mittlere, S-förmig gebogene Längslinie und Seiten mit hohem Kiele. Chromatophor: eine dem Gürtel anliegende Platte. Meist marin.

1. Kiel mit dicken Punkten und 14-16 Streifen auf 10 $\mu$. 1. A. alata ${ }^{*}$. Kiel ohne solche Punkte und mit $19-20$ Streifen auf Io $\mu$ 1. A. alata $\mathrm{Kg}$. (Taf. VII, 40)

Schale linear-elliptisch, mit zugespitzten Enden, ungefähr vier Punkte auf $10 \mu$. In der Mitte tief eingeschnürt. Länge 50- г $30 \mu$. 
2. A. pahudosa W. Sm. (Taf. VII, 39)

Schale elliptisch-lanzettlich, mit zugespitzten Enden. Länge $40-80 \mu$. Beide Formen in brackischem Wasser.

\section{Mastogloia Thw.}

Zwei innere Scheidewände. Zellen meist $\mathrm{zu}$ mehreren in rundlichen Schleimmassen.

\section{M. smithi Thw. (Taf. VII, 4I)}

Schalenseite elliptisch, mit vorgezogenen Ecken und $18-22$ punktreihigen Querstreifen. Querwände mit lang gestrecktem, ovalem, nahe an den Enden eingeschnürtem, medianem Fenster Die übrigbleibenden Seitenränder der Quersepten durch radiale Wände (als Rippen erscheinend) in Kämmerchen geteilt. Länge $25-75 \mu$. Schr veränderlich, bald mehr konisch (var. lanceolata J. Br.) bald mehr kopfig. In Seen und Bächen, hin und wieder, häufig.

\section{Fam. Gomphoneminae.}

Gürtelseite stark-, Schalenseite meist nur schwach-keilförmig. Mit Rhaphe. Auf Stielen festsitzend oder in Gallertröhren eingeschlossen; Zellen lösen sich leicht los, können also auch einzeln angetroffen werden. Chromatophor: eine der Gürtelseite anliegende, nach der andern Seite umgeschlagene Platte. Zwei Mutterzellen bilden zwei ungeschlechtliche, ihnen selbst parallele Auxosporen.

1. Gürtelansicht gerade . . . . 1. Gomphonema (S. 2 I I) I*. Gürtelansicht gebogen . . . . . 2. Rhoicospheniq (S. 213)

\section{Gomphonema Ag.}

Schalenseite Navicula-ähnlich, mit granulierten Querstreifen, bisweilen auch mit mittlerer Querbinde. Auf Gallertstielen oder frei.

1. Individuen auf Gallertsticlen (Gomphonema Ag.) . . . . 2

2. Das breitere Ende köpfchenförmig abgeschnürt oder wenigstens vorgezogen . . . . . . . . . . . . 3 3. Das dickere Ende (Kopf) mit aufgesetzter Spitze . . I. G. acuminatum

3*. Ohne dieses Spitzchen 
4. Kopf nur vorgezogen, kaum abgeschnürt . . . 5 5. Kopf breit, Zellen auf langen Gallertstielen

2. G. capitatum

5*. Ende nur köpfchenförmig vorgezogen, kurze Gallertstiele . . . . . . . . 3. G. tenellum

4*. Kopf stark abgeschnürt, oben breit abgerundet .

4. G. constrictum

2*. Das breitere Ende nicht so

6. Das breitere Ende mit aufgesetzter, kleiner Spitze .

5. G. cristatum

6*. Ohne solche Spitze. . . . . . . . . . . 7

7. Schalen breit keulenförmig. . . . . . . . 8

8. Mit wenig vorgezogenem, breitem Ende, also mit zwei seichten Einschnürungen . 2. G. capitatum

8*. Zellen ohne jede Einschnürung 6. G. olivaceum

$7 *$. Schalen lanzettlich . . . . . . . . . . . . 9

9. Querstreifen parallel . . . . . . . . . . 10

ı. Lanzettlich, mit vorgezogenen Enden . . . . .

3. G. tenellum

IO*. Schmal lanzettlich, mit stumpfen, nicht vorgezogenen Enden . . . . . . 7. G. intricatum

$9^{*}$. Streifen in der Mitte konvergierend .

8. G. dichotomum

$1^{*}$. Individuen nur in der Jugend durch Gallerte am Fuss-Ende befestigt, sonst freilebend (Sphenella Kg.) 9. G. vulgare

I. G. acuminatum Ehrbg.

Keulenförmig, mit bauchiger Mitte, nach unten wenig ausgeschweift, in einen langen Fuss verlängert. Die keilförmige Gürtelansicht mit geraden Seiten. Etwas veränderlich. Länge 30-70 $\mu, 6$ Streifen auf 10 $\mu$. Sehr häufig, besonders in stehendem Wasser.

2. G. capitatum Ehrbg.

Etwas plumpere Form; mit dickem, etwas vorgezogenem Ende und bauchig erweiterter Mitte. Länge 20-90 $\mu$; II-I5 Streifen auf го $\mu$. Häufig, in Teichen und Gräben.

3. G. tenellum W.Sm.

In Bezug auf dic Querachse fast symmetrisch, Enden etwas köpfchenförmig vorgezogen. Kurze Gallertstiele. Länge Io-35 $\mu$, 12-15 Streifen auf 10 $\mu$. Häufig. 
4. G. constrictum Ehrbg. (Taf. VII, 42)

Mit bauchig erweiterter Mitte und etwas ausgeschweiftem Fusse. Der Kopf stark verbreitert, meist breiter als die Mitte. Länge $25-70 \mu, 7$ (nach anderen 10-12) Streifen auf 10 $\mu$. Sehr verbreitet.

\section{G. cristatum Ralfs}

Gleichmässig keilförmig zugespitzt; das breit abgerundete Ende mit aufgesetzter, abgerundeter Spitze. Querstreifen $(8-10$ auf $10 \mu$ in der Mitte sehr wenig konvergierend. Länge $20-84 \mu$. In Teichen und Flüssen, nicht selten.

6. G. olivaceum Ehrbg.

Plumpe Zellen mit breitem Fusse; oberer Teil der Zellen wenig breiter als die nicht verdickte Zellmitte oder kaum schmäler Auf Gallertstielen oder in schleimiger Masse eingebettet. Länge $8-45 \mu$, I0-I4 Streifen auf 1o $\mu$. Häufig.

7. G. (Gomph.) intricatum $\mathrm{Kg}$.

Schmal lanzettliche Form mit meist bauchiger Mitte; die parallelen Streifen ( $12-13$ auf $10 \mu$ ) lassen in der Mitte eine freie Stelle. Dicke Gallertstiele. Länge 20-6o $\mu$. Hier und da, auch an feuchten Felsen.

Bei der var. angustata (Kg.) J. Br. bleiben 4-12 Zellen vereint und bilden einen Mcridion-ähnlichen Fächer. Seltener.

8. G. dichotomum $\mathrm{Kg}$. (Taf. VII, 43)

Die schmal lanzettlichen Zellen fast symmetrisch in Bezug auf die Querachse, doch die obere Hälfte meist kürzer und breiter als die untere. Die Streifen ( $12-$ I 4 auf Io $\mu$ ) erreichen die Mittellinic. Länge $25-65 \mu$. Zellen immer paarweise. Ziemlich häufig, an Algen.

9. G. (Sphenella) vulgare $\mathrm{Kg}$.

Lanzettlich, nach den etwas vorgezogenen Enden verdünnt. Feine Streifung (2oStreifen auf $10 \mu$ ); Gürtelseite mehr oder weniger keilförmig. Einzeln oder zu 3-6 vereint. In stehendem Wasser, ziemlich häufig.

\section{Rhoicosphenia Grun.}

Die gestielten Zellen mit gekrümmten, keilförmigen Gürtelbändern, in Bezug auf die Längsachse symmetrisch. Die konkave Seite mit Rhaphe und drei Knoten, die konvexe nur mit Pseudorhaphe. 
R/. curvata (Kg.) Grun. (Taf. VII, 44)

Zellen in Schalenansicht wenig keilförmig, mit zugerundeten Enden; auf Gallertstielen. Länge 12-65 $\mu, 8,5-14$ Streifen auf to $\mu$. Hier und da, häufig.

\section{XIV: Fam. Cymbellinae.}

In Gürtelansicht symmetrisch, in Schalenansicht unsymmetrisch. Rhaphe dem einen Schalenrande genähert, gerade oder gebogen. Eine grosse, dem Gürtelbande anliegende Platte bildet das Chromatophor. Zwei Mutterzellen bilden zwei parallele Auxosporen.

I. Schalen ohne Querrippen . . . . . . . . . . . . . 2

2. Schalen nicht sehr asymmetrisch, Rhaphe von dem Gürtelbandrande abgerückt, das schmale Gürtelband ohne Streifen . . . . . . . . . . J. Cymbella (S. 2 I 4)

$2^{*}$. Schalen stark asymmetrisch; Centralknoten und Rhaphe der konkaven Seite sehr genähert . 2. Amphora (S. 216) I*. Schalen mit Querrippen; Rhaphe oft schwer erkennbar . 3 3. Rhaphe nicht auf einem Kiele . 3. Epithomia (S. 217) $3^{*}$. Rhaphe auf erhabenem Kiele. . 4. Rhopalodia(S.218)

\section{Cymbella Ag.}

Die Zellen wie die Apfelsinenscheibchen nach der langen Gürtelseite keilförmig zugeschärft. Rhaphe meist C-förmig gebogen. Chromatophor: eine den langen Gürtelseiten anliegende Platte, die aber zu den übrigen Seiten herumgeschlagen ist. Zwei Zellen bilden zwei geschlechtliche Auxosporen. Zellen in Gallertschläuchen, $\mathrm{ab}$ und $\mathrm{zu}$ frei.

I. Zellen auf verzweigten Gallertstielen oder frei (Cocconema Ehrbg.) . . . . . . . . . . . . . . . . . . . . 2

2. Mittellinie gerade oder fast garade . . . . . . 3 3. Zellen vor den Enden eingeschnürt . . . . . . . 4 4. Das Ende bildet nur eine scharf vorgezogene Spitze . 1. C. cuspidata 4*. Das Ende ist ein breiter, abgerundeter Kopf . 
3*. Zellen nicht eingeschnürt . . . . . . . . . 5

5. Länge über $70 \mu$. . . . . 3. C. ehrenbergi

$5^{*}$. Länge nicht über $45 \mu$. . . . 4. C. maculata

$2^{*}$. Mittellinie deutlich gekrümmt . . . . . . . . 6

6. Länge bis $85 \mu$. . . . . . . . . . . . . . . 7

7. Schale schlank, $5 \frac{1}{2}$ Mal so lang als breit; Mittellinie wenig gekrümmt. . . . . 5. C.cymbiformis

7*. Schale halb-oval, zwei bis vier Mal so lang als breit; Mittellinie stark gekrümmt . . 6. C. cistula

6*. Länge über $110 \mu$. . . . . . . . . . 8

8. Meist auf Gallertstielen, 3-7 Mal so lang als breit .

7. C. lanceolata

8*. Freischwimmend, 4-5 Mal so lang als breit

8. C. gastroides

I*. Zellen in Gallertschläuchen; Rhaphe fast gerade, Streifung an den Enden strahlig, die Endknoten vom Rande entfernt (Encyonema Kg.) . . . . . . . . . . . . . . . . 9

9. Streifen stark, nicht granuliert . . 9. C. prostrata

9*. Streifen granuliert . . . . . . 10. C. caespitosa

I. C. (Cocconema) cuspidata $\mathrm{Kg}$.

Schale breit elliptisch, $2^{1 /}{ }_{12}-3$ Mal so lang als breit. Mittelknoten stark, Endknoten ganz klein. Ein heller, streifenloser Raum um den Mittelknoten. Länge 30-75 $\mu$, 14,5 Streifen auf der schmäleren, Io auf der breiteren Scite auf ıо $\mu$. Ob häufig? (mit der folgenden Art oft verwechselt!)

2. C. (Cocc.) naviculaeformis Auerswd.

Schalen $2^{3} / 4-4^{1 / 2}$ Mal so lang als breit. Mittellinie der Bauchseite genähert; Endknoten grösser als der Mittelknoten. Länge $25-40 \mu$. Auf der schmäleren Seite kommen 17 , auf der breiteren circa 13,5 Streifen auf Io $\mu$. Häufig, in Teichen.

3. C. (Cocc.) ehrenbergi $\mathrm{Kg}$.

Die etwas schiefen Schalen drei bis vier Mal so lang als breit, mit stumpfen Enden. Bauchseite viel weniger gekrümmt als der Rücken. Die starken, nicht granulierten Querstreifen $(5-7$ auf $10 \mu)$ konvergieren in der Mitte. Länge $60-140 \mu$. Häufig.

4. C. (Cocc.) maculata $\mathrm{Kg}$.

Schalen halb-elliptisch, drei Mal so lang als breit, gleichmässig von der Mitte zu den Enden verschmälert. Rücken 
hoch gewölbt, Bauch gerade oder wenig konvex; Rhaphe dem Bauchrande genähert. Deutlicher Mittel- und Endknoten. Grobe Streifung (1o Streifen auf 1o $\mu$ ). Verbreitet.

5. C. (Cocc.) cymbiformis (Ehrbg.) Bréb.

Leicht gebogene, schlanke Form. Bauchrand fast gerade, in der Mitte wenig angeschwollen. Die leicht gekrümmte Mittellinie dem Bauchrande genähert. Mit deutlichem Mittel- und Endknoten. Streifen granuliert $(6-8$ auf Io $\mu)$. Länge $40-80 \mu$. In Teichen und Gräben.

6. C. (Cocc.) cistula (Hempr.) Kirchn. (Taf. VII, 45)

Mit stark konvexem Rücken und fast geradem Bauche bei etwas angeschwollener Mitte. Länge 20-80 $\mu ; 8-12$ Streifen auf то $\mu$. In Teichen und Flüssen, häufig.

7. C. (Cocc.) lanceolata (Ehrbg.) Kirchn.

Wie vorige Art. Enden abgestumpft, Mittellinie bogig gekrümmt. Länge I10-205 $\mu, 7-12$ geperlte Streifen auf $10 \mu$. Auf dichotom verzweigten und gegliederten Stielen. Häufig.

8. C. (Cocc.) gastroides $\mathrm{Kg}$.

Aehnelt $C$. cistula, doch schlanker, halb elliptisch und mit gröberen Streifen (6 auf $10 \mu$ ). Länge $180-250 \mu$. Sehr häufig.

9. C. (Encyonema) prostrata (Berk.) Ralfs (Taf. VII, 46)

Plumpe, halb elliptische Schalen mit angeschwollener Bauchseite und abgerundeten Enden (diese oft unregelmässig verbogen). Rhaphe geradlinig. Zellen in unverzweigten Gallertröhren. Länge $30-60 \mu$, Breite $20-65 \mu ; 7-9$ Streifen auf $10 \mu$. Häufig.

Iо. C. (Enc.) caespitosa (Kg.) Schütt

Zellen zarter, mit dünneren Enden und stark gewölbtem Rücken. In verzweigten Gallertröhren. Länge ${ }_{15}-38 \mu$, Breite 13-15 $\mu ; 9-12$ Streifen auf 10 $\mu$. Verbreitet.

\section{Amphora Ehrbg.}

Rhaphe zwei Mal gebogen, dem Bauchrande genähert, ebenso der Centralknoten. Einzeln lebend, frei oder auf Algen festsitzend. 
I. Mittelknoten rund . . . . . . . . . . . . . . 2

2. Gürtelband glatt, Schale quergestreift

I. A. ovalis

$2^{*}$. Schale und Gürtelband quergestreift 2. A. lineolata I*. Mittelknoten bandförmig, breit gezogen (zum Kreuz) . . 3. A. pediculus

I. A. ovalis $\mathrm{Kg}$. (Taf. VII, 49)

Gürtelansicht oval, mit abgerundeten Enden; Schalenansicht halbmondförmig. Streifen (9-12 auf 1o $\mu$ ) granuliert, bis zum Mittelpunkt reichend. Grösse sehr veränderlich. Länge I I-Iоo $\mu$. Ueberall, aber nicht häufig.

2. A. lineolata Ehrbg.

Gürtelansicht elliptisch, mit abgestutzten Enden. I6 Längsstreifen auf $10 \mu$. Länge $30-90 \mu$. In Teichen, nicht häufig.

3. A. pediculus (Kg.) Grun.

Kleine Form mit glattem Gürtelbande und glattem Querknoten. Streifen sehr fein $(25$ auf Io $\mu$ ). Länge I $2-40 \mu$. Auf Bacillariaceen (Nitzschia, Surirella etc.) und anderen festen Gegenständen. Weit verbreitet.

\section{Epithemia Kg.}

Zellen mit der konkaven (Bauch)-Seite auf anderen Algen epiphytisch festsitzend; Schalenseite C-förmig gekrümmt. Die der Bauchseite genäherte „Pseudorhaphe“ ist - bei einigen Arten wenigstens - eine echte Rhaphe.

I. Zwischen je zwei Querrippen nur eine Punktreihe . . . 2

2. Enden wenig vorgezogen, Zellen kaum verschmälert. .

I. E. turgida

2*. Enden deutlich vorgezogen und verdünnt

2. E. sorex

I*. Zwischen den Querrippen je 3-4 Punktreihen . . . . . 3

3. Enden nicht vorgezogen . . . 3. E. zebra

$3^{*}$. Enden deutlich vorgezogen . . . 4. E. argus

I. E. turgida Kg. (Taf. VII, 49)

Die starken Querrippen (4-6 auf $10 \mu$ ) konvergieren in der Nitte, Gürtelseiten mehr oder weniger konvex. Variiert etwas. Länge 25-1 Iо $\mu$. Sehr häufig, an Algen. 
2. E. sorex $\mathrm{Kg}$. (T́af. VII, 48)

Diese kleinere Form (Länge 8-35 $\mu$ ) hat schwächere Querrippen (5-7 auf Io $\mu$ ), die weniger stark als bei voriger Art konvergieren. Gürtelseiten stark konvex. Verbreitet.

3. E. zcbra Kg. (Taf. VII, 50)

Mit fast geradem Bauche und wenig konvexem Rücken. Gürtelseite mit parallelen Rändern. Länge $18-90 \mu ; 2,5-4$ Querrippen auf ıо $\mu$. Häufig.

4. E. argus Ehrbg.

Mit stärkeren Rippen als vorige Art [ $\mathrm{I}-2$ (nach andern 8-10) auf $10 \mu$, die ausserdem an den Gürtelbandrändern eine Reihe von Knöpfen bilden. Gürtelseite mit parallelen Rändern. Länge $33-90 \mu$. Nicht selten.

\section{Rhopalodia O. Muller.}

Gestalt von der Schalenseite nieren- oder sichelförmig. Mit deutlichem, etwas eingesenktem Mittel- und zwei Endknoten; die Rhaphe verläuft auf einer dachartigen Erhebung, die dorsalwärts verschoben ist und die Kante der Gürtelbandseite bildet.

I. Zellen wenig oder garnicht gekrümmt, lang linear, nur mit angeschwollener Mitte (Länge meist über $100 \mu$ ) . . . .

$$
\text { I. Rh. gibba }
$$

I*. Zellen mit fast geradem Bauchrande und hoch gewölbtem Rücken. Länge bis $75 \mu$ (selten $100 \mu$ ) 2. Rh. ventricosa

I. Rh. (Epithemia) gibba (Kg.) O. Müller (Taf. VII, 5 I)

Schalen in der Mitte und oft an den Enden angeschwollen, mit spitzen Enden und parallelen Querrippen (5-7 auf $10 \mu$ ). Die Punktreihen sehr zart. Länge $100(80)-180(250) \mu$. Ueberall, verbreitet.

2. Rh. (Epith.) ventricosa (Kg.) O. Müller

Enden mehr oder weniger vorgezogen, zugespitzt, meist herabgebogen. Querrippen parallel (5,5-6 auf Io $\mu$ ). Länge $37-73$ (го) $\mu$. 


\section{Fam. Nitzschiinae.}

Zellen zum Längsschnitte unsymmetrisch, gekielt. Kiel mit Punkten. Querschnitt rhombisch. Chromatophor verschieden, eine oder zwei Platten.

I. Zu Bändern vereinigt; Kiel median, Schale wenig konvex . 1. Bacillaria (S. 219)

I*. Einzellebend; Kiel seitlich verschoben, Schalen konvex.. 2. Nitzschia (S. 219)

\section{Bacillaria Gmelin.}

Zellen lang, stabförmig, mit deutlichen Querstreifen. Ketten in tafel- oder bandförmigen Ketten.

I. B. paradoxa Gmelin (Taf. VII, 52)

Eine äusserst interessante Form des Brackwassers (z. B. der Ostsee), die auch in salzigen Seen des Binnenlandes sich findet (so bei Halle). Dic Zellen bilden entweder Bänder wie Fragilaria, oder sie verschieben sich in der Längsrichtung gegen einander, ohne sich jedoch zu trennen. Dadurch bietet eine Kolonie beim Vorwärtsgleiten ein •anziehendes Schauspiel, das schon O. Fr. Müller und Ehrenberg unterhielt. Länge bis $160 \mu$, drei bis vier Querstreifen auf $10 \mu$.

\section{Nitzschia Hassall.}

Zellen meist frei, nach der Längsachse unsymmetrisch. Gürtelband- und Schalenfläche im spitzen Winkel zu einander. Schalen mit Kiel und Kielpunkten, die auch zu kurzen Rippen verlängert sein können. Chromatophor eine Platte mit centraler Durchbohrung.

I. Der Kiel auf der Schalenseite nach entgegengesetzen Seiten verschoben, Zellen gerade oder S-förmig gekrümmt (I. Nitzschia Hassall). . . . . . . . . . . . . . . . . . . 2

2. Kielpunkte sehr undeutlich, ebenso viel wie Querstreifen (Tryblionella W.Sm.) . . . . . . . . . . . . 3 3. Grosse Form, lanzettlich . . . . . I. N. tryblionella $3^{*}$. Mittelgross, linear, oft in der Mitte unmerklich eingezogen 2. N. angustata 
2*. Kielpunkte deutlich, höchstens halb so zahlreich wie die Querstreifen . . . . . . . . . . . . . 4

4. Mit starken, alternierenden Rippen, die nur bis zur Mitte gehen; von der Schalenseite gesehen, mit drei wellenförmigen Erhebungen (Grunowia Rabh.) . . . . . .

3. $N$. sinuata

4*. Rippen schwächer und meist länger, ohne wellige Erhebungen, höchstens gekrümmt . . . . . . . . 5

5. Zellen auf der Schalenseite in der Mitte zusammengezogen, bezw. vor den zugespitzten Enden wenig verdickt (Sectio: Constrictae) . . . . . . . . 6

6. Länge über $70 \mu$; Enden einfach zugespitzt, nicht verlängert . . . . . . 4. N. constricta

6*. Länge nicht über $65 \mu$, Enden etwas verlängert .7

7. Enden der Schalenseite höchstens etwas ausgezogen, meist keilförmig zugespitzt . 5. N. thermalis

$7 *$. Enden kopfförmig vorgezogen (auch auf der Gürtelseite zu sehen!). . . . . 6. N. parvula

$5^{*}$. Zellen nicht zusammengezogen . . . . . . . . 8

8. Zellen, von der Gürtelseite gesehen, schwach S-förmig gebogen; Kielpunkte nicht zu Rippen verlängert (Sectio: Sigmoideae, Gattung: Sigmatella Kg.). . 9

9. Die Ränder der Gürtelbandseiten parallel

7. $N$. sigmoidea

$9^{*}$. Die Gürtelseiten an den Enden zugespitzt

8. N. sigma

8*. Zellen nicht $\mathrm{S}$-förmig gebogen, linealisch oder an den Polen verdünnt. . . . . . . . . . 10

I0. Gürtelseiten linear oder an den Enden verdünnt, bisweilen schwach eingeschnürt oder schwach gekrümmt; Kiel excentrisch. Schale nicht in lange Spitzen ausgezogen (Sectio: Lineares) II

I I. Anzahl der Querstreifen doppelt so gross als die der Kielpunkte; mittelgrosse Form . .

\section{9. $N$. gracitis}

I I*. Vier Mal so viele Querstreifen als Kielpunkte; mittelgrosse und kleine Formen . . . . I 2

12. Kiel fast central, kaum excentrisch . . 13 13. Länge $60 \mu$ und mehr 10. N. linearis I $3^{*}$. Länge höchstens $25 \mu$ 11. $N$. minutissima 
I $2^{*}$. Kiel deutlich excentrisch .

14. Kielpunkte stark (10-I3 auf 1o $\mu$ )...

12. N. communis

I4*. Kielpunkte zart (16-20 auf го $\mu$ ) . 13. N. palea

Io*. Schalenseite nicht linear, in lange, dünne Enden ausgezogen, Kielpunkte kaum sichtbar; sehr feine Kieselschale [Sectio: Nitsschiella (Rabh.) Grun.] . 14. N. acicularis

I*. Kielknoten auf derselben (konkaven) Seite. Schalen ungleichseitig, bogig gekrümmt, Epithemia-ähnlich (II.Hantzschia Grun.) 15. N. amphioxys

I. N. tryblionella Hantzsch (= Tryblionella hantzschiana Grun.) (Taf. VII, 53)

Grosse, breit lanzettliche Schalen mit zugespitzten Enden. Länge $92-$ I $2 \mu$, Breite $20-27 \mu$. Mit $60-70$ über die ganze Schale gehenden, ein wenig gebogenen Querstreifen und gleichvielen Kielpunkten. Bisher meist nur in warmen Quellen gefunden.

2. N. (Trybl.) angustata (W.Sm.)

Viel kleinere Form mit linearen Schalen, die bisweilen in der Mitte etwas eingeengt sind. Etwa 140 Streifen auf I00 $\mu$. Nicht selten, in stehendem und langsam fliessendem Wasser.

3. N. (Grunowia) sinuata (Rab.) (= Denticula sin. W. Sm.)

Sehr veränderlich. Ausser den Rippen (4-5 auf Io $\mu$ ) noch feine Querstreifen $(22-25$ auf $10 \mu$ ). Mit etwas vorgezogenen Enden. Gürtelseite linear. Einzeln oder in Bändern. Länge 15-55 $\mu$. Häufig in Bächen höherer Gebirge; in der Ebene selten.

\section{N. constricta $\mathrm{Kg}$.}

Schalenseite linear, ein wenig lanzettlich; Kiel stark und sehr excentrisch. Querstreifen sehr fein $(25-30$ auf io $\mu)$. Starke Kieselschale. Länge 75- пг $\mu$. Hier und da, in Seen, meist einzeln.

\section{N. thermalis Auerswd.}

Schalenseite linear, Enden kegelförmig und etwas verlängert, mit abgerundeten Spitzen. Querstriche $(32-38$ auf $10 \mu$ ) kaum sichtbar; Gürtelseite gleicht einer Sohle mit mehr oder weniger breit abgestumpften Ecken. Länge $30-35 \mu$. Hier und da, ziemlich häufig. 
6. N. parvula. W. Sm.

Schalenseite linear, in der Mitte leicht - oft nicht ganz gleichmässig - verengert; die Gürtelseite nicht (?) central verengt. Streifung kaum sichtbar (27 Streifen auf 10 $\mu$ ). Mit zarter Schale. Länge $25-40 \mu$. Seltener.

7. N. sigmoidea W. Sm. (Taf. VII, 54)

Grosse Form mit (auf der Gürtelseite) gerade abgestutzten Enden, liegt meist auf der Gürtelseite. Schalenseite mit keilförmig zugespitzten Enden. Neun Kielpunkte und 27-36 Querstreifen kommen auf ro $\mu$. Variiert ziemlich. Eine weniger gekrümmte, dickere Form mit deutlichen Querstrichen wird als var. brebissoni (Kg.) J. Brun unterschieden, während eine Form mit zarterer Struktur und schmälerer Gürtelansicht die var. vermicularis (Hantzsch) bildet. Länge $100-500 \mu$. Die typische Form hier und da gemein, die Varietäten seltener.

8. N. sigma W. Sm.

Mittelgrosse Form mit mehr oder weniger deutlichen Querstreifen (23-27 auf 1o $\mu$ ); S-förmig gebogen in Gürtel- und Schalenansicht. Enden zugespitzt. Ebenfalls veränderlich: die var. curvula (Ehrbg.) J. Brun ist viel kleiner, mit 27-36 schwer sichtbaren Querstreifen; die noch kleinere var. clausi (Hantzsch) mit leichter Einschnürung vor den Enden. I.änge der typischen Form 55-125 $\mu$. Nicht häufig.

9. N. gracilis Hantzsch

Schalen mit stark verdünnten, vorgezogenen Enden; Kiel excentrisch. Etwa 12 Kielpunkte und über 25 Querstriche auf го $\mu$. Selten.

10. N. linearis (Ag.) W. Sm.

Schalenseite mit lang zugespitzten oder abgerundeten Enden. 8-9 starke Kielpunkte auf $10 \mu$, Streifung kaum sichtbar. Länge 50-I $45 \mu$. Die var. temiis (W. Sm.) J. Brun, deren Gürtelseite viel schmäler ist, und deren Schalenseite lang zugespitzte Enden mit IO-I 2 Kielpunkten auf Io $\mu$ hat, ist ziemlich verbreitet, während die typische Form überall gemein ist.

I1. N. minutissima W. Sm.

Lang lanzettliche Schalenseiten mit verlängerten Polen; kleine, aber deutliche Kielpunkte (I $1-13$ auf $10 \mu$ ). Querstriche 
sind unsichtbar (nach andern 25 auf Io $\mu$ ). Gürtelansicht linear oder nach den Enden zu schwach verdünnt. Verbreitet.

I2. N. communis Rabh. (erw.)

Gürtelseiten breit (oder schmal) lineal, mit verdünnten Enden. Schalenseite lanzettlich, mit zugespitzten Enden. Starke Kielpunkte (Io-I4 auf Io $\mu$ ). Variiert stark, so inbetreff der Breite der Gürtelseiten [bei der var. minuta (Bleisch.) sind sie schmal linear]. Länge $20-30 \mu$. Nicht zu häufig.

I3. N. palea W. Sm.

Kleine, lineare Form, die sich von der vorigen vor allem durch zartere Kielpunkte ( $16-20$ auf $10 \mu$ ) unterscheidet. Freischwimmend oder festsitzend [ $f$. dissipata (Rabh.) Kirchn.]. Sehr häufig, in jedem stehenden Gewässer.

I4. N. (Nitzschiella) acicularis (Rabh.) W. Sm. (Taf. VII, 55)

Schalenseite lang lanzettlich, die Hörner von $1 / 4$ der Gesamtlänge, hin und wieder gebogen, mit $20-23$ Kielpunkten auf ıо $\mu$. Gürtelansicht linear, mit zugespitzten Enden. Meist freilebend. Länge $35-50 \mu$. Ziemlich häufig.

15. N. (Hantzschia) amphioxys (Ehrbg.) Kg. (Taf. VII, 56)

Die schwach gebogene Schalenseite mit parallelen Bauchund Rückenrändern. Enden gewöhnlich wenig kopfförmig vorgezogen. Deutliche Querstreifen $(14-16)$ und grosse Kielpunkte (7-9 auf 10 $\mu$ ). Ziemlich variable Form. [Die var. vizax (W.Sm.) Grun. und elongata (Hantzsch) sind grösser und langgestreckter als die typische Art]. Länge 35-105 $\mu$. Ueberall verbreitet, (auch im Meere).

\section{Surirelloideae.}

\section{Fam. Surirellinae.}

Schalen symmetrisch zur Längsachse, mit geflügelten, oft quergerippten Randkielen. Letztere mit kanalartiger Rhaphe. Ohne Knoten. Chromatophoren: zwei den Schalen anliegende Platten.

I. Die Schalenoberfläche mit Querwellen, ohne Mittelrippe . .

1. Cymatopleura (S. 224) 
I*. Die Schalenoberfläche nicht so gebaut . . . . . . . . 2

2. Schalenumriss mehr oder weniger elliptisch, mit starken Querrippen; Kiel geflügelt . . 2. Surirella (S. 224)

2*. Schalenumriss fast kreisförmig 3. Campylodiscus (S.226)

\section{Cymatopleura W. Sm.}

Schalen elliptisch, zur Längs- und Querachse symmetrisch. Oberfläche unduliert, Pseudorhaphe schwer sichtbar. Gürtelansicht stabförmig, die Wellen als Erhebungen zeigend. Eine Auxospore aus zwei Zellen.

I. Schalenseite elliptisch, oval, Mitte am breitesten . . . .

\section{C. elliptica}

I*. Schalenseite mehr oder weniger lang elliptisch, mit eingeschnürter Mitte . . . . . . 2. C. solea

I. C. elliptica (Bréb.) W.Sm.

Mit zugespitzten oder abgerundeten Enden und vier bis acht breiten Querwellen, von denen die mittlere geradlinig, die seitlichen nach aussen gebogen sind. Mit Perlenrand (3-4 Punkte auf $10 \mu$ ). [Die seltene var. constricta (Grun.) hat eine eingeschnürte Mitte und abgerundete Enden]. Länge $75-$ I $35 \mu$. Nicht selten.

\section{C. solea (Bréb.) W. Sm. (Taf. VII, 57)}

Die meist verlängerten Schalen mit centraler Einschnürung, keilförmigen oder abgerundeten Enden und 4-6 oft wenig starken Querwellen. I0-I 2 (nach anderen 6-7) unregelmässig gewellte oder punktierte Querlinien auf $10 \mu$. Rand deutlich geperlt oder gezähnt. Meist $4-5 \mathrm{Mal}$ so lang als breit. [Die var. gracilis Grun. bis ı Mal so lang als breit, während die var. apiculata (W.Sm.) Pritsch. bei etwas vorgezogenen Spitzen nur $2-3 \mathrm{Mal}$ so lang als breit ist]. Länge $50-300 \mu$. Die typische Form überall, häufig.

\section{Surirella Turpin.}

Sehr schöne Diatomee von keilförmiger, elliptischer oder linearer Gestalt, bisweilen tordiert, mit Pseudorhaphe. Mit starken Querrippen und deutlichen, seitlichen Kielen. Eine Auxospore aus zwei Zellen. 
I. Schale nicht um die mittlere Längsachse gedreht . . . 2

2. Die kurzen Querrippen erreichen die undeutliche Mittellinie nicht . . . . . . . . I. S. ovata

$2^{*}$. Querrippen lang, erreichen die Mittellinie . . . . . 3

3. Schalen- und Gürtelseite symmetrisch nach der Querachse, Schalenseite nicht keilförmig . . . . . 4

4. Flügel deutlich; Länge über $50 \mu$. . . . . 5

5. Lanzettlich, Enden deutlich vorgezogen. .

2. S. craticula

$5^{*}$. Mehr elliptisch, Enden nicht so

3. S. biseriata

$4^{*}$. Flügel undeutlich; Länge bis $35 \mu$.

4. S. angusta

3*. Schalenseite keilförmig verschmälert . . . . . 6

6. Eng stehende, kräftige Querrippen $(2,5$ auf io $\mu)$

5. S. tenera

6*. Wenig starke Querrippen $(1,5-2$ auf $10 \mu)$

I*. Schalen um die mittlere Längsachse 8 -förmig gedreht.

7. S. spiralis

I. S. ovata Kg. (erw.) (Taf. VII, 58)

Gestalt sehr veränderlich, eiförmig bis linear; mit kurzen, meist undeutlichen Flügeln und nur randständigen Querrippen. Folgende Varietäten sind zu unterscheiden:

I. Mehr oder weniger eiförmig .

2. Kleine Form, bis $50 \mu$ lang, mit deutlichen Flügeln. Länge $20-50 \mu ; 4,5-6$ Rippen auf $10 \mu$

\section{typische Form}

$2^{*}$. Grössere Form, über $55 \mu$ lang, mit einem abgerundeten und einem spitzen Ende, undeutlichen Flügeln und punktierten Querstreifen. Länge 55-95 $\mu$; 3-5 Rippen und 12,5-14 Streifen auf 10 $\mu$

$$
\text { var. ovalis (Bréb.) Kirchn. }
$$

I*. Langgezogen eiförmig bis linear, Enden abgerundet . . 3

3. Lang eiförmig bis elliptisch, klein. Länge I 2,5-23 $\mu$; 6-7 Rippen auf ro $\mu$. var. minuta (Bréb.) Kirchn.

$3^{*}$. Lang elliptisch bis linear, in der Mitte hin und wieder verengt. Länge $15-33 \mu, 6$ Rippen auf го $\mu$. . .

Ueberall häufig, var.minuta gemein. 
2. S.craticula Ehrbg.

Mit deutlicher Mittellinie und starken, divergierenden, in der Mitte entfernter stehenden Querrippen [3-3,5(5) auf $10 \mu]$. Länge $45-60$ (120) $\mu$. Ziemlich selten.

3. S. biseriata (Bréb.) (Taf. VII, 59)

Sehr veränderliche Form. Elliptisch-lanzettlich; die konisch zugespitzten Enden stumpf. Rippen breit und kaum konvergent $(2-8$ auf $10 \mu)$. Gürtelseite ein langes Viereck mit abgerundeten Ecken. Länge $200-225 \mu$.

Die var. linearis (W. Sm.) ist kleiner (50-I I5 $\mu$ ) und viel schmaler linear, mit ganz zugestumpften Enden. Zwischen den Rippen $(3-5$ auf $10 \mu$ ) mit punktförmigen Erhebungen. Beide Formen ziemlich häufig.

4. S. angusta $\mathrm{Kg}$.

Kleine, lineare Form (Länge 20-35 $\mu$ ) mit scharf keilförmig zugespitzten Enden. Die deutlichen Querrippen $(5-7$ auf $10 \mu)$ parallel. Hier und da, häufig.

5. S. tenera Greg.

Schmal lanzettlich, mit schmaler, scharfer Mittellinie, engen Querrippen und wenig geflügeltem Rande, sonst der folgenden Art ähnlich. Länge $98-160 \mu$, Breite $27-35 \mu$. Hin und wieder.

6. S. splendida $\mathrm{Kg}$.

Grosse, schöne Form. Schalenseite oval-keilförmig, Querrippen $[2-3$ (nach andern $1,5-1,9$ ) auf 1o $\mu$ ] flach, schr breit, ziemlich konvergent. Kiel stark geflügelt. Gürtelseite ein wenig konisch. Länge $100-250 \mu$. Nicht selten.

7. S. spiralis Kg. (Taf. VII, 6o)

Zellen achtförmig gedreht. Schalenseite länglich-elliptisch, mit grossen Randperlen. Breite, wenig konvergente Rippen [1,6 (2-3) auf $10 \mu$ ], einen freien, lanzettlichen, mit unregelmässigen Punkten besetzten Raum freilassend. Länge $90-250 \mu$. Hier und da, scheint im Gebirge häufiger zu sein.

\section{Campylodiscus Ehrbg.}

Schalen kreisförmig und durch Verbiegung etwas unregelmässig erscheinend; dazu sattelförmig verbogen. Chromatophoren: zwei den Schalen anliegende Platten. 
C. noricus Ehrbg. (Taf. VII, 61)

Mit $40-50$ radialen Rippen. Mit einer Reihe von Punkten dazwischen [var. costata (W. Sm.) J. Br. mit zwei Punktreihen]. Freier, unregelmässig punktierter, viereckiger Raum in der Mitte. Am Rande mit grossen, den Rippen entsprechenden Perlen. Länge $50-135 \mu$. In Sümpfen etc., ziemlich verbreitet, aber nicht zahlreich.

\author{
IV. Peridiniaceae \\ (Dinoflagellaten, Cilioflagellaten, Peridineen).
}

\title{
Litteratur:
}

Ausser O. Fr. Müller, Paula Schrank, Ehrenberg, Claparède und Lachmann seien genannt:

v. Stein, Fr., Der Organismus der Infusionstiere III, 2. Leipzig I 883. Klebs, G., Die Peridineen des Süsswassers. (Untersuchungen aus dem Bot. Inst. zu Tübingen Bd. I). Leipzig 1883 .

Bütschli, A., Protozoa (In Bronns Klassen und Ordnungen des Tierreichs II). Leipzig $1883-87$.

Schilling, Die Süsswasserperidineen. (In der Flora oder allgem. bot. Zeitung. Bd. 74). Marburg 1891.

Schütt, F., Peridiniales. (In Engler-Prantls Natürlichen Pflanzenfamilien Bd. I, 1). Leipzig 1896.

Die Peridineen bilden eine eigenartige Gruppe von Organismen, die trotz unleugbarer Beziehungen $z u$ anderen Gruppen, wie Bacillariaceen und Desmidiaceen eine ziemlich isolierte Stellung einnimmt. So erklärt sich auch die Unsicherheit, womit man bis vor kurzem die Peridineen behandelte. Ehrenberg sowie Claparède und Lachmann u. a. stellten sie $z u$ den Tieren und zwar zu den Flagellaten, obwohl sie mit letzteren nichts als die Begeisselung gemein haben; Leuckart, Klebs und Schilling hingegen traten für die pflanzliche Natur der Peridineen ein. Ihre Ansicht wird jetzt von der Mehrzahl der Forscher geteilt, und selbst. die Thatsache, dass Formen von Glenodinium und Gymnodinium nach Art tierischer Organismen 
feste Nahrung aufnehmen, kann die jetzige Stellung der Peridineen wohl nicht mehr erschüttern.

Neben der Begeisselung ist der Besitz einer Quer- und einer Längsfurche, von denen die letztere häufig nur schwach ausgebildet ist oder selbst gänzlich fehlt, charakteristisch für die Peridineen. In diesen Furchen liegt je eine lange Geissel: diejenige der Längsfurche wird beim Schwärmen nachgeschleppt, ist also eine Schleppgeissel und dient als Steuer; die andere ist das Lokomotionsorgan. Sie liegt innerhalb ihrer Furche dem Körper eng an und ist in ununterbrochener welliger Bewegung begriffen, wodurch sie eine Reihe feiner Cilien vortäuscht. Die von Claparède und Lachmann eingeführte Bezeichnung "Cilioflagellaten“ geht auf diese Täuschung zurück. Erst Klebs gelang es, jene zweite Geissel aufzufinden und damit die Irrtümer seiner Vorgänger zu berichtigen.

Die niederen Formen verharren entweder völlig nackt oder sind höchstens mit einer dünnen Membran versehen. Die höchst stehenden Gattungen Ceratium und Peridinium sind durch eine feste, skulpturierte Hülle aus Cellulosestoff ausgezeichnet, die an Festigkeit und Eigenart des Baues nur von der DiatomeenSchale übertroffen wird, ohne jedoch wie diese verkieselt $z u$ sein. Die Schalen sind bei den genannten Gattungen aus mehreren Tafeln von regelmässiger Gestalt und Anordnung zusammengesetzt und bieten systematisch wichtige Unterscheidungsmerkmale. Wie die schematischen Abbildungen auf Taf. VIII, $6 \mathrm{ff}$. zeigen, ist die Anordnung im grossen und ganzen folgende: Auf der Vorderseite erstreckt sich eine fünfeckige Platte, die „Rautenplatte“, von der Baucheinschnürung gegen den $\mathrm{Pol}$ hin, den sie berührt oder nicht erreicht $(P$. cinctum $)$. Um den Pol und die eine oder zwei dorsalen Scheitelplatten herum lagern kreisförmig zwei Zonen von Platten: Es sind die vier oder fünf seitlichen Scheitelplatten, die von den sieben die Querfurche begrenzenden Rand(vorderen Basal-) platten umschlossen werden. Auf der Rückseite liegen der Querfurche die hinteren Rand- (Basal-)zellen an, die ihrerseits wiederum zwei End- (Antapikal-) platten umgrenzen. Die Anordnung im einzelnen ist bei jeder Spezies anders. Bei Ceratium ist die Anzahl der Platten etwas vermindert, und ihre Anordnung, wie aus Taf. VIII, $6 \mathrm{zu}$ ersehen, erheblich einfacher.

Die Chromatophoren sind kleine Plättchen von gelber oder brauner bis grüner Farbe, da das grüne Chlorophyll durch das 
rotgelbe, wasserlösliche „Peridinin" mehr oder weniger verdeckt wird. Erstes Assimilationsprodukt ist ein mcist rotgelb gefärbtes, fettes Oel.

Die (ungeschlechtliche), Vermehrung findet gewöhnlich im ruhenden Zustande statt. Gewöhnlich spielt sich die Teilung in einer gallertigen Hülle oder in der alten Muttermembran ab. Bei Ceratium und anderen ist eine wahrscheinlich als Längsteilung aufzufassende Vermehrung im beweglichen Zustande, ähnlich derjenigen der Desmidien, bekannt (die Teilungsebene geht schief durch die Geisselbasis; jede Tochterzelle erhält ein Stückchen alter Muttermembran mit, während die andere Hälfte der Hülle neu gebildet werden muss). Die Kopulation, die einige Forscher beobachtet haben wollen, bedarf noch der Bestätigung. Einige Formen, wie Ceratizım, bilden die sogenannten "gehörnten Cysten", deren Entstehung ebenfalls noch etwas unklar ist.

Die Mehrzahl der Peridineen lebt im Meere und bildet mit den Bacillariaceen die Hauptmasse des marinen Planktons, das für. die tierischen Bewohner der See als Nahrung von der grössten Bedeutung ist. Im Süsswasser sind nur einige Peridineen (so besonders Ceratium hirundinella) Planktonalgen, sie sind jedoch nicht von solcher wirtschaftlichen Bedeutung. Die wenigen Süsswasserbewohner leben zumeist in grossen Mengen zwischen andern Algen, Charen etc. am Rande von Sümpfen und Teichen.

Einige marine Formen tragen zum Meeresleuchten bei, in der gleichen Weise, wie auch die verwandten zwei Cystoflagellaten (Noctiluca miliaris und Leptodiscus medusoides). Das einige Male beschriebene Leuchten von Süsswasser-Peridineen ist wahrscheinlich auf die Anwesenheit von Leuchtbakterien zurückzuführen.

[Zur Untersuchung der Geisseln gebrauche man $1 \%$ Chromsäure (Klebs), da bei anderer Fixierung meist die Geisseln am Körper dicht anliegen bleiben oder ganz abfallen].

I. Alge ohne starke, skulpturierte Cellulose-Membran, nackt oder in gallertartiger Hülle (I. Amphidinieae) . . . . . . . 2

2. Die Querfurche nur einseitig . I. Hemidinium (S. 230)

2*. Die Querfurche fast kreisförmig . . . . . . . . . 3

3. Die Querfurche stark nach vorn geschoben, so dass der vordere Teil kopfförmig wird

$$
\text { 2. Amphidinium (S. 230) }
$$

3*. Die Querfurche der Mitte genähert

$$
\text { 3. Gymnodinium (S. 230) }
$$


$I^{*}$. Alge mit Cellulose-Membran, die meist aus mehreren Platten zusammengesetzt ist (II. Peridinicac) . . . . . . . . . 4

4. Unvollkommen gepanzert, Hülle aus zwei strukturlosen Schalen und Gürtel bestehend 4. Glcnodinium (S. 232)

4*. Schalen- und Gürtelfläche gepanzert . . . . . . . 5

5. Gestalt in Hörner ausgezogen; eine Endplatte. . .

5. Ceratium (S. 233)

$5^{*}$. Gestalt rundlich; mit drei Endplatten

$$
\text { 6. Peridinium (S. 233) }
$$

\section{Hemidinium Stein.}

Kleine, asymmetrische Formen mit sehr zarter Zellwand. Die beiden Furchen entstehen in der Mitte der Bauchseite. Die kleinen Chromatophoren hellgelb bis braunrot.

H. nasutum Stein (Taf. VIII, 1)

Länge der Zelle $24,75 \mu$, Breite 16,7 I $\mu$. In allen Teichen und Sümpfen, häufig.

\section{Amphidinium Clap. u. Lachm.}

Von ei- bis kugelförmiger Gestalt. Längsfurche am ganzen zentralen Teile des mehr oder weniger kugeligen Hinterkörpers. Ohne Membran (?). Bandförmige Chromatophoren von brauner Farbe, meist strahlig angeordnet. Ohne Augenfleck.

Amph. lacustre Stein (Taf. VIII, 2)

Länge $23 \mu$, Breite $18,4 \mu$. In Sümpfen und (salzigen) Seen.

\section{Gymnodinium Stein.}

Die Querfurche verläuft mehr oder weniger steil rechtsschraubig; Längsfurche fast nur auf die hintere Körperhälfte beschränkt. Meist vollkommen nackt, nur im ruhenden Zustande mit schleimiger oder fester Cystenhülle. Chromatophoren, wenn vorhanden, von gelb- bis rotbrauner oder spangrüner Farbe. Mit oder ohne Augenfleck.

I. Chromatophoren spangrün. . . . . . I. G. acruginosum I*. Chromatophoren fehlen oder sind gelb bis·braun . . . 2

2. Chromatophoren fehlen . . . . . . . . . . . . 3 3. Körper vollkommen asymmetrisch, Querfurche ungewöhnlich steil verlaufend . . 2. G. hyalinum 
$3^{*}$. Körper symmetrisch; die Querfurche läuft in sich zurück 3. G. vorticella

2*. Chromatophoren vorhanden . . . . . . . . 4

4. Längsfurche fehlt oder ist undeutlich . . . . . 5

5. Querfurche kaum ạngedeutet . . 4. G. paradoxum

5*. Querfurche deutlich . . . . 5. G. pulvisculus

4*. Längsfurche deutlich . . . . . . . . . 6

6. Sehr klein (Länge $23 \mu$ ); asymmetrisch, indem die Enden der Querfurche sich bei weitem nicht in einem Punkte treffen . . . . . . . . 6. G. pusillum

6*. Grössere Formen symmetrischen Baues . . . . . 7

7. Querfurche dem Hinterende genähert, die beiden Hälften also ungleich . . . 7. G. pahıstre

$7^{*}$. Querfurche fast genau in der Mittellinie.

8. G. fuscum

1. G. aeruginosum Stein

Gestalt länglich. Länge 33,75 $\mu$, Breite 21,69 $\mu$. Ohne Augenfleck. Fast allenthalben reichlich.

2. G. hyalinum Schilling

Gestalt oval. Länge $23,6 \mu$, Breite $20,7 \mu$. Längsfurche eine schwache Vertiefung. In 'Teichen.

3. G. vorticella Stein

Die Vorderhälfte nimmt zwei, die Hinterhälfte ein Drittel der Körpergrösse ein. Aussehen helmförmig. Mit lebhaft rotem Augenfleck, wie vorige Art. Länge 30-40 $\mu$. Nährt sich tierisch und besonders von Chlamydomonaden. In Teichen.

4. G. paradoxımn Schilling

Gestalt kugelig. Länge $36,8 \mu$, Breite $34,5 \mu$. Die dunkelrotbraunen Chromatophoren in der Mitte des Körpers angehäuft. Mit Augenfleck. Zeigt schwerfällige Bewegung. In Sümpfen.

5. G. pulvisculus Klebs

Gestalt breit oval. Das hintere Ende breit abgerundet. Wie vorige Art.

6. G. pusillum Schilling

Der kleinste Vertreter der Gattung. Länge $23 \mu$, Breite I 8,4 $\mu$. Aehnelt dem G. hyalinum. Grosse, hellgelbe Chromatophoren. Mit Augenfleck. Wie vorige Art, häufig. 
7. G. palustre Schilling

Körperhälften ungleich gross; die grössere Vorderhälfte mit stumpfem Scheitel. Gelb- bis dunkelbraune Chromatophoren. Ohne Augenfleck. Länge 44,17 $\mu$, Breite $37,5 \mu$. In Sümpfen.

8. G. fuscum Stein (Taf. VIII, 3)

Gestalt immer etwas langgestreckt. Die hintere Körperhälfte läuft in eine Spitze aus. Chromatophoren. klein, gelbbraun. Ohne Augenfleck. Nicht selten.

\section{Glenodinium Ehrbg.}

Zelloberfläche glatt (Ausnahme scheint selten!). Die Chromatophoren sind kleine, gelb- bis schwarzbraune Platten.

1. Die Körperhälften einander nahezu gleich

2. Länge über $40 \mu$. . . . . . . I. Gl. cinctum

2*. Länge überschreitet $30 \mu$ nicht . . . . . . . . . 3

3. Chromatophoren rot- bis schwarzbraun

2. Gl. cornifax

3*. Chromatophoren hellgelb . . 3. Gl.pulvisculus

I*. Körperhälften einander nicht gleich . . . . . . . . . 4

4. Chromatophoren schwarzbraun . . 4. Gl.uliginosum

4*. Chromatophoren hellgelb . . . . 5. Gl. neglectum

1. Gl. cinctum Ehrbg. (Taf. VIII, 4)

Gestalt nahezu kugelig. Länge $43 \mu$. An der Querfurche mit hervortretendem Rande. Längsfurche bildet eine tiefe Rinne. Membran ist eine dünne, biegsame Hülle. Chromatophoren gelbbraun. Hufeisenförmiger Augenfleck. (Bei Behandlung mit Chlorzinkjod wird die Hülle violett). Fast in jedem Sumpfe.

2. Gl. cornifax Schilling

Etwas länglich. Länge $25 \mu$, Breite $20 \mu$. Mit Augenfleck. (Die Hülle wird mit Chlorzinkjod schwarzblau). In Sümpfen, oft zahlreich.

3. Gl. pulvisculus Stein

Länge $23 \mu$, Breite $18 \mu$. Die vordere Körperhälfte breit abgerundet. Ohne Augenfleck. (Die Hülle wird mit Chlorzinkjod schwarzblau). Sehr verbreitet.

4. Gl.uliginosum Schilling

Gestalt kugelig. Länge $38 \mu$, Breite $30 \mu$. Die vordere, kugelig abgerundete Körperhälfte grösser als die hintere. Ohne Augenfleck. (Die Hülle wird mit Chlorzinkjod rot). In Torfmooren, verbrcitet. 
5. Gl. neglectum Schilling

Mit voriger Art zusammen und ihr ähnlich, doch kleiner. Länge $31 \mu$, Breite $29 \mu$. (Die Hülle bleibt mit Chlorzinkjod ungefärbt). Mit Augenfleck.

\section{Ceratium Schrank.}

Mit starker, dorsoventraler Abplattung, durch die Hörner ganz asymmetrisch. Die vordere Körperhälfte mit cinem apikalen Horne, die hintere mit ein bis zwei postaequatorialen und einem antapikalen Horne. Längsfurche in schiefer Richtung verlaufend. Panzer mit insgesamt io Tafeln, sechs davon in der Vorder- und vier in der Hinterhälfte. Chromatophoren klein, gelbbraun. Ohne Augenfleck. Sehr grosse Formen.

I. Gestalt plump, bis i $23 \mu$ lang . . . . I. C. tetraceros $I^{*}$. Gestalt schlank, mit längeren Hörnern, bis $450 \mu$ lang . •

2. C. hirundinella

I. C. tetraceros Schrank ( $=$ C. cornutum Clap. et Lachm.)

Etwa $64 \mu$ breit. Mit meist drei Hörnern. In Sümpfen, Teichen etc., verbreitet.

2. C. hirundinella O. Fr. Müll. (Schwalbenschwanz-Alge) (Taf. VIII, 5 u. 6)

Mit vier (selten drei) Hörnern. Variiert in interessanter Weise, sowohl der Jahreszeit nach („Saisondimorphismus") als auch nach der Lokalität („Lokalrassen“), indem die Hörner bald stärker, bald schwächer divergieren, bald kürzer, bald länger ausgebildet sind. Im Plankton von grösseren Seen.

\section{Peridinium Ehrbg.}

Gestalt symmetrisch; auf der Scheitelansicht nierenförmig. Hintere Körperhälfte kleiner als die vordere. Mit insgesamt 20-2 I Tafeln, und zwar'13-I4 auf der vorderen, sieben auf der hinteren Hälfte. Membran wird mit Chlorzinkjod nur rötlichbraun. Chromatophoren hell- bis dunkelbraun.

1. Sehr kleine Form, nicht über $20 \mu$ lang 1. P. minimum ${ }^{*}$. Ueber $30 \mu$ lang . . . . . . . . . . . . . . . . 2

2. Tafeln der Hülle ohne Netzstruktur . . . . . . 3

3. Langgestreckt, die vordere Körperhälfte mit einem Horne, die hintere mit zwei grossen Stacheln . . 2. P. quadridens 
3*. Breit eiförmig, anders gebaut . 3. P. umbonatum 2*. Tafeln mit Netzstruktur . . . . . . . . . . . . 4 4. Die „Rautenplatte" reicht nicht bis zum Pole. . . 4. P. cinctum

4*. Die „Rautenplatte“ reicht bis zum Pole . . . . 5 5. Die Platten gerade; die sie umzichenden Leisten einfach ausgebildet . . 5. P. tabulatum

$5^{*}$. Die Platten nach innen konkav; auf den Kanten mit Flügelleisten . . . 6. P. bipes

I. P. minimum Schilling

Breite $16,88 \mu$, eiförmig. Tafeln ohne Skulptur. Chromatophoren hellgelb. Ohne Augenfleck. "Wackelt" durch das Gesichtsfeld. Sehr verbreitet.

2. P. quadridens Stein (Taf. VIII, II)

Langgestreckt, Länge $34 \mu$, Breite $27 \mu$; die Zwischentafelzonen ohne Quersteifung. Chromatophoren dunkelbraun. Mit Augenfleck. Nicht sehr häufig.

3. P. umbonatum Stein (Taf. VIII, 8)

Zelle 3 I $\mu$ lang und $26 \mu$ breit. Die Quer- und Längsfurche sehr breit. Chromatophoren rotbraun. Ohne Augenfleck. Zeigt kreisende Bewegung. Sehr verbreitet.

4. P. cinctum Ehrbg. (Taf. VIII, 9)

Gestalt kugelig bis eiförmig. Länge $46 \mu$, Breite $43 \mu$. Sehr breite Leisten zwischen den Tafeln. Vordere Panzerhälfte unsymmetrisch. Chromatophoren tief braun. Meist unter P.tabulatum, verbreitet.

5. P. tabulatum Clap. et Lachm. (Taf. VIII, 7)

Von kugeliger bis eiförmiger Gestalt. Länge $48 \mu$, Breite $43 \%$. Die Netzleisten der Tafeln mit kleinen Stacheln. Chromatophoren tief braun. Ohne Augenfleck. Ueberall und sehr häufig.

6. P. bipes Stein (Taf. VIII, Io)

Gestalt breit eiförmig. Länge $45 \mu$, Breite $43 \mu$. Chromatophoren tief braun. Ohne Augenfleck. Unter den beiden vorigen Arten, häufig. 


\section{Characeae}

(Armleuchter-Gewächse).

$\mathrm{Da}$ die hierhergehörigen Formen die Grösse der mikroskopischen Organismen erheblich überschreiten und schon bei Lupenvergrösserung zu studieren sind, so ist von einer Bearbeitung an dieser Stelle abgesehen. Wer sich damit näher beschäftigen will, benutze:

Sydow, P., Die bisher bekannten europäischen Characeen. Berlin 1882. Migula, W., Die Characeen Deutschlands, Oesterreichs und der Schweiz, Bd. V. von Dr. L. Rabenhorsts Kryptogamen-Flora. II. Aufl. Leipzig 1897 .

Die chlorophyllgrünen Pflanzen haben einen gegliederten, oft durch Kalkinkrustation brüchigen Stengel, an dessen Knoten zahlreiche Zweige stehen, die die männlichen Geschlechtszellen (Antheridien) und die weiblichen Organe (Sporenknospen) tragen. Die Antheridien entwickeln Spermatozoide, die das Ei befruchten, das dann von einer Hülle umrindet wird. Aus der Oospore bildet sich die neue Pflanze erst mittelbar bei der Keimung aus.

\section{Phaeophyceae}

(Braunalgen).

\section{Litteratur:}

Hauck, Die Meeresalgen Deutschlands und Oesterreichs in Dr. L. Rabenhorsts Kryptogamen-Flora, II. Aufl. Leipzig 1885.

Kjellmann, F. R., Phaeophyceae in Engler u. Prantls Natürlichen Pflanzenfamilien. Bd. I, 2. Leipzig I891.

Diese fast nur marine Gruppe von meist hoch entwickelten Algen ist durch einen wasserlöslichen, das grüne Chlorophyll verdeckenden, braunen Farbstoff (Phycophaeïn) ausgezeichnet. Vermehrung geschlechtlich durch Oogonien und Antheridien (kommt bei Süsswasserformen nicht vor) oder durch Isogameten oder Zoo* 
sporen; alle Schwärmer, geschlechtliche wie ungeschlechtliche, haben zwei seitlich inserierte Geisseln, von denen die eine beim Schwimmen nach vorn gerichtet ist, die andere nachschleppt.

Aus dieser Gruppe sind am bekanntesten die braunen Meeres-Tange, wie Fucus und andere; im Süsswasser giebt es nur die folgenden vier oder fünf Gattungen:

I. Zellen frei lebend, höchstens epiphytisch, nie im Innern von andern Pflanzen

2. Die Alge bildet kleine, gallertige Scheiben mit zahlreichen Zellen und langen Gallertfäden

$$
\text { I. Naegeliella (S. 236) }
$$

$2^{*}$. Die Alge ist anders gebaut

3. Langer, verzweigter, gallertiger Tallus, in dem die einzelnen Zellen zerstreut liegen

Mastigophore: Hydrumes

3*. Thallus ohne solche auffällige Gallertausbildung 4 4. Krustenförmig, der Unterlage aufgewachsen. .

2. Lithoderma (S. 237)

4*. Die Alge besteht aus verzweigten Fäden . . 5

5. Alle Fäden aufrecht; Zoosporangien den vegetativen Zellen gleich

Confervoidee: Phacothamnium (S. I31)

$5^{*}$. Ein horizontaler Faden, von dem zahlreiche aufrechte Fäden entspringen; Zoosporangien keulenförmig angeschwollen

3. Pleurocladia (S. 237)

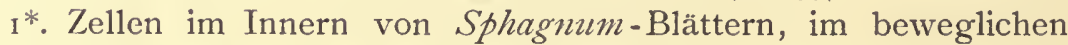
Zustande als Amoeben herumkriechend

4. Chlamydomyxa (S. 237)

\section{Naegeliella Correns.}

Eine epiphytische Alge zweifelhafter Stellung im Systeme, die trotz des alkohol-löslichen Farbstoffes noch am ehesten bei den Phaeophyceen Platz hat, wenn sie sich auch von den anderen Gattungen prinzipiell unterscheidet und den Protococcoiden nähert. Mit Hydrurus scheint sie nichts gemein $z \mathrm{u}$ haben. Die Zellen mit grossen; gelbbraunen Chromatophoren, ohne Pyrenoide und Stärke, aber mit Oel. Schwärmsporen mit zwei seitlichen Cilien, die unmittelbar eine neue Pflanze bilden. 


\section{N. Alagellifera Correns (Taf. VIII, 12)}

Länge der Zellen I - $16 \mu$, Breite 9-14 $\mu$. Auf Cladophora, scheint selten.

\section{Lithoderma Aresch.}

Die Alge bildet horizontal ausgebreitete Krusten auf Steinen, Muscheln etc. Zweierlei Fortpflanzungsorgane sind bekannt: verkehrt eiförmige, aus Oberflächenzellen hervorgehende Sporen und mehrfächerige, seitlich inserierte Organe zur Bildung von Gameten (Gametangien).

L. fontanum Flah. (Taf. VIII, 13)

Die Alge ist schwarzbraun, von einem Durchmesser von $5-15 \mathrm{~cm}$, mit $15-20$ vertikal gereihten Zellen von $6-12 \mu$ Dicke. In Gebirgsbächen, selten.

Das verwandte $L$. fuviatile Aresch. bildet einen winzig kleinen, nur 5-6-schichtigen Thallus.

$\mathrm{Ob}$ das von Hansgirg beschriebene, ebenfalls krustenbildende Phacodermatium rivulare Hansg. mit $2,5-9 \mu$ dicken Zellen, die je ein goldgelbes Chromatophor haben, aufrecht zu halten ist, ist noch fraglich (Taf. VIII, I4).

\section{Pleurocladia A. Br.}

Sporangien birnförmig; Gametangien länglich schotenförmig. Pl. lacustris A. Br. (Taf. VIII, i5)

Olivenbraune, lockere Ueberzüge auf Steinen bildend. In Seen, selten.

\section{Chlamydomyxa Arch.}

Der als Vertreter einer eigenen Familie (der Chlamydomyxaceen Hieron.) bekannte Organismus nimmt eine interessante Mittelstellung zwischen Phaeophyceen und Vampyrellaceen ein, indem er bald deutliche Pflanzennatur zeigt (Cellulose-Membran), bald als Amöbe sich tierisch ernährt.

Chl. labyrinthuloides Arch. (Taf. VIII, 16)

In torfigen Gewässcrn, im Innern von Sphagnum-Blättern als Raumparasit. 


\section{Rhodophyceae}

(F1orideae, Rotalgen).

Litteratur:

Ausser $\mathrm{Hauck}$ besonders:

Schmitz, Fr. und P. Hauptfleisch, Rhodophyceae in Engler und

Prantls Natürlichen Pflanzenfamilien. Leipzig $1896 / 97$.

Meist marine Formen, die sich oft durch eine schöne, rote Farbe und einen fein zerschlitzten Thallus auszeichnen; im Süsswasser nur einige wenige, mehr unscheinbare Gattungen. Die Gruppe steht ziemlich isoliert neben den anderen grossen Algentypen, wenn sie auch nach Schmitz Anklänge an die Coleochaetaceen aufweist, was jedoch von Wille bestritten wird.

Die geschlechtliche Fortpflanzung besteht in einer Befruchtung von Eiern durch Spermatien, d. h. unbewegliche, kleine männliche Zellen. Die Spermatien entstehen an Antheridien; die Eizelle, das "Carpogon", ist bei den echten Florideen in ein langes Empfängnishaar, das „Trichogyn", ausgezogen, an dem die vom Wasser herbeigeschwemmten Spermatien zur Befruchtung festkleben. Die weitere Entwicklung des Eies ist meist sehr kompliziert; gewöhnlich entstehen oft in sogenannten Cystocarpien eingeschlossene Fadenbüschel, („Gonimoblaste") an denen die Eisporen sich bilden.

Die ungeschlechtliche Fortpflanzung geschieht durch meist in der Vierzahl vorhandene Sporen (,Tetrasporen").

Die Abtrennung der Bangiaceen ist durch die einfache Ausbildung des Eiapparates und der Fruchtbildung gerechtfertigt: über deren systematische Stellung überhaupt und besonders über diejenige der weiter unten aufgeführten Gattungen siehe die Bemerkungen bei den Bangiaceen (S. 242).

I. Zellen krustenförmig dem Substrate aufliegènd

\section{Hildenbrandia (S. 239)}

I*. Zellen nicht so

2. Zellen isoliert in Schleimfäden eingeschlossen

7. Allogonium (S. 242)

$2^{*}$. Thallus anders gebaut

3. Zellen in kugeliger Schleimhülle, mit langen Borsten .

8. Gloeochaete (S. 243) 
3*. Zellen ohne lange Borsten . . . . . . . . . . . 4

4. Zellen einzeln . . . . . . . . . . . . . . 5

5. Zellen weinrot, in einem schleimigen Lager, an feuchten Mauern . . . 9. Porphyridium (S. 243)

5*. Chromatophor blaugrün . . . . . . . . . 6

6. Chromatophoren in Fäden von einem Punkte ausstrahlend oder in wandständigen Stäbchen. Zellen oblong . . . . 10. Glaucocystis (S. 243)

6*. Zellen gleichmässig blaugrün, in lange Spitzen ausgezogen . . . 11. Asterothrix (S. 244)

4*. Pflanzen mehrzellig . . . . . . . . . . . . 7

7. Thallus besteht aus verzweigten, dicht behaarten Fäden . . . . . 2. Thorea (S. 240)

$7 *$. Thallus ohne Haarbildungen . . . . . . . . 8

8. Zellfaden unverzweigt, ein- oder mehrreihig. . . 6. Bangia (S. 242)

$8^{*}$. Zellfaden verzweigt oder dick, mit knotenförmigen Verdickungen

9. Thallus besteht aus steifen, braunen Borsten . 3. Lemanea (S. 240)

9*. Thallus weich und zart, auch schlüpfrig . Io 10. Einfach verzweigte Zellreihen . . . . .

4. Chantransia (S. 240)

10*. Zellreihen reichlich büschelig verzweigt oder feine, weiche Fäden bildend .

5. Batrachospermum (S. 24I)

\section{Florideen.}

\section{Hildenbrandia Nardo.}

Sehr kleinzelliges, krustenförmiges, den Unebenheiten des Substrates eng angeschmiegtes Lager. Sporangien unregelmässig $\mathrm{zu}$ mehreren in lysigenen (durch Auflösen von Zellwänden entstandenen), becherförmigen Behältern (Konceptakeln).

H. rivularis (Liebmann) Bréb. (Taf. VIII, 17)

Bisher nur steril gefunden. Thallus von purpurroter Farbc. An und in ihm wächst häufig eine wasserbewohnende Flechte (Hadubrandia decipiens Schmitz), deren Fruktifikationsorgane nicht mit denen der $H$. rivularis zu verwechseln sind. 


\section{Thorea Bory.}

Bildet aufrechte, stielrunde, reich verzweigte, schlüpfrige Fäden mit Markschicht und Rinde. Sporangien in grosser Anzahl in der Rindenschicht. Von Schmitz nicht $z u$ den Florideen gestellt.

Th. ramosissima Bory (Taf. VIII, 18 )

Der Thallus wird fusslang, pferdehaar-dick und stärker; dunkelgrünbraun, getrocknet violett. In Flüssen, selten.

\section{Lemanea Bory.}

An den knotigen Anschwellungen sind dic Antheridien entwickelt, während die Cystocarpien im Innern des Thallus zerstreut sind. Ensteht aus einem fädigen, Chantransia-artigem Vorkeime.

I. Die Antheridien bilden gesonderte Höcker (I. Sacheria Sirodot)

\section{L. fuviatilis}

I*. Die Antheriđienzweige bilden am Thallus einen ringförmigen Höcker (II. Lemanea Bory) . . . . . 2. L. tonulosa

\section{L. Auviatilis C. Ag.}

Thallus, auch trocken, schwarzbraun bis schwarzviolett, meist verzweigt, 6- $16 \mathrm{~cm}$ lang. Die Antheridien tragenden Papillen meist zu dreien im Quirl stehend. In schnell fliessenden Bächen und Flüssen, in Mühlgräben etc., nicht in der Tiefebene.

2. L. torulosa (C. Ag.) Sirodot (Taf. VIII, 19)

Fäden mehr oder weniger gebogen, meist unverzweigt, $5-8 \mathrm{~cm}$ lang und $2 \mathrm{~mm}$ dick, oliven- bis dunkelbraun. Vorkommen wie bei voriger Art.

\section{Chantransia (DC) Schmitz.}

Unregelmässig verzweigte Zellfäden, oft in ein abfallendes Haar auslaufend. Fortpflanzung durch ungeschlechtliche Sporen; nur bei einer Art (Ch. corymbifera Thuret) sind bisher Cystocarpien beobachtet. Es ist mehr als wahrscheinlich, dass die unten angeführten Arten nur jugendliche Entwickelungsformen von Batrachospermum und Lemanea darstellen; dies ist von Sirodot und anderen für $C h$. chalybea und $C h$. hermanni thatsächlich auch nachgewiesen. Da die Chantransien sich aber 
oft jahrelang ungeschlechtlich fortpflanzen, mögen sie hier als selbständige Arten aufgeführt sein.

I. Aestchen straff aufrecht angedrückt . . I. Ch. chalybea ${ }_{1}$. Aestchen fast wagerecht abstehend . . . . . . . . . 2

2. Vegetative Zellen $8-9 \mu$ dick, 2-4 Mal so lang .. 2. Ch. violacea 2*. Vegetative Zellen I I-I4 $\mu$ dick, 2-3 Mal so lang 3. Ch. pygmaea

I. Ch. [Andouinella (Bonn.) Bonn.] chalybea Fries (Taf. VIII, 20) Thallus stahlblau bis bräunlich, bis ro $\mathrm{mm}$ lange Rasen bildend. Sporen-Häufchen auf kurzen Seitenästen. In Quellen und klaren Bächen an Steinen festsitzend, nicht selten.

2. Ch. violacea $\mathrm{Kg}$.

Räschen nur 2-3 $\mathrm{mm}$ hoch, polsterförmig, lebhaft violett bis rötlich. Vorkommen wie bei voriger Art, doch mehr in Gebirgen.

3. Ch. pygmaea $\mathrm{Kg}$.

Räschen wie bei voriger Art, rundlich bis linsenförmig, dunkelstahlblau bis rötlich. Vorkommen wie bei voriger Art.

\section{Batrachospermum Roth.}

Die typische Pflanze entsteht als Seitenspross auf der Chantransia-Form. An den farblosen Hauptachsen stehen meist dicht büschelige, dunkelgefärbte Zweigknäuel aus rosenkranzförmigen, feinen Zweigen.

Von den Quirlen nach abwärts wachsen einige Zellfäden, die eine Berindung der Hauptachse bewirken. Die Karpogonien mit Trichogynen an den Zweigen; Antheridien an der Spitze der Achsen.

Die angeführten zwei Batrachospermum-Arten hat Sirodot in 17 neue geteilt:

1. An den Berindungszellfäden sind wenige oder keine (Interstitial-) Zweige entwickelt . . . . . . B. moniliforme I*. Mit zahlreich entwickelten Interstitialzweigen 


\section{B. moniliforme Roth (Taf. VIII, 21)}

Bildet $2 \mathrm{~cm}$ bis $2 \mathrm{dm}$ lange, schlüpfrige Rasen von schwärzlicher bis purpurroter oder blaugrüner Farbe. Die Zweigwirtel dem blossen Auge als Knötchen erscheinend. Sehr variable Art. In Bächen, Teichen etc., wohl ziemlich verbreitet.

\section{B. vagum (Roth) Ag.}

Thallus 2-12 cm lang, schön spangrün, meist dichotom verzweigt. In torfigen Gewässern, seltener.

\section{Bangiaceen etc.}

Bangia wird vielfach (Berthold) zu den Rhodophyceen gestellt, gehört aber wahrscheinlich - trotz der Farbe - nicht hierher, sondern in die Nähe der Ulvaceen und speziell der Gattung Prasiola (J.Agardh und Schmitz). Was die übrigen unten beschriebenen blaugrünen Algen anlangt, so sind sie nach dem Vorgange von Kirchner und Schmitz in die Nähe von Bangia gestellt, da sie infolge deutlicher Ausbildung eines Zellkernes und der Chromatophoren in der Gruppe der Schizophyceen ein Analogon nicht haben (mit Ausnahme allerdings von Chroothece und Zachariasia, die logischerweise ebenfalls hätten ausgeschaltet werden müssen).

Asterothrix ist eine ganz unsichere Gattung, auch die Stellung von Porphyridium ist noch nicht endgültig festgestellt.

\section{Bangia Lyngbye.}

Thallus festgeheftet, aufrecht, fadenförmig, meist stielrund. Beliebige Thalluszellen können sowohl ungeschlechtliche Sporangien, wie Spermatozoide und Eizellen bilden. Rot gefärbt.

B. atropurpurea (Dillw.) C. Ag. (Taf. VIII, 22)

Bildet 2-10 $\mathrm{cm}$ lange, bis $60 \mu$ dicke, unverzweigte Fäden aus einer oder mehreren Zellreihen. In Quellen und lebhaft fliessenden Bächen.

\section{Allogonium $\mathrm{Kg}$.}

Die in Gallerte cingeschlossenen Zellen cylindrisch oder kugelig, einreihig angeordnet. Mit Pyrenoiden. 
All. wolleanum Hansg. (Taf. VIII, 23)

In mohnkorn- bis erbsengrossem Lager; Zellen 9-I 2 (I5) $\mu$ breit und $\mathrm{I}-3$ Mal so lang. Chromatophoren klein, scheibenförmig, wandständig, im Alter undeutlich. An feuchten Felsen, in Bergbächen.

\section{Gloeochaete Lagerh.}

Mehrere Zellen in gemeinsamer Gallerthülle an Fadenalgen festsitzend. Chromatophoren: wandständige Körner. Zweiteilung und Schwärmsporen (?), daher vielleicht zu den Tetrasporaceen zu stellen.

I. Zellen mit einer Borste . . . . . . I. Gl. wittrockiana I*. Zellen mit je zwei Borsten. . . . . . 2. Gl. bicornis

I. Gl. wittrockiana Lagerh. (= Schrammia barbata Dang.) (Taf. VIII, 24).

Familien $2-4$ zellig, $30-70 \mu$ gross. Zellen $5-17 \mu$ breit. In Torfgewässern und Sümpfen.

2. Gl. bicornis Kirchn.

Familien 2-8 zellig. In Sümpfen, selten.

\section{Porphyridium Naeg.}

Die nur ausserhalb des Wassers am Grunde von feuchten Mauern blutrote Schleimüberzüge bildende Alge hat bisher noch keine feste Stellung im Systeme erhalten; auch die Versuche der letzten Jahre, Porphyridium als Aphanocapsa cruenta (Ag.) Hansg. zu Lyngbya antliaria (S. 65) zu ziehen (Hansgirg), sind wohl ebenso unberechtigt, wie in ihm eine Abteilung von Pleurococcus oder Trentepohlia zu sehen.

\section{Io. Glaucocystis Itzigsohn.}

Zellen einzeln oder $\mathrm{zu} 4-8$ in gemeinsamer Muttermembran. Chromatophoren entweder strahlenförmig als Fäden von der Mitte der Zelle „spinnenbeinartig“" ausstrahlend oder als gerade oder gebogene Stäbchen der Wand anliegend: letzterer Fall tritt bei der Teilung ein. Jede Zelle zerfällt bei der Teilung in $4-8$ Tochterzellen. 
Gl. nostochinearum Itzigs. (Taf. VIII, 25)

Zellen $13-18 \mu$ dick, $22-28 \mu$ lang. In torfigem Wasser, meist zwischen Sphagnum.

\section{Asterothrix $\mathrm{Kg}$.}

Thallus sternförmig verzweigt; Aestchen starr, zugespitzt. Vermehrung unbekannt.

A. tripus A. Br. (Taf. VIII, 26)

Dicke I $-3 \mu$, Länge $30-50 \mu$. Färbung blass gelblich oder bläulich grün. Unter anderen Algen, in Sümpfeṇ. 


\title{
III. Fungi
}

\author{
(Pilze).
}

Litteratur:

Rabenhorsts Kryptogamenflora, Bd. I., 2. Auf., bearbeitet von Winter, Rehm, A. Fischer und E. Fischer; für das folgende kommt nur in

Betracht: Abteilung IV: Phycomycetes, bearbeitet von Alfred Fischer. Leipzig 1892.

Chlorophyllfreie, deshalb saprophytisch oder parasitisch lebende pflanzliche Organismen. Die tiefst stehende Gruppe der Pilze, die Phycomyceten (Siphomyceten, Algenpilze) schliessen sich, was schon ihr Name sagt, zum Teil eng an viele Algen (Siphoneen und andere) an. Die Art der Fortpflanzung, der ThallusAusbildung etc. ist bei beiden Gruppen im Grunde dieselbe, so dass der Gedanke nahe liegt, in den Pilzen rückgebildete Algen zu sehen, was in der That von vielen Forschern behauptet, von anderen aber, wenigstens in dieser Allgemeinheit, bestritten wird.

Von den echten Pilzen (Eumyceten, Mycomyceten) finden sich nur gelegentlich Vertreter im süssen Wasser vor; am ehesten noch begegnet man Formen, die zu den Saccharomyceten (Hefepilzen) gehören, und häufig auch keimenden Sporen des überall verbreiteten Pinselschimmels (Penicillium crustaceum) und anderer Saprophyten. Nur das an Mühlrädern etc. hin und wieder gallertige Polster bildende Selenosporium aquaeductunm Radlkfr. und Rabh. mit seinen sichelförmig gekrümmten, mehrzelligen Konidien ist von besonderer Wichtigkeit. Die anderen bilden die grosse Masse der Luft bewohnenden Arten, der Brandpilze, Hutpilze und der unzähligen anderen makroskopischen und mikroskopischen Parasiten und Saprophyten.

Hier kommen in erster Linie die

\section{Phycomyceten}

in Betracht und von ihnen nur - da alle endophytischen Organismen ausgeschlossen seien - die im Wasser frei lebenden. 
Ihr Vegetationskörper ist einzellig (vgl. dazu Vauchcria (S. 139); die ungeschlechtliche Vermehrung geschieht durch Schwärmsporen, unbewegliche Sporen oder Konidien; die geschlechtliche durch Zygosporen oder Oosporen.

Die erste Gruppe der

\section{Archimyceten}

(Chytridinen), die von A. Fischer mit Recht an den Anfang des Pilzreiches gestellt wird, zeigt noch deutliche Beziehungen $\mathrm{zu}$ Organismen, die - selbst von sehr beachtenswerter Seite (De Bary, Zopf) - zu den Tieren gerechnet werden, mindestens aber keine typischen Pflanzen sind. Die Archimyceten sind monokarp, d. h. sie fruktifizieren nur ein Mal und gehen dann zu Grunde; die Fortpflanzung geschieht durch Schwärmsporen und meist ungeschlechtlich entstehende Dauersporen. Es seien nur zwei Vertreter genannt:

I. Chytridium A. Br. (Ch. olla A. Br. Taf. VIII, 27) als Prototyp der Gruppe. Die Abbildung zeigt diesen Parasiten in mehreren Exemplaren. in einem Oogon von Oedogonium (vgl. S. 133).

2. Polyphagus euglenae Now. findet sich in den grünen Häuten, die sich aus den ruhenden Zellen von Euglenen (siehe diese) zusammensetzen, diese oft stark dezimierend (Taf. VIII, 28).

Die zweite Gruppe, diejenige der

\section{Zygomyceten,}

die wie die folgende polykarp ist, d. h. mehrmals Fruktifikationsorgane treibt, pflanzt sich geschlechtlich durch $\mathrm{Zygosporen}$ fort, die durch Konjugation entstehen (vgl. die Konjugaten unter den Algen S. 141). Von der gewöhnlich ausserhalb des Wassers lebenden Gruppe seien nur Mucor mucedo (L.) Bref., der Köpfchenschimmel, und der ebenso häufige Rhizopus nigricans Ehrbg. erwähnt.

Erst bei der dritten Gruppe, den

\section{Oomyceten}

befinden sich wieder wasserbewohnende Formen. Diese bilden reich verzweigte Mycelien, die häufig im Wasser fluten. Die ungeschlechtliche Vermehrung geschieht durch Konidien oder Schwärmsporen, die geschlechtliche durch Eibefruchtung: ein 
Mycel-Ast (Antheridium) wächst an das die Eier enthaltende Oogon heran, durchbohrt dessen Wandung und dringt zur Befruchtung ein; so entsteht die Oospore. Auch Bildung von Gemmen, (d. h. reich mit Protoplasma gefüllten, abgeschnürten Mycelteilen, die zur Erhaltung der Art dienen) und ungeschlechtlich entwickelten Oosporen oder Parthenosporen ist beobachtet.

Die Familie der Peronosporaceen (z. B. Phytophthora infestans (Mont.) De By., der berüchtigte Kartoffelpilz) enthält ausser wenigen Pythium-Arten nur parasitische 'Luftbewohner, während die Familie der Saprolegniaceen mit einer Ausnahme nur saprophytische Wasserbewohner umfasst. Es seien nur einige wichtige Gattungen erwähnt:

Apodya lactea (Ag.) Cornu (= Leptomitus lacteus Ag.) ist als Abwässer-Organismus wichtig. Ausgezeichnet ist sie vor allen übrigen Saprolegniaceen durch Einschnürungen, die den schlauchförmigen Thallus in cylindrische Zellen teilen; dazu liegen in jedem Abschnitt noch ein oder mehrere stark lichtbrechende sogenannte Cellulinkörner in der Nähe der Einschnürung. Durch diese und überhaupt den ganzen Bau unterscheidet sie sich leicht von Sphaerotilus natans $\mathrm{Kg}$. (S. 44), von dem sie makroskopisch schwer zu trennen ist. Der Pilz bedeckt wie das genannte Fadenbakterium den Boden von Abzugsgräben bei Fabriken, Abdeckereien etc. mit seinen langen flutenden, weisslichen oder durch Eisen gelb gefärbten oder schwärzlichen Rasen oft so zahlreich, „dass es aussieht, als ob noch Wolle tragende Schaffelle dort ausgebreitet wären." Doch kann er auch dick-pergamentartig wachsen, so z. B. an Wehren (Taf. VIII, 29).

Saprolegnia N.v. Es. ist eine erst durch die klassischen Arbeiten De Barys (1883 und 1888) gründlich erforschte Gattung, deren Arten erst durch den genannten Forscher scharf charakterisiert wurden. Er löste auch die allbekannte, nunmehr nur noch einen historischen Wert beanspruchende Art $S$. ferax Aut. in mehrere, z. B. S. mixta De By., S. thureti De By. (wohl die häufigste Art) und andere auf. Alle kommen auf toten Insekten, z. B. Fliegen etc. überall vor.

Achlya N. v. Es. unterscheidet sich von voriger Gattung dadurch, dass die Schwärmsporen vor der Oeffnung des Sporangiums in Haufen liegen bleiben.

Achl. polyandra (Hildebr.) De By. die häufigste Art. 


\section{B. Tierische Organismen.}

I. Einzellige Lebewesen . . . . . . . . . I. Protozoa

I*. Mehrzellige Lebewesen (Metazoa) . . . . . II. Rotatoria 


\section{Protozoa}

(Urtiere).

Einzellige Organismen, die durch Plasmafortsätze, durch Geisseln oder durch Wimpern sich bewegen. Die Nahrungsaufnahme erfolgt durch Umfliessen der Nahrungsstoffe, durch Verschlucken oder durch Einstrudelung. Pflanzliche und saprophytische Ernährung findet sich mehr vereinzelt. Die Fortpflanzung geschieht durch einfache Teilung im ruhenden oder beweglichen Zustande. Bei den höheren Formen sind von Zeit zu Zeit Konjugationen oder Kopulationen notwendig. Encystierungen sind vielfach beobachtet. Man unterscheidet:

I. Ohne schwingende Geisseln oder Wimpern, nur mit Pseudopodien . . . . . . . . . I. Sarcodina (S. 49)

I*. Mit schwingenden Geisseln, Wimpern oder Saugröhren . 2

2. Mit langen Geisseln, meist in beschränkter Anzahl . . 2. Mastigophora

2*. Mit zahlreichen Wimpern oder mit Saugröhren . . . 3 3. Mit Wimpern . . . . 3. Ciliata

$3^{*}$. Mit Saugröhren . . . 4. Suctoria

\section{Sarcodina.}

Litteratur:

Claparède, E. et J. Lachmann, Etudes sur les Infusoires et Rhizopodes. Genève et Bale, I 858-6r.

Bütschli, A., Protozoa (In Bronns Klassen und Ordnungen des Tierreichs, Bd. 1). Leipzig $1883-87$. 
Leidy, J., Fresh-water Rhizopods of North America. Report of the

U. St. geologic. survey of the territories, I3d. XII. Washington 1879 . Hertwig, R. und E. Lesser, Ueber Rhizopoden und denselben nahestehende Organismen. Arch. für mikr. Anat. Bd. X. Supplem. Bonn 1874 .

Schaudinn, Fr., Heliozoa. In dem Wërke „Das Tierreich.“ Berlin 1896.

Die Sarkodinen repräsentieren ohne Zweifel die tiefst stehenden tierischen Organismen: Ihr Körper besteht lediglich aus einem völlig nackten Plasma, wofür Dujardin den Namen Sarkode einführte, der dann für die Benennung der ganzen Gruppe wichtig wurde. Die Sarkodinen sind unregelmässige Tiere, d. h. ihr Körper besitzt keine bestimmte Gestalt; vielmehr ist seine Form infolge der steten Bewegungen des Protoplasmas einem ständigen Wechsel unterworfen. Bei allen Sarkodinen findet sich die Fähigkeit, an jeder beliebigen Stelle der Körperoberfläche wurzeloder fussartige Fortsätze, sogenannte Scheinfüsschen oder Pseudopodien, auszustrecken und wieder einzuziehen; doch sind diese niemals zu echten Geisseln oder Wimpern entwickelt.

Mit Ausnahme weniger Formen, die ihre Nahrung mit dem ganzen Körper umfliessen, dienen die Pseudopodien dazu, die an ihnen etwa haften gebliebenen Nährstoffe durch einfaches Zurückfliessen ins Centrum des Plasmaleibes zu schaffen. Die Verdauung geschieht lediglich durch die unmittelbare Berührung der Nahrung mit dem Plasmaleib der Sarkodine. Auch bei der Ortsvieränderung spielen die Scheinfüsschen eine wichtige Rolle, indem die Körpermasse in die letzteren nachfliesst.

Im ganzen äusseren Habitus erinnern zahlreiche Sarkodinen an die Schleimpilze (Myxomyceten), um so mehr, als nach den Untersuchungen von M. Schultze und F. Cohn eine völlige Identität zwischen den Protoplasmen beider Gruppen herrscht. Doch findet sich in den Fortpflanzungsverhältnissen ein tiefgreifender Unterschied: Während bei den Myxomyceten die Vermehrung durch Sporen, die in sporangienähnlichen Fortpflanzungskörpern erzeugt werden, vor sich geht, geschieht bei den Sarkodinen die Vermehrung nur durch einfache oder mehrfache Teilung oder durch Sprossung.

Die Sarkodinen werden eingeteilt in Rhizopoden (Wurzelfüssler), Heliozoen (Sonnenticrchen) und Radiolarien (Strahllinge). Die letzteren sind nur im Meere zu Hause und meist durch ein wunderbar zierliches Kieselskelett ausgezeichnet. Die 
beiden erst genannten, hier nur in'Betracht kommenden Gruppen, unterscheiden sich nach folgenden Merkmalen:

1. Körper unregelmässig; Pseudopodien meist ziemlich rasch wechselnd . . . . . . . . I Rhizopoda (S. 251)

I*. Körper fast kúgelig; Pseudopodien lang, fein, starr und nadelartig, vom Körper radial ausstrahlend

2. Heliozoa (S. 271)

\section{Rhizopoda (Wurzelfüssler).}

Das Plasma des Rhizopoden-I.eibes ist bei den verschiedenen Formen mehr oder weniger flüssig. Bei der Mehrzahl der Arten ist es durchaus homogen und überall mit äusserst feinen Granula versehen; nur eine Reihe von Amöben zeigt ein hiervon abweichendes Verhalten, indem ihr Plasma eine deutliche Differenzierung in eine Mark- und eine Rindenschicht besitzt. Die erstere (Entoplasma) ist in diesen Fällen fein granuliert; die äussere Schicht (Ektoplasma) ist knorpelartig durchscheinend (hyalin).

Innerhalb des Plasmas finden sich die verschiedenartigsten Einschlüsse, so als Nahrung dienende Fremdkörper, Gasbläschen, die vielleicht als Schwimmblase dienen, indem sie Lageveränderungen ins Werk setzen helfen, sowie Fettröpfchen. Nicht selten sind Flüssigkeitsräume vorhanden, deren Zahl sich so weit steigern kann, dass das Plasma eine wabige Struktur erhält. Manche Formen sind durch einen Farbstoffgehalt ausgezeichnet, so dass die bläulichgrüne Färbung des Plasmas gänzlich überdeckt wird. Gewisse Amöben bergen in ihrem Innern zahlreiche kleine Algen, sogenannte Zoochlorellen, so dass sie eine völlig grüne Färbung annehmen. Aus den Untersuchungen von A. Gruber geht hervor, dass solche chlorophyllführende Amőben viele Jahre lang ohne nennenswerte Nahrung sich nicht nur völlig frisch erhalten, sondern sich auch kräftig vermehren, während ihre chlorophyll-losen Schwestern meist einem raschen Tode anheim fallen. Die beiden heterogenen Organismen, Alge und Amöbe, haben sich offenbar zu gemeinsamem Vorteil an einander geschlossen, um eine „solide Firma im Kampfe ums Dasein" zu bilden (Symbiose).

Auch stark lichtbrechende Körperchen, die wahrscheinlich Exkretstoffe repräsentieren, treten hin und wieder als Plasma-Ein- 
schlüsse auf. Eine kontraktile Vakuole ist nicht immer vorhanden; bei manchen Formen dagegen finden sich bis zwanzig derartiger, jedenfalls als Exkretionsorgane dienender Gebilde. Ein Kern ist stets vorhanden, wenn auch nicht immer sichtbar. Bei manchen Formen finden sich mehrere (selbst bis über 'hundert) Kerne. Die Pseudopodien sind entweder dick, fingerförmig oder lappig und unverzweigt oder dünn, zuweilen verästelt und netzartig verschmolzen.

Zahlreiche Rhizopoden umgeben sich mit einem Gehäuse, das entweder ganz eine Absonderung des Plasmas darstellt und ausschliesslich chitinöser Natur ist, oder mittels chitiniger Sekrete aus Fremdkörpern, wie Diatomeenschalen, Sandkörnern und dergl., ähnlich den Röhren der Phryganidenlarven, zusammengekittet ist. Die Gehäuse besitzen stets mindestens eine Oeffnung für den Austritt der Pseudopodien. Ein Kalkgehäuse findet sich nur bei marinen Formen, bei den sogenannten Foraminiferen, die als Gesteinsbildner wichtig waren und sind.

In ungünstige Existenzbedingungen gebracht oder nach reichlicher Nahrungsaufnahme encystieren sich zahlreiche Formen. Doch steht diese Encystierung wahrscheinlich nur in seltenen Fällen mit der Vermehrung im Zusammenhange. Die letztere geschieht meist durch einfache oder mehrfache Teilung. Eine Art Schwärmerbildung ist bei der auch durch Koloniebildung ausgezeichneten Microgromia, Knospung bei Arcella beobachtet. Nicht selten findet sich eine vorübergehende oder dauernde Verschmelzung mehrerer Individuen; jedoch ist der Zusammenhang dieser Erscheinungen mit der Fortpflanzung nicht sicher erwiesen.

Das folgende schliesst sich an Bütschli und Leidy an.

I. Körper völlig nackt (A. Amoebaea Ehrbg.: Amoebaea lobosa) 2

2. Nicht mit zahlreichen Kernen, Vakuolen, Glanzkörpern und stabförmigen Einschlüssen . . . . . . . . . . . 3

3. Pseudopodien meist nicht strahlenartig, nie geisselartig beweglich . . . . . . . . . . . . . . . . 4

4. Pseudopodien nicht schwimmhautartig gestaltet . . 5

5. Mit Pseudopodien . . . . . . . . . . . 6

6. Ohne kontraktile Vakuole I. Protamoeba (S. 255)

6*. Mit kontraktilen Vakuolen . . . . . . . . 7

7. Kern nicht sichtbar . 2. Gloidium (S. 255)

$7^{*}$. Kern deutlich . . . . . . . . . . 8 
8. Oberfläche ohne feine Stacheln . . . . . 9

9. Hinderende ohne fadenförmige Fortsätze .

3. Amoeba (S. 255)

$9^{*}$. Hinderende mit fadenförmigen, Pilzfäden ähnlichen Fortsätzen 4. Ouramoeba (S. 256)

8*. Oberfläche mit feinen Stacheln . . . . .

5. Dinamoeba (S. 257)

$5^{*}$. Ohne Pseudopodien fliessend sich fortbewegend .

6. Hyalodiscus (S. 257)

4*. Pseudopodien schwimmhautartig

$$
\text { 7. Plakopus (S. 257) }
$$

3*. Pseudopodien allseitig ausstrahlend, vielfach geisselartig beweglich . . . . . . . . . . . . 10 ı. Höchstens mit schwacher Geisselbewegung . . .

8. Dactylosphaera (S. 257)

10*. Geisselbewegung heftig . . 9. Podostoma (S. 258)

'2*. Mit zahlreichen Kernen, Vakuolen, Glanzkörpern und stabförmigen Einschlüssen, grosse Form 10. Pelomyxa (S. 258)

I*. Körper mit Gehäuse (B. Testacea M. Schultze: Imperforata Carpent.)

II. Schale nur mit einer Oeffnung . . . . . . . I2

12. Pseudopodien stumpf, mehr oder weniger lappenförmig

(I. Arcellina Ehrbg.) . . . . . . . . . . . . ${ }_{13}$

13. Schale flexil, dem Plasmaleib eng angeschmiegt .

1. Cochliopoduum (S. 259)

13*. Schale nicht flexil .

14. Schale vom Tierkörper nicht erfüllt, nie mit Fremdkörpern oder mit rundlichen Scheibchen . . 15 I5. Mit äusserst feiner Gitterstruktur

15*. Schale nicht so

2. Arcella (S. 259)

16. Schale strukturlos - 3. Hyalosphenia (S. 260)

16*. Schale aus quadratischen Plättchen aufgebaut 4. Quadrula (S. 26I)

14*. Schale vom Tierkörper nahezu erfüllt, mit Fremdkörpern oder rundlichen Scheibchen . . . I I7

17. Schalenöffnung und Gipfel des Hinterendes nicht excentrisch . . . . . . . . . . 18

18. Schale mit Fremdkörpern 
18*. Schale mit rundlichen bis fast viereckigen Plättchen . . . . 6. Nebela (S. 264)

17 *. Schalenöffnung und Gipfel des Hinterendes in excentrischer Lage . . 7. Centropyxis (S. 265)

12*. Pseudopodien spitz, fadenartig, zum Teile anastomosierend .. . . . . . . . . . . . . . . . . 19

19. Pseudopodien wenig anastomosierend; Schale meist mit besonderen Struktur-Elementen (II. Euglyphina Btschli) . . . . . . . . . . . . . 20

20. Schale mit grösseren, hexagonalen oder rundlichen

Platten, nicht retorten- oder birnförmig . . . 21

21. Mit nur einer kontraktilen Vakuole . . 22

22. Schale ohne gelenkig eingefügte, bewegliche

Stacheln 1 ) . . . . . . . . . . . . 23

23. Oeffnung nie schief gestellt, dagegen gezähnelt; Schale mit oder ohne Hals. . 24

24. Schale am Halse oder Hinterende mit Stacheln . . . 1. Euglypha (S. 266)

$24^{*}$. Schale ohne Hals und ohne Stacheln

3. Assulina (S. 267)

$23^{*}$. Oeffnung häufig schief gestellt, meist nicht gezähnelt; Scchale mit kurzem Halse

5. Sphenoderia (S. 268)

$22^{*}$. Schale mit gelenkig eingefügten, beweglichen Stacheln . . . . 2. Placocista (S. 267)

$2 \mathrm{I}^{*}$. Mit drei kontraktilen Vakuolen

$$
\text { 4. Trinema (S. 268) }
$$

20*. Schale nur mit ganz feiner Felderung, birn- oder retortenförmig, teilweise mit Fremdkörpern . 25

25. Ohne hornartige Fortsätze am Hinterende. . .

6. Cyphoderia (S. 268)

25*. Mit hornartigen Fortsätzen am Hinterende.

7. Campascus (S. 269)

19*. Pseudopodien vielfach anastomosierend; Schale gewöhnlich völlig strukturlos (III. Gromïna Btschli) 26 26. Oeffnung nicht endständig, etwas hinter dem Körperpole . . . . . I. Lieberkühnia (S. 269)

1) Hierher gehört auch die Gattung Paulinella (S. 269), deren Schale aus fünf Rtihen hinter einander geordneter, breit hexagonaler Kieselplättchen besteht. 
26*. Oeffnung endständig

27. Plasmakörper die Schale nicht ganz erfüllend . 2. Microgromia (S. 269)

27 *. Plasmakörper die Schale völlig ausfüllend . 28

28. Schale ohne aufgelagerte Fremdkörper . 29 29. Pseudopodien vielfach anastomosierend; meist ohne kontraktile Vakuole.

3. Gromia (S. 27o)

29*. Pseudopodien nicht anastomosierend; mit zahlreichen kontraktilen Vakuolen.

4. Pamphagus (S. 270)

28*. Schale mit Fremdkörpern

5. Pseudodifflugia (S. 27 1)

.11*. Schale an jedem Pole mit einer Oeffnung (IV. Amphistomina Btschli) . . . . . . I. Diplophrys (S. 27 I)

A. Amoebaea Ehrbg. (Unbeschalte Rhizopoden).

\section{Fam. Amoebaea lobosa}

Pseudopodien ohne Netzbildung.

\section{Protamoeba Haeckel.}

Körper nur klein, Kern bisher nicht nachgewiesen. Fortpflanzung durch Zweiteilung im beweglichen Zustande.

Pr.primitiva Haeckel (Taf. IX, I)

Beständig die Form wechselnd, mit einem oder wenigen (3-6) kurzen, abgerundeten Pseudopodien. Durchmesser $30-50 \mu$. In Tümpeln.

\section{Gloidium Sorokin.}

Kontraktile Vakuole vorhanden, Kern nicht sichtbar. Fortpflanzung durch Vierteilung im beweglichen Zustande.

Gl. quadrifidum Sorokin. (Taf. IX, 2)

Körperform etwa kugelig. Ektoplasma hyalin, Entoplasma schaumig, mit gelblichen oder rötlichen Körnchen. Encystierung. Durchmesser $30 \mu$.

\section{Amoeba Ehrbg.}

Körper im Ruhezustande kugelig bis eiförmig, farblos und durchscheinend; im beweglichen Zustande verschieden gestaltig. 
Ektoplasma krystallhell; Entoplasma fein granulär, mit mannigfachen Einschlüssen. Mit Kern und kontraktiler Vakuole. Encystierung beobachtet. Vermehrung durch Zweiteilung im beweglichen Zustande.

I. Durchmesser wenigstens $70 \mu$, meist über $100 \mu$. . . 2

2. Oberfläche ohne Falten, Körper lebhaft beweglich

1. A. proteus

2*. Oberfläche mit Falten, Körper träge

2. A. verrucosa

1*. Durchmesser höchstens $60 \mu$, meist viel geringer

3. A. radiosa

I. A. proteus Leidy ( $=A$. princeps Ehrbg.) (Taf. IX, 3)

Körper ziemlich breit, fast farblos; im reflektierten Lichte gelblich weiss. Im Ruhezustand kugelig bis eiförmig; gewöhnlich stark amoeboid beweglich. Pseudopodien fingerförmig, einfach oder verzweigt. Kontraktile Vakuole meist in der Einzahl. Durchmesser ca. $350-600 \mu$. In Altwasser, häufig.

\section{A. verrucosa Ehrbg. (Taf. IX, 4)}

Körper oft bewegungslos, träge, kugelig oder eiförmig, an der Oberfläche mehr oder weniger faltig. Pseudopodien kurz, breit, ebenfalls an der Aussenfläche mit Runzeln versehen. Entoplasma granuliert, Ektoplasma hyalin. Kontraktile Vakuole ansehnlich. Kern deutlich. Jugendliche Individuen sind rege beweglich. Länge 80-180 $\mu$, Breite 72-160 $\mu$. Sehr häufig.

3. A. radiosa Ehrbg.

Körper meist klein, farblos, durchscheinend, träge; während des Schwimmens gewöhnlich sternförmig, mit etwa kugeliger Centralmasse, von der $2-3(-12)$ Pseudopodien von verschiedener Länge und Stärke ausstrahlen; beim Kriechen tritt der radiäre Charakter weniger deutlich hervor. Eine grosse oder mehrere kleine kontraktile Vakuolen. Kern meist deutlich. Innenplasma mit ölartigen Einschlüssen. Durchmesser I2-45 (selten 60) $\mu$. Zwischen Wasserpflanzen, in Sümpfen.

4. Ouramoeba Leidy.

Der Gattung Amoeba sehr ähnlich, aber am Hinterende mit fadenförmigen, biegsamen Anhängseln. 
Ou. vorax Leidy

Sehr ähnlich Amoeba proteus. Fädige Anhänge von wechselnder Anzahl. Durchmesser kugeliger Individuen ca. I $40 \mu$ Länge während der Bewegung bis $330 \mu$. Selten.

\section{Dinamoeba Leidy.}

Der Gattung Amoeba sehr ähnlich. Hinterende des Körpers mit warzenartigen Vorsprüngen. Oberfläche mit feinen, stachelartigen Anhängen versehen. Ist mit der vorigen Gattung wahrscheinlich zu Amoeba zu ziehen.

D. mirabilis Leidy

Körper rund, eiförmig bis lang gestreckt. Pseudopodien zahlreich, besonders am Vorderende. Durchmesser kugelförmiger Individuen 64-160 $\mu$; Länge kriechender Tiere ${ }_{5} 50 \mu$, Breite $60 \mu$. Zwischen Desmidien.

\section{Hyalodiscus Hertw. und Less.}

Körper scheibenförmig, ohne Pseudopodien sich fliessend fortbewegend. Mit Kern und kontraktiler Vakuole.

H. limax (Duj.)

Körper durchscheinend, vorn und hinten gerundet. Bewegung fast geradlinig. Kern und kontraktile Vakuole sehr deutlich, meist im Hinterende. Länge ca. гоо $\mu$, Breite $30 \mu$. In Altwasser unter Spaltpilzen, häufig.

H. guttula (Duj.)

Etwas kleiner, rundlich. (Taf. IX, 5)

\section{Plakopus F. E. Schulze.}

Körper wenig formwechselnd. Pseudopodien: schwimmhautartige, geradkantig zusammenstossende Fortsätze, die trichterförmige Hohlräume einschliessen. Zuweilen nimmt der Körper die Form von Hyalodiscus an.

Pl. ruber F. E. Schulze (Taf. IX, 6)

Farbe ziegelrot. Durchmesser $200-600 \mu$.

\section{Dactylosphaera Hertw. und Less.}

Pseudopodien gewöhnlich finger- oder strahlenartig, allseitig ausstrahlend, zuweilen ein wenig geisselartig schwingend; selten kurz und bruchsackartig. Körper rundlich. 
D. radiosa Hertw. und Less. (Taf. IX, 7)

Körper rundlich, Durchmesser bis $20 \mu$; mit 5 -1o langen, spitzen, allseitig vom Körper ausstrahlenden, ziemlich formbeständigen Pseudopodien. Zur Ortsveränderung werden diese eingezogen und andere, stumpfe ausgestreckt. In Altwasser, häufig.

\section{Podostoma Clap. und Lachm.}

Sehr ähnlich Dactylosphaera radiosa, jedoch die zeitweilig vorhandenen langen Pseudopodicn heftig geisselartig beweglich.

P. filigerum Clap. und Lachm.

In Altwasser, mit Algen und Infusorien.

\section{Iо. Pelomyxa Greeff.}

Körper von verschiedener Gestalt, amoebenartig, von bedeutender Grösse, immer durch stumpfe Pseudopodien vorwärts fliessend. Mit zahlreichen Vakuolen, Kernen, sogenannten Glanzkörpern und stabartigen Gebilden.

\section{$P$.palustris Greeff (Taf. IX, 8)}

Am Hinterende gewöhnlich ohne Fortsätze. Durchmesser bis $2 \mathrm{~mm}$. In Sumpfwasser, nicht selten.

Die verwandte $P$. villosa Leidy besitzt am Hinterende meist zahlreiche kleine Fortsätze.

Das durch den Besitz einer starken Gallerthülle, die von kurzen Pseudopodien durchbrochen wird, ausgezeichnetc Genus Amphizonella Greeff bewohnt wohl nur feuchte Erde. [Amph. auerbachi (Lachm.) Durchmesser $27-65 \mu$ ].

Die zweite Familie (Amoebaea reticulosa Btschli.) ist durch netzbildende Pseudopodien ausgezeichnet. Vertreter fast ausschliesslich marin.

B. Testacea M. Schultze (Beschalte Rhizopoden).

Imperforata Carpenter.

Die Schalenwandungen sind nicht mit zahlreichen feinen Poren versehen; nur eine bis zwei grösscre Mündungsöffnungen sind vorhanden. Selten mehrere kleine Oeffnungen. 


\section{Fam. Arcellina.}

Schalenbau einachsig, schüsselförmig bis langgestreckt; manchmal etwas bilateral symmetrisch, wenn die Mündungsöfnung verlagert ist. Pseudopodien stumpf, lappenförmig. Mit Kern und kontraktiler Vakuole.

\section{Cochliopodium Hertw. und Less.}

Schale flexil, kappenartig, eng dem Körper sich anschmiegend. Gehäusemündung gross; Pseudopodien in einem Bündel aus der Oeffnung austretend. Mehrere kontraktile Vakuolen. Ein Kern.

I. Schale glatt, farblos . . . . . . . C. pellucidum $1^{*}$. Schale mit haarartigem Ueberzuge . .2. C.pilosum

I. C. pellucidum Hertw. und Less. (= C. bilimbosum Leidy) Innenplasma mit grossem, rundem Kern. Pseudopodien meist in geringer Anzahl, hyalin, zuweilen gekrümmt. Durchmesser des Tieres bei Kugelgestalt $24-56 \mu$. In frischem Wasser, zwischen Algen.

2. C. pilosum Hertw. und Less. (= C. vestitum Leidy) (Taf. IX, 9) Plasmakörper vielfach mit Chlorophyllkörpern. Durchmesser $40-60 \mu$.

\section{Arcella Ehrbg.}

Schale uhrglasförmig. Unterseite flach, Oberseite gewölbt. In der Mitte der Unterseite die kreisförmige Oeffnung. Schalenoberfläche mit äusserst feiner, hexagonaler Felderung. Plasmaleib die Schale nicht völlig ausfüllend, mit zahlreichen Kernen und kontraktilen Vakuolen.

A. vulgaris Ehrbg. (Taf. IX, 10)

Schale anfangs durchsichtig; später dunkel, bräunlich bis schwärzlich; von wechselnder Gestalt: bald flach, bald hoch gewölbt; fast glatt oder mit feinen Facetten, mit Eindrücken, Ecken oder vortretenden Spitzen. Von einer mittleren scheibenförmigen Plasmamasse strahlen fadenförmige Fortsätze nach den Rändern aus. Breite $48-152 \mu$; Breite der Mündung $12-48 \mu$; Höhe $36-72 \mu$. Zwischen Wasserpflanzen, gemein.

Leidy führt noch folgende Spezies auf: 
1. Schale unten mit mehr oder weniger langen Zähnen; in der Seitenansicht kronenförmig, mehr als zwei Mal so breit wie hoch . . . . . . . . . . . . A. dentata Ehrbg.

I*. Schale ohne Zähne

2. Höhe der Schale grösser als die Breite der Basis .

$2^{*}$. Schale breiter als hoch A. mitrata Leidy

3. Basalrand bis zum vierten Teil oder bis zur Hälfte der Schalenhöhe ansteigend. . A. artocrea Leidy

$3^{*}$. Basalrand nicht so . . . . A. discoides Ehrbg.

Als Jugendzustände der A. vulgaris sind zu deuten Pyxidicula operculata Ehrbg. und Pseudochlamy's patella Clap. und Lachm.

\section{Hyalosphenia Stein.}

Schale ei- oder birnförmig, parallel der Längsachse zusammengedrückt. Körper die Schale nicht ausfüllend. Kern gross, central gelegen. Pseudopodien wenig zahlreich, fingerförmig. Mundöffnung elliptisch.

1. Schale farblos, stark zusammengedrückt, eiförmig

$$
\text { 1. H. cuneata }
$$

I*. Schale gefärbt

2. Schale mit in Längsreihen geordneten, halbkugeligen Eindrücken . . . . . . . . . . 2. H. elegans

2*. Schale ohne solche Eindrücke . . . . . . . . . 3 3. Länge höchstens $92 \mu$, meist nur $2-3$ Pseudopodien 3. H1. tincta

$3^{*}$. Länge wenigstens $108 \mu$, mindestens 6 Pseudopodien 4. II. papitio

I. H. cuncata Stein (= H. lata F. E. Schulze) (Taf. IX, I I)

Mundöffnung oval. Plasmakörper birnförmig, mit nur einem bis zwei Pseudopodien. Länge $60-76 \mu$, Breite $44-60 \mu$, Dicke $20 \mu$.

2. H. elegans Leidy

Schale zusammengedrückt flaschenförmig, mit langem, cylindrischem Halse, hellbraun gefärbt. Pseudopodien gewöhnlich 3-4 an Zahl. Länge 88-108 $\mu$, Breite 40-6o $\mu$, Dicke 20-28 $\mu$.

\section{II. tincta Leidy}

Schale zusammengedrückt birnförmig, hellgelb gefärbt. Länge $76-92 \mu$, Breite $56-64 \mu$, Dicke $28 \mu$. 
4. II. papilno Leidy

Schale zusammengedrückt, lang eiförmig, seltener birnförmig; gelblich gefärbt. Plasmakörper häufig mit Chlorophyllkörpern. Länge I08-1 $40 \mu$, Breite $68-84 \mu$, Dicke $32-40 \mu$. In Sümpfen.

\section{Quadrula F. E. Schulze.}

Schale eiförmig, etwas zusammengedrückt, aus viereckigen, glashellen Plättchen zusammengesetzt, hinten zuweilen mit Stacheln. Tierkörper die Schale nicht erfüllend.

Q. symmetrica F. E. Schulze (Taf. IX, I2)

Schale farblos; ebenso der Plasmakörper. Ein bis drei oder mehr Pseudopodien. Länge $80-140 \mu$, Breite 40-96 $28-48 \mu$. In Sumpfwasser.

\section{Difflugia Leclerc.}

Gehäuse aus Fremdkörpern, wie Diatomeen-Schalen, Spongien-Nadeln, hyalinen Quarzkörnern etc., zusammengekittet. Der Plasmakörper füllt den grösseren Teil der Schale aus. Kern und kontraktile Vakuole. Pseudopodien etwa sechs an Zahl oder mehr, cylindrisch, einfach oder verästelt, an den Enden gewöhnlich abgerundet.

1. Schale nicht retortenförmig, Oeffnung nicht in tangentialer Lage (Difflugia) . . . . . . . . . . . . . . . . 2

2. Gehäuseöffnung weder gelappt, noch gezähnelt, noch mit eingeschlagenem Rande.

3. Schale ohne deutliche Halsbildung I. D. globulosa

$3^{*}$. Schale mit deutlicher Halsbildung . . . . . . . . 4

4. Hinterende meist gerundet, nicht deutlich stachelartig zugeschärft . . . . . . . . . . . . 5

5. Schale mit reichlichen Fremdkörpern . . . . 6

6. Schale flaschenförmig . . . 2. D. pyriformis

6*. Schale krugförmig . . . 3. D. urceolata

$5^{*}$. Schale mit spärlichen Fremdkörpern, fast ausschliesslich chitinös . . . . 4. D. cratera

$4^{*}$. Hinterende mit langem Stachel oder deutlicher $\mathrm{Zu}$ schärfung . . . . . . . 5. D. acuminata

$2^{*}$. Gehäuseöffnung gezähnelt, gelappt oder mit eingeschlagenem Rande 
7. Oeffnung gelappt oder gezähnelt . . . . . . 8

8. Hinterende ohne Dornen . . . . . . . . . . . 9

9. Schale kugelig bis eiförmig. . 6. D. lobostoma

9*. Schale halbkugelig . . . . . 7. D. arcula

8*. Hinterende mit Dornen . . . . 8. D. corona

$7 *$. Oeffnung nur mit eingeschlagenem, nie gelapptem Rande

9. D. constricta

I*. Schale retortenförmig, Oeffnung tangential (Lecquereusia Schlumbg.) . . . . . . . . 10. D. spiralis

I. D. globulosa Dujard.

Schale kugelig oder eiförmig; an der Oralseite mehr oder weniger abgestutzt. Gehäusemündung kreisrund, manchmal mit kurzem Halse versehen. Als Baustoff dienen Quarzsand und Diatomeen-Schalen; zuweilen ist die Schale fast nur chitinig. Länge $36-260 \mu$, Breite $30-18_{4} \mu$. In Sumpfwasser.

2. D. pyriformis Perty

Schale flaschenförmig, mit einem cylindrischen Halse von verschiedener Länge, vielfach seitlich etwas zusammengedrückt, aufgebaut aus Sandkörnchen und Diatomeen-Schalen; Mündung rund oder elliptisch. Plasmakörper meist grün durch Chlorophyllkörner. Länge $60-580 \mu$, Breite $40-240 \mu$. Vorkommen wie bei voriger Art.

3. D. urceolata Carter

Schale krugförmig. Körper kugelig bis eiförmig. Hals kurz. Schalenöffnung gross, kreisrund, häufig mit einem kleinen Rande. Hinterende rund oder zugespitzt; mit oder ohne stachelartige Fortsätze. Schale gewöhnlich mit hyalinen Quarzkörnern. Länge $180-520 \mu$, Breite $140-380 \mu$. In Sumpfwasser.

4. D. cratera Leidy

Schale mit kugeligem oder eiförmigem Bauche und weit cylindrischem Halse; Gehäuseöffnung breit, vielfach mit einem kleinem Rande. Hülle zum grössten Teile chitinös, mit wenigen aufgelagerten Sandpartikelchen. Länge 56-66 $\mu$, Breite 36-42 $\mu$; Breite des Halses $28-36 \mu$. An Ceratophyllum.

Der Bewohner der beschriebenen Schale ist das nicht genau bekannte Infusor Codonella lacustris Entz.

5. D. acuninata Ehrbg.

Schale krugförmig oder länglich oval; Hinterende zugeschärft oder in einen langen Stachel verlängert, selten mit 
zwei oder drei Spitzen. Oeffnung des Gehäuses rund. Schale mit Quarzkörnern, seltener mit Diatomeen. Länge $84-400(520) \mu$, Breite $36-184 \mu$; Breite der Oeffnung 24-100 $\mu$. In Teichen.

\section{D. lobostoma Leidy (Taf. IX, 13)}

Schale kugelig bis eiförmig, aus Quarzsand bestehend, selten mit Diatomeen-Panzern. Oeffnung 3-6- (manchmal sogar noch mehr-) lappig. Hinterende gerundet. Plasmakörper farblos oder grün. Länge $80-140 \mu$, Breite $60-\mathrm{I} 28 \mu$; Weite der Oeffnung $24-48 \mu$. In Sumpfwasser.

\section{D. arcula Leidy}

Schale halbkugelig; Hinterende konvex. Oeffnung in der Mitte der etwas eingestülpten Basalseite, dreilappig. Schale als gelbliche Chitinhaut entwickelt, mit spärlichen Fremdkörpern; letztere lagern namentlich am Hinterende. Breite II 2 - I $44 \mu$, Höhe $60-80 \mu$; Weite der Oeffnung $28-40 \mu$.

\section{D. corona Wallich}

Schale etwa kugelig, mit aufgelagertem Quarzsand; Hinterende mit einer Anzahl kegelförmiger Dornen. Oeffnung rund, mit zahlreichen Zähnchen oder Einbuchtungen. Durchmesser I $40-320 \mu$; Weite der Oeffnung 6o-I $80 \mu$; Länge der Dornen $40-60 \mu$. In Teichen.

\section{D. constricta (Ehrbg.) Leidy}

Schale breit eiförmig; Hinterende gerundet oder in schiefer Richtung ausgezogen, mit einem bis sechs oder auch ohne Dornen. Oeffnung weit, rund oder elliptisch, Rand nach innen eingeschlagen. Schalenoberfläche mit hyalinem Quarzsand oder nur mit Chitinhaut, farblos oder bräunlich. Länge $90-340 \mu$, Breite 78-180 $\mu$. Zwischen Wasserpflanzen, gemein.

Io. D. spiralis Ehrbg. (= Lecquereusia jurassica Schlumbg.)

Schale retortenförmig; Bauch rundlich, seitlich zusammengedrückt; Hals kurz, weit, cylindrisch, mit runder oder elliptischer Oeffnung. Die Schalenachse beschreibt einen Umgang einer Spirale; Oeffnung also tangential gelegen. Oberfläche der Schale mit wellenförmig erhabenen oder wurmförmigen Falten. Länge 96-1 $88 \mu$, Breite $68-164 \mu$, Dicke $68-134 \mu$. In Sumpfwasser, nicht selten. 


\section{Nebela Leidy.}

Schale gewöhnlich birnförmig, durchscheinend, farblos; meist mit besonderen Struktur-Elementen von verschiedener Grösse und Gestalt, gewöhnlich in Form von runden oder etwa rechteckigen Scheibchen. Oeffnung endständig, oval. Plasmakörper farblos, sehr ähnlich Difflugia. Ueberhaupt wird diese Gattung vielfach mit der vorigen vereinigt.

I. Ohne Fortsätze oder nur mit zweien . . ... . . . 2

2. Ohne Haarbesatz, nicht flaschenförmig . . . . . 3

3. Ohne Kiel und ohne Fortsätze . . . . . . . 4

4. Schale länger als breit . . 1. N. collaris

4*. Schale breiter als lang . . 2. N. flabcllulum

3*. Mit Kiel oder seitlichen Fortsätzen . . . . . . 5

5. Nur mit Kiel, ohne freie seitliche Fortsätze . 6

6. Kiel zart. . . . . 3. N. carinata

6*. Kiel stark . . . . 4. N. hippocrepis

$5^{*}$. Mit einem Paar freier, seitlicher Fortsätze

5. N. ansata

2*. Mit Haarbesatz, flaschenförmig . . 6. N. barbata

I*. Mit 4-5 freien Fortsätzen . . . . . 7. N. caudata

\section{N. collaris (Ehrbg.) Leidy}

Schale zusammengedrückt eiförmig, länger als breit; von der Breitseite aus gesehen am Hinterende stark konvex, an den Seitenrändern ganz seicht eingebuchtet. Oeffnung oval, ganzrandig. Schale farblos, gewöhnlich aus ovalen oder kreisrunden Scheibchen zusammengesetzt. Pseudopodien fingerförmig, 3-6 an Zahl. Länge $64-208 \mu$, Breite $36-120 \mu$, Dicke $20-60 \mu$. In Sumpfwasser.

\section{N. Alabellulum Leidy}

Schale zusammengedrückt eiförmig oder birnförmig, meist breiter als lang. Hals, wenn vorhanden, kurz. Sehr ähnlich der vorigen Art. Länge 68-96 $\mu$, Breite $72-104 \mu$, Dicke $32-48 \mu$.

\section{N. carinata (Archer) Leidy}

Sehr ähnlich $N$. collaris, aber mit einem feinen Chitinkiel, der sich jederseits vom Halse bis zum Hinterende erstreckt. Länge I $44-240 \mu$, Breite $88-168 \mu$, Dicke $40-72 \mu$. In Sumpfwasser. 
4. N. hippocrepis Leidy

Schale zusammengedrückt eiförmig; mit einem dicken Kiele, der sich rings um den Körper vom Hinterende an den Seiten entlang zieht und mit fingerförmigen Fortsätzen endet. Länge $252-260 \mu$, Breite mit Kiel $140-160 \mu$, Dicke 68-72 $\mu$. In Sümpfen.

\section{N. ansata Leidy}

Schale zusammengedrückt eiförmig; mit einem Paar seitlicher, kegelförmiger, divergierender Fortsätze. Sonst wie N.collaris. Länge $216-260 \mu$, Breite zwischen den Enden der seitlichen Dornen $132-164 \mu$. In Sumpfwasser.

\section{N. barbata Leidy}

Schale flaschenförmig, leicht zusammengedrückt; Hals cylindrisch, etwa so lang wie der eiförmige Bauchteil. Mund oval, ganzrandig. Schale transparent, farblos, aus rundlichen Scheiben zusammengesetzt, mit kurzen haarartigen Gebilden bedeckt. Länge $80-120 \mu$, Breite $44-56 \mu$, Dicke $36-48 \mu$. Wic vorige Art.

\section{N. caudata Leidy}

Schale zusammengedrückt eiförmig, am Hinterende und an den Seiten mit 4-5 langen Fortsätzen, farblos, transparent. Länge ohne die Fortsätze $80 \mu$, Breite $60 \mu$, Dicke $32 \mu$; Länge der Fortsätze $16-24 \mu$. Selten.

\section{Centropyxis Stein.}

Schale scheibenförmig oder oval, mit einer Anzahl Stacheln. Oeffnung mit stark eingeschlagenen Rändern, excentrisch; Gipfel des Hinterendes ebenfalls excentrisch, aber nach entgegengesetzter Richtung wie die Oeffnung. Farbe des Gehäuses häufig braun; Baustoff chitinig, mit aufgelagerten Quarzkörnern. Plasma farblos, Pseudopodien fingerförmig.

C. aculeata (Ehrbg.) Stein

Meist mit Stacheln. Höhe $36-80 \mu$, Länge $88-260 \mu$, Breite $72-220 \mu$; Länge der Stacheln $20-60 \mu$. In Sumpfwasser, mit Arcella vulgaris zusammen, häufig. 


\section{Fam. Euglyphina.}

Schale chitinig oder kieselig, aus sechseckigen oder rundlichen Scheibchen zusammengesetzt. Pseudopodien fadenartig, wenig anastomosierend. Mit Kern und kontraktiler Vakuole.

\section{Euglypha Duj.}

Schale ei- oder flaschenförmig, aus hexagonalen, in schiefen Reihen gestellten Platten gebildet, mit endständiger, gezackter Oeffnung, hinten zuweilen mit Stacheln. Hintere Körperhälfte homogen, mit Kern und kontraktiler Vakuole; vordere Hälfte körnig, mittlere Grenzschicht oft mit dunklen Körnchen. Pseudopodien ohne Netzbildung.

1. Hinterende mit Dornen; Hals ohne lange Stacheln . . . 2

2. Dornen nicht auf den Gipfelpunkt des Hinterendes beschränkt . . . . . . . . . . . . . . . . . . 2

3. Hinterende mit vier bis sechs Dornen. . . . . .

1. Eu. alveolata

$3^{*}$. Hinterende und Seitenteile mit zahlreichen Dornen

2. Eu. ciliata

$2^{*}$. Dornen auf den Gipfelpunkt des Hinterendes beschränkt 4

4. Mit Dornenbüschel . . . . 3. Eu. cristata

4*. Höchstens mit zwei Stacheln . 4. Eu. mucronata I*. Hinterende ohne Dornen, Hals mit langen Stacheln.

5. Eu. brachiata

1. Eu. alveolata Duj. (Taf. IX, 14).

Schale farblos, meișt regelmässig eiförmig, zuweilen flaschenförmig; im Querschnitt etwa kreisförmig. Hinterende breit, abgerundet, selten etwas zugespitzt. Scheiben des Gehäuses meist oval. Oeffnung rund mit 4-I2(?), gewöhnlich mit acht Zähnchen. Hinterende mit vier bis sechs Dornen. Länge $30-152 \mu$, Breite 18-88 $\mu$.

\section{Eu. ciliata (Ehrbg.) Leidy}

Schale zusammengedrückt eiförmig; im Querschnitt elliptisch; Hinterende abgerundet oder mehr oder weniger zugespitzt. Hinterende und Seitenteile mit zahlreichen Stacheln von verschiedener Länge und Stärke. Schalenplatten sechseckig. 
Oeffnung mit 6-14 Zähnen. Länge 56-100 $\mu$, Breite 24-6o $\mu$. In Sumpfwasser, gemein.

\section{Eu. cristata Leidy}

Gehäuse flaschenförmig, im Querschnitte kreisförmig, farblos, aus ovalen Platten zusammengesetzt; Oeffnung rund, mit 4-6 Zähnen. Vom Gipfelpunkte des Hinterendes entspringt ein Büschel von Dornen. Länge $40-72 \mu$, Breite $10-20 \mu$.

\section{Eu. mucronata Leidy}

Gehäuse wie bei voriger Art, jedoch am Gipfel des Hinterendes nur ein, höchstens zwei, spitze Dornen. Länge 108-140 $\mu$, Breite $32-44 \mu$; Länge des Dornes 20-44 $\mu$.

\section{Eu. brachiata Leidy}

Gehäuse wie bei Eu. cristata, jedoch am Hinterende ohne Dornen und mit 2-6 am Halse entspringender, nach hinten gerichteter, langer Stacheln. Länge $104-128 \mu$, Breite $28-40 \mu$.

\section{Placocista Leidy.}

Schale zusammengedrückt eiförmig, farblos; mit elliptischer, ganzrandiger Oeffnung; aufgebaut aus rundlichen, mit den Rändern cinander überdeckenden Platten, die in Längsreihen geordnet sind. Seitenränder mit spitzen Dornen, die der Schale gelenkig angegliedert sind. Plasmakörper wie bei voriger Gattung.

Pl. spinosa (Carter) Leidy

Gehäuseöffnung weit, elliptisch. Stacheln beweglich, mit einem kleinen Gelenkknopf. Länge 100-I $36 \mu$, Breite $36-60 \mu$. In Sumpfwasser.

\section{Assulina Leidy.}

Schale zusammengedrückt kugelig oder eiförmig, ohne Hals, aus ovalen oder hexagonalen Platten zusammengesetzt; Oeffnung elliptisch, mit zackigen Zähnen. Plasmakörper wie bei Englypha.

A. seminulum (Ehrbg.) Leidy

Schale so breit wie lang, braun gefärbt, ohne Dornen. Länge $44-80 \mu$, Breite $36-72 \mu$, Dicke $16-32 \mu$. In Sumpfwasser, gemein. 


\section{Trinema Duj.}

Schale länglich eiförmig; Mündung auf die flache Unterseite gerückt. Der Körper füllt die Schale nicht aus, hat im vorderen granulierten Teile drei kontraktile Blasen, im hinteren homogenen einen Kern mit Nukleolus. Pseudopodien ohne Netzbildung.

Tr. enchclys (Ehrbg.) (Taf. IX, 15)

Länge 16-100 $\mu$, Breite 10-6o $\mu$; Durchmesser der Oeffnung 5-24 $\mu$. In torfigem Wasser, nicht selten.

\section{Sphenoderia Schlumbg.}

Schale kugelig bis eiförmig, hyalin, häutig; mit kurzem, dickem Halse und weiter, elliptischer Oeffnung. Mit runden, ovalen oder hexagonalen Platten. Plasmakörper wie bei Euglypha.

1. Platten nur rund . . . . . . . . . I. Sph. lenta

1*. Auf den Breitseiten je ein Paar grosser, sechseckiger Platten

2. Sph. macrolepis

1. Sph. lenta Schlumbg. (= Euglypha globosa Carter)

Schale zart, membranös, kugelig bis eiförmig, zuweilen etwas zusammengedrückt; mit kurzem, breitem, zusammengedrücktem Halse und elliptischer, teilweise schief gestellter Oeffnung. Gehäuseplatten kreisrund, mit einander überdeckenden Rändern. Länge $32-56 \mu$, Breite $28-5^{2} \mu$. In Sumpfwasser, häufig.

2. Sph. macrolepis Leidy

Schale birnförmig, zusammengedrückt, mit breitem Halse und ovaler, schief gestellter Oeffnung; auf den breiteren Seiten mit je einem Paare hexagonaler Platten. Länge $20-28 \mu$.

\section{Cyphoderia Schlumbg.}

Schale länglich retortenförmig, sehr fein sechseckig gefeldert; die halsartige Verlängerung oben schief abgestutzt. Der Körper enthält in der vorderen Hälfte zahlreiche kontraktile Vakuolen, in der hinteren den Kern. Pseudopodien zahlreich, verästelt, aber ohne Netzbildung.

C. ampulla (Ehrbg.) Leidy (= C. margaritacea Schlumbg.) (Taf. IX, 16)

Oeffnung kreisförmig. Färbung des Gehäuses gewöhnlich gelblich. Länge $112-176 \mu$, Breite $40-80 \mu$. In Gräben, besonders in torfigen; nicht selten. 


\section{Campascus Leidy.}

Schale ähnlich wie bei der vorigen Gattung, jedoch am Hinterende jederseits mit einem hornartigen Fortsatze; Gehäuse aus einer homogenen, chitinigen Membran bestehend.

C. cornutus Leidy

Schale retortenförmig, mit kurzem, gebogenem Halse, durchscheinend, gelblich gefärbt, mit aufgelagerten Fremdkörpern; Oeffnung kreisförmig, von einem kleinen, farblosen Rande eingefasst. Länge $112-140 \mu$, Breite $180 \mu$.

\section{Paulinella Lauterb.}

Schale ei- bis feldflaschenförmig, im Querschnitt rund. Plasmakörper das Gehäuse nicht erfüllend. Pseudopodien sehr lang, dünn, zugespitzt.

P. chromatophora Lauterb.

Mit zwei grossen, wurstförmigen, blaugrünen Chromatophoren. Länge $20-30 \mu$, Breite $\mathrm{I}_{5}-20 \mu$. In Altwasser, unter Diatomeen.

\section{Fam. Gromiina.}

Schale chitinös, meist völlig strukturlos, mit ziemlich verengter Oeffnung. Pseudopodien dünn, vielfach anastomosierend.

\section{Lieberkuhnia Clap. und Lachm.}

Körper eiförmig. Hülle zart, eng den Körper umschliessend; Mündung etwas hinter dem Körperende. Pseudopodien ein Netzwerk bildend. Kontraktile Vakuole nicht beobachtet.

L. paludosa (Cienk.) (Taf. IX, 17)

Kerne in grösserer Anzahl. Länge etwa $350 \mu$.

\section{Microgromia R. Hertw.}

Mündung halsartig ausgezogen. Körper die Schale nicht völlig erfüllend. Pseudopodien von einem Pseudopodienstiele entspringend. Kern und kontraktile Vakuole in.der Einzahl vorhanden. 
M. socialis Hertw. und Less, (Taf. IX, 18)

Schwärmerbildung durch Querteilung, Koloniebildung durch Längsteilung. In Tümpeln.

[Hierher gehören das feuchte Erde und faulende Stoffe bewohnende Genus Platoum F. E. Schulze und.das in einem Salzteiche bei Klausenburg (Ungarn) beobachtete Genus Plectophrys Entz].

\section{Gromia Duj.}

Schale gelbbraun, kugelig oder eiförmig, chitinös, dem Körper anliegend, Mündung endständig. Pseudopodien fadenförmig, verzweigt und zuweilen netzförmig verschmolzen. Kerne sind vorhanden, Vakuolen fehlen gewöhnlich.

Gr. Aluviatilis Duj.

Schale fast kugelig. Durchmesser $90-250 \mu$. Zwischen Wasserpflanzen.

\section{Pamphagus Bailey.}

Plasmakörper farblos; bekleidet mit einer hyalinen, strukturlosen, flexilen Membran, die dem Körper anliegt. Kern gross, deutlich. Kontraktile Vakuolen zahlreich. Oeffnung der Schale eng, endständig. Pseudopodien fadenförmig, nicht anastomosierend.

I. Ohne Hals. . . . . . . . . . . 1. P. mutabilis

${ }_{1}{ }^{*}$. Mit Hals . . . . . . . . . . 2. P. hyalimus

I. P. mutabilis Bailey

Körper zusammengedrückt ei- bis birnförmig. Gehäuseöffnung mit verdicktem Rande. Plasma zuweilen blass gelblich. Nährt sich von einzelligen Algen. Länge $40-$ I $00 \mu$, Breite 28 bis $68 \mu$. In Sümpfen.

2. P. hyalinus Leidy (= Gromia hyal. Schlumbg.) (Taf. IX, 19) Körper fast kugelig; mit kurzem, halsartigem Ansatz. Plasma mit Oel-ähnlichen Einschlüssen. Kern mit grossem, deutlichem Nukleolus. Länge $32-48 \mu$, Breite $44 \mu$. Oft mehrere Individuen gesellig mit den Pseudopodien zusammenhängend. 


\section{Pseudodifflugia Schlumbg.}

Schale dünn, chitinös, mit aufgelagerten, feinem Quarzsande oder anderen Fremdkörpern. Oeffnung endständig. Plasma farblos, mit grossem Kerne. Pseudopodien zahlreich, fädig, verästelt.

Ps. gracilis Schlumbg. (= Pleurophrys sphaerica Clap. und Lachm.) (Taf. IX, 20)

Schalen von variabler Form, meist kugelig, eiförmig; nur selten ein wenig zusammengedrückt, zuweilen leicht gekrümmt. Farblos oder bräunlich. Länge $40-160 \mu$, Breite $20-100 \mu$. In Torfstichen, nicht häufig.

\section{Fam. Amphistomina.}

Schale chitinös, auch aus Fremdkörpern gebildet; etwa citronenförmig gestaltet, an jedem Pole mit einer Oeffnung. Pseudopodien fadenförmig, spitzig, netzbildend. Mit Kern.

\section{Diplophrys Barker.}

Körper klein, kugelig; mit zarter, homogener Membran bekleidet. Plasmakörper transparent, Kern central. Mit einer gelb oder rot gefärbten Oelkugel. Pseudopodien zart, aus beiden Oeffnungen ausstrahlend. Tiere in der Jugend häufig zu Gruppen vereint.

\section{D. archeri Barker}

Durchmesser $10-20 \mu$.

Die übrigen Familien der Imperforata, sowie sämtliche Perforata sind marin oder fossil. Sie sind zum Teile wichtige Gesteinsbildnèr.

\section{Meliozoa (Sonnentierchen).}

Die Heliozoen besitzen fast sämtlich eine kugelige Gestalt. Ihr Plasma lässt meist eine Differenzierung in Entoplasma und Ektoplasma erkennen. Die Pseudopodien sind fein, stachelartig und .strahlen allscitig von der Körperoberfläche aus; nur bei 
wenigen Formen finden sich zeitweilig einzelne breite, stumpflappige Plasmafortsätze (Vampyrella). Im Innern der Pseudopodien lagern vielfach die als Stützapparate dienenden Achsenfäden, welche bei manchen Formen mit excentrisch gelegenem Kerne bis ins Innere der Körpermasse sich erstrecken und hier zu einem Centralkörper zusammentreten. Die Pseudopodien dienen vielfach zum Auffangen von Beutetieren. Schon bei blosser Berührung mit den Scheinfüsschen pflegen die gefangenen Tiere ihre Bewegungsfähigkeit einzubüssen. Nach dem Körper des Sonnentieres gelangt die Nahrung entweder durch blosses Herabgleiten an den Pseudopodien; oder die benachbarten Scheinfüsschen neigen sich über dem Beutetiere zusammen und drücken es in eine ihm gegenüber entstehende Höhlung der Körperoberfläche; oder endlich, es erhebt sich von der Körperoberfläche ein Plasmafortsatz, der nach Umschliessung der Nahrung sich wieder zurückzieht. Kern und pulsierende Vakuole sind gewöhnlich in der Ein- oder Mehrzahl vorhanden.

Zahlreiche Formen besitzen Hüllenbildung. Im einfachsten Falle handelt es sich dabei um Gallerthüllen, die bei einigen Arten durch Anlagerung von Fremdkörpern verstärkt sind. Ausserdem ist vielfach Kieselsäure zur Gehäusebildung benutzt; und zwar sind entweder die Kieselkörper nur lose zusammengehäuft, oder sie bilden ein geschlossenes, kugeliges Gehäuse.

Die Vermehrung besteht vielfach in einer blossen Zweiteilung, die sich bei Actinosphaerium auch künstlich ins Werk setzen lässt. Knospung wurde beobachtet bei Acanthocystis, Schwärmerbildung bei Clathrulina. Sehr verbreitet sind Encystierungen als Einleitung zu Fortpflanzungsakten. Bei der ausgesprochenen Neigung mancher Spezies zur Koloniebildung sind Konjugationsvorgänge $\mathrm{zu}$ erwarten. Namentlich bei Actinosphaerium sind solche auch beobachtet. Es gelang bei dieser Form sogar fünf verschiedenen Individuen entnommene Plasmastücke $\mathrm{zu}$ einem neuen Individuum künstlich $\mathrm{zu}$ verschmelzen.

Die folgende systematische Uebersicht ist in enger Anlehnung an Schaudinn gegeben.

1. Nackt oder nur vorübergehend mit Gallerthülle (I. Aphrothoraca). 
2. Körper nicht formbeständig . . . . . . . . . . . 3 3. Deutliche Scheidung in Ekto- und Entoplasma . . . I. Vampyrella (S. 274)

3*. Plasma völlig gleichartig . . 2. Nuclearia (S. 274) 2*. Körper formbeständig . . . . . . . . . . . . . 4

4. Achsenfäden reichen bis zur Oberfläche des Kernes . . 3. Actinophrys (S. 274)

$4^{*}$ Achsenfäden endigen an der Grenze von Ekto- und Entoplasma . . . . . . 4. Actinosphaerium (S. 274)

I*. Mit Gallerthülle. . . . . . . : . . . . . . . . . 5

5. Ohne selbst erzeugte Kieselteile (II. Chlamydophora) . 6

6. Hülle ohne Fremdkörper . . . . . . . . . . . 7

7. Hülle von körniger Struktur, mit stacheliger Oberfläche . . . . . . . I. Heterophrys (S. 275)

$7^{*}$. Hülle von fädiger Struktur, mit zackiger Oberfläche . 2. Spaerastrum (S. 275)

6*. Hülle mit Fremdkörpern . . . . . . . . . 8

8. Im Centrum des Plasmas eine grosse, gelbe Oelkugel .

3. Elaeorhanis (S. 275)

8*. Ohne Oelkugel . . . . 4. Lithocolla (S. 275)

$5^{*}$. Mit Hülle aus selbsterzeugten, isolierten Kieselteilen (III. Chalarothoraca) . . . . . . . . . . . . . . 9

9. Hülle aus Kugeln oder Plättchen . . . . . . 10 10. Hülle aus kleinen Kugeln I. Hyalolampe (S. 276) 10*. Hülle aus ovalen Täfelchen 2. Pinaciophora (S. 276) $10^{* *}$. Hülle aus Kugeln und sichelförmigen Plättchen . 3. Diplocystis (S. 276)

9*. Hülle aus Nadeln . . . . . . . . . . . I I

11. Hülle aus tangentialen Nadeln . . . . . . . .

4. Raphidiophrys (S. 277)

II*. Hülle aus radiären Stacheln 5. Acanthocystis (S. 277)

I*. Mit Gitterschale (IV. Desmothoraca) 1. Clathrulina (S. 279)

\section{Fam. Aphrothoraca.}

Körper im gewöhnlichen Zustande ohne Hülle und Skelett, nur während der Encystierungen mit Umhüllungen. 


\section{x. Vampyrella Cienk.}

Körper rundlich oder gestreckt, amöboid veränderlich. Ektoplasma hyalin; mit spärlichen, nicht kontraktilen Vakuolen. Entoplasma gefärbt. Pseudopodien mit oder ohne Körnchenströmung, strahlig.

$V$. spirogyrae Cienk. [= Vamp. lateritia (Fresen.) Leidy] (Taf. IX, 23)

Erscheint zumeist in Actinophrys-ähnlicher Form. Das granulierte Entoplasma führt einen Farbstoff, der zwischen orange, grünlich und bräunlichgelb wechselt. Kern nicht sichtbar. Von Zeit zu Zeit werden stumpfe, lappige, rasch wechselnde PlasmaFortsätze entsendet. (Vgl. auch Seite I und 2). Durchmesser 20-75 $\mu$; Länge kriechender Tiere bis $240 \mu$. Unter Algen.

\section{Nuclearia Cienk.}

Körper kugelig oder amöbenartig; mit gleichartigem, vakuolisiertem Plasma. Kerne und kontraktile Vakuolen sind vorhanden. Pseudopodien überall oder nur an einem Teile des Körpers ausstrahlend. Zuweilen mit dicker, von den Pseudopodien durchbrochener Gallerthülle.

N. delicatula Cienk. (Taf. IX, 24)

Durchmesser des kugeligen Körpers bis $60 \mu$; 3 -6 Kerne vorhanden. Frisst Diatomeen und andere Algen, saugt auch schon getötete Spirogyra-Zellen etc. noch vollständig aus.

\section{Actinophrys Ehrbg.}

Körper rund, Ento- und Ektoplasma in einander übergehend; letzteres mit zahlreicheren und grösseren Hohlräumen und einer pulsierenden Vakuole. Pseudopodien mit Körnchenströmung.

A. sol Ehrbg. (Taf. IX, 2 I)

Durchmesser circa $50 \mu$. In Schmutzwasser, häufig; oft Kolonien bildend.

\section{Actinosphaerium St.}

Ektoplasma mit 2-I4 oberflächlich gelegenen, pulsierenden Vakuolen, von dem zahlreiche Kerne einschliessenden Entoplasma deutlich getrennt.

A. eichhorni (Ehrbg.) (Taf. IX, 22)

Durchmesser bis I mm. Bisweilen mit grünen Algen erfüllt. In Altwasser, häufig. Lebt von kleinen Rotatorien. 


\section{Fam. Chlamydophora.}

Körper mit einer kugeligen, gewöhnlich gallertigen und weichen Hülle versehen. Kieselige Elemente fehlen durchaus, dagegen finden sich hin und wieder aufgelagerte Fremdkörper.

\section{Heterophrys Arch.}

Kugelig, Ento- und Ektoplasma deutlich geschieden. Ein Kern sowie eine bis mehrere kontraktile Vakuolen sind vorhanden. Pseudopodien allseitig ausstrahlend, dünn, mit Körnchenströmung. Kugelige, innen hyaline, aussen gekörnt erscheinende Gallerthülle. Oberfläche mit feinen, radiären Fortsätzen.

I. Pseudopodien doppelt so lang als der Körperdurchmesser; körniger Teil der Hülle dick. Durchmesser $25-80 \mu$. . . I. H. myriopoda Arch. I*. Pseudopodien fünf Mal so lang als der Körperdurchmesser; körniger Teil der Hülle sehr dünn. Durchmesser circa $20 \mu$ (Taf. IX, 25) . . . . . . . . 2. H. spinifera Arch:

\section{Sphaerastrum Greeff.}

Kugelig. Gallerthülle dick, mit einer undeutlichen Struktur von wellenförmig verlaufenden Fäden; Oberfläche mit zackigen oder lappenförmigen Fortsätzen besetzt. Einzeln lebend und Kolonien bildend.

S. fockei (Arch.) (Taf. IX, 26)

Durchmesser circa $30 \mu$. Kolonien von bis 20 Individuen in gemeinsamer Hülle.

\section{Elaeorhanis Greeff.}

Kugelig. Pseudopodien nur in geringer Anzahl. Hülle locker aus Diatomeen und Sandkörnchen aufgebaut.

E. cincta Greeff (Taf. IX, 27)

Durchmesser $20-30 \mu$.

4. Lithocolla F. E. Schulze.

Kugelig. Mit Kern und pulsierender Vakuole. Pseudopodien allseitig, dünn. Gallerthülle dünn, mit einer einfachen Schicht von Sandkörnchen bedeckt. 
L. globosa F. E. Schulze (Taf. IX, 28)

Durchmesser $25-28 \mu$, Pseudopodien circa $50 \mu$ lang, matt kirschrot gefärbt.

\section{Fam. Ghalarothoraca.}

Die Tiere erzeugen isolierte Kiesel-Elemente, die eine kugelige, lose Hülle zusammensetzen.

\section{Hyalolampe Greeff.}

Kugelig, klein, lebhaft beweglich. Plasma gleichartig, mit centralem Kern, ohne pulsierende Vakuole. Pseudopodien wenig zahlreich, allseitig ausstrahlend, sehr zart, ohne Körnchenströmung. Hülle aus mehreren Lagen sehr kleiner Kieselkugeln aufgebaut.

I. Kieselkugeln der Hülle $\mathrm{I}-4 \mu$ gross, in $2-3$ Lagen über einander geordnet. Durchmesser circa $50 \mu$ (Taf. X, I). . . I. H. fenestrata Greeff

${ }^{*}$ *. Kieselkugeln der Hülle unmessbar klein, in $4-5$ Lagen. Durchmesser $30-40 \mu$. . . 2. H. exigua Hertw. u. Less.

\section{Pinaciophora Greeff.}

Kugelig. Ento - und Ektoplasma deutlich verschieden, ersteres excentrisch gelegen. Hülle aus dicht an einander liegenden Kieseltäfelchen gebildet, welche die Gestalt eines Ovals mit zugespitzten Polen besitzen und eine feine, zur Oberfläche senkrechte Streifung zeigen.

P. fuviatilis Greeff (Taf. X, 2)

Durchmesser circa $50 \mu$. Entoplasma rotbraun.

\section{Diplocystis Pen.}

Kugelig, klein. Ekto- und Entoplasma deutlich geschieden. Kern und pulsierende Vakuole sind vorhanden. Pseudopodien sehr lang, mit Achsenfäden. Hülle im Innern aus mehreren Lagen sichelförmig gekrümmter Plättchen, aussen aus mehreren Lagen winziger Kügelchen bestehend.

D. gracilis Pen. (Taf. $\mathrm{X}, 3$ )

Durchmesser $30-35 \mu$. Im Ektoplasma häufig Chlorophyllkörner. 


\section{Raphidiophrys Arch.}

Kugelig. Ekto- und Entoplasma nicht getrennt. Pseudopodien fein, mit Körnchenströmung und Achsenfäden. Hülle aus Kieselnadeln.

I. Einzeln lebend . . . . . . . I. R. pallida $1^{*}$. Kolonie bildend

2. Nadeln wenig gebogen. . . . . 2. R. viridis

2*. Nadeln stark hakenartig gekrümmt 3. R. elegans

I. R. pallida F. E. Schulze

Durchmesser circa $80 \mu$. Mit pulsierender Vakuole; Achsenfäden mit Centralkorn. Nadeln wenig gebogen, beiderseits spitz.

2. R. viridis Arch.

Durchmesser $60-80 \mu$. Ohne pulsierende Vakuole und ohne Centralkorn. Mit Zoochlorellen.

3. R. elegans Hertw. u. Less. (Taf. X, 4)

Durchmesser $32-40 \mu$. Ohne Centralkorn. Nadeln beider. seits stumpf. Mit Zoochlorellen.

\section{Acanthocystis Cart.}

Kugelig. Ekto- und Entoplasma deutlich getrennt. Ersteres mit mehreren kleinen pulsierenden Vakuolen, letzteres excentrisch und mit einem Kern. Pseudopodien fein, mit in einem Centralkorn sich vereinigenden Achsenfäden. Skelett aus radiären Stacheln; daneben sind bei manchen Arten auch tangentiale Elemente vorhanden.

I. Ohne tangentiale Skelett-Elemente . . . . . . . . 2

2. Nur eine Art von Stacheln . . . I. A. spinifera

2*. Zwei verschiedene Arten von Stacheln . . . . . . 3

3. Stacheln gabelförmig . . . 2. A. turfacea

$3^{*}$. Stacheln trichter- und trompetenförmig

\section{A. lemani}

I*. Tangentiale Skelett-Elemente sind vorhanden . . . . . 4

4. Stacheln dünn, mit Fussplättchen oder knopfförmiger Verdickung

5. Stacheln mit Fussplättchen . . 4. A. aculeata 
$5^{*}$. Stacheln knopfartig verdickt .5. A.pectinata

4*. Stacheln stark, ohne Fussplättchen 6. A. erinaccus

I. A. spinifera Greeff

Durchmesser circa $25 \mu$. Stacheln gerade, mit Basalplättchen, die sich zu einer Kapsel dicht zusammenschliessen.

2. A. turfacea Cart. (Taf. X, 5)

Durchmesser roo-150 $\mu$. Neben kurzen, dünnen, langgegabelten Radiärstacheln doppelt so lange, dicke, kurz gegabelte, hohle Stacheln. Beide Arten mit Fussplättchen, die auf der Körperoberfläche aufsitzen.

3. A. lemani Pen.

Durchmesser $30-35 \mu$. Neben winzigen, trichterförmigen Radiärstacheln lange, hohle, trompetenartig erweiterte Stacheln.

4. A. aculeata Hertw. u. Less.

Durchmesser circa $20 \mu$. Radiärstacheln dünn, gebogen, mit einfacher Spitze und Basalplättchen. Daneben tangential gelagerte Stäbchen.

5. A. pectinata Pen.

Durchmesser ${ }_{15}-25 \mu$. Radiärstacheln kurz ( $1 / 7$ des Körperdurchmessers). Daneben feine, tangentialc Kicselplättchen.

6. A. erinaceus Pen.

Durchmesser $15-25 \mu$. Radiärstacheln kurz (1/4 des Körperdurchmessers), gebogen, mit verdickter Basis. Daneben tangentiale, sich berührende Schüppchen.

\section{Fam. Desmothoraca.}

Die Hülle besteht in einer kieseligen, festen Hohlkugel, die von zahlreichen Löchern gitterartig durchbrochen wird.

\section{Clathrulina Cienk.}

Kieselschale kugelig, von zahlreichen rundlichen Löchern gitterartig durchbrochen; auf röhrenförmigem, am Grunde zer- 
fasertem Stiele. Der Weichkörper füllt die Schale nicht aus. Plasma vakuolär und gleichartig. Ein centraler Kern und mehrere pulsierende Vakuolen. Pseudopodien fein, mit Körnchenströmung, hin und wieder verästelt.

C. clegans Cienk (Taf. X, 6)

Durchmesser der Schale circa $72 \mu$, Länge des Stieles bis $3 \mathrm{~mm}$.

\section{Mastigophora (Flagellata)}

Flagellaten, Geissellinge.

\section{Litteratur:}

Stein, Fried. v., Der Organismus der Infusionstiere, III. Abteilung, I. Hälfte. Leipzig 1878.

Bütschli, O., Mastigophora in $\mathrm{H}$. Bronns Klassen und Ordnungen des Tierreichs I. Bd. Protozoa II. Abteilg. Leipzig und Heidelberg I $883-87$.

Kent, W. Saville, A Manual of the Infusoria . . Vol. I und III (Atlas). London $1880-82$,

Klebs, G., Ueber die Organisation einiger Flagellatengruppen und ihre Beziehungen zu Algen und Flagellaten. (In Pfeffers Untersuchungen aus dem Bot. Inst. in Tübingen Bd. I). Leipzig 1883-85.

Klebs, G., Flagellatenstudien, Teil I und II. 'In der Zeitschrift für wissenschaftliche Zoologie. Bd. LV. Leipzig 1893.

Blochmann, Fried., Abt. I. Protozoa in Kirchner und Blochmanns mikroskopischer Tierwelt des Süsswassers. Hamburg 1895.

In nächster Zeit (Ostern 1900) wird eine kritische Bearbeitung dieser Gruppe von Dr. Senn in Engler-Prantls Natürlichen Pflanzenfamilien erscheinen.

Die Mastigophoren zeigen zu den meisten Gruppen niederer Organismen deutliche Verwandtschaftsbeziehungen. Nach den zahlreichen Untersuchungen der letzten Jahre hat sich mit immer grösserer Klarheit ergeben, dass man in den "Geissellingen“ wahrscheinlich die Ursprungsformen nicht allein für Infusorien und Metazoen, sondern auch für die Gesamtheit der pflanzlichen Organismen $z u$ sehen hat. So ist es erklärlich, dass Botaniker 
und Zoologen in gleicher Weise Ansprüche auf dieses Grenzgebiet zwischen Tier- und Pflanzenreich erhoben haben. Am natürlichsten wäre es, die Mastigophoren zusammen mit einigen anderen Gruppen in cinem besonderen Zwischenreiche unterzubringen, wie es Häckel durch Begründung des ProtistenReiches, dem die Klebsschen Protobionten etwa entsprechen, versucht hat. Will man sich dieser Gruppierung, die eine Abgrenzung der Protisten gegen zwei Reiche notwendig macht, nicht anschliessen, sondern die Protobionten auf das Tier- und Pflanzenreich verteilen, so haben die Mastigophoren unstreitig nähere Beziehungen zu den tierischen Organismen.

Immerhin aber fehlt es nicht an Argumenten, die auf eine Verwandtschaft der Mastigophoren mit den Algen hinweisen, so dass es unmöglich wird, eine scharfe Grenzlinie zu ziehen. Namentlich ist das häufige Vorkommen von Chromatophoren, das vor allem die Euglenen und Chrysomonadinen auszeichnet, ein $\mathrm{Zug}$ rein pflanzlicher Organisation und die Bedingung, die zahlreichen Vertretern eine Assimilation von Kohlensäure, d. h. eine holophytische Ernährungsweise, gestattet. Nebenbei allerdings findet, wie sich aus den eleganten Versuchen Zumsteins folgern lässt, wohl auch bei allen gefärbten Spezies noch saprophytische Ernährung. Da es Zumstein gelungen ist, gefärbte Formen farblos zu züchten, so folgt hieraus, wie wenig das Vorhandensein von Chromatophoren als systematisches Kriterium geeignet ist. In dem nämlichen Sinne spricht auch die Thatsache, dass eine und dieselbe Gattung sowohl gefärbte als ungefärbte Spezies umfassen kann.

Dass die Familie der Volvocineen, die meist den Flagellaten eingereiht wird, richtiger zu den Algen zu ziehen ist, geschieht nicht in Rücksicht auf den Chlorophyllgehalt, sondern vielmehr wegen des Besitzes einer Cellulose-Membran, die den typischen Mastigophoren abgeht, und wegen der Art der Teilung, die kaum irgendwo in der für unsere Gruppe typischen Längsteilung besteht.

Ist das Verwandtschaftsverhältnis der Mastigophoren zu manchen Gruppen nur theoretisch erschlossen, so giebt es nach den Rhizopoden hin eine kontinuierliche Reihe von Uebergangsformen. $\mathrm{Zu}$ den letzteren gehören vor allem zahlreiche Protomastiginen, die sich durch amoeboide Gestaltsänderung ihres Körpers und durch Entsendung von finger- oder strahlenförmigen Pseudopodien an Amoeben und Heliozoen eng anschliessen. 
Bei diesen tief stehenden Formen ist es noch nicht zur Ausbildung einer distinkten, vom Plasma deutlich unterschiedenen Haut gekommen; höchstens zeigen die äusseren Plasmapartien eine grössere Konsistenz als die inneren. Bei höheren Formen erscheint diese $\mathrm{Hautschicht}$ als ein differenziertes, vom Innenplasma unterscheidbares Organ der Zelle und heisst dann Plasmamembran (Periplast). Dieses noch dem lebenden Plasma zuzurechnende Periplast ist nicht zu verwechseln mit der Cellulosemembran der Pflanzenzellc (z. B. der Volvocineen), die ein totes Ausscheidungsprodukt der Zelle darstellt; es teilt sich daher bei jeder Teilung mit und ist durch Plasmolyse vom Innenplasma nicht $z u$ trennen, was beides für die Cellulosemembran nicht gilt. Zweitens ist das Periplast nicht zu verwechseln mit den in den verschiedensten Modifikationen auftretenden Hüllen- und Gehäusebildungen, die als Ausscheidungsprodukte nach jeder Teilung neu gebildet werden müssen. Alle mit solcher Plasmamembran versehenen Formen sind $\mathrm{zu}$ amoeboïden Bewegungen nicht mehr fähig; ein Teil von ihnen ist jedoch noch mehr oder weniger metabolisch (Euglena, Distigma), während andere völlig starr (Phacus) sind.

Das Plasma umschliesst meist nur einen, vielfach bläschenförmigen Kern und eine bis viele kontraktile Vakuolen.

Das Hauptcharakteristikum sind die Geisseln, die in der Einoder Mehrzahl meist am Vorderende sich befinden, im Querschnitt mehr oder weniger cylindrisch sind und nach Alfr. Fischer ausserdem bei einigen Formen mit ganz feinen Härchen besetzt sind. Bei einer Anzahl von Formen (Craspemonadinen) ist die Geisselbasis resp. das Vorderende des Körpers umschlossen von einem einfachen oder doppelten, offenbar aus dem Plasma der Hautschicht gebildeten Kragen. Gewöhnlich sind die Geisseln nach vorn gerichtet und verursachen durch ihr Hin- und Herschlagen die Vorwärtsbewegung des Körpers, die bald in einem langsamen Dahingleiten (Peranema), bald in einem Hinkriechen auf der Unterlage besteht (andere Peranemiden), bald unter fortwährendem Rotieren (einige Eugleniden) oder endlich durch sprungweises Hin- und Herhüpfen (Bodoninen) erfolgt. Bei einigen Formen ist eine nach hinten gerichtete Schleppgeissel ausgebildet, die als Steuer und als Organ zur Umkehrung der Schwimmrichtung dient (Anisonema). 
Eine zweite Funktion der Geissel ist vielleicht die Zuführung der Nahrung zu der Mundstelle. Diese ist bei den niedrigsten Formen noch nicht bestimmt lokalisiert: hier wird die Nahrung noch an der ganzen Körperoberfläche aufgenommen. Bei höher organisierten Formen findet sich gewöhnlich in der Nähe der Geisselbasis eine bestimmte Mundstelle, die im einfachsten Falle in einer Verdünnung der Plasma-Hautschicht besteht (Bodonina u. s. w.), sonst aber in der Form einer persistenten Oeffnung auftritt, der häufig noch ein stabförmiges Hülfsorgan (Peranema) beigesellt ist. Bei fehlender Mundöffnung findet ein Aussaugen der Nahrung oder eine Aufnahme mittelst einer Mundvakuole statt. Der Membrantrichter mancher Formen (Euglenen) ist wahrscheinlich nichts anderes als die äussere Oeffnung des Ausführungskanales der Vakuole. Die Ausscheidung der Speisereste kann bei den höchst entwickelten Mastigophoren durch einen (bestimmt lokalisierten?) After stattfinden.

Als Stoffwechselprodukte finden sich Fett-Tröpfchen (Peranemiden), Stärke (Chilomonas), Paramylum (ein stärke-ähnliches, in Jod nicht blau sich verfärbendes Kohlehydrat: bei Euglenen und vielen anderen) und Leukosin (Chrysomonadinen).

Die Fortpflanzung besteht mit seltenen Ausnahmen in einer am Vorderende beginnenden Längsteilung, die meist im freischwimmenden Zustande erfolgt. In einigen wenigen Fällen findet die Vermehrung innerhalb einer Schleimhülle statt (Euglena viridis). Eine geschlechtliche Fortpflanzung ist bisher nicht sicher beobachtet. Ausbildung von Dauerzuständen hingegen ist mehrfach konstatiert. Die Tochterindividuen bleiben bei vielen Formen mit der Mutterzelle vereint, so dass Koloniebildung eintritt.

Das unten verwendete System ist im engen Anschlusse an Klebs ausgearbeitet. Für eine einfache Tabelle bieten die komplizierten Verwandtschaftsverhältnisse erhebliche Schwierigkeiten.

I. Körper farblos, vielfach amöboid, häufig mit mehr als zwei Geisseln .

2. Körper ohne Plasma-Membran, amöboid oder metabolisch 3

3. Geisseln in der Ein- oder Zweizahl; wenn in Dreizahl, stets zwei als Nebengeisseln entwickelt. (Vgl. auch die Trimastigina).

I. Protomastigina S. 283) 
$3^{*}$. Geisseln in der Drei- oder Mehrzahl

2. Polymastigina

2*. Körper mit deutlicher Plasma-Membran, nur metabolisch

3. Euglenoidina

I*. Körper gefärbt (gelb oder grün)

4. Körper mit Plasma-Membran .

(3. Euglenoidina)

4*. Körper olne Plasma-Membran, nur mit Hautschicht . 5

5. Mit grünen Chromatophoren . . . . . . 6

6. Mit einer oder zwei Geisseln .

6*. Mit zahlreichen Geisseln

4. Chloromonadina

5. Holomastigina

$5^{*}$. Mit gelben Chromatophoren (selten ungefärbt) .

6. Chromomonadina

\section{Protomastigina.}

Kleine Formen von niedriger Organisation. Ohne deutliche Plasma-Membran. Körper viclfach amöboid, stets farblos. Kontraktile Vakuole vorhanden, gewöhnlich am Vorderende gelegen. Geisseln in der Ein- oder Zweizah1 am Vorderende. Mit bestimmten Mundstellen, aber ohne distinkte Mundöffnung. Ernährung meist tierisch.

I. Geisseln in der Ein- oder Zweizahl; im letzteren Falle nur selten unterschieden als nach vorn gerichtete Lokomotionsgeissel und nach hinten gerichtete Schleppgeissel, dann aber Nahrungsaufnahme durch Pseudopodien . . . . . . . 2

2. Mit einer 'oder zwei Geisseln von ungleicher Grösse oder Richtung . . . . . . . . . . . . . . 3 3. Ohne Kragen . . . . . . . . . . . . . . . . 4 4. Nahrungsaufnahme durch Pseudopodien . . . . . I. Rhizomastigina (S. 284)

4*. Nahrungsaufnahme durch Nahrungsvakuole, oder unmittelbar, aber nicht durch Pseudopodien . . . 5

5. Mit einer Geissel . . . . . . . . . . . . 6

6. Ohne fingerförmigen Peristomfortsatz, höchstens mit sehr schief abgestutztem Vorderende. . .

2. Cercomonadina (S. 286) 
6*. Mit fingerförmigem Peristomfortsatze

5. Bikoecina (S. 29I)

5*. Mit mehr als einer Geissel . . . . . . . . . 7

7. Tiere meist freischwimmend, keine gestielten

Kolonien bildend . . 3. Monadina (S. 288)

$7 *$. Tiere in gestielten Kolonien

4. Dendromonadina (S. 289)

3*. Mit Kragen . . . . . 6. Craspemonadina (S. 292)

$2^{*}$. Mit zwei Geisseln von gleicher Grösse und Richtung . 8

8. Nicht Kolonie bildend . .8. Amphimonadina (S. 30I)

8*. Kolonien, die in gemeinsamer Gallerthülle oder in verzweigten Gallertröhren liegen

7. Spongomonadina (S. 299)

I*. Mit Lokomotions- und Schleppgeissel; Nahrungsaufnahme an bestimmter Stelle, meist des Vorderendes.

9. Bodonina (S. 302)

\section{Fam. Rhizomastigina.}

Freischwimmende, meist längliche Formen, die häufig in einen amöbenartigen Zustand übergehen, während dessen aber die Geisseln erhalten bleiben. Am Vorderende mit einer oder zwei Geisseln. Kern am Vorder-, kontraktile Vakuole häufig am Hinterende. Nahrungsaufnahme durch Pseudopodien. Die Rhizomastigina leiten von den Sarkodinen zu den Mastigophoren über.

1. Mit einer Geissel . . . . . I. Mastigamoeba (S. 284)

I*. Mit zwei Geisseln . . . . . . . . . . . . . . . . 2

2. Pseudopodien nicht scharf abgesetzt, ohne Achsenfaden

2. Dimastigamocba (S. 285)

2*. Pseudopodien scharf (Heliozoen-artig) abgesetzt, mit Achsenfaden . . . . 3. Dimorpha (S. 286)

\section{Mastigamoeba F. E. Schulze.}

Körper im freischwimmenden Zustande gewöhnlich oval oder länglich; im kriechenden Zustande mit zahlreichen Pseudopodien. Das Vorderende trägt eine ansehnliche Geissel. Plasma homogen, Zellkern am Vorderende. 
1. Körper mit deutlicher Scheidung eines glashellen Ekto- und eines körnigen Entoplasmas . . . . 1. M. aspera

I*. Plasma homogen

2. Körper beim Schwimmen etwa eiförmig; im Amöbenzustande mit wenigen Pseudopodien

2. M. invertens

$2^{*}$. Körper beim Schwimmen etwa kugelig, mit kurzen, verästelten Pseudopodien; letztere im Amöbenzustande zahlreich . . . . . . . 3. M. ramulosa

I. M. aspera F. E. Sch.

Körper spindelförmig, oben und unten abgeplattet. Zwei oder mehr Vakuolen im hinteren Körperende. Durchmesser circa $100 \mu$. Länge der Geisseln $60-80 \mu$. Scheint fast ausschliesslich zu kriechen. Entoplasma häufig orangerot. Zwischen grünen Wasserpflanzen, selten. (Die ganze Oberfläche ist nach F. E. Schulze mit kleinen, stäbchenförmigen Gebilden besetzt).

2. M. invertens $\mathrm{K} 1$. (Taf. $\mathrm{X}, 7$ )

Geissel beim Schwimmen nach vorn, während des Kriechens nach hinten gekehrt, etwa zwei Mal so lang als der Körper. Kontraktile Vakuole stets an der Geisselbasis. Länge 8-12 $\mu$. Vermehrung durch Längsteilung nach Bildung einer zweiten Geissel. Bewegung hin- und herzitternd. Im Detritus.

3. M. ramulosa S. K.

Geissel 2-3 Mal so lang wie der Körper. Kern am Vorderende; Nukleolus eckig, langsame Formänderungen zeigend. Bewegung wie bei voriger Art.

\section{Dimastigamoeba Blochm.}

Körperform länglich bis rundlich im frei schwimmenden Zustande. Als Amoebe mit meist breiteren oder schmäleren Pseudopodien. Das Vorderende trägt eine nach vorn und eine nach hinten gerichtete Geissel.

I. Beide Geisseln auch im Amöbenzustande ausgestreckt . . 2

2. Hinterende nur wenig zugespitzt . I D. ovata

2*. Hinterende schwanzartig, sehr variabel

I*. Eine Geissel im Amöbenzustande eingerollt

2 D. longicauda 
I. D. ovata (K1.) Blochm.

Beim Schwimmen dick eiförmig bis kugelig; beim Kriechen mit stumpfen Pseudopodien. Kontraktile Vakuole vorn. Die Geisseln nahezu gleich lang, während der Nahrungsaufnahme schwer sichtbar. Länge $18-21 \mu$, Breite $15-19 \mu$.

2. D. longicanda (Duj.) Blochm. (Taf. $\mathrm{X}, 8$ )

Beim Schwimmen eiförmig; beim Kriechen mit zahlreichen häufig verästelten Pseudopodien. Geisseln nahezu gleich lang. Kontraktile Vakuole in der.Ein- oder Zweizahl, gewöhnlich am Vorderende. Länge $18-36 \mu$, Breite $9-14 \mu$.

3. D. radiata K1. (Taf. X, 9)

Körper beim Schwimmen eiförmig, nach hinten verjüngt. Schleppgeissel etwas länger als die Vordergeissel. Im Amöbenzustande ist eine Geissel eingerollt. Kontraktile Vakuole am Hinterende. Länge 10-14 $\mu$, Brcite $5-9 \mu$. Vermehrung wie bei voriger Art. In faulenden Kulturen. Diese Art bildet den Uebergang zur folgenden Gattung.

Die verwandte D. laciniaegerens (Krass.) Kl. (= Cercobodo l.) ist mit den Geisseln am Substrate festgeheftet. Wirft vor der Teilung die Geisseln ab.

\section{Dimorpha (Gruber).}

Der vorigen Gattung sehr ähnlich, jedoch mit feinstrahligen, Heliozoen-ähnlichen Pseudopodien, deren Achsenfäden - auch bei eingezogenen Scheinfüsschen - ins Innere bis zu einem centralen Kerne zu verfolgen sind.

D. mutans Grub. (Taf. X, Io)

Vermehrung wahrscheinlich durch Längsteilung im beweglichen Zustande; Geisseln im Kreuzungspunkte der Achsenfäden entspringend. Länge etwa $15 \mu$. Selten.

\section{Fam. Cercomonadina.}

Körper klein; häufig amöboid, besonders am Hinterende. Am Vorderende eine Geissel. Nahrungsaufnahme an der Geisselbasis durch eine Vakuole. Vermehrung durch Zweiteilung im beweglichen Zustande. Selten mit Gehäusebildung. 
I. Ohne Gehäuse . . . . . . . . . . . . .. . . . 2

2. Körperform kugelig oder elliptisch, nie verbogen dreieckig . . . . . . . . . . . . . . . 3

3. Am Hinterende mit langem, schwanzartigem Fortsatze . . . . . . I. Cercomonas (S. 287)

$3^{*}$. Hinterende ohne Schwanzfortsatz, höchstens amöboid 2. Oikomonas (S. 287)

2*. Körper in der Form eines verbogenen, dreieckigen Plättchens . . . . . 3. Phyllomonas (S. 288) 1*. Mit Gehäuse . . . . . . 4. Codonoeca (S. 288)

\section{Cercomonas Duj.}

Klein, mit Schwanz nicht über $60 \mu$; farblos; kugelig oder elliptisch. Vorderende mit starker Geissel, Hinterende schwanzartig ausgezogen. Kern am Vorderende. Kontraktile Vakuole in der Ein- oder Mehrzahl.

\section{C. crassicanda Duj. (Taf. X, i I)}

Schwanzbasis ziemlich dick, Anhänge breit; 2-3 kontraktile Vakuolen vorn. Länge $30-40 \mu$. Vielleicht gehört auch die von Klebs zu Dimastigamoeba gezogene C. longicauda mit feinem Schwanzende hierher.

\section{Oikomonas S. K.}

Klein, nicht länger als $15 \mu$. Gestalt oval, mehr oder weniger amöboid, vornehmlich am Hinterende. Neben der Geisselbasis eine vorspringende Lippe, die vermöge einer Vakuole zur Nahrungsaufnahme dient. Im Sumpfwasser, häufig.

1. Vorn mit Lippenfortsatz; Vakuole in der Einzahl.

I. O. termo

1*. Ohne Lippenfortsatz; Vakuole meist in Zweizahl

2. O. mutabilis

I. O. termo (Ehrbg.) J.-Cl.

Freischwimmend oder auf fadenförmigem Stiele von wechselnder Länge. Kern etwa in der Mitte. Durchmesser $5-6 \mu$. Eine der häufigsten Flagellaten. 
2. O. mutabilis S. K. (Taf. X, 12)

Wie vorige Art, Stiel von Körperlänge. Kern im Vorderende. Durchmesser des festsitzenden Tieres circa $15 \mu$. Sehr häufig. Bewegung geradlinig und gleichmässig.

\section{Phyllomonas K1.}

Klein, ein dreieckiges, verbogenes Plättchen bildend; an einer Ecke eine bei der Bewegung nachschleifende Geissel. Kontraktile Vakuole an einer anderen Ecke.

Ph. contorta K1. (Taf. X, 13)

Körperplasma homogen, wenig granuliert. Länge $6-7 \mu$, Breite $5-6 \mu$. Bei der Bewegung lebhaft hin- und herzitternd. In Sumpfwasser, vereinzelt.

\section{Codonoeca J.-Cl.}

Mit ovalem oder becherförmigem Gehäuse; letzteres ist farblos, gallertig und besitzt eine weite Mündung; es ist auf einem Stiele befestigt und wird vom Tierkörper nur zum Teile ausgefüllt. Kontraktile Vakuole am Hinterende.

C. inclinata S. K. (Taf. X, I4)

Gehäuse oval, schief auf dem Stiele sitzend. Dieser von doppelter Körperlänge. Länge des Gehäuses circa $16 \mu$. In Sumpfwasser.

Die verwandte $C$. costata J.-Cl. hat ein glockenförmiges, längsgestreiftes Gehäuse.

\section{Fam. Monadina.}

Nie mit echtem Peristomfortsatze, höchstens mit amöboiden Vorstülpungen. Mit Haupt- und Nebengeisseln (ob mehreren?). Ohne Gehäuse.

\section{Monas (Ehrbg.) St.}

Körper eiförmig, kugelig oder wechselnd gestaltet. Nahrungsaufnahme gewöhnlich durch Mundvakuole. Kern im Vorderende. Mundleiste meist vorhanden. 
I. Mit Mundleiste

2. Mit Augenfleck . . . . . . 1. M. vivipara

2*. Ohne Augenfleck . . . . . . 2. M. guttula

I*. Ohne Mundleiste . .

3. Grösse circa is $\mu$. . . . 3. M. arhabdomonas

$3^{*}$. Länge nicht über $5 \mu$. . . . 4. M. minima

I. M. (Spumella) vivipara Ehrbg. (Taf. X, I5)

Länge $20-30 \mu$. Geissel zart. Festsetzung mit verschmälertem Hinterende. In Sumpfwasser, häufig.

2. M. guttula Ehrbg.

Länge $10 \mu$. Körper rund, vom fadenförmigen Stiele scharf abgesetzt. Mit Cystenbildung. Vorkommen wie bei voriger Art.

3. M. arhabdomonas (Fisch) H. Meyer

Geissel kurz. Wohl meist, und zwar mit zitternder Bewegung, frei umherschwimmend. Kurz vor der Teilung wird die eine Geissel abgestossen. Häufig, in Infusionen.

4. M. minima H. Meyer (Taf. X, 16)

Gestalt eckig oval. Geissel sehr dick, kürzer als der Körper. Im festsitzenden Zustande der $M$. gutulla ähnlich. Meist in rascher Bewegung.

Die $M$. sociabilis H. Meyer enthält I.eukosin-Körner und bildet freischwimmende Kolonien. Länge jeder Monade circa I $5 \mu$.

\section{Fam. Dendromonadina.}

Kleine Formen. Mit Hauptgeissel und einer Nebengeissel; Vorderende mit einem Peristomfortsatze. Koloniebildung.

I. Stielgerüst höchstens zwei Mal dichotomisch verästelt. Auf Cyclops festgewachsen . . . I. Cephalothammium (S. 290) I*. Stielgerüst öfter dichotomisch verästelt . . . . . . . . 2

2. Stielgerüst zart . . . . 2. Dendromonas (S. 290)

2*. Stielgerüst dick, meist bräunlich .

3. Anthophysa (S. 290)

Eyferths Einfachste Lebeformen. 3. Aufl. 


\section{Cephalothamnium St.}

Stielgerüst solide, steif, ohne Färbung, nur wenige Male dichotomisch verästelt. Die Anzahl der Tiere, die auf den Enden der Stiele sitzen, ist wechselnd.

\section{C. caespitosum S. K. (Taf. X, I7)}

Gestalt gewöhnlich schief birnförmig. An den Zweig-Enden je 2-8 Individuen. Länge des einzelnen Tieres $20 \mu$. In frischem Wasser.

Das keilförmige C. cuneatum S. K. sitzt auf längeren Stielen.

\section{Dendromonas St.}

Kolonien ziemlich gross. Stielgerüst dünn, farblos.

1. Tiere nicht auf gleicher Höhe (Cladonema S. K.) I. D. $\operatorname{laxa}$

I*. Tiere auf gleicher Höhe; Stielgerüst starr (Dendromonas im eig. Sinne) . . . . . . . . . 2. D. virgaria

I. D. (Cladonema) laxa (S. K.) Blochm. (Taf. X, I8)

Körper unregelmässig birnförmig, vorn schief abgestutzt. Kontraktile Vakuole im Hinterende. Kern etwa in der Mitte. Länge circa $8 \mu$. In Sumpfwasser, an Myriophyllım und anderen Pflanzen.

2. D. virgaria (Weisse) S. K.

Gestalt des Einzeltieres und Lage des Kernes wie bei voriger Art. Stielgerüst streng dichotom; Kolonien doldenförmig, oft über 100 Individuen umfassend. Zwei kontraktile Vakuolen im Hinterende. In Sumpfwasser. Nicht sehr häufig.

\section{Anthophysa Bory.}

Gestalt schief birnförmig. Peristomfortsatz undeutlich bis lang schnabelförmig. Die verschieden langen Geisseln entspringen in der Eindellung des abgeschrägten Vorderendes. Bis zu bo Individuen bilden köpfchenförmige Kolonien. Diese sitzen meist auf dicken Stielen, von denen sie sich sehr leicht loslösen, um dann durch das Wasser zu rollen. Die Stiele sind nach Art eines Seiles aus zahllosen feinen Fäserchen aufgebaut und lagern im Alter (braunes) Eisenhydroxyd ab. Die losgelösten Stiele 
finden sich häufig bei der Brunnenwasser-Untersuchung und bedecken bei starker Entwicklung dieser Flagellate die Wasseroberfläche mit einer braunen Schicht.

A. vegetans (O. F. Muell.) Btschli (Taf. X, I9)

Länge der Monaden $30 \mu$ und mehr. In Sumpfwasser, häufig.

\section{Fam. Bik o e cina.}

Körper oval, am Vorderende verjüngt; vorn mit starker Geissel und Peristomfortsatz. Kontraktile Vakuole am Hinterende, Kern etwa central gelegen. Hinterende durch einen seitlichen, zarten, kontraktilen Fortsatz (wahrscheinlich als eine zweite Geissel aufzufassen!) im Grunde eines vasenförmigen, häufig gestielten Gehäuses befestigt. Vielfach Koloniebildung. Fortpflanzung durch Querteilung (?) innerhalb des Gehäuses.

'I. Peristomfortsatz zungenförmig; meist ohne Koloniebildung .

I. Bikosoeca (S. 291)

$1^{*}$. Peristomfortsatz breit; mit Koloniebildung . . . . . . .

2. Poteriodendron (S. 292)

\section{Bikosoeca J.-Cl.}

Peristomfortsatz nur wenig entwickelt. Ohne oder mit Gehäusestiel. Mit einer langen Geissel (nach Sav. Kent existiert noch eine kurze Nebengeissel).

I. Gehäuse gestielt . . . . . I. B. lacustris

I*. Gehäuse ungestielt . . . . . 2. B. socialis

I. B. lacustris J.-Cl. (Taf. X, 20)

Körper etwa zwei Mal so lang als breit. Zwei oder drei kontraktile Vakuolen im Hinterende. Länge des Tieres etwa 12-I5 $\mu$. In Sumpfwasser, häufig.

2. B. socialis Lauterb.

Mit den Hinterenden zu freischwimmenden, Anthophysaähnlichen Kolonien vereinigt. Länge der Monaden Io $\mu$, der Kolonien bis $60 \mu$. In Teichen. 


\section{Poteriodendron St.}

Peristomfortsatz breiter als bei voriger Gattung, etwa rüsselförmig gestaltet; nach Stein mit kragenförmigem Fortsatze. Da die jungen Tiere sich auf dem Mündungsrande der Gehäuse der älteren festsetzen, ist Koloniebildung die Regel. Gehäusestiele meist ziemlich lang. Plasmastiel des Tieres nicht seitlich entspringend.

$P$. petiolatum St. (Taf. X, 2 I)

Das hyaline, kelchförmige Gehäuse 40-50 $\mu$ lang. In Sumpfwasser, nicht häufig.

\section{Fam. Craspem on ad ina.}

Körper metabolisch; auch amöboid; kugelig oder ellipsoidisch, am Vorderende zum Teil mit halsartiger Verschmälerung. Einige Kolonien bildende Formen sind asymmetrisch. Am Vorderende eine Geissel und ein meist einfacher, selten doppelter, aus einer zarten Plasma-Membran gebildeter, ringförmiger, kontraktiler Kragen, der die Geisselbasis umschliesst. Der Kragen leistet wahrscheinlich bei der Nahrungs-Aufnahme Hülfe. Kontraktile Vakuole im hinteren Körperende, in der Ein- oder Mehrzahl. Vielfach Gehäusebildung. Vermehrung durch Längs- oder Quer-(?) Teilung. Encystierung ist beobachtet.

I. Kragen eng, kegelförmig, gestaltsbeständig; Individuen in Schleimröhren kolonicbildend . . I. Phalansterina (S. 292) 1*. Kragen ansehnlich, gestaltsveränderlich, im ausgebreiteten Zustande verkehrt kegelförmig . . 2. Choanoflagellata(S.293)

\section{Phalansterina.}

Diese Gruppe scheint durch Poteriodendron den Uebergang zu den Bikoecinen zu bilden, da der Kragen nur rudimentär ausgebildet und im Schleime der Gallertröhren eingeschlossen ist.

\section{Phalansterium Cienk.}

Tiere in stark körnigen Schleimröhren. Kolonien oft scheibenförmig (indem die sie zusammensetzenden Einzelröhren inner- 
halb einer Ebene gleich Radien von einem gemeinsamen Centrum ausstrahlen) oder frei sich erhebend unter dichotomischer Verästelung. Ein bis zwei Individuen sitzen in jeder Röhre. Encystierung beobachtet. Zwei kontraktile Vakuolen im Hinterende. Querteilung (?). In Sumpfwasser.

I. Die Gallertröhren erheben sich und sind bäumchen-artig verzweigt . . . . . . . . . . . . . I. P. digitatum

$1^{*}$. Die Gallertröhren bilden eine Scheibe und sind dem Substrate angedrückt . . . . . . . 2. P. consociatum

1. P. digitatum St. (Taf. $\mathrm{X}, 22$ )

Körper $\mathrm{I}^{1 / 2}$ Mal so lang als breit. Jedes Ende eines Astes enthält ein oder (nach Teilung) zwei Individuen. Der Kragen verdeckt etwa $1 / \mathrm{s}$ der Geissel. Kolonien $1 / 2 \mathrm{~mm}$ hoch und höher.

\section{P. consociatum Cienk.}

Die scheibenförmige Kolonie erscheint in regelmässige Sektoren zerlegt: Durchmesser der Kolonie etwa $60 \mu$.

\section{Choanoflagellata (eig. Craspemonadina), Kragenmonaden.}

Die Choanoflagellaten wurden von Bütschli und Saville Kent den übrigen Flagellaten nebengeordnet, von Klebs und Francé jedoch mit Recht in die Nähe der Monaden gestellt, weil man in dem Vorhandensein des Kragens ein so wichtiges systematisches Kriterium nicht erblicken kann. Bemerkenswert ist diese Gruppe noch dadurch geworden, dass man in ihr eine Zeit lang die Urformen für die Spongien suchen zu müssen glaubte, bei denen sịch ja in den inneren Kanälen ganz ähnliche Kragenzellen finden. Die hauptsächlichsten Vertreter und Verfechter dieser Ansicht waren James Clark und Sav. Kent, von denen der letztere die Spongien sogar mit den Protozoen vereinigte. Heute huldigt wohl niemand mehr dieser Ansicht, nachdem Bütschli, F. E. Schulze und andere sich energisch dagegen erklärten.

Die meisten hierher gehörenden Formen sind festsitzend, haben eine Geissel, eine kontraktile Vakuole, einen Zellkern, Oeleinschlüsse etc. Der Kragen scheint eine komplizierte Gestalt zu haben und auf der einen Seite offen zu sein, und zwar so, dass von dem oberen Rande des Kragens nach dem Körper zu 
eine spiralige Furche herabläuft, deren Ende an der Körperscite in einer Vakuole oder Mundstelle endet (ob bei allen?). Der Kragen selbst ist beweglich und kann sich schirmförmig ausbreiten und zusammenklappen; ja er soll sogar - wie auch die Geissel zurückziehbar sein (?). Der Kragen ist so zart, dass man meist nur zwei trichterförmig stchende Stäbchen, die Querschnitte der Seitenwandung, zu sehen bekommt. Meist sehr kleine Formen. Die folgende Einteilung in engem Anschlusse an Francé.

I. Individuen gehäuselos . . . . . . . . . . . . . 2

2. Freischwimmende Formen . . . . . . . . . 3 3. Mit Schleimhülle. . . . . . . . . . . . 4 4. Individuen regellos in einer Schleimmasse . . . . 6. Protospongia (S. 296)

$4^{*}$. Individuen an radiär stehenden Stielen

5. Sphaerocca (S. 296)

$3^{*}$. Ohne Schleimhülle .

5. Individuen $\mathrm{zu}$ Bändern vereinigt. . . . . . .

$5^{*}$. Individuen an radiären Stielen

7. Codonodesmus (S. 296)

4. Asterosiga (S. 296)

2*. Festsitzende Formen . . . . . . . . . . . . 6

6. Nur ein Kragen vorhanden . . . . . . . . . . 7

7. Stiel fehlend oder kleiner als die Körperlänge .

I. Monosiga (S. 294)

$7^{*}$. Stiel lang, meist unverzweigt; höchstens einmal gegabelt. . . . . . . 2. Codonosiga (S. 295)

7**. Stiel lang, verzweigt . . 3. Codonocladium (S. 295)

6*. Zwei Kragen entwickelt . . 8. Diplosiga (S. 297)

I*. Individuen mit Gehäusebildung. . . . . . . . . . 8

8. Nur ein Kragen vorhanden . . . . . . . . . . . 9

9. Freilebend . . . . . . 10. Lagenocca (S. 298)

9*. Festsitzend . . . . . . . 9. Salpingoeca (S. 297)

8*. Zwei Kragen vorhanden . . I I. Diplosigopsis (S. 299)

\section{Monosiga S. K.}

Individuen stets einzeln lebend, mit kurzem Sticle. Kragen stets deutlich.

I. Körper rund bis eiförmig. . . . 1. M. ovata

$1^{*}$. Körper spindelförmig . . . . . 2. M. fusiformis

${ }_{1 * *}$. Körper langgestreckt, wurmförmig 3. M. angustata 
1. M. ovata S. K. (Taf. X, 23)

Meist gesellschaftlich an Cladophoren oder leeren Chitinhülsen von Insektenpanzern. Länge bis $15 \mu$. Stiel oft gänzlich fehlend. Häufig.

2. M. fusiformis S. K.

Körper drei. Mal so lang als breit; ohne Stiel. Zwei kontraktile Vakuolen. Länge bis io $\mu$. Auf Cyclops-Arten.

3. M. angustata S. K.

Körper vier Mal so lang als breit, ohne Stiel. Kontraktile Vakuole und Länge wie bei $M$. fusiformis. Ebenfalls auf Krebschen.

\section{Codo(no)siga J.-Cl.}

Individuen in der Ein- oder Mehrzahl auf langen, gewöhnlich unverzweigten Stielen. Bekannteste Gattung.

I. Stiel lang, unverzweigt oder ganz kurz gabelig. Individuen einzeln, oder in Trauben am Ende des Stieles.

I. C. botrytis

I*. Stiel deutlich gabelig geteilt. . . . 2. C. furcata

1. C. botrytis Ehrbg. (Taf. X, 24)

Körperform variabel, Länge $8-30 \mu$. Meist auf jedem Stiele nur ein Individium, doch auch bis über 20 vergesellschaftet. Länge des Stieles 2-10 Mal so gross als der Körper. Häufig.

2. C. furcata S. K.

Voriger Art sehr ähnlich. Jede Kolonie nur aus zwei Zellen gebildet.

\section{Codonocladium St.}

Aehnlich Codonosiga. Kolonie bildend durch Verästelung oder durch Aneinanderhaften der Stiele. Verästelung vielfach doldenartig.

I. Verästelung døldenartig . . . . . I. C. umbellatum

1*. Verästelung nach Art einer Trugdolde 2. C. corymbosum

I. C. umbellatum (Tatem) St. (Taf. X, 25)

Mannigfaltig im Aufbau der Kolonien. Anzahl der Doldenzweige 4-IO. Manchmal trägt jeder Doldenstiel eine Dolde zweiter Ordnung. Länge circa $30 \mu$. In stagnierendem Wasser. 
2. C. corymbosum Entz

Körper mit kleinem, eng anschliessendem Gehäuse. Kolonien bis zu vier Individuen umfassend. In Salzteichen.

\section{Asterosiga S. K.}

Nackt, gestielt, Kolonie bildend. Stiele von gemeinsamem Centrum ausstrahlend.

A. radiata Zach. (Taf. X, 26)

Kolonien bis 120 Individuen umfassend. Durchmesser der Kolonięn $60-90 \mu$. Bewegung langsam rotierend, ähnlich den Volvox-Kugeln.

\section{Sphaeroeca Lauterb.}

Kolonie bildend. Die Stiele der einzelnen Individuen strahlen nicht von gemeinsamem Centrum aus, sondern eine gallertartige Hülle stellt den Konnex her.

Sph. volvox Lauterb. (Tafel X, 27)

Kolonien freischwimmend. Körper rundlich birnförmig, hinten zugespitzt. Stiel zwei Mal, Geissel fünf Mal so lang als der Körper. Vakuole am Hinterende. Durchmesser der Kolonien $120-200 \mu$. Länge der Einzeltiere ohne Kragen 8-12 $\mu$. Auf der Oberfläche des Schlammes dahinrollend; in stehendem Wasser.

\section{Protospongia S. K.}

Nackt, stiellos, bildet in gemeinsamer Gallertmasse lagernde Kolonien.

Pr. hacckeli S. K. (Taf. X, 28)

Kolcnien 6-I 2 (60) Individuen fassend. Länge des Einzeltieres $8 \mu$. Gestalt oval bis birnförmig. Schlingvakuole deutlich, ihr gegenüber die kontraktile Vakuole. Kern klein, im vorderen Körperdrittel.

\section{Codonodesmus St.}

Nackt; Individuen ketten- oder bandartig verbunden.

C. phalanx Stein. (Taf. X, 29)

I.änge ${ }_{15} \mu$. In Sumpfwasser (?) 


\section{Diplosiga Frenzel.}

Nackt, solitär; mit zwei Kragen.

1. Jeder der Kragen mit besonderer Basis 1. D. socialis

I*. Beide Kragen von derselben Basis entspringend

2. D. frequentissima

I. D. socialis Frenzel

Bis auf den doppelten Kragen sehr ähnlich einer Monosiga.

2. D. frequentissima Zach. (Taf. X, 30)

Stiel von verschiedener Länge. Grösse circa $12 \mu$.

\section{Salpingoeca J.-Cl.}

Individuen einzeln lebend, mit Schale und einem Kragen. Aehnlich Monosiga. Sehr formenreiche Gattung.

1. Gehäuse höchstens in eine Spitze ausgezogen . . . . . 2 2. Gehäuse weit halsartig ausgezogen . . . . . . 3 3. Gehäuse unten abgeplattet. . . . I. S. brinnea

$3^{*}$. Gehäuse unten halbkugelig abgerundet oder zugespitzt 2. S. amphoridium

2*. Gehäuse nahezu kugelig (siehe auch $2^{* *}$ ) . . . . . 4

4. Gehäuse hinten mit scharfer Spitze 3. S. napiformis

4*. Gehäuse hinten ohne scharfe Spitze 4. S. pyxidrum

$2^{* *}$. Gehäuse langgestreckt, meist vorn und hinten verschmälert, ohne bedeutende halsartige Verlängerung . . . . 5

5. Gehäuse vom Tierkörper völlig ausgefüllt .

\section{S. minuta}

5*. Gehäuse nicht völlig vom Tierkörper erfüllt . . . . 6

6. Gehäuseöffnung trompetenartig . 6. S. vaginicola

6*. Gehäuseöffnung mit kurzem Halse .

7. S. fusiformis

I*. Gehäuse mit deutlicher Stielbildung. . . . . . . . . 7

7. Stiel dünn, fadenförmig . . . . 8. S. convallaria

7*. Stiel dick, massiv . . . . . 9. S. ringens

\section{S. brunnea Stokes}

Körper das Gehäuse fast ausfüllend; letzteres braun gefärbt. Länge ${ }_{5} 5-20 \mu$, Breite variabel. Auf Vauchicria. 
2. S. amphoridium J.-Cl. (Taf. X, 31)

Gesellig lebend. Körper füllt das Gehäuse meist aus. Länge bis $15 \mu$.

3. S. napiformis S. K. (Taf. X, 32)

Gehäuse mit mächtiger bauchiger Erweiterung, hinten plötzlich in eine Spitze verjüngt, die manchmal in eine Haftscheibe umgewandelt ist. Länge des Gehäuses $20 \mu$. Körperplasma zu Gestaltsänderungen neigend. Gemein. Auf Difflugia-Schalen, Protococcus-Zellen etc.

4. S. pyxidium S. K.

Körper das Gehäuse nicht ausfüllend, klein (bis herab zu $5 \mu$ ).

5. S. minuta S. K.

Gehäuse eiförmig. Grösse $12-15 \mu$. Auf organischem Detritus.

6. S. vaginicola $\mathrm{St}$.

Gehäuse bis acht Mal länger als breit. Kontraktile Vakuole gross, am unteren Ende, in Zeiträumen von ${ }_{5} 5$ Sekunden pulsierend. In stark faulendem Wasser, an Conferven sitzend.

7. S. fusiformis S. K.

Gehäuse spindelförmig. Am hinteren Körperende wahrscheinlich ein feiner Faden, der das Tier blitzschnell in den Grund des Gehäuses zurückzieht.

8. S. convallaria St.

Stiel unten in eine winzige Haftscheibe verbreitert. Gehäuse weich und gallertig.

9. S. ringens S. K.

Gehäuse lang kelchförmig. Körper langgestreckt. Länge des Stieles variabel.

\section{Lagenoeca S. K.}

Tiere mit Schale, ohne Stiel. Nur ein Kragen entwickelt. Freischwimmend.

L. globulosa Francé (Taf.'X, 33)

Gehäuse kugelig bis oval, dick, farblos; Länge $10-15 \mu$. Kragen gross, wenig formbeständig. Krern central gelegen. Pulsierende Vakuole und Schlingvakuole excentrisch. Vermehrung durch Längsteilung. Schwimmt lebhaft umher. 
II. Diplosigopsis Francé.

Tiere-mit Schale und zwei Kragen, festsitzend.

D. entzi Francé (Taf. X, 34)

Schalenöffnung klein; Gehäuse zart, vom Körper nicht völlig (oft nur bis zur Hälftc) erfüllt (Schalendurchmesser 6-8 $\mu$; Körperdurchmesser $4-6 \mu$ ). Körper kugelig oder vorn halsartig verjüngt. Tiere gesellig mit anderen Craspedomonaden.

\section{Fam. Spongomonadina.}

Körper klein, oval. Geisseln in der Zweizahl, dicht beisammen stehend. Kern und kontraktile. Vakuole etwa central. Vermehrung (hauptsächlich) durch Längsteilung. Stets Kolonieoder Stockbildung innerhalb gemeinsamer Gallerte oder verzweigter Gallertröhren.

1. Tiere in einer gemeinsamen Gallertmasse, aus der nur die Geisseln herausragen. . . . . I. Spongomonas (S. 299)

I*. Tiere in verzweigten Gallertröhren

2. Die einzelnen Aeste des Stockes frei sich erhebend . 2. Cladomonas (S. 300)

2*. Die Aeste je zu mehreren zu fächerförmigen Gebilden verbunden . . . . . 3. Rhipidodendron (S.300)

\section{r. Spongomonas St.}

Kolonien gross (bis $3 \mathrm{~cm}$ Länge), verschieden gestaltet: wurmförmig bis scheibenförmig, frei sich von dem Untergrunde erhebend oder frei herabhängend; kugelig, sackartig oder gelappt. Gallerte deutlich granuliert.

1. Die gallertigen Kolonien stellen ein darmartiges, braunes Gebilde dar . . . . . . . I. Sp. intestinum

I*. Die Kolonien mehr oder weniger rundlich . . . . . . 2

2. Kolonien scheibenförmig, aufgewachsen . . . . . . .

2. Sp. discus

$2^{*}$. Kolonien sackförmig, an einem dünnen Stiele befestigt 3. Sp. sacculus 
I. Sp. intestinum (Cienk.) St. (Taf. X, 35)

Die einzelnen Flagellaten mehr oder weniger rundlich; Geisseln zwei Mal so lang als der Körper. In Sumpfwasser mit Anthophysa etc.

2. Sp. discus St.

Geisseln 2-3 Mal so lang als der Körper. Tiere grösser als vorige Art. Scheibe meist regelmässig.

3. Sp. sacculus S. K. (Taf. X, 36)

Tiere länglich-eiförmig; Geisseln wie bei Sp. intestimum. Kontraktile Vakuole seitlich. Die ganze braune Kolonie hängt herab und ist oft bis $1 \mathrm{~cm}$ gross. In Morästen.

Die verwandte $S p$. uvella St. sitzt in aufrechten Säcken.

\section{Cladomonas St.}

Gallertröhren dichotomisch, baumartig verzweigt; Aeste nicht zusammengewachsen. Grösse der Stöcke nicht erheblich (circa $75 \mu$ hoch). Die Tiere sitzen in den Enden der einzelnen Aeste.

Cl. fruticulosa St. (Taf. X, 37)

Geisseln von doppelter Körperlänge; Gallerte braun. Scheint selten zu sein.

\section{Rhipidodendron St.}

Kolonien aus einer sich fortgesetzt meist in einer Ebene dichotom teilenden Gallertröhre bestehend. Die Aeste bleiben zunächst eine Strecke lang verwachsen und setzen also fächerförmige Gebilde zusammen. Auf den Fächern erster Ordnung erheben sich vielfach solche zweiter und dritter Ordnung. Höhe der Kolonien bis $300 \mu$.

Rh. splendidum St. (Taf. X, 38)

Dic Gallertröhren hängen in grosser Anzahl zusammen. (Bei Rh. huxleyi S. K. bilden meist nur vier Röhren einen Zweig; Verzweigung auch regelmässig dichotom, was bei Rh. splendidum nicht der Fall ist). Geissel von doppelter Körperlänge. Bis $300 \mu$ lang. In Sumpfivasser (?). 
VIII. Fam. Amphimonadina.

Kleine Formen mit zwei gleich langen Geisseln, amöboid oder metabolisch.

I. Tiere ohne Gehäuse . . . . . . . . . . . . . . 2

2. Tiere meist auf Stielen festsitzend, rundlich . . . . 3

3. Stiel vom Körper scharf abgesetzt.

$3^{*}$. Körper in einen dicken Stiel ausgezogen

1. Amphimonas (S. 301)

2. Deltomonas (S. 301)

$2^{*}$. Tiere immer freischwimmend, herzförmig

$$
\text { 3. Streptomonas (S. 301) }
$$

I*. Tiere mit Gehäuse, festsitzend . . 4. Diplomita (S. 302)

\section{Amphimonas Duj.}

Formen klein, metabolisch, meist ellipsoidisch bis kugelig; mit dem hinteren Pole häufig festsitzend. Geisseln einander mehr oder weniger genähert. Kontraktile Vakuole in der Ein- oder Zweizahl.

\section{A. globosa S. K. (Taf. X, 39)}

Körper rund; auf langem, dünnem, peitschen-ähnlichem Stiele, der mindestens drei Mal so lang als der Körper ist. Geisseln von gleicher Länge, doppelt so lang als der Körper, unregelmässig vibrierend. Zwei kontraktile Vakuolen im Hinterende. Länge über го $\mu$. In Sumpfwasser, an Myriophyllhım.

\section{Deltomonas S. K.}

Der vorigen Gattung ähnlich, doch ohne scharf abgegrenzten Stiel.

D. cyclopum S. K. (Taf. X, 40)

Gestalt mehr oder weniger langgezogen dreieckig. Geisseln an den Vorderecken entspringend. Kontraktile Vakuole etwas vor der Körpermitte. Oft in grosser Menge an Cyclops-Arten. Kleiner als Amphimonas globosa. In Sumpfwasser.

\section{Streptomonas K1.}

Körper herzförmig, vorn mit tiefer Ausrandung und zwei Geisseln von gleicher Länge. Kern im Vorderteile. Auf der Bauch- und Rückenseite ein nach hinten flügelartig sich erhebender Kiel. 
St. cordata (Py.) K1. (Taf. X, 4I)

Kern bläschenförmig; kontraktile Vakuole im Hinterende, scharf konturiert. Bewegung meist um die Längsachse rotierend. Länge $15 \mu$, Breite $i_{\jmath} \mu$.

\section{Diplomita S. K.}

Die mehr oder weniger eiförmigen Tiere sitzen auf einem kontraktilen Stiele innerhalb des Gehäuses. Gehäuse tonnenförmig, ebenfalls gestielt. Kontraktile Vakuole hinten. Am Vorderende mit Augenfleck.

D. socialis S. K. (Taf. X, 42)

Gehäuse hellbraun gefärbt. Etwas kleiner als Streptomonas cordata. In Sumpfwasser.

\section{Fam. Bodonina.}

Kleine bis mittelgrosse Formen, nackt, mehr oder weniger - besonders am Hinterende - amöboid. Zwei Geisseln, die aus einer seitlichen Vertiefung des Vorderendes entspringen, und deren eine nach vorn, deren andere nach hinten gerichtet ist. Kontraktile Vakuole am Vorderende. Kern central. Ernährung wohl nur tierisch.

1. Auf der Bauchseite meist ohne Furche; wenn eine solche vorhanden, dann etwas schraubig. . . . . . . . . . 2

2. Vorderende mit kleinem, nach der Seite, selten nach vorn offenem Ausschnitte . . . . . . . . . . . . . 3

3. Keine der Geisseln zu einem schnabelartigen Fortsatze umgewandelt . . . . . . . . . . . . 4 4. Gestalt länglich, meist vorn zugespitzt; beide Geisseln am Vorderende entspringend

$$
\text { 1. Bodo (S. 303) }
$$

4*. Gestalt bohnenförmig. Die eine Geissel in der Mitte der Bauchseite entspringend

2. Pleuromonas (S. 304)

3*. Vordergeissel zu einem beweglichen Schnabel umgewandelt . . . . 3. Rhynchomonas (S. 304) 
2*. Vorderende mit grossem, nach oben und nach der Seite offenen Ausschnitte . . . 4. Phyllomitus (S. 305)

$I^{*}$. Auf der Bauchseite eine vorn breite, nach hinten verjüngte Furche . . . . . . 5. Colponema (S. 305)

\section{Bodo (Ehrbg.) St.}

Körper nackt, gewöhnlich ein wenig amöboid. Vorderende zugespitzt, mit seitlicher Mulde, in der die beiden Geisseln entspringen. Häufig die hintere Geissel länger als die vordere. Nahrungs-Aufnahme nur an der Spitze des Vorderendes. Längsteilung im beweglichen Zustande, selten in Cysten. Dauercysten beobachtet.

1. Hintere Geissel zwei bis mehrere Male so lang wie die vordere 2

2. Geisselgrube nicht in eine bauchständige Furche ausgezogen . . . . . . . . . . . . . . . . 3

3. Vorderende schnabelförmig; Länge bis $5 \mu$. . .

I. B. minimus

$3^{*}$. Vorderende ohne deutlichen Schnabel; Länge über $9 \mu$ 2. B. globosus

$2^{*}$. Geisselgrube in eine bauchständige, etwas schraubig verlaufende Furche ausgezogen; Bewegung oft hin und her schnellend . . . . . 3. B. saltans

I*. Hintere Geissel nur wenig länger als die vordere . . . 4

4. Geisselgrube seitlich am Vorderende; Länge höchstens $10 \mu$. . . . . . . . . . . . . . . . . . . 5

5. Körper schmal eiförmig; Breite über $4 \mu$. . . . . 4. B. celer

$5^{*}$. Körper schmal lanzettlich; Breite höchštens $3 \mu$. . 5. B. angustatus

4*. Geisselgrube direkt am Vorderende; Länge über ıо $\mu$. 6. B. caudatus

\section{B. minimus $\mathrm{K} 1$.}

Klein, dick bohnenförmig. Geisselgrube deutlich. Schnabel stumpf. Hintere Geissel zwei Mal so lang wie die vordere. Kontraktile Vakuole am Vorderende. Bewegung langsam kriechend. Nahrung besteht in Bakterien. Länge $4-5 \mu$, Breite $2-2,5 \mu$. 
2. B. globosus St. (Taf. XI, I)

Kugelig oder dick eiförmig. Nahrungs-Aufnahme durch Anbohren und Aussaugen von Algen. Kontraktile Vakuole mehr central gelegen. Länge $9-13 \mu$, Breite $8-12 \mu$. Sehr häufig.

3. B. saltans Ehrbg.

Eiförmig, etwas zusammengedrückt. Hintere Geissel 2 bis $3 \mathrm{Mal}$ so lang wie die vordere. Zeitweilig festgeheftet und hin und her schnellend. Sehr häufig, in Infusionen.

4. B. celer $\mathrm{K} 1$.

Körper hinten breiter als vorn, häufig gekrümmt. Nahrungsaufnahme durch Anbohren und Verschlucken von Monaden. Länge $8-10 \mu$, Breite $4-5,5 \mu$. Lebhafte Schwimmbewegung. Sehr gefrässige Spezies.

5. B. angustatus (Duj.) Btschli e. p.

Vordere Geissel länger als die Körperhälfte; hintere Geissel ${ }_{1}^{1} / 2$ Mal so lang wie der Körper. Länge $8-12 \mu$, Breite $1,5-3 \mu$.

6. B. caudatus (Duj.) St. (Taf. XI, 3)

Körper vorn breiter als hinten, vielgestaltig, stark abgeplattét. Kontraktile Vakuole an der Geisselbasis. Nahrungsaufnahme durch Verschlucken von Bakterien. Länge $11-19 \mu$, Breite $5-8 \mu$. Sehr gemein, in Infusionen.

[Eine etwa gleich grosse Form B. edax Kl. (Taf. XI, 2) hat eine gewölbte Rücken - und eine gefurchte Bauchseite. Länge I I- $14 \mu]$.

\section{Pleuromonas Py.}

Gestalt bohnenförmig, ein wenig amöboid. Zwei Geisseln: die eine am Vorderende, die andere in der Mitte der Bauchseite entspringend. Kontraktile Vakuole am Vorderende. Nahrungsaufnahme auf der Rückenseite mittels einer Vakuole.

Pl. jaculans Py. (Taf. XI, 4)

Mit den Charakteren der Gattung. Iänge 5-10 $\mu$, Breite $6 \mu$. Häufig.

\section{Rhynchomonas $\mathrm{K} 1$.}

Eiförmig, etwas abgeplattet. Vordergeissel zu einer beweglichen Lippe oder Nase umgewandelt; Hintergeissel in einer seitlichen Grube des Vorderendes entspringend. Kontraktile Vakuole im Vorderende. 
Rh. nasuta (Stokes) K1. (Taf. XI, 5)

Länge $5-6 \mu$, Breite $2-3 \mu$. Nicht selten.

\section{Phyllomitus St.}

Eiförmig bis länglich. Mundstelle als grosser Ausschnitt des Vorderendes entwickelt; in ihm entspringen die beiden Geisseln, deren hintere als Schleppgeissel dient. Kontraktile Vakuole im Vorderende. Kann feste Körper direkt verschlucken.

I. Längenunterschied der Geisseln gering I. Ph. amylophagus I*. Längenunterschied der Geisseln deutlich 2. Ph. undulans

1. Ph. amylophagus K1. (Taf. XI, 6)

Länglich, nach vorn verjüngt. Nahrung besteht hauptsächlich aus Stärkekörnern. Länge $19-25 \mu$, Breite $7-13 \mu$. Nicht selten, in Infusionen mit stärkehaltigen Pflanzenteilen.

2. Ph. undulans St.

Eiförmig; der vorigen Art sehr ähnlich, doch kürzer. Die Schleppgeissel ist die längere.

\section{Colponema St.}

Körper breit ellipsoidisch, etwas zusammengedrückt; vorn schief abgestutzt. Schleppgeissel in der Bauchfurche liegend, länger als die Vordergeissel. Im Vorderende eine grosse kontraktile Vakuole.

C. loxodes St. (Taf. XI, 7)

Das Plasma ist erfüllt von lichtbrechenden, fettartigen Kugeln. Bewegung lebhaft hin- und herschwimmend. Länge $18 \mu$, Breite $1+\mu$.

$\mathrm{Zu}$ den Bodoninen gehört vielleicht auch Thaumatonema setiferum Lauterb. (Taf. XI, 8), das auf der Oberfläche mit starren Borsten besetzt ist und imstande sein soll, ziemlich lange, verästelte Pseudopodien auszusenden. Auch eine Verwandtschaft dieser Form mit den Rhizomastiginen ist nicht ausgeschlossen, falls nämlich die Nahrungs-Aufnahme mittels der Pseudopodien stattfindet. Gewisse Organisationsverhältnisse (Vakuole) weisen jedoch auch in die Nähe von Vacuolaria (S. 330) 


\section{Polymastigina.}

Kleine bis mittelgrosse Formen, ohne Plasma-Membran. Körper amöboid oder metabolisch. Geisseln in der Drei- oder Mehrzahl, gewöhnlich von verschiedener Länge. Kohtraktile Vakuole vielfach im Hinterende; der Kern dagegen häufig im Vorderende. Aufnahme der festen Nahrung nie am Vorderende. Fortpflanzung durch Längsteilung im beweglichen Zustande. Cysten vereinzelt beobachtet.

I. Mit drei Geisseln . . . . . . I. Trimastigina (S. 306)

I*. Mit mehr als drei Geisseln . . . . . . . . . . . . 2

2. Mit nur einer Mundstelle, Geisseln nicht in zwei Gruppen gesondert . . . . . . 2. Tetramitina (S. 307)

2*. Mit zwei Mundstellen, Geisseln in zwei Gruppen gesondert 3. Distomata (S. 308)

\section{Fam. Trimastigina.}

I. Meist festsitzend, auf der Epidermis von Forellen schmarotzend; die drei Geisseln entspringen am Vorderende . . . . .

\section{Costia (S. 306)}

I*. Meist freischwimmend; eine Geissel am Vorderende und je cine seitlich etwa in der Körpermitte entspringend . . .

2. Dallingeria (S. 306)

\section{Costia Leclercq.}

Im festsitzenden Zustande liegen die Geisseln in einer ventralen Furche, im freischwimmenden Zustande sind sie nach vorn gerichtet.

C. necatrix (Henneguy) Leclercq (Taf. XI, 9)

sichmarotzt an jungen Forellen, deren Tod sie herbeiführen soll.

\section{Dallingeria $\mathbf{S} . \mathrm{K}$.}

Körperform länglich, in der Mitte mit einer Einschnürung. Vorderende verjüngt. Die Tiere heften sich vielfach mit den 
seitlichen Geisseln fest und führen durch deren Kontraktionen schnellende Bewegungen aus. Kern im Hinterende. Längsteilung. Es soll Kopulation beobachtet sein.

D. drysdali S. K. (Taf. XI, Io)

Geisseln doppelt so lang wie der Körper. Kontraktile Vakuole? In Infusionen.

\section{Fam. Tetramitina.}

Körper im Schnitt eiförmig, nach hinten meist verjüngt; vorn mit 4-6 Geisseln von häufig ungleicher Länge, die z.T. nach hinten ausgestreckt sind. Am Vorderende seitlich eine muldenförmige Mundstelle, durch die feste Substanzen aufgenommen werden. Kern meist im Vorderende.

\section{Tetramitus Py.}

Körper breit oder schmal elliptisch, am Vorderende mit vier Geisseln. Kontraktile Vakuole meist im Hinterende.

1. Körper ohne Furche; Mundstelle nur breit oval . . . . I. T. descissus

I*. Körper mit Furche; Mundstelle schmal, lang . . . . . 2

2. Mit schnabelförmigem Fortsatze an einer Seite . . .

2. T. rostratus

2*. Ohne derartigen Fortsatz 3

3. Furche etwas schraubig . . 3. T. sulcatus

$3^{*}$. Furche nicht schraubig, seitlich 4. T. pyriformis

I. T. descissus Py. (Taf. XI, I 1)

Schmal eiförmig, nach hinten verjüngt, vorne mit schiefer Abstutzung. Mundstelle breit oval. Länge I3-28 4 . Breite 7-I $5 \mu$. Bewegung: untcr Rotatorien lebhaft umherschwimmend.

2. T. rostratus Py.

Am Vorderende mit vier Geisseln von ungleicher Länge aus einer in eine schmale, ventrale Furche verlängerten Grube entspringend. Unterhalb des Schnabels die muldenförmige Mundstelle. Kern und kontraktile Vakuole vorn. Länge $18-30 \mu$, Breite 8-11 $\mu$. 
3. T. sulcatus St.

Dick eiförmig, etwas zusammengedrückt, nach hinten verjüngt. Vier Geisseln von ungleicher Länge entspringen einer vorn gelegenen Einsenkung, die eine etwas schraubige Furche bis gegen das Hinterende entsendet. Kern vorn, Vakuole hinten. Länge $17 \mu$, Breite I $_{5} \mu$.

\section{T. pyriformis $\mathrm{K} 1$.}

Körper ähnlich voriger Art, vorn gewölbt. An der einen Seite eine schmale, bis zum Hinterende reichende Mulde (Körper daher an der Seite schief abgestutzt). Oberhalb der Mulde vier Geisseln, von denen die längste nach hinten getragen wird. Vakuole hinten. Länge $11-13 \mu$, Breite $10-12 \mu$.

\section{Fam. Distomata.}

Körper verschieden gestaltet, stets etwas zusammengedrückt; deutlich asymmetrisch. Auf jeder Seite, nahe den entgegengesetzten Rändern, je eine Furche oder Mulde (Mundstelle). Geisseln $\mathrm{zu}$ sechs, acht oder $\mathrm{zu}$ vielen von meist ungleicher Länge und in zwei Gruppen gesondert. Kern stets im Vorderende. Kontraktile Vakuole gewöhnlich hinten.

I. Höchstens mit acht Geisseln . . . . . . . . . . 2 2. Mit sechs Geisseln . . . . I. Trigonomonas(S.309) 2*. Mit acht Geisseln . . . . . . . . . . . . 3

3. Meist drei Geisseln an jeder Vorderecke, zwei Geisseln am Hinterende; nie Differenzierung in Bewegungsgeisseln und Mundcilien . . . . . . 4 4. Nicht mit einer klappenförmigen Mundöffnung des Hinterendes fressend 2. Hexamitus (S. 309)

$4^{*}$. Mit klappenförmiger Mundöffnung des Hinterendes fressend . . . 3. Urophagus (S. 310)

$3^{*}$. Je vier Geisseln jederseits etwa in der Mitte des Seitenrandes entspringend, als Bewegungsgeisseln und Mundcilien differenziert. 4. Trepomonas (S. 310) I*. Zahlreiche, kleine Geisseln. . . . 5. Spironema (S. 312) 


\section{Trigonomonas $\mathrm{K} 1$.}

Körper etwa dreieckig, vorn breit abgerundet bis schief abgestutzt, nach hinten verjüngt, stark zusammengedrückt. Je drei Geisseln unterhalb der Vorderecken. Auf jeder Seite eine etwas spiralige Mundstelle.

\section{Tr. compressa K1. (Taf. XI, I2)}

Plasma zart, häufig von zahlreichen Vakuolen erfüllt. Kern am Vorderende. Länge $24-33 \mu$, Breite 1o $-16 \mu$. In faulenden Flüssigkeiten. Nicht häufig.

\section{Hexamitus Duj.}

Körper oval, nur wenig abgeplattet. Vorderende abgerundet, jederseits mit drei Geisseln; Hinterende jederseits mit einer Geissel, die je einer seitlichen, auf verschiedenen Seiten sich öffnenden Furche entspringen. Kern stets im Vorderende. Vielfach mit Glykogen-Kugeln im Plasma.

I. Mit einer kontraktilen Vakuole. . . . . . . . . . . 2

2. Geisseln nicht in besonderen, schmalen Furchen, sondern in den Mundspalten entspringend . . . . . . . 3

3. Systole der kontraktilen Vakuole am Hinterende 4 4. Mundspalte bis zum hinteren Körperrande reichend. . . . . . . . 1. H. inflatus

4*. Mundspalte kaum bis zur Körpermitte reichend 2. H. pusilhus

$3^{*}$. Systole der kontraktilen Vakuole an einem Seitenrande . . . . . . . . 3. H. fissus

$2^{*}$. Geisseln in besonderen, schmalen Furchen

4. H. crassus

I*. Mit zwei kontraktilen Vakuolen; an beiden Seiten eine etwas spiralig verlaufende Längsfurche . . . 5. H. fusiformis

I. H. inflatus Duj. (Taf. XI, í)

Körper dick eiförmig, nahezu cylindrisch; hinten gerundet oder ausgerandet. Schleppgeissel vom Hinterende ab gerechnet bis zwei Mal so lang wie der Körper. Mundspalte schmal. Länge ${ }_{13}-25 \mu$, Breite 9-15 $\mu$. In Sümpfen und Teichen, sehr häufig; auch in jeder faulenden Flüssigkeit. 
2. H. pusillus $\mathrm{K} 1$.

Schleppgeissel das Hinterende um eine Körperlänge übcrragend. Länge $10-13 \mu$, Breite $8-10 \mu$. Weniger häufig als vorige Art.

\section{H. fissus $\mathrm{K} 1$.}

Gestalt birnförmig, hinten mit kurzem Stachel endigend. Schleppgeisseln das Hinterende nicht um Körperlänge überragend. Mundspalte von der Geisselbasis bis zum Endstachel sich erstreckend. Länge $20-26 \mu$, Breite $9-13 \mu$. Vorkommen zerstreut.

4. H. crassus $\mathrm{K} 1$.

Gestalt dick eiförmig, hinten mit breiter Abrundung. Schleppgeisseln vom Hinterende gerechnet kaum länger als der Körper. Neben jeder der die Schleppgeisseln aufnehmenden Furchen je eine bis über die Körpermitte reichende Mundspalte. Länge $24-35 \mu$, Breite $14-18 \mu$. Nicht sehr häufig.

5. II. fusiformis $\mathrm{K} 1$.

Gestalt schmal cylindrisch, zusammengedrückt, hinten manchmal ausgerandet. Schleppgeisseln den Körper nur wenig überragend. Länge $22-27 \mu$, Breite $10-12 \mu$. Nicht häufig.

Der verwandte $H$. intestinalis Duj., der durch den Mangel einer kontraktilen Vakuole charakterisiert ist, lebt im Darme von Wasservertebraten.

\section{Urophagus $\mathrm{K} 1$.}

Körper ciförmig bis länglich, hinten mit schnabelförmiger Zuspitzung. An jeder Schnabelseite eine Längsspalte, die cine Schleppgeissel aufnimmt. Am Vorderende zwei Paare von je drei Geisseln. Der Endschnabel aus zwei beweglichen, die Nahrung aufnehmenden Klappen bestehend. Kontraktile Vakuole gewöhnlich seitlich.

\section{U. rostratus (St.) Kl. (Taf. XI, $\mathrm{I} 4$ )}

Länge $16-25 \mu$, Breite 6-12 $\mu$. Die var. angustus hat einen schmalen, fast lanzettlichen Körper; ihre Bewegung ist langsam kriechend. Länge $12 \mu$, Breite $2 \mu$.

\section{Trepomonas Duj.}

Gestalt eiförmig bis kegelförmig, stets abgeplattet; vorn und hinten gewöhnlich abgerundet. Rechts und links, aber auf verschiedenen Seiten, befindet sich eine zur Nahrungs-Aufnahme. 
dienende Mulde oder Tasche; Körper-Querschnitt daher S-förmig. Acht Geisseln von ungleicher Ausbildung; in zwei jederseits von der Mitte des Seitenrandes entspringende Gruppen verteilt. Kern vorn, kontraktile Vakuole am Hinterende verschwindend. Bewegung besteht häufig in einem ununterbrochenen Drehen auf einer Stelle.

1. Jederseits mit zwei Bewegungsgeisseln und zwei Mundcilien 2 2. Bewegungsgeisseln von gleicher Länge. . . . . .

I. Tr. rotans

$2^{*}$. Bewegungsgeisseln von ungleicher Länge .

2. Tr. steini

I*. Jederseits mit einer Bewegungsgeissel und drei Mundcilien . 3. Tr. agilis

I. Tr. rotans K1. (Taf. XI, I5)

Körper breit oval, in der hinteren Hälfte stark abgeplattet, vorn breit abgerandet. Seitenränder jederseits leicht eingekrümmt, je eine seichte Mundtasche bildend. Jederseits eine Bewegungsgeissel nach vorn, die andere nach hinten gekehrt; Mundcilien von halber Körperlänge. Länge $10-13 \mu$, Breite $7-8 \mu$. Häufig.

2. Tr. steini $\mathrm{K} 1$.

Körper nach hinten verjüngt, mit schraubiger Drehung. Vordere Bewegungsgeisseln länger als die hinteren. Länge der Mundcilien wie bei voriger Art. Länge 7- I I $\mu$, Breite 3,5-6 $\mu$. Nicht häufig.

3. Tr. agilis Duj. (Taf. XI, I6)

Gestalt etwa oval, stark variabel. Sehr häufig.

Man unterscheidet folgende Varietäten:

I. Höchstens $25 \mu$ lang . . . . . . . . . . . . . 2

2. Körper vorn und hinten von gleicher Breite, schmal eiförmig; Mundtasche in Form einer langen, hellen Furche. Länge $7-8 \mu$, Breite $1,8-2 \mu$. . var. simplex

$2 *$. Körper nach vorn verjüngt. Mundtasche blasenartig er-

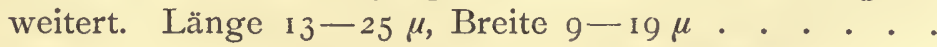
var. communis

I*. Länge $30 \mu$, Breite $15 \mu$. Körper vorn wenig verschmälert, sehr eckig. Körperrand an jeder Mundtasche kielartig hervortretend . . . . . . . . . var. angulatus 


\section{Spironema K1.}

Körper lanzettförmig, etwas abgeplattet, mit feinem Schwanzfaden, metabolisch. Jederseits eine seichte, am Vorderende entspringende, schraubig verlaufende Furche, deren einer Rand mit einer Längsreihe zahlreicher kleiner Geisseln versehen ist. Kontraktile Vakuole im Hinterende. Spironema bildet vielleicht einen Uebergang zu den Ciliaten.

Sp. multiciliatum K1. (Taf. XI, 17)

Länge 14-I $8 \mu$, Breite $2-3 \mu$. Bewegung schwerfällig; zeitweilig setzt sich das Tier mit dem steifen Schwanze fest. In Teichwasser, nicht häufig.

\section{Euglenoidina.}

Die äusserste Schicht hat sich zu einer deutlichen PlasmaMembran differenziert; Körper daher nicht mehr amöboid, häufig aber noch stark metabolisch. Die eine oder zwei Geisseln sitzen meist in einer Vertiefung, an die sich bei den Peranemiden ein Mund anschliessen kann; charakteristisch ist die grosse Vakuole im Vorderende, in die kleinere kontraktile Blasen einmünden; in ihrer Nähe, wenn vorhanden, der Augenfleck. Mit oder ohne Chromatophoren. Teilung in beweglichem oder ruhendem $\mathrm{Zu}$ stande.

Die grünen Formen, speziell die Euglenen, hat man in neuerer Zeit $\mathrm{zu}$ den Algen $\mathrm{zu}$ stellen gesucht, $\mathrm{zu}$ denen sie aber, wie im allgemeinen Teile gezeigt wurde, entschieden keine Verwandtschaft zeigen; dagegen treten ihre engen Beziehungen $z u$ den rein tierischen Peranemiden deutlich hervor.

I. Tiere ohne eigentlichen Mund, daher ohne Aufnahme fester Nahrung . . . . . . . . . . . . . . . . 2

2. Mit Chlorophyll . . . . . I: Euglenida (S. 3 I 2)

2*. Ohne Chlorophyll . . . . . 2. Astasiida (S. 32 I)

I*. Tiere mit Mundfalte, daher auch mit Aufnahme fester Nahrungsstoffe . . . . 3. Peranemida (S. 323)

\section{Euglenida.}

Die Euglenen ernähren sich holophytisch, d. h. wie grüne Pflanzen; doch macht schon die Thatsache, dass es auch farblose Formen unter ihnen giebt, wahrscheinlich, dass sie auch sapro- 
phytisch leben, d.h. organische Nahrung aufnehmen. In der That haben auch neuerdings angestellte Versuche aufs klarste bewiesen, dass die Euglenen bei weitem besser in organischer Nährlösung wachsen als in einfachen Salzlösungen. Im Dunkeln halten sie sich sehr lange lebendig und erbleichen schliesslich sogar. In der Regel mit Stigma, meist mit Paramylumkörnern erfüllt; Vorderende immer etwas schief abgestutzt, mit einer seichten Einbuchtung, in der die Geissel entspringt. Eine langsam pulsierende Haupt- und eine bis mehrere Nebenvakuolen mit einem in dem Membrantrichter endigenden Kanale. Grüne scheiben - oder bandförmige Chromatophoren, hin und wieder mit Pyrenoïd.

1. Mit einer Geissel . . . . . . . . . . . . . . 2

2. Membran elastisch, Tiere mehroder weniger metabolisch 3

3. Tiere ohne Gehäuse oder Schale. . . . . . 4

4. Tiere in normalem Zustande freischwimmend, bei ungünstigen Verhältnissen kugelig zusammengezogen. . . . . . I. Euglena (S. 313)

$4 *$ Tiere meist an Wassertieren etc. in Kolonien festsitzend, selten freischwimmend. . . . .

$$
\text { 2. Colacium (S. 317) }
$$

$3^{*}$. Tiere im Gehäuse oder in starrem Panzer . . . 5

5. In einem länglichen Gehäuse festsitzend . . 3. Ascoglena (S. 317)

$5 *$ In einem vom Körper abstehenden Panzer freischwimmend . . . 4. Trachelomonas (S. 318)

$2^{*}$. Membran ziemlich stark, Tiere also nicht metabolisch 6

6. Chromatophoren scheibenförmig .

5. Phacus (S. 319)

6*. Chromatophoren: zwei längsliegende kurze Bänder

6. Cryptoglena (S. 320)

I*. Mit zwei Geisseln . . . . . 7. Eutreptia (S. 320)

\section{Euglena (Ehrbg.) Duj.}

Beim Schwimmen immer mehr oder weniger langgestreckt, spindelförmig bis bandförmig. Die Vertreter der Gattung, besonders $E$. viridis, sind überall verbreitet, in reinem und schmutzigem Wasser wie in Abzugsgräben etc. Sie können das Eintrocknen ausgezeichnet vertragen. Hierbei und überhaupt bei ungünstigen Verhältnissen runden sich die Flagellaten unter 
Verlust der Geissel ab und umgeben sich meist mit einer Schleimhülle. In eben solcher findet oft auch die Vermehrung statt durch Längsteilung; die Tochter-Individuen verlassen durch ein Loch die Hülle. Alle Arten sind mehr oder weniger metabolisch, besonders wenn sie nach Verlust der Geissel langsam auf dem Boden vorwärts kriechen. Die Plasma-Membran ist meist deutlich spiralig gestreift. Die Euglenen färben oft durch ihre gewaltige Anzahl kleine, wasserarme, sumpfige Gräben dunkelgrün oder rot.

I. Körper breit spindelförmig oder langgestreckt eiförmig . 2 2. Chromatophor ohne deutlich beschaltes Pyrenoid.. . 3 3. Geissel von Körperlänge; Chromatophor nicht scheibenförmig . . . . . . . . . . 1. E. viridis

3*. Geissel 2-3 Mal so lang als der Körper . . . . . 4

4. Membran deutlich gestreift; Chromatophoren scheibenförmig . . . . . . . . . . 2. E. variabilis

4*. Membran nicht so; Chromatophor nicht scheibenförmig, häufig rot . . . . . . 3. E. sangzinea

2*. Chromatophor mit beschaltem Pyrenoid. . . . . . 5

5. Geissel zwei Mal so lang als der Körper . . . . .

5*. Geissel nur von Körperlänge . . . . . . . . 6

6. Chromatophor scheibenförmig, zart grün .

4. E. gracilis

6*. Chromatophor kurz bandförmig . 5. E. velato

I*. Körper nicht oder schmal spindelförmig

7. Körper ganz schmal spindelförmig .6. E. acus

$7^{*}$. Körper mehr oder weniger stabförmig, meist hinten zugespitzt . . . . . . . . . . . . 8

8. Membran in spiraliger Streifung mit Höckern besetzt; meist gelb bis braun gefärbt . . . 7. E. spirogyra

8*. Membran nicht so . . . . . . . . . . . . . . 9

9. Körper wenig metabolisch, gewöhnlich dreikantig spiralig tordiert . . . . . . . . . . . . Io 10. Membran zart gestreift, Endstachel sehr lang . 8. E. tripteris

10*. Membran mit deutlichen Spiralstreifen; Körper hinten kurz zugespitzt . . . . . 9. E. oxyuris

$9^{*}$. Körper stark metabolisch, kaum tordiert. 
II. Chromatophoren kurz bandförmig, mit deutlichem Pyrenoid . . . . . . Io. E. deses

II*. Chromatophoren klein, scheibenförmig; ohne deutliches Pyrenoid . . . . I I. E. ehrenbergi

\section{E. viridis Ehrbg. (Taf. XI, I8)}

Körper spindelförmig; nach beiden Seiten, am meisten nach hinten verschmälert. Kern im Hinterende. Chromatophor von der Mitte (wo zahlreiche Paramylumkörnchen liegen) gegen die Peripherie strahlend. Eine schon den ältesten Beobachtern bekannte und deshalb oft beschriebene Art, die sich fast überall im Sumpfwasser, besonders gern aber in Haus-Abwässern und Strassenpfützen und hier in grosser Anzahl, vorfindet. Im Laboratorium und auch im Freien bilden die kugeliger Dauerzustände oft eine dicke, grüne Decke auf dem Wasser, in der hin und wieder der unter den Pilzen beschriebene Parasit: Polyphagus euglenae (S. 246) verwüstend auftritt. Zwei Formen, die etwas grössere forma olivacea mit olivengrünen (?) Chromatophoren [dazu wenig metabolisch und mit einem centralen Paramylumkerne?] und die farblose forma hyalina, die beide an organischen Stoffen sehr angereichertes Sumpfwasser lieben, sind von der typischen $E$. viridis leicht $z u$ unterscheiden und werden von einigen Forschern auch als selbständige Arten abgetrennt. Länge $52 \mu$.

\section{E. variabilis $\mathrm{K} 1$.}

Körper kurz cylindrisch bis eiförmig, vorn breit abgerundet; Augenflecke gross. Am Hinterende oft mit Endspitze, oft auch nach hinten nur verjüngt. An der Hauptvakuole ein grösseres, cylindrisches Paramylumkorn. Länge $30-50 \mu$. Scheint selten.

3. E. sanguinea Ehrbg.

Körper etwas langgestreckt, eiförmig; neben der Hauptvakuole ein Paramylumkorn. Besonders interessant durch ihre Fähigkeit, unter bestimmten, noch unbekannten Bedingungen (so an manchen Lokalitäten) sich durch Hämatochrom blutrot zu färben. Wenn die Tiere in grosser Anzahl vorhanden sind, verleihen sie dem Wasser eine blutrote Farbe. Länge 50- 120 $\mu$. Verbreitet, aber meist einzeln.

4. E. gracilis K1. (Taf. XI, 19)

Körper langgestreckt, cylindrisch, stark durchsichtig; die 
zahlreichen, sehr dicht liegenden Chromatophoren mit je einem Paramylumkerne. Zellkern in der Körpermitte. Länge $40-50 \mu$. Hin und wieder.

5. E. velata $\mathrm{Kl}$.

Körper langgestreckt eiförmig, nach hinten allmählich verschmälert, mit kurzer Endspitze; Chromatophoren oft lappig eingeschnitten. Länge fast $100 \mu$. Eine gelbbraun gefärbte forma gramulata bildet gallertige, unbenetzte Ueberzüge auf Wasser.

Die verwandte, zierliche $E$. pisciformis $\mathrm{K} 1$. hat meist nur zwei etwas schief verlaufende Chlorophyllbänder.

6. E. acus Ehrbg.

Der nadelförmige Körper nach hinten in eine farblose Spitze ausgezogen; auch vorne mit farblosem, langem, schief abgestutztem Halse. Mit mehreren grossen, stabförmigen Paramylumkörnern und sehr kurzer Cilie. Länge $110-180 \mu$ : Auch hier ist eine forma hyalina, eine farblose Varietät, mit oder ohne Augenfleck bekannt geworden.

\section{E. spirogyra Ehrbg.}

Diese durch die Struktur der Membran leicht kenntliche Art ist etwa $90 \mu$ lang. Der mehr oder weniger cylindrische Körper mit kurzer, farbloser Endspitze. Die Membran lagert Eisenhydroxyd ab und ist dadurch gelb bis braun gefärbt. Vor und hinter dem Kerne je ein grosses, ringförmiges Paramylumkorn. Die fast schwarze forma fusca ist breit bandförmig und fast noch einmal so gross. Verbreitet, in frischem, wie sumpfigem Wasser.

8. E. tripteris (Duj.) K1.

Der plattgedrückte, kaum metabolische Körper stark um die Längsachse gedreht; mit je einem grossen, stabartigen Paramylumkorn vor und hinter dem centralen Kerne. Länge etwa $70-80 \mu$. Nicht überall.

9. E. oxyuris Schmarda (Taf. XI, 20)

Der langgestreckte Körper etwas tordiert. Vor und hinter dem Kerne je ein ringförmiges Paramylumkorn. Cilie von halber Körperlänge. Länge fast $400 \mu$. 'Vereinzelt.

10. E. deses Ehrbg. (Taf. XI, 2 I)

Der langgestreckte Körper mit kurzer Endspitze, cylindrisch. Die forma intermedia hat scheibenförmige, pyrcnoidlose Chromato- 
phoren. Sehr metabolisch. Länge $80-120 \mu$. Sehr verbreitete Form, besonders auch in Strassenpfützen.

I I. E. ehrenbergi K1.

Körper schmal bandförmig, vorn und hinten breit abgerundet. Chromatophoren viel kleiner als bei voriger Art. Die stabförmigen Paramylumkörner sehr gross. Tordiert sich während des Schwimmens häufig. Länge fast $300 \mu$. Gesellig, doch nicht so häufig wie die übrigen.

\section{Colacium Ehrbg.}

Die Gattung schliesst sich eng an Euglena an, nur sind die Tiere im gewöhnlichen Zustande auf kleinen Krebschen, Rotatorien etc. mit ihrem Vorderende festgewachsen, wobei sie einen längeren oder kürzeren Stiel und eine Körperhülle aus Gallerte ausscheiden. Im freischwimmenden Zustande besitzen sie eine Geissel. Der Körper ist etwas metabolisch. Die scheibenförmigen Chromatophoren besitzen kein Pyrenoid.

I. An dem breit abgerundeten Vorderende ist eine Haube farblosen, fein längsgestreiften Plasmas zu sehen

\section{C. calvum}

I*. Vorderende zugespitzt, ohne Plasmakappe 2. C. vesiculosum

\section{C. calvum St. (Taf. XI, 22)}

- Die einzelnen Tiere sind etwa $2 \frac{1}{2}$ Mal so lang als breit, mit breit abgerundetem Vorder- und Hinterende; sie sitzen zu 2-4 mit ganz kurzen, dicken Stielen auf Cyclops und andern Wasserkrebsen. Länge $40 \mu$. Nicht häufig.

2. C. vesiculosum Ehrbg. (Taf. XI, 23)

Im ausgestreckten Zustande meist nach den Enden hin zugespitzt, mit zahlreichen Chromatophoren. Die Stiele sind kurz oder lang, oft $2-3$ Mal verzweigt. Etwa $30 \mu$ lang. Vorkommen wie bei voriger Art, doch häufiger.

Das verwandte (oder als Varietät hierher zuziehende) C.arbuscula St. hat nur wenige Chromatophoren und sitzt an längeren Stielen auf Rotatorien.

\section{Ascoglena St.}

Auch diese Gattung ist der Euglena äusserst ähnlich; nur in ein bräunliches, am vorderen, freien Ende hyalines Gehäuse 
eingeschlossen und mit dem Hinterende festgewachsen. Das Gehäuse selbst sitzt an Wasserpflanzen oder an der Wasseroberfläche.

A. vaginicola St. (Taf. XI, 24)

Das Tier selbst der Euglena gracilis ähnlich und sehr metabolisch. Das Gehäuse etwa $40 \mu$ lang. Wohl nicht häufig.

\section{Trachelomonas Ehrbg.}

Diese Euglene schliesst sich, was denBau des Körpers anlangt, der vorigen Gattung eng an; doch schwimmt sie in einer spröden, vom Körper abstehenden, meist durch Eisenverbindungen braun gefärbten Hülle frei umher. Diese Hülle hat nur vorn eine kleine Oeffnung zum Durchtritt für die sehr lange Geissel. Die Tiere leben meist zahlreich zusammen.

I. Hülle fast kugelrund oder breit oval, hellbraun

I. Tr. volvocina

I*. Hülle nicht so, länger als breit. . . . . . . . . . . 2

2. Hülle glatt oder mit kleinen Stacheln und Höckern besetzt, nicht mit langen Stacheln am Hinterende . . 3

3. Hülle glatt, cylindrisch. . . 2. Tr. lagenella

$3^{*}$. Hülle meist mit feinen Stacheln besetzt . . . . 4 4. Hülle rund oval. . . . 3. Tr. hispida

$4^{*}$. Hülle nach hinten zugespitzt.

4. Tr. caudata

2*. Hülle mit längeren Stacheln, meist am Hinterende . 5

5. Hülle nach hinten verschmälert (4. Tr. caudata)

$5^{*}$. Hülle rund oval . . . . . 5. Tr. armata

1. Tr. volvocina Ehrbg. (Taf. XI, 25)

Die Oeffnung für die Geissel ist meist nur etwas ringförmig verdickt, selten kragenförmig gestaltet. Die Hülle fein granuliert oder mit schiefen Streifungen [ forma rugulosa (St.)]; auch eine farblose Varietät ( forma hyalina $\mathrm{K}$ l.) ist beobachtet. Länge $10-20 \mu$. Sehr häufig und verbreitet.

2. Tr. lagenella St.

Hülle mit deutlicher Kragenöffnung, breit cylindrisch, etwa ${ }^{1} 1 / 2$ Mal so lang als breit. (Die verwandte Tr. cylindrica Ehrbg. ist wenigstens zwei Mal so lang als breit und auch sonst kleiner.) Länge höchstens $30 \mu$. Nicht selten. 
3. Tr. hispida St.

Hülle olıne oder mit Kragen, meist ganz dunkelbraun gefärbt. Länge $20-30 \mu$. Sehr häufig, zwischen Algen.

4. Tr. caudata St. (Taf. XI, 26)

Hülle ringsum mit Stacheln besetzt, am Hinterende oft mit einem grösseren Stachel; vorn mit hohem, vorn erweitertem Kragen. Etwas grösser als vorige Art. (Die ähnlich gestaltete Tr. reticulata Kl. hat eine stachellose Hülle ohne Kragen.) Nicht häufig.

5. Tr. armata (Ehrbg.) St.

Hülle mit kurzem Kragen, aber mit grösseren Stacheln (vorn und) hinten besetzt; sonst glatt, dunkelbraun. Länge über $40 \mu$. Nicht häufig.

\section{Phacus Nitzsch.}

Diese früher zu Euglena gerechnete Gattung ist besonders durch das Fehlen der Metabolie ausgezeichnet. Der Körper ist meist deutlich breit gedrückt, selten eiförmig oder cylindrisch. Paramylumkörner scheiben- oder ringförmig.

I. Körper fast drehrund. Paramylumkorn ringförmig. (I. Lepocinclis Py., Chloropeltis St.).

1. Ph. ovum

I*. Körper mehr oder weniger deutlich flachgedrückt. Paramylumkorn scheibenförmig. (II. Phacus i. eig. S.) . . . . . . 2

2. Schwanzstachel schiefstehend . . . . . . . . 3

3. Mit kielartig verdickten Seitenrändern. . . . .

2. Ph. alata

3*. Seitenränder nicht verdickt . 3. Ph. pleuronectes

2*. Schwanzstachel gerade . . . . . . . . . . 4

4. Stachel lang, gleich $1 / 3$ bis $1 / 1$ der Körperlänge; Tier stark abgeflacht, oft tordiert.. . 4. Ph. longicauda.

4*. Stachel kurz, Körper birnförmig 5. Ph. pyrum

I. Ph. (Lepocinclis Py.) orum (Ehrbg.) K1. (Taf. XI, 27)

Körper fast kugelig, mit stachelartiger Erhebung am Hinterende. Membran deutlich spiralig gestreift, sonst glatt. Länge $20-27 \mu$. Hin und wieder.

2. Ph. alata $\mathrm{K} 1$.

Von der Gestalt der folgenden Art, doch mit flügelartigen Verdickungen der Seitenränder. In jedem Flügel ein grosses Paramylumkorn. Fast $20 \mu$ lang. Zwischen Algen, nicht häufig. 
3. Ph. pleuronectes (O. F. Mü11.) Nitzsch (Taf. XI, 28)

Körper platt, nach hinten etwas breiter und plötzlich in eine schiefe, kurze Spitze zusammengezogen. Am vorderen Ende mit schiefer, vorspringender Membranfalte. Membran deutlich längsgestreift. In der Mitte, oberhalb des Kernes ein grosses Paramylumkorn. Länge $30-50 \mu$. Die var. hyalina Kl. ist farblos, die var. triquetra (Ehrbg.) Kl. hat einen Rückenkiel. Sehr häufige Form, in reinem Wasser, in Sümpfen und Strassenlachen etc.

4. Ph. longicauda (Ehrbg.) Duj. (Taf. XI, 29)

Interessanteste Flagellate, besonders im tordierten Zustande, wenn sie sich langsam schraubend durch das Wasser bewegt. Endspitze farblos, oft schr lang. Oberhalb des Kernes ein grosses Paramylumkorn. Ziemlich häufig, doch meist einzeln.'

\section{Ph. pyrum (Ehrbg.) St.}

Körper vorn abgerundet; hịten mit langer, farbloser Spitze. Spiralstreifung sehr deutlich; noch etwas metabolisch. Zwei seitliche, gelappte Chromatophoren mit je einem Pyrenoid. Sonst noch zwei Reihen kleiner Paramylumkörner. Länge $30 \mu$. Ziemlich häufig.

\section{Cryptoglena Ehrbg.}

Der starre Körper oval, nach hinten etwas zugespitzt, auf der Bauchseite mit einer Längsfurche und im ganzen etwas zusammengedrückt. Auf den Seiten des Körpers liegen zwei Schalen einer festeren Substanz, die sich in Choralhydrat, Kalilauge und Essigsäure deutlich erkennen lassen. Kern im Hinterende. Am Innenrande des einen Chlorophyllbandes der Augenfleck.

Cr. pigra Ehrbg. (Taf. XI, 3o)

Länge I I-I $5 \mu$, Breite $6-7 \mu$. Nicht in Teichen, doch meist einzeln.

\section{Eutreptia Py.}

Körper spindelförmig oder abgeflacht cylindrisch, nach hinten stark verschmälert; mit zwei Geisseln. Membran zart gestreift. Chromatophoren ohne Pyrenoid. Paramylumkörner meist rundlich. Das Tier ist sehr metabolisch. In der Bewegung gleicht diese Gattung sehr der Astasia margaritifera (S. 321 ).

Eu. viridis Py. (Taf. XI, 31)

Länge $40-50 \mu$, Breite $13 \mu$. Wohl ziemlich selten. 


\section{Astasiida.}

Der langgestreckte, meist etwas gestreifte Körper ist starr oder. z. T. sehr metabolisch. Das Vorderende ohne Augenfleck, sonst wie bei voriger Familie, doch kommt neben der Hauptgeissel noch eine kleine Nebengeissel vor. Ohne Chlorophyll. Teilung nur im beweglichen Zustande. Alle Astasien sind Saprophyten.

1. Körper sehr metabolisch . . . . . . . . . . . . . 2

2. Mit einer Geissel . . . . I. Astasia (S. 321)

2*. Mit einer Haupt- und einer nach vorn gerichteten Nebengeissel . . . . . . 2. Distigma (S. 322) 1*. Körper starr, nicht metabolisch . . . . . . . . . . . 3

3. Körper meist gekrümmt, mit einer Geissel . 3. Menoidium (S. 322)

$3^{*}$. Körper nicht gekrümmt, mit einer Haupt- und einer sehr kleinen Nebengeissel . . . 4. Sphenomonas (S. 323)

\section{Astasia Duj.}

Der farblose, äusserst metabolische Körper ist in der Bewegung meist nahezu spindelförmig; mit einer Geissel. Nur saprophytisch lebend.

1. Plasma-Membran schwach spiralig gestreift . . . . . 2

2. In der Bewegung nach hinten stark spindelförmig verschmälert . . . . . . . . . . 1. A. margaritifera

$2^{*}$. In der Bewegung cylindrisch, gekrümmt, nach vorn stark verschmälert . . . . . . 2. A. curvata

I*. Plasma-Membran stark spiralig gestreift; Körper in der Bewegung plattgedrückt eiförmig. . . 3. A. inflata

I. A. margaritifera Schmarda (Taf. XI, 32)

Angefüllt mit nur kleinen, abgeflachten Paramylumkörnern. Länge $50-60 \mu$. Häufig, in faulendem Wasser.

2. A. curvata $\mathrm{Kl}$. (= A. distorta Duj.)

Dreht sich während der Bewegung häufig oder flacht sich ab; Euglena-ähnlich. Vorderende abgestutzt. Paramylumkörner klein. Länge etwa $45 \mu$. Nicht selten.

Eyferths Einfachste Lebeformen. 3. Aufl. 
3. A. inflata Duj.

Viel weniger metabolisch als die vorigen Arten; Paramylumkörner grösser als bei den vorigen. Länge circa $35 \mu$. Vorkommen wie bei voriger Art.

\section{Distigma Ehrbg.}

Diese Gattung führt auch während des Schwimmens die lebhaftesten metabolischen Bewegungen aus, die für sie und Eutreptia viridis (S. 320) charakteristisch sind. Das Hinterende wird nämlich lang ausgezogen, und die ganze Masse des Körpers scheint sich in eine entstehende Endanschwellung hineinzuziehen, beziehungsweise rückt die Anschwellung dem Vorderende zu. Sobald dieses eingezogen ișt, beginnt wieder das Hinterende sich lang auszuziehen, und so fort. Der vorigen Gattung nahe verwandt, nur mit einer zweiten kleinen, nach vorn gerichteten Geissel.

D. proteus Ehrbg. [ = D. tenax (O. F. Müll.)] (Taf. XI, 33)

In dem in der Mitte ausgerandeten Vorderende zieht sich ein deutlicher Kanal von der Gejsselbasis bis zur Hauptvakuole. Meist äusserst reich an Paramylumkörnern. Doppelte Grösse der vorigen Arten. Nicht selten, in Sumpfwasser.

\section{Menoidium Py.}

Der starre, nicht metabolische Körper ist meist etwas gekrümmt und mit einer einzigen Geissel versehen. Plasma-Membran längsstreifig. Cylindrische Paramylumkörner.

I. Tiere vorn in einen zweispitzigen Hals verschmälert

I*. Vorn und hinten abgerundet. . . . . 2. M. incurvum

$$
\text { I. M. pellucidum }
$$

I. M. pellucidum Py. (Taf. XI, 34)

Der zarte, durchsichtige Körper sichelförmig, mit dicht längsgestreifter Membran; erinnert an Euglena acus und Astasia curvata. Länge $40 \mu$. Häufig.

2. M. incurvum (Fres.) K1. (= Rhabdomonas inc. Fres.)

Körper cylindrisch; Membran mit weit von einander abstehenden Längsstreifen. Länge I5-2 I $\mu$. Nicht häufig. 


\section{Sphenomonas St.}

Der starre, gerade Körper mit einem oder mehreren Längskielen. Im ausgerandeten Vorderende eine Haupt- und eine Nebengeissel. Im Hinterende ein homogener Gallertkörper.

Sph. teres (St.) K1.

Der spindelförmige Körper mit schwachem Längskiele. Membran zart längsstreifig. Nebengeissel sehr klein. Der Organismus kriecht auf dem Vorderende gleitend, bei schräg nach oben gestelltem Körper auf dem Substrate und schwimmt nie frei. Länge etwa $30 \mu$. Wie alle Verwandten im Sumpfwasser.

Die verwandte Sph. quadrangularis St. (Taf. XI, 35) hat vier deutliche Längskiele und ist wahrscheinlich viel seltener.

\section{Peranemida.}

Der starre oder metabolische Körper hat eine gestreifte Membran und eine oder zwei Geisseln am Vorderende, wo auch die Mundöffnung sich befindet. Zum Unterschiede gegen die vorige Familie ernähren sich die Peranemeen durch Aufnahme fester Nahrung. Deshalb ist der Membrantrichter der Eugleniden und Astasiiden zum Munde umgewandelt, der häufig noch besondere Membran-Apparate besitzt. Eine Stelle am Hinterende scheint eine weniger dichte Membran zu besitzen und als Zellafter zu fungieren. Mit Fett-Tröpfchen und Paramylumkörnern. Höchst entwickelte Flagellaten.

I. Körper metabolisch; Plasma-Membran meist spiralig gestreift 2 2. Mit einer Geissel (A: Peranemeae) . . . . . . . . . 3

3. Mit einfacher Mundöffnung, ohne Staborgan; spindelförmig . . . . . . . . I. Euglenopsis (S. 324)

3*. Mit Staborgan . . . . . . . . . . . 4

4. Körper länglich, nach vorn zugespitzt . . . . .

$$
\text { 2. Peranema (S. 324) }
$$

$4^{*}$. Körper flaschenförmig, nach vorn $z u$ einem zarten, häutigen Trichter erweitert 3. Urceolus (S. 325)

$2^{*}$. Mit zwei verschieden langen Geisseln (B: Heteronemeae) 5

5. Membran meist stark spiralig gestreift; Schleppgeissel kürzer als die vordere . . 4. Heteronema (S. 325)

$5^{*}$. Membran fein gestreift; Schleppgeissel länger und dicker als die vordere . . . . 5. Dinema (S. 326) 
I*. Körper (meist) starr . . . . . . . . . . . . . . . 6

6. Mit einer Geissel; Membran nicht spiralig gestreift (C: Petalomonadeae).

7. Die derbe Geissel entspringt am Vorderende; in dessen Mitte die kontraktile Vakuole, darunter der Kern. .

6. Scytomonas (S. 327)

7*. Die meist schiefe Geissel entspringt aus einer seitlichen Grube; kontraktile Vakuole an der einen, Kern an der anderen Seite des Körpers 7. Petalomonas (S. 327)

6*. Mit zwei ungleichen Geisseln (D: Anisonemeae) . . . 8

8. Mit acht deutlichen, spiraligen Kielen . . . . . .

8. Tropidoscyphus (S. 328)

8*. Ohne solche Kiele . . . . . . . . . . . . . . 9

9. Ohne Staborgan; mit Bauchfurche .

9*. Mit Staborgan; ohne Bauchfurche

$$
\text { 9. Anisonema (S. 328) }
$$

10. Entosiphon (S. 329)

\section{A. Peranemeae.}

\section{Euglenopsis K1.}

Am Vorderende, aber etwas seitlich, eine längliche Mundfalte, in der die Geissel entspringt.

Eu. vorax K1. (Taf. XI, 36)

Steht seiner Organisation nach zwischen den drei Gruppen der Euglenoidinen. Meist erfüllt von Stärkekörnern. Mässig metabolisch. Membran mehr oder weniger gestreift. Kontraktile Vakuole vorn. I Länge $20-26 \mu$. In Infusionen stärkereicher Pflanzenteile.

\section{Peranema (Duj.) St.}

Körper nach hinten verbreitert. Die derbe Geissel in einer Bauchfalte des Vorderendes. Darunter die Mundöffnung, an die sich ein aus zwei kurzen Stäben bestehender Mundapparat anschliesst.

P. trichophorum (Ehrbg.) St. (Taf. XI, 37)

Ziemlich variabel. Beim Schwimmen gleitet das Tier langsam und gleichmässig ohne Drehung durch das Wasser, wobei nur die Spitze der Geissel in Bewegung ist. Ein wenig trägt auch die 
Metabolie zur Bewegung bei. Vakuole vorn. Kern in der Mitte. Sehr gefrässig; verzehrt besonders gern Euglenen. Länge bis $80 \mu$. Im Sumpfwasser.

\section{Urceolus Mereschkowski.}

Von dem Trichter am Vorderende führt eine schlundartige Röhre zur Mundöffnung im Innern; daneben die fast den ganzen Körper(?) durchsetzende Geisseltasche. Membran glatt oder gestreift. Gleitet mit dem Halstrichter auf dem Substrate vorwärts den übrigen Teil des Körpers schief oder steil aufrichtend. Etwas metabolisch. Nach Stein und Penard hin und wieder mit anklebenden Fremdkörpern [dann vielleicht identisch mit Urceolopsis (sabulosa) Stokes]. Ernährung animalisch. Mit Fetttröpfchen im Plasma. Kontraktile Vakuole vorn.

Urc. cyclostomus (St.) Mereschk. (= Phialonema cycl. St.) (Taf. XI, 38)

Membran spiralig gestreift. Halstrichter schief abgestutzt. Länge bis $30 . \mu$. In stehendem Wasser.

Bei dem verwandten Urc. ovatus Möbius (mit oben erweitertem Halstrichter) und bei Urc. alenizini Mereschk. (mit geradem Trichter) ist die Membran glatt.

\section{B. Heteronemeae.}

\section{Heteronema (Duj.) St.}

Der langgestreckte Körper vorn zugespitzt. Auf der Bauchscite am Vorderende eine Mundfalte; in dieser vorn die lange, starke Vordergeissel, in der Mitte eine kürzere Schleppgeissel. Bisher hat ein Staborgan noch nicht nachgewiesen werden können. Diese Gattung bildet den Uebergang zu den Anisonema-Arten. Alle Arten kommen in stehendem Wasser vor.

I. Membran ohne Spiralstreifen. . . . 1. H. acus

I*. Membran mit Spiralstreifen, oder Körper tordiert. . . . 2

2. Schleppgeissel länger als der Körper 2. H. globulifenum

2*. Schleppgeissel kürzer oder so lang als der Körper • 3

3. Körper stark schraubig gedreht 3. H. spirale

$3^{*}$. Nur die Körpermembran stark spiralig gestreift 
I. H. acus (Ehrbg.) St. (Taf. XI, 39)

Körper langgestreckt spindelförmig; Schleppgeissel kaum halb so lang wie der Körper. Nimmt feste Nahrungstoffe, z. B. Stärkekörner, auf, ernährt sich aber vielleicht auch saprophytisch. Schwimmt entweder frei umher, indem es sich um die Längsachse dreht, oder es kriecht mit dem Vorderende in metabolischen Bewegungen auf dem Substrate. Sehr variabel. Länge $45-50 \mu$.

2. H. globuliferum (Ehrbg.) St.

Der rundliche Körper mit spitzem Vorderende und breit abgerundetem Hinterende. Membran stark spiralig gestreift; Vordergeissel von über doppelter Körperlänge. Bewegung stets kriechend.

\section{H. spirale $\mathrm{K} 1$.}

Körper länglich eiförmig, vorn und hinten zugespitzt. Membran nicht gestreift. Vordergeissel 2-3 Mal so lang als der Körper. Mit Fett-Tröpfchen und Paramylumkörnern. Vakuole im Vorder-, Kern im Hinterende. Länge $42 \mu$.

4. H. nebulosum (Duj.) KI. (= Zygoselmis neb. Duj.) (Taf. XI, 40)

Körper dick, tonnenförmig, mit stark zusammengezogenem, engem, hellem Vorderende; Membran stark spiralig gestreift, fast gerippt. Eine der gefrässigsten Flagellaten, verschlingt selbst sehr grosse Organismen wie Chlamydomonaden, Diatomeen etc. Länge $40-60 \mu$.

\section{Dinema Py.}

Der beiderseits abgerundete Körper länglich oval, mit sehr dicker Membran. Die den Mund bogig umlaufende Schleppgeissel sehr stark und lang. Der Mund auf der Bauchseite am Ende einer Falte, in der die schwache, vordere Geissel entspringt. An der Schleppgeissel-Basis die kontraktile Vakuole. Frisst besonders gern Diatomeen. Eine hoch entwickelte Flagellate, bei der. es vielleicht schon zur Ausbildung von Trichocysten gekommen ist.

D. griseolum Py. (Taf. XI, 4I)

Länge $75-80 \mu$. Wohl selten. 


\section{Petalomonadeae.}

\section{Scytomonas St.}

Der kleine, eiförmige Körper vorn zugespitzt und abgestutzt; Nahrungs-Aufnahme geschieht durch Aussaugen von Bakterien. Zeigt Verwandtschaft zu Monaden-Formen. Häufig ist eine von hinten (statt von vorn) ausgehende Längsteilung beobachtet.

Sc. pusilla St. (Taf. XI, 42) häufig.

Länge $4 \frac{1}{2}-6 \mu$. In faulenden Algenkulturen, ziemlich

\section{Petalomonas St.}

Der meist etwas abgeplattete Körper unsymmetrisch; sehr verschieden, oft bizarr gestaltet, meist mit Rippen auf dem gewölbten Rücken. Seitlich von dem bauchständigen Munde entspringt die zur Körperachse oft schief stehende Geissel. Die verschiedenen Arten wegen ihrer Veränderlichkeit oft sehr schwer zu trennen.

r. Mit einem oder mehreren starken Kielen auf dem Rücken 2

2. Mit zwei Kielen . . . . . . . P. abscissa

2*. Mit einem Kiele . . . . . . 2. P. steini

I*. Ohne Kiele, höchstens mit Rillen . . . . . . . . . . 3

3. Bauchseite deutlich gefurcht, oft auch der Rücken . .

3. P. mediocanellata

$3^{*}$. Bauchseite nicht so. . . . . . . . . . . . . . 4

4. Körper stark zusammengedrückt, Hinterende abgerundet . . . . . . . . 4. P. inflexa

$4^{*}$. Körper dick eiförmig, hinten in sechs dicken Fortsätzen endend . . . . . 5. P. sexlobata

I. P. abscissa (Duj.) St. (Taf. XI, 43)

Körper breit eiförmig, vorn und hinten abgerundet; Bauchseite abgeplattet oder ausgebuchtet. Länge $15-30 \mu$.

2. P. steini $\mathrm{K} 1$.

Körper gegen das Vorderende verschmälert, im Querschnitte etwa dreieckig. Länge $40-50 \mu$.

3. P. mediocanellata St.

Der eiförmige, etwas abgeplattete Körper mit gewölbtem Rücken. Länge $7-25 \mu$ und länger. Sehr häufig und äusserst variabel. 
4. P. inflexa $\mathrm{Kl}$.

Der stark zusammengedrückte Körper mit einem oder beiden Rändern eingekrümmt, oft auf dem Rücken mit seichter Furche oder mit schief stehender Geissel. Länge 8-12 $\mu$ und darüber. Verbreitet.

5. P. sexlobata K1. (Taf. XI, 44)

Das Tier gleicht einer halb geschlossenen Faust; die nach innen gekrümmten Fortsätze den Fingern. Die Zwischenräume zwischen ihnen setzen sich als Rillen etwas auf den Körper fort. Länge $27-30 \mu$. Scheint nicht häufig.

\section{Anisonemeae.}

\section{Tropidoscyphus St.}

Auf der Bauchseite mit langgezogener Mundspalte, in der die lange Haupt- und die kurze [nach vorn ausgestreckte (?)] Nebengeissel entspringen. Körper mehr oder weniger langgestreckt, hinten zugespitzt.

Tr. octocostatus St. (Taf. XI, 45)

Länge etwa $40 \mu$. In stehendem Wasser.

\section{Anisonema Duj.}

Der mehr oder weniger eiförmige Körper deutlich abgeplattet. In der bauchständigen Furche des Vorderendes die zwei Geisseln, von denen die eine als Schleppgeissel ausgebildet ist. Links von der Mundöffnung die kontraktile Vakuole. Kern auf der rechten Seite.

I. Körper metabolisch; beide Geisseln etwa gleich lang [Subg.: Metanema (K1.)]. . . . . . . . . . . . . . . . . 2

2. Membran glatt ....... . . A. variabile

2*. Membran mit weiten Spiralstreifen . 2. A. striatum

$1^{*}$. Körper starr; Schleppgeissel länger als die vordere [Subg.: Anisonema (Duj.) K1.] . . . . . . . . . . . . . . 3

3. Die beiden Geisseln etwa an einem Punkte entspringend; die Schleppgeissel an der Basis nicht umgebogen. . . 3. A. ovale

$3^{*}$. Die Schleppgeissel entspringt deutlich unterhalb der vorderen Geissel und ist am Grunde umgebogen

4. A. acinus 
I. A. variabile $\mathrm{Kl}$.

Körper breit eiförmig, vorn und hinten ausgerandet; auf der Bauchseite des Vorderendes eine seichte Furche. Länge etwa i $5 \mu$.

2. A. striatum $\mathrm{K} 1$. (Taf. XI, 46)

- Körper sehr platt gedrückt, vorn und hinten abgerundet; Furche auf der Bauchseite kurz. Schwimmt meist wie Peranema. Länge I $5 \mu$.

3. A. ovale $\mathrm{K} 1$.

Körper platt eiförmig, oft ziemlich breit; auf der Bauchseite eine schwache Längsfurche. Membran glatt; Kern bläschenförmig. Länge $10-12 \mu$. Liegt oft längere Zeit ruhig und beschreibt dann wieder, plötzlich lebhaft zuckend regelmässige Kurven.

\section{A. acimus Duj. (Taf. XI, 47)}

Körper abgeflacht eiförmig, mit starker Bauchfurche. Der linke, besonders hervortretende Furchenrand nach vorn verdickt. Die hintere Geissel mehr als zwei Mal so lang wie die vordere, verhältnismässig dick. Membran glatt oder gestreift. Kern feinkörnig. Länge $25-40 \mu$. Sehr verbreitet. (Das vorn abgerundete, graue A.truncatum St. scheint eine Varietät von A. acinus zu sein.)

Die von Lauterborn in die Nähe von Anisonema gestellte Gattung Thaumatonema mit Pseudopodien-Bildung und ohne Mund gehört wahrscheinlich zu den Protomastiginen; zu den Peranemiden jedenfalls nicht (vgl. S. 305).

\section{Io. Entosiphon St.}

Der Körper ist eiförmig, ohne Bauchfurche; hintere Geissel nicht viel länger als die vordere und meist seitlich ausgestreckt. Kern bläschenförmig.

I. Membran mit deutlichen Längsfurchen . I. E sulcatum I*. Membran nur zart längsgestreift . . . 2. E. obliquum

E. sulcatum (Duj.) St. (Taf. XI, 48)

Körper vorn gerade abgerundet; das vorstülpbare Staborgan bis ans Hinterende reichend. Vorn eine tiefe, mulden- 
förmige Einsenkung. Schiesst ruckweise vorwärts oder zittert hin und her. Länge $20-25 \mu$. Nicht selten.

2. E. obliquum $\mathrm{K} 1$.

Hinten zugespitzt; der eine Seitenrand stärker gewölbt als der andere. Staborgan erreicht höchstens halbe Körpcrlänge, unbeweglich. Länge etwa $15 \mu$. Ziemlich häufig.

\section{Chloxomonadina.}

Ohne Plasma-Membran. Körper mehr oder weniger amöboid. Kontraktile Vakuole am Vorderende. Kern im Centrum der Zelle gelegen. Zahlreiche scheibenförmige, hellgrüne Chlorophyllkörper vorhanden. Als Assimilationsprodukt tritt Fett auf. Augenfleck fehlt (?). Ernährung holophytisch. Mit zwei ungleichen Geisseln [oder mit nur einer Geissel? vgl. Coelomonas (S. 331)]. Entweder freischwimmend und nur während der Teilung in Gallerte eingelagert oder meist unbeweglich in Tetraspora-ähnlichen Kolonien und nur kurze Zeit beweglich.

In dieser Gruppe hat man in letzter Zeit nahe Verwandte der Confervales zu sehen geglaubt [wegen der gleichen Chromatophorenfarbe, des Assimilationsproduktes (Oel) und der Geisseln]; doch muss diese Ansicht noch durch weitere Untersuchungen gestützt werden. In ihrer gegenwärtigen Umgrenzung macht die Gruppe einen etwas sehr gekünstelten Eindruck.

1. Beide Geisseln etwa gleich lang, die eine dem Körper dicht anliegend . . . . . . . ...Vacuolaria (S. 330)

I*. Eine Geissel deutlich länger als die andere . . . . . . 2

2. Immer freischwimmend . . . . . . . . . . . 3

3. Grösse nicht über $15 \mu$. 2. Chloramoeba (S. 33I)

$3^{*}$. Grösse über $30 \mu$. . . 3. Rhapliidomonas (S. 331)

2*. Meist in Tetraspora-ähnlichen Kolonien

4. Chlorosaccus (S. 33I)

\section{Vacuolaria Cienk.}

Oval bis länglich, mit amöboider Beweglichkeit. Periplast als weiche, stark lichtbrechende Haut entwickelt. Am Vorderende zwei Geisseln von etwas ungleicher Länge und eine kontraktile Vakuole. Mit zahlreichen Chlorophyllkörpern. 
$V$. virescens Cienk. (Taf. XI, 49)

Chlorophyllkörper meist elliptisch. Die eine Geissel meist nicht auf den ersten Blick zu sehen. Länge 50-130 $\mu$. Nicht selten.

Vielleicht gehört hierher auch die Coelomonas grandis St. benannte Form, bei der Stein zwar nur eine Geissel gezeichnet, die zweite aber möglichenfalls (nach $\mathrm{Klebs}$ ) übersehen hat: mit einer ventralen Längsfurche.

\section{Chloramoeba Bohlin.}

Das Tier ist wegen der fehlenden Membran noch sehr amöboid, auch während des Schwimmens. Mit einer langen $\left(1 \frac{1}{2}-2\right.$ Mal so gross wie die Körperlänge) Geissel und einer kleinen, bogenförmigen Nebengeissel, an deren Basis die kontraktile Vakuole sich befindet. Die 2-6 Chromatophoren gelbgrün.

Chl. heteromorpha Bohlin (Taf. XI, 50)

Körper 7-13 $u$ lang. In Algenkulturen entdeckt.

\section{Rhaphidomonas St.}

Eine bisher nur von Stein gesehene, noch nicht näher untersuchte Form, die Trichocysten (wohl Schleimfäden) besitzen soll, sonst aber wohl der Vacuolaria gleicht. Mit einer (oder zwei) Geisseln.

Rh. semen (Ehrbg.) St. (Taf. XI, 52)

Ueber $50 \mu$ gross.

\section{Chlorosaccus Lagerh.}

Während der grössten Zeit des Lebens in Gallerte eingeschlossen und durch Teilung in je vier Tochterzellen sich vermehrend. $\mathrm{Zu}$ Zeiten verlassen die Flagellaten als Schwärmer die Hüllen, um sich an anderen Stellen festzusetzen. Die zwei Chromatophoren ohne Pyrenoide, gelbgrün. Dauercysten beobachtet. Wohl besser zu den Algen zu stellen.

Chl. fuidus A. Luther (Taf. XI, 51)

In hellgrünen Kolonien, die bis $15 \mathrm{~mm}$ breit, freischwimmend oder fest geheftet sein können. Zellen Io-I I $\mu$ lang, 5-8 $\mu$ breit. In Seen, bei uns noch nicht gefunden.

\section{Holomastigina.}

Der nackte Körper noch schwacher amöboider Bewegung fähig; auf der ganzen Oberfläche mit langen, gleichartigen Geisseln 
bedeckt. Die Nahrungs - Aufnahme, die tierisch ist, geschieht durch Pseudopodien an der ganzen Körperoberfläche.

Die interessante Gruppe bedarf noch eingehender Untersuchungen.

\section{Multicilia Cienk. (= Polymastix Grub.).}

Kontraktile Vakuolen zahlreich unter der Oberfläche. Erst zwei Vertreter bekannt, von denen nur einer im Süsswasser vorkommt.

M. lacustris Lauterb. (Taf. XI, 53)

Frisst besonders gern Chlamydomonaden, deren kontrahierter grüner Inhalt meist die ganze Zelle in Körnern anfüllt. Durchmesser $30-40 \mu$. In stehendem Wasser, selten.

\section{Chromomonadina.}

Kleine bis mittelgrosse Formen. Ohne Plasma-Membran, nur mit einfacher Hautschicht. Körper vielfach ein wenig amoeboid; nackt oder mit Hülle. Geisseln in der Ein- oder Zweizahl am Vorderende. Gewöhnlich sind ein oder zwei meist gelbbraune Farbstoffplatten vorhanden. Vielfach gallertumhüllte Kolonien. Ernährung meist pflanzlich, doch daneben auch oft animalisch oder saprophytisch.

1. Zellen bilden nicht einen mehrere Centimeter langen Thallus 2

2. Körper ohne einen schlundartigen Kanal, mit gelben Chromatophoren (1. Chrysomonadina) . . . . . . . 3

3. Tiere nackt, nur im ruhenden Zustande mit Gallerthülle; nie Kolonie bildend

A. Chrysomonadina nuda (S. 333)

$3^{*}$. Tiere mit Hülle; wenn ohne, dann Kolonie bildend 4 4. Mit Gehäuse oder Schale . . . . . . .

B. Chrysomonadina loricata (S. 336)

$4^{*}$. Hülle hautartig, eng anliegend, selten fehlend .

C. Chrysomonadina membranata (S. 338)

2*. Körper vorn mit Ausschnitt, von dem ein ventraler, schlundartiger Kanal entspringt; mit grünen Chromatophoren oder farblos.

2. Cryptomonadina St. (S. 340)

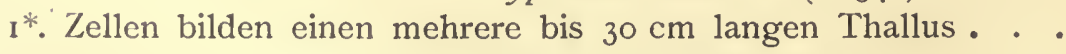
Anhang: Hydrurina (S. 341) 


\section{Fam. Chrysomonadina.}

Selten nackte, meist mit Hülle versehene, einzeln oder kolonieweise lebende Formen; mit einer oder zwei Geisseln, häufig auch mit Augenfleck, stets mit zwei gelbbraunen Chromatophoren. Längsteilung im beweglichen Zustande, häufig auch in Ruhestadien. Einfache Dauercysten.

Die Chrysomonadinen werden häufig mit noch anderen gelben Organismen (Hydrurus, Phaeothaminion, Braunalgen, Peridineen etc.) zu der grossen Gruppe der Chrysophyceen zusammengestellt. Obwohl diese Vereinigung sicherlich etwas für sich hat und gewisse Verwandtschaftsbeziehungen zum Ausdrucke bringt, so würden doch hierdurch auf der anderen Seite wieder unnatürliche Abgrenzungen notwendig sein. Die gelben Flagellaten sind nämlich von gewissen Protomastiginen nur durch das Vorhandensein der Chromatophoren zu unterscheiden, selbst Rhizomastiginen-Formen sind bei ihnen vertreten. Jedenfalls werden ihnen spätere Forscher eine natürlichere Stellung im Systeme verschaffen.

\section{A. Chrysomonadina nuda.}

I. Körper mit einer Geissel . . . . . . . . . . . . . 2

2. Ohne Augenfleck; mit zwei Farbstoffplatten

1. Chrysamoeba (S. 333)

2*. Mit Augenfleck; wenn ohne, dann nur eine Farbstoffplatte . . . . . . . 2. Chromulina (S. 334)

I*. Mit zwei Geisseln . . . . . . . . . . . . . . . . 3

3. Meist mit Augenfleck, nicht mit einem Stiele festgeheftet 3. Ochromonas (S. 335)

$3^{*}$. Ohne Augenfleck, auf steifem Gallertstiele festsitzend 4. Stylochrysalis (S. 336)

\section{Chrysamoeba K1.}

Körper im beweglichen Zustande dick oval; zuweilen amöbenförmig, mit zahlreichen feinen, nach allen Seiten strahlenden Pseudopodien. Mit 2-3 kleinen kontraktilen und einer grösseren konstanten Vakuole.

Chr. radians $\mathrm{K} 1$. (Taf. XI, 54)

Länge $12-15 \mu$. Selten. 


\section{Chromulina Cienk.}

Körper kugelig bis oval; stets amoeboid, namentlich am Hinterende. Mit einer oder zwei Farbstoffplatten. Teilung in gallertumhüllten Ruhezuständen.

I. Mit Augenfleck . . . . . . . . . . . . . . . . . 2

2. Mit zwei Farbstoffplatten . . . . . . . . . 3

3. Periplast etwas körnig, Länge über го $\mu$. . . . I. Chr. favicans

3*. Periplast glatt, Länge nur selten wenig über $5 \mu$. 2. Chr. ochracea

2*. Mit einer Farbstoffplatte . . . . . . . . . . . 4 4. Mit zwei kontraktilen Vakuolen am Vorderende. 3. Chr. verrucosa 4*. Mit einer kontraktilen Vakuole am Vorderende. 4. Chr. ovalis I*. Ohne Augenfleck . . . . . . . . . 5. Chr. rosanoffi

I. Chr. Aavicans (Ehrbg.) Btschli. (Taf. XI, 55)

Körper im beweglichen Zustande länglich, veränderlich; im Vorderende mit einer oder zwei kontraktilen Vakuolen. Im Hinterende gewöhnlich Nahrungsballen. Länge 14-16 $\mu$, Breite 7- $13 \mu$.

2. Chr.ochracea (Ehrbg.) Btschli.

Körper klein, mit Abplattung, rundlich oder herzförmig. Eine kontraktile Vakuole am Vorderende. Länge $3,6-5,4 \mu$. Sehr häufig.

3. Chr. vernucosa Kl.

Körper dick eiförmig. Farbstoffplatte gross, stark verbogen. Plasma-Membran mit höckerartigen Vorsprüngen. Hinten mit Nahrungsballen. Vereinzelt.

4. Chr. ovalis K1.

Im beweglichen Zustande eiförmig, hinten vielfach zugespitzt. Farbstoffplatte muldenförmig. Teilung im geissellosen Zustande hinter einer Gallerthülle. Länge $8-13 \mu$, Breite $5-7 \mu$. Nicht eben selten.

5. Chr. rosanoffi (Woronin) Btschli. (= Chromophyton rosan. Woron.) (Taf. XI, 56)

Klein, gewöhnlich oval, wenig amoeboid. Mit einer kontraktilen Vakuole und einer schmalen Farbstoffplatte. Teilung 
hinter Gallerthülle. Bildet einen staubartigen, goldgelben Ueberzug auf der Wasseroberfläche, besonders gern auf Wasserkübeln in Gewächshäusern. Dabei sind die kleinen Zellen nicht vom Wasser benetzt, sondern stehen mit ihm nur durch einen kleinen Stiel in Berührung. Im Herbst bilden sie Dauerzustände, die in den Höhlungen der Sphagnum-Blätter überwintern. Der obenerwähnte Stiel, der die Wasseroberfläche wie eine Haut durchbohrt, fehlt bei der nahe verwandten Ch. woroniniana Fisch.

\section{Ochromonas Wysotzki.}

Körperform verschieden, deutlich amoeboid. Vorne mit zwei Geisseln (einer Haupt- und einer Nebengeissel) und einer kontraktilen Vakuole. Farbstoffplatten in der Ein- oder Zweizahl. Oft mit Leukosin. Teilung im beweglichen und ruhenden $\mathrm{Zu}$ stande. Ernährung häufig tierisch.

I. Mit zwei Chromatophoren . . . . . . . . . . 2

2. Diese von mehr als halber Körperlänge . . . . . 3

3. Hauptgeissel von Körperlänge; kein Augenfleck . I. O. variabilis

$3^{*}$. Hauptgeissel länger als der Körper

2. O. mutabilis

2*. Chromatophor nur von $1 / 4$ der Körperlänge, sehr schwach 3. O. granulosa

I*, Mit einem gewundenen Chromatophor. 4. O. crenata

I. O. variabilis $\mathrm{H}$. Meyer

6-9 $\mu$ lang, 5-8 $\mu$ breit; meist rundlich. Nebengeissel gleich $1 / 4$ der Körperlänge. Pulsationszeit der kontraktilen Vakuole 45 Sekunden.

2. O. mutabilis $\mathrm{K} 1$. (Taf. XI, 57)

Körper länglich eiförmig, vorn mit Ausrandung oder Abstutzung. Hauptgeissel länger, Nebengeissel kürzer als der Körper. Kontraktile Vakuole im Vorderende. Bewegung langsam unter gleichmässiger Rotation; teilweise festsitzend. Länge $16-24 \mu$.

3. O.granulosa H. Meyer

Körper 1 2--20 $\mu$ lang, 6- i $5 \mu$ breit, oval, doch oft mit Lippe oder Schwanz-Spitze versehen. Nebengeissel wie bei 0 . variabilis. 
Pulsationszeit der Vakuole is Sekunden. Mit Augenfleck. Mit Leukosin und Fett. (Bei der ähnlichen O. tenera $\mathrm{H}$. Meyer liegt die Vakuole im Hinterende, Pulsationszeit der Vakuole 35 Sekunden; meist festsitzend.)

4. O. crenata K1.

Körper rundlich bis länglich, mit zahlreichen peripherischen, warzenförmigen Vorsprüngen. Nebengeissel sehr klein. Mit Augenfleck und vorn gelegener Vakuole. Nahrungs-Aufnahme durch Vakuolen. Länge $14-20 \mu$. (Bei der gleichfalls warzigen O. chromata $\mathrm{H}$. Meyer (Taf. XI, 58) sind zwei dunkelbraune Chromatophoren vorhanden.)

\section{Stylochrysalis St.}

Klein, eiförmig; mit zwei Geisseln von gleicher Länge, zwei Farbstoffplatten, ohne Augenfleck. Auf steifem Gallertstiele festsitzend.

St. parasitica St. (Taf. XI, 6o)

Körper etwa io $\mu$ lang, auf Eudorina-Kolonien aufgewachsen.

\section{B. Chrysomonadina loricata.}

I. Mit einer Geissel und einer kontraktilen Vakuole . . . I. Chrysococcus (S. 336) I*. Mit zwei Geisseln und zwei kontraktilen Vakuolen . . 2 2. Mit Haupt- und Nebengeissel. . 2. Dinobryon (S. 337) 2*. Geisseln von gleicher Länge . . 3. Chry'sopyxis (S. 338)

\section{Chrysococcus K1.}

Körper Chromulina-ähnlich, mit Augenfleck und zwei Farbstoffplatten. Das Hinterende mit Leukosin. Schale derb, bräunlich, eng, bis auf die Geisselöffnung geschlossen. Teilung innerhalb der Schale.

Chr. rufescens K1. (Taf. XI, 59)

Länge $8-10 \mu$. In Teichen, selten aber in grosser Individuenzahl auftretend. 


\section{Dinobryon Ehrbg.}

Körper länglich, hinten spitz ausgezogen und mit Augenfleck; meist mit zwei Farbstoffplatten. Das mit Leukosin erfüllte Hinterende befestigt das Tier zum Teil in dem vasen-, becher-oder röhrenförmigen, oben offenen Gehäuse. Teilung innerhalb des Gehäuses; die Tochterzellen setzen sich am inneren oder äusseren Rande des Bechers fest. Cysten mit starker Kieselhülle an der Gehäuse-Mündung. Einzeln oder in Kolonien. Bildet eine der wenigen pelagischen Flagellaten-Gattungen.

1. Gehäuse nicht röhren-, sondern becherförmig, ohne Anwachsringe am vorderen Ende . . . . . . . . . . 2

2. Ohne peristom-artigen Fortsatz am Vorderende, freischwimmend (I. Eudinobryon) . . . . . . . . . 3

3. Gehäuse gestielt . . . . . 1. D. sertularia

$3 *$. Gehäuse ohne besonderen Stiel, mit mehreren Einschnürungen in der Mitte; Tiere einzeln lebend . .

2. D. undulatum

2*. Meist mit peristom-artigem Fortsatz seitlich am Vorderende; festsitzend, meist einzeln (II. Epipyxis Ehrbg.). .

3. D. utriculus

I*. Gehäuse röhrenförmig, mit Anwachsringen (III. Hyalobryon Lauterb.) . . . . . . . . . 4. D. ramosum

I. D. sertularia Ehrbg. (Taf. XI, 6I)

Langgestreckt, hinten zugespitzt, kontraktil. Gehäuse (aus Cellulose!) becherförmig, mit kurzer Spitze. Kolonien freischwimmend, buscḩörmig. Im Plankton von Seen und Tümpeln, häufig.

Die schlankeren, lang zugespitzten Gehäuse von D. stipitatum St. sind in parallelen Reihen angeordnet.

2. D. undulatum K1. (Taf. XI, 62)

Schmal eiförmig, hinten nicht besonders zugespitzt. Gehäuse dick vasenförmig, bräunlich durch Einlagerung von Eisenoxydhydrat. Nicht koloniebildend, freischwimmend.

3. D. utriculus (Ehrbg.) K1. (= Epipyxis utr. Ehrbg.)

Langgestreckt, hinten stark zugespitzt, kontraktil. Gehäuse lang becherförmig. Tiere einzeln oder $\mathrm{zu}$ mehreren festsitzend. 
4. D. (Hyalobryon Lauterb.) ramosum Lauterb. (Taf. XI, 63)

Die Gehäuse äusserst zart, daher fast nur bei Färbung (mit Anilinfarben!) $\mathrm{zu}$ erkennen. Tier mit dem $12 \mu$ langen Schwanzfaden etwa $30 \mu$ lang. Gehäuse etwa $50-55 \mu$ lang und $6-7 \mu$ breit. Wohl nicht häufig.

\section{Chrysopyxis St.}

Körper dick oval bis kugelig, vorn und hinten abgerundet. Mit Augenfleck. - Kontraktile Vakuolen im Hinterende. Gehäuse dick bauchig, einzeln, festsitzend.

Chr. bipes St. (Taf. XI, 64)

Gehäuse meist mit zwei spitzen, langen Fortsätzen auf Algenfäden "reitend" befestigt. Körper am Grunde des über Iо $\mu$ grossen Gehäuses.

\section{Chrysomonadina membranata.}

I. Mit einer oder zwei gleich langen Geisseln . . . . . . 2

2. Mit nur einer kontraktilen Vakuole

I. Hymenomonas (S. 338)

2*. Mit mehreren kleineren kontraktilen und einer grösseren, nicht pulsierenden Vakuole. . . . . . . . . 3

3. Mit einer Geissel . . . . . . . . . . . 4

4. Die Tiere in freischwimmenden Kolonien, mit

Kieselnadeln . . . 2. Chrysosphaerclla (S.339)

$4^{*}$. Die Tiere leben einzeln . . . . . . . . . 5

5. Mit einem oder zwei Augenflecken, Körper glatt : . . . 3. Microglena (S. 339)

5*. Ohne Augenfleck, Körper mit zahlreichen langen Borsten . 4. Mallomonas (S. 339)

3*. Mit zwei gleich langen Geisseln . . .. . . . 6

6. Kolonien nicht in Gallerte eingebettet .

6*. Kolonien in Gallerthülle

5. Synura (S. 339)

6. Syncrypta (S. 340)

I*. Mit einer kurzen und einer langen Geissel; in Kolonien

7. Uroglena (S. 340)

I. Hymenomonas St.

Länglich cylindrisch bis stark abgerundet; Vorderende vielfach breit, ausgerandet. Hülle dick, etwas bräunlich, weich. Mit 
zwei gleich langen Geisseln, einem Augenflecke, zwei Farbstoffplatten. Kontraktile Vakuole im Vorderende. Einzeln frei umher schwimmend. Teilung im geissellosen Zustande.

H. roseola St. (Taf. XI, 65)

Hülle an der Aussenwandung mit ringförmigen Körperchen. Länge $14-25 \mu$, Breite 10-18 4 . Selten.

\section{Chrysosphaerella Lauterb.}

Jedes Individuum der Kolonie mit verkieselter, aus kleinen Plättchen zusammengesetzter Hülle. Mit zwei Chromatophoren mit je einem Stigma. Mit einer Geissel. Die Kolonie von einem Mantel zarter, gebogener Kieselnadeln umgeben. Ausserdem gehen von der Hülle jedes einzelnen Tieres zwei lange, hohle Kieselnadeln aus, die an ihrem Basalteile beweglich sind.

Chr. longispina Lauterb. (Taf. XI, 66)

Durchmesser der Kolonien 40-50 $\mu$; Einzeltier etwa is $\mu$ lang. Pelagisch in Teichen. Ist wohl eine der schönsten Chrysomonadinen.

\section{Microglena Ehrbg.}

Eiförmig, etwas zusammengedrückt. Die zarte, weiche Hülle mit verstreuten Körnchen versehen. Mit zwei (?) Farbstoffplatten - und fünf bis sechs kleinen pulsierenden Vakuolen. Unkontraktile Blase im Vorderende. Das Innere mit Leukosin erfüllt.

M. punctifera Ehrbg. (Taf. XI, 67)

Länge $30 \mu$, Breite $19 \mu$. Selten.

\section{Mallomonas Py.}

Schmal eiförmig. Hülle netzförmig; mit langen, steifen Borsten besetzt. Mit zwei Farbstoffplatten. Im Hinterende mehrere kontraktile Vakuolen und reichliches Leukosin, im Vorderende eine nicht pulsierende Blase. Cysten mit Kieselhaut.

M. ploessli Py. (Taf. XI, 68)

Länge $20-26 \mu$, Breite $7-\mathrm{I} 2 \mu$.

\section{Synura Ehrbg.}

Eiförmig. Ohne Augenfleck oder mit mehreren (?), mit zwei Farbstoffplatten. Vakuolen wie bei voriger Gattung. Bildet freischwimmende, kugelige. Kolonien. Cysten mit Doppelhaut. 
S. uvella Ehrbg. (Taf. XI, 69)

Körper bis etwa $30 \mu$ lang, die Kolonie doppelt so gross. Ziemlich häufig.

\section{Syncrypta Ehrbg.}

Sehr ähnlich der vorigen Gattung. Kolonien von Gallerthülle umschlossen. Dauercysten ebenfalls mit Gallerthülle.

S. volvox Ehrbg. (Taf. XI, 70)

Kolonie kaum so gross wie bei voriger Art. Selten.

\section{Uroglena Ehrbg.}

Birnförmig. Mit Augenfleck, zwei Farbstoffplatten und einer kontraktilen Vakuole im Vorderende. Individuen an der Peripherie einer Gallertkugel, radial gestellt, ohne in direktem Zusammenhange $\mathrm{zu}$ stehen.

U. volvox Ehrbg. (Taf. XI, 7 I )

Länge der Einzeltiere etwa $15 \mu$, der Kolonie fast doppelt so gross wie bei den vorigen. Kopulation beobachtet (?). Vorkommen wie bei voriger Art.

\section{Fam. Cryptomonadina.}

Mit äusserst zartem, hautartigem Periplast; nicht amoeboid nur wenig metabolisch, gewöhnlich abgeplattet eiförmig. Zwei Geisseln von gleicher Länge aus dem Ausschnitt des Vorderrandes entspringend. Gewöhnlich mit zwei Farbstoffplatten von gelbbrauner bis blaugrüner Färbung. Kern im Hinterende; kontraktile Vakuole im Vorderende. Längsteilung im beweglichen Zustande oder hinter Gallerthülle. Ernährung rein pflanzlich oder saprophytisch.

I. Ohne Chromatophoren . . . . . . . . . . . . 2

2. Vorn mit einer Reihe lichtbrechender Körnchen

2*. Ohne solche Körnchen; stärkehaltig

I. Cyathomonas (S. 34I)

2. Chilomonas (S. 34I)

I*. Mit Chromatophoren . . . . . 3. Cryptomonas (S. 34I) 


\section{Cyathomonas Fromentel.}

Körper klein, oval, vorn schief abgestutzt, stark zusammengedrückt. Geisseln von gleicher Länge. Kern an der längeren Körperseite, gegenüber der kontraktilen Vakuole. Längsteilung.

C. (Monas, Spumella) truncata (St.) (Taf. XI, 72)

Geisseln von Körperlänge. Kontraktile Vakuole an der kürzeren Längsseite. Länge bis $23 \mu$. Scheint nicht häufig.

\section{Chilomonas Ehrbg.}

Körper oval, seitlich etwas zưsammengedrückt. Vorn abgestutzt, mit peristom-artiger Aushöhlung, an deren höherer I.ippe die zwei gleich langen Geisseln sich inserieren. Schlund röhrenförmig, bis zur Körpermitte sich erstreckend. Kontraktile Vakuole im Vorderende, dorsal gelegen. Kern im hinteren Körperende. Ernährung saprophytisch.

Ch. paramaecium Ehrbg. (Taf. XI, 73)

Körper fein längsgestreift. Länge bis $30 \mu$. In Infusionen häufig.

\section{Cryptomonas Ehrbg.}

Voriger Gattung ähnlich; aber mit zwei an den Seitenflächen liegenden, grünen bis braunen Chromatophoren. Ernährung rein pflanzlich.

Cr. ovata Ehrbg. (Taf. XI, 74)

Körper lang eiförmig. Länge bis $30 \mu$. Zwischen Conferven, häufig.

\section{Anhang: Hydrurina.}

\section{Hydrurus Agardh.}

Zellen rundlich bis oval, selbst spindelförmig, nackt; am Vorderende mit wandständiger, gelbbrauner Farbstoffplatte und nacktem Pyrenoid; am Hinterende mit 5-6 kontraktilen Vakuolen und fettig glänzenden, nach dem Absterben zerfliessenden Kügelchen. Kern in der Zellmitte. Die durch Gallerte vereinigten Zellen bilden einen bis $30 \mathrm{~cm}$ langen, am Ende stark verzweigten Thallus mit Spitzenwachstum. (Verwandtschaft mit den Algen.) Längsteilung. Tetraëdrische, eingeisselige Sporen. Dauerzellen rundlich, mit verkieselter Aussenhaut, auf der einen Seite mit halbringförmigem Anhange. 
H. foetidus (Vauch.) Kirchn. (Taf. XI, 75)

Dicke der Zellen 6-10 $\mu$. Bildet in schnell fliessenden Gewässern braune Ueberzüge auf Steinen, besonders im Kalkgebirge. Ist hier und da wohl nicht selten.

\section{Ciliata. \\ (Wimper-Infusorien, Wimperlinge). \\ Litteratur:}

Ehrenberg, Chr. Fr., Die Infusionstierchen als vollkommene Organismen. Leipzig 1838 .

Dujardin, F., Histoire naturelle des Infusoires. Paris $184 \mathrm{I}$.

Claparède und Lachmann, F́tudes sur les Infusoires et Rhizopodes. Mém. instit. Génévoise. Bd. V-VII. Genève 1858-6i.

v. Stein, F., Der Organismus der Infusionstiere. Abth. I, II. Leipzig 1859 und 1867 .

-, Die Infusionstiere auf ihre Entwicklungsgeschichte untersucht. Leipzig 1854 .

Engelmann, Th. W., Zur Naturgeschichte der Infusionstiere. Zeitschrift für wissenschaftl. Zoologie. Bd. XI. Leipzig 1862.

Wrześniowski, A., Beiträge zur Naturgeschichte der Infusorien. Zeitschrift für wissenschaftliche Zoologie, Bd. 29. Leipzig 1877 .

Kent, W. S., A manual of the Infusoria. Bd. II. London 1880-82 Mit Atlas.

Bütschli, O., Bronns Klassen und Ordnungen des Tierreichs. Bd. I. Protozoa. Abt. III. Leipzig I $887-89$.

Schewiakoff, W., Beiträge zur Kenntnis der holotrichen Ciliaten. Bibliotheca Zoologica, Heft 5. Cassel 1889 .

Blochmann, Fried., Abt. I. Protozo' in Kirchner und Blochmanns mikroskopischer Tierwelt des Süsswassers. Hamburg 1895.

Roux, J., Observations sur quelques Infusoires Ciliés des environs de Genève. Rev. Suisse de Zool. T. 6. Genève 1899.

In den Wimper-Infusorien erreichen die solitär lebenden Zellen ihre höchste Entwicklung; kein Wunder ist es daher, wenn diese Protozoen lange Zeit hindurch für höhere Tiere gehalten wurden. Schon die Differenzierung des Plasmas in deutlich zu unterscheidende Schichten ist bei den Ciliaten besser als bei allen übrigen einzelligen Tieren durchgeführt. $\mathrm{Zu}$ äusserst wird der Körper meist begrenzt von einer plasmatischen Cuticula, die bei einigen Colepinen zu einem panzerartigen Gebilde 
entwickelt ist. Auf die Cuticula folgt eine Schicht homogenen, hyalinen Plasmas, die sogenannte Rindenschicht oder das Ektoplasma, welches im Innern das gewöhnlich dünnflüssige, in rotierender Bewegung begriffene Entoplasma einschliesst.

Die Ektoplasma-Lage ist häufig der Sitz fibrillöser, kontraktiler Elemente, deren Zusammenziehung dem Körper vielfach eine deutliche spiralige Kannelirung verleiht. Formen, deren Dünnheit eine gleichzeitige Betrachtung von Vorder- und Rückseite gestattet, zeigen daher oft eine schiefwinklige, spiralige Felderung. Erinnern schon diese Gebilde an die Muskeln der höheren Tiere, so gilt dies noch mehr von den schnellenden Stielfäden der Vorticelliden, die innerhalb besonderer Scheiden in steiler Schraubenlinie verlaufen und aus der Vereinigung mehrerer ektoplasmatischer Fibrillen ihre Entstehung nehmen.

Als Hauptbewegungsorgane fungieren die Wimpern oder Cilien, deren Anwesenheit das erste Kriterium für die Wimperinfusorien bildet. Sie sind Protoplasma-Fortsätze und zeigen in ihrer Entwicklung und Lokalisation die bunteste Mannigfaltigkeit. Während sie bei manchen Arten so fein sind, dass sie nur in der Ruhelage oder nach Anwendung von Reagentien, wie verdünnter Essigsäure oder Chromsäure, deutlich hervortreten, erreichen sie bei anderen eine beträchtliche Stärke und können selbst zu mächtigen Griffeln oder Cirren ausgebildet sein, die ihren Träger auf weite Strecken hinwegzuschleudern im Stando sind. Die.Bewimperung kann sich völlig gleichmässig über den ganzen Körper ausdehnen: man spricht in diesen Falle von holotrichen Ciliaten, wenn die Länge der Cilien überall nahezu gleich ist; von heterotrichen hingegen, wenn eine Wimperzone durch stärkere Entwicklung ausgezeichnet ist. Ist die Bewimperung ausschliesslich auf die Bauchseite beschränkt, so hat man eine hypotriche Form vor sich, während Ciliaten, die nur cinzelne Wimper-Zonen oder -Büschel aufweisen, als peritriche bezeichnet werden. Bevor Bütschli auf die wichtigen Mundverhältnisse aufmerksam machte, war die Art der Bewimperung das wichtigste Einteilungsprinzip.

Vielfach ist die Bewimperung in den Dienst der Nahrungsaufnahme gezogen. Abgesehen von einer geringen Anzahl parasitischer Formen besitzen sämtliche Wimper-Infusorien eine Mundöffnung. Im einfachsten Falle ist diese rund bis spaltförmig. Vielfach liegt sie in einer je nach den Gattungen verschieden 
gestalteten Vertiefung, dem Peristome. Zahlreiche Gattungen nehmen die Nahrungskörper durch einfaches Verschlucken auf. Bei der Mehrzahl der Ciliaten jedoch wird die Nahrung eingestrudelt. $\mathrm{Zu}$ diesem $\mathrm{Zwecke}$ ist die Mundöffnung häufig von längeren oder kürzeren Cilien umstellt, die $\mathrm{zu}$ blattartigen Flächen, Membranellen genannt, zusammengeschlossen sein können. Vielfach finden sich auch an einer oder an beiden Seiten der Mundöffnung undulierende Membranen, die hin und wieder eine mächtige Entwicklung erlangen. Oft ist die Umgebung der Mundöffnung äusserlich mit einer Reihe besonders kräftiger Wimpern, einer „adoralen Wimperzone“, versehen, die bei den einzelnen Gattungen jeweils eine ganz spezifische Ausbildung zeigt.

An den Mund schliesst sich meist ein Schlund an, der entweder zarthäutig ist oder ein starres Rohr darstellt oder endlich mit Stütz-Stäbchen ausgestattet ist, die ihm ein fischreusenartiges Aussehen erteilen. Vielfach ist der Schlund ebenfalls mit Cilien, Membranellen oder undulierenden Membranen versehen; auch setzt sich bei einigen Formen die adorale Zone in ihn fort.

Nach Passierung des Schlundes gelangen die Nahrungsstoffe in das Entoplasma, dessen rotierenden Bewegungen sie folgen. Bei Formen, die nur kleine Partikelchen, wie z. B. Monaden, verschlucken, kommt es hierbei vielfach zur Anhäufung kugeliger Ballen, die Ehrenberg seiner Zeit für nahrungerfüllte Mägen hielt; eine Auffassung, die er durch die Benennung "Polygastrica" in die Systematik übertrug. Im Entoplasma werden den Nahrungskörpern die assimilierbaren Substanzen entzogen. Die unverdaulichen Reste werden durch einen feinen Porus, die Afteröffnung, wieder ausgestossen. Viele Ciliaten verschlucken grössere Tiere (selbst Rotatorien) oder Pflanzen, namentlich Oscillarien und Diatomeen. Durch solche grössere verschluckte Nahrungskörper wird die Körperform der Tiere oft. bis zur Unkenntlichkeit verzerrt.

Neben Nahrungs-Vakuolen sind kontraktile Vakuolen mit ganz wenigen Ausnahmen stets in der Ein- oder Mehrzahl vorhanden und deutlich sichtbar; sie dienen wahrscheinlich durch Beschleunigung des Wasserwechsels respiratorischen, durch $\mathrm{Ab}-$ führung unbrauchbarer Zerfallstoffe exkretorischen Zwecken. Bei Anwesenheit von nur einer kontraktilen Vakuole liegt diese gewöhnlich nahe am Hinterende des Körpers. Zuführungskanäle, oder 
richtiger „Flüssigkeitsfäden", die in die pulsierende Vakuole münden, finden sich vielfach in der Ein- und Zweizahl, oder sie streben, Strahlen vergleichbar, in grösserer Anzahl auf die Blase zu. Besonders bei matt gewordenen, absterbenden Tieren sind sie oft deutlich wahrnehmbar.

Von anderen Plasma-Einschlüssen sind in erster Linie die Zoochlorellen zu nennen: kleine Algen, die mit ihren Wirten in Symbiose leben (Brandes' Assimilationsgewebe) (vgl. Taf. XII, $29 \mathrm{~b})$. Ausserdem finden sich hin und wieder violette oder gelbe Pigmente, die häufig eine bestimmte Färbung ihrer Träger verursachen; namentlich enthalten manche Nassula-Arten zahlreiche gefärbte Tropfen. Andere, stark lichtbrechende Einschluss-Körper finden sich zuweilen im Plasma regellos gehäuft (Exkretkörner).

Im Rindenplasma lagern namentlich bei holotrichen Formen oft dicht gedrängt zahlreiche kleine, stabförmige Körperchen, sogenannte Trichocysten, die, obwohl äusserlich wenig hervortretend, dennoch durch ihre dunkle Farbe und starke Lichtbrechung auffallen. Diese Gebilde besitzen die Fähigkeit, als lange, starre Fäden hervorzuschiessen; bei Druck oder Anwendung von starker Essigsäure ist dieser Vorgang, wenigstens bei den meisten Arten, leicht zu beobachten. Bei einigen Formen hingegen ist es bisher noch nicht gelungen, die Trichocysten zum Ausschnellen zu bringen. Da kleinere Tiere von Trichocysten getroffen sogleich gelähmt werden, so hat man in diesen Organen wohl Angriffs- oder Schutz-Apparate zu sehen. Echte Nesselkapseln finden sich in der Gattung Epistylis.

Pseudopodien-Bildung kommt nur ganz vereinzelt vor; so heften sich z. B. die Stentoren am Hinterende vermittelst pseudopodien-artiger Gebilde fest. Dagegen sind Tastborsten von grösserer oder geringerer Beweglichkeit keineswegs selten.

So zeigt also die Organisation der Ciliaten eine Fülle von Differenzierungen, die in hohem Masse an die Metazoen erinnern. Sie weist eine ganze Anzahl von Organen auf, die funktionell ganz denen der höheren Tiere gleichen, morphologisch aber durch den Umstand, dass sie alle nur einem einzigen Zell-Leibe angehören, gänzlich verschieden sind. Sie haben sämtlich nur den Wert von Zellorganen, und eine exakte Namengebung dürfte eigentlich nur von Zellmund, Zellafter etc. sprechen. So illustrieren die Ciliaten in trefflichster Weise, wie viel die Natur mit den bescheidensten Mitteln zu leisten vermag. 
Auch die Kernverhältnisse der Ciliaten zeigen schon hochentwickelte Differenzierungen. Im Entoplasma findet sich ein grosser, von einer feinen Membran eingehüllter Kern, der sogenannte Makronukleus. Er leitet wahrscheinlich in erster Linie die rein vegetativen Funktionen des Kell-Leibes. Seine Gestalt ist im einfachsten Falle kugelig oder ellipsoïd; vielfach jedoch wird sie lang, bandförmig, ja selbst rosenkranzförmig. In der Nähe des Makronukleus liegen gewöhnlich ein oder mehrere kleinere Kerne, die sogenannten Mikronuklei.

Eine wichtige Rolle spielt der Mikronukleus bei der Fortpflanzung. Gewöhnlich besteht diese in einer Querteilung im beweglichen Zustande, die mit einer Verdoppelung sämtlicher Zellorgane verbunden ist. Schrägteilungen kommen nur bei wenigen Formen vor. Das Gleiche gilt von der Vermehrung im ruhenden Zustande. In diesem Falle nimmt das Infusor meist Kugelgestalt an und scheidet eine Cystenhaut aus, innerhalb deren dann eine Zwei- oder Vielteilung sich abspielt. Die Zeitdauer, die ein Teilungsprozess in Anspruch nimmt, ist je nach den Arten verschieden. So spielt sich bei Vorticella microstoma die Teilung in etwa $1 / 2$ Stunde $a b$, während sie bei Stylonichia mytilus bis zwei Stunden währen kann. Von grossem Einfluss auf die Geschwindigkeit der Vermehrung ist die Temperatur.

Knospung ist nur bei einigen Peritrichen beobachtet. Charakteristisch ist, dass die beiden auf diesem Wege erzeugten 'Tochter-Individuen beträchtliche Grössendifferenzen aufweisen.

Hat längere Zeit hindurch ungeschlechtliche Fortpflanzung stattgefunden, so macht sich allmählich ein "Sinken der Lebensenergie" bemerklich, und es bedarf zu ihrer Auffrischung eines Geschlechts-Aktes. In einigen wenigen Fällen besteht dieser in ciner vollkommenen Verschmelzung zweier Individuen. Einige Stylonicliza-Arten zeigen diese Verhältnisse. Bei der Mehrzahl der Ciliaten tritt eine nur vorübergehende Kopulation zweier Individuen ein, die von dem Austausch gewisser Kernteile begleitet ist. Beide Individuen legen sich gewöhnlich mit den Mundöffnungen gegen einander, so dass ihre Plasma-Massen miteinander kommunizieren. Die Makronuklei verschwinden hierauf, während sich die Mikronuklei in jedem Individuum erst in zwei, dann in vier Teile spalten. Von den so entstandenen vier Mikronuklei jeder Zelle verschwinden drei, und der vierte, übrigbleibende zerfällt abermals in zwei Teilstücke. Das eine 
der letzteren nennt man ruhenden oder stationären Kern, das andere wandernden oder migratorischen Kern. Der Wanderkern einer jeden der beiden kopulierenden Zellen wandert hierauf durch die zwischen den letzteren bestehende Plasma-Verbindung hinüber in den Körper seines Partners und verbindet sich mit dem dort befindlichen Ruhekerne. Damit ist der Geschlechts-Akt vollzogen und die Kopulation wird aufgehoben. In den meisten Fällen sind die kopulierenden Individuen von gleicher Grösse, nur bei den Vorticellinen sind Makrogonidien und Mikrogonidien ausgebildet, die miteinander in dauernde Verschmelzung (Konjugation) eingehen. Die Mikrogonidien werden entweder durch Knospung oder durch rasch auf einander folgende Teilungen erzeugt.

Von besonderem Werte wird die geschlechtliche Vermehrung der Ciliaten durch den Vergleich mit den analogen Verhältnissen der Metazoen. In beiden Fällen tritt mit der Zeit eine Erschöpfung der Lebens-Energie ein: bei den Wimperinfusorien geht die Fähigkeit kräftige Nachkommen durch einfache Querteilung zu erzeugen verloren; bei den vielzelligen Tieren führt Senilismus mit Notwendigkeit den Tod herbei. In beiden Fällen ist zur Erzeugung frischer Lebens-Energie ein Geschlechts-Akt erforderlich. Der Unterschied besteht nur darin, dass bei den Ciliaten die nach dem Geschlechts-Akt erzeugten Tochterzellen keinen Zusammenhang haben, also solitär leben, während sie bei den Metazoen als Zellenstaat verbunden bleiben.

Ruhezustände sind bei zahlreichen Wimper-Infusorien aufgefunden worden. Namentlich beim Eintritt ungünstiger Lebensbedingungen runden sich die Tierc zur Kugel ab und umgeben sich mit einer starken Cystenwand, unter der sie ohne Gefahr ganz trocken liegen können. Auf dem Objektträger oder im Uhrschälchen kann man diesen Vorgang mitunter leicht verfolgen. Die Ruhezustände sind für die Verbreitung der Ciliaten von grosser Wichtigkeit, da derartige Dauercysten vom Winde oder an den Füssen der Wasservögel hängend leicht von Ort $\mathrm{zu}$ Ort getragen werden.

Gegen äussere Verletzung, die beim Ueberführen auf den Objektträger oft unabsichtlich vorkommt, verhalten sich die verschiedenen Arten sehr ungleich. Manche zerfliessen sofort bei der geringsten Verletzung; einige werden sogar durch ihr eigenes Wimperspiel zerrissen, wenn der Körper an die Grenze des Wassertropfens gelangt und der Aussenfläche adhäriert 
(Tintinnus); andere dagegen resorbieren grosse Plasma-Tropfen, die bei Verwundungen ausgetreten sind, und ergänzen abgerissene Stücke. Solche losgelöste Partien bleiben oft noch längere Zeit erkennbar. So sieht man häufig abgerissene Peristomfelder von Stylonichien, die durch die adoralen Wimpern im Kreise herum gewirbelt werden.

Die folgenden Bestimmungs-Tabellen sind, was die Charakteristik der Hauptabteilungen und Gattungen angeht, in Anlehnung an Bütschli gegeben.

I. Mund nur bei der Nahrungs-Aufnahme geöffnet, ohne undulierende Membranen; Schlund nie mit Wimpergebilden. Dic Nahrung wird stets verschlungen [A. Gymnostomata] . . 2

2. Mund terminal gelegen oder nur sehr wenig nach hinten verschoben, meist rundlich . . . 1. Enchelina (S. 349)

2*. Mund nicht terminal oder von Vorderende bis weit nach hinten sich erstreckend . . . . . . . . . . . . 3

3. Mund meist spaltenförmig über die Bauchseite nach hinten ziehend; Schlund meist fehlend; wenn vorhanden, kurz und nur mit zartem Stäbchenapparat

\section{Trachelina (S. 356)}

3*. Mund weit hinten gelegen; Schlund mit deutlichem Stäbchenapparat. Tiere selten mit Schlundröhre . . .

3. Chlamydodonta (S. 359)

I*. Mund meist geöffnet. Mundränder mit undulierenden Membranen; oder Schlund mit undulierenden Membranen oder mit Cilien versehen. Die Nahrung wird durch Einstrudelung aufgenommen [B. Trichostomata] . . . . . . . . . 4

4. Mundrand oder Schlund mit einer oder zwei undulierenden Membranen, ohne adorale Zone . [I. Aspirotricha (S. 363)

$4^{*}$. Mund mit deutlicher adoraler Zone von meist spiraligem Verlaufe, so dass ein Peristomfeld gebildet wird [II. Spirotricha]

5. Körper mit deutlich unterschiedener Rücken- und Bauchseite. Nur auf letzterer die zur Bewegung dienenden Cilien . . . . . . . . 3. Hypotricha

5*. Körper nicht ausgesprochen dorso-ventral abgeplattet. Die zur Bewegung dienenden Cilien nicht auf die Bauchseite beschränkt. . . . . . . . . . . . 6

6. Cịlienkleid vollständig bis mehr oder weniger reduciert 7 
7. Cilienkleid des Körpers gleichmässig, allseitig; wenn reduciert, ein mächtiger, breit beginnender Schwanzanhang. . . . . . . . r. Heterotricha

$7 *$. Cilienkleid ziemlich stark reduciert; kein Schwanzanhang vorhanden . . . 2. Oligotricha

6*. Abgesehen von der adoralen Zone höchstens noch ein einziger, mit dieser in Verbindung stehender Wimpernkranz. Meist festsitzend . . . 4. Peritricha

\section{A. Gymnostomata.}

Die Nahrungskörper werden nie eingestrudelt, sondern stets verschlungen; Bewimperung meist holotrich, nicht selten jedoch auch stark reduciert.

\section{Fam. Enchelina.}

Schlund nicht immer deutlich; meist als gerade, stets unbewimperte Röhre entwickelt.

I. Bewimperung fast gleichmässig, allseitig; Körper ohne Panzer 2 2. Körper nur mit Cilien versehen; ohne Tentakel . . . 3 3. Körper eiförmig oder flaschenförmig; nie aber hinter einem Mundkegel mit einem Kranze längerer Cilien . 4 4. Körper hinten mit langer Springborste . . . . . . 2. Urotricha (S. 35 I)

4*. Körper ohne Springborste . . . . . . . . 5

5. Schlund mehr oder weniger deutlich, höchstens mit ganz schwachem Stäbchenapparat. Körper nie vorne halsartig verjüngt . . . . . 1. Holophrya (S. 350)

$5^{*}$. Schlund verschieden; stets deutlich, mit starken Stäbchen oder mit Längsstreifen, wenn der Körper nicht halsartig ausgezogen ist . . . . . 6

6. Vorderende halsartig ausgezogen . . . . . 7

7. Vorderende nicht seitlich abgeplattet, stark verjüngt . . . . . . . 3. Enchelys (S. 351)

7*. Vorderende seitlich abgeplattet, nach der Bauchseite schief abgestutzt, weniger stark verjüngt .

4. Spathidium (S. 352) 
6*. Vorderende nicht halsartig ausgezogen

$$
\text { 5. Prorodon (S. 352) }
$$

3*. Körper vorn mit Mundkegel, hinter dem Munde mit einem Kranze längerer Wimpern . . . . . . . 8

8. Körper hinten zugespitzt, vorn stumpf kegelig . . .

6. Dinophrya (S. 353)

8*. Körper flaschenförmig, vorn halsartig ausgezogen . .

7. Lacrymaria (S. 354)

2*. Neben den Cilien auch Tentakel 8. Actinolobus (S. 355)

I*. Bewimperung ungleichmässig, oder der Körper gepanzert 9

9. Körper bepanzert . . . . . 9. Coleps (S. 355)

9*. Körper ohne Panzer . . . . . . . . . . . . . . 10

Iо. Körper nur mit Ciliengürteln . . . . . . . . . II

II. Mundkegel nur wenig entwickelt

10. Didinium (S. 355)

II*. Mundkegel ansehnlich . I I. Mesodinium (S. 356)

I0*. Körper mit Membranellen. I2. Askenasia (S. 356)

\section{Holophryina.}

\section{Holophrya Ehrbg.}

Körper ellipsoidisch bis cylindrisch, hinten etwas zugespitzt biegsam. Kontraktile Vakuole am Hinterende. Cilien zart, in der Nähe des Mundes zuweilen etwas länger.

I. Mit einer grossen kontraktilen Vakuole, höchstens mit noch einigen kleinen in ihrer Nähe, die aber nicht in Längsireihen angeordnet sind. . . . . . . . . . . . . . . . . 2

2. Mit Trichocysten. . . . . . . I. H. nigricans

2*. Ohne Trichocysten . . . . . . . 2. H. discolor

I*. Mit zahlreichen kontraktilen Vakuolen . . . . . . . 3

3. Mund terminal gelegen. Makronukleus lang bandförmig 3. H. coleps

$3^{*}$. Mund unterhalb des Körperpoles gelegen. Makronukleus ellipsoidisch . . . . . . . 4. H. lieberkïhni

I. HI. nigricans Lauterb.

Körperform etwa kugelig. Schlund längsstreifig. Länge $110-180 \mu$. In stehendem Wasser. 
2. H. discolor Ehrbg. (Taf. XII, I)

Gestalt meist länglich oval. Mundöffnung polar. Länge 95-130 $\mu$. Nicht häufig, in frischem Wasser.

3. H. coleps (Ehrbg.)

Körperform lang eiförmig. Kern gekrümmt. Ausser einer endständigen pulsierenden Vakuole noch eine Reihe kontraktiler Blasen an dem einen Längsrande. Länge bis $450 \mu$. Vorkommen wie bei voriger Art.

4. H. lieberkühni Btschli.

Körper plump eiförmig. Ausser einer endständigen pulsierenden Vakuole noch zwei Längsreihen derartiger Organe. Länge bis $160 \mu$.

Das hier sich einreihende Genus Ichthyophthirius Fouquet lebt parasitisch auf der Haut von Süsswasserfischen und verursacht namentlich unter den jugendlichen Individuen eine tötliche Krankheit.

\section{Urotricha Cl. u. L.}

Mund sehr erweiterungsfähig. Schlund lang, fein. Kontraktile Vakuole an dem zum Teil unbewimperten Hinterende. Körper grob spiral gestreift. Hinterende mit langen Tastborsten.

I. Cilien am Munde nicht verkürzt . . . I. U. farcta I*. Cilien am Munde verkürzt. . . . . 2. U. globosa

I. U. farcta (Ehrbg.) Cl. u. L.

Länge etwa $40 \mu$. Bewegung abwechselnd langsam kreiselnd und springend. Zwischen Algen, häufig.

2. U. globosa Schewiakoff (Taf. XII, 2)

Körper eiförmig, am Hinterende mit langer Tastborste. Cilien lang, am Munde kürzer und feiner. Makronukleus kugelig. Bewegung schnell, häufig die Richtung ändernd. Länge 15-17 $\mu$, Breite $13-$ I $5 \mu$.

\section{Enchelys Ehrbg.}

Cilien kurz, fein; Körper länglich oder eiförmig, hinten gerundet. Mund-Ende schräg abgestutzt. Mund grubenförmig oder von einer sphinkter-artigen Lippe umgeben. 
I. Kontraktile Vakuolen zahlreich. . . . I. E. arcuata I*. Kontraktile Vakuole in der Einzahl . . 2. E. farcimen

I. E. arcuata Cl. u. L. (Taf. XII, 3)

Vakuolen in einem Bogen entlang dem Körperrande angeordnet; Kern länglich. Länge etwa $80 \mu$.

2. E. farcimen Ehrbg.

Kern oval. Körper am Vorderende etwas verbreitert. Länge $30-60 \mu$. In stagnierendem Wasser.

\section{Spathidium Duj.}

Körper etwa beutelförmig, flexil. Die Abstutzung des Vorderendes wird vielfach ganz von der spaltförmigen Mundöffnung eingenommen. Die Mundränder sind wulstig verdickt

1. Vorderende verjüngt; Kern etwa wurstförmig

\section{Sp. spathula}

I*. Vorderende nicht verjüngt; Kern kugelig 2. Sp. lieberkühni

I. Sp.spathula (O. F. Muell.) (Taf. XII, 4)

Mund nicht die ganze Abstutzung des Vorderendes einnehmend. Grosse kontraktile Vakuole am hinteren Körperpole. Länge $180-240 \mu$. In stagnierendem Wasser.

2. Sp. lieberkühni Btschli.

Körper sackförmig. Kleiner als vorige Art.

\section{Prorodon Ehrbg.}

Körper eiförmig, an den Polen gleichmässig abgerundet. Die Tiere bewegen sich sehr rasch, rastlos um die Längsachse drehend und kreiselnd, zuweilen sich überschlagend. Cilien in der Nähe des Mundes dichter.

I. Makronukleus lang, bandförmig, gekrümmt . . . . . . 2

2. Vorderende schief abgestutzt . . . I. P. niveus

2*. Vorderende nicht schief abgestutzt. 2. P. farctus I*. Makronukleus rundlich bis ovoïd . . . . . . . . . . 3

3. Mit Trichocysten versehen . . . . . . . . . . . 4

4. Mund deutlich unterhalb des Körperendes gelegen; Körperform nahezu kugelig. - 3. P. armatus 
4*. Mund entweder genau oder nahezu terminal. Körperform cylindrisch . . . . 4. P.griseus

3*. Ohne Trichocysten . . . . . . . . . . . . . 5

5. Schlund mit zartem Stäbchenapparat [vgl. auch Holophrya discolor (S. 351)] . . 5. P. teres

5*. Schlund ohne Stäbchenapparat.6. P. edentatus

1. P. niveus Ehrbg. (= Pseudoprorodon niv. Blochm.)

Vorderende schief abgestutzt, an ihm der Mund. Kern lang, gekrümmt. Länge $330-420 \mu$. Zwischen Algen.

2. P. farctus (Cl. u. L.) (= Enchelyodon f. Cl. u. L.)

Körper lang, cylindrisch, ansehnlich. Am Hinterende mit einer grossen und mehreren kleinen kontraktilen Vakuolen.

3. P. armatus $\mathrm{Cl}$. u. L.

Kern etwa oval. Vorderende des Körpers mit Trichocysten. Länge etwa 1оo $\mu$. In Sumpfwasser.

4. P. griseus Cl. u. L.

Körper cylindrisch, mit Längsstreifen versehen. Kern oval, zweiteilig. Länge etwa $100 \mu$. In stagnierendem Wasser.

5. P.teres Ehrbg. (Taf. XII, 5)

Körperform sehr verschieden. Stäbchenapparat zart. I.änge bis $166 \mu$. In stagnierendem Torfwasser.

6. P. edentatus Cl. u. L.

Körper langgestreckt, mit Längsstreifung versehen. Schlund ohne Stäbchenapparat. Kern länglich oval. Länge $100-150 \mu$. Gemein.

\section{Dinophrya Btschli.}

Körper etwa cylindrisch, hinten stachelartig ausgezogen. Mundkegel unbewimpert, auf seiner Spitze die kleine Mundöffnung. Schlund zart, mit feinen Stäbchen. Cilien an der Basis des Mundkegels ansehnlich. Kern eiförmig. Kontraktile Vakuole am Hinterende.

D. lieberkühni Btschli. (Taf. XII, 6)

Mit den Charakteren der Gattung. Länge etwa ıо $\mu$. 


\section{Lacrymaria Ehrbg.}

Gestalt flaschenförmig, kontraktil; Schlund mit feinem Reusenapparat.

I. Körper stark bandförmig abgeplattet (Trachelophyllıım Cl.u.L.) 2

2. Hals lang und dünn . . . . . . I. L. apiculata

2*. Hals kurz . . . . . . . . . . 2. L. pusilla

I*. Körper nicht bandförmig abgeplattet . . . . . . . . 3

3. Vorderende ohne Mundzapfen . . 3. L. elegans

3*. Vorderende mit Mundzapfen (Lacrymaria s. str. Ehrbg.) 4 4. Drei Vakuolen . . . . . . 4. L. olor

4*. Eine Vakuole am Hinterende . . . . . . . 5

5. Hals kurz, dick. . . . 5. L. vermicularis

5*. Hals kurz, schlank. . . 6. L. coronata

1. L. apiculata (Cl. u. L.) (= Trachelophyllum ap. Py.)

Körper abgeplattet. Schlund lang, geradlinig, als dunkle Linie sichtbar. Mund sehr erweiterungsfähig. Aspidisa lynceus wird vollständig verschlungen, Stylonychia pustulata ausgesogen. Länge ${ }_{5} 50 \mu$. In stagnierendem Wasser. Bewegung meist nicht schnellend und nicht drehend.

Eine durch stärker entwickelten Trichiten-Apparat und durch ihre Länge (bis $370 \mu$ ) ausgezeichnete Form L. lamella (O. F. Mül1.) führt Blochmann wiederum als besondere Spezies.

2. L. pusilla Cl. u. L. (= Trachelophyllum pus.)

Körperform voriger Art ähnlich, aber kleiner. Länge etwa $40 \mu$.

\section{L. elegans Engelm. [= Lagynus elegans (Engelm.)]}

Körper metabolisch, mit Längsstreifen versehen, schnellend, in ausgestrecktem Zustande spindelförmig; hinten spitz, vorn mit sehr langem, vollständig retraktilem, beständig in zierlichen Kurven sich schlängelndem Halse. Beim Zusammenschnellen wird der Körper fast kugelig. Die erhabenen Streifen der Oberfläche treten dann sehr stark hervor. Länge $170 \mu$.

\section{L. olor Ehrbg. (Taf. XII, 7)}

Voriger Art ähnlich. Die Tiere schwimmen mit vorgestrecktem Halse bald vor- bald rückwärts. Länge ohne Hals bis $200 \mu$. In klarem Wasser, zwischen Algen. 
5. L. vermicularis (Ehrbg.) (= Phialina verm. Ehrbg.)

Körper zuweilen durch Zoochlorellen grün. Länge etwa 120 $\mu$. Bewegung stürmisch kreiselnd. Zwischen Algen.

6. L. coronata C1. u. L. var. aquae dulcis Roux

Hals mit mehreren Cilienkränzen. Körper mit grauen oder schwarzen Körnchen erfüllt. Kontraktile Vakuole am Hinterende, manchmal mit zwei Zuführungskanälen. Schlund kurz, röhrenförmig, unbewaffnet. Makronukleus gekrümmt bandförmig. Länge $70-90 \mu$. Am Boden stehender Gewässer; die typische Form im Meere.

\section{Actinobolina.}

Neben den Cilien sind tentakelartige, retraktile Gebilde vorhanden. Bewimperung wie bei voriger Unterfamilie.

\section{Actinobolus St.}

Körper ähnlich Holophrya. Schlund trichterförmig, längsstreifig(?). Die zurückziehbaren Tentakel dienen auch zum Festheften. Kontraktile Vakuole in der Einzahl, am Hinterende.

A. radians St. (Taf. XII, 8)

Kern wurstförmig; Cilien lang. Tentakel etwa von Körperlänge. Mund zitzenförmig vorspringend. Bewegung schnell rotierend.

\section{Colepina.}

\section{Coleps Ehrbg.}

Körper tonnenförmig, Vorderende breit abgestutzt, ganz von der Mundöffnung eingenommen; Panzer aus zahlreichen nicht verwachsenen Stücken bestehend; Schlund weit trichterförmig und längsgestreift. Nicht selten mit Zoochlorellen versehen.

C. hirtus Ehrbg. (Taf. XII, 9)

Oft fast schwarz erscheinend im mikroskopischen Bilde. Bewegung wankend. Ueberall gemein, wo organischer Detritus vorhanden.

Die seltenere Form $C$. amphacanthus Ehrbg. ist gegen das Hinterende stark erweitert.

\section{Cyclodinina.}

ro. Didinium St.

Gestalt ovoid, vorn flach oder etwas vertieft. Aus der Mitte des Vorderendes tritt ein konischer Rüssel hervor, an dessen 
Spitze die sehr erweiterungsfähige Mundöffnung liegt. Schlund mit feinen Stäbchen versehen. Einen oder zwei Ciliengürtel. Makronukleus hufeisenförmig.

D. nasutum St.

Mit zwei Ciliengürteln. Verschlingt grosse Infusorien; Bewegung kreiselnd, stürmisch, wie schwärmende Vorticellen. Länge etwa $180 \mu$. An der staubigen Oberfläche des Wassers, auch in Mistpfützen.

Das seltene D. balbianii Btschli. (Taf. XII, Io) hat nur einen Ciliengürtel.

Die Gattung

II. Mesodinium St.,

die durch ein konisches, an der Spitze den Mund, an der Basis zahlreiche starke Cilien tragendes Vorderende ausgezeichnet ist, ist in der Spezies M. acaries St. (Taf. XII, I I) verbreitet.

12. Askenasia Blochm.

Mundöffnung am Vorderpole. An der Basis des Mundkegels zahlreiche (etwa 6o) Gruppen feiner, langer Cilien; dahinter befinden sich Membranellen ron etwa dreieckiger Gestalt, zwischen denen lange, feine Borsten stehen.

A. elegans Blochm. (Taf. XII, I2)

Körper dick eiförmig, nach vorn konisch verjüngt. Kontraktile Vakuole nahezu central. Makronukleus ellipsoidisch, Mikronukleus anliegend. Länge bis $50 \mu$. Selten.

\section{Fam. Trachelina.}

Körper deutlich bilateral oder asymmetrisch; nur selten drehrund; meist stark seitlich komprimiert. Das vor dem Munde resp. um ihn gelegene Körperstück vielfach rüsselartig verengt.

I. Mund an der konvexen Bauchkante des Rüssels gelegen 2

2. Mundspalt die ganze Rüsselkante einnehmend . . . 3

3. Rüssel ziemlich oder bedeutend entwickelt; Körper selten ganz abgeplattet, nie von hyalinem Saume umzogen . . . . . . . . . . . . . . . 4 
4. Meist das Vorderende des Körpers abgeplattet; Rüssel mässig lang . I. Amphileptus (S. 357)

$4^{*}$. Die rechte Seite stark abgeplattet, die linke stark gewölbt. Erstereallein mit Cilien versehen. Rüssel stark entwickelt. . . 2. Lionotus (S. 357)

$3^{*}$. Rüssel nur wenig entwickelt; Körper meist ganz abgeplattet, von einem hyalinen Saume umgeben .

3. Loxophyllum (S. 358)

2*. Mund an der Basis des Rüssels. . . . . . . . 5

5. Entoplasma baumartig verästelt . . . . . . .

4. Trachelius (S. 358)

5*. Entoplasma nicht so; Hals sehr lang.

5. Dileptus (S. 359)

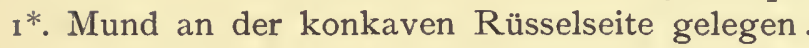

6. Loxodes (S. 359)

\section{Amphileptus Cl. u. L.}

Kontraktil. Rüsselteil längs der Bauchkante schief abgeschrägt. Streifung allseitig und regulär. Kern zwei- oder viergliedrig. Bewegung hin und her schleichend.

1. Körper lanzettlich, über $150 \mu$ lang . . 1. A carchesï

I*. Körper lanzettlich-eiförmig, kleiner . . 2. A. claparedei

I. A. carchesii St. (Taf. XII, I3)

Körper schmal, hinten zugespitzt, abgeplattet. Wimpern gleichmässig in Längsreihen verteilt. Trichocysten vorhanden am Körper und an der Spitze des beweglichen Rüssels. Länge bis $160 \mu$. In klarem Wasser.

2. A. claparedei St.

Kleiner als vorige Art, Körper weniger schlank. In fauligem Wasser.

\section{Lionotus Wrzesn.}

Körper sehr ähnlich Amphileptus; Rüssel meist sehr lang, selbst länger als der Körper. Trichocysten gewöhnlich vorhanden. Bewegung gleitend.

I. Nur eine kontraktile Vakuole, und zwar am Hinterende. .

I. L. anser

I*. Zahlreiche, unregelmässig verstreute pulsierende Vakuolen . 
I. L. anser (O. F. Müll.) (= Lionotus folium Wrzesn.)

Körper eiförmig. Hals gleich ${ }^{1} / 2$ der Gesamtlänge des Körpers. Kern doppelt. Länge etwa $200 \mu$. Zwischen Schilfblättern. Häufig.

2. L. vesiculosus Stokes (Taf. XII, I4)

Körper sehr kontraktil, in unkontrahiertem Zustande etwa $20 \mathrm{Mal}$ so lang als breit (Länge $580 \mu$, Breite $30 \mu$ ), linealisch. Rüssel sehr lang. In der Umgebung des Mundes starke Wimpern. Mit Trichocysten. Bis 20 Vakuolen. Länge in kontrahiertem Zustande $300 \mu$, Breite $45 \mu$. In klarem Wasser.

\section{Loxophyllum Duj.}

Kontraktil und biegsam. An der ganzen Bauchkante Trichocysten. Bewegung gleitend. Mund wie bei Amphileptus.

I. Kern strang-oder perlschnur-artig . . 1. L. meleagris

I*. Kern zweigliedrig . . . . . . . . . . . . . . . . 2

2. Länge bis $200 \mu$; Körper nnd Hals lang gestreckt. Vorderende länger, Hinterende kürzer zugespitzt

\section{L. fasciola}

$2^{*}$. Länge höchstens $80 \mu$; Hinterende etwas abgerundet, Vorderende mit stumpfer Spitze. . 3. L. lamella

I. L. meleagris (O. F. Muell.) Duj.

Körper mit hyalinem Saume. An der Bauchkante und auf dem Rücken mit Trichocysten. Kern strang- oder perschnurförmig. Kontraktile Vakuole mit einem längs des Rückens nach vorne ziehendem Kanale. Länge bis $370 \mu$. Verschlingt kleine Rotatorien, wie Colurus. In stagnierenden Gewässern.

2. L. fasciola (Ehrbg.) Cl. u. L.

(Taf. XII, 15)

Körper und Hals langgestreckt. Hinterende spitz. Länge bis $200 \mu$. Bewegung langsam, abwechselnd vor- und rückwärts schwimmend.

3. L. lamella $\mathrm{Cl}$. und $\mathrm{L}$.

Körper linearisch. Länge bis $80 \mu$. Gemein.

\section{Trachelius $\mathrm{Cl}$. und $\mathrm{L}$.}

Körper ellipsoid. Bewimperung allseitig gleichmässig. In der Mitte des Körpers eine trichterförmige Grube. Zahlreiche kontraktile Vakuolen. Mund von sphinkter-artigem Saume umgeben. Oft mit vertiefter Grube in der Körpermitte. 
T. ovum Ehrbg. (= Enchelys pupa O. F. Müll.?) (Taf. XII, 16)

Länge bis $330 \mu$. Schwimmt oft rückwärts. In stagnierendem Wasser, nicht häufig.

\section{Dileptus Duj.}

Hals lang, sehr beweglich. Bewimperung allseitig fein. Trichocysten an der ventralen Rüsselkante. Hinterende zugespitzt.

D. gigas Wrzesn. $(=D$. anser O. F. Müll. = Amphileptus gig.

Cl. und L.) (Taf. XII, I 7)

Körper langgestreckt, bräunlich-gelb, hinten dünn, schwanzartig ausgezogen; Hals mehr oder weniger lang, stark komprimiert. Das Verhältnis zwischen Halslänge und Totallänge ist sehr schwankend. Wimpern des Körpers kurz, dünn. An der Bauchkante stärkere adorale Wimpern. Mund an der Basis des Halses, von einem wimperlosen Wulste umgeben. Schlund trichterförmig, längsstreifig. After rückenständig, an der Basis des Schwanzes. Länge $600 \mu-1,5 \mathrm{~mm}$. Sehr gefrässige Spezies, verschlingt grosse Rotatorien.

\section{Loxodes Cl. u. L.}

Biegsam. Das schnabelartige Vorderende kontraktil. Hinterende etwas zugespitzt. Rechte Seite flach, linke mässig gewölbt; erstere deutlich längsgestreift und bewimpert, letztere nackt und glatt. An der ventralen Schnabelkante ist eine schmale Rinne, die an der Schnabelbasis in den Mund übergeht. Am Rückenrande eine Längsreihe von Vakuolen mit stark lichtbrechenden Körperchen.

L. rostrum Ehrbg. (= Pelicida rostrata Duj.) (Taf. XII, I8)

Mundfläche und Schlund braun. Mund und Peristom liegen vollkommen auf der bewimperten Seite, linker Peristomrand dem linken Körperrande sehr nahe. Länge $450-580 \mu$. In stagnierendem Wasser. Bewegung gleitend oder kletternd.

\section{Fam. Chlamydodonta.}

Körper oval bis nierenförmig, nie sehr langgestreckt.

I. Körper drehrund, allseitig bewimpert I. Nassula (S. 360) 
I*. Körper meist stark abgeplattet; Bewimperung entweder auf die Bauchseite beschränkt, oder wenigstens auf ihr viel stärker . . . . . . . . . . . . . . 2

2. Hinterende ohne beweglichen Schwanzgriffel . . . 3

3. Mund median in der vorderen Körperhälfte . . 4

4. Körper fast drehrund. Bauchfläche vorn breit und abgerundet, senkrecht mit der stark gewölbten Rückenfläche zusammentreffend. Erstere nach hinten sich verjüngend und in eine Schwanzspitze auslaufend . . . 4. Phascolodon (S. 362)

4*. Körper abgeplattet. Vorderende schnabelartig zugespitzt und nach links umgebogen. Hinterende meist breit abgerundet .

\section{Chilodon (S. 361)}

$3^{*}$. Mund median im hinteren Körperviertel .

3. Opisthodon (S. 362)

$2^{*}$. Hinterende mit beweglichem Schwanzgriffel . . . 5

5. Schlundröhre ohne Stäbchen . . . . . . 6

6. Bauchfläche auf ein schmales, nach links gekrümmtes Band reduziert; dieses gleichmässig bewimpert . . . . . 5. Trochilia (S. 362)

6*. Gestalt der Bauchfläche ebenso, aber nur am Aussenrande der Bauchseite eine Wimperzone.

6. Ervilia (S. 363)

5*. Schlundröhre mit Stäbchen . 7. Dysteropsis (S. 363)

\section{Nassula Ehrbg.}

Körper biegsam und kontraktil. Mundöffnung auf der Bauchseite. Vom Munde aus zieht eine Reihe stärkerer Cirren durch eine linkseitig gelegene Einbuchtung des Körpers bis auf den Rücken.

I. Mit Trichocysten . . . . . . . . . . . . . . . . 2

2. Schlund fischreusenförmig. Ansehnliche Form

2*. Schlund keulenförmig. Kleine Form

$$
\text { I. N. ornata }
$$

\section{2. $N$. lateritia}

1*. Ohne Trichocysten (vgl. auch $N$. ornata oben) . . . . . 3 3. Schlund reusenförmig. Körper länglich . 
3*. Schlundstäbchen nur undeutlich. Körper kurz, walzenförmig. . . . . . . . 4. N. ambigua

I. N.ornata Ehrbg. $(=N$. aurea Ehrbg. ? = Acidophorus orn. St.)

Körper kurz, geđrungen. Farbe gelblich, weiss, mit violettem Flecke. Die Trichocysten sind, wenn vorhanden, links neben dem Munde gelegen. Reusen-Apparat mit zwei protoplasmatischen Ringen. Länge etwa $200-240 \mu$. In Gräben und Teichen, einzeln.

2. N. lateritia Cl. u. L.

Körper eiförmig; vor dem Munde mit einem Ausschnitte versehen. Farbe häufig blass-rot. Länge etwa $50 \mu$. Zwischen Algen.

3. N. elegans Ehrbg. (Taf. XII, I9)

Körper langgestreckt. Länge bis $160 \mu$. Reusen-Apparat einfach. Schwimmt vor- und rückwärts, um die Längsachse drehend. Nährt sich wie auch $N$. ornata besonders gern von Oscillatorien, deren blauer Farbstoff in Vakuolen durch die Nassula verteilt dieser eine blaue oder violette Färbung verleiht. Zwischen Algen und Lemnen.

4. N. ambigua C1. u. L. (= Liosiphon amb. St.)

Körper kurz, fast cylindrisch.

\section{Chilodon Ehrbg.}

Schnabel schief abgestutzt und etwas nach links gekrümmt, beständig umhertastend. Bauch fein längsgestreift. Von der vorspringenden linken Ecke des Schnabels läuft zum Rande des Mundes ein bogig gekrümmter Wimperstreifen, der bei kleinen Individuen wie eine gebogene Borste aussieht. Schlund fischreusenartig, mit feinen Stäbchen. Vakuolen sehr wechselnd. Kern oval.

I. Schlundapparat spiralig gekrümmt . I. Ch. uncinatus I*. Schlundapparat nicht spiralig . . . 2. Ch. cuculhulus

1. Ch. uncinatus Ehrbg. (=Ch. dentatus From.)

Makronukleus körnig, einer Himbeere ähnlich. Tiere bei der Untersuchung meist schon tot, weil den kleinsten Aenderungen des Wassers erliegend. Zwei Vakuolen: eine vorne, die andere hinten. In stehendem Wasser, häufig. 
2. Ch. cuculhulus Ehrbg. (= Loxodes cuc. Duj.) (Taf. XII, 20)

Länge $20-190 \mu$. Gross zwischen Algen und Oscillarien, klein in Infusionen. Bewegung langsam, gleitend, selten um die Längs-Achse drehend. [Die abgebildete Form, desgleichen diejenige Steins, ist nach Blochmann eine besondere Art $(C h$. steini Blochm.) und unterscheidet sich von Ch. cucullulus unter anderm durch die Anwesenheit von kontraktilen Vakuolen auch im hyalinen Schnabel; Länge bis $320 \mu$.] Verschlingt besonders Bacillarien. In Infusionen, Pfützen, sowie in stehenden und fliessenden Gewässern; sehr gemein.

\section{Opisthodon St.}

Körper oval. Vorderende allmählich zugespitzt, mit krempenartig aufgebogenem Rande; Hinterende breit abgerundet. Stäbchenapparat schwach, jedoch deutlich.

O. niemeccensis St. (Taf. XII, 21)

Körper starr, nur an den Rändern biegsam; Plasma stets mehr oder weniger getrübt oder rotbraun gefärbt. Kontraktile Vakuole gross, central gelegen. Länge $60-100 \mu$. Schwimmt häufig mit dem Hinterende voran. Im Bodensatze torfiger Gewässer.

\section{Phascolodon St.}

Bauchfläche längsgestreift. Zwei ventrale, kontraktile Vakuolen. Rasch schwimmend, um die Längsachse rotierend. Mund vorn in der Bauchfläche. Schlund trichterförmig, fischreusenartig, nach rechts gekehrt.

Ph. vorticella St. (Taf. XII, 22)

Kern oval, in der Mitte des Körpers. Länge $60-80 \mu$. An der staubigen Oberfläche des Wassers, mit kleinen Algen.

\section{Trochilia (Duj.) St.}

Körper gepanzert, eiförmig. Schlundröhre glatt, nicht mit Stäbchen versehen.

Tr. palustris St. (Taf. XII, 23)

Die mittlere bewimperte Längszone der Bauchfläche trägt vorn und hinten je eine mächtige Borste; die hintere ist gekrümmt. Zwei Vakuolen. Länge $20-30 \mu$. Einzeln, in Sumpfwasser. 


\section{Ervilia Duj. (= Dysteria St.)}

Körper von der Form eines Kümmelkornes, gepanzert. Schlund glatt, ohne Stäbchen-Apparat.

\section{E. fluviatilis (St.) (Taf. XII, 24)}

Körper nach vorn und nach hinten verengert; am Vorderende schief abgestutzt, auf der Rückseite fünf feine Längskiele. Länge $25 \mu$. In Flüssen und Bächen, nicht selten.

\section{Dysteropsis Roux.}

Körper eiförmig; Bauchseite in der Mitte eben. Mund am vorderen Körperteile. Schlund lang, konisch; Stäbchen breit, in geringer Anzahl. Cilien nur auf der rechten Vorderhälfte der Bauchseite, auf fünf gekrümmte Parallelreihen verteilt. Bewegung schnell, auf der Bauchseite gleitend. Nahrung: vegetabilische Reste.

D. minuta Roux (Taf. XII, 25)

Länge $28 \mu$, Breite $16 \mu$. Körper durchscheinend. Zwvei Vakuolen. In klarem Wasser, an Wasserpflanzen (Potamogeton, Typha), mit Chilodon und Cinetochilum.

\section{B. Trichostomata.}

Die Nahrung wird durch Einstrudelung aufgenommen oder durch besondere Wimpergebilde zum Munde geleitet.

\section{Aspirotricha.}

Gestalt meist asymmetrisch. Ein Stäbchenapparat ist nie im Schlunde entwickelt. An den Rändern der Mundöffnung oder im Schlunde befinden sich $\mathrm{I}-2$ undulierende Membranen. Die Nahrung wird durch Einstrudelung aufgenommen.

I. Mund vorhanden

2. Mund ohne deutliches Peristomfeld

$$
\text { 1. Chilifera (S. 364) }
$$

$2^{*}$. Mund mit Peristomgrube oder Peristomrinne. . . . 3

3. Bewimperung allseitig oder auf die Mundseite beschränkt . . . . . . . . . . 4 
4. Körper stark unsymmetrisch. Mund stets am Hinterende, mit hinten beginnender Peristomrinne . . . . . 2. Microthoracina (S. 369)

4*. Körper nicht stark unsymmetrisch. Peristom breit oder rinnenförmig; im letzteren Falle vorn beginnend . . . . . . . . . . . . . . 5

5. Schlund deutlich, röhrenförmig, lang, mit undulierender Membran oder Cilienreihe. .

3. Paramaecina (S. 37 I)

$5^{*}$. Schlund undeutlich oder fehlend.

5. Pleuronemina (S. 372)

3*. Bewimperung auf zwei breite Gürtel reduziert

4. Urocentrina (S. 372)

$1^{*}$. Mund fehlt ....... 6. Opalinina (S. 374)

\section{Fam. Chilifera.}

Mund in der vorderen Körperhälfte. Schlund wenig deutlich bis beutelförmig. Undulierende Membranen an den Mundrändern oder im Schlunde.

I. Mundöffnung am Vorderende; dieses völlig einnehmend . 2

2. Oberfläche des Körpers nicht narbig. Schlund mit zwei undulierenden Membranen . . . I. Leucophrys (S. 365)

$2^{*}$. Oberfläche des Körpers narbig. Im Schluncie nur eine undulierende Membran; zwei an den Mundrändern . . .

2. Leucophryidium (S.366)

I*. Mundöffnung mehr oder weniger nach hinten auf die Bauchfläche verlagert . . . . . . . . . . . . . 3

3. Hinterende ohne Tastborste . . . . . . . . . 4

4. Schlund kaum angedeutet, ohne undulierende Membranen oder Cilien . . . . . . . . . . . . . . 5

5. Mund an beiden Rändern mit undulierenden Membranen . . . . . . 3. Glaucoma (S. 366)

$5^{*}$. Mund nur an einem Rande mit undulierender Membran . . . . . . . . . . . 6

6. Membran am rechten Mundrande

4. Trichoda (S. 366) 
6*. Membran am linken Mundrande

$$
\text { 5. Frontonia (S. } 366 \text { ) }
$$

$4^{*}$. Schlund deutlich, mit undulierenden Membranen, Cilien, wenigstens aber mit einer lippenartigen Bildung am Hinterrande der Mundöffnung . . . . . . . . . 7

7. An der Konkavseite des Mundes ein uhrglasförmiger Körper; daneben meist ein schwarzer oder roter Pigmentfleck . . . . . 6. Ophryoglena (S. 367)

$7^{*}$. Ohne diese Auszeichnungen; Körper mehr oder weniger nierenförmig

8. Mund nicht sehr weit vom Vorderende gelegen, etwa dreieckig. Schlund meist ansehnlich . . . . . 9

9. An der Bauchseite nur schwach nierenförmig eingebuchtet. Länge etwa $100 \mu$. . . . . . . .

$$
\text { 7. Colpidium (S. 367) }
$$

9*. An der Bauchseite stark nierenförmig eingebuchtet, kleiner als $100 \mu$. . . 8. Colpoda (S. 368)

8*. Mund dicht vor der Mitte der Bauchseite gelegen, oval; Schlund kurz, nach rechts ziehend, an der rechten Seite mit undulierender Membran

9. Chasmatostoma (S. 368)

$3^{*}$. Hinterende mit Tastborste

9. Chasmatostoma (S. 368)

10. Bewimperung gleichmässig 10. Uronema (S. 369)

IO*. Bewimperung und Längsstreifung auf die beiden mittleren Körperviertel beschränkt . . . . . . . . . . II

II. Vom Munde zieht keine Reihe längerer Wimpern nach dem Rücken . . . 1 I. Urozona (S. 369)

I1*. Vom Munde zieht über die rechte Seite eine Reihe längerer Wimpern schief nach dem hinteren Teile des Rückens . . . . 12. Loxocephahıs (S. 369)

\section{Leucophrys St.}

Biegsam. Mund lang spaltenförmig, am Vorderende: Bewimperung gleichmässig. Bewegung wälzend. Schwimmt auf einer Seite liegend.

L. patula Ehrbg. (Taf. XII, 26)

Körper kurz. Länge $80-130 \mu$. 


\section{Leucophryidium Roux.}

Körperform ähnlich Leucophrys. Oberfläche narbig. Linke Mundmembran stärker als die rechte. Cilien fein, kurz, in Längsreihen angeordnet. Bewegung rasch rotierend unter häufigem Wechsel der Richtung. Verzehrt Infusorien und Flagellaten.

\section{L. putrinum Roux (Taf. XII, 27)}

Farbe hellgelb, Vakuole gross, am Hinterende. Nahrungsvakuolen gross. Länge $130 \mu$, Breite $75 \mu$. In fauligem Wasser und in Infusionen.

\section{Glaucoma Ehrbg.}

Körper meist eiförmig. Mund bauchständig. Bewimperung gleichmässig. Undulierende Membranen ungleich, beständig nickend.

Gl. scintillans Ehrbg. (Taf. XII, 28)

Körper eiförmig. Länge $20-40 \mu$. Gemein, in allen stagnierenden Gewässern und Infusionen.

Die etwas birnförmige Gl.pyriformis (St.) mit fingerförmig hervorragender undulierender Membran wird 40-80 $\mu$ lang. Vorkommen wie bei voriger Art.

\section{Trichoda Ehrbg.}

Körper drehrund, eiförmig bis spindelförmig, Mund am rechten Rande mit zitternder Lippe, im hinteren Winkel des etwa bis zur Mitte des Körpers reichenden, ovalen oder spitzwinkligen Peristoms. Diese Gattung wird meist mit Glaucoma vereinigt.

T. pura Ehrbg.

Körper länglich eiförmig, vorn etwas dünner als hinten. Länge bis $30 \mu$. In Aufgüssen.

\section{Frontonia Cl. u. L. (Cyrtostomum St).}

Körper cylindrisch. Bewimperung und Streifung regelmässig. Mund oval, an der Bauchseite gelegen; am linken Rande mit grosser undulierender Membran. Körper oft mit Diatomeen angefüllt. Trichocysten meist vorhanden.

1. Rechts neben dem Munde drei Reihen von Cilien. Mit dicht gereihten Trichocysten. Hinterende nicht zugespitzt

$$
\text { I. Fr. leucas }
$$


I*. Links neben dem Munde eine Anzahl starker Cilien. Hinterende stumpf zugespitzt . . . . . . . 2. Fr. acuminata

1. Fr. leucas C1. u. L. (Taf. XII, 29)

Körper zusammengedrückt. Vakuole neben der Mundspalte, mit radial stehenden, oft geschlängelten Kanälen. Manchmal durch Zoochlorellen grün gefärbt. I.änge $180-200(453) \mu$, meist von nur geringer Grösse. In stagnierendem Wasser.

2. Fr. acuminata Cl. u. L.

Körper etwa herzförmig; das Hinterende in einen stumpfen Zipfel verlängert. Länge $\mathrm{i} 30 \mu$ und mehr. In bruchigen Gewässern.

Die eiförmige, dunkelfarbige Fr. atra Cl. u. L. fällt wahrscheinlich (Blochmann) mit Fr. acuminata zusammen.

\section{Ophryoglena Cl. u. L. (Panophrys St).}

Körper oval. Bewimperung und Streifung regelmässig. Mund am Ende des ersten Körperviertels, gewöhnlich geschlossen, von der Form eines nach links offenen Halbmondes, dessen hinteres Ende spiralig eingerollt und mit kräftigen Wimpern umsäumt ist. Vakuolen in der Ein- oder Mehrzahl vorhanden, meist mit strahligem Kanalsystem. An der Konkavseite des Mundes ein uhrglasförmiger Körper.

O. flavicans Lieberk. (Taf. XII, 30)

Körper meist mit rotem bis schwarzem Pigmentflecke in der Nähe des halbmondförmigen Mundes. Schlund lang, mit undulierender Membran. Länge bis über $500 \mu$. In Sumpfwasser.

[Die Spezies O. fava Cl. u. L. ist vielleicht nicht aufrecht zu halten:

Körper länglich oval, hinten etwas schmäler als vorn. Farbe gelblich. Länge etwa $180 \mu$.]

\section{Colpidium St.}

Körper eiförmig, vorn dünner als hinten. Mund mit zwei undulierenden Membranen, deren rechte sich in den Schlund hinabzieht, wo sie an der Dorsalseite festgewachsen ist. Eine kontraktile Vakuole in der Körpermitte.

C. colpoda St. (Taf. XII, 31)

Länge etwa $100 \mu$. Die Bildung von kugeligen Speiseballen (Scheinmägen) ist bei diesem Tiere besonders gut zu beobachten. 
Gemein, in stagnierenden Gewässern. In Form und Grösse sehr verschieden. Eine fast cylindrische, sehr stark bewimperte Form ist vielleicht als besondere Art abzutrennen.

Hier reiht sich ein die etwas unsichere Gattung Pleurochilidium St. Körper formbeständig, oval, platt, vorn schief abgestutzt, mit dicken Trichocysten. Mund nahe der vorderen Ecke, mit einer zitternden Lippe.

P. strigilatum St.

Körper farblos. Länge 80-100 $\mu$. In bruchigen Gewässern. Verschlingt grosse Diatomaceen, wodurch häufig die Körperform verzerrt wird.

\section{Colpoda O. F. Muell.}

Aehnlich Colpidium. Kontraktile Vakuole am Hinterende. Teilung nur nach Encystierung.

\section{.C. cucullus Ehrbg. (Taf. XII, 32)}

Körper etwa eiförmig, auf der Bauchseite stark nierenförmig eingebuchtet; mit starker Furchung, so dass der Vorderrand gekerbt erscheint. Kern oval, central gelegen. Schlund mässig lang. Länge etwa $80 \mu$. In Aufgüssen von nassem $\mathrm{Heu}$ und auch sonst überall.

C. steini Mps.

Im wesentlichen voriger Art gleich, aber kleiner und mit bläschenförmigem Kerne. Vermehrung durch kugelige Cysten. Sehr gemein.

\section{Chasmatostoma Engelm.}

Körper formbeständig, etwas plattgedrückt. Mundspalte klein, oval, mit innen befestigter undulierender Membran.

C. reniforme Engelm. (Taf. XII, 33)

Körper vorn etwas verschmälert und stumpf abgerundet. Am Munde noch eine zweite undulierende Membran(?). Makronukleus rund, in der hinteren Körperhälfte. Schwimmt in Bogen auf der Bauchseite. Länge etwa $60 \mu$. Oft mit Colpoda cucullus, in Wiesengräben. 
Io. Uronema Duj.

Körper etwa eiförmig, wenig abgeplattet. Bauchseite in der Mundgegend etwas eingebuchtet. Längsstreifung stark. Mund grubenförmig, mit einer oder zwei undulierenden Membranen. Schlund fehlt. Makronukleus rund, central gelegen.

$U$. (Cryptochilum Mps.) griseolum (Mps.) $(=U$. marinum Duj.) (Taf. XII, 34)

Körper langgestreckt. Tastborste fast wimperartig beweglich. Kontraktile Vakuole am Hinterende. Länge bis $70 \mu$.

\section{Urozona Schewiak.}

Körper kegelförmig, vorn und hinten abgerundet. Tastborste schief stehend. Schlund röhrenförmig. Makronukleus rund, im hinteren Körperteile.

U. bütschlii Schewiak. (Taf. XII, 35)

Kontraktile Vakuole am Hinterende. Mund etwa in der Körpermitte. Länge etwa $70 \mu$.

\section{Loxocephalus (Eberh.) S. K.}

Schlund mit kurzen Cilien, die büschelförmig aus dem Munde heraushängen(?). Makronukleus rund, central gelegen.

L. granulosus S. K. (Taf. XII, 36)

Kontraktile Vakuole etwa in der Mitte der Bauchseite. Länge etwa $60 \mu$.

Den bedeutend grösseren L. luridus Eberh. stellt Blochmann zu Frontonia.

\section{Fam. Microthoracina.}

Stark asymmetrisch. Mund stets in der hinteren Körperhälfte. Bewimperung spärlich.

I. Hinterende ohne zackenartige Fortsätze . . . . . . . 2

2. Rücken- und Bauchkante konvex; Mund rechts mit grosser, links mit kleiner undulierender Membran . . . 1. Cinetochilum (S. 370)

2*. Bauchkante gerade, Rückenkante konvex; Mund nur rechts mit undulierender Membran . . . . . . . .

2. Microthorax (S. 370)

I*. Hinterende mit zahlreichen zackenartigen Fortsätzen

$$
\text { 3. Epalxis (S. 37o) }
$$




\section{Cinetochilum Py.}

Körper platt. Mund hinter der Mitte des Körpers. Am abgeschrägten Hinterende mehrere stärkere Wimpern, sonst gleichmässig bewimpert. Am rechten Mundrande eine grosse undulierende Membran, am linken eine kleinere. Kontraktile Vakuole am Hinterende.

C. margaritaceum Py. (Taf. XII, 37)

Körper farblos, durchsichtig. Länge $22-33 \mu$. In bruchigen Gewässern. Bewegung schwimmend, kriechend oder springend. Frisst Diatomaceen und Algen-Schwärmsporen.

\section{Microthorax Engelm.}

Voriger Gattung ähnlich. Peristom klein, mehr nach rechts verlagert.

I. Rückenseite glatt . . . . . . . . 1. M.pusillus

I*. Rückenseite mit drei tiefen Längsfurchen 2. M. sulcatus

I. M. pusillus Engelm.

Körper farblos, plattgedrückt, schildförmig; unten bewimpert, oben kahl. Peristom am hinteren Körperrande, rechts mit undulierender Membran. Makronukleus rund, central gelegen. Kontraktile Vakuole in der Nähe des Peristoms. Länge bis $32 \mu$. In Gräben und Buchten rasch fliessender Bäche.

2. M. sulcatus Engelm. (Taf. XII, 38)

Körper wie bei voriger Art. Länge aber bis $57 \%$. Selten.

\section{Epalxis Roux.}

Körper dreieckig, dorsoventral abgeplattet. Linke Seite gewölbt. Hinterende schief abgestutzt. Mund in der Vorderhälfte. Bewimperung lang. Bewegung unermüdlich, rasch.

E. mirabilis Roux (Taf. XII, 39)

Länge $32-40 \mu$. Breite $27-30 \mu$. Makronukleus am linken Körperrande; ebenda zahlreiche lichtbrechende Tröpfchen. In stagnierendem Wasser. Selten. 


\section{Fam. Paramaecina.}

Schlund röhrenförmig, an der Dorsalwand mit langer undulierender Membran oder Cilienreihe. Bewimperung dicht und gleichmässig.

\section{Paramaecium St.}

Flexil. Mund etwa in der Mitte der Bauchseite; häufig Trichocysten vorhanden. Gewöhnlich zwei Vakuolen mit meist strahligem Kanalsystem.

I. Körper spindelförmig, wenigstens drei Mal so lang wie breit 2

2. Körper hinten spitz und mit längeren Cilien versehen. Mikronukleus in der Einzahl vorhanden. 1. P. caudatum

2*. Körper hinten stumpf abgerundet. Cilien überall von gleicher Länge. Mikronukleus doppelt . 2. P. aurelia

I*. Körper etwa eiförmig, nur doppelt so lang wie breit . . 3

3. Mit Trichocysten; grün gefärbt . . . 3. P. bursaria

$3^{*}$. Meist ohne Trichocysten; nicht grün . . 4. P. putrinum

I. P. caudatum Ehrbg. (Taf. XII, 40)

Körper lang spindelförmig. Vakuolen in der Zweizahl, mit radienartig 'angeordneten Zuführungskanälen. Makronukleus eiförmig. Trichocysten häufig vorhanden. Länge $120-330 \mu$. In stehendem Wasser, gemeinste Spezies.

2. P. aurelia (O. F. Muell.)

Körper lang, dünn, vorn rundlich. Vakuolen in der linken Körperhälfte. Peristomfurche lang, tief und eng. Farbe gelblichweiss. Kern oval. Länge $100-250 \mu$. Ueberall, in fauligen Aufgüssen.

3. P. bursaria (Ehrbg.) Focke (Taf. XII, 41)

Körper platt, oval, vorn schräg abgestutzt. Vakuolen auf der Rückenseite. Peristomfurche flach, vorn sehr breit. Unter dem Trichocystenkleid meist zahlreiche Zoochlorellen. Makronukleus nierenförmig, mit anliegendem Mikronukleus. Länge ca. $120 \mu$. Gemein, zwischen Pflanzen in allen stehenden Gewässern. Farblose Exemplare kommen nur selten vor; sie sind meist etwas schmäler als die grünen. Bei still stehenden Tieren ist die Rotation des Innenplasmas leicht sichtbar.

4. P. putrinum Cl. u. L.

Mit zwei Vakuolen. Ohne Chlorophyll. In fauligen Infusionen. Sonst $P$. bursaria sehr ähnlich. 


\section{Fam. Urocentrina.} förmig.

Mund im Centrum der Bauchseite. Schlund lang röhren-

\section{Urocentrum Nitzsch.}

Flexil. Körper fast cylindrisch, vorn und hinten abgerundet. Vakuole endständig, mit vier langen Kanälen. Bewegung pfeilschnell bei gleichzeitiger Rotation um die Längsachse. In der hinteren Hälfte der Bauchrinne eine sich leicht in Cilien zerfasernde, dünne plasmatische Leiste.

U. turbo Ehrbg. (Taf. XII, 42)

$\mathrm{Da}$ die Cilien auf drei sich kreuzenden protoplasmatischen Leisten stehen, so erscheint der Körper an den bewimperten Stellen in Dreiecke gefeldert. Mit Trichocysten. Makronukleus hufeisenförmig. Nährt sich von Bakterien. Vakuole gross. Länge $50-80 \mu$. Zwischen Wasserpflanzen; hier und da, wie es scheint, nicht selten.

\section{Fam. Pleuronemina.}

Bewimperung stark und allseitig. Am linken Peristomrand eine grosse undulierende Membran, am rechten eine zartere Membran oder eine Cilienreihe. Schlund fehlend oder undeutlich.

I. Vorderende schräg von rechts nach links absteigend abgestutzt. Peristom mit drei undulierenden Membranen . .

I. Lembadion (S. 373)

I*. Vorder- und Hinterende gleichmässig abgerundet oder abgestutzt. Peristom nur links mit undulierender Membran; rechts mit einer Reihe starker Cilien . . . . . . . . 2

2. Peristomrinne linksseitig stärker geöffnet. Die linksseitige undulierende Membran greift auf den rechten Mundrand über und bildet so eine Tasche; mittelgrosse Formen 3 3. Vorder- und Hinterende abgerundet

2. Pleuronema (S. 373)

$3^{*}$. Vorder- und Hinterende gerade abgestutzt .

3. Cristigera (S. 373)

2*. Mundbucht deutlich rechtsseitig geöffnet. Eine Taschenbildung durch die linksseitige undulierende Membran ist nur angedeutet; kleine Formen . 4. Cyclidium (S. 374) 


\section{Lembadion Py.}

Körper ovoid, formbeständig. Peristom tief muldenförmig, die ganze rechte Körperhälfte bis nahe zum Hinterrande einnehmend. Am linken Rande befindet sich eine sehr grosse, undulierende Membran, die bis zum Aussenrande reicht, häufig aufgerichtet und nach links eingerollt ist, wobei ein Zipfel über den Vorderrand des Peristoms hervorragt. Zuweilen bewegt sie sich klappenartig auf und nieder. Mund: ein langer, winkliger Spalt in der Mitte des Peristoms. Am rechten Peristomrande eine kleinere Membran. In der Peristornhöhle eine dritte undulierende Membran.

\section{L. bullinum (O. F. Muell.) Py. (Taf. XII, 43)}

Körper hinten mit mehreren längeren Wimpern, Blase am linken Rande des Peristoms. Makronukleuś bohnenförmig, im hinteren Teile des Körpers. Länge bis $70 \mu$. Bewegung in gerader Richtung, oft wackelnd und besonders beim Rückwärtsschwimmen um die Längsachse drehend. Liebt vor allem Diatomeen als Nahrung. In frischem Wasser, selten.

\section{Pleuronema Duj.}

Körper eiförmig, formbeständig, vorn dünner als hinten. Peristom rinnenförmig, nahe am rechten Seitenrande. Es endigt hinter der Körpermitte in einem nach links gezogenen Ausschnitte, worin der Mund liegt. Die Ränder der grossen undulierenden Membran sind häufig zerschlitzt und sehen dann langen, gebogenen Wimpern überaus ähnlich. Am rechten Peristomrande eine kleinere undulierende Membran.

Pl. chrysalis St. (Taf. XII, 44)

Länge $100 \mu$. Steht meist still; nur bei Beunruhigung macht es rasche, geradlinige Bewegungen.

\section{Cristigera Roux.}

Körper eiförmig, im hinteren Teile abgeplattet, leicht seitlich komprimiert. Bauchseite konkav. Rücken gewölbt. Peristomrinne im vorderen Körperteile. Cilien lang; am Vorderende ein Kranz langer, feiner Borsten, woran sich Längsreihen feiner Wimpern ansetzen. Am Hinterende lange, starke Cilien, eine 
lange Tastborste am hinteren Pole. Bewegung sehr lebhaft, rotierend, springend und plötzlich still stehend. Nahrung besteht in Algen.

C. pleuronemoïdes Roux (Taf. XII, 45)

Farbe gelbbraun. Vakuole am Hinterende. Länge $65-70 \mu$. In klarem, stagnierendem Wasser. Selten.

\section{Cyclidium Ehrbg.}

Sehr ähnlich Pleuronema, nur viel kleiner. Eine Borste des Hinterendes durch besondere Länge ausgezeichnet.

C. glaucoma Ehrbg. (Taf. XII, 46)

Bewegung - abwechselnd mit Stillstand - sehr rasch in wechselnder Richtung, oft stossweise (wie Gyrinus natator). Länge $8-20 \mu$. Farbe bläulich. Gemein, besonders in fauligen Infusionen.

\section{Fam. Opalinina.}

Körper oval bis wurmförmig. Mund und After fehlen. Cuticula permeabel für Nährstoffe. Lebensweise stets parasitisch im Darm von Oligochaeten, Planarien, Clepsine, Palidina, Anuren. Im Rektum der Frösche findet sich oft fast ausschliesslich Opalina ranarum.

\section{Spirotricha.}

Adorale Zone stets vorhanden, meist aus Membranellen bestehend und mit spiraligem Verlauf. So wird ein mehr oder weniger vollkommen umschriebenes Peristomfeld abgegrenzt.

\section{A. Heterotricha.}

I. Körper beutelförmig bis trichterförmig . . . . . . . . 2

2. Peristomfläche unbewimpert . . . . . . . . 3

3. Peristom rinnenförmig . . I. Plagiotomina (S. 375)

$3^{*}$. Peristom ein etwa dreieckiges, vorn breiteres Feld .

2. Bursarina (S. 377)

$2^{*}$. Peristomfläche bewimpert und spiralig gestreift, fast senkrecht zur Körperachse gestellt .

3. Stentorina (S. 378) 
I*. Gestalt einem Glockenmantel ähnlich. Am ausgehöhlten Hinterende ein mächtiger, schwanzartiger Fortsatz . . .

4. Gyrocoryna (S: 380$)$

\section{Fam. Plagiotomina.}

Mund in der Mitte oder am Hinterende des Körpers. Die adorale Zone hat einen geradlinigen Verlauf.

I. Körper stark komprimiert. Vorderende hakenartig ventralwärts umgebogen . . . . . . I. Blepharisma (S. 375)

I*. Körper nicht oder nur wenig komprimiert . . . . . . 2

2. Körper fast starr; am rechten Peristomrande eine undulierende Membran. Kontraktile Vakuole ohne $\mathrm{Zu}$ führungskanal . . . . . 2. Metopus (S. 376)

2*. Körper sehr kontraktil und biegsam. Undulierende Membran fehlt (?). Kontraktile Vakuole mit Zuführungskanal . . . . . . 3. Spirostomum (S.376)

\section{Blepharisma Py.}

Körper ziemlich formbeständig, platt, fast lanzettlich, vorn spitz, sichelförmig nach links gekrümmt. Undulierende Membran an der Basis des Innenrandes meist eingerollt, wodurch sie borstenförmig erscheint. Adorale Zone am linken Peristomrande stark entwickelt; setzt sich schraubig in den Anfangsteil des Schlundes fort. Farblos oder rötlich gefärbt.

1. Körper etwa rhombisch in linksseitiger Ansicht; hinten stachelartig ausgezogen. . . . 1. Bl.musculus

$I^{*}$. Körper langgestreckt in linksseitiger Ansicht; hinten abgestutzt .

1. Bl. musculus (Ehrbg.)

Kontraktile Vakiole am Grunde des stachelartigen Fortsatzes. Kern aus mehreren perlschnurartig aneinander gereihten, kugelförmigen Abschnitten bestehend, etwa im vorderen Körperdrittel gelegen. Kleiner als folgende Art.

2. Bl. lateritia St. (Taf. XII, 47)

Körper von der Form eines Gärtnermessers (Hippe), pfirsichblüt-, purpur- oder ziegelrot, selten farblos. Vakuole am Hinter- 
ende. Die Peristomränder kreuzen sich über dem Munde. Länge 1 25-200 $\mu$. Bewegung vor- und rückwärts gleitend oder wälzend. Verbreitet; in stagnierenden Gewässern, auch in Altwasser häufig. Hierzu gehört die Varietät Bl. lat. var. minima Roux. Länge $16-43 \mu$. Farblos.

Eine dritte, seltenere Art, Bl. undulans St., zeichnet sich durch eine stark entwickelte undulierende Membran aus. Sie ist jedoch so variabel, dass zur Ermittelung ihrer Charaktere weitere Untersuchungen nötig sind.

\section{Metopus Cl. u. L.}

Sehr ähnlich Blepharisma. Körperform in hohem Masse variabel: langgestreckt, walzig, spindelförmig, kugelig oder eiförmig. drehrund oder wenig platt; Vorderende meist spiralig verdreht. Peristom spaltförmig, diagonal von links nach rechts laufend, von einer Kuppe des Vorderendes überragt; darin eine Gruppe stark lichtbrechender Körperchen.

M. sigmoïdes $\mathrm{Cl}$. u. L. (Taf. XII, 48)

Körper S-förmig gebogen; Wimpern an den beiden Körperenden oft länger als sonst, die Wimpern der Stirnkuppe gruppenweise wogend. Makronukleus scheibenförmig, in der Mitte des Körpers, dicht hinter dem Munde. Vakuole nahe am Hinterende. Bewegung sehr rasch um die Längsachse drehend. Länge bis $250 \mu$. In Sümpfen und Altwasser, nicht häufig.

Hierher gehört die seltene Gattung

\section{Plagiopyla St.}

Körper länglich oval, platt. Peristom rinnenförmig, quer in der rechten vorderen Körperhälfte. An seinem Ende der mit kurzem Schlund versehene Mund. Am Unterrande des Peristoms eine schmale undulierende Membran.

Pl. nasuta St. (Taf. XII, 49)

Wenig verbreitet.

\section{Spirostomum Ehrbg.}

Körper sehr kontraktil und flexil, sehr langgestreckt, walzenförmig oder etwas abgeplattet; vorn gerundet; bis zur Kugelform metabolisch. Peristom lang, rinnenförmig. Die adorale Zone setzt sich spiralig in den Schlund fort. Vakuole das ganze 
Hinterende einnehmend, nach vorn in einen gefässartigen Kanal auslaufend.

1. Körper lineal-spindelförmig, abgeplattet. Peristom meist nur $1 / 3$ der Körperlänge einnehmend . . . I. Sp. teres

$1^{*}$. Körper sehr lang walzenförmig, Peristom wenigstens bis zur Körpermitte reichend. . . . . . . . 2. Sp. ambiguum

I. Sp. teres Cl. u. L.

Körper vorn stärker verengt als hinten, hinten abgestutzt; Kern oval bis spindelförmig. Länge bis $45^{\circ} \mu$. Im torfigen Bodensatz der Gewässer, oft zahlreich.

2. Sp. ambiguum Ehrbg. (Taf. XII, 5o)

Körper vorn und hinten gleichmässig abgerundet oder hinten abgestutzt. Kern ein langer, rosenkranzförmig gegliederter Strang. Grösstes Infusor. Länge bis $4500 \mu(=4,5 \mathrm{~mm})$ und mehr. Vorkommen wie bei voriger Art.

\section{Fam. Bursarina.}

Peristomfeld mehr oder weniger dreieckig und ausgehöhlt. Adorale Zone nur am linken Peristomfelde, höchstens bis zur vorderen Ecke des rechten Randes übergreifend.

I. Am rechten Peristomrande eine deutliche undulierende Membran . . . . . . . . . . I. Condylostoma (S. 377) I*. Peristomfeld ohne undulierende Membran .

\section{Bursaria (S. 378)}

\section{Condylostoma Duj.}

Körper metabolisch, fast walzenförmig, wenig platt, vorn schief abgestutzt. Peristomfeld harfenförmig, innerhalb der adoralen Wimperspirale mit einer grossen, kappenförmigen undulierenden Membran. Wimpern der Bauchseite etwas grösser und spärlicher als die des Rückens.

C. vorticella Ehrbg. (Taf. XII, 5 I)

Körperstreifung weitläufig, Nukleus rosenkranzförmig, Länge bis $20 \mu$. Bewegung rastlos drehend und wälzend. In stagnierenden Tümpeln. 


\section{Bursaria O. F. Muell.}

Körper sehr gross, breit eiförmig, mässig platt, vorn stark abgestutzt. Peristom weit, taschenförmig; mit einem vorderen, terminalen und einem seitlichen, spaltförmigen Eingang. Schlund sehr entwickelt. Steifung schraubig.

B. truncatella O. F. Muell. (Taf. XII, 52)

Nukleus lang, dünn, geschlängelt. Vakuolen, wenn vorhanden, zahlreich. Länge bis $1,5 \mathrm{~mm}$. Bewegung langsam, schwerfällig. In Sümpfen, Tümpeln etc. selten, zuweilen zahlreich.

$\mathrm{Zu}$ den vorstehenden Heterotrichen gehört noch eine Reihe parasitisch in den Eingeweiden höherer und niederer Tiere lebender Arten: Balantidium Cl. u. L. (B. entozoon im Darme der Frösche, B. coli St. im Mastdarm von Menschen und Schweinen u. a.). - Nyctotherus Leidy ( $N$. cordiformis CI. in Batrachiern, N. ovalis Leidy in Blatta orientalis. - Plagiotoma Duj. (Pl. lumbrici Duj. in Regenwürmern).

\section{Fam. Stentorina.}

Peristom kurz und am Vorderende befindlich. Schlund röhrenförmig.

1. Peristom nicht das ganze Vorderende einnehmend . . . .

I. Climacostomum (S. 378)

I*. Peristom das ganze Vorderende einnehmend, senkrecht zur Längsachse gerichtet. . . . . . 2. Stentor (S. 379)

\section{Climacostomum St.}

Körper oval, formbeständig, etwa doppelt so lang als breit, vorn schief abgestutzt. Peristom kurz, harfenförmig, das vordere Drittel der Bauchseite einnehmend. Vakuole mit zwei $\mathrm{Zu}$ führungskanälen.

I. Kern lang strangförmig, schleifenartig zusammengelegt. Körper meist tiefgrün gefärbt. Länge etwa $200 \mu$. . . .

$$
\text { 1. Cl. virens }
$$

$I^{*}$. Kern klein, rundlich. Körper farblos; Länge bis 1 зо $\mu$

$$
\text { 2. Cl. patulum }
$$


I. Cl. virens St. (Taf. XII, 53)

Körper etwas nach links gekrümmt; die rechte Ecke nach links vorspringend, hinten unter der endständigen Blase etwas ausgerandet. Kern lang. Schlund bogig gekrümmt, eng, jedoch das Verschlingen grosser Körper gestattend. Länge $200-360 \mu$. Zwischen Algen, häufig.

2. Cl. patulum St.

Körper kurz eiförmig, vorn schief abgestutzt, meist farblos. Länge г $30 \mu$. Zwischen Algen, nicht selten.

\section{Stentor Oken.}

Körper drehrund, nach vorn mehr oder weniger trichterförmig erweitert, metabolisch, meist mit dem dünnen Hinterende festgeheftet. Das Peristom nimmt das ganze Vorderende des Körpers ein. Sein Rand zeigt eine rechtsgewundene Spirale von mehr als einem vollen Umgang und verläuft mit den adoralen Wimpern an der tiefsten Stelle des Feldes in den Mund, dem ein röhrenförmiger Schlund anhängt. After nahe hinter dem Peristom an der linken Seite. Kontraktile Vakuole linksseitig, nahe dem Peristomrande, mit zwei Zuführungskanälen. Beim Schwimmen, das bald geradlinig, bald kreiselnd geschieht, ist die Körperform sehr veränderlich, beständig wechselnd, pyramidal bis cylindrisch; kontrahiert ist der Körper fast kugelförmig, mit stark vortretender Streifung. Tiere, wenn festsitzend, zuweilen mit Gallerthülle.

I. Kern rosenkranzförmig . . . . . . . . . . . . . 2

2. Körper grün oder farblos . . . . I. St.polymorphus

2*. Farbe gleichmässig blau . . . . 2. St. coeruleus

I*. Kern lang, mehr oder weniger geschlängelt, ungegliedert 3 3. Peristomrand ohne stachelartige Tastborsten . . . . .

3. St. roeseli

$3^{*}$. Peristomrand mit stachelartigen Tastborsten 4. St. barretti

1**. Kern einfach rundlich

4. Durchmesser des Peristomes gleich $1 / 2$ der Körperlänge 5. St. igneus

4*. Durchmesser des Peristomes gleich $1 / 3$ der Körperlänge 6. St. niger 
I. St. polymorphus Ehrbg. (= St. muelleri Ehrbg.)

Länge bis $1 \mathrm{~mm}$. Durchmesser des Peristomes am ausgestreckten Tiere gleich $1 / 3$ der Körperlänge. Grün oder farblos. Vielfach mit langen Tastborsten. Ueberall, in stagnierenden Gewässern, oft zahllos an Reisern, Grashalmen etc., die wie mit einem feinen Flaum überzogen scheinen. Meist gesellig mit Rotatorien.

2. St. coeruleus Ehrbg.

Ebenfalls häufig mit Tastborsten, überhaupt voriger Art ähnlich. Länge bis I mm. Häufiger als vorige Art.

3. St. roeseli Ehrbg. (Taf. XII, 54)

Peristom-Durchmesser am ausgestreckten Tiere gleich 1/4 der Körperlänge. Tiere im Grunde einer Gallerthülse festsitzend. Länge bis $1 / 2 \mathrm{~mm}$. Verbreitet.

4. St. barretti Barrett

Körper sehr schlank; die untere Hälfte stielartig verjüngt, in einem röhrenförmigen Gehäuse sitzend. Tastborsten des Körpers sehr lang. Durchmesser des Peristoms etwa $1 / 5$ der Körperlänge. Etwa ebenso gross wie vorige Art.

5. St. igneus Ehrbg. (Taf. XII, 55)

Kleiner als vorige Arten, wenig formveränderlich, doppelt so lang wie breit. Innenplasma mit Chlorophyllkörnern, im Aussenplasma gewöhnlich ein rotes Pigment. Länge $330 \mu$. Schwimmt beständig unter Drehen, ist nie sesshaft.

6. St. niger Ehrbg.

Gelb oder braun gefärbt, sehr metabolisch. Länge bis $250 \mu$.

Hier reiht sich die marine Gattung Folliculina Lamarck (Freia Cl. u. L.), die durch ohrförmige Peristomfortsätze ausgezeichnet ist, ein.

\section{Fam. Gyrocoryna.}

Körper glatt, formbeständig, länglich; vorn gerundet, hinten lang ausgezogen und spiralig verdreht; in einen langen, griffelförmigen Schwanz endigend. Adorale Wimperzone an einem tiefen, spiraligen Peristom - A usschnitt, der in anderthalb Umgängen das mittlere Drittel des Körpers einnimmt und mit der glocken- 
förmigen Körperwand scharfe Kanten bildet. Bauchfläche des Körpers mit langen, griffelförmigen Wimpern.

\section{Gyrocoris St.}

Schwanzanhang fast so lang als der Körper. In der Schwanzbasis die kontraktile Vakuole; weiter nach vorn drei bis vier Makronuklei. Formbeständig und farblos.

C. oxyura St. (= Caenomorpha medusula Py.) (Taf. XII, 56)

Bewegung stürmisch und rastlos, der Griffel ist dabei nach hinten und unten gerichtet. An der Bauchseite meist zwei Längsreihen starker Cilien; ebensolche befinden sich am Glockenrande.

\section{B. Oligotricha.}

Körperform meist kugelig bis beutelförmig oder umgekehrt kegelförmig. Die adorale Zone ist beinahe oder vollkommen kreisförmig geschlossen. Bewimperung des Rumpfes entweder gut entwickelt oder reduziert.

I. Gehäusebildung fehlt (I. Halterina) . . . . . . . . . 2

2. Rumpf ohne lange, steife Borsten . . . . . . . .

$$
\text { I. Strombidium (S. 381) }
$$

$2 *$. Ausser der adoralen Zone noch lange, steife Borsten am Rumpfe . . . . . . . 2. Halteria (S. 382)

$1^{*}$. Stets Gehäusebildung vorhanden (II. Tintinnoina). . . . .

Tintinnidium (S. 382)

\section{Fam. Halterina.}

Körper meist kugelig, flexil. Peristomfeld unbewimpert, vorgewölbt. Am Rumpfe höchstens einige zerstreute, ventrale Cilien.

\section{Strombidium Cl. u. L.}

Meist formbeständig. Die adorale Zone beschreibt einen vollen Umgang. Bewegung stürmisch, rasch wälzend und umherschiessend.

I. Schlund deutlich, mit Membranellen . . I. Str. viride I*. Schlund undeutlich . . . . . . 2. Str. tiirbo 
I. Str. viride St. (Taf. XIII, I)

Körper eiförmig;Vorderende häufig abgestutzt. Schlund kurz. Peristom eiförmig; adorale Zone mächtig entwickelt; rechter Innenrand des Peristoms mit zarter undulierender Membran. In der Körpermitte ein Gürtel auffallend langer Trichocysten. Vakuole in der Körpermitte. Meist grün durch Zoochlorellen. Selten. An der Oberfläche klaren; stagnierenden Wassers. Länge $65-80 \mu$, Breite $42-45 \mu$.

2. St. turbo Cl. u. L.

Mund excentrisch. Körper vielfach durch Chlorophyllkörner grün. Länge etwa $35 \mu$.

\section{Halteria Duj.}

Körper fast kugelig und formbeständig. Bewegung rastlos, äusserst stürmisch, im Zickzack; selten ein momentaner Stillstand. Die steifen Borsten des Rumpfes bilden einen mehr oder weniger deutlichen äquatorialen Kranz.

H. grandinella (O. F. Muell.) (Taf. III, 2)

Körperform etwa kugelig. Zwischen den steifen Borsten keine längeren, rückwärts gerichteten Cilien. Kontraktile Vakuole in der Vorderhälfte. Kern oval bis nierenförmig. Länge etwa $30 \mu$.

Die Spezies H. volvox Cl. u. L., die zwischen den steifen Borsten noch kürzere, rückwärts gerichtete Cilien haben soll, ist noch zweifelhaft.

\section{Fam. Tintinnoina.}

Körper kegelförmig, mit stielartig verlängertem, kontraktilem Hinterende, das im Grunde einer unregelmässigen Gallerthülle festgeheftet ist. Die meisten Arten sind Meeresbewohner. Am Rumpfe der marinen Formen befinden sich jedenfalls vier schraubige, von vorn nach hinten verlaufende Cilienreihen.

\section{Tintinnidium S. $\mathbf{K}$.}

Tiere in unregelmässig verbogener Gallerthülle, seltener frei schwärmend.

T. fuviatile (St.) (Taf. XIII, 3)

Körper fingerhutförmig; die vordere Aushöhlung bildet das Peristom, dessen Boden beweglich ist und beständig auf und 
nieder wogt. Mund excentrisch, mit kurzem Schlund. Die adorale Zone besteht in einem geschlossenen Kranze sehr kräftiger, fast griffelförmiger Wimpern, die sich schräg von rechts nach links so übereinander legen können, dass ein vollständiger Verschluss der Peristom-Öffnung zu Stande kommt. Körper äusserlich nackt, nur mit einer kurzen Längsreihe von Wimpern unterhalb der adoralen Zone. Stiel sehr kontraktil und schnellend; er wird, wenn das Tier die Hülle verlässt, ganz in den Körper zurückgezogen. Beim Schwärmen bewegt sich das Tier äusserst stürmisch. Vakuole vorn neben dem Schlunde. Kern oval, hinten. Länge $40 \mu$. An der staubigen Oberfläche des Wassers, oft zahlreich.

Hier schiebt sich die ungenügend bekannte Gattung Codonella Häck. ein, von der ein Vertreter als Difflugia cratera Leidy auf S. 262 aufgeführt wurde.

$\mathrm{Zu}$ den Oligotrichen-Infusorien gehören ausser den hier aufgeführten Familien noch die parasitisch im Rumen und Retikulum der Wiederkäuer lebenden: Ophryoscolecina St. mit gepanzertem Körper, enthaltend die Gattungen Ophryoscolex St. (O. purkinjei und $O$. inermis) mit einem Gürtel griffelförmiger Wimpern und Entodinium St. (E. bursa, E. dentata, E. caudata) ohne solchen Gürtel.

\section{Hypotricha.}

Körper meist stark dorsoventral abgeplattet. Bauch eben, Rücken gewölbt. Peristomfeld meist dreieckig, auf der Bauchfläche gelegen. Adorale Zone vom Munde über den Stirnrand bis zur rechten Vorderecke des Peristoms sich erstreckend. Schlund nur wenig entwickelt. Bewimperung zeigt deutliche Differenzierung auf der Bauch- und Rückenseite; auf ersterer befinden sich die zur Bewegung dienenden Cilien, auf letzterer Längsreihen steifer Borsten.

I. Bewimperung der Bauchseite noch dicht und ziemlich gleichmässig; oder, wenn reduziert, auf einige Längsreihen beschränkt. Zwei ununterbrochene Randreihen stets vorhanden

I. Oxytrichina . . . 2

2. Mindestens zwei ununterbrochene Bauchreihen vorhanden. Bauchcilien nicht in Cirren umgewandelt

A. Urostylinae (S. 384) 
$2^{*}$. Bauchreihen unterbrochen, einzelne ihrer Cilien zu Cirren umgewandelt . . . . . B. Pleurotrichina (S. 387)

2**. Eine oder zwei Bauchreihen aus borstenförmigen, zum Teil unregelmässig stehenden Cirren

C. Psilotrichina (S. 393)

I*. Bauchbewimperung stark reduziert, namentlich die Randreihen zurückgebildet . . . . . . . . . . . . . . . . 3

3. Einige wenige Randcirren an den Seiten des Körpers oder des Hinterendes noch vorhanden

$3^{*}$. Randreihen vollkommen geschwunden

$$
\text { 2. Euplotina (S. 394) }
$$

3. Aspidiscina (S. 395)

\section{Fam. Oxytrichina.}

Stirnfeld und Peristom meist deutlich von einander abgegrenzt. Bauchbewimperung gleichmässig. Stirn- und Aftercirren vorhanden. Kontraktile Vakuole dorsal gelegen in der Mitte der linken Körperhälfte.

\section{A. Urostylinae.}

Stirn- und Aftercirren meist deutlich.

1. Deutliche Aftercirren vorhanden . 1. Urostyla (S. 384)

I*. Ohne deutliche Aftercirren . . . . . . . . . . 2

2. Hinterende nicht schwanzartig ausgezogen. . . . . 3

3. Sechs schräge Reihen kurzer Bauchwimpern. Körper nierenförmig. . . . . 2. Kerona (S. 385)

$3^{*}$. Eine schräge Reihe Bauchwimpern. Körper vorn halsartig verlängert . . . 3. Stichotricha (S. 385)

$2^{*}$. Hinterende deutlich schwanzartig ausgezogen

$$
\text { 4. Uroleptus (S. 386) }
$$

\section{Urostyla Ehrbg.}

In hohem Masse flexil, wenig kontraktil. Körper eiförmig, langgestreckt, häufig gelb bis braun gefärbt. Mund mit zwei 
undulierenden Membranen und drei Cilienreihen versehen. 5- I 2 Aftercirren und drei oder mehr Stirncirren entwickelt.

I. Mit fünf medianen Längsreihen von Bauchwimpern . . .

I. U. weissei

$1^{*}$. Mit vielen über die ganze Bauchfläche verteilten Bauchwimperreihen .

2. Mit zahlreichen Stirnwimpern . . 2. U. grandis

$2^{*}$. Mit drei Stirnwimpern. . . . 3. U. viridis

I. U. weissei St. (Taf. XIII, 4)

Schlanker als folgende Art. 3-5 Stirncirren und 7-8 Afterwimpern. Länge $280 \mu$. Farbe schwefelgelb bis bräunlich. Gemein, oft massenhaft in stagnierenden Gewässern.

Die Spezies U. Alavicans Wrzesn. ist vielleicht nur eine Varietät von $U$. weissei. Sie besitzt 7-8 Stirnwimpern.

2. U. grandis Ehrbg.

Körper dick, plump, eiförmig; mit zahlreichen Stirnwimpern und I0-I 2 Afterwimpern. Kern meist nicht sichtbar. Gestalt sehr wechselnd, Farbe gelblich. Länge $160-250 \mu$. In Gräben zwischen Lemnen, Oscillarien etc., auch in Altwässern. Sehr gefrässig, verschlingt andere grosse Infusorien, selbst gepanzerte Formen, und Rädertiere; bleibt deshalb bald allein in den Kulturen übrig.

\section{U. viridis. St.}

Körper lanzettlich, mit fünf Afterwimpern. Länge I 10-I $60 \mu$. Farbe grün. In Torfstichen.

\section{Kerona Ehrbg.}

Körper nierenförmig, nach hinten zugespitzt, formbeständig, aber schmiegsam; mit sechs schrägen, bogenförmigen Reihen kurzborstiger, beständig schwingender Bauchwimpern.

K. polyporum Ehrbg. (Alastor p. Py.) (Taf. XIII, 5)

Länge 1 25-200 $\mu$. Auf Hydren, wahrscheinlich symbiotisch.

\section{Stichotricha Py.}

Körper spindelförmig, metabolisch, farblos oder grün. Peristom lang und schmal, spaltförmig, mit sehr langen, beständig 
auf und nieder wogenden adoralen Wimpern, bis zur Körpermitte sich erstreckend; über den Randwimpern eine Reihe kurzer, borstenförmiger Bauchwimpern. Ohne Stirn- und Afterwimpern. Am verschmälerten Vorderende jederseits eine Reihe grosser Dorsalborsten.

I. In verzweigten Gallertgehäusen lebend; Hinterende abgerundet 1. St. socialis

I*. Meist frei schwärmend; Hinterende zugespitzt

2. St. secunda

I. St. socialis Gruber (Taf. XIII, 7)

In verzweigten, braun gefärbten Gallertgehäusen. Ist wahrscheinlich trotz Grubers Darstellung identisch mit St. secunda.

2. St. secunda Py. (Taf. XIII, 6)

Länge $125-200 \mu$. In sumpfigen Gewässern. Schwimmt schnell und anhaltend mit Drehen um die Längsachse oder steckt in Schlupfwinkeln, fährt zuweilen plötzlich zurück.

\section{Uroleptus St.}

Körper langgestreckt, hinten schwanzartig verlängert, metabolisch bis formbeständig, farblos, rosa oder violett. Ausser den Randwimpern zwei nahestehende Längsreihen von Bauchwimpern. Afterwimpern fehlen, drei Stirncirren vorhanden. Alle Arten leben in stagnierenden Gewässern. Bewegung wie bei Stichotricha, häufig plötzlich zurückfahrend.

I. Körper länglich birnförmig, hinten erweitert.

r. U. musculus

1*. Körper nicht birnförmig, sondern schmal lineal-spindelförmig 2

2. Randwimpern nach hinten an Länge abnehmend. . .

2. U. rattulus

2*. Randwimpern nach hinten an Länge zunehmend . . 3 3. Länge bis $220 \mu$, Körper vorn eiförmig zugerundet .

3. U. violaceus

$3^{*}$. Länge bis $140 \mu$, Körper vorn kopfförmig erweitert

4. U. piscis

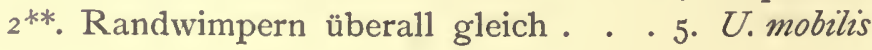


I. U. musculus Ehrbg.

Körper hinten plötzlich in ein kurzes, kegelförmiges Schwänzchen verengt. Länge $180 \mu$. Zwischen Oscillariaceen. Bewegung schwerfällig.

2. U. rattulus St.

Körper starr, lineal, vorn gerundet, hinten mit langem, pfriemenförmigem Schwanz. Randwimpern kurz. Länge $100 \mu$. In Torfstichen.

3. U. violaceus $\mathrm{St}$.

Körper starr, plattgedrückt; lineal rechteckig, nach hinten schwach schwanzartig verengert und am Ende abgestutzt. Länge bis $220 \mu$. In Torfstichen.

4. U.piscis (Ehrbg.) (= Amphisia piscis Ehrbg.) (Taf. XIII, 8) Körper sehr kontraktil, vorn gerundet und schwach kopfförmig, hinten in einen nachschleppenden Schwanz verengt. Randwimpern lang, vorstehend. Länge I $40 \mu$. In stagnierenden Gewässern, häufig.

[U. agilis Engelm.

Körper schlank spindelförmig, vorn gerundet; mit vier stärkeren und drei schwächeren Stirnwimpern, vor der Mitte am breitesten, nach hinten allmählich spitz zulaufend; mit langen Endwimpern. Schwimmt schnell in oft wechselnder Richtung. In stagnierendem Wasser oft zahlreich, in Altwasser lange zu erhalten. (Wahrscheinlich identisch mit der vorigen Art.)]

5. U. mobilis Engelm. (Taf. XIII, 9)

Körper formbeständig, biegsam; drehrund, etwa I 2 Mal so lang wie breit, nach hinten allmählich stumpf zugespitzt. Sechs längliche Kerne. Länge etwa $30 \mu$.

\section{B. Pleurotrichina.}

Stirncirren deutlich entwickelt, im typischen Zustande acht an der Zahl in untenstehend skizzierter Stellung. 
I. Acht Stirncirren in typischer Stellung vorhanden . . . 2 2. Peristom schmal, lang, etwa in der Körpermitte knieförmig umgebogen . . . . . 4. Gonostomum (S. 390) $2 *$. Peristom breit oder schmal, nicht in der Körpermitte knieförmig umgebogen . . . . . . . . . . . . 3

3. Neben fünf starken Bauchcirren noch Reihen kleinerer Cirren, oder überhaupt nur eine bis zwei Reihen wenig differenzierter Bauchcirren. Peristom breit dréieckig . . . . . . . . . . . . . . . 4

4. Nur acht Stirncirren; fünf differenzierte Bauchcirren . . . 2. Pleurotricha (S. 389)

$4^{*}$. An die drei hinteren der acht Stirncirren schliessen sich noch einige weitere Cirren an; Bauchcirren nur wenig differenziert . . . . . . . . .

3. Gastrostyla (S. 389)

$3^{*}$. Nur fünf Bauchcirren. Peristom gross, oft bis zur Körpermitte reichend . . . . . . . . 5

5. Rechter Peristomrand geradlinig, vorn nach links umbiegend . . 5. Oxytricha (S. 391)

$5^{*}$. Rechter Peristomrand S-förmig gebogen; nicht oder nur wenig vorn nach links gebogen. . . 6. Stylonychia (S. 392)

I*. Nur drei Stirncirren entwickelt, mit 3-4 Längsreihen von Bauchwimpern, Körper starr I. Onychodromus (S. 388)

\section{Onychodromus St.}

Körper länglich elliptisch, fast rechteckig, farblos und formbeständig. Peristom breit dreieckig, halb so breit wie der Körper und bis zu dessen Mitte sich erstreckend. Auf der linken Rückenseite meist zwei zapfenartige Fortsätze. Ausser den Randwimpern 3-4 Längsreihen von Bauchwimpern. Die beiden rechten Stirncirren finden in zwei Längswimperreihen ihre Fortsetzung. 5-6 grosse Aftercirren. Kontraktile Vakuole nahe am Peristomwinkel. Mit vier oder mehr Kernen.

\section{O. grandis St. (Taf. XIII, Io)}

Länge 100-330 $\mu$. In Sümpfen, Gräben etc.; selten. Bewegung langsam, schwerfällig. Sehr gefrässig, verschont selbst die eigene Art nicht. 


\section{Pleurotricha St.}

Körper elliptisch, farblos und formbeständig. Am Peristom zwei undulierende Membranen. Fünf grosse Bauchcirren in untenstehend skizzierter Stellung,

-

fünf in zwei Gruppen stehende Afterwimpern: die eine nur zwei Wimpern umfassende Gruppe befindet sich sehr weit hinten. Bewegung schnell, fast springend, abwechselnd nach links und rechts.

I. Körper breit eiförmig . . . . . . . Pl. grandis I*. Körper lanzettförmig . . . . . . . . 2. Pl. lanceolata

I. Pl. grandis St. (Taf. XIII, 11 )

Jederseits drei Reihen borstenförmiger und sehr dicker, griffelförmiger Bauchwimpern. Länge $100-200 \mu$. Zwischen Callitriche.

2. Pl. lanceolata Ehrbg.

Nur auf der rechten Seite eine vollständige und eine kürzere Reihe borstenförmiger Bauchwimpern. Etwas kleiner als vorige Art. Selten.

\section{Gastrostyla Engelm.}

Körper elliptisch, vorn schmäler, hinten gerundet; flexil, aber wenig kontraktil. Fünf Aftercirren ähnlich gestellt wie bei Pleurotricha. Ausser den Randwimpern eine schräge Reihe kräftiger Bauchwimpern.

I. Körper vorn in eine ungleichschenklige, zitzenförmige Spitze ausgezogen . . . . . . . . . . I. G. mystacea

$1^{*}$. Vorderende einfach gerundet. . . . . . . . . . . . 2

2. Mit vier Kernen . . . . . . 2. G. steini

2*. Mit zwei Kernen . . . . . . 3. G. setifera

I. G. mystacea (St.)

Körper $2 \frac{1}{2}-3 \mathrm{Mal}$ so lang wie breit, flach eiförmig, vorn ungleichmässig zugespitzt; mit langen adoralen Wimpern, zusammenstossenden Randwimpern sowie dünnen, versteckten Afterwimpern. Die Bauchwimpern sind dicht stehend, fein und borstig. Länge $120-160 \mu$. In Mistpfützen. 
2. G, steini Engelm. (Taf. XIII, i 2)

Körper elliptisch, formbeständig, nach vorn verschmälert, hinten mehr oder weniger stumpf abgerundet. 5-6 starke, griffelförmige Stirnwimpern; 4-5 starke Afterwimpern, die nicht sämtlich den Hinterrand überragen. Randwimpern nach hinten an Länge zunehmend. Länge $150-320 \mu$. Encystiert sich beim Eintrocknen seines Gewässers. Bewegung rastlos, schnell in oft wechselnder Richtung. In Gräben, auch in Altwasser.

\section{G. setifera (Engelm.)}

Körper lanzettlich, formbeständig. Fünf griffelförmige und 4-6 borstenförmige Stirnwimpern. Adorale Zone fast bis zur Körpermitte reichend. Jederseits eine Reihe von Randwimpern, die am Hinterende in einander übergehen. Länge etwa $270 \mu$.

\section{Gonostomum Sterki.}

Körperform meist schmal, vorn und hinten zugespitzt. Peristom sehr schmal, etwa in der Körpermitte unter stumpfem Winkel auf die Bauchfläche umbiegend. Meist drei deutliche Schwanzborsten. Makronukleus zweigliedrig.

I. Afterwimpern vollständig versteckt unter dem Körper; Wimpern der adoralen Zone etwa gleichlang . . . . .

$$
\text { I. G. affine }
$$

I*. Afterwimpern stark, zum Teil den Körperrand überragend, Wimpern der adoralen Zone nach hinten an Länge abnehmend

2. G. strenum

I. G. affine (St.) (Taf. XIII, I3)

Körper eiförmig, $3_{12}^{1 / 1}-41 / 2$ Mal so lang wie breit, vorne zugespitzt. Peristom lang: Randwimpern vorstehend. Länge $80-100 \mu$. In sumpfigen Gewässern.

2. G. strenuum (Engelm.)

Körper lanzettlich, am Vorderende stärker verjüngt als am Hinterende. Peristomfeld nicht deutlich. Stirnfeld mit Io griffelförmigen Wimpern. Vier starke Afterwimpern und zwei borstenförmige Endwimpern. Länge $\mathbf{1} 50 \mu$. In Gräben, zwischen Wasserlinsen. 


\section{Oxytricha Ehrbg.}

Körper länglich oval, hinten rundlich; flexil und kontraktil. Rücken gewölbt, Bauchseite flach. Cirren ganz ähnlich wie bei Pleurotricha. Peristom gross, zuweilen bis nahe zur Körpermitte sich erstreckend; Mund am Innenrande des Peristoms.

1. Afterwimpern gänzlich versteckt unter dem Körper. Körper $3^{1 / 2}-4^{1 / 2}$ Mal so lang als breit, vorn ungleichschenklig und stumpf zugespitzt, mit wenigen kurz griffelförmigen Bauchwimpern. . . . . . . . . . . . . 1. O. ferruginea

I*. Afterwimpern hinten über den Körperrand hervorragend . 2

2. Randwimpern fast sämtlich unter dem Bauche verborgen 3

3. Mit vier langen Endborsten und mehreren Reihen dorsal eingefügter, langer, überaus feiner Wimpern

\section{O. parallela}

$3^{*}$. Ohne lange Endborsten und ohne feine Dorsalwimpern . . . . . . 3. O.pellionella

2*. Randwimpern die Seitenränder überragend, hinten zusammenstossend . . . . . . . . . . . . . . . 4

4. Afterwimpern stark, griffelförmig. Körper plattgedrückt . . . . . . . 4. O. fallax

4*. Afterwimpern dünn, wenig hervorragend. Körper hoch gewölbt . . . . . 5. O.platystoma

I. O. ferruginea St.

Körper breit, hinten etwas erweitert und gerundet, mit vorragenden Randwimpern, langen, versteckten Afterwimpern und wenigen kurzen Bauchwimpern. Länge $160 \mu$. Rostrot, beweglich.

2. O. parallela Engelm.

Körper metabolisch, fast in der ganzen Erstreckung von gleicher Breite, vorn und hinten stumpf abgerundet. Adorale Wimpern kräftig, aber kurz. Fünf griffelförmige und drei borstenförmige Stirnwimpern. Fünf zerstreut stehende Bauchwimpern; ebensoviel Afterwimpern. Berwegung lebhaft. Länge etwa $200 \mu$.

3. O.pellionella Ehrbg. (Taf. XIII, 14)

Körper langgestreckt; Afterwimpern meist hakenförmig nach links gekrümmt. Länge bis $80 \mu$. Ueberall, in stehenden Gewässern. 
4. O. fallax St.

Körper eiförmig, vorn plötzlich fast gleichschenklig in stumpfem Winkel verjüngt. Länge $140-160 \mu$. In fliessenden Wässern.

5. O. platystoma Ehrbg.

Körper länglich, verkehrt eiförmig. Peristom weit. Randwimpern vorstehend, Bauchwimpern spärlich, Afterwimpern schwach griffelförmig. Länge $100 \mu$. Zuweilen zahlreich.

\section{Stylonychia St.}

Körper länglich oval, formbeständig. Peristom von halber Breite des Körpers, bis zur Mitte sich erstreckend. Ausser den Randwimpern fünf zweireihig stehende Bauchwimpern und fünf sehr lange, starke, griffelförmige Afterwimpern. Die beiden Randwimperreihen sind bei den meisten Arten am Hinterende durch eine Lücke getrennt, in welcher noch drei sehr lange, borstenförmige, divergierende Schwanzwimpern stehen.

I. Peristom vorn etwas nach links gekrümmt (Histrio Sterki) 2 2. Schwanzwimpern fehlen . . . . . 1. St. histrio

2*. Die Randwimperreihen am Hinterende durch $4-7$ starre, dünne Borsten getrennt . . . . . 2. St. macrostyla

$1^{*}$. Peristom vorn nicht nach links gewendet, Schwanzwimpern vorhanden (Stylonychia s. str. Ehrbg.) . . . . . . . . . 3

3. Körper vorn breiter als in der Mitte, hinten mit keilförmigem Schwanze . . . . 3. St. mytilus

$3^{*}$. Körper vor und hinter der Mitte gleich breit, hinten stumpf eiförmig zugestutzt . . . 4. St.pustulata

1. St. histrio Ehrbg.

Körper länglich elliptisch, vorn und hinten zugespitzt. - Die beiden Randwimperreihen sind nicht durch eine Lücke getrennt. Aftercilien gebogen, die zwei rechten nach links, die drei linken nach rechts, unten genähert; sie erreichen den Hinterrand nicht. Länge $125 \mu$. Bewegung abwechselnd mässig rasch vorwärts und blitzschnell im Bogen zurück. Ueberall in klaren Gewässern, zwischen Algen und an Pflanzen. [Diese Spezies kann auch als Subgenus Histrio abgetrennt werden.] 
2. St. macrostyla (Wrzesn.)

Körper hyalin, biegsam, flachgedrückt, linear, nach hinten sich stetig verschmälernd, am Ende zugespitzt. Sieben hakenförmige Stirnwimpern; fünf Afterwimpern, die den Körperrand nicht überragen. Länge $120 \mu$, Breite $30 \mu$. Schwimmt vielfach stürmisch umher.

3. St. mytihus Ehrbg. (Taf. XIII, 15)

Körper hinten stetig verengt, keilförmig, am Ende abgestutzt. Länge 100-300 $\mu$, Cysten 50-1 $00 \mu$. Bewegung stossweise, zuweilen drehend. Die Tiere stehen auch oft lange still oder laufen an Algen etc. entlang. Ueberall; in stagnierenden, auch fauligen Gewässern, gemein.

4. St. pustulata Ehrbg.

Körper hinten stumpf eiförmig. Länge $150 \mu$. Cysten kugelig, mit Warzen besetzt. Sehr gemein, in allen fauligen Infusionen, natürlichen wie künstlichen.

\section{Psilotrichina.}

Stirn- und Bauchcirren nicht deutlich. Aftercirren vielfach vorhanden.

1. Vier deutliche Stirncirren . . . 1. Dipleurostyla (S. 393)

1*. Höchstens drei Stirnborsten im Anschluss an die einfache Bauchreihe noch erhalten . . . 2. Balladina (S. 394)

Das durch das Fehlen der Stirn- und Aftercirren charakterisierte, hinten schnabelartig verjüngte, mit zwei Reihen Bauchwimpern versehene Genus Psilotricha St. lebt mit der einzigen, seltenen Spezies Ps. acuminata St. in Mistjauchetümpeln.

\section{r. Dipleurostyla Roux.}

Körper vorn abgerundet, nach hinten verschmälert, in einer nach rechts gekehrten Spitze endigend. Bauchseite eben. Am linken Peristomrand mächtige Bewimperung, am rechten Rand eine undulierende Membran. Rechts vorn zwei lange Dornen. Vier starke Analcirren. Bewegung sehr rasch.

D. acuminata Roux (Taf. XIII, I7)

Vakuole am Hinterende, rechts. Zellafter dorsal gelegen. In stagnierendem Wasser. Länge $70 \mu$, Breite $40 \mu$. 


\section{Balladina Kowaleski.}

Körper oval. Fünf Aftercirren in schiefer Reihe. Bewegung rasch, rastlos.

I. Bauchcirren ziemlich sparsam; Seitenränder convex . . .

I. B. parvula Kow.

$1^{*}$. Bauchcirren viel zahlreicher. Körper vorn und hinten abgerundet, Seitenränder gerade und parallel. Peristom klein, nur $1 / 5$ der Körperlänge erreichend, am rechten Rande mit undulierender Membran. Rückenborsten sehr lang (bis Iо $\mu$ ). Membranellen der adoralen Zone sehr lang. Länge 32-35 $\mu$, Breite II-I $2 \mu$. (Taf. XIII, I6) . . . . 2. B. elongata Roux

\section{Fam. Euplotina.}

Körper meist formbeständig. Auf dem Stirnbauchfeld meist eine Anzahl grosser Cirren. Kontraktile Vakuole weit hinten auf der rechten Seite neben dem After.

\section{Euplotes St.}

Körper starr, farblos und durchsichtig oder durch Zoochlorellen grün, schildförmig. Rücken gewölbt, meist mit scharfen Längsrippen. Peristom harfen- oder sichelförmig. 5-- Io cirrenartige Cilien auf dem Stirnbauchfeld, fünf grosse Aftercirren. Kern strangförmig. Bewegung schnell. Die Tiere stehen und laufen auf den Afterwimpern.

I. Körper vorn gerade abgestutzt, mit neun Bauchwimpern. .

$$
\text { I. E. patella }
$$

I*. Körper vorn und hinten schief abgeschnitten, mit zehn Bauchwimpern . . . . . . . 2. E. charon

I. E. patella Ehrbg. (Taf. XIII, I8)

Mit einer dreieckigen Oberlippe, innerhalb des Peristoms eine besondere adorale Rinne. Neun Bauchwimpern; die beiden rechten Afterwimpern verästelt. Länge bis $100 \mu$. Körper oft 
grün. Bewegung schnell und anhaltend, schwankend. Ueberall in stagnierenden Gewässern, häufig.

2. E. charon Ehrbg.

Körper kurz oval, nach links schwach bauchig erweitert. Io Bauchwimpern. Encystiert sich häufig. Länge $75 \mu$. Ueberall an der staubigen Oberfläche des Wassers, in fauligen Infusionen etc. Die Tiere stehen, laufen und schwimmen, plötzlich abwechselnd.

\section{Fam. Aspidiscina.}

Stirn- und Aftercirren ausgebildet. Peristom sehr schmal, an den linken Rand verschoben. Die adorale Zone reicht nur bis zum Vorderende des linken Randes, ohne das stark verbreiterte Stirnfeld zu umziehen. Kern lang, bandförmig.

\section{Aspidisca Ehrbg.}

Körper starr. Rücken gewölbt, mit Längskielen versehen. Bauchseite plan. Rechter Rand der letzteren wulstig verdickt. Rechter Peristomrand in eine die Peristomrinne überdeckende Lamelle ausgewachsen, die in Form einer zahnartigen Ecke den linken Körperrand überragt. Sieben Stirncirren, 5-12 Aftercirren. Kern hufeisenförmig gekrümmt. Bewegung schnell, kreiselnd. Die Tiere laufen und klettern oft auf den Cilien.

I. Mitten auf dem platten Rücken ein nach hinten gerichteter Stachel . . . . . . . . . . . I. A.turrita

I*. Kein Rückenstachel vorhanden . . . . . . . . . . . 2

2. Rücken mit sechs stumpfen Längskielen . . . . . . 2. A. costata

$2^{*}$. Rücken glatt oder mit drei schwachen Längskielen . . 3. A. lynceus

1. A. turrita C1. u. L. (= Euplotes turritus Ehrbg.)

Körper nach hinten verbreitert, hinten fast abgestutzt. Länge $20 \mu$. In Frischwasser, an Pflanzenresten laufend. 
2. A. costata St.

Körper fast eiförmig, auf der linken Seite eingebuchtet, trübe bis schmutzig-gelb gefärbt. Rücken mit fünf tiefen Längsfurchen. Länge $27 \mu$. Gemein, auch in Altwasser, zwischen faulenden Pflanzenresten.

3. A. lynceus Ehrbg. (= Coccudina crassa Duj.) (Taf. XIII, 19) Körper von vorn nach hinten verbreitert, am Ende fast abgestutzt. Länge $40 \mu$. Gemein, in süssem Wasser; auch im Brakwasser.

\section{Peritricha.}

Schlund röhrenförmig, meist stark bewimpert. Kontraktile Vakuole in der Mundgegend.

I. Peristomrand zu einem Spiraltrichter eingerollt.

1*. Kein Spiraltrichter vorhanden

I. Spirochonina (S. 397)

2. Vorticellina (S. 397) 2

2. Im Umkreise der adoralen Zone ein ringförmiger Peristomsaum . . . . . . . . . . . • . . . . 3 3. Peristom gross . . . B. Vorticellidina (S. 398) 4 4. Gehäuselos, höchstens Gallertröhren vorhanden 5 5. Gestielt . . . . . . . . . 6 6. Ohne Stielfaden

6*. Mit Stielfaden

III. Acontractilia (S. 404)

II. Contractilia (S. 400)

5*. Ungestielt . . . I. Scyphidina (S. 399)

4*. Mit Gehäuse . . . IV. Cothurnina (S. 408)

$3^{*}$. Peristom klein, am Vorderende der Rückenseite gelegen. Gehäuse vom Körper abstehend, mit Verschluss-Apparat an der Mündung . . . . . .

C. Lagenophryina (S. 409)

$2^{*}$. Kein ringförmiger Peristomsaum vorhanden

A. Urceolarina (S. 397) 


\section{Fam. Spirochonina.}

\section{Spirochona St.}

Farblos und formbeständig; Gestalt lang birnförmig, mit kurzem Stiele oder kleiner Haftscheibe. Peristom ganz am Vorderende und senkrecht zur Längsachse orientiert, klein. Adorale Zone zart, von der Mundöffnung im Grunde des Spiraltrichters sich erstreckend. Steifere Borsten am freien Rande des basalen Umgangs der Trichtermembran. Fortpflanzung durch Knospung.

S. gemmipara St. (Taf. XIII, 20)

Mit Haftscheibe. Kern ellipsoidisch. Länge etwa г 1о $\mu$. Auf Kiemenblättern von Gammarus pulex.

Die Spezies Sp. scheuteni St. lebt an Fiederborsten von Brakwasserkrebsen.

\section{Fam. Vorticellina.}

\section{A. Urceolarina.}

Körper kreiselförmig, ohne Stiel. Frei beweglich. Unterer Wimpernkranz dauernd erhalten und beim Schwimmen sowie beim Kriechen wichtig. Die von ihm umschlossene Fläche zur Haftscheibe entwickelt. Adorale Wimperspirale vorhanden.

\section{Trichodina St.}

Farblos und etwas kontraktil; Haftapparat aus einem Ringe bestehend, der aus zahlreichen, strahlig zusammengeordneten Stücken aufgebaut ist.

I. Haftapparat mit Häkchen . . . . . . . . . . . . . 2

2. Häkchen beiderseits ..... . 1. T. pediculus

2*. Häkchen nur links . . . . . . 2. T. steini I*. Haftapparat ohne Häkchen . . . . 3. T. mitra

I. T.pediculus Ehrbg. (Taf. XIII, 2 1)

Körper durch Einziehung des Vorderendes flach schachtelförmig; im ausgestreckten Zustande turbanförmig. Durchmesser bis $66 \mu$. Auf Hydren, Stichlingen und Kiemen des Hechtes lebend. 
2. T. steini C1. u. L.

Auf Planarien.

3. T. mitra v. Sieb.

Körper länger gestreckt als bei $T$.pediculus, fast walzenförmig. Durchmesser $60 \mu$, Länge bis $140 \mu$. Auf Planarien.

Hierher gehört auch die Gattung Trichodinopsis Cl. u. L. (Tr. paradoxa parasitisch in Cyclostoma elegans).

\section{B. Vorticellidina.}

Körper kugelig bis glocken- oder napfförmig, metabolisch, schnellend; oben mit weitem Peristom, dessen Ränder meist wulstig verdickt und umgeschlagen sind. Aus dem Peristom ragt hinten ein gestielter, mützenförmiger Fortsatz (Wirbelorgan), dessen Rand und Stiel zwei Umgänge einer linksgewundenen Spirale langer Wimpern trägt. Dieses Wirbelorgan wird beim Zusammenschnellen ganz in den Körper eingezogen; dabei verkürzt sich der Körper birnförmig, und die Ränder des Peristoms schliessen sich über dem Scheitel des Wirbelorgans zusammen. Unter dem höchsten Punkte des entfalteten Wirbelorganes liegt im Grunde eines geräumigen Vorhofes, in welchen der zweite Umgang der adoralen Wimperspirale hinabsteigt, der Mund, auf den ein kurzer, nach hinten gekrümmter, mit wenigen kräftigen Wimpern besetzter Schlund folgt. Der Mund steht bei gestreckter Lage des Körpers stets offen; dicht neben ihm liegt der gewöhnlich geschlossene After. Mit dem Hinterende des Körpers ist die Mehrzahl der Vorticellidinen in normalem Zustande festgeheftet an Stielen, die selbst wieder, einzeln oder von zahlreichen Gliedern einer Familie, an anderen leblosen oder lebenden Körpern festsitzen. Die Stiele sind entweder gallertig steif, oder sie haben einen excentrisch gelegenen, steil spiraligen Stielfaden, der wie ein Muskel sich zusammenziehen kann, und mittels dessen sie einzeln oder gemeinschaftlich in spiraliger Form kontrahierbar sind. Der Stielfaden tritt in den Körper des Tieres mit dem konisch erweiterten, ausgehöhlten Ende ein, reicht aber nicht bis zum Grunde des Stieles. Die Tiere variieren sehr in Form und Grösse, sind deshalb vielfach nur schwer in gute Arten zu scheiden. Die Organisation ist bei allen ähnlich. Eine Vakuole unterhalb des Wirbelorganes neben dem Ende 
des Schlundes ist bei allen und ein meist strangförmiger Makronukleus bei den meisten Vorticellidinen sichtbar.

$\mathrm{Zu}$ gewissen Zeiten lösen sich die Tiere von ihren Stielen $\mathrm{ab}$ und schwärmen frei umher, nachdem sich nahe dem Hinterende in einer ringförmigen Falte ein neuer Wimperkranz entfaltet hat, während die adorale Wimperzone eingeht. Der Körper ist dann bei allen Arten fast ganz übereinstimmend nahezu walzenförmig; er schwimmt meistens sehr rasch, rüttelnd, mit dem Hinterende voran, setzt sich gewöhnlich nach einiger Zeit an einer anderen Stelle wieder fest und nimmt wieder die normale Form an, oder aber er encystiert sich.

\section{Scyphidina.}

I. Hinterende schwanzartig, mit zwei Schnellborsten versehen . I*. Hinterende ohne Schnellborsten

3. Astylozoon (S. 400)

2. Hinten ohne Saugnapf, gerundet

2. Gerda (S. 400)

2*. Hinten mit Saugnapf . . . . . I. Scyphidia (S. 399)

\section{Scyphidia Lachm. (Duj.)}

Körper fast oder völlig cylindrisch, geringelt, hinten mit einem cylindrischen Wulste, der am Hinterende des Körpers einen Saugnapf bildet, mittels dessen das Tier sich festheftet. Wirbelorgan wenig erhoben, in der Mitte meist mit vorspringendem Nabel.

1. Körper cylindrisch, ohne Ringwulst in der Körpermitte . 2 2. Haftwulst dick; Körper vorn und hinten verjüngt. . . I. Sc. limacina

2*. Haftwulst dünn; Körper an den Enden nicht verjüngt . 2. Sc. physarum

I*. Körper länglich urnenförmig, vor der Körpermitte mit einem stärkeren Ringwulste. . . 3. Sc. amoebea

I. Sc. limacina Lachm.

Körper fast cylindrisch, an beiden Enden dünner werdend. Peristomrand nicht nach aussen umgeschlagen. Länge $150 \mu$. Auf Planorbis-Gehäusen. 
2. Sc. physarum Lachm. (Taf. XIII, 22)

Körper cylindrisch, an den Enden nicht dünner. Der Peristomrand kann nach aussen umgeschlagen werden. Länge $150 \mu$. Auf Physa fontinalis.

\section{Sc. amoebea Grenfell}

Körper bei Kontraktion birnförmig, fein querstreifig. Kurz . vor der Körpermitte ein stärkerer Ringwulst. Im Vorderende meist einige Nahrungsvakuolen. Länge $70-82 \mu$, Breite $25-28 \mu$.

\section{Gerda Lachm.}

Körper länglich, sehr kontraktil, fast cylindrisch, hinten ohne Saugnapf. Wirbelorgan sehr klein; Peristom eng, sein Rand nicht umgeschlagen. Vakuole - abweichend von allen anderen Vorticellinen - hinten. Die Tiere schwimmen oft frei, setzen sich aber gern an Algenfäden $u$. dergl. fest.

G. glans Lachm. (Taf. XIII, 23)

Körper lang. gestreckt, hinten verdickt, geringelt. Bei halber Kontraktion ähnelt die hintere Verdickung dem Näpfchen einer Eichel. Länge' $200 \mu$. In Torfmooren.

\section{Astylozoon Engelm.}

Körper glockenförmig und kontraktil, ähnlich Vorticella microstoma, aber ohne Stiel. Peristomrand wulstig verdickt und umgeschlagen. Hinterende des Körpers spitz, nach der Rückenseite gebogen, am Ende mit einer oder zwei starken Schnellborsten.

A. fallax Engelm. (Taf. XIII, 24)

Körperoberfläche glatt. Wirbelorgan nach hinten ansteigend. Kern klein, nierenförmig. Cysten kugelig; Durchmesser $38-50 \mu$. Länge der Tiere $100 \mu$.

\section{Contractilia.}

I. Jedes Tier auf besonderem Stiele . 1. Vorticella (S. 40 I)

I*. Tiere an verästelten Stielen . . . . . . . . , . . . 2

2. Die Stielfäden der einzelnen Aeste stehen nicht mit einander in Verbindung . . . 2. Carchesium (S. 402) 2*. Die Stielfäden stehen in kontinuierlichem Zusammenhange 3. Zoothamnium (S. 403) 


\section{Vorticella Ehrbg.}

Körper meist birnförmig, vorn verengt; Peristomrand etwas nach aussen umgeschlagen. Wirbelorgan wenig vorragend. Die Tiere haben zwar alle besondere, spiralig kontraktile Stiele, heften sich damit aber gern gesellig, oft zu kugelförmigen „Kolonien“ vereinigt, fest und erscheinen als weissliche Wölkchen an den Wurzeln der Lemnen, den Fiederblättern der Ceratophyllen und an anderen Pflanzen, an Fühlern und Beinen von Cyklopen, Käfern, Asseln, Krebsen und anderen Tieren, oder auch an den Wänden von Gefässen. Oft schnellt plötzlich die ganze „Kolonie“ - alle Tiere gleichzeitig - zusammen und breitet sich bald darauf langsam, stetig wieder aus. Manche Arten leben nur in frischen Wassern, andere nur in verdorbenen.

I. Körper nach vorne stark verengt, etwa eiförmig . . . . . I. V. microstoma

I*. Körper glockenförmig, am Vorderende also erweitert . . 2

2. Körper von oben nach unten zusammengedrückt, schüsse1förmig . . . . . . . . . . . . 2. V. patellina

2*. Körper nicht so zusammengedrückt, glockenförmig · 3 3. Körperoberfläche mit deutlichen Ringfurchen . .

$3^{*}$. Ringfurchung fehlt .

3. V. convallaria

4. Körperoberfläche ohne warzenartige Protuberanzen . . . . . . . . . . . . 5

5. Stiel etwa 7 Mal so lang wie der Körper .

4. V. campanula

$5^{*}$. Stiel nur 4-5 Mal so lang wie der Körper

5. V. nebulifera

$4 *$ Körperoberfläche mit warzenartigen Protuberanzen . . . . . 6. V. monilata

1. V. microstoma Ehrbg. (Taf. XIII, 26a)

Körper mit starken, gekreuzten Furchen, die besonders bei der Kontraktion hervortreten. Farbe bläulich oder grau. Länge bis гоo $\mu$, Stiel dünn. Ueberall in fauligen Infusionen, stinkenden Pfützen und Gossen, gemein.

2. V.patellina Ehrbg. (Taf. XIII, $26 \mathrm{~d}$ )

Stiel dick. Länge bis $80 \mu$. An Lemnen-Wurzeln etc. Eyferths Einfachste Lebeformen. 3. Auf. 
3. V. convallaria Ehrbg. (Taf. XIII, 26c)

Körper klar, durchsichtig, zuweilen grün. Länge 50-100 $\mu$, Stiel eben so lang, aber dicker als bei $T$. microstoma. In mässig verdorbenem Wasser, an der Oberfläche vegetabilischer Infusionen; mit $V$. microstoma.

4. V. campanula Ehrbg. (Taf. XIII, 26 b)

Körpèr gross, halbkugelig, bläulich. Stiel dick. Länge bis $200 \mu$. Bildet dicke, bläuliche Wolken an Wasserpflanzen.

5. V. nebulifera Ehrbg. (Taf. XIII, 25)

Körper wie bei $V$. convallaria geformt, zuweilen grün. Kern hufeisenförmig. Länge 40-80 $\mu$. In klarem Wasser.

6. V. monilata Tatem (Taf. XIII, 26 c)

Körper glockenförmig. Kern lang, bandförmig; oben und unten mit rechtwinkliger Umknickung. Länge etwa $60 \mu$.

\section{Carchesium Ehrbg.}

Tiere sehr kontraktil, in baumförmigen Kolonien, auf kontraktilen Stielen. Jede Kolonie besitzt einen langen Hauptstiel, woran sich Nebenäste, deren jeder mit besonderem Stielfaden versehen ist, anheften. Manche Stiele bleiben unverästelt. Die Kontraktion der Stiele erstreckt sich gewöhnlich auf die ganze Kolonie, kann aber auch auf einzelne Individuen beschränkt bleiben.

I. Stiel deutlich gegliedert oder fein transversal gestreift. . 2 2. Körper glatt . . . . . . . . 1. C. epistylis

$2^{*}$. Körper fein, aber deutlich quergestreift .

$$
\text { 2. C. aselli }
$$

I*. Stiel nicht gegliedert.

3. Tiere stehen nicht in gleicher Höhe, Endverzweigung etwa traubig . . . . . . . . . . . . . 4 4. Cuticula glatt . . . . . 3. C. polypinum $4^{*}$. Cuticula fein gestreift . . . 4. C. spectabile

$3^{*}$. Tiere etwa in gleicher Höhe, Endverzweigung also doldentraubig . . . . . . 5. C. lachmanni

I. C. epistylis $\mathrm{Cl}$.

Körper sehr schmal, glatt. Kern in einer Transversal-Ebene gebogen. Länge $50 \mu$. An Phryganeiden-Larven. 
2. C. aselli Engelm. (Taf. XIII, 28)

Körper langgestreckt, fast cylindrisch; Vakuole auf der Bauchseite. Stiel fein transversal gestreift, Stielfaden central. Länge $100 \mu$, vielfach nur halb so gross. An Wasserasseln.

3. C. polypimum Ehrbg. (Taf. XIII, 27)

Körper fast trichterförmig, aufgerichtet oder am Stiele herabhängend. Peristomrand weit, dick, nach aussen umgerollt, seitlich als $\Lambda$ ussackung vortretend. Wirbelorgan nur wenig vortretend, mit flacher Scheibe, die Peristom-Mündung fast ganz ausfüllend. Kern in einer Längsebene. Stielfaden excentrisch. Länge 45 bis $100 \mu$. Verbreitet, als schimmelartiger Ueberzug.

4. C. spectabile Ehrbg.

Körper fingerhutförmig. Kern in einer Längsebene, gebogen und mehrfach ausgebuchtet. Stielfaden excentrisch. Länge $100 \mu$. In ziemlich stinkendem Flusswasser.

5. C. lachmanni S. K.

Die langgestielten Tiere in dichten Trupps zusammen, so dass sie in stark verschmutzten Abwässern, in denen sie allein vorkommen, an hineinhängenden Blättern, Halmen etc. dichte, weisse Ueberzüge bilden.

\section{Zoothamnium St.}

Körper kontraktil. Tiere in baumförmigen Kolonien auf kontraktilen Stielen, 'welche sämtlich einen gemeinschaftlichen, mit den Stiele verzweigten Stielfaden besitzen, der in der Regel nicht bis zum Grunde des Hauptstieles sich erstreckt.

1. Körper fast walzenförmig . . . . . . . . . . . 2

2. Stiel dick . . . . . . 1. Z. arbuscula

2*. Stiel dünn . . . . . . . . 2. Z. parasitica

I*. Körper oval, hinten schwach verengt, vorn schief abgestutzt 3. Z. affine

I. Z. arbuscula Ehrbg. (Taf. XIII, 29)

Peristom nur durch eine seichte Einschnürung abgesetzt. Länge $50 \mu$. Auf Ceratophyllım, nicht häufig.

2. Z. parasitica St.

Sehr ähnlich Z. arbuscula. Auf den Kiemen der Wasserasseln. 
3. 7. affine St.

Stöcke wicderholt dichotom verästelt. Individuen nahezu von gleicher Höhe. Aeste glatt oder geringelt. Iänge $60-80 \mu$. An den Beinen der Flohkrebse.

\section{Acontractilia.}

I. Kolonien in Gallerte eingehüllt. . 3. Ophrydium (S. 407)

I*. Kolonien ohne Gallerte .

2. Peristomsaum mehr oder weniger ausbreitungsfähig; Peristom-Ende höchstens ganz wenig verjüngt

$$
\text { I. Epistylis (S. 404) }
$$

2*. Peristomsaum selbst in unkontrahiertem Zustande nie ausgebreitet oder umgeschlagen; Peristom-Ende verjüngt

$$
\text { 2. Opercularia (S. 406) }
$$

Hier reiht sich ein die Gattung Glossatella Btschli., die einer sehr kurzgestielten oder stiellosen Vorticelle im Habitus ähnelt und durch eine riesige, etwa die Körperhöhe erreichende undulierende Membran ausgezeichnet ist.

Gl. tintinnabulum S. K. (Taf. XIII, 30)

Länge bis $40 \mu$. Auf Tritonlarven.

\section{Epistylis Ehrbg.}

Körper kontraktil, glockenförmig bis cylindrisch; Vorderende wenig verjüngt. Tiere in baumförmigen Kolonien mit starren, verzweigten Stielen. Stiel des Wirbelorgans kurz und dick.

I. Stiel breit und sehr kurz, so dass das Tier sitzend erscheint I. E. brcvipes

I*. Stiel länger; Tiere nicht sitzend erscheinend.

2. Kontraktile Vakuole mit langem, kanalartigem Reservoir; Peristom nicht breiter als der Rumpf 2. E. oplirydiuformis

$2^{*}$. Kontraktile Vakuole ohne derartiges Reservoir; Peristomfeld breiter oder schmäler als der Rumpf . . . . . 3

3. Stiel dick, unregelmässig wulstartig quergerunzelt . 3. E. steini

3*. Stiel nicht wulstartig quergerunzelt. . . . . 4

4. Schlundröhre bis zur Körpermitte oder darüber hinaus reichend; Körperoberfläche höchstens mit feiner Querstreifung . . . . . . . 5 
5. Körper breit glockenförmig; Kern den Körper der Quere nach durchziehend.

4. E. umbellaria

5*. Körper etwa eiförmig; Kern von vorn nach hinten den Körper durchziehend.

5. E. nympharum

4*. Schlundröhre nicht bis zur Körpermitte reichend; Hinterende des Körpers quergefaltet . . .

6. E. plicatilis

I. E. brevipes $\mathrm{Cl}$.

Körper lang, cylindrisch; Kern oval.

2. E. ophrydïformis Nüsslin

Körper langgestreckt. Vestibulum trichterförmig, mit Cilien versehen. Schlund nicht sehr weit in den Körper eindringend. In der Nähe des Schlund-Endes die kontraktile Vakuole. Kern lang, bandförmig, der Längsachse des Körpers parallel.

3. E. steini Wrzesn.

Stiel niedrig, hohl, nach dem Körper zu keulenförmig verdickt, an der Aussenfläche quergerunzelt; dichotom verästelt. Körperoberfläche quergestreift. Peristomrand breit, aufgewulstet. Schlund eng, lang. Kern hufeisenförmig, wagerecht gestellt, den Schlund umfassend. Länge circa $34 \mu$, Breite des Peristoms $24 \mu$.

4. E. umbellaria Lachm. (Taf. XIII, 32)

Körper glockenförmig. Vestibulum sehr lang, bis zur Körpermitte sich erstreckend, mit Cilien versehen. Schlund sehr eng, schief nach hinten bis zum Beginne des letzten Körperviertels reichend. Kern in der vorderen Hälfte. Häufig mit paarweise angeordneten Nesselkapseln.

5. E. nympharum Engelm.

Kolonien nicht sehr reich an Individuen (8-12). Einzeltier mittelgross; am Hinterende etwas verjüngt; etwa drei Mal so lang wie breit. Oberfläche fein quergestreift. Cilienkranz häufig schief gestellt. Peristomrand verdickt. Schlund weit in den Körper eindringend (fast bis zur Hälfte), etwas gebogen, an der Wandung mit Cilien versehen. Kontraktile Vakuole vorn neben dem Schlunde, sehr rasch pulsierend. Makronukleus bandförmig, gekrümmt, so lang wie der Körper. Mikronukleus anliegend. 
Je zwei Individuen sitzen meist auf einem Stiele. Letzterer ist farblos und glatt. Länge $100-120 \mu$, Breite bis $48 \mu$. An Mückenlarven.

6. E. plicatilis Ehrbg. (Taf. XIIJ, $3 \mathrm{I}$ )

Tiere der Kolonie sämtlich in gleicher Höhe. Länge 80--100 $\mu$. Auf den Gehäusen von Wasserschnecken.

\section{Opercularia St.}

Körper eiförmig bis spindelförmig, vorn abgestutzt, kontraktil. Peristom-Ende stets verjüngt. Wirbelorgan lang hervorragend. Cuticula stark entwickelt.

I. Körper stark geringelt . . . . . . . . . . . . . . 2

2. Körper länggestreckt, fast walzenförmig . . . . . 3

3. Schlund lang; Stieläste nicht quergestreift . . . .

I. O. berberina

$3^{*}$. Schlund kurz; Stieläste quergestreift

2. O. cylindrata

2*. Körper ovoid .' . . . . . . 3. O. nutans

I*. Körper höchstens am Hinterende geringelt, vielfach aber mit feinen Querstreifen . .. . . . . . . . . . . 4 4. Stiel glatt . . . . . . 4. O. coarctata 4*. Stiel längsgestreift . . . . . . . . . . . . 5

5. Körper vorn mit Querstreifen, hinten mit Querfurchen 5. O. glomerata

5*. Körper ohne Querstreifen und Querfurchen.

6. O. articulata

I. O. berberina St.

Körper stark geringelt, selbst im gestreckten Zustande, mehr noch im kontrahierten; Aeste dünn, ungleich, gebogen. Länge $100-125 \mu$. An Wasserkäfern, besonders an der Spitze des Hinterleibes.

2. O. cylindrata Wrzesn.

Körper walzenförmig, nach hinten ein wenig verjüngt, vorn gerade abgestutzt. Peristom kreisrund. Wimperorgan niedrig, kurz gestielt, oben wenig gewölbt. Vestibulum weit, bauchig aufgetrieben, bewimpert. Schlund eng, überaus kurz. Kontraktile Vakuole neben der bauchigen Auftreibung des Schlundes. Kern 
hufeisenförmig, der Körperachsc parallel. Cuticula glashell. Stiel hoch, Aeste fein quergestreift. Lärge etwa $50 \mu$. An Cyclops.

3. O. mutans Ci. u. L.

Körper kontrahiert scheinbar zweilippig, oft abwärts gebogen. 'Stiel hoch, stark verästelt. Länge $60 \mu$. An Wasserpflanzen.

4. O. coarctata (C1. u. L.)

Kolonien aus 3-4 Individuen bestehend. Einzeltier eiförmig, vorn und hinten verjüngt; Peristomrand nicht verdickt. Mund stark entwickelt, mit Cilien versehen. Schlund weit nach hinten (bis zur Körpermitte) sich erstreckend, deutlich sichtbar, bewimpert. Undulierende Membran gross, ähnlich wie bei Epistylis. Körperoberfläche fein quergestreift. 'Kontraktile Vakuole am Vorderende. Kern bandförmig, gekrümmt, in der Quere gelagert. Stiel glatt. Länge $60-65 \mu$, Breite $25-27 \mu$.

5. O. glomerata Roux

Körper lang eiförmig, fast fünf Mal so lang wie breit; vorn mit Querstreifen, hinten mit Querfurchen. Wimperorgan weit hervorragend, sehr schief gestellt. Schlund lang. In der Nähe seines Endes die kontraktile Vakuole. Kern wie bei $O$. coarctata. Stiel längsgestreift, gelblich gefärbt. I0-12 Individuen am Ende jedes Zweiges. Kolonien gross, bis über I $\mathrm{mm}$ hoch. Länge des Einzeltieres etwa $450 \mu$, Breite 145-150. An Hydrophilus piceus.

6. O. articulata Ehrbg. (Taf. XIII, 33)

Körper spindelförmig, vorn und hinten abgestutzt; Peristom ohne Auszeichnung. Wirbelorgan für sich kontraktil. Länge $55 \mu$. Kolonie 4-6 Individuen umfassend. An Wasserkäfern, besonders auf Brust und Beinen.

\section{Ophrydium Ehrbg.}

Körper langgestreckt, spindelförmig, metabolisch. Tiere in grosser Anzahl mit dem Hinterende an sehr kurzen Stielen an einer glashellen Gallertkugel befestigt, welche Wallnuss- bis Faustgrösse und darüber erreicht. Auf der Oberfläche solcher Kolonien sitzen die Tiere in becherförmigen Vertiefungen, worein sie sich zurückziehen können. Peristom wie bei den Vorticellinen, 
Schlund lang; Vakuole neben dem Ende des Schlundes. Kern lang, strangförmig. Körper geringelt und längsfaltig. Oft durch Zoochlorellen grün.

O. versatile Ehrbg. (Taf. XIII, 34)

Meist grün gefärbt. In Seen und Teichen, wo Charen wachsen, schwimmend oder an Wasserpflanzen angeheftet. Länge des gestreckten Tieres bis über $600 \mu$, der Kolonie bis $15 \mathrm{~cm}$.

[Hierher gehört als Varietät var. acaulis Roux, die dadurch sich auszeichnet, dass die Individuen häufig einzeln festgeheftet sind.]

Das verwandte $O$. eichhorni Ehrbg. (Taf. XIII, 35) stets ohne Zoochlorellen und in kleineren Kolonien.

\section{Cothurnina.}

I. Gehäuse mit dem Hinterende aufgewachsen oder von einem Stiele getragen . . . . . . 1. Cothurnia (S. 408)

1*. Gehäuse in der ganzen Länge auf der Unterlage festgewachsen und bilateral . . . . . . 2. Vaginicola (S. 409)

\section{Cothurnia Ehrbg.}

Körper keulenförmig und metabolisch, stets mit dem Hinterende festgeheftet im Grunde einer weiten, abstehenden, glashellen Hülle, welche selbst mit einem kurzen Stiele oder direkt mit dem Hinterende an Algenfäden oder dergleichen bcfestigt und vielfach mit ringförmigen Wülsten ausgestattet ist.

I. Gehäuse mit Deckel . . . . . . I. C. operculata I*. Gehäuse ohne Deckel . . . . . . . . . . . . . . 2

2. Stiel völlig glatt. . . . . . 2. C. crystallina 2*. Stiel geringelt . . . . . . . . . . . . 3

3. Gehäuse oben mit zwei gekrümmten, spitzen Zipfeln

3. C. sieboldi

3*. Gehäuse ohne Zipfel, cylindrisch, hinter der Mitte bauchig erweitert. . . . . . . . . 4 4

+. Auf dem Flusskrebse . . 4. C. astaci

4*. Auf Cyclops . . . . . 5. C. imberbis

1. C. operculata Gruber

Gchäuse mit einem Deckel verschen, den das Tier beim Zurückschnellen mitzicht, so dass er dann die obere Mündung vollständig verschliesst. 
2. C. crystallina Ehrbg. (Taf. XIII, 36)

Gehäuse walzenförmig, häufig in der Mitte bauchig erweitert. Mündung bei alten Tieren oft etwas nach aussen umgeschlagen, farblos oder rostrot. Am Hinterende gewöhnlich mit einem Stiele. Im Innern des Gehäuses vielfach zwei klappenartige Gebilde. Länge bis $250 \mu$. An I.emnenwurzeln etc., gemein. Eine grosse Varietät ist var. grandis $\mathrm{Py}$.

3. C. sieboldi St. krebses.

Länge bis г $25 \mu$. Auf den Kiemen, Borsten etc. des Fluss-

4. C. astaci St.

Steht der folgenden Art sehr nahe.

5. C. imberbis Ehrbg.

Körper schlank, fast walzenförmig, wenig länger als dic Hülle. Stiel des Gehäuses S-förmig. Länge 80-100 $\mu$. Auf Cyclops.

\section{Vaginicola Ehrbg.}

Körper langgestreckt, keulenförmig und metabolisch, mit dem Hinterende festgeheftet im Grunde einer weiten, abstehenden, glashellen Hülle, welche ohne Stiel mit der ganzen Länge an Algenfäden und dergl. festsitzt. Im übrigen ist die Organisation gleich der der Vorticellinen.

$V$. decumbens Ehrbg.

Hülle oval, plankonvex, braun, mit der flachen Seite aufliegend; vorn mit einem kurzen, halsartigen Ansatz, aus welchem sich das Tier fast rechtwinklig emporrichtet. Länge $80 \mu$. An Lemnenwurzeln etc.

Bei $V$. longicollis S. K. (Taf. XIII, 37) ist die Oeffnung des Gehäuses halsartig ausgezogen.

\section{Lagenophryina.}

\section{Lagenophrys St.}

Körper birnförmig und metabolisch. Wirbelorgan lang gestielt; Gehäuse stets vorhanden, oval, hinten stark verengt, plankonvex, mit der flachen Seite aufliegend. Mündung der 
Hülle verengt und mit einem zweilappigen Saum versehen, der bei Kontraktion des Tieres die Mündung schliesst. Tier dicht unter der Mündung seitlich mit dem Peristomrande angeheftet, frei in der Hülle hängend.

ı. Gehäuse fast herzförmig . . . . . I. L. vaginicola I*. Gehäuse kreisrund. . . . . . . . 2. L. ampulla

I. L. vaginicola $\mathrm{St}$. Länge etwa $60 \mu$. Auf Cyclops.

2. L. ampulla St. (Taf. XIII, 38)

Hülle hyalin, im Alter rostrot. Länge etwa $60 \mu$. Auf den Kiemen der Wasserasseln und Gammarus-Arten, gemein.

\section{Suctoria.}

(Acineten).

\section{Litteratur:}

Claparède E. et J.Lachmann. Études sur les Infusoires et les Rhizopodes. Genève et Bale, I 858-6r.

Gruber, A., Kleine Beiträge zur Kenntnis der Protozoen. Ber. der Naturf. Gesellsch. zu Freiburg. Bd. 7. 1879.

Maupas, E., Contribution à l'étude des Acinétiens. Arch. de Zool. expér. Bd. 9. 1881 .

Bütschli, O., Protozoa, in Bronns Klassen und Ordnungen des Tierreichs. Bd. I, Abt. 3. 1895 .

Blochmann, Fried., Abt. I. Protozoa in Kirchner und Blochmanns mikroskopischer Tierwelt des Süsswassers. Hamburg 1895 .

Die Suctorien stehen den Ciliaten ausserordentlich nahe, werden sogar vielfach nur als Unterabteilung der letzteren aufgeführt. Ihr kugeliger, einzelliger Körper ist durch das Fehlen einer Mundöffnung charakterisiert. Infolge dieses Mangels finden sich besondere Organe für die Nahrungs-Aufnahme. Es sind dies saugende Tentakel, die entweder mit einer Spitze oder mit einem kleinen Knöpfchen endigen und gewöhnlich retraktil sind. Vorübereilende Infusorien, welche die Tentakel berühren, bleiben sofort an ihnen hängen und vermögen sich auf keine Weise 
wieder $\mathrm{zu}$ befreien. An der Oberfläche sind die Suctorien mit einer Pellicula versehen, d. h. mit einer Schicht dichteren Plasmas, die allmählich in das meist in völliger Ruhe verharrende Innenplasma übergeht. Makronukleus und Mikronukleus sowie kontraktile Vakuolen in der Ein- oder Mehrzahl sind wie bei den Ciliaten vorhanden. Die Vermehrung geschieht vornehmlich durch Schwärmerbildung; und zwar kann man hier zwei Arten unterscheiden: exogene und endogene Schwärmerbildung. Bei der ersteren Vermehrungsweise löst sich der obere Teil des Suctorienkörpers los, um als bewimperter Schwärmer eine Zeit lang frei umherzuschwimmen und dann wieder in den sesshaften Zustand überzugehen. Die endogen gebildeten Schwärmer hingegen entstehen in einer Bruthöhle des mütterlichen Organismus, innerhalb deren sie bereits vor dem Ausschlüpfen Bewegungen zeigen. Knospung und Konjugationsvorgänge sind beobachtet. Viele Suctorien sind festsitzend; einige leben parasitisch. Gehäusebildung findet sich hin und wieder. Bei Eintritt ungünstiger Lebensbedingungen findet häufig Encystierung statt.

I. Nur wenig (höchstens fünf) undeutlich geknöpfte Tentakel vorhanden . . . . . . . . . . . . . . 2

2. Mit verbreiterter Basis aufgewachsen . . . . . .

$2^{*}$. Mit zugespitztem Hinterende aufgewachsen

$$
\text { I. Rhyncheta (S. 412) }
$$

$$
\text { 2. Urnula (S. 412) }
$$

I*. Tentakel gänzlich fehlend; wenn vorhanden, sämtlich oder zum Teil deutlich geknöpft; wenn ungeknöpft, dann in grosser Anzahl

3. Mit Gehäuse .

4. Apikal-Ende mit sechs strahlig angeordneten Spalten zum Durchtritt der Tentakel .3. Metacineta (S. 4I3)

4*. Apikal-Ende ohne derartige Spalten . . . . . . 5

5. Mit Stiel . . . . . 8. Acineta (S. 416)

5*. Ohne Stiel . . . . . 9. Solenophrya (S. 416)

$3^{*}$. Ohne Gehäuse

6. Mit Stiel.

7. Vermehrung durch Teilung in nahezu gleiche Tochtertiere; Umbildung der Vorderhälfte zum Schwärmer .

6. Podophrya (S. 414)

$7^{*}$. Vermehrung durch endogene Knospung.

7. Tokophrya (S. 4I4) 
6*. Ohne Stiel . . . . . . . . . . . . 81)

8. Tentakel von der ganzen Oberfläche ausstrahlend oder bei Parasiten fehlend . . . . . . . . . 9

9. Vermehrung durch nahezu gleiche Teilung oder äussere Knospung ... . 4. Sphaerophrya (S. 4I3)

9*. Vermehrung durch endogene Knospung .

5. Endosphaera (S. 414)

8*. Tentakel auf der Apikalfläche in Büscheln, oft an Lappen oder Armen sich erhebend. . . . . . Io Io. Tentakel deutlich in Büscheln stehend . . . I I II. Tentakel an knopf- bis armartigen Fortsätzen . 10. Trichophrya (S. 417)

II*. Tentakel an langen, häufig Aeste dritter Ordnung tragenden Fortsätzen II. Dendrosoma (S. 4I7) IO*. Tentakel nicht in Büscheln angeordnet. . . 12

12. Apikalseite mit fingerförmigen, nicht geknöpften Tentakeln . . . I3. Stylocometes (S. 41 7)

$12 *$. Tentakel zu zweien oder dreien an gegabelten Armen. . . . . I2. Dendrocometes (S. 417)

\section{Rhyncheta Zenker.}

Körper farblos, cylindrisch bis lang glockenförmig; am Vorderende mit einem die Länge des Körpers vielmals übertreffenden, rüsselartigen Tentakel von grosser Beweglichkeit. Kern in der Körpermitte, oval. Kontraktile Vakuole zwischen Kern und Tentakelbasis.

Rh. cyclopum Zenker (Taf. XIII; 39)

Länge bis $90 \mu$. Auf der Bauchseite von Cyclops zwischen den Beinen. Das Tentakel-Ende des Tieres ist meist nach hinten gerichtet.

\section{Urnula Cl. u. L.}

Tier mit farblosem, etwa beutelförmigem, zweiseitig symmetrischem Gehäuse, dessen zugespitztes Hinterende festgeheftet ist. Gehäuse-Mündung ein wenig verjüngt, rund bis dreieckig. Ticrkörper das Gehäuse mehr oder weniger vollkommen aus-

1) Vgl. auch Podophrya (S. 414). 
füllend; am Vorderende ein bis zwei, höchstens aber fünf, lange, dünne Tentakel von grosser Beweglichkeit. Kern in der Mitte, oval. Kontraktile Vakuole in der Ein-oder Mehrzahl.

U. epistylidis Cl. u. L. (Taf. XIII, 40)

Länge bis $80 \mu$. Auf Stielen von Epistylis.

\section{Metacineta Btschli.}

Gehäuse trichterförmig, auf einer hohlen, stielartigen Verlängerung von wechselnder Länge ruhend. Fortpflanzung durch Teilung in zwei Individuen von ungleicher Grösse. Aus den sechs Spalten der Apikalseite tritt je eine Tentakelreihe aus. Fortpflanzung durch freie Knospung. Kern rundlich.

M. mystacina (Ehrbg.) (Taf. XIII, 41)

Länge mit Gehäuse bis $700 \mu$. Lebt als Räuber an Vorticellen-Kolonien und bewältigt selbst grosse Carchesizm-Arten, die in $20-30$ Minuten ausgesogen sind.

\section{Spaerophrya Cl. u. L.}

Körper kugelig. Tentakel von der ganzen Körperoberfläche ausstrahlend oder fehlend. Fortpflanzung durch gleiche oder ungleiche Teilung sowie durch äussere Knospung. Der Schwärmer einer Sphaerophrya ist auf Tafel XIII, 43 abgebildet.

I. Freilebend .

2. Durchmesser über $30 \mu$. . . . 1. Sph. magna

2*. Durchmesser bis $15 \mu$. . . . . 2. Sph. pusilla

$1^{*}$. Parasitisch, häufig ohne Tentakel . . . . . . . . 3

3. In Stentoren . . . . . . 3. Sph. stentoris

$3^{*}$. In anderen Infusorien . . . . . (2. Sph.pusilla)

I. Sph. magna Mps. (Taf. XIII, 42)

Tentakel zahlreich, von verschiedener Länge. Kern rund. Schwärmer an einem Ende bewimpert. Länge ca. $50 \mu$. In Sumpfwasser.

2. Sph. pusilla Cl. u. L.

Körper rundlich. Kern rund. Kontraktile Vakuole in der Einzahl. Länge ca. $15 \mu$. Freilebend oder ektoparasitisch an Oxytricha oder entoparasitisch in Stylonychia, Urostyla, Paramaecium etc. 
3. Sph. stentoris Mps.

Schwärmer am Hinterende bewimpert, vorn mit geknöpften Tentakeln, mit rundem Kern und zwei kontraktilen Vakuolen. Länge des Parasiten ca. $50 \mu$. Besonders in Stentor roeseli.

\section{Endosphaera Engelm.}

Vorigem Genus sehr ähnlich. Knospenbildung ist jedoch endogen. Schwärmer vorn oder in der Mitte mit Ciliengürtel, stets ohne Tentakel. Parasitisch im Innern von Vorticellen und - Suctorien. Eine auf ihre Entwicklungsgeschichte noch nicht näher untersuchte, nur entoparasitische Form (Taf. XIII, 44).

\section{Podophrya Btschli.}

Körperform kugelig; Tentakel von der ganzen Oberfläche sich erhebend. Länge des Stieles sehr verschieden. Kern central gelegen, oval. Meist nur eine kontraktile Vakuole. Vermehrung durch Zerschnürung in nahezu gleiche Teile. Schwärmer mit breitem Ciliengürtel.

1. Kern gross, Tentakel mässig fein . . . 1. P. fixa

1*. Kern klein, Tentakel sehr lang und fein 2. P. libera

1. P. fixa Ehrbg.

Tentakel von verschiedener Länge, desgleichen der Sticl. Kern nierenförmig. Vakuole in der Ein- oder Zweizahl. Durchmesser $10-28 \mu$. Cysten tonnenförmig, mit ringförmigen Graten. In Altwasser, sehr häufig; saugt grosse Infusorien, selbst Oxytrichinen, aus.

2. P. libera Py. (Taf. XIII, 45)

Stielbildung nur selten. Tentakel von verschiedener Länge. Grösse etwa wie bei voriger Art. Cyste oval, mit Ringleisten.

\section{Tokophrya Btschli.}

Aehnlich Podophrya, jedoch mit endogener Knospenbildung. I. Stiel ziemlich dick, nach vorn $z u$ an Dicke zunehmend . 2 2. Tentakel nicht in Büscheln . . . . . . . . . 3 3. Kern hufeisenförmig . . . . . . . . . 4 4. Körper oben mit lappigem Fortsatze . . . : . 4*. Körper oben ohne Fortsatz . 2. T. cothurnata 
$3^{*}$ Kern verzweigt. . . . . 3. T. steini

$3^{* *}$ Kern oval . . . . . . . 4. T. lichtensteini

2*. Tentakel in Büscheln

5. Körper fünf bis sechs Mal so lang als breit . . . .

5. T. elongata

$5^{*}$. Körper rundlich oder länglich rechteckig 6. T. astaci I*. Stiel fein, von gleichmässiger Stärke . . . . . . . 6

6. Nur ein Tentakelbündel vorhanden . . . 7. T. carchesii

6*. Mehrere Tentakelbündel vorhanden . . . . . . . . . 7

7. Stiel kurz . . . . . . . 8. T. cyclopum

7*. Stiel lang . . . . . . . . . . . . . . . 8

8. Vier Tentakelbündel . . . . 9. T.quadripartita

8*. Drei Tentakelbündel . . . . . Io. T. pyrum

I. T. ferrum equinum (Cl. u. L.)

Körper glatt, nierenförmig, oben mit lappigem Vorsprung.

Stiel breit und kurz, in den Körper eintretend. Kern hufeisenförmig. Vakuolen zahlreich am Rande des Körpers. Auf Hydrophitus piceus.

2. T. cothurnata (Cl. u. L.) (Taf. XIII, 46)

Körper flach, oval oder nierenförmig. Stiel kurz und breit. Tentakel oben, glorienförmig. Kern hufeisenförmig. Vakuolen zahlreich am Rande des Körpers. Länge $10 \mu$. Auf Lemnen, Callitriche etc.

3. T. steini (Cl. u. L.)

Körper birnförmig. Stiel oben breit, nach unten dünner. Tentakel zerstreut, zahlreich. Kern verzweigt. Vakuolen zahlreich. Auf Opercularia articulata.

4. T. lichtensteini (Cl. u. L.)

Stiel wie bei voriger Art. Kern oval, Tentakel in zwei Bündeln. An Wasserkäfern.

5. T. elongata (Cl. u. L.)

Körper 5-6 Mal so lang als breit. Tentakel oben, unten und in zwei mittleren Bündeln. Stiel breit, gestreift. Kern bandförmig. Vakuolen zahlreich. Auf Paludina vivipara.

6. T. astaci (St.)

Körper rundlich oder länglich rechteckig. Stiel dick, nach unten dünner. Tentakel in vier Bündeln an den vier Ecken. Kern oval. Vakuolen zahlreich. Länge bis $30 \mu$. An Flusskrebsen, besonders an den Borsten der Afterfüsse. 
7. T. carchesii (Cl. u. L.)

Körper eiförmig, oben rundlich, unten verengt, mit einem Tentakel-Bündel; in dessen Nähe eine Vakuole. Kern oval. Länge 25-70 $\mu$. Auf Carchesium polypinum.

8. T. cyclopum (Cl. u. L.)

Körper fast eiförmig, oben rundlich, unten eingeschnürt; Stiel meist kurz. Tentakel in 2-5 Bündeln. Kern oval; Vakuolen $\mathrm{n}$ der Ein- oder Zweizahl. Länge $50 \mu$. Auf Cyclops quadricornis und Lemnen.

9. T. quadripartita (Cl. u. L.) (Taf. XIII, 47)

Körper fast eiförmig, unten verengt; mit langem Stiel, oben mit vier Tentakelbündeln auf vortretenden Warzen. Kern oval. Meist eine oder zwei Vakuolen. Länge 80-100 $\mu$. Auf Epistylis plicatilis, Paludinen etc.

\section{Iо. T. pyrum (Cl. u. L.)}

Körper birnförmig, graubraun; Stiel lang und breit. Tentakel in drei Bündeln: eins oben und zwei seitlich; zwei Vakuolen: eine oben, eine seitlich. Kern oval, dick. Länge $150 \mu$. Auf Lemnen.

\section{Acineta Ehrbg.}

Gehäuse den Körper ganz oder teilweise umhüllend. Kern rundlich oder gestreckt. Knospenbildung wahrscheinlich nur endogen. Schwärmer mit Wimpergürtel oder mit vollständigem Cilienkleid.

\section{A. linguifera Cl. u. L. (Taf. XIII, 48)}

Gehäuse kurz gestielt, seitlich zusammengedrückt, an den beiden schmalen Seiten tief eingebuchtet. Kern bandförmig ausgezogen. Länge etwa $200 \mu$. Auf Wassertieren und Pflanzen.

Bei der ähnlichen $A$. grandis $\mathrm{S}$. K. füllt das Tier das auf langem Stiele sitzende Gehäuse nicht ganz aus.

\section{Solenophrya Cl. u. L.}

Gehäuse stiellos. Tentakel in Büscheln.

S. crassa Cl. u. L. (Taf. XIII, 49)

Gehäuse oval, trogförmig, gelb. Länge bis $160 \mu$. An Lemnenwurzeln. 
Io. Trichophrya Cl. u. L.

Körperform rundlich oder gestreckt;' unregelmässig gelappt. Knospenbildung endogen.

T. epistylidis Cl. u. L. (Taf. XIII, 5o)

Körper lang, schmal, mit zahlreichen Tentakelbündeln. Kern bandförmig, gekrümmt. Vakuolen zahlreich. Länge $240 \mu$. An Epistylis-Stielen.

\section{Dendrosoma Ehrbg.}

Körper mit langen, zweigartigen, oft senkrecht zur Unterlage sich erhebenden Fortsätzen, an die sich Verästelungen zweiter und dritter Ordnung anschliessen können. An ihren knopfförmigen Enden tragen diese Fortsätze je ein Tentakelbündel. Kern verästelt. Vakuolen sehr zahlreich. Fortpflanzung wie bei voriger Gattung.

D. radians Ehrbg. (Taf. XIII, 51)

Körperfarbe bräunlich. Länge $60 \mu$ bis $2,4 \mathrm{~mm}$.

\section{Dendrocometes St.}

Körper etwa halbkugelig, mit chitiniger Grundfläche; mit meist vier Fortsätzen, deren jeder sich zwei Mal dreigabelig teilt. Jedes Zweigende mit einigen kurzen, ungeknöpften Tentakeln. Kern oval. Vakuole mit deutlichem Ausführungsgange. Knospung endogen.

D. paradoxus St. (Taf. XIII, 52)

Länge bis $100 \mu$. Auf Kiemen von Gammarus pulex und G. puteanus.

\section{Stylocometes St.}

Körper halbkugelig, in der Mitte der Grundfläche mit einem Haftring. Tentakel fingerförmig, ungeknöpft, auf der ganzen Apikalseite entspringend. Kern oval oder langgestreckt. Kontraktile Vakuole randständig. Fortpflanzung wie bei voriger Gattung.

St. digitatus Cl. u. L. (Taf. XIII, 53)

Länge bis $110 \mu$. Auf Kiemen von Asellus aquaticus und an Stöcken von Ophrydium versatile. 


\title{
II. Rotatoria
}

\author{
(Rädertiere).
}

\section{Litteratuir:}

Ehrenberg, Die Infusionstierchen als vollkommene Organismen. Leipzig I $83^{\circ} 8$.

Dujardin, Histoire naturelle des Infusoires. Paris $\mathbf{1} 84 \mathbf{I}$.

Leydig, F., Ueber den Bau und die systematische Stellung der Rädèrtiere. Zeitschr. für wissensch. Zool.; Bd. 6, i854.

Eckstein, K., Die Rotatorien der Umgegend von Giessen. Zeitschr. für wissensch. Zool,, Bd. 39,1883 .

Plate, L., Beiträge zur Naturgeschichte der Rotatorien. Jenaische Zeitschrift für Naturwissenschaften. Bd. 19. Jena I 885.

Hudson, C. T. and P. H. Gosse, The Rotifera or Wheel-Animalcules. London $1886-89$.

Janson, O., Versuch einer Uebersicht über die Rotatorien-Familie der Philodinaeen. Beilage zum I 2. Bande der Abhandl. des Naturw. Vereins zu Bremen. Bremen I 893 .

Weber, E.F., Faune rotatorienne du bassin du Léman. Revue Suisse de Zoologie. Bd. 5, 1897 .

Kirchner und Blochmann, Mikroskopische Pflanzen- und Tierwelt des Süsswassers. Bd. 2. I. Aufl. Braunschweig 1886.

Die Rädertiere stehen mit den bisher hier beschriebenen Tierformen in keiner näheren verwandtschaftlichen Beziehung. Sie sind vielzellig, gehören also den Metazoen an. Ihre systematische Stellung ist zwar nicht völlig sicher; doch ist man darüber einig, dass sie in die Nähe des Würmerreiches zu stellen sind.

Der Körper der Rotatorien ist im allgemeinen schlauch- förmig, streng bilateral.symmetrisch und zeigt eine deutliche Verschiedenheit der Rücken- und Bauchseite. Aeusserlich ist er von einer festen, homogenen, gewöhnlich durchsichtigen Haut bekleidet, die mittelst ringförmiger Hautfalten dem Körper eine Art segmentaler Gliederung verleiht und so eine Unterscheidung von Kopf, Rumpf und Fuss gestattet. Die äussere Haut ist chitinös, ist also in Kalilauge unlöslich. Sie ist völlig strukturlos. Während sie bei einer grossen Anzahl von Formen weich, biegsam und selbst faltig bleibt, zeigt sie bei anderen Gattungen 
eine panzerartige Erhärtung. Gewöhnlich beschränkt sich die Bepanzerung auf das Rumpfsegment, welches das weiteste ist, und worein Kopf und Fuss ganz oder teilweise zurückgezogen werden können. Nur bei den Dinochariden sind auch Fuss und Kopf mit besonderem Panzer ausgerüstet. Ist die Cuticula des Rumpfes weich, so zeigt sie meist keinerlei Skulpturen, sondern ist völlig glatt. Dornen finden sich auf ihr bei Philodina aculeata, flossenförmige Anhänge bei Polyarthra, ein kleines Schwänzchen am Hinterende bei Copeus labiatus und Notomimata tripus. Bei panzerartiger Erhärtung hingegen besitzt die Cuticula häufig charakteristische Skulpturen, so namentlich Leisten, Kiele, Facetten; häufig erscheint sie narbig oder gekörnelt; vorn oder hinten oder an beiden Enden ist sie zuweilen mit spitzen Dornen besetzt Vielfach besteht der Panzer nur aus einem einzigen etwa tonnenförmigen Stücke, das oben und unten mit einer Oeffnung für Kopf und Fuss versehen ist; doch setzt er sich häufig auch aus zwei oder mehr diskreten Platten zusammen, die durch eine zarte Cuticular-Verbindung vereinigt werden. Aeusserlich ist die Cuticula zuweilen klebrig, so dass die Tierchen an einander oder an fremden Gegenständen kleben bleiben (Colurus). Eine Gallertschichte findet sich über dem Panzer bei Copeus labiatus. Manche Formen sind umgeben von einer abstehenden Gallerthülle, die häufig durch regelmässige Auflagerung kleiner, pillenförmiger Fremdkörper verstärkt ist. Jene Fremdkörper bestehen aus dem eigenen Kote der Tiere und aus zufällig in die Nähe gelangten Schlammpartikelchen; geformt werden die "Pillen“ in einer in der Nähe des Mundes gelegenen, grubenartigen Vertiefung (Melicerta).

Die Cuticula wird erzeugt durch eine unter ihr lagernde Hypodermis. Die letztere zeigt keine Sonderung in Zellen, ist also ein Syncytium, und besitzt eine schwammige Struktur (deutlich sichtbar bei Asplanchna). Hin und wieder finden sich Kerne in sie eingestreut. Am Kopfe ist sie besonders stark entwickelt und zu halbkugeligen, polsterförmigen Partien verdickt, denen unten die Wassergefässe und Muskelfäden angeheftet sind. Häutung ist bisher noch nicht beobachtet. Zwar findet man oft leere Häute, aber fast stets mit Kiefer-Rudimenten im Innern, also von abgestorbenen Tieren.

Charakteristisch für die Rädertiere ist der am Vorderende befindliche, gewöhnlich einziehbare Wimper-Apparat. Die be- 
ständigen Schwingungen dieser Wimpern erregen kleine Strudel im Wasser, die entweder das Tier selbst fortbewegen oder, wenn letzteres sich mit dem Fusse festheftet, ihm Nahrungsstoffe herbeiziehen. Dem Beschauer verursacht dieses Wimperspiel eine merkwürdige optische Täuschung. Die Wimpern schwingen nämlich nicht gleichzeitig, sondern einzeln oder gruppenweise in fortlaufender Reihenfolge um ihre Basis und sind nur in dem Augenblicke sichtbar, in dem sie die Fokaldistanz des Objektes passieren, während der übrigen Zeit ihrer kegelmantelförmigen Bahn hingegen nicht. Dadurch nun, dass sie in fortlaufender Reihenfolge im Gesichtsfelde erscheinen und verschwinden, entsteht der Eindruck, als ob sie auf dem Rande des Kopfschirmes fortliefen, oder als ob dieser selbst sich wie ein Zahnrad um seine Achse drehe. Die älteren Forscher glaubten dies wirklich und nannten darnach die Tierchen Rotatorien (Rädertiere).

In seiner typischen Ausbildung besteht der Wimper-Apparat aus zwei Cilienreihen, einer äusseren und einer inneren. Die erstere, das Cingulum genannt, zeigt feine, sehr bewegliche Wimpern; die letztere, Trochus genannt, besitzt hingegen gewöhnlich lange, starke Wimpern. Das Cingulum setzt sich in die Mundöffnung hinein fort; der Trochus liegt dorsalwärts von der Mundöffriung und tritt mit ihr in keine nähere Verbindung. Beide Wimperkränze entsprechen wahrscheinlich den beiden vorderen Cilienschnuren der Trochosphaera-Larve; man nennt daher den Trochus auch praeoralen, das Cingulum auch postoralen Wimpernring.

Im einzelnen zeigt die Bewimperung die grösste Mannigfaltigkeit. Selten ist das Cingulum zu dominierender Ausbildung gelangt. Dies ist der Fall bei den Flosculariden. Hier umsäumt der mächtig entwickelte Aussenkranz den Rand des Mundtrichters, in dessen Grunde sich der stark reduzierte Trochus befindet. Der Rand dieses Mundtrichters ist bei Floscularia in 5-6 kurze, geknöpfte Zipfel ausgezogen, welche Büschel von sehr langen, steifen Haaren tragen, bei Stephanoceros in fünf lange Arme mit kurzen, wirtelförmig gruppierten Wimpern. Bei weitem häufiger ist der Innenkranz gegen das Cingulum vorherrschend; namentlich zeigen seine Cilien die Tendenz, sich zu starken Borsten umzuwandeln, die dann gewöhnlich ihre lebhafte Beweglichkeit einbüssen und an die Griffel der hypotrichen Infusorien erinnern. Deutlich zu erkennen ist der Doppelsaum bei gewissen Hydatinäen, 
wie durch Grenacher bei Microcodon nachgewiesen wurde. Vielfach hingegen zeigt der Trochus im ventralen und dorsalen Medianpunite Unterbrechungen und kann selbst in eine Anzahl borstentragender Polster aufgelöst sein. (Nach P1ate.)

Der Fuss bildet in der Regel die direkte Verlängerung des Körpers, wird aber oft nach der Bauchseite umgeschlagen. Nur bei der Gattung Pterodina entspringt er in der Mitte der Ventralseite. Bei manchen Formen ist der Fuss nur quergeringelt, selbst stielartig und am Ende mit Borsten besetzt; gewöhnlich aber besteht er aus mehreren deutlichen Gliedern und kann ganz oder teilweise in den Rumpf eingezogen werden. Meist sind auch die einzelnen Segmente in einander teleoskopartig einstülpbar. Die absolute wie auch die relative Länge der Glieder schwankt zwischen weiten Grenzen. Gewöhnlich sind drei Fussglieder entwickelt; deren letztes meist zwei getrennte Zehen trägt. Jede der letzteren ist mit besonderer Muskulatur und mit Drüsen ausgerüstet; vielfach sind auch Nebendornen ausgebildet. Daneben finden sich am Fusse hin und wieder borstenartige Anhänge. Seltener ist das Endglied des Fusses mit nur einer Zehe ausgestattet. Bei einigen Gattungen fehit der Fuss ganz.

Der Verdauungstraktus lässt stets mehrere deutlich getrennte Abschnitte unterscheiden. Die Mundöffnung ist nur bei wenigen Formen im Centrum des äusseren Wimperkranzes gelegen; gewöhnlich ist sie ventralwärts verschoben und liegt zwischen Cingulum und Trochus. An die inwendig bewimperte Mundhöhle setzt sich bei einigen Gattungen (Floscularia, Stephanoceros) eine Rachenhöhle an, die dann mit der ersteren nur durch eine kleine Oeffnung kommuniziert. Gewöhnlich folgt direkt ein eigentümlicher Kauapparat, der Schlundkopf. Von seiner Rückseite führt ein meist enger Schlund in den längs des Rückens sich erstreckenden Magen, an den (mehr oder weniger scharf abgesetzt) ein Darmrohr sich anschliesst.

Der Schlundkopf oder Kauer (Mastax) besteht aus einem hornigen (chitinisierten) Kiefergerüst, woran - wie an das Knochengerüst der höheren Tiere - kräftige Kaumuskeln sich anheften, so dass nur die vorderen Enden als Zähne frei austreten. Der Bau des Kiefergerüstes ist ziemlich kompliziert. Zunächst lagert in der ventralen Medianlinie ein etwa prismatisch gestaltetes Stück, das Fulcrum. Es dient zur Stütze zwei divergierenden, am oberen Innenrande gezähnelten Gliedern, den 
Rami. Rami und Fulcrum bilden zusammen den Incus. An der freien Spitze eines jeden Ramus setzt sich ein etwa hammerförmiges Stück an, der Malleus. Letzterer zeigt wiederum zwei deutlich verschiedene Glieder: ein oberes, inneres, mit starker Bezahnung versehenes, bewegliches, den Uncus; und ein dem zugehörigen Ramus paralleles, das Manubrium.

Form, Stärke und relative Lage der einzelnen Teile des Kiefergerüstes sind bei den verschiedenen Arten sehr abweichend, und demnach zeigt auch die äussere Form des Kauers alle möglichen Modifikationen. Bald ist er annähernd kugelig oder herzförmig, bald würfelförmig, tetraëdrisch, konisch oder cylindrisch.

Bei der Gattung Ascomorpha sind die Kiefer ganz verkümmert.

Neben, unter oder über dem Kauer sitzen grössere oder kleinere Drüsen, die als Speicheldrüsen anzusehen sein werden. Sie sind häufig vom Kauer ganz verdeckt und deshalb schwer deutlich zu unterscheiden, obwohl sie meist etwas gefärbt sind. Zwischen dem Kauer und der Mundöffnung ist bei vielen Arten ein aus grossen Blasen bestehendes Zellgewebe sichtbar.

Der Schlund (Oesophagus) ist eine meist enge, aber sehr dehnbare Röhre. Seine Wandungen sind in dèr Regel bewimpert; nur bei Synchaeta und Asplanchna fehlt die Bewimperung; bei ersterer wird die Nahrung durch eine Art peristaltischer Bewegungen in den Magen übergeführt; bei letzterer ist am Schlunde eine starke Längsmuskulatur entwickelt. Auch bei Scaridium longicaudum und Metopidia lepadella flimmert der

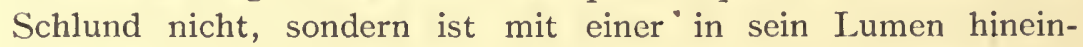
ragenden Längsfalte versehen, an der wellenförmige Bewegungen von vorn nach hinten herablaufen. (Nach Plate.)

Der Magen ist ein rundlicher oder länglicher Schlauch, dessen dicke Wandungen meist aus sehr grossen, .halbkugelig hervorgewölbten Zellen mit hellen Kernen und braunkörniger Masse bestehen, die.häufig auch gelbe Fett-Tropfen einschliessen. Innerhalb sind dic Magenzellen mit Flimmer-Epithel bekleidet. Das Gleiche gilt vom Darme, der bald länger bald kürzer als der Magen und von sehr verschiedener Gestalt ist. Oft verläuft der ganze Traktus gleichmässig vom Schlund bis zum After; bei ermatteten Tieren schwindet auch die Striktur, weshalb Ehrenberg vielen Rotatorien nur einen einfachen, konischen Darm zuschrieb. Bei starker Füllung sind aber beide Teile des Traktus 
stets wohl $\mathrm{zu}$ unterscheiden. Bei manchen Arten ist der Darm länger als die Leibeshöhle und deshalb nach dem Rücken zu S-förmig (Euchlanis) oder, wie bei den Tubicolarinen, welche die Kloake im Nacken haben, selbst hufeisenförmig gebogen. Bei den Tieren, die sich stark kontrahieren, bildet er eine Schlinge (Philodinen). Die Wandungen des Darmes und des Magens zeigen selbständige Kontraktion, haben also eine eigene Muskellage. Die innere Bewimperung ist im Darm besonders stark; sie bringt häufig - besonders bei sterbenden Tieren - den ganzen Inhalt in wimmelnde Bewegung.

Am Eingange des Magens finden sich bei allen Rotatorien zwei seitliche, drüsige Organe von wechselnder ( Gestalt, die häufig mit breiter Basis der Magenwand aufsitzen und kolbenförmig, nierenförmig, gelappt oder gestielt erscheinen. Diese Drüsen bestehen, wie die des Schlundkopfes, aus blasser Substanz mit hellen, Nukleolen führenden Kernen, zuweilen auch mit kleinen Fett-Tröpfchen. Die einzelnen Zellen sind nicht durch Membranen getrennt. Im Innern scheidet sich ein körniges Sekret aus, das wahrscheinlich zur Unterstützung der Verdauung in den Magen gelangt. Bei matten, abgezehrten 'Tieren sieht man die Drüsen entleert und zusammengeschrumpft.

Am Ende des Rumpfes, vor denı ersten Fussgliede, liegt ein Paar kolbenförmiger Drüsen, die leicht für Muskeln angesehen werden können. Sie bestehen im Innern aus einer homogenen, nicht in Zellen geschiedenen Plasma-Masse mit grossen eingestreuten Kèrnen; begrenzt sind sie nach aussen von einer strukturlosen, dünnen Membran. Sie liefern ein klebriges Sekret, das in die Zehen gelangt und zum Anheften des Tieres dient. Eine feine Oeffnung ist am Ende der Zehen bei vielen Arten bemerkt, und hinter dem griffelförmigen Endgliede von Mastigocerca carinata u. a. sieht man häufig auf dem Objektträger einen làngen Streifen feinkörniger, klebriger Masse; auch sieht man die Tiere oft grosse Anstrengungen machen, um sich loszureissen. Namentlich an den Brachionen beobachtet man häufig, dass sie sich unruhig umherwerfen. Meist sind die. Klebedrüsen in der Zweizahl vorhanden; nur bei starker Reduzierung der Zehen ist nur eine solche Drüse entwickelt, so bei Synchaeta und Rhinops. Bei Monocerca und Diurella sind die Klebedrüsen zu einer grossen, kontraktilen Blase umgewandelt, die bei der Zusammenziehung eine klebrige, rasch erhärtende Flüssigkeit entleert. 
Die Leibeshöhle ist ganz mit wässeriger, meist farbloser, zuweilen rötlich oder gelblich gefärbter Flüssigkeit erfüllt. Zuweilen sieht man helle Kügelchen darin cirkulieren. Ein Cirkulations-System ist nicht vorhanden.

Das Exkretions-System besteht aus langen, zu beiden Seiten des Tieres vom Kopfe herablaufenden, meist einfachen, zuweilen doppelten oder in ihrem Verlaufe anastomosierenden Kanälen mit dicken, zelligen, häufig Fettpünktchen enthaltenden Wandungen und engem Lumen. Ihr Verlauf ist vielfach geschlängelt, an bestimmten Stellen finden sich Duplikaturen oder Knäuel; an einigen Punkten sind sie der Cuticula angeheftet. An diesen Kanälen oder an besonderen, neben ihnen verlaufenden Fäden sitzen - ebenfalls an bestimmten Stellen - kleine, gestielte, cylindrische oder trompetenförmige (notenförmige) Anhänge, die gegen die Leibeshöhle geschlossen sind und im Inneren Flimmercilien enthalten. Diese sind in kontinuierlichen, von aussen nach innen verlaufenden, wellenförmigen Schwingungen, wonach sie „Zitterorgane" genannt sind. Ihre Zahl variiert sehr bei den verschiedenen Arten; meist sind 4, 8 oder 10, bei einigen viele (bis 50) vorhanden. Die beiden Kanäle münden gewöhnlich am Ende der Leibeshöhle in eine gemeinschaftliche, mit einem Netzwerk von Muskeln bedeckte, äusserst dehnbare und kontraktile Blase, die ihrerseits einen Ausführungsgang in den unbewimperten Endteil des Darmes hat, der hierdurch zur Kloake wird. In der Blase sammelt sich eine wässerige Flüssigkeit an, die von Zeit $\mathrm{zu}$ Zeit in ziemlich regelmässigen Intervallen durch plötzliche Kontraktion in dic Kloake entleert wird. Die Grösse der Blase ist sehr verschieden; bei einigen Arten ist sie so gross, dass sie im expandierten Zustande einen bedeutenden Teil der Leibeshöhle ausfüllt, bei anderen 'bleibt sie sehr klein. Bei einigen fehlt sie ganz, so dass beide Kanäle bei ihrem Zusammentritt direkt in die Kloake münden.

Die Bewegungen der einzelnen Körperteile werden durch ein stark entwickeltes Muskelsystem bewirkt. Die Muskeln sind teils sehr einfacher Natur. Gewöhnlich zeigen sie ein feinkörniges, centrales oder peripheres Plasma und eine zarte, strukturlose Membran. Einige Arten haben quergestreifte Muskeln (Scaridium longicáudum, Euchlanis triquetra, Pterodina patina u. a.) Häufig finden sich beide Arten in allen möglichen Uebergängen in eincm Individuum. Am stärksten ausgebildet sind die breiten 
oder runden Längsmuskeln, die - jederseits meist in zwei Paaren - nahe dem Ende des Rumpfes mit breiten, oft zerschlitzten Enden der Cuticula angeheftet sind und frei durch die Körperhöhle nach dem Kopfe verlaufen, in welchem sie sich verzweigen. Andere Längsmuskeln gehen vom mittleren Teile des Rumpfes nach der Fussbasis und in den Fuss hinein bis zu den Zehen; sie bestehen aus verschiedenen Strängen, die teils den einzelnen Fussgliedern, teils der Basis der Zehen angeheftet sind. Nicht minder kräftig entwickelt als diese Längsmuskeln sind - im Rumpfe - andere unter sich parallel und rechtwinklig zur Längsachse des Körpers geordnete, die dicht unter der Cuticula mehr oder weniger lange Ring-Elemente bilden. Bei manchen Arten sind auch diese Muskelzüge breit, bandförmig, bei anderen hingegen rund; sie bilden entweder nur kurze Bänder zu beiden Seiten des Körpers (Brachiomıs), oder sie laufen auf der Dorsalseite von einer Körperseite zur anderen. Auf der Bauchseite sind sie stets unterbrochen. Häufig sind je zwei benachbarte noch durch schräg laufende Fäden verbunden. Bei grösseren Arten sind die Ringmuskeln naturgemäss zahlreicher als bei kleinen. Manche Arten haben am Vorderteile des Rumpfes noch eine Anzahl dünnere, nicht weit von einander verlaufende, vollkommen geschlossene, häufig unter einander verbundene Ringmuskeln, die vielfach anastomosieren (Asplanchna priodonta).

Die Kontraktion der Ringmuskeln erzeugt häufig Längsfalten in der Cuticula und andere starke Difformitäten in der äusseren Gestalt der Tiere, auch werden durch sie die Längsmuskeln oft mehr oder weniger zusammengeschnürt. Die Halsringe schnüren bei ermatteten Tieren oft die Halsöffnung fast ganz zu (Asplanchna priodonta). Die Kontraktion der Längsmuskeln bewirkt die Einziehung des Kopfes resp. des Fusses in den Rumpfteil des Körpers, wobei letzterer zugleich verkürzt und in der Mitte bauchig aufgetrieben wird. Die Wiederausdehnung des Körpers scheint nicht durch Muskeln, sondern lediglich durch die Elastizität der Cuticula bewirkt $\mathrm{zu}$ werden.

Weniger kräftig als die vorhin bezeichneten Längsmuskeln sind andere, die der seitlichen Bewegung des Kopfes und Fusses dienen. Noch feinere Muskeln und Bindegewebsstränge halten die inneren Organe: Magendrüsen, Magen, Eierstock, in ihrer Lage oder erteilen ihnen bestimmte Bewegungen. Besonders wird der Magen beständig hin und her oder auf und nieder ge- 
worfen. An diesem feinen, meist verästelten Bindegewebe gewahrt man bei grösseren Arten auch häufig noch Ausläufer von kleinen, verzweigten Zellen, die frei in der Leibeshöhle flottieren und zuweilen kugelig aufgetrieben sind (Asplanchna brightwelli).

Weit einfacher als das Muskelsystem ist das Nervensystem der Rotatorien. Es ist nur bei den grösseren Arten, und selbst bei diesen nicht immer, deutlich erkennbar. Es besteht in der Hauptsache aus einem oft ziemlich umfangreichen Gehirnganglion, von dem einzelne Nervenfäden nach den Tastorganen gehen. Unmittelbar an diesem Hirnganglion sitzen die als Augen dienenden Pigmentflecke. Ist nur ein Auge vorhanden, so sitzt es meist an der Unterseite des Ganglions dicht über dem Schlundkopfe, selten an der Stirn (Furcularia). Wenn zwei Augen vorhanden sind, so befinden sich diese meistens an der Stirn, sind aber bei manchen Arten nur an jungen Tieren sichtbar und verschwinden später. Bei sehr vielen Rotatorien unterscheidet man an diesen Augen deutlich einen rundlichen, hellen, lichtbrechenden Körper und einen darunter liegenden, rot oder braun gefärbten Pigmentbecher, der dem Näpfchen einer Eichel vergleichbar ist. Häufig sitzt das Auge auch auf einer Hervorwölbung des Hirnknotens. Bei einigen einäugigen Rotatorien befinden sich neben dem eigentlichen Auge noch seitliche Pigmentpartien. Andererseits kommen auch ungefärbte Augen vor; bei einigen Gattungen endlich scheinen die Augen ganz zu fehlen, wenigstens sind solche noch nicht wahrgenommen.

Hinter dem Hirnganglion, meist diesem aufliegend oder angeheftet, finden sich bei vielen Rotatorien noch Klümpchen von weisser, opaker, bei durchfallendem Lichte also schwarz erscheinender Substanz, sogenannte Kalkbeutel (so bei vielen Notommata-Arten) oder auch durchscheinende, zellige Körper (Euchlanis), deren Bedeutung noch völlig rätselhaft ist.

Der weibliche Fortpllanzungs-Apparat besteht aus einem meist relativ grossen, unterhalb des Verdauungstraktus in der Bauchhöhle liegenden, platten, rundlichen oder hufeisenförmigen Eierstock. Dieser ist von einem dünnhäutigen Sacke eingeschlossen, der einen Ausführungsgang in die Kloake entsendet. Er besteht aus blasser, plasmatischer Grundmasse, worin grosse, homogene, längliche oder rundliche Kerne oder Keimflecke mit wasserhellem Hofe eingeschlossen sind. Durch Abschnürung eines Stückes vom Eierstock mit einem Kerne bildet sich das Ei. 
Die Rotatorien produzieren zweierlei Eier: dünnschalige Sommereier und dickschalige Winter- oder Dauereier. Letztere haben ausser der Dotterhaut eine von dieser oft durch einen Zwischenraum getrennte, oft gelbbraun oder rötlich gefärbte Schale, die äusserlich meistens mit Körnchen, Warzen, Facetten, Stacheln oder Haaren besetzt ist. Sie werden besonders im Frühjahre und im Herbst produziert und stets abgelegt und kommen auch erst nach einer längeren Ruhezeit zur Entwicklung, überdauern demnach sowohl das Eintrocknen der Gewässer im Sommer, wie das Einfrieren im Winter.

Die Sommereier entstehen augenscheinlich stets durch Parthenogenesis, d. h. bleiben unbefruchtet. Sie sind wiederum von zweierlei Art, je nachdem sich in ihnen Männchen oder Weibchen entwickeln. Letztere entstehen in weit grösserer Zahl als erstere. Hat aber ein Weibchen einmal angefangen, männiche Eier zu produzieren, so fährt es damit fort; nie werden beiderlei Eier zugleich gebildet. Wie die Männchen selbst, so sind auch die Eier, in denen sie, sich entwickeln, meist viel kleiner, oft kaum halb so gross, als die weiblichen. Die Sommereier werden meistens gleichfalls abgelegt und entwickeln sich ausserhalb des Tieres. Bei einigen Arten bleiben sie durch feine Fäden dem Muttertiere angeheftet, nicht allein bei den sesshaften Tubicolarinen, sondern auch bei frei beweglichen Formen (Brachionus, Anuraea, Polyarthra). Bei einigen Arten jedoch kommen die Sommereier konstant (Asplanchna) oder zu gewissen Zeiten (Philodinaeen) im Ei-Sacke des Tieres aus; dieser wird somit zum Uterus und das Tier lebendig gebärend. Diesem Umstande verdanken wir die erste Entdeckung der Rotatorien-Männchen (bei Asplanchna brightzvelli). Vorher waren zwar schon die Männchen einzelner Arten bekannt, wurden aber für besondere Arten oder für verkümmerte Tiere gehalten.

Bei der Entwicklung der Sommereier tritt - sei es', dass sie innerhalb, sei es, dass sie ausserhalb des Muttertieres erfolgt - zunächst (inaequale) Furchung des Dotters in der Nähe des einen Poles ein. Durch fortgesetzte Ablösung kleiner Partien zerfällt der Dotter in einen Haufen Furchungskugeln. Diese Furchungskugeln, die als Zellen mit soliden Kernen ohne sichtbaren Nukleolus erscheinen, bilden das Material zum Aufbau des Embryo. Letzterer zeigt bald Segmentierung des Körpers; auch der Kauer, besonders die Kiefer sind früh- 
zeitig erkennbar. Dann zeigen sich Wimpern am Kopfe und am Schwanz-Ende, ferner die Augen und bei vielen Arten in der Gegend der Kloake ein Haufen opaker Körperchen.

Bei den meisten Arten haben die Jungen sogleich die Gestalt der Alten, einige aber, besonders die Tubicolarinen, erleiden eine durchgreifende Metamorphose; bei Triarthra sind wenigstens die Flossen nicht sogleich fertig gebildet. Bei Tubicolaria und Melicerta werden die Taster und Räderorgane erst nach dem Ausschlüpfen entwickelt, während die im Ei gebildeten Augen allmählich eingehen. Am stärksten aber ist die Metamorphose bei Floscularia und Stephanoceros; diese schlüpfen als keulenförmige, mit Stirnwimpern versehene Larven aus, die.wenigstens bei Floscularia - eine Zeit lang umherschwärmen, bevor sie sich festsetzen und ihre bewimperten Arme entwickeln, während die Augen schwinden und der Schlundkopf weiter nach unten rückt. Auch der Wimperbesatz am Fuss-Ende geht bei den meisten Arten ein.

Die männlichen Rotatorien sind nur bei wenigen Formen den Weibchen an Gestalt und Grösse ähnlich; meistens sind sie viel kleiner, von vielen Arten sind sie noch nicht bekannt. Vor allem fehlt ihnen der ganze Verdauungs-Apparat. Wassergefässe, Blase, Muskel - und Nervensystem sind zwar vorhanden, aber weniger deutlich wahrnehmbar als bei den Weibchen, zumal die Tiere gewöhnlich ausserordentlich unruhig sind. Den grössten Teil der I-eibeshöhle füllt ein birn- oder kugelförmiger, dickwandiger Hoden, der mittels eines muskulösen Bandes am Kopfe befestigt ist, nach hinten einen langen, mit Flimmerhaaren ausgekleideten, ausstülpbaren Ausführungsgang in die Kloake hat. Am hinteren Ende des Hodens sind zwei mit opaken Körnchen angefüllte Drüsen angeheftet. Die Spermatozoen sind verhältnismässig grosse Spiralbänder mit dickem Kopfe. Die Begattung ist direkt erst bei wenigen Arten beobachtet. Bei einigen sieht man die Männchen sich den Weibchen seitlich oder am Halse anheften, ohne dass dort eine Oeffnung erkennbar ist. Bei Diglena catellina wurde eine Anheftung an die Kloakenmündung gesehen. Jedenfalls gelangen die Spermatozoen frei in die Ieibeshöhle der Weibchen; ihr Eindringen in die Eier jedoch ist noch nicht beobachtet, so dass es zweifelhaft ist, ob befruchtete Eier von den Weibchen überhaupt abgelegt werden. 
Von besonderem Interesse sind die schon von Leeuwenhoek beobachteten Anabiose-Erscheinungen zahlreicher Rotatorien, die im wesentlichen darin bestehen, dass die Tiere selbst nach jahrelangem Trockenliegen bei neuer Wasserzufuhr wieder aufleben können. Namentlich Gavarret hat diese Frage experimentell angegriffen und gefunden, dass viele Rädertiere eine trockene Hitze von $110^{0} \mathrm{C}$. leicht ertrugen; bei Erhitzung der Tiere im Wasser trat dagegen bereits bei einer Temperatur von $50^{\circ}$ bei allen Individuen der Tod ein, während $47^{\circ}$ noch ohne Schaden ertragen wurden. Die Richtigkeit dieser Angaben ist vielfach in Zweifel gezogen worden, so in erster Linie von Faggioli und Zacharias. Beiden gelang es nicht, Rädertiere, die länger als zwei Minuten im Uhrschälchen trocken gelegen hatten, wieder ins Leben zurückzurufen. Allein abgesehen davon, dass negative Befunde gegenüber positiven nicht die geringste Beweiskraft besitzen, verläuft die Eintrocknung im Uhrschälchen viel zu schnell, als dass die Tiere genug Zeit zu etwaigen Schutzvorkehrungen hätten. Höchst wahrscheinlich sind zahlreiche Rotatorien im Stande, eine gallertige Hülle auszuscheiden, die einerseits dem Körper stets den nötigen Feuchtigkeitsgehalt sichert, andererseits aber in ihrer Eigenschaft als schlechter Wärmeleiter eine schnelle Abtötung durch trockene Hitze verhindert. In der Natur wird bei dem langsamen Austrocknen der Sümpfe und Mooszweige wohl stets Zeit genug zur Abscheidung dieses Gallert-Sekretes sein; nicht aber ist dies der Fall bei dem verdunstenden Wassertropfen im Uhrschälchen. So erklären sich ungezwungen die Misserfolge Faggiolis und die positiven Angaben der Mehrzahl der Rotatorienforscher. Wie gross die Widerstandsfähigkeit mancher Rädertiere gegen Trockenheit ist, geht aus einer Beobachtung Kerners von Marilaun hervor, dem es glückte, Individuen nach fünfjähriger Eintrocknung wieder $\mathrm{zu}$ beleben. Wahrscheinlich kommen die Anabiose-Erscheinungen nur einem Teile der Rotatorien zu. (Nach Janson.)

Die folgende systematische Uebersicht schliesst sich hauptsächlich an Weber an.

I. Ohne bauchständige Wimperstreifen, mit Räderorgan . .

$$
\text { I. Rotifera (S. 430) }
$$

I*. Mit bauchständigen Wimperstreifen, ohne Räderorgan

\section{Gastrotricha}




\section{Rotatoria.}

I. Körper ohne zum Springen dienende, armartige Fortsätze 2

2. Kopf mit langem, retraktilem Rüssel, Fuss teleoskopartig einziehbar . . . . . . . . II. Bdelloida (S. 437)

2*. Kopf ohne Rüssel . . . . . . . . . . . . . . 3

3. Weibliche Tiere dauernd festsitzend, mit Gehäuse oder Gallertscheide, häufig koloniebildend . . . .

I. Rhizota (S. 430)

3*. Weibliche Tiere nie festsitzend (wenn nicht parasitisch), nie mit Gehäuse oder Gallerthülle, nie koloniebildend III. Ploïma (S. 443) • • 4 4. Rumpf ungepanzert A. Illoricata (S. 443) 4*. Rumpf gepanzert . . B. Loricata (S. 459)

.1*. Körper mit langen, dicken, flossenartigen Fortsätzen, die zum Springen dienen . . . . . IV. Scirtopoda

\section{Rhizota.}

Die erwachsenen Weibchen sind stets von einer Gallertmasse umgeben, worein sie durch Kontraktion sich zurückziehen können. Die meist röhrenförmige Hülle ist ein Sekretionsprodukt und vielfach durch Schlammpartikelchen oder Faekalmassen verstärkt. Vielfach ist Koloniebildung vorhanden. Der Fuss ist lang, aber nicht ins Innere des Körpers zurückziehbar, er enđigt mit einer Haftscheibe oder mit einer stumpfen Spitze. Das Räderorgan ist gut entwickelt. Die Männchen sind stets frej, ohne Gehäuse und nie koloniebildend.

1. Wimpern in Gruppen an vorspringenden, schmalen Zipfeln des trichterförmigen Mundrandes . [I. Floscularidae (S. 43 I)] 2

2. Wimpern in zahlreichen parallel gerichteten Büscheln an fünf langen, schmalen, konvergierenden Armen

$$
\text { 2. Stephanoceros (S. 433) }
$$

2*. Wimpern in Büscheln von der Spitze der mehr oder weniger schmalen Zipfel ausstrahlend

$$
\text { I. Floscularia (S. 43I) }
$$

$1^{*}$. Wimpern in kontinuierlicher Doppelreihe, an dem kreisförmigen, nierenförmigen oder zwei- bis vierlappigen Räderorgan; Mund nicht im Centrum des Wimperkranzes gelegen [II. Melicertidae (S. 433)] 3 
3. Tiere einzeln in Gehäusen, meist nicht koloniebildend 4 4. Ausser zwei kurzen ventralen Tastern, ein grosser dorsaler . . . . . 4. Cephalosiphon (S. 435)

$4^{*}$. Dorsaler Taster höchstens durch einen borstentragenden Knopf angedeutet, zwei grosse ventrale oder seitliche Taster vorhanden . . . . . . 5

5. Räderorgan vierlappig . . . . . . . . . 0 6. Hülle gallertartig . . 3. Tubicolaria (S. 435)

6*. Hülle mit Kügelchen aus Schlamm oder Kot bedeckt . . . . . . 1. Melicerta (S. 434)

5*. Räderorgan halbkreisförmig oder zweilappig . . 7

7. Dorsale Unterbrechung des Wimperkranzes nur klein . . . . . 5. Oecistes (S. 435)

7*. Dorsale Unterbrechung des Wimperkranzes gross

2. Limnias (S. 434)

$3^{*}$. Tiere stets koloniebildend . . . . . . . . . 8

8. Höchstens zwei ganz kurze ventrale Taster; Kolonien meist schwimmend . . . . . . . . . . . . . 9

9. Kolonien mit gemeinschaftlicher Gallerthülle . . .

9*: Ohne gemeinșchaftliche Gallerthülle

7. Lacinularia (S. 436)

6. Megalotrocha (S. 436)

8*. Ein oder zwei lange Taster vorhanden; Kolonien festsitzend. . . . . . 8. Conochilus (S. 437)

\section{Fam. Floscularidae.}

Kopfrand meist mit fünf bewimperten Vorsprüngen. Mund im Centrum des Vorderendes gelegen, trichterförmig. Im Grunde der Mundhöhlung befindet sich auf der ventralen Seite ein hufeisenförmiges Wimperband. Der Fuss ist meist lang, quer gestreift, nicht ins Körper-Innere zurückziehbar, mit einer Haftscheibe endigend. Kiefer hakenförmig. Die Männchen sind stets freilebend, klein, mit reduziertem Räderorgan und kurzem Fuss. Die Jungen sind keulenförmige Larven mit bewimpertem Kopf und Fuss-Ende und zwei deutlichen, roten Augen. Sie schwärmen eine Zeit lang umher, ehe sie sich festsetzen, um zur 
Stammform auszuwachsen. Die Augen gehen alsdann verloren.

\section{Floscularia Oken.}

Die erwachsenen Weibchen sind keulenförmig gestaltet, hinten verlängert in einen langen, geringelten Fuss. Körper eingehüllt in eine transparente, zuweilen mit Fremdkörpern behaftete, wahrscheinlich von den Fussdrüsen ausgeschiedene Gallertscheide. Zipfel des Kopfrandes mehr oder weniger lang, ihre Spitzen mit langen Borsten besetzt. Am Grunde des Mundtrichters befindet sich eine Höhlung, an die sich eine zweite ansetzt. Im Grunde der letzteren liegen die hakigen Kiefer. Exkretions-System besteht aus Blase und zwei mit je fünf Wimperfackeln versehenen Seitenkanälen. Gehirn deutlich sichtbar. Meist festgewachsen an Wasserpflanzen und Hölzern. Den Männchen fehlt ein Verdauungstraktus.

1. Kopfrand fünfzipfelig

2. Zipfel am freien Ende kugelig . . . . . . . . 3

3. Sämtliche Zipfel ziemlich gleichlang . . . . . .

1. Fl. coronetta

3*. Nur die vier ventralen Zipfel gleichlang; der fünfte, dorsale länger . . . . . . . . . . . : 4

4. Dorsalzipfel mit langem, wurmförmigem Fortsatz

2. Fl. cornuta

4*. Dorsalzipfel ohne Fortsatz . 3. Fl. ornata

$2^{*}$. Zipfel nicht kugelig, sondern abgerundet

4. Fl. proboscidea

I*. Kopfrand siebenzipfelig . . . . . 5. Fl. regalis

${ }^{* * *}$ Kopfrand ohne Zipfel . . . . . 6. Fl. edentata

I. Fl. coronetta Cubitt.

Zipfel schmal. Körper länglich. Hülle fast cylindrisch und sehr transparent. Dorsaler Taster leicht sichtbar; ebenso die Fussdrüsen. Länge $0,675-1,016 \mathrm{~mm}$.

2. Fl. comuta Dobie (F. appcndiculata Leydig) (Taf. XIV, 1)

Sehr ähnlich der vorigen Art. Wurmförmiger Fortsatz an der Basis des Dorsalzipfels zwei Mal so lang als letzterer. Haftscheibe des Fusses breit. Hülle lang, transparent. Augen gut sichtbar. Länge $0,508-0,635 \mathrm{~mm}$. Gemein. 
3. Fl. ornata Ehrbg.

Dorsalzipfel an der Basis dreieckig. Borsten lang. Die Zwischenräume zwischen den Zipfeln entbehren der Bewimperung. Fuss runzelig, oft mit Detritus behaftet. Die Augen sind gut sichtbar. Länge circa $0,508 \mathrm{~mm}$. An Ranunculaceen und Algen. Ei $50 \mu$ lang.

4. Fl. proboscidea Ehrbg.

Zipfel an der Basis verbreitert. Dorsalzipfel am längsten. Zwischenräume zwischen den Zipfeln mit langen Wimpern ausgestattet. Haftscheibe schmal. Dorsaltaster, zwei seitliche Taster und die Augen gut sichtbar. Länge $\mathrm{I} \mathrm{mm}$. Männchen selten.

5. Fl. regalis Hudson

Zipfel am Ende angeschwollen; der Dorsalzipfel am längsten, seine beiden Nachbarzipfel sehr kurz, die vier Ventralzipfel gleichlang. Die beiden Augen gut sichtbar. Länge circa o,6 mm.

6. Fl. edentata Collins

Borsten an der Ventralseite des Kopfrandes länger als auf der Dorsalseite. Körper und Fuss kurz, letzterer stark gestreift. Kiefer nur schwer sichtbar. Schlund stets voll Algen und Diatomeen. Länge $0,4 \mathrm{~mm}$. Selten.

\section{Stephanoceros Ehrbg.}

Das erwachsene Weibchen festsitzend. Die innere Organisation ist ähnlich den Floscularien. Fuss lang, geringelt, mit Haftscheibe endigend.

St. eichhorni Ehrbg. (Taf. XIV, 2)

Borsten senkrecht an den Armen stehend. Haftscheibe schmal. Röhre meist mit Erdpartikelchen behaftet. Schlund dunkelgelb gefärbt. Tiere mit der Röhre etwas gekrümmt. Augen und Taster gut sichtbar. Kiefer stark. Länge $\mathrm{I}-\mathrm{I}, 4 \mathrm{~mm}$. Männchen $0,317 \mathrm{~mm}$, Ei 50-70 $\mu$ lang.

\section{Fam. Melicertidae.}

-Erwachsene Weibchen festsitzend oder frei schwimmend. Das Räderorgan ist kreisrund, nierenförmig oder zwei- bis vierzipflig; im letzteren Falle sind die Zipfel breit, ähnlich Schmetter- 
lingsflügeln. Am Rande des Räderorganes befinden sich zwei durch eine Furche geschiedene, kontinuierliche Wimperreihen, die meist an der Dorsalseite durchbrochen sind. Der Mund liegt gewöhnlich ventral $z$ wischen den beiden Wimperreihen. Das Räderorgan ist stark gegen den Rücken geneigt. Fuss meist lang, quergestreift, mit Haftscheibe oder abgestutzter Spitze endigend. Männchen klein, mit rudimentärer Organisation.

\section{Melicerta Schrank.}

Körperform des erwachsenen Weibchens lang konisch, Fuss mit Haftscheibe. Gehäuse mit rundlichen Pillen umbaut, die in einer unterhalb der Mundöffnung befindlichen, bewimperten Höhlung aus dem eigenen Kote und zufällig in die Nähe gelangenden Fremdkörpern zusammengedreht und einzeln auf den Rand des Gehäuses aufgesetzt werden. Randwimperkranz an der Dorsalseite unterbrochen. Mundöffnung ventral; unterhalb von ihr eine bewimperte Lippe, die sich über die beschriebene Pillenpresse legt. Gehirn wenig sichtbar. Zwei lange Ventraltaster, ein borstentragender Dorsalknopf sowie zwei dorsale Haken sind vorhanden. Schlund lang, Magen gross, After dorsal. Ovarium unpaar. Männchen klein, larvenähnlich.

M. ringens Schrank (Taf. XIV, 3)

Länge I,3-2 mm. An Wasserpflanzen, häufig.

\section{Limnias Schrank.}

Gehäuse vielfach mit Fremdkörpern, gefärbt oder transparent. Räderorgan zweilappig, breiter als hoch. Mund und Unterlippe ähnlich Melicerta; doch fehlt die Pillenpresse. Ventraltaster deutlich, Dorsaltaster fehlend oder kurz. Fuss mit Haftscheibe.

I. Mit sieben Dorsalhöckern; Gehäuse geringelt . . . . . 2

2. Hülle transparent . . 1. L. annulatus

$2^{*}$. Hülle dunkelfarbig . . . 2. L. annulatus var. granulosus I*. Ohne Dorsalhöcker; Gehäuse glatt

3. L. ceratophylli

\section{L. annulatus Bailey}

Gehäuse cylindrisch, an den Rändern gelblich. Ventraltaster mässig lang. 
2. L. annulatus var. granulosus Weber

Länge $0,9 \mathrm{~mm}$.

3. L. ceratophylli Schrank (Taf. XIV, 4)

Gehäuse gelbbraun. Ventraltaster kurz. Längc $0,9 \mathrm{~mm}$.

\section{Tubicolaria Lamrk.}

Räderorgan schwach vierlappig, mit kräftigen Randwimpern. Zwei seitliche Taster deutlich sichtbar. Magendrüsen kugelig. Exkretionsorgane ohne Blase (nach Leydig). Junge mit zwei später schwindenden Augen.

T. najas Ehrbg.

länge o,660 mm. Ei $50 \mu$ lang. An Wasserpflanzen, wenig verbreitet.

\section{Cephalosiphon Ehrbg.}

Gchäuse konisch, von braunschwarzer Färbung. Körper länglich, gekrümmt; die Bauchseite ist konvex. Der After auf einem dorsalen Vorsprunge gelegen. Die Unterbrechung des Wimperkranzes ebenfalls dorsal. Fuss lang, mit Haftscheibe. Dorsaltaster mit Borsten an der Spitze. Die Augen sind sichtbar.

C. limnias Ehrbg. (Taf. XIV, 5)

Länge circa o,635 mm. An Wasserpflanzen, selten.

\section{Oecistes Ehrbg.}

Gallertscheide sehr unregelmässig, meist mit Fremdkörpern inkrustiert. Körper länglich, konisch. Fuss sehr lang (drei Mal so lang als der Körper), mit Haftscheibe, quergestreift. Ventraltaster sehr variabel. Dorsalhöcker zuweilen vorhanden. Junge mit zwiei später schwindenden Augen. Kiefer dreizähnig. Räderorgan meist ganzrandig.

I. Räderorgan gross; Ventraltaster rudimentär . . . . . . .

I. Oe. velatus

I*. Räderorgan klein; zwei Ventral-Lateral-Taster

2. Oe. socialis

I. Oe. velatus Gosse

Das Weibchen ist nur an der Basis des Fusses mit einer unregelmässig gestalteten, transparenten Gallertmasse versehen. 
Räderorgan gross, etwa kreisförmig, hyalin. Zwei Augen am Nacken. Fuss meist gekrümmt. Länge $0,3 \mathrm{~mm}$.

2. Oe socialis Weber (Taf. XIV, 6)

Körper länglich; Räderorgan klein. In Kolonien von 10-20 Individuen. Fuss zwei Mal so lang als der Körper und gestreift. Dorsalhäkchen fehlen. Tiere sehr lebhaft. Länge $0,2 \mathrm{~mm}$.

\section{Megalotrocha Ehrbg.}

Kolonien häufig in der Form von Gallertkugeln, entweder freischwimmend oder festgeheftet. Räderorgan nierenförmig, seine Fläche etwas gewölbt; die dorsale Unterbrechung des Wimperkranzes nur klein. Körper im vorderen Teile häufig mit Warzen versehen. Taster fehlend, oder die beiden ventralen als kurze Tentakel ausgebildet. Fuss meist glatt, breit.

I. Zwei kurze Ventraltaster vorhanden . . 1. M. semibullata I*. Taster sämtlich fehlend. . . . . 2. M. spinosa

I. M. semibullata Thorpe (Taf. XIV, 7)

Räderorgan nahezu viereckig. Am Körper unterhalb des Räderorganes zwei seitlich-ventrale Warzen. Augen nur in der Jugend entwickelt. Häufig mit angehefteten Eiern. Länge circa $0,88 \mathrm{~mm}$. Winterei: Länge $176 \mu$; Sommerei: Länge $160 \mu$.

2. M. spinosa Thorpe

Räderorgan etwa viereckig. Im vorderen Teile der Ventralseite ein Dornenbesatz. Augen beim erwachsenen Tiere sichtbar. Fuss lang, schwach. Häufig mit Eiern. Kolonien von 20-30 Individuen. Länge $0,88 \mathrm{~mm}$. Wintereier: Länge $200 \mu$, Breite $96 \mu$. Mit voriger Art zusammen.

\section{Lacinularia Oken.}

Räderorgan gross, hufeisenförmig. Augen nur in der Jugend vorhanden. Blase des Exkretions-Systemes fehlend ( $\mathrm{Huxley}$ ). Eier nicht angeheftet. Kolonien kugelig, bis erbsengross, freischwimmend oder an Wasserpflanzen festgeheftet, von 10-6o Individuen. Die Jungen setzen sich zunächst in der Nähe der Elternkolonie fest, vereinigen sich aber später zu neuen kugeligen Kolonien, die vom Mutterstocke abschwärmen. 
L. socialis Ehrbg. (Taf. XIV, 8 und 9)

Länge $0,66 \mathrm{~mm}$. Ei bis $50 \mu$. Verbreitct.

\section{Conochilus Ehrbg.}

Kolonien freischwimmend, von 2-30 in gemeinschaftlicher Gallertkugel radial gestellten Individuen; jedes Individuum mit besonderer Gallertscheide. Körper konisch oder eiförmig. Fuss kurz, breit, mit stark entwickelten Fussdrüsen. Räderorgan hufeisenförmig, ganzrandig. Die Unterbrechung des Wimperkranzes ist ventral. Mund nahe am Dorsalrande. Ventraltaster auf das Räderorgan verschoben. Gehirn deutlich mit zwei bleibenden Augen. Kiefer fünfzähnig. Fuss breit, meisselförmig. Muskulatur deutlich sichtbar.

I. Nur ein Taster auf dem Räderorgan. . I. C. unicornis I*. Zwei Taster vorhanden . . . . . . . 2. C. volvox

I. C. unicornis Rousselet (Taf. XIV, I0)

Kolonien zart, unsymmetrisch. Jedes Auge besteht aus einem kugeligen Linsenkörper und einem Becher von rotem oder braunem Pigment. Pelagisch. Länge $0,32 \mathrm{~mm}$.

2. C. volvox Ehrbg.

Kolonien bis $3 \mathrm{~mm}$ Durchmesser. Länge des Weibchens $0,16 \mathrm{~mm}$; Männchen halb so gross. Wintereier: Länge $90 \mu$, Breite $62 \mu$; braun gefärbt, in der Mitte lichter, blasig. Sommereier kleiner.

\section{Bdelloida.}

Tiere freilebend. Alle kriechen, schwimmen und sitzen abwechselnd, haben - ausser Callidina - beim Kriechen den Rüssel ausgestreckt, das Räderorgan eingezogen; beim Sitzen und Schwimmen dagegen das Räderorgan entfaltet und den Rüssel, sowie meistens auch den Fuss, eingezogen. Sie können sich meist bis fast zur Kugelform kontrahieren und bleiben dann beim Austrocknen lebensfähig. Das Kriechen geschieht ganz nach Art der Spanner-Raupen. Echte Gehäuse und Panzer sind nie ausgebildet. Der Fuss ist fernrohrartig einziehbar in das Innere des Körpers, mit Endzehen und Nebendornen, die selten gleichzeitig ausgestülpt werden. Der Kopf ist ebenfalls in den 
Körper zurückziehbar, er trägt das Räderorgan. Die Bewimperung besteht in einem Cilienbande, das vom Munde aus beiderseits nach der Dorsalseite aufsteigt und hier, ohne mit seinen freien Aesten sich zu vereinigen, jederseits spiralig eingeschlagen ist; innerhalb des Geheges dieses Wimperbandes befinden sich zwei von einander separierte, retraktile, mit randständigen Cilienkränzen versehene Scheiben. Hinter dem Räderorgan erhebt sich der einziehbare Rüssel, der an seiner Spitze häufig die Augen trägt, die dann mit dem Gehirn durch feine Nervenfäden verbunden sind. Taster im Nacken. Die Bedeckung des meist spindelförmigen Körpers bildet eine feine, chitinöse, transparente oder gefärbte Cuticula. Kauapparat mit starken Kiefern und mehreren Drüsen; Schlund kurz; Magen mit kleinen, konischen Drüsen, geschlängelt; Darm meist kugelig. Blase und zwei mit 5-6 Wimperfackeln versehene Seitenkanäle vorhanden. Ovarien paarig. Manche Spezies sind vivipar. Männchen nicht bekannt.

I. Rüssel gut entwickelt [I. Philodinadae (S. 438)] . . . . 2

2. Augen vorhanden . . . . . . . . . . . . . . 3

3. Augen im Nacken gelegen . . 1. Plitodina (S. 438)

3*. Augen am Rüssel befindlich . 2. Rotifer (S. 439)

2*. Augen fehlen . . ...... 3. Callidina (S. 441) I*. Rüssel nur als Warze angedeutet [II. Adinetadae (S. 442)] . 1. Adineta (S. 443)

\section{Fam. Philo in adae.}

\section{r. Philodina Ehrbg.}

Räderorgan ansehnlich. Rüssel kurz und dick. Rumpf und Fuss meist scharf geschieden. Letzterer kurz und meist viergliedrig, mit vier Zehen am letzten Segmente. Körper dick, weich, längsfaltig.

I. Fuss aus fünf Segmenten bestehend . . . . . . . . . 2

2. Farbe rötlich . . . . . . . Ph. roseola

2*. Ungefärbt . . . . . . . . 2. Ph. erythrophthalma

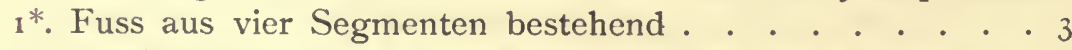

3. Rücken mit elf Stacheln . . 3. Ph. aculeata

$3^{*}$. Rücken ohne Stacheln . . . . . . . . . . 4 
4. Fussdornen dreigliedrig . . 4. Ph. macrostyla

$4^{*}$. Fussdornen nicht dreigliedrig . . . . . . 5

5. Körper gelb gefärbt . . 5. Ph. citrina

$5^{*}$. Körper ungefärbt . . . 6. Ph. megalotrocha

1. Ph. roseola Ehrbg.

Körper länglich, glatt. Fussdornen mit scharfen Spitzen; etwas länger; als das letzte Segment breit ist. Kiefer zweizähnig. Augen oval. Bleibt kolonienweise zusammen, legt die Eier in Haufen.

2. Ph. erythrophthalma Ehrbg.

Vielleicht nur Varietät der vorigen Art. Augen rund, rot. Länge $200-250 \mu$. $\mathrm{Ei}$ i $50 \mu$. In stagnierendem Wasser und Gläsern, auch im Dachrinnensande. Zu jeder Jahreszeit.

3. Ph. aculeata Ehrbg.

Körper länglich, mit scharfen, körnig rauhen, schmutzigen Längsfalten. Räderorgan klein. Fuss-Stacheln scharf spitzig, lang, an der Basis mit einem ringförmigen Cuticularwulste. Dorsaltaster an der Spitze dreiteilig. Augen rund. Kiefer dreizähnig. Länge o,48 mm. Ei $40 \mu$ lang. In Torfwasser, nicht häufig. Bewegung sehr träge.

4. Ph. macrostyla Ehrbg.

Augen länglich. Fussglieder lang. Länge $0,36 \mathrm{~mm}$, des Eies $50 \mu$.

5. Ph. citrina Ehrbg.

Körper glatt, mässig lang. Fuss kurz, breit. Kiefer zweizähnig. Länge $0,3-0,48 \mathrm{~mm}$.

6. Ph. megalotrocha Ehrbg. (Taf. XIV, i I)

Räderorgan gross. Fuss kurz, dick, scharf abgesetzt, mit zwei kurzen Dornen. Kiefer zweizähnig. Körper kurz, gedrungen. Länge $0,11-0,33 \mathrm{~mm}$. Ei: Länge $80^{\circ}-100 \mu$. Zwischen Algen, häufig.

\section{Rotifer Schrank.}

Körper länglich, schlank, weich, längsfaltig. Fuss vom Körper nicht scharf abgesetzt. Fussglieder lang. Augen zuweilen aus mehreren in zwei Parallelreihen angeordneten Pigmentmassen bestehend. Bewegung kriechend, drehend, windend. 
Vorzugsweise in stagnierenden Gewässern zwischen Detritus, weniger in künstlichen Infusionen, wo Plitodina vorherrscht.

1. Körper mit starken Lüngsfalten . . . . . . . . . 2

2. Klebrig, mit anhaftenden Fremdkörpern, mit starken Querfalten . . . . . . . . . . I. R. tardus

$2^{*}$. Ohne Fremdkörper. . . . . . 2. R. trisecatus I*. Körper höchstens schwach längsfaltig . . . . . . . 3 3. Fussdornen gekrümmt, mit beweglicher Spitze . . . . 3. R. elongatis

3*. Fussdornen gerade, Spitze starr. . . . . . . . 4 4. Körper gelbgrün. . . . . . 4. R. citrinus

$4^{*}$. Körper weisslich oder hyalin . . . . . . . . . 5 5. Rüssel kurz. . . . . . . . . . . . . . 6 6. Fussdornen gegliedert . . . 5. R. actinurus 6*. Fussdornen ungegliedert . . . . . . . . . 7

7. Dorsaltaster kurz . . . 6. R. vulgaris

$7^{*}$. Dòrsaltaster sehr lang . . . 7. R. macroceros

5*. Rüssel lang. . . . . . . . 8. R. macrurus

I. R. tardus Ehrbg.

Rumpf dunkelbraun, Kopf und Fuss farblos. Fussdornen lang. Kiefer zweizähnig. Augen oval, oft zerfallen. Bewegung träge. Länge $0,7 \mathrm{~mm}$, des Eies $50 \mu$.

2. R. trisecatus Weber

Körper weisslich, cylindrisch. Räderorgan klein. Fuss scharf vom Rumpfe geschieden, kurz; Rüssel lang. Dorsaltaster kurz. Fussdornen lang. Die drei Zehen lang, dreigliedrig. Kiefer zweizähnig. Rumpf am Ende des ersten Viertels mit Ringwulst. Länge bis $1,3 \mathrm{~mm}$.

3. R. elongatus Weber.

Körper weisslich, lang, allmählich in den Fuss übergehend. Fussdornen lang. Die drei Zehen lang und retraktil. Räderorgan schwach. Rüssel kurz. Kiefer zweizähnig. Länge 1,5 mm.

4. R. citrinus Ehrbg.

Rumpf allmählich in den Fuss übergehend, schwach längsfaltig. Rüssel stumpf. Dorsaltaster kurz. Kiefer zweizähnig. Länge bis $\mathrm{I}, \mathrm{I} \mathrm{mm}$, des Eies $0,1 \mathrm{~mm}$. 
5. R. actinurus Ehrbg. (Taf. XIV, I3)

Körper weisslích, schlank. Fuss $1 \frac{1}{2}$ Mal so lang als der Rumpf. Fussborsten lang, gegliedert. Die drei Zehen sehr lang, nach auswärts gebogen. Räderorgan klein. Rüssel kurz. Länge bis $\mathrm{r}, 6 \mathrm{~mm}$, des Eies $50 \mu$. In Aufgüssen mit Wasserpflanzen, selten.

\section{R. vulgaris Schrank}

Körper weisslich; nach hinten verschmälert und direkt in den Fuss übergehend. Die Fussdornen etwa $I \frac{1}{2}$ Mal so lang, als das sie tragende Segment breit ist. Kiefer zweizähnig. Länge $0,3-0,8 \mathrm{~mm}$.

\section{R. macrocerus Gosse (Taf. XIV, 12)}

Körper hyalin. Fuss kurz, mit kurzen Dornen. Räderorgan gross. Dorsaltaster ausserordentlich lang und beweglich. Pelagisch. Länge $0,25 \mathrm{~mm}$.

8. R. macrurus Ehrbg.

Körper weisslich, länglich oval. Fuss plötzlich verjüngt, sehr lang, mit kurzen Dornen. Räderorgan gross. Kiefer zweizähnig. Länge $0,8 \mathrm{~mm}$, des Eies $0,1 \mathrm{~mm}$.

\section{Callidina Ehrbg.}

Körper scharf gegliedert, meist bräunlich gefärbt; Integument klebrig, häufig mit Fremdkörpern bedeckt. Rüssel und-Fuss meist kurz. Letzterer aus vier Segmenten bestehend und mit drei bis vier Zehen oder einer Haftscheibe endigend. Augen fehlen. Kauapparat und Räderorgan schwach entwickelt. Manche Spezies scheiden eine Gallerthülle aus, die jedoch häufig verlassen wird.

1. Tiere in Gallerthüllen . . . . . 1. C. elegans

I*. Ohne Gallerthüllen . . . . . . . . . . . . . . . 2

2. Rüssel lang. . . . . . . . . . . . . . . . 3

3. Dorsaltaster kurz . . . . . . 2. C. longirostris

3*. Dorsaltaster lang, zweigliedrig . 3. C. brycei

$2^{*}$. Rüssel kurz. . . . . . . . . . . . . . . 4

4. Räderorgan hörnerartig ausgezogen . . . .

4. C. cornigera

4*. Räderorgan nicht hörnerartig ausgezogen . . 5 
5. Fuss am Ende mit Haftscheibe.

5. C. symbiotica

5*. Fuss mit vier Zehen . . 6. C. vorax

1. C. elegans Ehrbg. (Taf. XIV, 15)

Räderorgan von Halsbreite. Kiefer mit je zehn feinen Querleisten. Länge $0,33 \mathrm{~mm}$, des Eies $50 \mu$. In Aufgüssen auf Schilfstengel.

[Bei der sehr ähnlichen $C$. constricta Duj. ist das Räderorgan kleiner als Halsbreite; die Kiefer mit je acht Querleisten.]

2. C. longirostris Janson

Körper stark längsfaltig, mit mehreren ringförmigen Einschnürungen, braun gefärbt. Kopf und Fuss farblos. Integument mit Fremdkörpern behaftet. Fussdornen dreigliedrig. Drei Zehen vorhanden. Länge $0,43-0,6 \mathrm{~mm}$.

3. C. brycei Weber

Körper stark längsfaltig, Ventralseite mit acht Querfalten. Zwei Querreihen kurzer Dornen auf dem Rücken. Fuss kurz, dick, mit kurzen Dornen. Länge $0,4 \mathrm{~mm}$.

4. C. cornigera Bryce

Körper gedrungen, weisslich bis braun. Dorsaltaster kurz, mit Ringwulst endigend; auf letzterem ein Borstenkranz. Fussdornen kurz. Länge $0,3 \mathrm{~mm}$.

5. C. symbiotica Zelinka (Taf. XIV, 14)

Körper mit Längs- und Querfalten; Farbe braungelb. Räderorgan gross. Fuss kurz, mit kurzen Dornen. Länge o,36 mm.

6. C. vorax Janson

Körper rötlich gefärbt. Fuss kurz; mit kurzen, am freien Ende offenen Dornen. Die beiden äusseren Zehen länger als die inneren. Sehr gefrässig. Länge ca. o,4 mm. Vorwiegend Moosform.

\section{Fam. Adinetadae.}

Das Räderorgan besteht aus einem bewimperten Felde, das auf der Ventralseite der Kopfregion sich befindet und parallel der Körperachse gerichtet ist. Durch eine in der ventralen Medianlinie belegene, unbewimperte Zone ist die Wimperfläche in ein rechtes und ein linkes Wimperfeld zerlegt. Die unbewimperte Zone führt zur Mundöffnung. Der Rüssel ist zu 
einer vielfach mit Cilien versehenen, dorsalen Warze rückgebildet. Die Augen fehlen meist. Der Dorsaltaster ist kurz und breit.

\section{Adineta Hudson.}

Das einzige Genus der Adinetiden. A. vaga Davis (Taf. XIV, 16)

Körper transparent, farblos. Cuticula mit Longitudinalfalten. Fuss kurz, mit zwei kurzen Dornen. Kiefer zweizähnig. Dorsaltaster kurz. Länge $0,5-0,6 \mathrm{~mm}$.

\section{Plö̈ma.}

Abgesehen von einigen parasitischen Spezies sind die Ploïmiden frei lebend und ausgezeichnete Schwimmer. Ihre Körperform ist meist konisch oder eiförmig; einige sind wurmförmig oder abgeplattet. Am Kopfe befindet sich das Räderorgan, das mit zwei parallelen Wimperkränzen ausgestattet ist. Selten ist das Räderorgan als eine bewimperte Fläche entwickelt. Der Mund ist gewöhnlich ventral gelegen. Kopf und Rumpf sind meist nicht durch eine deutliche Nackengegend geschieden, vielfach bepanzert. Der Fuss ist gewöhnlich retraktil, nicht aber fernrohrartig einziehbar, quergeringelt und vielfach mit Dornen und Zehen versehen. Das Gehirn ist stark entwickelt und entsendet zahlreiche Nervenfasern. Augen sind meist vorhanden; ebenso wenigstens drei Taster, ein dorsaler und zwei ventrale. Bei einigen Arten finden sich Tastborsten auch am Fusse. Dás Ovarium ist stets unpaarig. Die Männchen sind in einigen Fällen ebenso entwickelt wie die Weibchen; die Regel ist jedoch ein geschlechtlicher Dimorphismus in der Art, dass die Männchen eine rudimentäre Organisation zeigen.

\section{A, Illoricata.}

Panzer fehlt; Körperbedeckung biegsam. Fuss, wenn vorhanden, stets gegabelt, meist wenig retraktil.

I. Weibchen mit vollständigem Verdauungstraktus . . . . 2 2. Körper mit langen, dünnen, chitinösen, zum Springen dienenden Fortsätzen . . . . [IV. TriarthradaeS.450)] 3 3. Körper jederseits mit sechs Fortsätzen . . . . . I. Polyarthra (S. 450) 
$3^{*}$. Körper nur mit zwei seitlichen und einem ventralen Fortsatze. . . . . . . 2. Triarthra (S. 450)

$2^{*}$. Körper ohne Springfortsätze

4. Fläche des Räderorgans höchstens mit einigen wenigen Wimperbüscheln .

5. Innerer Wimperkranz fehlend [VI. Notommatadac S. 452$)] 6$ 6. Rumpf scharf segmentiert 1. Taphrocampa (S. 452) 6*. Rumpf ohne scharfe Segmentierung . . . . . 7 7. Räderorgan ventral lippenförmig vorgestreckt . 4. Copeus (S. 454)

$7^{*}$. Räderorgan nur als bewimperte, an der Ventralseite des Kopfes gelegene Fläche ausgebildet. . 8. Diglena (S. 458)

$7^{* *}$. Räderorgan nicht derartig entwickelt . . . 8 8. Kopf mit drei Augen 7. Eosphora (S. 457) 8*. Kopf mit zwei Augen 3. Distemma (S. 454) $8^{* *}$. Kopf mit einem oder keinem Auge . . 9 9. Seitlich am Kopfe ohrartige, bewimperte Ausbuchtungen . . 2. Notommata (S. 453)

9*. Ohne ohrartige Ausbuchtungen . . . . 10 Io. Am Vorderende eine schief gegen die Körperachse gerichtete bewimperte Fläche

5. Proales (S. 455)

I0*. Ohne derartige Wimperfläche

6. Furcularia (S. 456)

5*. Innerer Wimperkranz deutlich entwickelt

[I. MicrocodidaeS.445)] i I

I I. Hirnmasse rot gefärbt . I. Microcodon (S. 445)

I I*. Hirnmasse nicht rot . . 2. Microcodides (S. 445)

$4^{*}$. Fläche des Räderorganes mit bewimperten Buckeln oder grossen, retraktilen Borsten . . . . . . . . . .12

I2. Randwimperkranz vollständig

$[\text { V.Hydatinadae }(\mathrm{S} .45 \mathrm{I})]_{13}$

13. Magen rund .. . 3. Triphylus (S. 452)

$13^{*}$. Magen birnförmig . . . . . . . . . . . 14

14. Auge unpigmentiert . I. Hydatina (S. 451)

14*. Auge pigmentiert . . 2. Notops (S. 451)

I $2^{*}$. Randwimperkranz mehrfach unterbrochen.

1*. Weibchen darmlos. [III. Synchaetadae (S. 449)] 
15. Gegabelter Fuss vorhanden . .2. Asplanchnopus (S. 448)

I5*. Ohne Fuss .. . . . . . . . . . . . . . . .16

16. Räderorgan mit zwei parallelen, Borsten tragenden Wülsten . . . . . 3. Ascomorpha (S. 446) 16*. Räderorgan mit nur einem Wimperbuckel .. . .

-1. Asplanchna (S. 448)

\section{Fam. Microcodidae.}

Räderorgan wenig retraktil. Mundöffnung central auf dem Räderorgan gelegen. Der Wimperapparat besteht aus einem randständigen, feinwimperigen Kranze und aus einem grosswimperigen Innenkranze. Fuss von verschiedener Länge. Nur ein Auge.

\section{Microcodon Ehrbg.}

Körper keilförmig, Rücken stark gewölbt. Fuss lang, schmal', griffelförmig, mit einer Spitze endigend. Räderorgan schräg gegen die Körperachse gerichtet, nach der Ventralseite neigend; mit herzförmiger Fläche, jederseits neben der Mundöffnung etwas gewölbt. Randwimperkranz im dorsalen und ventralen Medianpunkte mit einer minimalen Unterbrechung. An der Mundöffnung eine Anzahl Wimpern. Gehirn gross, rot; auf ihm ein Auge mit roter Pigmentmasse.

M. clavus Ehrbg. (Taf. XIV, 17)

Länge circa $0,2 \mathrm{~mm}$.

\section{Microcodides Bergendal.}

Körper eiförmig; Rücken gewölbt. Cuticula dick, auf dem Rücken mehr oder weniger faltig. Räderorgan kreisförmig; Randwimperkranz ohne Unterbrechung. Mund ventral gelegen, mit kleinen Cilien. Auge klein, mit rotem Pigmente. Fuss kurz, dreigliedrig.

M. chloena Gosse (Taf. XIV, 18)

Am Rumpfe vier schief verlaufende Falten; drei Falten scheiden Rumpf und Kopf. Zwei seitliche Cuticularfortsätze beschirmen die Seitentaster; vor dem Dorsaltaster ein zahnartiger Cuticularfortsatz. Länge circa $0,17 \mathrm{~mm}$. 


\section{Fam. Asplanchnadae.}

Körper sackförmig, vorn abgestumpft, hinten verbreitert, transparent. Kopf, Rumpf und Fuss nicht scharf geschieden. Räderorgan etwa kegelförmig, mit bewimperten oder unbewimperten Buckeln versehen. Randwimperkranz vorhanden. Innenkranz.fehlt. Zwischen den Buckeln des Räderorganes liegt ventralwärts die Mundöffnung. Ovarium unpaar. Harnblase gross; die beiden Seitenkanäle beschreiben in ihrer Nähe einige Windungen. Fuss fehlend oder sehr'klein, mit zwei Zehen endigend, scheinbar auf die Bauchseite gekrümmt. Gehirn gross mit zahlreichen Nervenbahnen. Zwei seitlich-ventrale und ebenso viele seitlich-dorsale Taster. Ein grosses dunkelrot bis schwärzlich gefärbtes Auge im Nacken. Männchen wenig bekannt.

\section{Asplanchna Gosse.}

Körper sackförmig, sehr gross; Kopfrand wulstig verdickt, spärlich bewimpert, am Munde cingebuchtet. Vielfach am Vorderende beiderseits flügelartige, mit einzelnen langen Griffeln besetzte Lappen. Auf der Fläche des Räderorganes zwei parallele, borstentragende Wülste, zwischen denen die Mundöffnung liegt. Gehirnknoten eiförmig, unterseits mit 'einem dunkelroten Auge, zwei nach hinten auslaufenden Nervenfäden, die mit verdickten Enden in Borstengruben am Rücken endigen und zwei ähnlichen an der Vorderseite. Schlundkopf sehr gross. Die unverdaulichen Stoffe werden in den kastenförmigen Kropf zurückgebracht, dann von der Kieferzange erfasst und durch die erweiterte Mundöffnung ausgeworfen. Schlund sehr lang, zarthäutig, längsfaltig, mit ovalen Drüsen. Magen rundlich, blind geschlossen, unten nur durch Bindegewebe mit dem Körper verbunden; er besteht aus grossen, gelbbraun gefärbten Zellen und enthält oft Fett-Tropfen. Wassergefässe und Blase deutlich sichtbar. Eierstock hufeisenförmig oder rundlich, platt; die Sommereier entwickeln sich im Uterus vollständig; die Jungen werden lebendig geboren. Wintereier mit blasigen Vorsprüngen. Die Muskulatur ist stark entwickelt; besonders die Längsmuskeln zum Einziehen des Kopfes sind sehr kräftig. Feinere Längsmuskeln zur Bewegung der einzelnen Teile sind sichtbar; ringförmige, halbringförmige und transversale vermitteln kompliziertere Bewegungen. Die 
Tiere finden sich besonders in grünem Wasser; sie schwimmen stets frei, langsam, in kleinen Kreisen. Ausser-kleinen Algen und Volvocineen verschlingen sie auch grosse Rotatorien, stachelige Anuraeen und Brachionen, ja Cyclopen und Branchiopoden, auch Junge der eigenen Art.

I. Eierstock oval bis kugelförmig . . . . 1. A. priodonta 1*. Eierstock hufeisen- oder mondförmig . . . . . . . . 2

2. Wimperfackeln $2 \times 6$ bis Io an Nebensträngen der Seitenkanäle . . . . . . . . . . . . 2. A. brightrvelli

2*. Wimperfackeln bis $2 \times 25$ an Nebensträngen

3. A. sieboldi

I. A. priodonta Gosse (Taf. XIV, 19)

Halsregion schmäler als der Rumpf. Ueber dem Gehirn ein Auge. Zwei Nebenaugen auf Vorsprüngen des Stirnwulstes. Von den Längsmuskeln ist nur das vordere Paar breit bandförmig, das hintere, am Halssaume endigende Paar ist schmal bandförmig; aber hinter dem schmalen Bande befindet sich noch ein sehr kräftiger, runder Muskel, der sich oben über die Hinterkante des Schlundkopfes biegt und in die Stirnwülste verzweigt. Schlundkopf mit eckigen Konturen. Kiefer kräftig, zusammengedrückt, mit fast geradem Innenrand, der mit spitzigen Zähnen gesägt ist. Der Endzahn ist kräftiger als die übrigen; an der Basis mit einem Seitenzahne. Magen halbkugelig, Drüsen klein. Harnblase ebenfalls sehr klein; Wimperfackeln nur $2 x_{4}$ an den mittleren Duplikaturen der Wassergefässe. Eierstock oval, klein. Halsgegend von einem Ringmuskel-Netze umzogen; die unteren Quermuskeln bilden nur halbe, dorsale Ringe, durch die die Cuticula in mehr oder weniger tiefe Falten gezogen wird. Länge $0,6-1 \mathrm{~mm}$. Männchen kegelförmig, vorn abgestutzt, hinten etwas gekrümmt. Länge $0,2-0,5 \mathrm{~mm}$.

\section{A. brightwelli Gosse}

Kopfrand gelblich gefärbt. Magen länglich, Drüsen nierenförmig. Eierstock hufeisenförmig. Blase sehr gross. Kiefer bogenförmig, cylindrisch, an der Spitze geteilt; auf dem Mittelteil mit nach innen gerichtetem, starkem, zahnförmigem Fortsatz; auf dem Hinterende mit je einem grösseren und einem kleineren Fortsatze. Die vier Hauptlängsmuskeln breit bandförmig; hinter ihnen noch mehrere dünne, runde. Halsgegend ohne Ringmuskeln. 
Länge $1 \mathrm{~mm}$ und darüber. Männchen den Weibchen an Gestalt ähnlich, auch nicht sehr viel kleiner, etwa o,6 mm lang.

3. A. sieboldi (Leydig)

Weibchen der vorigen Art sehr ähnlich. Ausser den griffeltragenden Wülsten am Munde, jederseits noch mit einer Borstengrube und einem borstentragenden, kleineren Höcker. Kiefer ähnlich wie bei voriger Art. Magen rundlich, Drüsen kugelig; Blase gross. Eierstock hufeisenförmig, Keimflecke aus kleinen, hellen Bläschen bestehend. Männchen von sehr abweichender Gestalt, kegelförmig, vorn abgestutzt, mit vier zipfelförmigen Armen, zwei kurzen am Halse und zwei längeren in der Mitte des Körpers; beim Schwimmen werden diese Arme an den Körper angeklappt.

\section{Asplanchnopus de Guerne.}

Sehr ähnlich Asplanchna, jedoch mit Fuss versehen, mit zahlreicheren bewimperten Buckeln auf dem Räderorgan und mit geräumigerem Magen. Ovarium hufeisenförmig, mit seinen freien Aesten den Magen umgebend; Keimflecke granuliert. Harnblase gross. Fuss mit zwei Drüsen. Körperhaut durchscheinend. Muskulatur sehr entwickelt; dorsale und ventrale Längsmuskeln vorhanden; Ringmuskeln namentlich in der Kopfregion zahlreich.

A. myrmeleo Ehrbg. (Taf. XIV, 20)

Auge und zwei Nebenaugen vorhanden. Fuss kurz, retraktil. Wimperfackeln sehr zahlreich (ca. 50). Magen kugelig; Drüsen gekerbt. Längsmuskeln breit, bandförmig. Länge ca. I mm. Länge des Männchens $0,4-0,5 \mathrm{~mm}$. Winterei kugelrund, mit körnigem Dotter und borstiger Schale.

\section{Ascomorpha Py.}

Körper sackförmig, klein. Cuticula dick, weniger transparent. Räderorgan nur aus einem Randwimperkranz bestehend, der. von einem Ringwulst getragen ist. Nur eine einzige bewimperte Warze erhebt sich innerhalb dieses Wimperkranzes. Das Exkretions-System ist reduziert; die Blase klein, Wimperfackeln gering an Zahl. Gehirn oval, gross. Auge gross. Taster 
sehr schwer sichtbar. Kiefer verkümmert, zahnlos. Magen sehr gross, stets vollgepfropft mit grünem Futter. Bewegung abwechselnd drehend und schiessend; Tiere häufig ohne Bewegung. A. helvetica Py. (Taf. XIV, 21 und 22)

Länge des Weibchens $0,17-0,2 \mathrm{~mm}$. Männchen krugförmig, mit kurzem Hals, $94 \mu$ lang. Eier $140 \mu$ lang.

\section{Fam. Synchaetadae.}

Körper kegelförmig. Der Randwimperkranz des Räderorgans in mehrere bogige Teile zerlegt. Innenkranz reduziert. Wimperbuckel und Tastborsten stets auf der Fläche des Räderorgans. Seitlich am Räderorgan mehr oder weniger retraktile, ohrförmige, bewimperte Lamellen. Mund ventral. Fuss kurz, mit zwei Zehen. Auge, Dorsaltaster, sowie zwei Ventraltaster vorhanden.

\section{Synchaeta Ehrbg.}

Schlund gross; Magen klein, kalbkugelig, mit kleinen, ovalen Drüsen. Tiere sehr beweglich, unruhig kreiselnd.

1. Räderorgan mit vier langen Tastborsten I. S. tremula

1*. Räderorgan mit zwei Wimperbuckeln und vier Borstenwarzen . . . . . . . . . . 2. S. pectinata

I**. Räderorgan mit einem Wimperbuckel und vier Borstenwarzen .

I. S. tremula Ehrbg. (Taf. XIV, 24)

Körper lang kegelförmig; Auge rot pigmentiert. Länge 0, I - $-2 \mathrm{~mm}$. Ei $40 \mu$ lang, mit dunkelkörnigem Dotter.

2. S. pectinata Ehrbg. (Taf. XIV, 23)

Körper kegelförmig. Ohrlamellen lang und breit. Auge rot oder bläulich pigmentiert. Länge $0,3 \mathrm{~mm}$. Ei mit rötlichen Fett-Tropfen. In torfigen Lachen.

3. S. oblonga Ehrbg.

Körper oval. Länge $0,16-0,25 \mathrm{~mm}$. Ei $50 \mu$ lang. Im Frühling zuweilen. häufig. 


\section{Fam. Triarthradae.}

Stets fusslos. Cuticula dick, mit Chitinspangen oder Panzer. Chitinfortsätze durch Muskeln beweglich, mit Borsten besetzt. Räderorgan mit randständigem Wimperkranz. Innerhalb des letzteren der Mund; zwei fingerartige, borstentragende Fortsätze, zuweilen lange Wimperbüschel. Der innere Wimperkranz ist stets stark rückgebildèt.

\section{Polyarthra Ehrbg.}

Körper vorn und hinten abgestutzt. Oberhalb der Mundöffnung ein dichter Wald kleiner, an der Spitze schwarze Knöpfchen tragender Borsten. Ein rundes, rotes Auge. Zwei vom Hirn auslaufende Nervenfäden endigen in Borstengruben nahe am Hinterteile. Längsmuskeln quergestreift. Blutflüssigkeit rötlichgelb. An jeder Seite des Körpers zwei Bündel von je drei flossenförmigen, beweglichen Anhängen. Kauer konisch, mit schwachen Kiefern; Magen und Darm kugelig, Drüsen rundlich, Blase klein.

\section{P. platyptera Ehrbg. (Taf.. XV, I)}

Flossenförmige Fortsätze gezähnelt, schwertförmig. Länge $0,125-0,16 \mathrm{~mm}$. Bewegung hüpfend, stossweise. In Tümpeln, zwischen Pflanzen. Wintereier $; 6 \mu$ lang.

\section{Triarthra Ehrbg.}

Körper eiförmig, Kopf deutlich abgesetzt, transparent,. mit zwei Augen an der Stirn. An beiden Seiten und in der Mitte der Brust eine sehr lange, griffelförmige Flosse. Innerhalb des Wimperkranzes nur drei kleine bewimperte Buckel. Kauer flach, mit verschmolzenen, zweizähnigen Kiefern. Bewegung hüpfend. Entwickelung zuweilen massenhaft, bis zur milchigen Trübung des Wassers; $z u$ anderen Zeiten selten.

I. Springborsten mehr als zwei Mal so lang wie der Körper, schwach gezähnelt. . . . . . . . I. Tr. longiseta

1*. Springborsten kaum zwei Mal so lang als der Körper, glatt

1. Tr. Longiseta Ehrbg.

2. Tr. mystacina

Augen entfernt stehend. Schlund lang. Länge mit Flossen 0,5 , ohne sie $0,166 \mathrm{~mm}$. Eier am Körper hängenbleibend, Länge $40-50 \mu$. In Gräben, Wasserkübeln, etc. 
2. Tr. mystacina Ehrbg. (Taf. XV, 2)

Augen sehr klein, genähert. Schlund sehr kurz. Länge o, I I mm. Ei $40 \mu$; Winterei $55 \mu$ lang, mit blasigen Vorsprüngen. Schlägt die Flossen häufig wie Arme über dem Kopfe zusammen.

\section{Fam. Hydatinadae.}

Körper kegel- bis saçförmig, vorn abgestutzt. Fuss mit zwei Zehen, gegliedert, retraktil. Muskulatur stark. Randständiger und innerer Wimperkranz gut entwickelt. Mund gewöhnlich halbkreisförmig. Bauchdrüsen über dem Magen gelegen. Gehirn gross, viereckig, entsendet Nerven nach dem Dorsaltaster und den beiden Lateraltastern.

\section{Hydatina Ehrbg.}

Körper kegelförmig. Längsmuskeln deutlich, Ringmuskeln fein. Räderorgan dreieckig, schief gestellt, den Gipfel des Kopfes einnehmend. Dorsalseite des Randwimperkranzes mit fünf durch längere Wimpern ausgezeichneten Warzen versehen. Nach innen von dieser Warzenreihe befinden sich zwei weitere Reihen kleiner Haare, von denen die äussere weit stärker ist als die innere Kauer mit starken, fünfzähnigen, gebogenen Kiefern. Schlund kurz; Magen birnförmig. Blase mässig gross, Seitenkanäle mit $2>4$ Wimperfackeln.

H. senta Ehrbg. (Taf. XV, 3)

Länge $0,5-0,6 \mathrm{~mm}$, des Eies $100 \mu$. Winterei mit kurzem Pelz. Im Frühling zuweilen massenhaft in stehenden Gewässern, plötzlich auftretend und wieder verschwindend. Männchen kleiner und schlanker, konisch.

\section{Notops Hudson.}

Fuss auf die Ventralseite verrückt, mit kurzen Zehen. Körper sackförmig oder viereckig. Cuticula weich oder verdickt, meist transparent. Muskulatur gut entwickelt. Schlund kurz. Eierstock hufeisenförmig. Blase gross. Auge mit rotem Pigment. Die drei Taster sind vorhanden, die beiden seitlichen etwas nach hinten verlagert. 
$N$. brachionus Ehrbg. (Taf. XV, 4)

Rumpf viereckig, nach hinten verbreitert, vorn mit einer leichten Einschnürung. Fuss wenig retraktil, die Verlängerung der Körperachse darstellend, dreigliedrig. Räderorgan mit drei Wimperbuckeln. Zwei Reihen langer Cilien am Mundtrichter. Bewegung langsam. Länge circa $0,5 \mathrm{~mm}$.

\section{Triphylus Ehrbg.}

Körper etwa cylinderförmig, Rücken gewölbt. Zwei mit Krystallkörper versehene Augen. Fuss kurz, retraktil, am Ende der Ventralseite.

Tr. Lacustris Ehrbg.

Räderorgan ohne borstentragende Papillen. Fuss gleich $1 / 5$ der Körperlänge. Haut in zwei dorsalen Längsbändern verdickt. Schlundkopf mit gabeligen Kiefern. Schlund lang. Länge $0,33 \mathrm{~mm}$. Ei 50-80 $\mu$ lang. In grünem Sumpfwasser, im Sommer.

\section{Fam. Notom matadae.}

Umfasst sehr heterogene Tiere. Körper meist nach hinten verbreitert. Kopf, Rumpf und Fuss gewöhnlich deutlich unterscheidbar. Rumpf vielfach mit einem Schwanzanhang. Fuss mit zwei Zehen. Cuticula weich, biegsam. Am Räderorgan finden sich niemals Wimperbuckel. Gehirn sackförmig oder dreilappig. Die drei Taster sehr variabel. Meist nur ein Auge vorhanden.

\section{Taphrocampa Gosse.}

Körper cylindrisch bis spindelförmig; Rücken stark konvex. Bauch konkav. Fuss kurz. Räderorgan besteht in einer eiförmigen, ventralen, bewimperten Fläche; seitlich mit zwei ohrförmigen Erweiterungen. Blase rundlich; jeder Seitenkanal mit vier Wimperfackeln. Gehirn birnförmig. Auge mit rotem Pigment. Taster schwer sichtbar.

1. Zehen kurz. - Rücken gewölbt. Bewegung langsam, meist kriechend. Länge o,2 mm (Taf. XV, 5) . T. annulosa Gosse $\mathrm{I}^{*}$. Zehen schmal und lang. Länge $0,25 \mathrm{~mm}$ T. selenura Gosse 


\section{Notommata Gosse.}

Körperform verschieden: cylindrisch, sackförmig, spindelförmig. Fuss kurz, mit kleinen Dornen. Räderorgan schief nach der Bauchseite verlagert, mit wohl entwickeltem Randwimperkranz. Innerer Kranz meist fehlend. Auf der Fläche zuweilen einige Wimperbüsche. Gehirn gross, birnförmig, mit Kalkkügelchen. Auge mit rotem Pigment. Taster zu borstentragenden Papillen reduziert. Bewegung meist langsam.

1. Gehirn durchsichtig . . . . . . . . . . . . . . . 2

2. Fuss sehr kurz, meist nicht sichtbar I. N. brachyota

$2^{*}$. Fuss länger. . . . . . . . . . . . . . . . 3

3. Zehen kurz . . . . . . 2. N. najas

$3^{*}$. Zehen lang . . . . . . . 3. N. ansata

I*. Gehirn nicht transparent .

4. Rumpf mit länglichem, konischem Schwanzanhang . .

4*. Rumpf mit kurzem Sterz

I. N. brachyota Ehrbg.

Körper spindelförmig. Ohren klein. Fuss sehr kurz; mit kurzen, konischen Zehen. Rumpf ohne Schwanzanhang. Gehirn mit zwei getrennten Kalkmassen. Länge 0,17-0,2 mm. Selten.

2. N. najas Ehrbg.

Körper spindelförmig, allmählich in den langen Fuss übergehend. Kopf so breit als der Rumpf, vorn abgestutzt. Ohren sehr klein. Schwanzanhang des Rumpfes bildet eine lamellöse Verbreiterung über der Basis des Fusses. Länge $0,5 \mathrm{~mm}$.

3. N. ansata Ehrbg.

Aehnlich $N$. aurita, nur kleiner. Zehen leicht gekrümmt. Länge 0,2-0,25. Zwischen Algen.

\section{N. tripues Ehrbg. (Taf. XV, 6)}

Körper nahezu eiförmig; Rücken gewölbt, Bauchseite plan. Fuss kurz, dick, mit zwei konischen, leicht gekrümmten Zehen. Ohren klein. Räderorgan eine eiförmige, ventral gelegene Scheibe bildend, worauf vier Büschel Tastborsten stehen. Gehirn mit meist dreilappiger Kalkmasse. Länge o, 17-0,2 mm. Bewegung langsam. Zwischen Wasserpflanzen. 
5. N. aurita Ehrbg.

Körper länglich, cylindrisch. Wimperorgan aus einer zum grösseren Teile ventral gelegenen bewimperten Scheibe bestehend. Rücken über dem Fusse aufgetrieben. Fuss kurz, zweigliedrig. Kopf mit kleinen, meist eingezogenen Ohren. Sterz in der Profilansicht deutlich. Gehirn im hinteren Teile mit zahlreichen Kalkkörperchen. Dorsaltaster gut entwickelt; Seitentaster zu Wimperbuckeln reduziert. Länge 0,25-0,3 $\mathrm{mm}$. Zwischen Algen, gemein.

[Sehr ähnlich, jedenfalls identisch ist $N$. lupus Eyf.: Kalkkörper mit rötlichen Punkten. Länge bis $0,5 \mathrm{~mm}$.]

\section{Distemma Ehrbg.}

Körper mehr oder weniger cylindrisch, nach vorn etwas verjüngt. Fuss mit zwei gekrümmten Zehen.

D. collinsi Gosse (Taf. XV, 7)

Körper lang, Kopf breit; Fuss kräftig. Zehen gekrümmt, spitz.

\section{Copeus Gosse.}

Körper konisch, hinten gewölbt. Kopf klein, scharf vom Rumpfe geschicden. Schwanzanhang des letzteren meist wohl entwickelt. Fuss gewöhnlich kurz, mit zwei konischen Zehen. Räderorgan ventral in eine Lippe ausgezogen, schief zur Körperachse gestellt. Ohrförmige Fortsätze überall vorhanden. ' Gehirn dreilappig; der mittlere Teil trägt ein rotes Auge.

1. Fuss zweigliedrig . . . . . . . 1. C. labiatus

$I^{*}$. Fuss dreigliedrig

2. Schwanzanhang breit, kurz, die Dorsalseite des Fusses bedeckend . . . . . . . . 2. C. pachyurus

$2 *$ Schwanzanhang als bewimperter Konus entwickelt

3. C. caudatus

1. C. labiatus Gosse (Taf. XV, 8)

Körper gross, dick, an beiden Enden dünner, hinten mit kleinem Schwanzanhang. Lippe des Räderorganes gross; ohrförmige Fortsätze ansehnlich. - Dorsaltaster lang, mit kurzen Wimpern. Lateraltaster als Borstenbüschel entwickelt. Kiefer massig. Schlund lang, dünn. Magen grosszellig, mit gelbkörnigem Inhalte und grossen Fett-Tropfen. Seitenkanäle mit sechs trompetenförmigen Wimperfackeln. Die Cuticula scheidet häufig eine 
Schleimhülle ab. Vor dem Hirnganglion vier helle, eiförmige Körper unbekannter Natur. Länge circa o,65 mm, des Eies o, I I mm. Bewegung lanğsam.

\section{2: C.pachyurus Gosse}

Körper kurz, dick. Schwanzanhang-transparent. Zehen leicht nach aussen gekrümmt. Rumpf im vorderen Teile eingeschnürt. Lippe des Räderorganes kurz, breit. Dorsaltaster kurz. Seitentaster stark nach hinten verschoben; als kleine, mit Tastborsten besetzte Kegel entwickelt. Länge circa $3,5 \mathrm{~mm}$. Selten.

\section{C. caudatus Collins}

Farblos. Körper schlank, spindelförmig. Bauchfläche plan. Ohren klein. Dorsaltaster kurz, stabförmig. Seitentaster mit langen Tastborsten. Lippe des Räderorganes sehr klein. Fuss lang. Länge $0,2 \mathrm{~mm}$. Selten.

\section{Proales Gosse.}

Ohrartige Fortsätze des. Kopfes und Schwanzanhang des Rumpfes fehlen. Körper cylindrisch. Kopf und Fuss nicht scharf abgesetzt. Vorderende des ersteren meist unbewimpert und halbkugelig vorspringend. Fuss wenig entwickelt, mit deutlichen Fussdrüsen. Gehirn eiförmig. Taster meist schwer sichtbar.

I. Freilebend

2. Fuss sehr kurz . . . . . . 1. Pr. decipiens

$2^{*}$. Fuss lang . . . . . . . . . . . . . . . . . 3

3. Auge nicht so breit als die Hälfte der Kopfgegend 4

4. Zehen kurz, gerade . . . 2. Pr.petromyzon

$4^{*}$. Zehen lang, mehr oder weniger gekrümmt . 5

5. Rumpf kurz vor der Basis des Fusses tief eingeschnitten . . . 3. Pr. gibba

$5^{*}$. Rumpf hinten ohne Einschnitt

$$
\text { 4. Pr. tigridia }
$$

3*. Auge breiter als die Kopfgegend 5. Pr. felis

I*. Parasitisch .

6. In Volvox globator . . . . . . . 6. Pr.parasitica

6*. In Vaucheria-Gallen . . . . . 7. Pr.wernecki 
1. Pr. decipiens Ehrbg.

Körper cylindrisch, wurmförmig, sehr weich und faltig, formveränderlich, meist in der Mitte etwas aufgetrieben, nach hinten zugespitzt; mit kurzen, konįschen Zehen und dicken Drüsen. Stirn flach oder gewölbt. Hirnknoten sehr gross, flach. An dem meist etwas nach der rechten Seite verschobenen Auge unterscheidet man sehr scharf einen roten Becher und eine helle Linse. Kieferblätter an beiden Paaren mehrzähnig. Länge $0,2 \mathrm{~mm}$. Im Detritus. Sehr träge.

2. Pr.petromyzon Ehrbg.

Körper eiförmig, an beiden Enden verjüngt. Rücken gewölbt, Bauchseite flach. Zehen kurz, spitz. Seitenkanäle lassen sich bis in den Kopf verfolgen. Länge $0,2 \mathrm{~mm}$. Vielfach zwischen Epistylis digitalis, die diese Spezies frisst.

3. Pr. gibba Ehrbg.

Körper aufgetrieben, Rücken stark gewölbt. Zehen schlank. Länge $0, I \mathrm{I}-0,16 \mathrm{~mm}$. In stagnierendem Wasser, zwischen Pflanzen.

4. Pr. tigridia Gosse (Taf. XV, 9)

Körper länglich, spindelförmig; im Profil etwa S-förmig. Rücken gewölbt. Cuticula des Rumpfes vorn und hinten quergefaltet. Rumpf vorn eingeschnürt. Länge $0,17 \mathrm{~mm}$.

5. Pr. felis Ehrbg.

Körper schlank, cylindrisch. Zehen leicht gekrümmt. Stirn mit gekrümmtem Taster.' Auge sehr gross. Länge o, I mm. Zwischen Algen und Detritus.

6. Pr. parasitica Ehrbg.

Körper oval, klein. Kiefer zangenförmig; Fuss klein, etwas nach vorn gerichtet. Länge $0,16 \mathrm{~mm}$, des Eies $80-$ I $00 \mu$. Winterei stachelig.

7. Pr. wernecki Ehrbg.

Körper länglich, an beiden Enden verjüngt. Mund mit zwei Tastborsten. Zehen kurz. Länge 0,25 mm, des Eies $100 \mu$ (cfr. S. 139).

\section{Furcularia Ehrbg.}

Körper länglich, cylindrisch bis spindelförmig, transparent. Rücken gewölbt. Räderorgan etwas schief gegen die Körper- 
achse gerichtet. Fuss meist kurz, breit; mit zwei langen, geraden Zehen. Kauer tetraëdrisch, mit schwachen Kiefern. Gehirn sackförmig. Auge mit rotem Pigment. Die drei Taster normal entwickelt, vielfach aber schwer sichtbar.

I. Zehen gerade . . . . . . . . . F. gracilis

I*. Zehen gekrümmt

2. Zehen ungleich

2. F. longiseta

2*. Zehen gleich lang

- 3. F. forficula

I. F. gracilis Ehrbg.

Körper schlank, fast cylindrisch. Zehen weniger lang. Länge $0,12 \mathrm{~mm}$. Ei $50 \mu$ lang, an Algen angeheftet. In grünem Wasser, zuweilen häufig.

2. F. longiseta Ehrbg.

Körper kurz, nach hinten verjüngt. Zehen von zwei- bis dreifacher Körperlänge. Auge über dem hinteren Teile des Hirnganglions. Cuticula sehr biegsam. Länge 0,2-0,25 mm, ohne Fuss $50 \mu$. Zwischen Wasserpflanzen; nicht selten, aber einzeln.

3. F. forficula Ehrbg. (Taf. XV, ı)

Körper länglich, cylindrisch; am Vorder- und Hinterende mit einer Querfalte." Zehen am Ende spitz, am Grunde der Dorsalseite gezähnelt. Ovarium lang, schmal. Bewegung sehr lebhaft. Länge $0,16 \mathrm{~mm}$.

\section{7.. Eosphora Ehrbg.}

Körper eiförmig; Kopf und Fuss scharf abgesetzt. -Am Kopfe zwei kleine, ohrförmige Fortsätze. Rumpf mit dorsaler Wölbung und einem breiten, kurzen S'chwanzanhang, der den Grund des Fusses bedeckt. Fuss meist lang, gegliedert, mit zwei Zehen. Räderorgan aus zwei Wimperkränzen bestehend; am Dorsalrande zwei Büschel langer Borsten. In ihrer Nähe die beiden Stirnaugen. Nacken-Auge unter dem dreilappigen Hirnknoten, über dem Schlundkopfe. Letzterer fast kubisch, die Kiefer zangenförmig. Schlund ziemlich dünn; Magen rundlich, grosszellig, mit ovalen Drüsen; Darm deutlich abgesetzt. Seitenkanäle und Blase dickwandig, erstere mit zwei Mal drei Wimperfackeln. Kräftige Raubtiere, die andere Wassertiere, besonders Rotiferen, aber selbst den doppelt so grossen Copeus labiatus sowie 
junge Entomostraken hineinwürgen; Bewegungen dem entsprechend energisch. Die Jungen haben schon im $\mathrm{Ei}$ neben dem Auge noch zwei schwärzliche, später schwindende Flecke.

г. Zehen lang . . . . . . . . . . . E. digitata

I*. Zehen kurz . . . . . . . . . . 2. E. najas

I. E. digitata Ehrbg.

Körper etwa eiförmig. Kopf weniger deutlich abgesetzt als bei folgender Art. An Stelle der beiden Borstenbüschel am dorsalen Stirnrande zwei lange Tastborsten. In den Zehen verlaufen die Ausführungsgänge der Fussdrüsen. Aussenmündungen dieser Kanäle sehr deutlich. Länge $0,25 \mathrm{~mm}$.

[Hiermit jedenfalls identisch ist E. elongata Ehrbg., die etwas länger und schlanker ist. Länge $0,3-0,45 \mathrm{~mm}$.]

2. E. najas Ehrbg. (Taf. XV, II)

Kopf breit, Hăls wenig schmäler als der Rumpf. Länge $0,25-0,3 \mathrm{~mm}$. Ei $50 \mu$ lang.

\section{Diglena Ehrbg.}

Körper gewöhnlich wurmförmig oder spindelförmig. Körper mit halbkugelig vorgewölbter Stirnfläche. Räderorgan ist als bewimperter, ventral gelegener Hof entwickelt. Fuss meist lang. Exkretionsorgane schwer sichtbar. Gehirn gross, eiförmig. Zwei Augen auf der Stirnregion. Taster zu bewimperten Buckeln reduziert.

I. Stirnaugen unpigmentiert . . . . . . D. circinator

$1^{*}$. Stirnaugen pigmentiert . . . . . . . . : . . . . 2

2. Zehen kurz. . . . . . . . 2. D. catellina

$2^{*}$. Zehen lang. . . . . . . . . . . . . . 3

3. Zehen gerade . . . . . . . . . . . 4

4. Stirnaugen nahe bei einander 3. D. grandis

$4 *$ Stirnaugen weit auseinander gerückt .

4. D. caudata

$3^{*}$. Zehen gekrümmt . . . . . . . . . . . . 5

5. Zehen sehr lang, nahe am Ende mit einer Einschnürung . . . . . . 5. D. uncinata

$5^{*}$. Zehen weniger lang, ohne Einschnürung .

6. D. forcipata 
1. D. circinator Gosse

Körper spindelförmig. Fuss mässig lang, mit zwei spitzen Zehen, die nach der Medianlinie des Tieres gekrümmt sind. Taster sehr schwer sichtbar. Länge $0,2 \mathrm{~mm}$. Selten.

2. D. catellina Ehrbg. (Taf. XV, 12)

Körper oblong, kurz, vorn und hinten abgestutzt. Fuss klein, eingezogen. Kopf vom Rumpfe durch eine Querfalte getrennt. Magen und Darm von dem meist stark entwickelten Eierstock vielfach zurückgedrängt. Länge $0,1-0,1+\mathrm{mm}$, des Eies $60-80 \mu$. Ueberall gemein, das ganze Jahr hindurch. In grünem Wasser, besonders an der Oberfläche oft massenhaft.

3. D. grandis Ehrbg.

Körper schlank, gross. Cuticula kapuzenartig über dic Stirn gezogen. Mundspalte sehr breit und lang, fast bis zur Körpermitte reichend. Fuss kurz, mit dicken Drüsen. Zehen meist gespreizt. Kauer herzförmig, vorstreckbar; die Kiefer sind als Greifzangen entwickelt, innen leierförmig gezähnelt. Schlund kurz; Magen mit langen, konischen Drüsen; Darm konisch. Blase klein, Seitenkanäle mit zwei Mal zwei Wimperfackeln. Raubtier. Bewegung energisch. Länge $0,2-0,25 \mathrm{~mm}$, des Eies $80 \mu$. Zwischen Algen, stellenweise häufig.

4. D. caudata Ehrbg.

Körper länglich konisch, vorn schief abgestutzt. Fuss kurz. Länge $0,1 \rightarrow 0,2 \mathrm{~mm}$. In grünem Wasser.

5. D. uncinata Milne (Taf. XV, ז3)

Körper etwa spindelförmig. Kopf vom Rumpf durch eine Querfalte getrennt. Kopf vorn in einen langen, an der Spitze ventralwärts umgebogenen Rüssel ausgezogen. Fuss kurz, Zehen schwertförmig. Schwanzanhang als rundlicher Höcker entwickelt.

6. D. forcipata Ehrbg.

Körper eiförmig, länglich. Schwanzanhang kurz abgerundet. Fuss vom Rumpf scharf abgesetzt.

\section{B. Loricata.}

Panzer stets vorhanden. Dieser kann weich oder hart, glatt oder mit Skulpturen versehen, gewölbt oder plan sein. 
I. Fuss fehlend ${ }^{1}$ ) . . . . . . . . . . . . . . . . 2

2. Dorsaltaster röhrenförmig, konisch, mit Borstenbüschel endigend. . . . . . . . [IX. Anuraeadae (S. 484)] . 3

3. Dorsalplatte des Panzers mit polygonaler Felderung. .

I. Anuraea (S. 485)

$3^{*}$. Dorsalplatte des Panzers ohne polygonale Felderung. .

2. Notholca (S. 486)

2*. Dorsaltaster zu einer borstentragenden Papille reduziert

[XII. Anapodidae (S. 489)]

I*. Fuss vorhanden .

4. Panzer in der dorsalen Mittellinie gespalten (Spaltung bei gefülltem Magen stets deutlich[III. Salpinadae (S. 468)] . 5

5. Panzer die Bauchseite nicht bedeckend.

$$
\text { 1. Diaschiza (S. 468) }
$$

5* Panzer den ganzen Körper umschliessend . . . . . 6

6. Körper im Schnitt dreieckig; Taster nur als Borstenbüschel angedeutet. . 3. Diploïs (S. 470)

6*. Körper im Schnitt mehr eiförmig; Dorsaltaster als borstentragender, dorsalwärts gerichteter Konus entwickelt . . . . .2. Salpina (S. 469)

4*. Panzer dorsal nicht gespalten . . . . . . . . . . 7

7. Fuss fast in der Mitte der Ventralseite entspringend und ohne Segmentierung . . . . . . . . . . . 8

8. Panzer in der Mittellinie der Ventralseite gespalten .

[X. Ploesomadae (S. 488)]

8*. Panzer auf der Ventralseite nur mit kleiner, kreisrunder Oeffnung für den Fuss . . . . . . . . . . . 9

9. Fuss mit bewimperter Scheibe endigend

[VII. Pterodinadae (S. 479)]

$9^{*}$ Fuss mit zwei kurzen, konischen Zehen

[XI. Gastropodidae (S. 488)]

$7^{*}$. Fuss am Ende oder nahe am Ende des Rumpfes entspringend; wenn in der Nähe der ventralen Mitte entspringend, stets segmentiert . . . . . . . . 10

10. Fuss mit besonderem Panzer; oder Kopf mit halbkreisförmigem Chitinschild [II. Dinocharidae (S. 465)] I I

I I. Fuss ohne besondere Chitinplatten; mit zwei Augen 3. Stephanops (S. 467)

11*. Fuss bepanzert; nur ein Auge vorhanden . . 12

1) cfr. auch Pumpholyx (S. 48r). 
12. Kopf mit zwei lateralen Chitinplatten .

$$
\text { I. Dinocharis (S. 465) }
$$

I2*. Kopf nur mit zarter Cuticula, ohne Panzerplatten

$$
\text { 2. Scaridium (S. 466) }
$$

IO*. Fuss ohne Panzerung; Kopf, wenn gepanzert, in anderer Weise .. . . . . . . . . . I3

13. Fuss deutlich drei- oder mehrgliedrig oder geringelt und ohne scharfe Segmentierung . . . 14 14. Vorderrand des Panzers mit Dornen . . . . .

[VIII. Brachionidae (S. 481)] 15

15. Fuss scharf segmentiert; deutliches Auge nicht vorhanden . . J. Noteus (S. 48I)

15*. Fuss geringelt oder nur undeutlich segmentiert; Auge deutlich . 2. Brachionus (S. 482)

14*. Vorderrand des Panzers ohne Dornen. . . 16

16. Nur ein Auge vorhanden

[IV. Euchlanidae (S. 470)]

16*. Zwei bis mehr Augen oder gar keins .

[VI. Coluridae (S. 475)] . I 7

17. Panzer seitlich komprimiert . . . . I8 18. Mit zwei Zehen.

I. Colurus (S. 476)

18*. Mit einer Zehe

$$
\text { 2. Monura (S. 477) }
$$

17 *. Panzer dorso-ventral komprimiert

$$
\text { 3. Metopidia (S. 477) }
$$

13*. Fuss aus einem oder zwei Segmenten bestehend I9 19. Panzer aus einem röhrenartigen Stücke . . . .

[I. Rattulidae (S. 462)] . 20

20. Fuss mit einer Zehe 1. Mastigocerca (S. 462)

20*. Fuss mit zwei ungleichen Zehen

$$
\text { 2. Coelopius (S. 464) }
$$

20**. Fuss mit zwei gleichen Zehen .

3. Rattulus (S. 465)

19*. Panzer aus dorsaler und ventraler Platte bestehend, die seitlich durch eine zarte Membran verbunden sind . . . . . [V. Cathypnadae (S. 473)] 2 I

21. Fuss zweigliedrig mit einer Zehe

$$
\text { 3. Monostyla (S. 475) }
$$

$2 \mathrm{I}^{*}$. Fuss eingliedrig, mit zwei Zehen 
22. Zehen schräg abgestutzt

22*. Zehen nicht schräg abgestutzt

1. Cathypna (S. 473)

2. Distyla (S. 474)

\section{Fam. Rattulidae.}

Panzer oben und unten offen, ohne Skulpturen, höchstens mit einem Längsgrat in der dorsalen Medianlinie, am Vorderrande zuweilen einige Dornen. Bei einigen Spezies bleibt die Cuticula zart und biegsam. Fuss teilweise vom Panzer bedeckt, häufig neben den Zehen mit accessorischen Griffeln. Kopf und Rumpf wenig scharf geschieden. Räderorgan nur aus einem randständigen Wimperkranze bestehend. Schlund lang; Magen und Darm scharf geschieden. Blase klein, Seitenkanäle mit je 3-4 Wimperfackeln. Gehirn gross; Taster als bewimperte Papillen entwickelt. Auge gross, rot.

\section{Mastigocerca Ehrbg.}

Körper länglich, spindelförmig. Zehe sehr lang. Rückenkièl unsymmetrisch. Auf der Fläche des Räderorganes an den Seiten eines fingerförmigen Fortsatzes lange Wimperbüschel. Schlund gebogen, Darm birnförmig. Bewegung wegen des langen Fussgriffels unbeholfen. Kauer sehr lang, fast cylindrisch, mit ungleichen Kiefern.

I. Panzer ohne Kiel . . . . . . . . . . . . . . . . 2

2. An der Basis der Zehe Nebengriffel '1. M. bicornis

2*. Zehe ohne Nebengriffel . . . . 2. M. stylata

I*. Panzer mit Kiel .. . . . . . . . . . . . . . . 3

3. Panzer ohne Dornen . . . . . . . . . . . 4

4. Kiel bis zur Mitte des Rückens sich erstreckend 3. M. carinata

4*. Kiel über zwei Drittel des Rückens sich erstreckend 4. M. rattus

$4^{* *}$. Kiel bis zum Fusse sich erstreckend.

5. M. lophoëssa

3*. Panzer mit Dornen . . . . . 6. M. cornuta 
1. M. bicornis Ehrbg.

Körper lang, cylindrisch. Panzer vorn in zwei Dornen von ungleicher Länge ausgezogen, deren grösserer leicht gekrümmt und dorsal gelegen ist. Fuss lang; mit langer, leicht gekrümmter Zehe, deren Basis vier ungleich lange Griffelchen trägt.

\section{M. stylata Gosse}

Körper unregelmässig oval. Panzer sehr biegsam. Zehe unter $1 / 3$ der Körperlänge. Auge gross, rot, wie eine Warze auf dem Rücken des Hirnknotens. Länge $0,14 \mathrm{~mm}$.

3. M. carinata Ehrbg. (Taf. XV, 14)

Körper länglich, eiförmig. Kiel hoch, querrunzelig. Zehe fast von der Länge des Körpers, an ihrer Basis vier Griffel von ungleicher Länge. Körper häufig fleischfarben. Länge mit Zehe $0,33 \mathrm{~mm}$. Ei $50 \mu$ lang. Zwischen Algen, ziemlich häufig.

4. M. rattus Ehrbg.

Körper eiförmig, vorn und hinten abgestutzt. Zehe fast von der Länge des Körpers, am Grunde mit vier ungleichen Nebengriffeln. Kauer eiförmig. Farbe oft rötlich. Länge bis $0,2 \mathrm{~mm}$, des Eies $50 \mu$.

\section{M. Lophoëssa Gosse}

Körper eiförmig. Kiel breit, niedrig, an der Basis des Fusses plötzlich endigend. Fuss breit; Zehe fast doppelt so lang als der Körper, mit langem, gekrümmtem, accessorischem Griffel und vier kleinen Stiften. Länge mit Zehe $0,35 \mathrm{~mm}$.

\section{M. cornuta Eyf.}

Körper lang konisch, Rücken mit starkem Kiel, der vorn in eine lange, gekrümmte (mediane) Spitze ausläuft; seitlich und ventral je zwei kürzere Spitzen. Vor dem Stirnhorne ein beweglicher, gekrümmter Taster. Kauer sehr lang; Kiefer mehrzähnig, ungleichschenklig, der linke Schenkel sehr lang. Fussgriffel etwa von der Länge des Körpers, schwach abwärts gebogen, so dass er mit der Rückenlinie und dem Stirndorn nahezu einen Kreisbogen bildet. Am Grunde des Griffels noch einige kürzere Dornen. Farbe meist gelblichbraun. Länge bis 0,55 mm, ohne Fuss 0,27 mm. Zwischen Algen, nicht selten. 


\section{Coelopus Gosse.}

Körper cylindrisch, mit dorsaler Krümmung. Panzer vorn und hinten etwas schief abgestutzt; Vorderrand häufig mit Dornen; Kiel meist wenig entwickelt. Räderorgan wie bei Mastigocerca. Fusszehen von ungleicher Länge, an ihren distalen Enden sich vereinigend, am Grunde mit accessorischen Griffeln. In ruhigem Wasser, zwischen Detritus. Bewegung kreisförmig.

I. Kiel sehr deutlich . . . . . . . . I. C. porcellus

I*. Kiel nur ganz schwach entwickelt oder fehlend . . . . 2

2. Rücken konvex . . . . . . 2. C. temuior

$2^{*}$. Rücken konkav . . . . . . 3. C. stylatus

I. C. porcellus Gosse

Körper fast cylindrisch, an beiden Enden etwas verjüngt, im Profil sichelförmig gekrümmt; Rücken konvex. Rücken mit hornigem Kiel, der meist in den Körper eingedrückt ist. Am dorsalen und ventralen Vorderrande mit scharfen, gegen einander gekrümmten Dornen von ungleicher Länge. Stirn mit kurzem, beweglichem Taster. Kauer sehr lang, mit ungleichen Kiefern. Schlundkopf kurz; Magen birnförmig mit konischen Drüsen; Darm lang, dünn. Länge mit Fuss $0,33 \mathrm{~mm}$, ohne Fuss $0,16-0,2 \mathrm{~mm}$. Variiert sehr in Gestalt und Grösse. Zwischen Algen, gemein.

\section{C. tenuior Gosse (Taf. XV, I5)}

Körper schlank, cylindrisch, leicht gekrümmt. Panzer zart; vorn mit zwei oder drei Dornen. Länge der Zehen sehr ungleich; die eine gleich $1 / 2$ der Körperlänge, die andere gleich $1 / 4$ der Körperlänge. Zwei kurze Nebengriffel. Länge $0,25 \mathrm{~mm}$.

3. C. stylatus Eyf.

Körper schlank konisch, vorn abgestutzt, schwach sichelförmig gebogen. Fussbasis an der Dorsalseite über die Bauchkante hinab verlängert. Kopf flach; Nacken mit einem langen, über die Stirn abwärts gekrümmten Dorn. Hirnganglion sehr lang, konisch; über dem Kauer mit einem keilförmigen, roten Auge. An der Stirn mit einem aus zwiebelförmiger Basis aufsteigendem Dorn, der sich mit dem Nackendorn kreuzt. Ventraler Vorderrand ebenfalls mit einem oder zwei kurzen Dornen. Kauer 
konisch. Schlund lang, gebogen; Magen birnförmig, mit ovalen Drüsen; Darm lang. Länge $0,27 \mathrm{~mm}$, ohne Fuss $0,2 \mathrm{~mm}$. In grünem Wasser, an der Oberfläche.

\section{Rattulus Ehrbg.}

Körper cylindrisch; Panzer weich, ohne Rückenkiel. Fuss mit zwei gekrümmten Zehen.

I. Gehirn durchsichtig . . . ! . . 1. R. helminthodes

1*. Gehirn undurchsichtig . . . . . . 2. R. cimolius

I. R: helminthodes Gosse (Taf. XV, 16)

Körper schlank. Zehen ohne Nebengriffel an der Basis. Länge $80 \mu$.

2. R. cimolius Gosse

Körper gekrümmt, Cuticula biegsam; Zehen kurz, gekrümmt, etwas abgeplattet. Länge $90 \mu$.

\section{Fam. Dinocharidae.}

Fuss, Rumpf und Kopf streng geschieden. Panzer aus einem Stück, glatt oder gefeldert, zuweilen mit Dornen; Seitenränder vielfach stark gezähnelt. Kopf mit einer aus mehreren mehr oder weniger getrennten Chitinplatten gebildeten Bepanzerung. Fuss lang, dreigliedrig; mit Dornen und zwei langen, nicht retraktilen Zehen versehen. Im Fuss zuweilen starke, quergestreifte Muskelzüge. 'Räderorgan mit randständigem, zuweilen unterbrochenem Wimperkranze; Innenkranz nur durch einige bewimperte Buckel repräsentiert. Blase klein, Seitenkanäle mit je 3-4 Wimperfackeln.

\section{Dinocharis Ehrbg.}

Panzer prismatisch oder fast cylindrisch, hinten fast geschlossen, scharfkantig, gekörnelt und deshalb wenig durchsichtig. Die steifen, nicht retraktilen Fussglieder sind ebenso gepanzert und mit Dornen besetzt; letztes Glied zweizehig. Kopf schwach 
bewimpert. Hirnknoten konisch, mit einem Nackenauge. Kauer herzförmig, mit ungezähnten Kiefern. Magen länglich, mit konischen Drüsen; Darm birnförmig, stark abgesetzt.

I. Dornen am Fusse undeutlich. . . . . I. D.panpera I*. Fuss mit deutlichen Dornen . . . . . . . . . . . . 2

2. An der Basis der Zehen ein Dorn . 2. D. pocillum 2*. An der Basis der Zehen kein Dorn 3. D. tetractis

I. D. paupera Ehrbg.

Zehen kürzer als bei den folgenden Arten.

2. D. pocillum Ehrbg. (Taf. XV, 17)

Panzer fast cylindrisch. Zweites Fussglied mit zwei langen, gekrümmten Dornen; Zehen lang, schwertförmig, über ihnen noch ein mittlerer gekrümmter Dorn. Länge $0,2 \mathrm{~mm}$. Häufig, aber einzeln in Torfbrüchen, auch in Altwasser, aber nie in Infusionen.

3. D. tetractis Ehrbg.

Panzer fast dreikantig. Dornen des vorderen Fussgliedes wie bei voriger Art, aber hinteres ohne Dorn. Länge ca. $0,38 \mathrm{~mm}$.

\section{Scaridium Ehrbg.}

Körper kurz, gedrungen, seitlich komprimiert, vorn und hinten abgestutzt; mit sehr langem Springfuss, der mit starken, quergestreiften Muskeln versehen ist, und dessen lange Glieder nicht einstülpbar, sondern durch Scheingelenke verbunden sind. Zehen sehr lang, schwertförmig. Fussmuskeln sehr deutlich quergestreift. Kopf spärlich bewimpert; mit kleinem, hakenförmigem Taster. Ein linsenförmiges, rotes Auge dicht über dem Kauer; dieser tetraëdrisch, mit weiter Höhlung und verkümmerten, unsymmetrischen Kiefern. Blase gross; Seitenkanäle mit je vier Wimperfackeln.

Sc. longicaudum Ehrbg. ('Taf. XV, 18 und 19)

Fuss doppelt so lang wie der Körper, Zehen halb so lang wie der Fuss. Springt (Bewegung übrigens unbehülflich). Lünge 0,33 mm, ohne Fuss o, I mm. Ei $50 \mu$ lang." Sommerei mit Haarbesatz, Winterei mit langen Stacheln. Zwischen Wasserpflanzen, häufig. 


\section{Stephanops Ehrbg.}

Körper cylindrisch, spindel- oder birnförmig. Kopf, Rumpf und Fuss sind scharf geschieden. Panzer schwach, prismatisch, flach; hinten meist in zwei oder drei spitze Dornen auslaufend. Rücken gewölbt; Bauchseite plan, selbst etwas eingezogen, so dass die Seitenkanten des Panzers wulstartig nach unten vortreten. Kopf - wie aus einer breiten Halsbinde - breit hervortretend, fast dreieckig (von vorn gesehen), mit breitem, halbkreisförmigem, einem Glorienschein nicht unähnlichem, hyalinem Schilde bedeckt. Die beiden Augen auf besonderen Warzen in den Aussenwinkeln des Kopfes, mit lichtbrechenden Körpern. In ihrer Nähe zwei bewegliche, durchsichtige, chitinöse Lamellen. Mundöffnung weit, bewimpert, vielfach mit zwei beweglichen, ohrförmigen Lappen. Kauer mit hammerartig arbeitenden Kiefern, die innen mit kleinen Zähnchen versehen sind. Magen, Drüsen, Darm, Blase und der wenige, grosse Eier enthaltende Eierstock ziemlich gross, so dass sie die Leibeshöhle fast ganz ausfüllen. Fuss kürzer als die Länge des Rumpfes; mit schlanken, spitzen Zehen, zwischen denen noch ein mittlerer, nach hinten gerichteter Dorn steht.

1. Panzer hinten ohne Dorn. . . . . . 1. St. muticus

'I*. Panzer hinten mit einem dreiteiligen, die Dorsalseite des ersten Fussgliedes bedeckenden Knopfe. . . 2. St. intermedius I**. Panzer mit echten Dornen

2. Panzer hinten mit drei Dornen. . 3. St. lamellaris

2*. Panzer hinten mit zwei Dornen . 4. St. cirrhatus

2**. Panzer mit mächtigem Rückendorn 5 . St. longispinatus

1. St. muticus Ehrbg.

Länge $0,1 \mathrm{~mm}$. Ei $40 \mu$ lang.

2. St. intermedius Burn.

Körpér birnförmig. Kopfschild an Breite gleich dem Rumpfe, vorn abgerundet. Panzer glatt, seitlich leicht taillenartig eingebuchtet. Fuss lang, Zehen gekrümmt. Länge o, I5 mm.

3. St. lamellaris Ehrbg. (Taf. XV, 20)

Kopfschild eiförmig, eben so breit wie der Rumpf. Panzer glatt, hinten stark gewölbt. Dornen spitz, gleich lang, parallel. Länge $\mathrm{O}, \mathrm{I}-\mathrm{O}, \mathrm{I} 6 \mathrm{~mm}$. Panzer $55 \mu$, Ei $40 \mu$ lang. Zwischen Wasserpflanzen, nicht selten. 
4. St. cirrhatus Ehrbg.

Länge $0,1 \mathrm{~mm}$. Ei $40 \mu$ lang.

5. St. longispinatus Tatem

Körper eiförmig. Bauchfläche konkav. Rücken gewölbt; Rückendorn leicht gekrümmt, länger als der Körper. Panzer durchscheinend, hinten abgerundet, den Fuss teilweise überdeckend. Länge $0,14-0,16 \mathrm{~mm}$.

\section{Fam. Salpinadae.}

Körper prismatisch, dreieckig oder eiförmig; Rücken gewölbt, Bauch plan. Fuss kurz, zwei- bis dreigliedrig. Panzer sehr transparent, glatt oder narbig, oben und unten offen. In der dorsalen Mittellinie gespalten. Ränder dieser Furche meist wulstig verdickt. Kopf breit, dick. Räderorgan mit zwei Wimperkränzen. Ganglion gross, eiförmig. Dorsaltaster als bewimperte Warze entwickelt. Fuss gegliedert, retraktil, mit zwei langen Zehen.

\section{Diaschiza Gosse.}

Körper cylindrisch oder kugelförmig, seitlich komprimiert. Fuss mit schwertförmigen, gekrümmten Zehen und einem Borstenbüschel auf der Dorsalseite. Panzer aus zwei gewölbten Platten bestehend, die Bauchseite nicht bedeckend, vorn und hinten abgestutzt. Auge gross, eiförmig.

I. Rückenfurche hinten viel breiter als vorn

I. D. semiaperta

I*. Rückenfurche vorn und hinten etwa gleich breit . . . . 2

2. Auge am hinteren Ende des Gehirnes

2. D. Lacimulata

2*. Auge am vorderen Ende des Gehirnes

3. D. valga

I. D. semiaperta Gosse

Körper cylindrisch. Rücken nach hinten ansteigend, dann plötzlich schräg abfallend, dachförmig, mit scharfer Oberkante. Zehen fast von halber Körperlänge, gekrümmt. Auge vorn an 
der Stirn. Ventralränder des Panzers leicht gekrümmt. Bewegung unruhig, hundeartig suchend. . Länge $0,25 \mathrm{~mm}$, des Eies $50 \mu$. Zwischen Algen.

2. D. lacinulata O. F. Müller (Taf. XV, 21)

Klein, Körper breit. Panzer zart, biegsam, nur $2 / 3$ des Rumpfes deckend; Seitenränder gerade. Länge 0,08-0,16 mm. Gemein; in allen Gewässern, das ganze Jahr über.

3. D. valga Gosse

Körper klein, cylindrisch, gekrümmt. Ventralrand des Panzers leicht gekrümmt, vorn in ein dornartiges Gebilde auslaufend. Fusszehen gekrümmt. Länge $0,17 \mathrm{~mm}$. Unter Algen und verwesenden Blättern.

\section{Salpina Ehrbg.}

Panzer oval, am Bauche geschlossen, vorn und hinten mit Dornen. Rücken doppelt gekielt; die beiden Kiele sind meist durch eine klaffende Spalte getrennt, klappen zuweilen aber auch dicht zusammen, je nachdem der Magen gefüllt oder leer ist. Kopf rundlich, mit kräftigen Wimpern und kurzem, bewimpertem Taster im Nacken. Hirnknoten rundlich, mit rotem Auge im Nacken. Kauer fast kubisch, mit starken, vier- bis fünfzähnigen Kiefern. Schlund gerade, faltig. Magen länglich, mit grosśen Drüsen; Darm birnförmig, scharf vom Magen abgesetzt. Eierstock und Blase gross. Fuss kurz und dick, aber dünnhäutig (wie eine Pumphose), mit dicken Drüsen und langen, dolchförmigen Zehen. Alle leben zwischen Algen, aṇ deren Fäden sie ihre Eier der Länge nach, wie Kokons, anheften.

I. Panzer vorn mit zwei Dornen . . . . . . . . . . . 2

2. Die drei, hinten am Körper befindlichen Spitzen von ziemlich gleicher Länge . . . . I. S. brevispina

$2^{*}$. Von den drei hinteren Spitzen die unteren lang, gerade; die obere kurz, abwärts gekrümmt. 2. S. ventralis

I*. Panzer vorn mit vier Dornen . . . . . . . . . . . 3

3. Vier vordere Dornen nahezu von gleicher Länge . .

3. S. mucronata

$3^{*}$. Dorsale Vorderdornen viel länger als die ventralen

4. S. spinigera 
I. S. brevispina Ehrbg.

Gestalt wie bei S.mucronata. Panzer runzelig, narbig. Ventraler Vorderrand leicht gezähnelt. Zwischen den beiden Vorderdornen eine breite, tiefe Ausbuchtung. Hinterdornen sämtlich kurz. Fuss lang, schmal. Länge $0,16-0,2 \mathrm{~mm}$. Ei $80 \mu$ lang.

2. S. ventralis Ehrbg.

Panzer vorn rauh, gekörnt. Länge $0,2 \mathrm{~mm}$. Ei $8 \mu$ lang.

3. S. mucronata Ehrbg. (Taf. XV, 22)

Körper von der Form eines dreiseitigen Prismas. Panzer runzelig. Zwischen den beiden dorsalen Vorderdornen eine tiefe Ausbuchtung. Oberer Hinterdorn kleiner als die unteren Hinterdornen. Magendrüsen lang, spindelförmig, unten mündend. Länge $0,16-0,25 \mathrm{~mm}$, des Eies $80 \mu$. An Algen der Länge nach angeheftet. Gemein.

4. S. spinigera Ehrbg.

Aehnlich voriger Art. Auf dem Rücken jederseits drei gekörnte Erhöhungen. Zwischen den beiden dorsalen Vorderdornen eine tiefe, halbkreisförmige A Asbuchtung. Alle drei Hinterdornen etwa von gleicher Länge; zwischen dem oberen und den beiden unteren eine breite Ausbuchtung. Fuss kurz. Länge 0,25-0,27 mm.

\section{Diploïs Gosse.}

Transversalschnitt des Panzers dreieckig. Körper länglich. Panzer wohl aus zwei dorsalen und einer ventralen Platte aufgebaut. Zwischen den beiden ersteren der Rückenspalt. Panzer transparent, glatt oder narbig. Kopf stark retraktil, mit einer Cuticularverdickung. Auge in der Ein- oder Zweizahl. Fuss dreigliedrig, kurz, mit zwei Zehen.

D. daviesae Gosse (Taf. XV, 23)

Länge $0,5 \mathrm{~mm}$.

\section{Fam. Euchlanidae.}

Körper etwa eiförmig, Rücken gewölbt, Bauch plan. Kopf breit, sehr retraktil, wenig scharf vom Rumpfe geschieden. Fuss deutlich dreigliedrig, mit langen, dolchförmigen Zehen. Letztere am freien Ende häufig breiter als an der Basis. Panzer aus 
Rücken- und Bauchschild bestehend, die seitlich durch eine clastische Membran verbunden sind. Letztere bildet eine mehr oder weniger breite und tiefe Furche. Häufig sind die Seitenränder der Platten flügelartig erweitert. Rückenplatte grösser als die Bauchplatte. Räderorgan mit Randwimperkranz, dessen Dorsalrand drei kleine mit Borsten besetzte Erhöhungen trägt. Auf der Fläche des Räderapparates drei Reihen Wimpern und zwei borstentragende Papillen. Mundtrichter weit, fein bewimpert. Kauer fast kubisch, mit starken, mehrzähnigen Kiefern. Magen rundlich, grosszellig, meist gelbbraun gefärbt, mit grossen Drüsen; Darm birnförmig, am Rücken über das Magenende aufsteigend. Blase gross. Eierstock flach, mit grossen Keimflecken. Am Ganglion setzt sich ein voluminöser Sack an, der vielleicht dem Kalkbeutel der Notommatadae entspricht.

\section{Euchlanis Ehrbg.}

Leben unter Algen. Schwimmen unruhig suchend umher.

I. Rückenschild seitlich flügelartig erweitert. . . . . . 2

2. Rücken gekielt . . . . . . . . . . . . . . . 3

3. Ein einfacher Rückenkiel. . . 1. E. triquetra

$3^{*}$. Vom hinteren Ausschnitte steigen zwei anfangs parallele, später divergierende und verstreichende Firste auf; zwischen ihnen erhebt sich nach vorn zu ein mittlerer, wellig gebogener Kiel, der sich im Nacken in zwei Ausläufer spaltet

2. E. bicarinata

2*. Ohne Rückenkiel . . . . . 3. E. piriformis

$1^{*}$. Rückenschild ohne flügelartige Erweiterung. . . . . . 4

4. Rückenplatte auf die Ventralseite übergreifend....

4. E. deflexa

4*. Rückenplatte nicht auf die Ventralseite übergreifend . 5 5. Rückenplatte am Hinterrande mit tiefer Kerbe . . 5. E. dilatata

$5^{*}$. Kerbe am Hinterrande des Rückenschildes nur seicht 6. E. macrura

I. E. triquetra Ehrbg:

Panzer hyalin; Rückenschild vorn und hinten ausgerandet. Bauchschild schmäler, etwas gewölbt. Kiefer vierzähnig. Magendrüsen flach, oval. Seitenkanäle mit je vier Wimperfackeln. 
Längsmuskeln deutlich quergestreift. Länge $0,5 \mathrm{~mm}$, des Eies 125 $\mu$. Zwischen Wasserpflanzen (Utricularia), nicht häufig.

[Unter dem Namen E. hyalina hat'Leydig eine Varietät beschrieben, die durch grosse Durchsichtigkeit und einen weniger hohen Rückenkiel ausgezeichnet sein soll.]

2. E. bicarinata Leydig

Panzer oval, wenig gewölbt, hinten mit einem Ausschnitt. Aehnlich voriger Spezies. Fuss mit zwei Borsten. Länge ohne Fuss ca. $0,28 \mathrm{~mm}$.

3. E. piriformis Gosse

Birnförmig, 'sehr transparent. Rückenschild: Seitenränder vorn je in einen ventralwärts gekrümmten Zipfel ausgezogen; Vorderrand U-förmig eingekerbt. Ventralplatte: Seitenränder ebenfalls in zwei flügelartige Anhänge ausgezogen, die gegen die analogen Gebilde des Rückenschildes gekrümmt sind; Vorderrand breit eingekerbt; Hinterrand abgerundet. Seitenkanäle mit je vier Wimperfackeln. Fuss kurz, am letzten Segmente mit zwei Paaren Borsten. Länge o,5-0,6 mm.

\section{E. deflexa Gosse}

Panzer breit eiförmig. Rückenschild auf die Bauchseite übergreifend, am Vorderrande U-förmig eingekerbt; am Hinterrande mit wenig bemerkbarer Kerbe. Ventralplatte vorn tief eingekerbt, ihre Seitenränder wellenartig gebogen. Am letzten Fussgliede zwei Paare langer Borsten, am vorletzten Fussgliede eine dorsale Protuberanz. Zehen kräftig und breit. Seitenkanäle mit je vier Wimperfackeln. Laterale Taster nach hinten bis zur Basis des Fusses verschoben. Kauer relativ klein; am Unterrande ragen beiderseits die grünlich gefärbten, gespaltenen Drüsen hervor. Magen - und Darminhalt oft grün. Längsmuskeln quergestreift. Länge $0,4-0,6 \mathrm{~mm}$. Nicht sehr häufig.

5. E. dilatata Ehrbg. (Taf. XV, 24)

Panzer breit eiförmig. Rückenschild am Vorderrande breit ausgebuchtet. Bauchschild schmäler als das Rückenschild, die Seitenränder beider Panzerplatten parallel. Am Vorderrande des Bauchschildes eine seichte Einkerbung; Hinterrand abgerundet. Fuss kurz, mit zwei schmalen, linealischen Zehen und zwei Borsten. An der Basis der Zehen eine Tasche mit rotem Pigment. Magen durch Kontraktion der ihn suspendiert haltenden Muskelzüge 
fortwährend hin und her geschoben. Blase gross; Seitenkanäle mit je vier Wimperfackeln. Ei o, $15 \times 0,7 \mathrm{~mm}$ gross, mit runzliger Schale, seitlich an Algenfäden angeheftet. Länge der Tiere $0,29-0,38 \mathrm{~mm}$. Männchen fast eben so gross. Ueberall, gemein.

\section{E. macrura Ehrbg.}

Panzer länglich eiförmig, nach vorn verjüngt. Rückenschild vorn breit ausgebuchtet. Bauchschild schmäler als das Rückenschild, vorn breit eingekerbt, am Hinterrande abgerundet. Fuss lang, mit zwei linealischen Zehen; am letzten Segmente mit einem Paare Borsten. Seitenkanäle mit je fünf Wimperfackeln. Länge $0,28-0,35 \mathrm{~mm}$. Gemein.

\section{Fam. Cathypnadae.}

Panzer meist glatt, aus Rücken - und Bauchschild bestehend, vorn und hinten offen. Hintere Oeffnung stets nach der Ventralseite verlagert. Vorn sind die Seitenränder beider Panzerplatten in Spitzen ausgezogen. Am Vorderrande finden sich gewöhnlich Ausbuchtungen. Kopf deutlich abgesetzt, breit, sehr retraktil. Räderorgan aus Randwimperkranz bestehend; fast stets zurückgezogen und dann als bewimperter Konus erscheinend. Ein Auge. Die drei Taster sind nur schwer sichtbar. Basalglied des kurzen Fusses erweitert.

\section{r. Cathypna Gosse.}

Körper eiförmig, dorso-ventral abgeplattet. Panzer transparent; beide Platten seitlich durch eine (eine Furche bildende) Cuticula verbunden. Diese Furche ist hinten breiter als vorn. Ganglion gross, Auge rot. Fuss mit zwei Zehen, deren Länge gleich $1 / 2$ der des Panzers ist.

C. luna Ehrbg. (Taf. XVI, I)

Panzer hinten gerundet. Rücken- und Bauchschild gleichartig gewölbt. Vorderrand des letzteren halbmondförmig ausgeschnitten. Fuss eingliedrig. Seitenkanäle mit je zwei Wimperfackeln. Länge o,18-0,20 mm. Zwischen Algen, gemein. 


\section{Distyla Eckstein.}

Panzer zart, biegsam. Seitenfurche nur schwach entwickelt. Die Fussöffnung der Bauchplatte mit einer chitinösen Einfassung. Kopf sehr beweglich, seitlich durch Cuticular-Verdickungen geschützt. Magen cylindrisch, Darm birnförmig. Blase eiförmig; Seitenkanäle nahezu gerade, bis zum Räderorgan sich erstreckend. Gehirn einfach oder dreilappig. Auge gross, rot. Taster nur schwer sichtbar. Fuss eingliedrig, kurz, mit zwei Zehen.

1. Dorsalplatte mit polygonaler Felderung 1. D. ludwigi

I*. Panzer mit parallelen Longitudinalfalten 2. D. Alexilis

I**. Panzer glatt, hinten mit einer kleinen Cuticularfalte

3. D. gissensis

\section{D. ludwigi Eckstein (Taf. XVI, 2)}

Körper eiförmig. Panzer stark, gekörnelt. Rückenschild in der Mittellinie rautenartig erhöht, hinten mit dreieckiger Spitze endigend. Bauchschild węniger stark gekrümmt, schmäler und kürzer, ohne polygonale Felderung. Vorderöffnung des Panzers an der Ventralseite mit halbmondförmigem Ausschnitt, seitlich mit zwei Dornen; hintere Oeffnung klein, mit Einfassung versehen. Magen gross, sackförmig; Darm birnförmig. Blase gross, kugelig; Seitenkanäle mit je vier Wimperfackeln. Fuss kurz, mit zwei langen Zehen. Länge 0,14-0,25 mm.

2. D. Aexilis Gosse

Körper ungefärbt, cylindrisch, nach vorn verjüngt. Panzer sehr zart, biegsam, hinten abgerundet. "Oeffnung für den Fuss weit; ebenso die vordere Panzeröffnung; letztere kreisrund, an jeder Seite mit einem kurzen Chitindorne. Fuss konisch, zweigliedrig, breit, mit zwei leicht gekrümmten Zehen. Ganglion einfach, am ventralen Hinterrande mit grossem Auge. Magen und Darm meist gelbbraun gefärbt. Blase gross. Seitenkanäle schwer sichtbar. Länge 0,1 2-0,14 mm.

3. D. gissensis Eckstein

Körper länglich, eiförmig. Panzer zart, biegsam, hinten abgcrundet. Seitenränder beider Panzerplatten vorn je in einen kurzen Dorn ausgezogen. Oeffnung für den Kopf gross, mit kreisrundem Rande. Fuss mit einem spitzen Griffel. Ganglion einfach, am Hinterrande mit grossem Auge. Seitenkanäle mit je drei Wimperfackeln. Länge $0,1-0,16 \mathrm{~mm}$. 


\section{Monostyla Ehrbg.}

Panzer flach, eiförmig, bei Kontraktion des Kopfes vorn sichelförmig ausgeschnitten. Hirnknoten flach, an der Unterseite mit einem roten Auge. Kauer ziemlich gross, fast kubisch, mit starken, etwas ungleichen Kiefern. Magen länglich, mit grossen Drüsen; Darm oval. Fuss zweigliedrig, mit einer langen, cylindrischen Zehe. - Blase und Eierstock nicht sehr gross.

I. Panzer am Vorderrande seitlich mit je zwei dreieckigen Dornen . . . . . . . . . . . . . M. quadridentata 1*. Panzer am Vorderende seitlich nur mit je einem Dorn. . 2 2. Zehe an der Basis ihrer Endspitze mit zwei sehr kleinen accessorischen Stiftchen . . . . 2. M. lunaris

$2^{*}$. Zehe ohne accessorische Griffel . . 3. M. bulla

r. M. quadridentata Ehrbg.

Länge $0,15 \mathrm{~mm}$. Zwischen Wasserpflanzen, selten.

2. M. hunaris Ehrbg. (Taf. XVI, 3)

Körper eiförmig. Rücken- und Bauchschild von gleicher Grösse und Gestalt; hinten abgerundet. Fuss kurz. Die Ausführungsgänge der Fussdrüsen münden an der Basis der Endspitze der Zehe, durchziehen also die letztere fast in ihrer ganzen Länge. Länge $0,16-0,18 \mathrm{~mm}$.

\section{M. bulla Gosse}

Körper eiförmig; im Schnitte fast kreisrund. Oeffnung des Panzers für den Fuss viereckig. Seitenkanäle wahrscheinlich mit je drei Wimperfackeln. Lünge $0,2 \mathrm{~mm}$.

\section{Fam. Coluridae.}

Panzer aus zwei lateralen Platten oder aus Dorsal- und Ventralschild bestehend. Kopf scharf abgesetzt, dorsal durch eine hyaline Chitinlamelle geschützt. Räderorgan aus einem kurzwimperigen Cilienkranze bestehend. Magen cylindrisch, Darm birnförmig, After an der Basis des Fusses. Dorsaltaster als bewimperte Papille entwickelt. Augen in der Zwei- oder Vierzahl. Fuss schmal, mit zwei Zehen. 


\section{Colurus Ehrbg.}

Panzer oval; aus zwei lateralen Platten, die dorsal verbunden sind, ventral auseinander klaffen. Dieser Spalt setzt sich vorn und hinten fort in die Oeffnungen für Kopf und Fuss. Kopf unter den Vorderrand des Panzers vollständig zurückziehbar. Hinterrand des Panzers mit Dornen ausgestattet. Kauer fast kubisch, mit hammerartig arbeitenden Kiefern. Schlund lang, Magen rundlich, Darm birnförmig. Blase und Ovar klein. Augen in der Zweizahl. Fuss mit 3-4 Segmenten.

I. Zehen länger als der Fuss.

2. Panzerplatten hinten in zwei stumpfe Spitzen ausgezogen

I. C. leptus

2*. Spitzen schärfer

2. C. caudatus

1*. Zehen kürzer als der Fuss.

3. Fuss deutlich viergliedrig . . . 3. C. uncinatus

$3^{*}$. Fuss dreigliedrig.

4. Hintere Panzerspitzen sehr lang, abwärts gerichtet .

4. C. deflexus

$4^{*}$. Hintere Panzerspitzen weniger lang, nur angedeutet oder fehlend.

5. Panzerplatten fast in der ganzen Länge des Rückens verwachsen . . . . . . . . 6

6. Panzerspitzen geradezu fehlend

5. C. grallator

6*. Panzerspitzen deutlich . 6. C. bicuspidatus

$5^{*}$. Panzerplatten im letzten Drittel des Rückens getrennt. . . . . . .7. C.obtusus

I. C. leptus Gosse

Panzerplatten für die ganze Iänge des Rückens verwachsen. Kopf-Ausschnitt kreisförmig. Fuss-Segmente von gleicher Länge. Fuss gleich $1 / 2$ der Körperlänge. Länge $0,1 \mathrm{~mm}$.

2. C. caudatus Ehrbg.

Länge $83 \mu$, des Eies $40 \mu$.

3. C. uncinatus Ehrbg.

Kauer dicht hinter der Mundöffnung. Am Anfange des Magens mehrere heftig schlagende Cilien. Länge $55-83 \mu$. Verbreitet. 
4. C. deflexus Ehrbg.

Zwei kleine, seitliche Augen. Nach Bilfinger ist die Länge der Panzerspitzen variabel. Länge $100 \mu$, des Eies $40 \mu$. 5. C. grallator Gosse

Kopf-Ausschnitt kreisförmig, schief gegen die Körperachse geneigt. Länge $80 \mu$.

6. C. bicuspidatus Ehrbg. (Taf. XVI, 4 und 5)

Vorderrand des Panzers dorsal eingekerbt; ebenso der Hinterrand. Länge $80 \mu$, des Eies $40 \mu$.

7. C. obtusus Gosse

Seitenränder der Ausbuchtungen für Kopf und Fuss abgerundet. Fuss gleich $1 / 2$ der Körperlänge. Länge $70 \mu$. Selten.

\section{Monura Ehrbg.}

Sehr ähnlich Colurus, jedoch nur mit einer Zehe.

M. dulcis Ehrbg. (Taf. XVI, 6)

Panzer eiförmig, hinten schief abgestutzt, zugespitzt. Augen auseinander stehend. Länge circa $90 \mu$. Zwischen Algen, gemein.

3. Metopidia Huds. und Gosse.

I. Mit Augen

2. Mit zwei Augen . . . . A. Metopidia s.str. (S. 477)

2*. Mit vier Augen . . . . . B. Squamella (S. 479),

I. Ohne Augen . . . . . . . C. Lepadella (S. 479)

A. Subgen. Metopidia Ehrbg.

Panzer oval; aus Rücken- und Bauchschild, die beide lateral verbunden sind, verwachsen; geschlossen bis auf eine vordere Ausrandung für den Austritt des Kopfes und einen hinteren Ausschnitt auf der Bauchseite für den Fuss. Am Bauche ziehen zwei aufgebogene, schmale Falten von der Fussbasis bis nahe zum Vorderende. Kopf mit einem schmalen Schilde bedeckt, welches an der Spitze über der Stirn vorn vorgebogen ist und angeblich zum Kratzen im Detritus gebraucht wird. Zwei Augen an der Stirn, seitlich. Fuss ziemlich lang, deutlich gegliedert, mit zwei schlanken, spitzen Zehen. Kauer fast kubisch, mit rechtwinklig gegliederten (hammerförmigen) Kiefern. Magen oval, mit grossen Drüsen. Darm gleichfalls oval. Eierstock und Blase ziemlich gross. 
I. Panzer mit Rückenkiel . . . . . . . . . . . . . . 2

2. Ventralplatte ebenfalls mit medianem Kiel.

I. M. oxysternum

2*. Ventralplatte ohne Kiel . . . . 2. M. triptèra

I*. Panzer ohne Rückenkiel . . . . . . . . . . . . . 3

3. Rückenschild hinten in einen spitzen Dorn ausgezogen .

3. M. acuminata

3*. Rückenschild ohne Dorn . . . . . . . . . 4

4. Querschnitt des Rückenschildes halbkreisförmig . . 4. M. lepadella

4*. Querschnitt des Rückenschildes dreieckig

5. M. solidus

I. M. oxysternum Gosse (Taf. XVI, 7)

Rückenschild im Querschnitt dreieckig. Bauchkiel bis zur Körpermitte reichend; hinter seinem Ende eine Aushöhlung. Seitenränder des Mund-Ausschnittes gezähnelt. Fuss lang, Zehen kurz. Länge $0,14-0,2 \mathrm{~mm}$.

2. M. triptera Ehrbg. (Taf. XVI, 8)

Rückenschild seitlich flügelartig erweitert, hinten etwas zugespitzt. Ventralplatte ebenfalls mit flügelartigen Erweiterungen, die rnit den analogen Gebilden der Dorsalplatte sich vereinigen. Zehen so lang wie der Fuss. Länge o,8-0,16 mm. Zwischen Algen, nicht häufig.

\section{M. acuminata Ehrbg.}

Panzer vorn leicht ausgerandet, mit spitz vortretenden Seitenkanten, hinten in eine lange Spitze endigend. Augen mit deutlichen, lichtbrechenden Kugeln. Magendrüsen oval. Länge o, I mm, des Eies $50 \mu$. Nicht häufig, mit M. solidus.

4. M. lepadella Ehrbg.

Panzer hyalin, vorn halbmondförmig ausgerandet; hinten rundlich, mit fast quadratischem Fuss-Ausschnitt. Magen und Darm fast gleich gross, Magendrüsen gestielt und gelappt (kleeblattförmig). Zehen etwas länger als der Fuss, am Grunde zwischen beiden ein kleiner, kreisrunder Ausschnitt. Länge (des Panzers) bis $166 \mu$, des Eies $83 \mu$. Zwischen Algen, zuweilen zahlreich. 
5. M. solidus Gosse

Sehr ähnlich voriger Art, aber viel breiter. Panzer fast kreisförmig, brillant durchscheinend; eine leichte Punktierung läuft um den Rand, wie die Umschrift einer Münze. Panzer o, 7 mm lang.

B. Subgen. Squamella Ehrbg.

Der vorigen Untergattung sehr ähnlich, aber mit vier Augen. Sq. bractea Ehrbg. [= Mctopidia br. (Ehrbg.)] (Taf. XVI, 9) Rückenschild vierseitig, Bauchschild vorn tief ausgeschnitten; beide Platten mit schmalem, gekörneltem Umschlag. Länge des Panzers $83 \mu$, des Eies $55 \mu$.

[Hiermit identisch ist nach Eckstein Sq. oblonga Ehrbg., deren Zehen etwas schlanker als bei $S q$. bractea sein sollen. Länge mit Fuss o, I I mm. In grünem Wasser.]

C. Subgen. Lepadella Ehrbg.

Ehenfalls Metopidia sehr ähnlich, aber augenlos.

I. Panzer vorn und hinten ausgerandet, vorn breiter als hinten

I. L. emarginata

1*. Panzer vorn und hinten etwas abgestutzt, ohne Ausrandung, vorn schmäler als hinten . . . . 2. L. ovalis

I. L. emarginata Ehrbg. [= Metopidia em. (Ehrbg.)] Länge $40 \mu$.

2. L. ovalis Ehrbg. [= Metopidia ov. (Ehrbg.)]

Länge $0, \mathrm{I} \mathrm{mm}$, des Eies $40 \mu$. Sehr gemein, in allen stagnierenden Wassern und Infusionen, jederzeit, zuweilen massenhaft bis zur milchigen Trübung des Wassers. [Nach Eckstein vielleicht identisch mit Squamella bractea.]

\section{Fam. Pterodinadae.}

Körper meist dorso-ventral abgeplattet. Panzer aus einem Stück, mit Oeffnung für Kopf und Fuss. Kopf kurz, konisch. Räderorgan bestehend aus einem dorsal unterbrochenen Randwimperkranz, dessen freie Enden eingeschlagen sind und eine Art Innenkranz bilden. Fuss lang, cylindrisch, an der Basis quergeringelt, gegen das Ende glatt, ohne Zehen, etwa in der Mitte der Ventralseite entspringend. 


\section{Pterodina Ehrbg.}

Panzer schildförmig, sehr flach, rundlich oder oval, den winzigen Körper weit überragend, glatt und weich. An der Stirn zwei Augen mit lichtbrechenden Körpern. Schlundkopf flach, mit verschmolzenen Kiefern. Magen sackförmig, mit langgestielten, gelappten und am Rande gekerbten Drüsen. Darm kugelig. Wassergefässe deutlich; Blase sehr klein und undeutlich. Eierstock hufeisenförmig, mit grossen Keimflecken. Längsmuskeln quergestreift.

I. Körper hinten seitlich mit je einem dreieckigen, zipfelförmigen Anhang . . . . . . . . . . . 1. Pt. emarginata

1*. Körper seitlich ohne zipfelförmige Anhänge. . : . . . 2

2. Panzer kreisrund oder nahezu kreisrund. . . . . . 3

3. Dorsaler Vorderrand mit starkem Dorn

\section{Pt. mucronata}

3*. Dorsaler Vorderrand ohne Dorn 3. Pt.patina

2*. Panzer elliptisch . . . . . . . . . . . . . . . 4

4. Augen entfernt gestellt . . . . . . . . . 5

5. Ventralseite mit Mediankiel 4. Pt. reflexa

$5^{*}$. Ventralseite ohne Mediankiel.

5. Pt. elliptica

4*. Augen genähert . . . . 6. Pt. clypeata

\section{Pt. emarginata Wierzejski}

Oeffnung für den Fuss weit nach hinten verlagert, etwa viereckig. Die Lateraltaster liegen hinter der Mitte des Rumpfes. Panzeroberfläche mit zerstreut stehender, starker Stichelung. Schwingt, mit dem Fuss lose an einen Algenfaden festgeheftet, minutenlang im Kreise. Länge i $5 \mu$. (Nach Bilfinger.)

2. Pt. mucronata Gosse

Dorsalseite gekörnelt, besonders dicht am Rande. Oeffnung für den Kopf ventral V-förmig eingekerbt. "Taster wie bei folgender Art. Oeffnung für den Fuss rund. Länge $0,14 \mathrm{~mm}$.

3. Pt.patina Ehrbg. (Taf. XVI, 10)

Körper namentlich an den Seitenrändern gekörnt; Seitenränder noch mit je sechs hyalinen Buckeln versehen. Oeffnung für den Fuss kreisförmig, im letzten Drittel der Ventralseite. 
Lateraltaster und Rückentaster in einer geraden Linie. Länge $0,2 \mathrm{~mm}$, des Eies $83 \mu$. Zwischen Algen, häufig. Liegt oft lange unbeweglich.

4. Pt. reflexa Gosse

Panzer leicht gekörnelt. Lateraltaster etwas hinter dem Dorsaltaster. Oeffnung für den Fuss oval. Am Dorsalrand der Vorderöffnung eine am Gipfel eingekerbte Protuberanz. Länge o, 1 I $\mathrm{mm}$.

5. Pt. elliptica Ehrbg.

Panzer vorn nicht ausgerandet. Stirn mit borstentragendem Zapfen. Länge $0_{5} 2-0,22 \mathrm{~mm}$, des Eies $83 \mu$.

6. Pt. clypeata Ehrbg.

Länge $0,2 \mathrm{~mm}$, des Panzers $0,16 \mathrm{~mm}$, des Eies $82 \mu$. An Asellus angeheftet.

[Hierher gehört das fusslose Gienus Pompholyx Gosse mit. der Spezies $P$. complanata Gosse (Taf. XVI, I I): Panzer fast kreisrund, vorn abgestutzt; Nackenende zu einer. stumpfen Spitze ansteigend. Länge des Panzers $80 \mu$.]

\section{Fam. Brachionidae.}

Panzer aus Dorsal- und Ventralplatte bestehend, die mit ihren Seitenrändern verbunden sind; meist transparent. Dorsalplatte gewölbt; Ventralplatte mehr plan. Oeffnung für den Fuss hufeisenförmig, am Hinterende des Bauchschildes. Dieser Oeffnung korrespondiert vielfach ein Ausschnitt des Rückenschildes.

\section{Noteus Ehrbg.}

Sehr ähnlich Brachionus, jedoch Panzer gefeldert, mit kleinen Zähnchen besetzt. Fuss scharf gegliedert, Augen fehlen. Rückenschild gewölbt, hinten nicht eingedrückt. Dorsaler Vorderrand mit zwei Chitinlamellen; Seitenränder vorn in je eine Spitze ausgezogen. Zwischen den beiden Dorsal-Lamellen eine U-förmige Einkerbung. Hinterrand des Panzers mit zwei lateralen Dornen. Fuss dreigliedrig, Basalglied mit vier queren Cuticularfalten. 
N. quadricornis Ehrbg. (Taf. XVI, 13 .'

Panzer ziemlich flach, Rücken facettiert und gekörnelt. Vorderrand mit scharfen, vorspringenden Seitenkanten und im Nacken mit zwei Zacken. Hinterende gleichfalls mit zwei längeren Zacken. Kopf innerhalb des bewimperten Randes mit drei bewimperten Lappen, ohne einzelne Borsten.' Nackentaster kurz, an der Basis erweitert; Seitentaster als bewimperte Papillen entwickelt. Schlundkopf vorstreckbar, mit bräunlichen Drüsen. Magen grosszellig, mit gestieltèn, am Rande gekerbten Drüsen. Eierstock querliegend, mit grossen Keimfleken. Seitenkanäle mit je vier Zitterorganen. Körper sehr durchsichtig. Länge $0,26-0,35 \mathrm{~mm}$, des Eies $83 \mu$. Zwischen Algen, selten. Panzer scheint ziemlich variabel $\mathrm{zu}$ sein.

\section{Brachionus Ehrbg.}

Panzer oval, topfförmig, vorn offen, am Rande der Bauchseite geschweift, seitlich und am dorsalen Vorderrande mit Dornen oder Zacken; hinten am Rücken meist eingedrückt. Kopfrand trichterförmig, bewimpert, etwas nach aussen umgebogen, am Munde eingebuchtet. Innerhalb des Randes erheben sich zwei seitliche, stark bewimperte, ohrförmige Räderorgane. In der Mitte des Kopfes ragt nach dem Nacken zu ein rüsselartiger, oben mit steifen Borsten besetzter Taster vor; hinter ihm der ziemlich lange, zurückgebogene Nackentaster mit spärlichen Endborsten. Manche Arten haben zwischen dem Stirntaster und den Räderorganen noch einzelne lange Borsten auf konischen Polstern. Hirnknoten in der Mitte der Unterseite, dicht vor dem roten Auge quer eingekerbt. Kauer prismatisch, oben mit kugeligen, farbigen Drüsen, vor ihm in der Halsgegend grossblasiges Bindegewebe. Schlund stark querfaltig, undulierend; Magen kugelig, grosszellig, dickwandig, mit grossen, meist gestielten Drüsen. Darm birnförmig. Eierstock oval, querliegend; mit grossen Keimflecken. Die Eier bleiben nach dem Ablegen meist an den Stielen an dem hinteren, eingedrückten Ende des Panzers hängen. Blase ziemlich gross; Seitenkanäle deutlich, mit je vier Wimperfackeln. Fúss quergeringelt oder gegliedert; mit dicken, kolbenförmigen Drüsen, breiten Muskeln und zwei sehr kurzen, an der Spitze durchbohrten Zehen, mit denen die Tiere sich häufig festhalten. 
I. Fuss mit Segmentierung . . . . . . . . . . . . . 2

2. Vorderrand mit vier Dornen . . . . Br. quadratus

2*. Vorderrand mit 12 Dornen . . . 2. Br. militaris

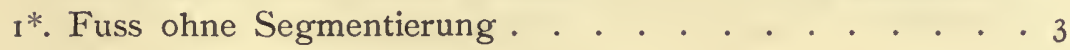

3. Panzer glatt oder fast glatt . . . . . . . . . 4

4. Vorderrand mit vier Dornen . 3. Br.pala

4*. Vorderrand mit sechs Dornen . . . . . . . . 5

5. Körper transparent . . 4. Br.urceolaris

5*. Farbe rötlich . . . . . 5. Br. rubens

3*. Panzer gekörnt . . . . . . 6. Br.bakeri

$3^{* *}$. Panzer von winkligen Rippen rauh $7 . B$ r. angularis

1. Br. quadratus Rousselet

Eine Varietät hierzu ist nach Bilfinger Br. leydigi Cohn, der durch facettierten Rückenpanzer ausgezeichnet ist. In den Facetten fein gekörnelt. Nackenrand mit sechs fast gleichen, spitzen Zähnen. Winterei mit cylindrischen Warzen.

2. Br. militaris Ehrbg.

Panzer rauh, hinten mit vier Dornen. Länge ohne Zacken $0,2 \mathrm{~mm}$, des Eies $83 \mu$.

3. Br.pala Ehrbg.

Körper länglich, eiförmig. Panzer zart und durchsichtig. Dornen des Vorderrandes von gleicher Länge; zwischen den beiden mittleren eine tiefe Einkerbung. Hinterrand ohne Dornen, seitlich nur zwei stumpfe Verlängerungen. Stirn mit zwei Tastborsten zwischen den Räderorganen. Kiefer fünfzähnig. Länge $0,2-0,5 \mathrm{~mm}$, mit Fuss 0,66 mm. Ei 0,15 mm lang, mit gelbrötlichen Fett-Tropfen. In Wassergefässen u. dergl., zuweilen häufig.

Diese Art hat eine Varietät var. amphiceros Ehrbg., die hinten vier flossenartig bewegliche Dornen zeigt, zwei nahe am Hinterende, zwei mehr seitlich. In Grösse und Form sind diese Dornen sehr variabel. Die seitlichen sind oft so in den Panzer eingeklappt, dass sie nicht sichtbar sind. Länge bis $0,23 \mathrm{~mm}$, des Eies 33 bis $100 \mu$. An der schaumigen Oberfläche des Wassers.

4. Br. urceolaris Ehrbg. (Taf. XVI, I2)

Körper vorn verjüngt. Panzer fast glatt, mit scharfen Seitenrändern (schildkrötenartig). Bauchseite flach, Rücken gewölbt, vorn mit sechs Dornen, hinten scharf eingedrückt. Länge 
$0,2-0,25 \mathrm{~mm}$, mit Fuss $0,25-0,33 \mathrm{~mm}$, des Sommereies 0,1 bis $0,13 \mathrm{~mm}$. Winterei mit runzeliger, gelbbrauner Schale. In trübem Wasser; häufig, zuweilen massenhaft. Männchen kurz cylindrisch, ungepanzert. Länge $75-90 \mu$, Breite $23-36 \mu$.

5. Br. rubens Ehrbg.

Vorigem ähnlich aber rötlich. An Daphnien und Cyclopen angeheftet.

\section{Br. bakeri Ehrbg.}

Panzer gekörnt. Am Vorderrande mit sechs Dornen, von denen die mittleren als lange gekrümmte, an der Innenscite gezähnnelte Hörner erscheinen. Die mittleren Dornen länger als die seitlichen; am kürzesten sind die zwischen den dorsalen und lateralen Dornen befindlichen Zacken. Die Ränder der Oeffnung für den Fuss sind in eine die Fussbasis einhüllende Scheide verlängert. Fuss lang, mit kurzen Zehen. länge $0,2-0,4 \mathrm{~mm}$, des Eies $110 \mu$. In langsam fliessendem Wasser, häufig, aber nicht massenhaft.

Hierzu gehört die Varietät var. rhenanus Lauterborn: Körper länglich, mehr oder weniger viereckig. Panzer wenig gekörnt. Die zwischen den medianen und lateralen Dornen des Vorderrandes befindlichen Zacken sehr klein. Länge $0,3-0,35 \mathrm{~mm}$.

\section{Br. angularis Gosse}

Panzer oval, fast sechseckig. Nackenrand mit zwei kleinen Zähnen, seitlich zuweilen noch Spuren von Zähnchen. Hinterende mit zwei kurzen, stumpfen Zacken. Braun, wenig transparent. Länge $0,12 \mathrm{~mm}$.

\section{Fam. Anuraeadae.}

Panzer aus Dorsal- und Ventralplatte; erstere gewölbt, letztere plan oder konkav; beide seitlich verschmolzen. Rückenschild meist gepanzert. Dorsaler Vorderrand meist mit sechs Dornen. Ventralplatte am hinteren Teile mit einem schmalen Querspalt für dic Kloakenöffnung. Schlund kurz, breit; Magen kugelig. Ovar hufeisenförmig. Blase gross, Seitenkanäle mit je vier Wimperfackeln. Dorsaltaster konisch. Ein Auge. 


\section{Anuraea Ehrbg.}

Panzer prismatisch, keil-'oder spińdelförmig. Rückenschild gefeldert, vielfach mit Mediankiel, gekörnelt. Beide Panzerplatten von gleicher Grösse. Die vorderen Mediandornen stark entwickelt. Hinterrand, wenn gerade, mit zwei lateralen Dornen; wenn gerundet, nur mit einem oder gar keinem Dorne. Zahlreiche, nur sporadisch erscheinende Arten. Man findet mehr leere Panzer als lebende Tiere. Die Eier bleiben oft am Panzer hängen.

i. Panzer hinten mit zwei lateralen Dornen

I. A. aculeata

I*. Panzer hinten mit einem Mediandorne. . . . . . . . 2

2. Ventralplatte hinten mit einem dornartigen, retraktilen Sporn . . . . . . . . . .2. A. schista

2*. Ventralplatte hinten ohne Sporn. . 3. A. cochlearis

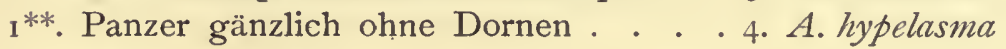

1. A. aculeata Ehrbg.

Körper rechteckig. Panzer gekörnelt, auf der Dorsalseite mit drei Reihen hexagonaler Felder; Medianlinie gekielt. Dornen des Vorderrandes normal, die mittelsten am längsten. Hintere Dornen lang, gebogen. Länge $0,25 \mathrm{~mm}$, ohne Dornen $166 \mu$. Ei $80 \mu$ lang.

Hierher gehören folgende sechs Varietäten:

I. Panzer hinten mit Dornen.

2. Felderung und Körnelung des Panzers undeutlich; linker oder rechter Hinterdorn reduziert, Dorsaltaster lang. . var. valga Ehrbg.

2*. Felderung und Körnelung deutlich, häufig Fremdkörper auf dem Panzer; Vorder- und Hinterdornen kurz. Länge $0,17 \mathrm{~mm}$. . . . . . . . . var. brcvispina Gosse

I*. Panzer hinten ohne Dornen

3. Panzer glatt, hinten gerundet, prismatisch. Länge $\mathrm{O,I}$ bis o, I mm, des Eies $50 \mu$. . var. squaniula Ehrbg.

3*. Panzer gekörnelt. . . . . . . . . . . . . . . 4

4. Panzer oblong, Vorderrand mit sechs Dornen; die mittleren gekrümmt. Länge i $66 \mu$, des Eies $55 \mu$. var. falculata Ehrbg. 
4*. Panzer von vorn gesehen fast quadratisch, Rücken facettiert. Vorderrand mit sechs Dornen, die mittleren grösser als die anderen, nach aussen und vorn gekrümmt. Länge I 10 $\mu$, des Eies $55 \mu$.

var. curvicornis Ehrbg.

2. A. schista Gosse

Panzer am Hinterrande mit einem Mediandorne. Unterscheidet sich von der folgenden Spezies durch den Besitz eines retraktilen, am Vorderrande der ventralen Panzerplatte befindlichen Dornes.

\section{A. cochlearis Gosse (Taf. XVI, I4)}

Körper cylindrisch-konisch, hinten mit einem langen Mediandorne. Rückenschild gewölbt, mit Körnelung und hexagonaler Felderung und deutlichem Mediankiele. Vorderrand mit sechs Dornen; die beiden mittleren lang, nach dem Kopfe gebeugt; die vier übrigen sind untereinander ziemlich gleich. Länge 0,16 bis $0,22 \mathrm{~mm}$.

Hierher gehören als Varietäten:

I. Hinterdorn völlig rückgebildet, Rückenkiel sehr deutlich. Länge $0,12 \mathrm{~mm}$. . . . . . . var. tecta Gosse

I*. Hinterdorn zwar kurz, aber noch vorhanden. Panzer in der Vorderansicht fast quadratisch oder dreieckig. Länge 0,1 bis $0,13 \mathrm{~mm}$, des Eies $60 \mu$. . . . . var. stipitata Ehrbg.

\section{A. hypelasma Gosse}

Körper eiförmig, vorn und hinten abgestutzt, transparent, ohne jegliche Bedornung. Aus der Kloakalöffnung kann ein membranöses Organ ausgestreckt werden, das vielleicht als Analogon eines Fusses aufzufassen ist. Beiderscits eine tiefe Längsfalte oder klaffende Spalte zwischen Rücken- und Bauchschild. Auge gross, blass. Länge $0,12 \mathrm{~mm}$.

\section{Notholca Gosse.}

Dem vorigen Genus ähnlich, jedoch besitzt die Dorsalplatte keine polygonale Felderung, sondern eine Anzahl von durch Furchen getrennten Längskielen. Vorderrand mit sechs Dornen. Durch die Kloakenöffnung des Panzers wird ein membranöses, retraktiles Organ ausgestreckt, das zur Anheftung des Tieres dient. 
I. Seitenränder des Panzers mit flügelförmigen, transparenten Verbreiterungen.

2. Mit beweglichen Seitendornen . . 1. N. spinifera

2*. Ohne bewegliche Seitendornen . . 2. N. striata I*. Seitenränder ohne flügelartige Verbreiterungen . . . . 3 3. Ventralplatte hinten mit retraktilem Dorn . . . . . .

$3^{*}$. Ventralplatte hinten ohne Dorn . . 4. N. longispina

I. N. spinifera Gosse

Sehr ähnlich $N$. striata Ehrbg., nur mit beweglichen Seitendornen.

\section{N. striata Ehrbg. (Taf. XVI, I5)}

Körper breit eiförmig. Vorderdornen voin ungleicher Länge; ventraler Vorderrand ausgebuchtet. Dorsalkiele deutlich und scharf, an Zahl zwölf. Länge o,16-o,2 mm, des Eies $80 \mu$.

Hierher gehören als Varietäten:

1. Rücken mit zwölf deutlichen Längsrippen. Panzer nach hinten stielartig verdünnt. Ende abgestutzt. Länge $\mathrm{O}$, I I bis $0,2 \mathrm{~mm}$, des Eies $50 \mu$. . . var. acuminata Ehrbg. 1*. Längsrippen undeutlich. Länge o,1 $2-0,16 \mathrm{~mm}$ var. labis Gosse

\section{N. foliacea Ehrbg.}

Körper keilförmig, vorn abgestutzt, hinten zugespitzt. Längsrippen der Dorsalplatte nach dem Mediankiel konvergierend. Ventralplatte undeutlich längsrippig. Vorderrand mit einem gekörnelten Querband. Kiefer vierzähnig. Länge 0,14-0,16 mm.

4. N. longispina Kellicott (Taf. XVI, 16)

Körper von der Form einer dreiseitigen Pyramidc. Vorderrand mit sechs Dornen, die beiden Mediandornen hiervon von ungleicher Länge. Vorderrand der Ventralplatte bildet eine bewegliche Lamelle. Panzer hinten in einen langen Dorn ausgezogen. Hinterer Teil der Ventralseite mit einer Konkavität, worin die Eier angeheftet sind. Länge $0,6-0,65 \mathrm{~mm}$. 


\section{Fam. Ploesomadae.}

Körper kegelförmig. Panzer narbig, an der Ventralseite gespalten, besteht gewöhnlich aus sechs Stücken (vordere und hintere Dorsalplatte, zwei dorsale Seitenplatten und zwei ventrale Seitenplatten). Dorsaler Vorderrand häufig mit drei Dornen; am Ende des Kopfschildes eine von einem chitinigen Ringwulst umgebene, kleine Vertiefung, in der sich eine Oeffnung für den Dorsaltaster befindet. Vom Ringwulste nehmen ein oder zwei Längskiele ihren Ursprung. Vorderes und hinteres Dorsalschild durch Querkanten und Falten geschieden. Die lateralen Panzerstücke meist aus mehreren Teilen zusammengesetzt. Kauer oval; Magen gross, mit grossen Zellen. Blase klein. Ganglion birnförmig, mit grossem, rötlich oder schwärzlich gefärbtem Auge. Fuss etwa in der Mitte der Bauchseite entspringend, an der Basis quergeringelt, an der Spitze glatt.

\section{Ploesoma Herrick.}

Rücken gewölbt, Bauch flach.

I. Panzer hart, nicht oder nur schwach narbig

1*. Panzer weich, stark narbig . . . . 2. Pl. hudsoni

i. Pl. truncatum Leander (Taf. XVI, i 7)

Von dem die Oeffnung für den Dorsaltaster umgebenden, hier trapezförmig gestalteten Wulste, gehen nach vorn zwei divergierende Kiele. Auge rot. Länge $0,2-0,3 \mathrm{~mm}$.

2. Pl. hudsoni Imhof

Panzer aus einem V-förmigen Nackenschild und zwei lateroventralen Iängsschienen bestehend. Letztere mit je einer Oeffnung für den Durchtritt der Lateraltaster, nur bis zur Ursprungsstclle des Fusses reichend. Länge $0,32-0,4 \mathrm{~mm}$.

\section{Fam. Gastropodidae.}

Körper etwa cylindrisch, im Profil eiförmig. Panzer glatt, durchsichtig, mit zwei kreisrunden Oeffnungen für Kopf und Fuss. Letzterer stets ventral und stark retraktil, mit zwei kleinen 
Zehen, quergeringelt. Magen gross, gefärbt. Blase klein; Seitenkanäle mit je vier Wimperfackeln. Ganglion birnförmig. Drei Taster als bewimperte Papillen sichtbar.

\section{Gastropus Imhof.}

G. stylifer Imhof (Taf. XVI,-18)

Körper hinten abgerundet. Fuss gekrümmt. Magen gelappt, lebhaft blau oder grün gefärbt, mit zahlreichen FettTröpfchen. Hypodermis des Panzers lila.

\section{Fam. An apodidae.}

Körper elliptisch, im Profil eiförmig, vorn abgestutzt. Panzer zart, aus Dorsal- und Ventralplatte bestehend; beide verbunden durch eine Cuticularfalte; hinten mit einer kleinen Kloakalöffnung. Fuss fehlt. Räderorgan gut entwickelt; mit Randwimperkranz. Innerhalb des letzteren mehrere bewimperté, retraktile Papillen. Zwischen diesen ein kahler, fingerförmiger, am Gipfel verbreiterter Fortsatz. Schlund kurz; Magen geräumig, gelappt (ähnlich Ascomorpha). Kloake hinten offen zwischen beiden Panzerplatten. Seitenkanäle mit zwei Wimperfackeln. Ovar eiförmig. Ein rotes Auge.

\section{Anapus Bergendal.}

Panzer zuweilen mit leichter Querstrichelung; vordere Oeffnung gross, kreisrund.

1. Panzer mit feiner Querstrichelung. . . I. A. ovalis

1*. Panzer ohne Strichelung . . . . . . 2. A. testudo

I. A. ovalis Bergendal (Taf. XVI, 19)

Körper leicht dorso-ventral abgeplattet. Dorsal- und Ventralplatte ungefähr von gleichen Dimensionen. Am Räderorgan vier bewimperte Papillen, die beiden äusseren davon grösser als die inneren. Länge $0,13-, 02 \mathrm{~mm}$.

2. A. testudo Lauterborn

Am Räderorgan nur zwei bewimperte Papillen. Der vorigen Arț sehr ähnlich. Länge $0,1-0,14 \mathrm{~mm}$. 


\section{Seirtopoda.}

Freilebende Rotatorien, nie Kolonie bildend, ohne Hülle und Panzer. Ausgezeichnete Schwimmer; nie kriechend; mit armartigen Fortsätzen, die zum Springen dienen und mit langen Chitinborsten besetzt sind. Körper cylindrisch-konisch; Kopf breit, abgestutzt, durch eine Einschnürung vom Rumpfe getrennt. Räderorgan nach Art der Bdelloida. Fuss fehlt. Dafür am Hinterende zwei fingerförmige, am Gipfel bewimperte Fortsätze, die einen $\mathrm{zu}$ vorübergehender Fixierung dienenden Schleim absondern.

\section{Fam. Pedalionidae.}

Cuticula dünn, biegsam. An der Spitze der sechs Armfortsătze lange, gefiederte Borsten. Armfortsätze cylindrisch, am Ende konisch, meist der Körperachse parallel. Gehirn gross. Zwei rote Augen. Ein Dorsal- und zwei Lateraltaster. Eier am Körper befestigt.

\section{Pedalion Hudson.}

Mit einem dorsalen, einem ventralen, zwci latero-dorsalen und zwei latero-ventralen Fortsätze.

\section{P. mirum Hudson (Taf. XVI, 20 u. 2 I)}

Körper kurz. Kopf breit, vom Rumpfe durch eine ringförmige Einschnürung getrennt. Hinterende mehr oder weniger zugespitzt, auf der Dorsalseite mit zwei fingerförmigen, am Gipfel verbreiterten und bewimperten Fortsätzen. Ventraler und dorsaler Armfortsatz länger als die übrigen; am längsten der ventrale. Länge $0,35-0,4 \mathrm{~mm}$. 


\section{Gastrotricha.}

\section{Litteratur:}

Zelinka, C., Die Gastrotrichen. Eine monographische Darstellung ihrer Anatomie, Biologie und Systematik. Zeitschr. f. wiss. Zool. Bd. 49. Leipzig 1890.

Der Körper der Gastrotrichen ist im allgemeinen walzenförmig gestaltet. Am Vorderende zeigt er eine mehr oder weniger deutliche halsartige Einziehung. Die Bauchfläche ist söhlig. Häufig ist der Rumpf durch ein in ihm enthaltenes, reifendes Ei stark aufgetrieben. Das Hinterende trägt gewöhnlich eine Schwanzgabel, die jedoch auch fehlen kann. Die Jugendformen weichen von der soeben beschriebenen Gestalt der ausgewachsenen Tiere erheblich ab. Trotzdem aber findet keine Metamorphose statt; sondern durch einfaches Wachstum erhalten die jugendlichen Individuen schliesslich ihre definitive Form.

Die Haut der Gastrotrichen besteht wie die der Rädertiere aus einer dünnen, syncytialen Hypodermis und einer Cuticula. Die Cuticula ist nur selten glatt, gewöhnlich trägt sie einen Besatz von Schuppen, die ihrerseits vielfach mit Stacheln ausgerüstet sind. Dabei ist die Bekleidung der Rücken- und Bauchseite zumeist verschieden. Die Form der Schuppen und Stacheln bietet wichtige Unterscheidungsmerkmale der einzelnen Arten.

Der Lokomotionsapparat besteht aus zwei ventral gelegenen, von vorn nach hinten verlaufenden Flimmerbändern, die aus in regelmässigen Abständen geordneten Querreihen bestehen. In jeder Reihe zählt man etwa elf Haare. Manche Formen zeigen auch am Kopfe eine' starke Bewimperung. In gleicher Weise wie bei den Rotiferen dient auch bei den Gastrotrichen der Wimperapparat mit zur Herbeistrudelung der Nahrung.

Das Exkretions-System ist am besten sichtbar an lebenden, aber stark gequetschten Exemplaren. Es besteht aus einem Flimmerrohr, einem daran anschliessenden, vielfach gewundenen Kanale und einem kurzen, direkt nach aussen mündenden Endstücke. Kontraktile Blasen fehlen vollständig.

Der Hauptteil des Nervensystemes ist das Hirnganglion, das nach hinten einen peripheren Nervenstrang entsendet. Von 
Sinnesorganen sind nur Tastorgane entwickelt. Als solche sind anzusprechen Haarbüschel am Kopfe, sowie Einzelhaare an Hals und Rumpf. Die Muskulatur zeigt eine gute Ausbildung.

Der Verdauungskanal, der sich von der ventral gelegenen Mundöffnung als gerades Rohr bis 'zu dem am dorsalen Hinterende gelegenen After erstreckt, lässt vier Abschnitte unterscheiden: I. Mund, 2. Vorderdarm oder Oesophagus, 3. Mitteloder Magendarm, 4. Hinterdarm mit Anus und Rektum. Die chitinige Mundröhre ist konisch, ihr freies Ende ist verjüngt, aus ihrer Mitte ragt ein Kranz nach aussen gebogener Borsten hervor, die eine gut schliessende Reuse bilden. Die Röhre ist vorstreckbar, ihre Innenwand zeigt eine plisséartige Fältelung. Der Vorderdarm ist im Leben meist geschlossen, nur bei der Nahrungsaufnahme öffnet er sich für einen Augenblick. Am Uebergange zum Mitteldarm befindet sich ein Reusenapparat in Form einer gefalteten Membran. Der Mitteldarm zeigt vier Reihen alternierend gestellter, sechseckiger Zellen, die häufig Glanzkörper einschliessen. Besondere Darmdrüsen fehlen. Der Enddarm scheint am lebenden Tiere vor den Klebdrüsen, die sich durch die Schwanzgabeln erstrecken und ein zum Festheften dienendes Sekret produzieren, aufzuhören; doch befindet sich über der Schwanzgabel ein als dunkler Fleck erscheinender, dorsaler After.

Hinter der Einschnürung, die den birnförmigen Enddarm vom Mitteldarme trennt, liegen die paarigen Ovarien. Die Eier sind ausschliesslich Dauereier. Sie werden sorgfältig versteckt abgelegt. Durch zahlreiche Höcker, Stacheln und Widerhaken tragende Säulchen sind sie in ihrer Umgebung gewöhnlich fest verankert. Männliche Geschlechtsorgane sind bisher nicht mit Sicherheit nachgewiesen.

Die Nahrung der Gastrotrichen besteht in kleinen Wasserorganismen und deren Resten.

Das Folgende wie das Vorstehende schliesst sich eng an Zelinka an.

I. Tier mit Gabelschwanz . . . . . . . . . . . . . . 2

2. Tier ohne Stacheln . . . . . . . . . ' . . 3

3. Haut glatt . . . . . . I. Ichthydium (S. 493)

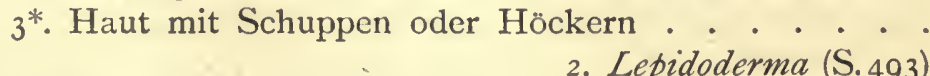

$2^{*}$. Tier mit Stacheln 
4. Schwanzgabel einfach . . 3. Chaetonotus (S. 493)

4*. Schwanzgabel dichotomisch . 4. Chaetura (S. 495)

I*. Schwanz nicht gegabelt . . . . . . . . . . . . . 5

5. Kopf mit Tentake1 . . . . . 5. Gossea (S. 496)

5*. Kopf ohne Tentakel . . . . 6. Dasydytes (S. 496)

\section{Ichthydium Ehrbg.}

I. podura O. F. Müller (Taf. XVI, 22)

Körperbau gedrungen. Kopf breit, leicht dreilappig. Hals breit, allmählich eingeschnürt. Rumpf breit, hinten jäh abgerundet. Haut weich, häufig in Falten gelegt. Länge $75 \mu$. Auf Wasserlinsen, Seerosenblättern, Characeen und sonst.

\section{Lepidoderma Zelinka.}

I. Mit grossen, wappenschildförmigen Schuppen . . . . . .

I*. Mit winzigen, dreieckigen Schuppen . .2. L. ocellatum

\section{L. squamatum}

I. L. squamatum Duj. (Taf. XVI, 23)

Zwei Schuppenpaare am Hinterende täuschen vier Borsten vor. Am Kopf und Hals sieben, am Hinterleibe acht alternierende Längsreihen von Schuppen. Kopf leicht fünflappig, so breit wie der Hinterleib $(33 \mu)$, allmählich in den ziemlich breiten Hals übergehend. Länge i $8-200 \mu$.

2. L. ocellatum Metschn.

Oberfläche mit feinen Längslinien, die aus dreieckigen Verdickungen bestehen. Länge $83-140 \mu$.

\section{Chaetonotus Ehrbg.}

Stacheln entweder direkt auf der Haut oder auf Schuppen sitzend.

I. Rückenstacheln ohne erhebliche Grössen-Unterschiede, hinten höchstens doppelt so lang als vorn . . . . . . . . . 2

2. Stacheln ohne Nebenspitzen . . . . . . . . . . . 3 3. Kopf und Hals scharf abgesctzt . . I. Ch. maximus $3^{*}$. Kopf allmählich in den Hals übergehend 
$2^{*}$. Stacheln mit Nebenspitzen .

4. Eine Nebenspitze vor der Hauptspitze . . . . . .5

5. Schuppen dreiflügelig . . . 3. Ch. hystrix

5*. Schuppen wappenschildförmig . . 4. Ch. similis

4*. Zwei Nebenspitzen.am Grunde der Stacheln .

5. Ch. schultzei

I*. Eine Anzahl Rückenstacheln sehr lang.

6. Stacheln ohne Nebenspitze. . . 6. Ch. larus

6*. Stacheln mit einer Nebenspitze vor der Hauptspitze . . 7

7. 23 grosse Stacheln in sieben Längsreihen

7. Ch. macrochaetus

$7^{*}$. 18 grosse Stacheln in fünf Längsreihen :

8. Ch. persetosus

1. Ch. maximus Ehrbg. (Taf. XVI, 24)

Am Rücken und an den Seiten mit einfachen, runden Stacheln versehen, deren Länge nach hinten zunimmt. Länge der Stacheln vorn $5 \mu$, hinten 10-1 $2 \mu$. Schuppen einem Wappenschilde ähnlich, an dessen Hinterrande sich der Stachel erhebt. Kopf fünflappig. Zwischen den Flimmerbändern sind die Schuppen klein. Mundröhre längsriefig. Länge 112-225 $\mu$. Häufig, in Gläsẹrn mit Characeen.

2. Ch. brevispinosus Zelinka

Körper gedrungen. Elf Stachelreihen; Stacheln nach hinten an Länge zunehmend. Zwei Stacheln vor der Schwanzgabel durch Länge und Krümmung ausgezeichnet. Schuppen kreisrund, am Hinterrande mit eckiger Einkerbung, in der Mitte die Stacheln tragend. Kopf dick, rundlich, leicht dreilappig. Hals dick. Zwischenraum zwischen den Flimmerbändern zartschuppig. Mundröhre gekörnt oder kurzstreifig. Länge 95-150 $u$.

3. Ch. hystrix Metschn.

Körper gedrungen. Schuppen dreilappig. Neun Stachelreihen. Stacheln hinten fast vier Mal so lang als vorn, an den Seiten kurz; mit kleiner Nebenspitze, am Hinterrande der Schuppen sich erhebend. Kopf oval, mit vier nur leise angedeuteten Einschnitten. Zwischenraum zwischen den Flimmerbändern mit zarten, hinten verdickten Schuppen, manchmal mit kururzem Stachelkleid. Mundröhre sehr kurz, längsriefig. Länge 90-1 $30 \mu$. Auf Blättern von Wasserpflanzen. Selten. 
4. Ch. similis Zelinka

Stacheln dreikantig, mit Nebenstacheln versehen, am Kopf circa $7 \mu$, hinten circa $14 \mu$ lang. Schuppen und Mundröhre wie bei Ch.maximus. Zwischen den Flimmerbändern sind die Schuppen zart und mit kurzen Stacheln ausgerüstet. Länge II2-220 $\mu$.

5. Ch. schultzei Metschn.

Stacheln mit zwei kürzeren Nebenspitzen, ihr Längenverhältnis am Kopf und am Schwanz wie bei voriger Art. Schuppen am Hinterrande mit tiefem, parabolischem Ausschnitte. Hals wenig deutlich. Kopf dreilappig. Zwischenraum zwischen den Flimmerbändern mit kleinen Borsten besetzt, deren Länge nach hinten zunimmt. Mundröhre längsriefig. Länge $360-400 \mu$.

\section{Ch. larus O. F. Müller}

Stacheln einfach, dreikantig; hinten vier Mal so lang als vorn; vorn in neun, hinten in sieben Längsreihen angeordnet, deren jede 16 Stacheln, darunter $6-7$ grosse, umfasst. Schuppen hinten mit ticfem, parabolischem Ausschnitt, am Hinterrande die Stacheln tragend. Kopf etwa rundlich, dreieckig angeschwollen. Zwischenraum zwischen den Flimmerreihen ganz hinten mit niedrigem Borstenbesatz. Mundröhre längsstreifig. Länge go bis I $50 \mu$.

\section{Ch. macrochaetus Zelinka}

Aehnlich voriger Art. Neun Stachelreihen mit Einschluss der Seitenstacheln. Stacheln der sieben Mittelreihen am Rumpfe lang. Die Rückenstacheln mit je zwei Nebenspitzen. Schuppen gross, pflugscharförmig, hinten die Stacheln tragend. Zwischenraum zwischen den Flimmerreihen mit rundlichen Schuppen. Länge 77 - $100 \mu$.

8. Ch. persetosus Zelinka (Taf. XVI, 25)

Neun Stachelreihen. Mittelstacheln hinten bis neun Mal länger als vorn. In der Mittellinie sind vier, seitlich je drei Stacheln durch besondere Stellung ausgezeichnet. Kopf leicht fünflappig. Zwischenraum zwischen den Flimmerreihen mit sechseckigen Schuppen. Mundröhre längsstreifig. Länge 77-8I $\mu$.

\section{Chaetura Metschn.}

Haut gewulstet.

Ch. capricornia Metschn. (Taf. XVI, 26)

Kopf breiter als der Rumpf. Ueber dem Schwanze mit einer Querreihe gekrümmter Stacheln. Sumpfwasser. 


\section{Dasydytes Gosse.}

Borsten tragend; Kopf scharf abgesetzt, tentakellos. Schwanzgabel fehlt.

D. longisetosum Metschn. (Taf. XVI, 27)

Kopf eiförmig, vollständig bewimpert, vorn mit einer Platte ausgerüstet. Hals und Rücken auf der Dorsalseite mit langen, die Körperkonturen überragenden Borsten. Hinten zwei Tastborsten. Länge $80 \mu$.

\section{Gossea Zelinka.}

Kopf mit Tentakel. Hinterende .leicht eingekerbt, ohne Schwanzgabel, mit Büscheln starrer Borsten.

G. antennigera (Gosse) (Taf. XVI, 28)

Kopf und Hals zu einem länglich runden Abschnitte vereinigt. Zwei schwingende. Cilienbündel rechts. Länge $150 \mu$. 


\section{Register.*)}

Acanthococcus Lagerh. 92.

— hirtus Reinsch III, 9. 92.

Acanthocystis Cart. (272) 277.

- aculeata Hertw. u. Less. 278.

- erinaceus Pen. 278.

- lemani Pen. 278.

- pectinata Pen. 278.

- spinifera Greeff 278 .

- turfacea Cart. X, 5. 278.

Achlyá N. v. Es. 247.

- polyandra De By. 247.

Achnanthes Bory I97.

- coarctata Grun. 198.

- delicatula Kg. I98.

— exilis Kg. VII, 25. Ig8.

- flexella Bréb. VII, 26. I98.

- lanceolata (Bréb.) I98.

- minutissima Kg. 198.

- subsessilis $\mathrm{Kg}$. $\mathrm{I} 98$.

Achnanthidium flexellum Kg. VII, 26. 198.

Achnanthinae 197.

Achnanthoideae 197.

Acidophorus ornatus St. 36 I.

Acineta Ehrbg. 416.

- grandis S. K. 416.

- linguifera Cl. u.L. XIII, 48. 4 I 6.

Acineten 4 IOO.

Acontractilia 404.

Actinastrum hantzschi Lagerh. III, 26. 96.

Actinobolina 355.

Actinobolus St. 355 .

- radians St. XII, 8. 355.
Actinomyces bovis Harz 44.

Actinophrys Ehrbg. 274.

- sol Ehrbg. IX, 2 I. 274.

Actinosphaerium St. (272) 274.

- eichhorni (Ehrbg.) 1X, 22. 274.

Adineta Huds. 443.

- vaga Dav. XIV, I6. 443.

Adinetadae 442.

Aegagropila (Kg.) I 37 .

Aeolosoma quaternarium 10.

Alastor polyporum Py. XIII, 5. 385.

Algen, echte 83 .

Algenpilze 245.

Allogonium Kg. 242.

- wolleanum Hansg. VIII, 23. 243.

Amoeba Ehrbg. 255.

- princeps Ehrbg. IX, 3. 256.

- proteus Leidy IX, 3. 256.

- radiosa Ehrbg. 256.

- verrucosa Ehrbg. IX, 4. 256.

Amoebaea 255.

- lobosa 255 .

- reticulosa 258 .

Amoebobacter bacillosus Win. 37 .

- granula Win. 35 .

- roseus Win. I, 2. 34.

Amphidinium Cl. u. L. 230.

- lacustre St. VIII, 2. 230.

Amphileptus Cl. u. L. (I 7 ) 357.

- carchesii St. XII, I3. 357.

- claparedei St. 357.

- gigas Cl. u. L. XII, 17. 359.

Amphimonadina 301 .

Amphimonas Duj. 301.

*) Die in Klammern stehenden Ziffern verweisen auf Stellen, wo über die betreffende Form eine nur nebensächliche Angabe steht. 
Amphimonas globosa S.K. X, 39. 301.

Amphipleura Kg. 209.

- pellucida Kg. VII, 36. 209.

Amphiprora Ehrbg. 210.

— alata Kg. VII, 40. 2 Io.

- paludosa W. Sm. VII, 39. 2 I I.

Amphisia piscis Ehrbg. XIII, 8. 387.

Amphistomina 27 I.

Amphithrix Kg. 79.

— ianthina Born. et Fl. II, 36. 79. Amphizonella auerbachi (Lachm.) 258 . Amphora Ehrbg. 216.

- lineolata Ehrbg. 217.

- ovalis Kg. VII, 49. 217.

- pediculus Grun. 2 I 7 .

Anabaena Bory $7 \mathrm{I}$.

- catenula Born. et Fl. 72.

- circinalis Rabh. 72.

- flos aquaé Bréb. II, 18. 7 I.

- halensis Jancz. 7 I.

- oscillarioides Bory II, I9. 72.

- spiroides Kleb. 72.

— variabilis $\mathrm{Kg} .7 \mathrm{I}$.

Anabaeneae 68.

Anapodidae 489 .

Anapus Brgdl. 489 .

— ovalis Brgdl. XVI, I9. 489 .

_- testudo Ltb. 489.

Andouinella chalybea Fries VIII, 20. 241.

Anisonema Duj. 328.

- acinus Duj. XI, 47. 329.

- ovale Kl. 329.

— striatum KI. XI, 46. 329.

- truncatum St. 329.

- variabile Kl. 329.

Anisonemeae 328 .

Anomalae Hansg. 140.

Anthophysa Bory 290.

- vegetans Btschli. X, 19. (1 2) 29 I.

Anuraea Ehrbg. 485 .

- aculeata Ehrbg. 485 .

- cochlearis Gosse XVI, 14. 485.

- hypelasma Gosse 485 .

- schista Gosse 485 .

Anuraeadae 484.

Aphanizomenon Morren 72.

- flos aquae Ralfs II, 20. 72.
Aphanocapsa Naeg. 53.

- castagnei Rabh. 54.

- cruenta Hansg. 243.

- pulchra Rabh. I, 33. 54.

- testacea Naeg. 54.

Aphanochaete A. Br. 129.

- repens A. Br. V, I7. I 30 .

Aphanothece Naeg. 54.

- castagnei Rabh. 54.

- microscopicá Naeg. I, 35. 54.

- stagnina A. Br. I, 34. 54.

Aphrothoraca 273.

Apiocystis Naeg. 102.

- brauniana Naeg. III, 39. 102.

Apodya lactea Cornu VIII, 29. 247.

Arcella Ehrbg. (252) 259.

- artocrea Leidy 260.

- dentata Ehrbg. 260.

- discoides Ehrbg. 260.

- mitrata Leidy 260 .

- vulgaris Ehrbg. IX, I0. 259.

Arcellina 259.

Archimyceten 246.

Armleuchter-Gewächse 235.

Arthrodesmus Ehrbg. I 59.

- convergens Ehrbg. VI, 23. I 59.

- incus Hass. VI, 24. I 59.

- octocornis Ehrbg. 159.

Arthrospira Stitz. 63.

- jenneri Stitz. II, 4. 63.

Ascococcus Billr. 33 .

- billrothi Cohn I, I. 34.

- gelatinosus Kirchn. 34 .

- roseo-persicinus (Win.) 34.

- rufus (Win.) 34.

- violaceus Kirchn. 34 .

Ascoglena St. 3 I 7 .

- vaginicola St. XI, 24. 3I 8.

Ascomorpha Py. 448.

- helvetica Py. XIV, 2 I u. 22. 479.

Askenasia Blochm. 356 .

- elegans Blochm. XII, I 2. 356.

Aspidisca Ehrbg. 395.

- costata St. 396.

- lynceus Ehrbg. XIII, 19. 396.

— turrita Cl. u. L. 395.

Aspidiscina 395 . 
Aspirotricha 363.

Asplanchna Gosse (419. 422. 425 . 426) 446.

- brightwelli Gosse 447.

- priodonta Gosse XIV, I9. 447.

- sieboldi (Leyd.) 448.

Asplanchnadae 446 .

Asplanchnopus de Guerne 448 .

- myrmeleo Ehrbg. XIV, 20. 448.

Assulina Leidy 267.

- seminulum Leidy 267.

Astasia Duj. 32 I.

- curvata Kl. $32 \mathrm{I}$.

- distorta Duj $32 \mathrm{r}$.

- inflata Duj. 322.

- margaritifera Schda. XI, 32. 32 I.

Astasiida 321.

Asterionella Hass. 194.

- formosa Hass. VII, 20. I94.

- gracillima Heib. VII, 2 r. I 94.

Asterosiga S. K. 296.

- radiata Zach. X, 26. 296.

Asterothrix Kg. (242) 244.

- tripus A. Br. VIII, 26. 244.

Astylozoon Engelm. 400.

- fallax Engelm. XIII, 24. 400.

Attheya West 187 .

- zachariasi J. Br. VII, 5. 187.

Aulosira Kirchn. 73.

- laxa Kirchn. II, 22. 73.

Aulosireae 68.

Bacillaria Gmelin 2 I6.

- paradoxa Gmelin VII, 52. 219.

Bacillariaceae I 78 .

Bacillus Cohn 39.

- anthracis 40.

- coli 39.

- fluorescens 39.

- lineola (O. F. Müll.) 39.

- megatherium De By. 39.

- prodigiosus (28) 40.

- subtiliformis 39 .

— subtilis Cohn I, I I. (3 I. 32) 39.

- termo (Ehrbg.) 39.

- tetani 40.

- typhi 40.

- vulgaris 39 .
Bacillus vulgatus 39 .

Bacteriaceae 25. 36 .

Balantidium coli St. 378 .

- entozoon 378.

Balladina Kowal. 394 .

- elongata Roux XIII, r6. 394.

- parvula Kowal. 394.

Bambusina Kg. I 46.

Bangia Lyngbye 242.

- atropurpurea Ag. VIII, 22. 242.

Bangiaceen 242.

Batrachospermum Roth (59) $24 \mathrm{I}$.

- moniliforme Roth VIII, 21. 242.

- vagum Ag. 242.

Bdelloida 437.

Beggiatoa Trev. (I 2. 30) 47 .

- alba Trev. I, 24. 48.

- arachnoidea Ag. 48.

- leptomitiformis Trev. 48.

Beggiatoaceae 47.

Biddulphioideae 186.

Bikoecina $29 \mathrm{I}$.

Bikosoeca J.-Cl. 29 I.

- lacustris J.-Cl. X, 20. $29 \mathrm{r}$.

- socialis Lauterb. $29 \mathrm{I}$.

Binuclearia Wittr. I 25.

- tatrana Wittr. V, 10. I 25.

Blaualgen 48.

Blepharisma Py. 375 .

- lateritia St. XII, 47. 375.

- musculus (Ehrbg.) 375.

- undulans St. 376 .

Blutalge I 14.

Bodo St. 303 .

- angustatus Btschli. 304.

- caudatus St. XI, 3. 304.

- celer Kl. 304.

- edax Kl. XI, 2. 304.

- globosus St. XI, I. 304.

- minimus Kl. 303 .

- saltans Ehrbg. 304.

Bodonina 302.

Botrydiaceae I 39.

Botrydium WVallr. I 39 .

- granulatum Grev. V, 36. 139.

Botryococcus Kg. IOI.

- brauni Kg. III, 37. 102.

- terricola Kl. IO2. 
Brachionidae $48 \mathrm{I}$.

Brachionus Ehrbg. 482.

- angularis Gosse 484 .

- bakeri Ehrbg. 484 .

- militaris Ehrbg. 483 .

- pala Ehrbg. 483 .

- quadratus Rouss. 483.

- rubens Ehrbg. 484 .

- urceolaris Ehrbg. XVI, 1 2. 483.

Brachythrix Hansg. 59.

Braunalgen 235.

Bulbochaete Ag. I 34 .

- pygmaea Pringsh. 135 .

- rectangularis Wittr. V, 29. 135.

- setigera Ag. I34.

Bumilleria Borzì I 24 .

— sicula Borzì V, 7. 124.

Bursaria O. F. Müll. 378 .

- truncatella Müll. XII, 52. 378 .

Bursarina 377 .

Caenomorpha medusula Py. XII, 56. 381.

Callidina Ehrbg. 44I.

- brycei Wbr. 442.

- constricta Duj. 442.

- cornigera Bryce 442.

- elegans Ehrbg. XIV, I5. 442.

- longirostris Jans. 442.

- symbiotica Zel. XIV, I 4.442.

- vorax Jans. 442.

Calothrix Ag. $=$ Dillwynella By. 80 .

- ascendens Born. et Fl. 80 .

- fusca Born. et Fl. II, 38. 80.

- parietina Thuret 80 .

- thermalis Hansg. 8o.

Campascus Leidy 269.

- cornutus Leidy 269.

Campylodiscus Ehrbg. 226.

- noricus Ehrbg. VII, 6I. 227.

Canthocamptus II.

Capsosira Kg. 78.

- brebissoni Kg. II, 33. 78.

Carchesium Ehrbg. 402.

- aselli Engelm. XIII, 28. 403.

- epistylis $\mathrm{Cl} .402$.

- lachmanni S. K. 403.

-- polypinum Ehrbg. XIII, 27. 403.
Carchesium spectabile Ehrbg. 403. Cathyna Gosse 473.

- luna Ehrbg. XVI, I. 473.

Cathypnadae 473 .

Centricae 182.

Centropyxis St. 265.

- aculeata St. 265.

Cephalosiphon Ehrbg. 435.

- limnias Ehrbg. XIV, 5. 435.

Cephalothamnium St. 290.

- caespitosum S. K. X, 17. 290.

- cuneatum S. K. 290.

Ceratium Schrank 233.

- cornutum Cl. u. L. 233.

- hirundinella O. F. Müll. VIII,

5 u. 6.233.

- tetraceros Schrank 233.

Ceratoneis Ehrbg. 195.

- arcus Kg. VII, 22. 195.

Cercidium elongatum Dang. 115.

Cercobodo laciniaegerens Krass. 286.

Cercomonadina 286.

Cercomonas Duj. 287.

- crassicauda Duj. X, I I. 287.

Chaetomorpha Kg. I 36.

- herbipolensis Lagerh. V, 32. 136.

- implexa Kg. I 36.

- linum Kg. I 36.

Chaetonema Nowak. I 29.

- irregulare Nowak. V, I6. I 29.

Chaetonotus Ehrbg. 493.

- brevispinosus Zel. 494.

- hystrix Metschn. 494.

- larus O.F. Müll. 495.

- macrochaetus Zel. 495.

- maximus Ehrbg. XVI, 24. 494.

- persetosus Zel. XVI, 25. 495.

- schultzei Metschn. 495.

- similis Zel. 495 .

Chaetopeltis Berth. 132 .

- orbicularis Berth. V, 25. I 32 .

Chaetophora Schrank 127.

- elegans Ag. V, I 2. I 28.

- endiviaefolia Ag. V, I 3. I 28.

- pisiformis Ag. I 28.

- tuberculosa Ag. I 28.

Chaetophoraceae 126.

Chaetophoreae I 27. 
Chaetosphaeridium Kleb. I 30.

- pringsheimi Kleb. V, I8. I30.

Chaetura Metschn. 495.

- capricornia Metschn. XVI, 26. 495.

Chalarothoraca 276.

Chamaesiphon A. Br. u. Grun. 58.

- confervicola A. Br. I, 48. 59 .

- fuscus Hansg. 59.

— incrustans Grun. 59.

Chamaesiphonaceae 57 .

Chantransia Schmitz 240.

- chalybea Fries VIII, 20. $24 \mathrm{I}$.

- corymbifera Thuret 240.

- hermanni 240.

- pygmaea Kg. $24 \mathrm{I}$.

- violacea $\mathrm{Kg} .24 \mathrm{I}$.

Characeae 235 .

Characieae I04.

Characium A. Br. 106.

- longipes Rabh. I06.

- naegelii A. Br. IV, 4. 106.

- subulatum A. Br. Io6.

Chasmatostoma Engelm. 368.

- reniforme Engelm. XII, 33. 368.

Chilifera 364.

Chilodon Ehrbg. 36r.

- cucullulus Ehrbg. XII, 20. 362.

- dentatus From. 36r.

- steini Blochm. XII, 20. 362.

- uncinatus Ehrbg. 361 .

Chilomonas Ehrbg. 341 .

- paramaecium Ehrbg. XI, 73.34 I.

Chlamydobacteriaceae 43 .

Chlamydodonta 359 .

Chlamydomonadeae I I 2.

Chlamydomonas Ehrbg. I 13.

- brauni Gorosch. IV, I6. I I4.

- ehrenbergi Gorosch. I I4.

- grandis St. I I3.

- kleini Schmidle I 14.

- pulvisculus Ehrbg. I 13.

- reinhardi Dang. I 14.

- reticulata Gorosch. I I3.

— steini Gorosch. IV, I7. I 14.

Chlamydomyxa Arch. 237.

- labyrinthuloides Arch. VIII, 16. 237.
Chlamydophora 275.

Chloramoeba Bohlin 331.

- heteromorpha Bohl. XI, 50. 33 I .

Chloraster Ehrbg. I 12.

- gyrans Ehrbg. IV, I 2. I I 2.

Chlorangium St. I I 5 .

- stentorinum St. IV, I9. I I 5 .

Chlorella infusionum Beyer. 87 .

- protogenitum (Beyer.) 87 .

Chlorochytrium lemnae Cohn 105.

Chlorogonium (Ehrbg.) I 5 .

- euchlorum Ehrbg. IV, 20. I I 5 .

Chloromonadina 330.

Chloropeltis St. 3 I 9.

Chlorophyceae 86.

Chlorosaccus Lagerh. 331.

— fluidus A. Luth. XI, 5 I. 33 I.

Chlorosphaera Kl. IOI.

- alismatis KI. IOI.

- angulosa Kl. III, 36. Iог.

- endophyta Kl. IOI.

Chlorotylium Kg. I 30 .

- cataractarum $\mathrm{Kg}$. V, 20. I 30 .

Choanoflagellata 293.

Chodatella Lemmerm. 96.

- ciliata Lemmerm. 97.

- longiseta Lemmerm. III, 27. 96.

- quadriseta Lemmerm. 96.

Cholerabazillus (30) $4 \mathrm{I}$.

Chromatium Py. 38.

- minus Win. 38 .

- minutissimum Win. 38 .

- okeni Py. I, 9. (28) 38.

- vinosum Win. 38 .

- weissi Py. 38.

Chromomonadina 332 .

Chromophyton rosanoffi Woron. XI, 56. 334 .

Chromulina Cienk. 334.

- flavicans Btschli. XI, 55. 334.

— ochracea Btschli. 334.

- ovalis Kl. 334 .

- rosanoffi Btschli. XI, 56. 334.

— verrucosa Kl. 334.

- woroniniana Fisch. 335.

Chroococcaceae 50.

Chroococcus Naeg. $5 \mathrm{I}$.

- helveticus Naeg. 52. 
Chroococcus macrococcus Rabh. 52.

- minor Naeg. 52.

- minutus Naeg. 52.

— turgidus Naeg. I, 26. 52.

Chroolepideae I3O.

Chroolepus Ag. I3I.

Chroothece Hansg. 52 (242).

— richteriana Hansg. I, 28. 53.

Chrysamoeba Kl. 333.

- radians Kl. XI, 54. 333 .

Chrysococcus Kl. 336.

- rufescens Kl. XI, 59. 336.

Chrysomonadina 333.

- loricata 336.

- membranata 338 .

- nuda 333 .

Chrysophyceen 333 .

Chrysopyxis St. 338 .

- bipes St. XI, 64. 338.

Chrysosphaerella Ltb. 339.

- longispina Ltb. XI, 66. 339.

Chytridium olla A. Br. VIII, 27. 246.

Ciliata 342.

Cilioflagellaten 227.

Cinetochilum Py. 370 .

- margaritaceum Py. XII, 37. 370.

Cladomonas St. 300.

- fruticulosa St. X, 37. 300.

Cladonema laxa S. K. X, r 8. 290.

Cladophora Kg. I 37 .

- aegagropila Rabh. I38.

- crispata Kg. 137.

- fluitans $\mathrm{Kg}$. I 38 .

- fracta Kg. 137.

- glomerata $\mathrm{Kg} . \mathrm{V}, 34$. 137 .

Cladophoraceae I36.

Cladothrix (I 2. 20) 44 .

- bovis 44 .

- dichotoma I, I8. 44.

Clastidium Kirchn. 58.

- setigerum Kirchn. I, 47. 58.

Clathrocystis Henfr. 55.

- aeruginosa Henfr. I, 37. 55.

Clathrulina Cienk. (272) 278.

- elegans Cienk. X,6. 279.

Climacostomum St. 378 .

- patulum St. 379 .

- virens St. XII, 53. 379.
Closterium Nitzsch 149.

- acerosum Ehrbg. 152.

- acutum Bréb. 153.

- attenuatum Ehrbg. I52.

- cornu Ehrbg. I53.

- costatum Corda I52.

- dianae Ehrbg. I53.

- didymotocorum Corda 152.

- ehrenbergi Menegh. I 54.

- gracile Bréb. I52.

- jenneri Ralfs I53.

- juncidum Ralfs I52.

- kuetzingi Bréb. VI, I 4. I 54.

- leibleini Kg. I 54.

- lunula Ehrbg. I52.

— moniliferum Ehrbg. VI, I 3. I 54.

- obtusum Bréb. I 5 I.

- parvulum Naeg. I 53.

- rostratum Ehrbg. I 54.

- setaceum Ehrbg. 154.

- striolatum Ehrbg. 153.

- turgidum Ehrbg. 152.

- venus $\mathrm{Kg}$. I53.

Coccaceae 33 .

Coccochloris (Spr.) 54 .

Coccogoneae 50.

Coccomonas St. I 16.

- orbicularis St. IV, 23. I I 6.

Cocconeidinae I99.

Cocconeis Ehrbg. I99.

- communis Heib. VII, 27. 199.

Cocconema Ehrbg. 2 I 5 .

Coccudina crassa Duj. XIII, 19. 396.

Cochliopodium Hertw. u. Less. 259.

— bilimbosum Leidy 259.

— pellucidum Hertw. u. Less. 259.

- pilosum H. u. Less. IX, 9. 259.

- vestitum Leidy IX, 9. 259.

Codonella lacustris $262.3^{8} 3$.

Codonocladium St. 295.

- corymbosum Entz 296.

- umbellatum St. X, 25. 295.

Codonodesmus St. 296.

- phalanx St. X, 29. 296.

Codonoeca J.-CI. 288.

- costata J.-Cl. 288.

— inclinata S. K. X, I4. 288.

Codonosiga $=$ Codosiga. 
Codosiga J.-Cl. 295.

- botrytis Ehrbg. X, 24. 295.

- furcata S. K. 295.

Coelastrum Naeg. 95.

- microporum Naeg. 96.

- sphaericum Naeg. III, 24. 95.

Coelomonas grandis St. $33 \mathrm{I}$.

Coelopus Gosse 464.

- porcellus Gosse 464.

- stylatus Eyf. 464.

- tenuior Gosse XV, I 5. 464.

Coelosphaerium Naeg. 55.

-- kützingianum Naeg. I, 39. 55 .

Cohniella B. Schroed. 94.

- staurogeniaeformis Schr. III, 20. 94.

Colacium Ehrbg. 317.

— arbuscula St. 3 I 7.

- calvum St. XI, 22. 3 I 7.

- vesiculosum Ehrbg. XI, 23. 317.

Coleochaetaceae 135 .

Coleochaete Bréb. I 35 .

- orbicularis Pringsh. I35.

- pulvinata A. Br. V, 30. I 35 .

- scutata Bréb. V, 31 . I 36.

Colepina 355.

Coleps Ehrbg. 355 .

- amphacanthus Ehrbg. 355.

- hirtus Ehrbg. XII, 9. 355.

Colletonema lacustris Ag. 208.

Colpidium St. 367.

- colpoda St. XII, 3 I. (I 2. 2 I) 367.

Colpoda O. F. Müll. 368 .

- cucullus Ehrbg. XII, 32. (13) 368.

— steini Mps. 368.

Colponema St. 305.

- loxodes St. XI, 7. 305.

Coluridae 475 .

Colurus Ehrbg. 4 I9. 476.

- bicuspidatus Ehrbg. XVI, 3 u. 4 .

(2I) 477 .

- caudatus Ehrbg. 476 .

- deflexus Ehrbg. 477 .

- grallator Gosse 477 .

- leptus Gosse 476.

- obtusus Gosse 477.

- uncinatus Ehrbg. 476 .

Condylostoma Duj. 377 .
Condylostoma vorticella Ehrbg. XII, 51. 377.

Conferva Lagerh. I 24.

- bombycina Wille V, 8. I 24.

- utriculosa $\mathrm{Kg}$. I 24.

Confervoideae I 19.

Conjugata Vauch. = Spirogyra L.

I 72.

Conjugatae 141 .

Conochaete Klebahn I 30.

- klebahni Schmidle V, I 9. I 30.

Conochilus Ehrbg. 437.

- unicornis Rouss. XIV, IO. 437.

- volvox Ehrbg. 437.

Contractilia 400.

Copeus Gosse 454.

- caudatus Collins 455.

- labiatus Gosse XV, 8. 454.

- pachyurus Gosse 455 .

Corniculatae Walz 140.

Coscinodiscinae $\mathrm{I} 84$.

Coscinodiscus Ehrbg. I 85.

- subtilis Grun. 185 .

Cosmarium Lund $=$ Ursinella Turp. und Dysphinctium Naeg. I6o.

— bioculatum Bréb. I62.

- botrytis Menegh. VI, 26. 163.

- broomei Thwaites 163.

- connatum Bréb. I6I.

- crenatum Ralfs 162 .

- cucurbita Bréb. I6I.

- granatum Bréb. 162.

- margaritiferum Menegh. I62.

- meneghínii Bréb. 162.

- ornatum Ralfs VI, 27. I63.

- palangula Bréb. I6I.

- phaseolus Bréb. 163.

- pyramidatum Bréb. I62.

- quadratum Ralfs I62.

- undulatum Corda 162.

Cosmocladium Bréb. I63.

- pulchellum Bréb. 163 .

- saxonicum De By. VI, 28. 163.

Costia Leclercq 306.

- necatrix Lecl. XI, 9. 306.

Cothurnia Ehrbg. 408.

- astaci St. 409.

- crystallina Ehrbg. XIII, 36. 409. 
Cothurnia imberbis Ehrbg. 409.

- operculata Grub. 408.

— sieboldi St. 409.

Cothurnina 408.

Craspemonadina 292.

Craterospermum A. Br. 175 .

Crenothrix (20.43) 47.

- polyspora Cohn I, 23. 47.

Cristigera Roux 373.

- pleuronemoïdes R. XII, 45. 374.

Crucigenia Morren 95.

- rectangularis Naeg. III, 23. 95.

Cryptochilum griseolum Mps. XII, 34 . 369.

Cryptoglena Ehrbg. 320.

- pigra Ehrbg. XI, 30. 320.

Cryptomonadina 340.

Cryptomonas Ehrbg. 34I.

- ovata Ehrbg. XI, 74. 34I.

Cyanophyceae 48 .

Cyathomonas From. 34I.

- truncata (St.) XI, 72. $34 \mathrm{I}$.

Cyclidium Ehrbg. 374.

- glaucoma Eb. XII, 46. (2I) 374 .

Cyclodinina 355 .

Cyclops II. 20. 2 r.

Cyclotella Kg. I 84 .

- kuetzingiana Thw. VII, 3. 185.

- meneghiniana Rabh. 185 .

- operculata Kg. 184.

Cylindrocapsa Reinsch I 32.

- involuta Reinsch V, 26. I32.

Cylindrocapsaceae 132 .

Cylindrocystis De By. I 55 .

- brebissoni Menegh. VI, I6. 155.

Cylindromonas fontinalis Hansg. IV, I 5. II 3 .

Cylindrospermum Kg. 72.

- majus Kg. II, 2 I. 73.

- stagnale Born. et Fl. 72.

Cylindrotheca Rbh. I 86.

- gracilis Grun. VII, 7. I 86.

Cymatopleura W. Sm. 224.

- elliptica W. Sm. 224.

- solea W. Sm. VII, 57. 224.

Cymbella Ag. 2 I 4.

- caespitosa Schütt 2I6.

- cistula Kirchn. VII, 45. 2 I6.
Cymbella cuspidata Kg. 2 I5.

- cymbiformis Bréb. 216.

- ehrenbergi Kg. 2 I 5.

- gastroides Kg. 216.

- lanceolata Kirchn. 216.

- maculata Kg. 2 I5.

- naviculaeformis Auerswd. 215.

- prostrata Ralfs VII, 46. 2 I6.

Cymbellinae $2 \mathrm{I} 4$.

Cyphoderia Schlumbg. 268.

- ampulla Leidy IX, I6. 268.

- margaritacea Schbg. IX, 16. 268.

Cypris II. 20. 21.

Cyrtostomum St. 366.

Cystobacter Schröt. 37.

- erectus Schröt. 37.

- fuscus Schröt. 37.

Cystopleura Bréb. = Epithemia Kg. 217.

Dactylococcopsis Hansg. 53.

- rhaphidioides Hsg. I, 29. 53.

Dactylococcus Naeg. 98.

- caudatus Hansg. 99.

- infusionum Naeg. III, 29. 99.

Dactylosphaera Hertw. u. Less. 257.

- radiosa H. u. L. IX, 7. 258.

Dactylothece Naeg. 90.

- brauni Lagerh. III, I. 90.

Dallingeria S. K. 306.

- drysdali S. K. XI, I0. 307.

Daphnia I I. 20. 2 I.

Dasydytes Gosse 496.

- longisetum Metschn. XVI, 27. 496.

Debarya Wittr. 176.

- glyptosperma Wittr. VI, 40. 176.

Deltomonas S. K. 30 I.

- cyclopum S. K. X, 40. 30I.

Dendrocometes St. 417.

- paradoxus St. XIII, 52. 417.

Dendromonadina 289 .

Dendromonas St. 290.

- laxa Blochm. X, I8. 290.

- virgaria S. K. 290.

Dendrosoma Ehrbg. 417.

- radians Ehrbg. XIII, 5 I. 4 I 7.

Denticula Kg. I 89 . 
Denticula elegans Kg. VII, I 2. I 89.

— frigida Kg. I 89 .

- sinuata W. Sm. 22 I.

Desmidiaceae 142.

Desmidium Ralfs 148 .

- aptogonum Bréb. I 48.

- swartzi Ag. VI, IO. I 48 .

Desmonema Berk. et Thur. 73 .

— wrangeli Born. et Fl. II, 24. 73.

Desmothoraca 278.

Diaschiza Gosse 468.

- lacinulata O. F. M. XV,2 I. 469.

- semiaperta Gosse 468.

- valga Gosse 469 .

Diatoma D. C. I 90.

- anceps Kirchn. I 90.

- elongatum Ag. I 90.

- hiemale Heib. I9r.

- vulgare Bory VII, I4. Igo.

Diatomaceae 178.

Diatomella Grev. I 87 .

- balfouriana Grev. VII, 8. I87.

Diatominae I go.

Dicranochaete Hieron. 105.

- reniformis Hieron. IV, I. 105.

Dictyosphaerium Naeg. I03.

- ehrenbergianum Naeg. IO3.

— pulchellum Wood III, 42. 103.

Didinium St. 355 .

— balbianii Btschli. XII, IO. 356.

- nasutum St. 356 .

Didymoideae Hansg. I 48.

Didymoprium $\mathrm{Kg}$. 147.

- grevillei Kg. VI, 7. 147.

Difflugia Lecl. $26 \mathrm{r}$.

- acuminata Ehrbg. 262.

— arcula Leidy 263.

- constricta Leidy 263 .

- corona Wallich 263.

- cratera Leidy 262.

- globulosa Duj. 262.

- lobostoma Leidy IX, I3. 263.

- pyriformis Py. 262.

- spiralis Ehrbg. 263.

- urceolata Cart. 262.

Diglena Ehrbg. $45^{8}$.

_ catellina Ehrbg. XV, I 2. 459.

- caudata Ehrbg. 459 .
Diglena circinator Gosse 459 .

- grandis Ehrbg. 459.

- forcipata Ehrbg. 459 .

- uncinata Milne XV, I 3. 459.

Dileptus Duj. 359.

— anser O. F. Müll. XII, I 7. 359.

- gigas Wrzesn. XII, I 7. 359.

Dillwynella Bory $=$ Calothrix Ag. 80 .

Dimastigamoeba Blochm. 285 .

- laciniaegerens Kl. 286.

- longicauda Blochm. X, 8. 286.

- ovata Blochm. 286.

- radiata Kl. X, 9. 286.

Dimorpha (Gruber) 286.

- mutans Grub. X, Io. 286.

Dimorphococcus A. Br. 9 I.

- lunatus A. Br. III, 7. 9I.

Dinamoeba Leidy 257.

- mirabilis Leidy 257.

Dinema Py. 326.

- griseolum Py. XI, 41. 326.

Dinocharidae 465 .

Dinocharis Ehrbg. 465.

- paupera Ehrbg. 466.

- pocillum Ehrbg. XIV, 39. 466.

— tetractis Ehrbg. 466.

Dinobryon Ehrbg. 337.

- ramosum Ltb. XI, 63. 338.

- sertularia Ehrbg. XI, 6I. 337.

- stipitatum St. 337 .

- undulatum Kl. XI, 62. 337.

— utriculus Kl. 337 .

Dinoflagellaten 227 .

Dinophrya Btschli. 353 .

— lieberkuehni Btschli. XII,6. 353.

Dipleurostyla Roux 393.

- acuminata Roux XIII, I 7 393.

Diplococcus 34 .

Diplocolon heppi Naeg. 76 .

Diplocystis Pen. 276 .

- gracilis $\mathrm{X}, 3.276$.

Diploïs Gosse 470 .

- daviesae Gosse XV, 23. 470.

Diplomita S. K. 302.

- socialis S. K. X, 42. 302 .

Diplophrys Barker $27 \mathrm{I}$.

- archeri Barker $27 \mathrm{I}$.

Diplosiga Frenzel 297. 
Diplosiga frequentissima Z.X, 30. 297. - socialis Frenzel 297.

Diplosigopsis Francé 299.

- entzi Francé X, 34. 299.

Discoideae 183 .

Distemma Ehrbg. 454 .

- collinsi Gosse XV, 7. 454.

Distigma Ehrbg. 322.

- proteus Ehrbg. XI, 33. 322.

- tenax (O.F. Müll.) XI, 33. 322.

Distomata 308.

Distyla Eckst. 474.

- flexilis Gosse 474 .

- gissensis Eckst. 474 .

- ludwigi Eckst. XVI, 2. 474.

Docidium Lund. 157.

- baculum (Bréb.) VI, 19. 157.

- dilatatum Lund. 157 .

Dolichospermum 7 I.

Dorylaimus stagnalis 10

Draparnaldia Bory 127 .

- glomerata Ag. I 27.

- plumosa Ag. V, I I. 127

Dysphinctium Naeg. $=$ Cosmarium p. p. 160 .

Dysteria St. 363 .

Dysteropsis Roux 363 .

- minuta Roux XII, 25. 363 .

Eisenbakterien 3 I.

Elaeorhanis Greeff 275 .

- cincta Greeff IX, 27. 275.

Enchelina 349.

Enchelyodon farctus Cl. u. L. 353 .

Enchelys Ehrbg. $35 \mathrm{I}$.

- arcuata Cl. u. L. XII, 3. $35^{2}$.

- farcimen Ehrbg. 352.

- pupa O. F. Müll. XII, I6. 359.

Encyonema Kg. 2 I 6.

Endoclonium Szym. 129.

- chroolepiforme Szym. I 29.

Endosphaera Engelm. 414.

Endosphaera biennis Kl. 105 .

Endosphaereae 104.

Enteromorpha Harv. I 2 I.

- intestinalis Linck V, 4. I 22.

Entodinium St. 383.

Entosiphon St. 329 .
Entosiphon obliquum Kl. 330.

- sulcatum St. XI, 48.329.

Eosphora Ehrbg. 457 .

- digitata Ehrbg. 458.

- elongata Ehrbg. 458.

- najas Ehrbg. XV, I I. $45^{8}$.

Epalxis Roux 370.

- mirabilis Roux XII, 39. 370.

Epipyxis utriculus Ehrbg. 337 .

Epistylis Ehrbg. (12.21) 404 .

- brevipes $\mathrm{Cl} .405$.

- nympharum Engelm. 405.

- plicatilis Ehrbg. XIII, 3I. 406.

- ophrydiiformis Nüssl. 405 .

- umbellaria Lachm. XIII, 32. 305.

- steini Wrzesn. 405.

Epithemia $\mathrm{Kg}$. = Cystopleura Bréb.

217.

- argus Ehrbg. 218.

- gibba Kg. VII, 5 I. 2 I 8.

- sorex VII, 48. 2 I 8.

— turgida $\mathrm{Kg}$. VII, 49. 2 I 7 .

- ventricosa Kg. 2 I 8:

- zebra VII, 30. 2 I 8.

Eremosphaera De By. 92.

- viridis De By. III, Io. 92.

Ervilia Duj. 363.

- fluviatilis St. XII, 24. 363 .

Euastrum Ralfs 163.

- ansatum Ralfs I65.

- binale Ralfs 164 .

— didelta Ralfs VI, 29. I65.

— elegans $\mathrm{Kg} . \mathrm{I}_{5}$.

- oblongum Ralfs 165 .

- pectinatum Bréb. 165.

- verrucosum Ehrbg. 164 .

Eucampiinae 186.

Euchlanidae 470.

Euchlanis Ehrbg. (423. 424) 47 I.

- bicarinata Ldg. 472 .

- deflexa Gosse 472.

- dilatata Ehrbg. XV,24. (1 3) 472.

- hyalina Ldg. 472 .

- macrura Ehrbg. 473.

- piriformis Gosse 472.

- triquetra Ehrbg. 471.

Eucladophora Hauck 137.

Eucoleochaete Hansg. I 35. 
Eudesmidieae Hansg. 145.

Eudinobryon 337.

Eudorina (I IO) I I 8.

- elegans Ebg. IV, 29. (I I O) I I 8.

Euglena Duj. 3 I3.

- acus Ehrbg. 3 I6.

- deses Ehrbg. XI, 2 I. 3 I6.

- ehrenbergi Kl. 3 I 7 .

- gracilis Kl. XI, 19. 315.

- oxyuris Schda. XI, 20. 316.

- pisciformis Kl. 316.

- sanguinea Ehrbg. (I4) 315 .

- spirogyra Ehrbg. 316.

— tripteris Kl. 3 I6.

- variabilis Kl. 3 I5.

- velata Kl. 316.

— viridis Ehrbg. XI, ז8. 315.

Euglenida 3 I 2.

Euglenoidina 3 I 2.

Euglenopsis Kl. 324 .

- vorax Kl. XI, 36. 324.

Euglypha Duj. 266.

- alveolata Duj. IX, I4. 266.

- brachiata Leidy 267 .

— ciliata Leidy 266.

- cristata Leidy 267.

- globosa Cart. 268.

- mucronata Leidy 267.

Euglyphina 266.

Eumesocarpus Hansg. 175.

Eumicrasterias De Wild. I 66.

Eumyceten 245.

Eunotia Ehrbg. I95.

- arcus Rabh. VII, 23. I96.

- diodon Ehrbg. VII, 24. 197.

- exigua Rabh. I96.

- gracilis Rabh. 196.

- lunaris Ehrbg. I97.

- major Rabh. I96.

- pectinalis Dillw. Ig6.

- tetraodon Ehrbg. 197.

- triodon Ehrbg. 197,

Eunotiinae 195.

Euphyceae 83.

Euplotes St. 394.

- charon Ehrbg. (I 2. 2 I) 395.

- patella Ehrbg. XIII, I 8. 394.

- turritus Ehrbg. 395.
Euplotina 394.

Eurivularia Kirchn. 8I.

Euscytonema Born. et Fl. 74 .

Euspirogyra Hansg. 172.

Eutreptia Py. 320.

- viridis Py. XI, 3 I. 320.

Flagellata 279 .

Florideae 238.

Floscularia Oken 432.

- appendiculata Ldg. XIV, I. 432.

- cornuta Dob. XIV, I. 432.

- coronetta Cubitt. 432.

- edentata Collins 433 .

- ornata Ehrbg. 433.

- proboscidea Ehrbg. 433.

- regalis Huds. 433.

Floscularidae 431 .

Folliculina Lmk. 380.

Fragilaria Lyngb. I 9 I.

- capucina Desmar VII, I6. 192.

- construens Grun. 192.

- crotonensis Kitton I92.

- harrisoni Grun. I92.

- mutabilis Grun. VII, 15. 192.

- virescens Ralfs VII, 17. I 92.

Fragilariinae I9I.

Fragilarioideae 187 .

Freia Cl. u. L. 380 .

Frontonia Cl. u. L. 366.

- acuminata Cl. u. L. 367 .

- atra Cl. u. L. 367 .

- leucas Cl. u. L. XII, 29. 367.

Froschlaichpilz 29.

Fungi 245.

Furcularia Ehrbg. 456 .

- forficula Ehrbg. XV, ro. 457 .

- gracilis Ehrbg. 457.

- longiseta Ehrbg. 457.

Gallerthaaralge $8 \mathrm{I}$.

Gallionella Ehrbg. 46.

- ferruginea Ehrbg. I, 22. 46.

Gastropodidae 488.

Gastropus Imhof 4,89 .

- stylifer Imhof XVI, I 8. 480

Gastrostyla Engelm. 389 .

- mystacea (St.) 389. 
Gastrostyla setifera (Engelm.) 390. — steini Engelm. XIII, I 2. 390.

Gastrotricha 49 I.

Geissellinge 279.

Geminella Lagerh. 9 r.

- interrupta Lagerh. III, 5. $9 \mathrm{I}$.

Genicularia De By. 145 .

- spirotaenia De By. VI, 2. 146.

Gerda Lachm. 400.

- glans Lachm. XIII, 23. 400.

Glaucocystis Itzigs. 243.

- nostochinearum Itzigs. VIII, 25. 244.

Glaucoma Ehrbg. 366.

- pyriformis (St.) 366.

- scintillans E. XII, 28. (2 r) 366.

Glaucothrix Kirchn. 45 .

- putealis Kirchn. I, I 9. 45.

Glenodinium Ehrbg. 232.

- cinctum Ehrbg. VIII, 4. 232.

- cornifax Schilling 232.

- neglectum Schilling 233 .

- pulvisculus St. 232.

- uliginosum Schilling 232.

Gloeocapsa Naeg. 53 .

- magma Kg. 53 .

- polydermatica Kg. I, 30. 53 .

Gloeochaete Lagerh. 243.

- bicornis Kirchn. 243.

- wittrockiana Lgh. VIII, 24. 243.

Gloeocystis Naeg. 99.

- gigas Lagerh. III, 33. 100.

- rupestris Rabh. Ioo.

- vesiculosa Naeg. Ioo.

Gloeoplax Schmidle I 28.

- weberi Schmidle V, I4. I18.

Gloeothece Naeg. 53.

- confluens Naeg. 53 .

- linearis Naeg. I, 3r. 53.

- monococca Rabh. 53 .

Gloeotrichia Kirchn. 81.

Gloidium Sorokin 255 .

- quadrifidum Sorok. IX, 2. 255.

Glossatella Btschli. 404.

- tintinnabulum S. K. XII, 30.404.

Godlewskia Jancz. 59.

- aggregata Jancz. I, 49. 59.

Golenkinia Chodat 99.
Golenkinia radiata C. III, 32. 99.

Gomphonema Ag. 2 Ir.

- acuminatum Ehrbg. 2 I 2.

- capitatum Ehrbg. 212.

- constrictum Ebg. VII, 42. 2 I3.

- cristatum Ralfs 2 I3.

- dichotomum Kg. VII, 43. 213 .

- intricatum Kg. 2 I3.

- olivaceum Ehrbg. 213.

- tenellum W. Sm. 2 I 2.

- vulgare $\mathrm{Kg} .2 \mathrm{I} 3$.

Gomphoneminae 2 II.

Gomphosphaera $\mathrm{Kg} .55$.

- aponina I, 38.55.

Gonatozygon De By. 145 .

- asperum Rabh. 145.

- brebissoni De By. VI, I. I45.

Gongrosira Kg. I3I.

- de baryana Rabh. V, 23. I3I.

Gonium Mill. I 7 .

- pectorale (O. F. Müll.) IV, 26.

(I 3) 117.

- tetras A. B. II 7 .

Gonostomum Sterki 390.

- affine (St.) XIII, I3. 390.

- strenuum (Engelm.) 390.

Gossea Zel. 496.

- antennigera (Gosse) XVI, 28. 496.

Gromia Duj. 270.

- fluviatilis Duj. 270.

- hyalina Schlumb. IX, 19. 270.

Gromiina 269.

Grünalgen 86.

Grunowia sinuata Rabh. 22 r.

Gymnodinium St. 230.

- aeruginosum St. $23 \mathrm{r}$.

- fuscum St. VIII, 3. 232.

- hyalinum Schilling $23 \mathrm{r}$.

— palustre Schilling 232.

- paradoxum Schilling 23x.

- pulvisculus Kl. $23 \mathrm{I}$.

— pusillum Schilling 23r.

- vorticella St. 23 I.

Gymnostomata 349 .

Gymnozyga Ehrbg. I 46.

- brebissoni Nordst. VI, 5. 146. Gyrocoris St. 38r. 
Gyrocoris oxyura St. X゙II, 56. 38I. $\mid$ Holophrya Ehrbg. 350.

Gyrocoryna 380.

Hadubrandia decipiens Schmitz 239. Halteria Duj. 382.

- grandinella (O. F. M.) XIII, 2. 382.

- volvox Cl. u. L. 382 .

Halterina $38 \mathrm{I}$.

Hantzschia amphioxys E. VII, 56. 223.

Hapalosiphon Naeg. 77.

- pumilus Kirchn. II, 3I. 77 .

Hassallia byssoidea Berk. 76 .

Hefepilze 245 .

Helierella B. = Micrasterias Ag. 165 .

Heliozoa 27 I.

Hemidinium St. 230.

- nasutum St. VIII, I. 230.

Heteronema St. 325 .

— acus St. XI, 39. 326.

- globuliferum St. 326.

- nebulosum Kl. XI, 40. 326.

- spirale Kl. 326 .

Heteronemeae 325 .

Heterophrys Arch. 275.

- myriopoda Arch. 275.

- spinifera Arch. IX, 25. 275.

Heterotricha 374.

Heubazillus I, I I. (3I. 32) 39.

Hexamitus Duj. 309.

- crassus Kl. 3 IO.

- fissus Kl. 3 ro.

- fusiformis Kl. 3 Io.

- inflatus Duj. XI, I 3. 309.

- intestinalis Duj. 310.

- pusillus Kl. 3 IO.

Hildenbrandia Nardo 239.

- rivularis Bréb. VIII, I7. 239.

Himantidium 196.

Histrio Sterki 392.

Holacanthum Wille I $57 .^{\circ}$

- aculeatum Lund 157.

- cristatum Lund VI, 2O, 158.

- fasciculatum Lund 158 .

Holomastigina $33 \mathrm{I}$.

Holopedium Lagerh. 56.

- geminatum Lagerh. 56.

- irregulare Lagerh. I, 4I. 56.
- coleps (Ehrbg.) $35 \mathrm{I}$.

- discolor Ehrbg. XII, I. 35 I.

- lieberkuehni Btschli. 35 I.

- nigricans Ltb. 350 .

Holophryina 350 .

Homoeothrix Thuret 79 .

- juliana Kirchn. II, 37. 8o.

Hormidium $\mathrm{Kg}$. I 23.

- flaccidum (Kg.) 123.

- parietinum Kg. (I 2 I) I 23.

- varium $\mathrm{Kg}$. 123.

Hormogoneae 59.

Hormotila Borzì IO2.

- mucigena Borzì III, 40. IO2.

Hyalobryon ramosum Ltb. XI, 63 .

338.

Hyalodiscus Hertw. u. Less. 257.

- $\operatorname{limax}$ (Duj.) 257.

- guttula (Duj.) IX, 5. 257.

Hyalolampe Greeff 276.

- exigua Hertw. u. Less. 276.

- fenestrata Greeff X, I. 276.

Hyalosphenia St. 260.

- cuneata St. IX, I I. 260.

- elegans Leidy 260.

- lata F. E. Schulze IX, I I. 260.

- papilio Leidy 26 I.

- tincta Leidy 260.

Hyalotheca Ehrbg. 146.

- dissiliens Bréb. VI, 4. I 46.

- mucosa Ehrbg. VI, 3. I 46.

Hydatina Ehrbg. $45 \mathrm{I}$.

- senta Ehrbg. XV, 3. (I4) 45 I.

Hydatinadae $45 \mathrm{I}$.

Hydra I I.

Hydrocoleum Kg. 66.

- homoeotrichum Kg. II, 9. 66.

- oligotrichum A. Br. 66.

Hydrocoryne Schwabe 76 .

- spongiosa Schwabe II, 29. 76.

Hydrodictyeae IO4.

Hydrodictyon $\mathrm{Kg}$. IOg.

- utriculatum Lagerh. IV, IO. (I4) IOg.

Hydrurina $34 \mathrm{I}$.

Hydrurus Agardh 34I.

- foetidus Kirchn. XI, 75. 342 . 
Hymenomonas St. 338.

- roseola St. XI, 65. 339.

Hypheothrix Kg. 65.

- coriacea Kg. 65 .

- lardacea Rabh. 66.

- lateritia $\mathrm{Kg}$. II, 7. 65.

Hypotricha 383 .

Jchthydium Ehrbg. 493.

- podura O. F. M. XI, 22. 493.

Ichthyophthirius Fouquet $35 \mathrm{I}$.

Illoricata 443 .

Imperforata 258 .

Inactis $\mathrm{Kg}$. em. Thuret 67 .

- fasciculata Grun. II, I I. 67.

- pulvinata Kg. 67.

- tinctoria Thur. 67.

Inoderma $\mathrm{Kg}$. $\mathrm{I} 00$.

- lamellosum Kg. Iоo.

- majus Hansg. III, 34. 100.

Isocystideae 68 .

Isocystis Borzì 69 .

— infusionum Borzì II, I 5. 69.

Kartoffelpilz 247.

Kentrosphaera Borzì 99.

- facciolae Borzì III, 30. 99.

Kerona Ehrbg. 385.

- polyporum Ehrbg. XIII, 5. 385 .

Kieselalgen 178 .

Kirchneriella Schmidle 9I.

- lunata Schmidle III, 4. 9J.

Kommabazillus 4I.

Kragenmonaden 293.

Kraushaaralge 123.

Kugelbakterien 33 .

Lacinularia Oken 436.

— socialis Ebrbg. XIV, 8 u. 9. 437.

Lacrymaria Ehrbg. 354.

— apiculata (Cl. u. L.) 354.

- coronata Cl. u. L. 355 .

- elegans Engelm. 354.

- olor Ehrbg. XII, 7. 354.

- pusilla Cl. u. L. 354 .

- vermicularis (Ehrbg.) $355^{\circ}$

Lagenoeca S. K. 298.

- globulosa Francé X, 33. 298.
Lagenophryina 409.

Lagenophrys St. 409.

- ampulla St. XIII, 38. 4 Io.

- vaginicola St. 4 Io.

Lagerheimia Chodat 99.

- wratislaviense B.Schr. III, 3I. 99.

Lagynus elegans (Engelm.) 354.

Lamprocystis Schroet. 36 .

- roseo-persicina Schroet. I, 7. 36.

Lampropedia Schroet. 35 .

- hyalina Schroet. 35 .

- ochracea Mettenh. 35.

- rosea (Win.) I, 4. 35 .

Lecquereusia jurassica Schlumbg. 263 .

Lemanea Bory 240.

- fluviatilis C. Ag. 240.

- torulosa Sirodot VIII, 19. 240.

Lembadion Py. 373.

- bullinum Py. XII, 43. 373.

Lepadella Ehrbg. 479.

- emarginata Ehrbg. 479.

- ovalis Ehrbg. 479.

Lepidoderma Zel. 493.

- ocellatum Metschn. 493.

- squamatum Duj. XVI, 23. 493.

Lepocinclis ovum Ehrbg. XI, 27. 3 I 9.

Leptochaete Borzì 79 .

- nidulans Hansg. II, 35. 79.

- stagnalis Hansg. 79.

Leptodiscus medusoides 229 .

Leptomitus lacteus Ag. (I 2 ) 247.

Leptothrix Kg. 45.

- buccalis 46 .

- epiphytica (Mig.) 46.

- fluitans (Mig.) 46.

- hyalina (Mig.) 46.

- innominata 46 .

- ochracea Kg. (3I) 46.

- parasitica Kg. I, 2 I. 46.

Leuconostoc mesenterioides (29) 35 .

Leucophryidium Roux 366.

- putrinum Roux XII, 27. 366.

Leucophrys St. 365.

- patula Ehrbg. XII, 26. 365.

Lieberkuehnia Cl. u. L. $26 \mathrm{~g}$.

- paludosa (Cienk.) IX, I7. 269.

Limnias Schrank 434.

- annulatus Bailey 434. 
Limnias ceratophylli S. XIV, 4. 435. Lionotus Wrzesn. 357.

- anser (O. F. Müll.) 358 .

- folium Wrzesn. 358 .

- vesiculosus Stok. XII, I4. 358.

Liosiphon ambiguum St. 361 .

Lithocolla F. E. Schulze 275.

- globosa F. E. Sch. IX, 28. 276.

Lithoderma Aresch. 237.

- fluviatile Aresch. 237.

- fontanum Flahaut VIII, I3.

237.

Loricata 459 .

Loxocephalus S. K. 369 .

- granulosus S. K. XII, 36. 369.

- luridus Eberh. 369.

Loxodes Cl. u. L. 359.

- cucullulus Duj. XII, 20. 362.

- rostrum Ehrbg. XII, I8. 359.

Loxophyllum Duj. 358.

- fasciola Cl. u. L. XII, I 5. 358.

- lamella Cl. u. L. $35^{8}$.

- meleagris Duj. $35^{8}$.

Lynceus sphaericus I I.

Lyngbya Ag. 65.

- antliaria (243).

- contorta Lemmerm. 65.

- epiphytica Hieron. 65 .

Lysigonium Lk. = Melosira Ag. I 83 .

- fasciatum O.K. = Mel. varians

Ag. VII, I. I 83 .

Macrobiotus macronyx I I.

Mallomonas Py. 339.

- ploessli Py. XI, 68. 339.

Mastigamoeba F. E. Schulze 284.

— aspera F. E. Sch. 285 .

- invertens Kl. X, 7. 285 .

- ramulosa S. K. 285.

Mastigocerca Ehrbg. 462.

- bicornis Ehrbg. 463 .

- carinata Ebg. XV, I 4. (423) 463.

- cornuta Eyf. 463 .

- lophoëssa Gosse 463 .

- rattus Ehrbg. 463 .

- stylata Gosse 463 .

Mastigocladus Cohn 77 .

- laminosus Cohn II, 30. 77.
Mastigophora 279.

Mastogloia Thw. 2 I I.

- smithi Thw. VII, 4I. 2 I I.

Megalotrocha Ehrbg. 436.

- semibullata Thorpe XIV, $7 \cdot 436$.

- spinosa Thorpe 436.

Melicerta Schrank (419) 434.

- ringens Schr. XIV, 3. 434.

Melicertidae 433.

Melosira Ag. = Lysigonium Lk. I 83.

- arenaria Moore VII, 2. I 84.

- distans $\mathrm{Kg} .183$.

- orichalcea $\mathrm{Kg}$. $\mathrm{I} 84$.

- subflexilis Kg. 183 .

- varians $\mathrm{Ag} .=$ Lysigonium fasciatum O.K. VII, I. 183 .

Melosirinae 183 .

Menoidium Py. 322.

- incurvum Kl. 322.

- pellucidum Py. XI, 34. 322.

Meridion Ag. I 89 .

- circulare Ag. VII, I3. I 89.

- constrictum Ralfs I90.

Meridioninae 189 .

Merismopedia Lagerh. 55 .

- convoluta Bréb. 56.

- elegans A. Br. 56.

- glauca Naeg. I, 40. 56 .

- punctata Meyen 56 .

Mesocarpus Wittr. 175.

Mesodinium St. 356 .

— acarus St. XII, I I. $35^{6}$.

Mesostigma Lauterb. I 15 .

— viride Lauterb. I I 5 .

Mesotacnium Naeg. I 48.

- brauni De By. VI, I I. I 49.

- endlicherianum Naeg. 149.

— violascens De By. I 49 .

Metacineta Btschli. 4 I 3 .

- mystacina (Ehrbg.) XIII, 4 I . 4 I 3.

Metanema (Kl.) 328.

Metopidia Ehrbg. 477.

Metopidia Huds. u. Gosse 477.

- acuminata Ehrbg. 478.

- bractea (Ehrbg.) XVI, 9. 479.

- emarginata (Ehrbg.) 479.

- lepadella Ehrbg. (422) 478.

- oblonga (Ehrbg.) 479. 
Metopidia ovalis (Ehrbg.) 479.

— oxysternum Gosse XVI, 7 . 478.

- solidus Gosse 479.

- triptera Ehrbg. XVI, 8. 478.

Metopus Cl. u. L. 376 .

- sigmoïdes Cl. u. L. XII, 48. 376 .

Micrasterias Corda = Rhaphidium

Kg. 94 .

- falcata $=$ Rh. polym. Fres. III, 18. 94 .

Micrasterias Ag. $=$ Helierella B. I65.

- crux melitensis Ralfs VI,30. I 66.

- furcata Ag. I66.

- jenneri Ralfs I66.

- oscitans Ralfs i 66.

- papillifera Bréb. I67.

- rotata Ralfs 167.

- truncata Bréb. I66.

Microchaete Thur. 73 .

- goeppertiana Kirchn. II, 23. 73.

Micrococcus Cohn 36.

- agilis Ali-Cohen 36 .

- aureus Aut. 36 .

- luteus Cohn 36.

- pyogenes aureus Schröt. 36 .

- ruber Mig. I, 6. 36 .

- ureae Leube 36 .

Microcodidae 445 .

Microcodides Bgndl. 445.

- chloena Gosse XIV, I8. 445.

Microcodon Ehrbg. (42.I) 445.

- clavus Ehrbg. XIV, I7. 445.

Microcoleus Desmaz. 67.

- lacustris Farlow 68.

- paludosus Gom. II, I 3. 68.

- vaginatus Gom. II, I 4. 68.

Microcystis Kg. 54 .

- elabens $\mathrm{Kg} .55$.

- flos aquae Kirchn. I, 36. 55.

- marginata $\mathrm{Kg} .54$.

- olivacea $\mathrm{Kg}$. 55 .

Microglena Ehrbg. 339 .

- punctifera Ehrbg. XI,67. 339 .

Microgromia R. Hertw. (252) 269.

- socialis H. u. L. IX, I8. 270.

Microspira comma Schr. I, I3: 4 I .

Microspora Lagerh. I 25.

- amoena Rabh. V, 9. I 25.
Microspora floccosa Thur. 125.

- stagnorum Lagerh. 125.

Microthamnion Naeg. 13 I.

- kuetzingianum Naeg. V, 2 I. I 3 I.

- strictissimum Rabh. V, 22. I 3 I.

Microthoracina 369 .

Microthorax Engelm. 370 .

- pusillus Engelm. 370 .

- sulcatus Engelm. XII, 38. 370.

Milzbrandbazillus 30 .

Mischococcus Naeg. IO3.

- confervicola Naeg. III, 4I. IO3.

Monadina 288.

Monas St. 288.

- arhabdomonas H. Mejer 289.

- guttula Ehrbg. (I 2. 2 I) $28 \mathrm{~g}$.

- minima H. Meyer X, I6. 289.

- sociabilis H. Meyer $28 \mathrm{~g}$.

- truncata XI, 72. $34 \mathrm{I}$.

- vivipara Ebg. X, 15. (2 I) 289.

Monosiga S. K. 294.

- angustata S. K. 295.

- fusiformis S. K. 295.

- ovata S. K. X, 23. 295.

Monostroma Wittr. I 2 I.

--) bullosum Thur. V, I. I 2 I.

Monostyla Ehrbg. 475 .

- bulla Gosse 475 .

- lunaris Ehrbg. XVI, 3. 475.

- quadridentata Ehrbg. 475 .

Monura Ehrbg. 477.

- dulcis Ehrbg. XVI, 6. 477.

Mougeotia Wittr. $=$ Serpentinaria

S. F. Gray I 75 .

- genuflexa Ag. I75.

- laetevirens Wittr. I75.

- parvula Hass. I75.

— viridis Wittr. VI, 39. I75.

Mougeotieae I I I.

Mougeotiopsis E. Palla 176.

- calospora E. Palla VI, 42. I 76.

Mucor mucedo Bref. 246.

Multicilia Cienk. 332 .

- lacustris Lautb. XI, 53. 332.

Mycoideae 132 .

Mycomyceten 245 .

Myconostoc Cohn 40.

- gregarium Cohn I, I 2. 40. 
Myochrotes Born. et Fl. 74.

Myxomyceten 250 .

Myxophyceae 48 .

Naegeliella Correns 236.

- flagellifera C. VIII, I 2. 237.

Nais I0. 2 I.

Nassula Ehrbg. (345) 360.

- ambigua Cl. u. L. 361 .

- aurea Ehrbg. 36r.

- elegans Ehrbg. XII, I9. 36 I.

- lateritia Cl. u. L. $36 \mathrm{I}$.

- ornata Ehrbg. 361 .

Navicula Bory 200.

- acuta (Sm.) 208.

- affinis Ehrbg. VII, 32. 207.

- amphilepta Ehrbg. 208.

- amphisbaena Bory 207.

- anceps (Ehrbg.) 208.

- atomus Grun. 207.

- bacillum Ehrbg. 208.

- borealis (Ehrbg.) 204.

- boryana Pont. 208.

- brebissoni Kg. VII, 31. 204.

- cardinalis (Ehrbg.) 204.

- crassinervia Bréb. 207.

- cryptocephala Kg. 206.

— cuspidata Kg. VII, 33. . 206.

- dicephala Kg. 206.

- divergens (W. Sm.) 204.

- elliptica $\mathrm{Kg} .207$.

- firma Kg. 207.

- gastrum Ehrbg. 206.

- gibba (Ehrbg.) 205.

- gracilis (Ehrbg.) 205.

— inflata Kg. 206.

- iridis Ehrbg. 207.

- lacustris Kg. 208.

- lanceolata Kg. 205.

- limosa Ag. 207.

- major (W. Sm.) VII, 28. 205.

- méniscus Schum. 208.

- mesolepta (W.Sm.) VII, 30. 204.

- nobilis (Ehrbg.) 205.

- oblonga $\mathrm{Kg} .205$.

- phoenicenteron(N.)VII, 34. 208.

- producta (W. Sm.) 207.

- radiosa (W. Sm.) 205:

Eyferths Einfachste Lebeformen. 3. Auf.
Navicula rhynchocephala Kg. 206.

- stauroptera Grun. 204.

- tumida W. Sm. 206.

- viridis (W. Sm.) VII, 29. 204.

Naviculinae 199.

Naviculoideae I 99.

Nebela Leidy 264.

- ansata Leidy 265.

- barbata Leidy $26_{5}$.

- carinata Leidy 264.

- caudata Leidy 265 .

- collaris Leidy 264.

- flabellulum Leidy 264.

- hippocrepis Leidy 265.

Nephrocytium Naeg. 93 .

- agardhianum Naeg. III, I3. 93.

- naegelii Grun. 93.

Nitratbakterien 29.

Nitritbakterien 29.

Nitzschia Hassall 2 I g.

- acicularis W. Sm. VII, 55. 223.

- amphioxys Kg. VII, 56. 223.

- angustata (W. Sm.) 22 I.

-- communis Rabh. 223.

- constricta Kg. $22 \mathrm{I}$.

- gracilis Hantzsch 222.

- linearis W. Sm. 222.

- minutissima W. Sm. 222.

- palea W. Sm. 223

- parvula W. Sm. 222.

- sigma W. Sm. 222.

- sigmoidea W.Sm. VII, 54. 222.

- sinuata (Rabh.) $22 \mathrm{I}$.

- thermalis Auerswd. 221.

- tryblionella H. VII, 53. $22 \mathrm{I}$.

Nitzschiella acicularis R. VII, 55. 223.

Nitzschiinae 2 I 9.

Noctiluca miliaris 29. 229.

Nodularia Mertens 7 I.

- major Kirchn. II, I7. 7 I.

Nostoc Vauch. 69.

- carneum Ag. 70.

- coeruleum Lyngbye 70.

-- commune Vauch. 70.

- linckia Bornet 70 .

- paludosum Kg. II, I6. 70.

- piscinale $\mathrm{Kg} .70$.

- pruniforme Ag. 70 . 
Nostoc punctiforme Hariot 70.

- spongiaeforme Ag. 70.

- verrucosum Vauch. 70.

Nostocaceae 68.

Nostochopsis Wood 78.

- lobata Wood II, 34. 78.

Noteus Ehrbg. 48I.

- quadricornis E. XVI, I3. 482.

Notholca Gosse 486.

- foliacea Ehrbg. 487.

- longispina Kellic. XVI, I 6. 487.

- spinifera Gosse 487 .

- striata Ehrbg. XVI, I5. 487.

Notommata Gosse 453 .

- ansata Ehrbg. 453 .

- aurita Ehrbg. 454 .

- brachyota Ehrbg. 453.

- lupus Eyf. 454.

- najas Ehrbg. 453.

- tripus Ehrbg. XV, 6. 453 .

Notommatadae 452 .

Notops Huds. 45I.

- brachionus Ehrbg. XV, 4.452.

Nuclearia Cienk. 274.

- delicatula Cienk. IX, 24. 274.

Nyctotherus cordiformis $\mathrm{Cl} .378$.

— ovalis Leidy 378.

Ochromonas Wysotzki 335 .

- chromata H. Meyer XI, 58. 336.

- crenata KI. 336.

- granulosa H. Meyer 335 .

- mutabilis Kl. XI, 57 . 335 .

- variabilis $H$. Meyer 335 .

Odontidium hiemale Kg. I9I.

- anceps Ehrbg. 190.

Oecistes Ehrbg. 435.

- socialis Wbr. XIV, 6. 436.

- velatus Gosse 435 .

Oedogoniaceae 132 .

Oedogonium L. = Prolifera V. I 33.

- capillare Kg. I 34 .

- crispum Wittr. I33.

- echinospermum A. Br. I34.

- pringsheimi Cram. V, 27. 133.

- rothi Pringsh. 134.

- undulatum A. Br. I 34 .

- vaucheri A. Br. 133 .
Oikomonas S. K. 287.

— mutabilis S. K. X, I2. 288.

- termo J.-Cl. 287.

Oligotricha $38 \mathrm{r}$.

Oncobyrsa C. A. Ag. 57.

- lacustris Kirchn. 57.

- rivularis Menegh. I, 44. 57.

Onychodromus St. 388.

- grandis St. XIII, IO. 388.

Oocardium Naeg. I60.

- stratum Naeg. VI, 25. 160.

Oocystis Naeg. 93.

- marssoni Lemmerm. 93.

- naegelii A. Br. 93.

- solitaria Wittr. III, I4. 93.

Oomyceten 246.

Opalina ranarum 374 .

Opalinina 374 .

Opercularia St. 406.

- articulata Ehrbg. XIII, 33. 407.

- berberina St. 406.

- coarctata (Cl. u. L.) 407.

- cylindrata Wrzesn. 406.

- glomerata Roux 407.

- nutans Cl. u. L. 407.

Ophiocytium Naeg. em. Lemm. Io6.

- arbuscula Lemm. IV, 5. 107.

- capitatum Wolle IV, 7. 107.

- cochleare A. Br. 107.

- gracilipes Lemmerm. 107.

- majus Naeg. IV, 6. 107.

- parvulum A. Br. 107.

Ophrydium Ehrbg. 407.

- eichhorni Ehrbg. XIII, 35. 408.

- versatile Ehrbg. XIII, 34. 408.

Ophryoglena Cl. u. L. 367.

- flava Cl. u. L. 367.

- flavicans Lieberk. XII, 30. 367.

Ophryoscolecina 383 .

Ophryoscolex inermis 383 .

- purkinjei 383 .

Opisthodon St. 362 .

- niemeccensis St. XII, 21. 362.

Orthosira arenaria Sm. VII, 2. I 84 .

- orichalcea Sm. 184.

Oscillaria = Oscillatoria Vauch. 61.

Oscillatoria Vauch. = Oscillaria 6r.

- chalybea Mertens 63 . 
Oscillatoria formosa Bory 63 .

- limosa Ag. II, I. 62.

- margaritifera Kg. 62.

- princeps Vauch. 62.

- rubescens D. C. 62.

- splendida Grev. II, 2. 63.

- tenuis Ag. II, 3. 62.

- terebriformis Ag. 63.

Oscillatoriaceae 60.

Ouramoeba Leidy 256 . — vorax Leidy 257.

Oxytricha Ehrbg. 39 I.

— fallax St. 392.

- ferruginea St. 39I

- parallela Engelm. 391.

- pellionella Ehrbg. XIII, I 4. 39 I.

- platystoma Ehrbg. 392.

Oxytrichina 384 .

Palmella Lyngb. IoI.

- botryoides Kg. IOI.

- mucosa Kg. Iоr.

- stigeoclonii Cienk. IOI.

Palmodactylon Naeg. IO2.

- varium Naeg. III, 38. 102.

Palmodictyon Kg. 90.

— viride Kg. III, 2. 90

Pamphagus Bailey 270.

- hyalinus Leidy IX, 19. 270.

- mutabilis Bailey 270.

Pandorina Bory (I IO) II 7 .

- morum Bory IV, 28. (I3) I I8.

Panophrys St. 367 .

Paramaecina $37 \mathrm{I}$.

Paramaecium St. 37 I.

- aurelia (O.F. Müll.) (I 2.2 I) 37 I.

- bursaria Focke XII, 4 I . (13) 37 I.

- caudatum Ehrbg. XII, 40. 37 I.

- putrinum Cl. u. L. (I 2) 37 I.

Paulinella Lauterb. 269.

- chromatophora Lauterb. 269.

Pedalion Hudson 490.

- mirum Huds. XVI, 20 u. 2 I. 490.

Pedalionidae 490.

Pediastrum Meyen 107.

- biradiatum Meyen I09.

- boryanum Menegh. Io8.

- duplex Meyen IV, 9. I08.
Pediastrum integrum Naeg. Io8.

- simplex Meyen IV, 8. IoS.

- tetras Ralfs 108.

Pelicida rostrata Duj. XII, I 8. 359.

Pelomyxa Greeff 258.

- palustris Greeff IX, 8. 258.

- villosa Leidy 258 .

Penicillium crustaceum 245 .

Penium De By. I54.

- cylindrus Bréb. 155 .

- digitus Bréb. 155.

- interruptum Bréb. VI, I5. 155.

- margaritaceum Bréb. 155.

- navicula Bréb. 155 .

Pennatae 187.

Peranema St. 324.

- trichophorum St. XI, 37. 324.

Peranemeae 324 .

Peranemida 323 .

Perforata $27 \mathrm{I}$.

Peridiniaceae 227.

Peridinium Ehrbg. 233.

- bipes St. VIII, I0. 234.

- cinctum Ehrbg. VIII, 9. 234.

- minimum Schilling 234.

- quadridens St. VIII, I I. 234.

- tabulatum Cl. u. L. VIII, 7. 234.

- umbonatum St. VIII, 8. 234.

Perionella Gobi 105.

- hyalothecae Gobi IV, 3. 105.

Peritricha 396.

Peronosporaceen 247 .

Petalomonadeae 327 .

Petalomonas St. 327.

- abscissa St. XI, 43. 327.

— inflexa Kl. 328.

- mediocanellata St. 327 .

- sexlobata KI. XI, 44. 328 .

- steini KI. 327 .

Petalonema Berk. 75 .

- alatum Berk. II, 27. 75.

- crustaceum Kirchn. 75.

Phacoteae I 6 .

Phacotus Py. II6.

- angulosus St. IV, 22. II6.

- lenticularis St. I I6.

Phacus Nitzsch 319.

- alata Kl. 319. 
Phacus longicauda Duj. XI, 29. 320.

- ovum Kl. XI, 27. 319.

- pleuronectes Ntz. XI, 28. 320.

- pyrum St. 320 .

Phaeodermatium rivulare Hansg.VIII, I 4. 237 .

Phaeophyceà 235.

Phaeothamnion Lagerh. I 3 I.

- confervicolum Lgh. V, 24. I 3 I.

Phalansterina 292.

Phalansterium Cienk. 292.

- consociatum Cienk. 293.

- digitatum St. X, 22. 293.

Phascolodon St. 362 .

- vorticella St. XII, 22. 262.

Phialina vermicularis Ebg. 355 .

Phialonema cylostomum St. XI, 38 . 325 .

Philodina Ehrbg. (2I) 438.

- aculeata Ehrbg. 439.

- citrina Ehrbg. 439.

- erythrophthalma Ehrbg. 439.

- macrostyla Ehrbg. 439.

- megalotrocha Ebg. XIV, I I. 439.

- roseola Ehrbg. 439.

Philodinadae 438.

Phormidium Kg. 64 .

- corium Gom. 64.

- incrustatum Gom. 64.

- purpurascens Gom. 64.

- subfuscum Kg. II, 6. 65.

- tenue Gom. 64.

- uncinatum Gom. 65.

- valderianum Gom. 64 .

Phycochromaceae 48 .

Phycomyceten 245.

Phyllactidium Hansg. I 35 .

Phyllomitus St. 305.

- amylophagus KI. XI, 6. 305.

- undulans St. 305 .

Phyllomonas Kl. 288.

- contorta Kl. X, I3. 288.

Phytophthora infestans De By. 247.

Pilze 245.

Pinaciophora Greeff 276 .

- fluviatilis Greeff X, 2. 276.

Pinnularia Ehrbg. $2 \mathrm{O}_{4}$.

Pinselschimmel 245 .
Placocista Leidy 267.

- spinosa Leidy 267.

Plagiopyla St. 376 .

- nasuta St. XII, 49. 376.

Plagiotoma lumbrici Duj. 378 .

Plagiotomina 375 .

Plakopus F. E. Schulze 257.

- ruber F. E. Schulze IX, 6. 257.

Platoum F. E. Schulze 270.

Plectonema Thur. 74.

- nostocorum Born. 74.

- tommasinianum Born. II, 25. 74.

Plectophrys Entz 270.

Pleurenterium (Lund.) I 7 I.

- sexcostatum Ld. VI, 34. 17 I.

Pleurocapsa Thur. 58.

- cuprea Hansg. I, 46. $5^{8}$.

- fluviatilis Lagerh. $5^{8}$.

Pleurocarpus A. Br. I 75 .

Pleurochilidium St. 368.

- strigilatum St. 368.

Pleurocladia A. Br. 237.

- lacustris A. Br. VIII, I 5. 237.

Pleurococcaceae 87.

Pleurococcus Menegh. 92 (243).

- vulgaris Menegh. III, I I. 92.

Pleuromonas Py. 304.

- jaculans Py. XI, 4. 3C4.

Pleuronema Duj. 373.

- chrysalis St. XII, 44. 373.

Pleuronemina 372.

Pleurophrys sphaerica Cl. u. L. IX, 20. $27 \mathrm{I}$.

Pleurosigma IV. Sm. = Scalprum Corda 209.

- acuminatum Grun. VII, 38. 2 I

- angulatum W. Sm. 209.

- attenuatum W.Sm. VII,37. 210.

- scalproides Rabh. 210.

- spenceri W. Sm. 2 Io.

Pleurotaeniopsis Lund. I 58.

- cosmarioides (De By.) I59.

- cucumis Lund. VI, 22. I59.

- ralfsi (Bréb.) I59.

- turgidus Lund. I59.

Pleurotaenium Lund. I 56.

- nodulosum De By. I57.

- trabecula Naeg. VI, I 8. 156. 
Pleurotricha St. 389 .

- grandis St. XIII, I I. 389 .

- lanceolata Ehrbg. 389.

Pleurotrichina 387 .

Ploesoma Herrick 488.

- hudsoni Imhof 488 .

- truncatum Leand. XVI, I7. 488.

Ploesomadae 488.

Ploïma 443.

Podophrya Btschli. 4 I 4.

- fixa Ehrbg. 414.

- libera Py. XIII, 45. 4 I 4.

Podostoma Cl. u. L. $25^{8}$.

— filigerum Cl. u. L. $25^{8}$.

Polyarthra Ehrbg. 450.

- platyptera Ehrbg. XV, I. 450.

Polyblepharidae I 12.

Polyblepharis Dang. I 2.

- singularis Dang. IV, I 3. I I 2.

Polycystis Kirchn. 54 .

Polyedrium Naeg. 93.

- enorme De By. III, I 5. 93.

- trigonum Naeg. III, I6. 94.

Polygastrica 344 .

Polymastigina 306.

Polymastix Grub. 332 .

Polyphagus euglenae Now. VIII, 28. 246.

Polytoma Ehrbg. I I 5 .

- uvella Ehrbg. IV, 2 I. I I5.

Pompholyx Gosse 48I.

- complanata G. XVI, I 1. 48 I.

Porphyridium Naeg. 242. 243.

Poteriodendron St. 292.

- petiolatum St. X, 2 I. 292.

Prasiola Menegh. I $2 \mathrm{I}$.

- calophylla Kg. I 2 I.

- cripsa Kg. V, 2. 12 I (1 25).

- sauteri Męnegh. 121.

Proales Gosse 455 .

- decipiens Ehrbg. 456.

- felis Ehrbg. 456.

- gibba Ehrbg. 456 .

- parasitica Ehrbg. 456 .

- petromyzon Ehrbg. 456 .

- tigridia Gosse XV, 9. 456.

- wernecki Ehrbg. (139) 456.
Prolifera Vauch. = Oedogonium L.

I 33 .

Prorodon Ehrbg. $35^{2}$.

- armatus Cl. u. L. $35 \hat{\jmath}$.

- edentatus Cl. u. L. 353 .

- farctus (Cl. u. L.) 353 .

- griseus Cl. u. L. 353.

- niveus Ehrbg. 353 .

- teres Ehrbg. XII, 5. 353.

Protamoeba Haeckel 255 .

- primitiva Haeckel IX, I. 255.

Protococcaceae 103.

Protococceae 103.

Protococcoideae 87 .

Protococcus Ag. I 04.

- infusionum Kirchn. I05.

- viridis Ag. I05.

Protoderma Kg. I 2 I.

— viride $\mathrm{Kg} . \mathrm{V}, 3 . \mathrm{I} 2 \mathrm{I}$.

Protomastigina 283 .

Protosiphon Kl. I05.

— botryoides Kl. IV, 2. I05.

Protospongia S. K. 296.

— haeckeli S. K. X, 28. 296.

Protozoa 249.

Pseudochlamys patella Cl. u. L. 260.

Pseudodifflugia Schlumbg. 27 I.

- gracilis Schlumbg. IX, 20. 27 I.

Pseudo-Eunotia Grun. I 96.

Pseudoprorodon niveus Blchm. 353 .

Psilonemateae 59.

Psilotricha St. 393 .

- acuminata St. 393.

Psilotrichina 393.

Pterodina Ehrbg. (424) 480.

- clypeata Ehrbg. 481.

- elliptica Ehrbg. 48I.

- emarginata Wierzejski 480.

- mucronata Gosse 480.

- patina Ehrbg. XVI, Io. 480.

- reflexa Gosse 481 .

Pterodinadae 479.

Pteromonas Seligo I 16.

— alata Seligo IV, 24. I I 6.

Pyrami(do)monas Schmarda I 12.

- tetrarhynchus (Schd.) IV, I I. I 12.

Pythium 247.

Pyxidicula operculata Ehrbg. 260. 
Quadrula F. E. Schulze 26 I.

— symmetrica F.E.Sch. IX, I 2. 26 I.

Radiolarien 250.

Rädertiere 418.

Raphidiophrys Arch. 277.

- elegans Hertw.u.Less. X, 4. 277.

- pallida F. E. Schulze 277.

- viridis Arch. 277.

Raphidium $=$ Rhaphidium 94 .

Rattulus Ehrbg. 465 .

- cimolius Gosse 465 .

- helminthodes G. XIV, 38. 465.

Rhabdochromatium Win. 38.

- fusiforme Win. 39.

- minus Win. 39.

- roseum Win. I, Io. 39.

Rhabdomonas incurva Fres. 322.

Rhabdonema 2 I.

Rhaphidium Kg. = Micrasterias Corda

94.

— longissimum B. Schröd. 94.

- polymorphum Fresen. = M.

falcata III, 18. 94.

Rhaphidomonas St. 331 .

- semen St. XI, 52. 331.

Rhipidodendron St. 300.

- huxleyi S. K. 300.

- splendidum St. X, 38. 300.

Rhizoclonium Kg. I 36.

- fontinale Kg. V, 33. 137.

- hieroglyphicum Kg. I 36 .

Rhizomastigina 284 .

Rhizopoda 25 I.

Rhizopus nigricans Ehrbg. 246.

Rhizosolenia Ehrbg. I 86.

- longiseta Zach. VII,6. I 86.

Rhizosoleniinae I 86.

Rhizota 430.

Rhodophyceae 238 .

Rhoicosphenia Grun. 213.

- curvata Grun. VII, 44. 2 I4.

Rhopalodia O. F. Müll. 2 I 8.

- gibba O. F. M. VII, 51. 218.

- ventricosa O. F. Müll. 2.18.

Rhyncheta Zenker 4i2.

- cyclopum Zkr. XIII, 39. 4 I 2.

Rhynchomonas Kl. 304
Rhynchomonas nasuta Kl. XI, 5. 305.

Richteriella Lemmerm. 97.

— botryoides Lem. III, 28. 97.

Rivularia, Ag. 8I.

- echinulata Engl. Bot. II, 40. 81.

- haematites Ag. 82.

- minutula Born. et Fl. II, 4 I. 82.

- natans Welw. 82 .

- pisum Ag. 8I.

Rivulariaceae 78 .

Rotalgen 238.

Rotatoria 418.

Rotifer Schrank 439.

- actinurus Ehrbg. XIV, 13. 441.

- citrinus Ehrbg. 440.

- elongatus Wbr. 440.

- macrocerus Gosse XIV, I 2. 44 I.

- macrurus Ehrbg. 44I.

- tardus Ehrbg. 440.

- trisecatus Wbr. 440.

- vulgaris Schrk. (2I) 44 I.

Saccharomyceten 245 .

Salmacis Hansg. I73. I 74.

Salpeterbakterien 30.

Salpina Ehrbg. 469.

- brevispina Ehrbg. 470.

- mucronata Ehrbg. XV, 22. 470.

- spinigera Ehrbg. 470.

- ventralis Fhrbg. 470 .

Salpinadae 468.

Salpingoeca J.-Cl. 297 .

- amphoridium J.-Cl. X, 31. 298.

- brunnea Stokes 297.

- convallaria St. 298.

- fusiformis S. K. 298.

- minuta S. K. 298.

- napiformis S. K. X, 32. 298.

- pyxidium S. K. 298.

- ringens S. K. 298.

- vaginicola St. 298.

Saprolegnia N. v. Es. 247 .

- ferax Aut. 247.

- mixta De By. 247.

- thureti De By. 247.

Saprolegniaceen 247.

Sarcina Goodsir I, 5. (2 I) 35. 
Sarcina lutea Schröter 35.

- paludosa Schröter 36 .

- rosea Schröter 36.

- ventriculi Goods. 36.

Sarcodina 249.

Scalprum Corda $\doteq$ Pleurosigma W. Sm. 209.

- fusiforme = Pl. acum. VII, 38 . 2 IO.

Scaridium Ehrbg. 466.

- longicaudum Ehrbg. XV, $40 \mathrm{u}$. 41. $(422.424) 466$.

Scenedesmus Meyen 94.

- bijugatus Kg. 95 .

- obliquus Kg. III, 22. 95.

- quadricauda Bréb. III, 2 I. 95.

Scheidenbakterien 43 .

Schizacanthum Wille: I 58.

- armatum Lund. VI, 2 I. I 58.

Schizochlamys A. Br. 90.

- gelatinosa A. Br. III, 3. 9I.

Schizogonium murale (Kg.) 125 .

Schizomeris leibleini Kg. I 22.

Schizomycetes 25 .

Schizophyceae 48 .

Schizophytae 25.

Schizothrix Kirchn. 67.

- brauni Gom. 67.

- muelleri Naeg. II, I 2. 67.

Schlauchalgen I38.

Schrammia barbata D. VIII, 24. 243.

Schraubenbakterien 40.

Schroederia Lemmerm. 94.

- setigera Lem. III, I7. 94.

Schwalbenschwanzalge 233 .

Schwefelbakterien (30) $47^{\circ}$.

Scirtopoda 490.

Scoliopleura Grun. 2 I 0.

- campylogramma Rabh. 2 Io.

Scotinosphaera paradoxa Kl. I05.

Scyphidia Lachm. 399.

- amoebea Grenf. 400.

- limacina Lachm. 399.

- physarum Lachm. XIII, 22. 400.

Scyphidina 399.

Scytomonas St. 327 .

- pusilla St. XI, 42. 327.

Scytonema Ag. 74 .
Scytonema crispum Born. II, 26. 75.

- mirabile Born. 75.

- ocellatum Lyngbye 75 .

Scytonemaceae 73 .

Selenastrum Reinsch 94 .

- bibraianum Reinsch III, I 9. 94.

Selenosporium aquaeductuum Radlkfr. (I 2) 245 .

Serpentinaria S.F. Gray $=$ Mougeotia Wittr. 175.

Siphomyceten 245 .

Siphoneae 138 .

Sirogonium Wittr: I73 u. I74.

Solenoideae I 86.

Solenophrya Cl. u. L. 416.

- crassa Cl. u. L. XIII, 49. 4 I 6.

Sonnentierchen $27 \mathrm{I}$.

Sorastrum Kg. 96.

- spinulosum Naeg. III, 25. 96.

Spaltalgen 48 .

Spathidium Duj. $35^{2}$.

- lieberkuehni Btschli. 352.

- spathula (O. F. M.) XII, 4. 352.

Sphaerastrum Greeff 275 .

- fockei (Arch.) IX, 26. 275.

Sphaerella Sommerf. (I IO) I I 4 .

- nivalis Sommerf. I 14 .

- pluvialis Wittr. IV, I 8. (I 4 ) I I 4 .

Sphaeroeca Lauterb. 296.

- volvox Ltb. X, 27. 296.

Sphaerogonium Hansg. 59.

Sphaerophrya Cl. u. L. 4 I 3.

- magna Mps. XIII, 42. 4I3.

- pusilla Cl. u. L. 4 I 3 .

- stentoris Mps. 4I 4 .

Sphaeroplea Ag. I38.

- annulina Ag. V, 35. I 38 .

Sphaeropleaceae I 38 .

Sphaerotilus Kg. 44.

- natans $\mathrm{Kg}$. I, I7. 44.

Sphaerozosma Arch. $147^{\circ}$

- excavatum Rabh. VI, 9. I48.

- vertebratum Ralfs VI, 8. I47.

Sphaerozyga Born. et Fl. 7 I.

Sphenella vulgaris (Kg.) 2 I 3.

Sphenoderia Schlumbg. 268.

- lenta Schlumbg. 268.

- macrolepis Leidy 268. 
Sphenomonas St. 323 .

- quadrangularis St. XI, 35. 323.

- teres Kl. 323.

Spirillaceae 40.

Spirillum Ehrbg. $4 \mathrm{I}$.

- rufum Perty 42.

- rugula Winter I, I5. 42.

- sanguineum Cohn I, I4. 4I.

- serpens Winter 42.

- sputigenum 42 .

- tenerrimum Lehm. u. Neum. 42.

- tenue Ehrbg. 42.

- undula Ehrbg. (28) 42.

- volutans 4 I. 42.

Spirochaete Ehrbg. (2 I) 42 .

- dentium 43.

- obermeieri Cohn 43 .

— plicatilis Ehrbg. I, I6. 42.

Spirochona St. 397 .

- gemmipara St. XIII, 20. 397.

- scheuteni St. 397.

Spirochonina 397.

Spirogyra Linck = Conjugata Vauch.

(2) 172.

- affinis Petit 173.

— bellis. Petit 174 .

- communis $\mathrm{Kg}$. $\mathrm{I} 74$.

- crassa Kg. 174.

- decimina Kg. 174.

- gracilis $\mathrm{Kg} .174$.

- jugalis $\mathrm{Kg}$. 174 .

- longata Kg. I74.

- nitida Linck 174 .

- orthospira Naeg. 174.

- porticalis Cleve VI, 35. 173.

- rivularis Rabh. I74.

— stictica Wittr. VI, 37. 175.

- tenuissima $\mathrm{Kg} .175$.

— weberi Kg. VI, 36. I75.

Spirogyreae 17 I.

Spironema Kl. 3 I 2.

- multiciliatum Kl. XI, I7. 312 .

Spirostomum Ehrbg. 376.

— ambiguum Ehrbg. XII, 50. 377.

- teres Cl. u. L. 377.

Spirotaenia Bréb. I 49.

- condensata Bréb. VI, I 2. I49.

- obscura Ralfs 149.
Spirotaenieae Haupt凡. I43.

Spirotricha 374.

Spirulina Turpin 63.

- major $\mathrm{Kg}$. II, 5. 63.

- meneghiniana Zan. 63 .

Spondylomorum Ehrbg. I 6.

- quaternarium Ebg. IV, 25. 117.

Spondylosium Arch. I 46.

- depressum Arch. VI, 6. 147.

- pulchellum Arch. I 47.

Spongomonadina 299.

Spongomonas St. 299.

- discus St. 300.

- intestinum St. X, 35. 300.

- sacculus S. K. X, 36. 300.

- uvella St. 300.

Spumella truncata $=$ Cyathomonas

tr. XI, 72. 34 I.

Squamella Ehrbg. 479.

- bractea Ehrbg. XVI, 9. 479.

- oblonga Ehrbg. 479.

Stäbchenbakterien 36 .

Staurastrum Lund. 167.

- aculeatum Menegh. I6g.

- alternans Bréb. I6g.

- cuspidatum Bréb. VI, 32. 170.

- dejectum Bréb. VI, 33. 170.

- dilatatum Ehrbg. 169 .

- furcatum Bréb. I 70.

- furćigerum Bréb. 170.

- gracile Ralfs VI, 31. 170.

— hexacerum Wittr. 169. 宣

- hirsutum Bréb. I69.

- margaritaceum Menegh. I6g.

- muticum Bréb. I69.

- orbiculare Ralfs I68.

- polymorphum Bréb. 170.

- punctulatum Bréb. I69.

— teliferum Ralfs I70.

— vestitum Ralfs I69.

Staurogenia Kg. 9 I.

- lauterborni Schmidle III,6. 9 I.

Stauroneis lanceolata Kg. 208.

Stauroptera Ehrbg. 204.

Staurosira Ehrlig. 192.

Staurospermum Wittr. 175.

Stentor Oken 379.

_ baretti Barrett 380. 
Stentor coeruleus Ehrbg. 380.

- igneus Ehrbg. XII, 55. 380.

- muelleri Ehrbg. 380.

- niger Ehrbg. 380 .

- polymorphus Ehrbg. 380 .

- roeseli Ehrbg. XII. 54. 380.

Stentorina 378.

Stephanoceros Ehrbg. 433.

- eichhorni Ehrbg. XIV, 2. 433.

Stephanodiscus Ehrbg. 185.

- astraea Grun. I 85 .

- hantzschianus Grun. VII, 4. 185.

Stephanops Ehrbg. 467 .

- cirrhatus Ehrbg. 468.

- intermedius Burn. 467 .

- lamellaris Ehrbg. XV, 20. 467.

- longispinatus Tatem 468 .

- muticus Ehrbg. 467.

Stephanosphaera Cohn I 17.

- pluvialis Cohn IV, 27. I I 7 .

Stichococcus Naeg. (83. 84) 92.。

- bacillaris Naeg. III, I 2. 92.

- flaccidus (Kg.) 93.

Stichotricha Py. 385 .

— secunda Py. XIII, 6. 386.

— socialis Grub. XIII, 7. 386.

Stickstoff bakterien 30 .

Stigeoclonium (Kg.) I 29.

- flagelliferum Kg. I 29.

- tenue $\mathrm{Kg}$. V, I5. I 29.

Stigonema (Ag.) 77 .

- hormoides Born. 78 .

- ocellatum Thur. II, 32. 78.

- panniforme Hieron. 78.

Stigonemataceae 77 .

Strahllinge 250.

Streptococcus Billroth 34.

- cinereus Zimmerm. 34.

- erysipelatos Fehl. J, 3. 34.

- granula (Win.) 35 .

- lacteus Schröter 34 .

- margaritaceus Schröter 34.

- mesenterioides Mig. (29) 35.

- roseus (Win.) I, 2. 34 .

Streptomonas Kl. 30 I.

- cordata Kl. X, 41. 302.

Strombidium Cl. u. L. 38 I.

- turbo Cl. u. L. 382 .
Strombidium viride St. XIII, I. 382.

Stylochrysalis St. 336.

- parasitica St. XI, 6o. 336.

Stylocometes St. 4 I 7 .

- digitatus Cl.u. L. XIII, 53. 4 I 7.

Stylonychia St. (346) 392.

- histrio Ehrbg. 392.

- macrostyla (Wrzesn.) 393.

- mytilus Ehrbg. XIII, I5. (346)

393 .

- pustulata Ehrbg. 393 .

Suctoria 410.

Suriraya Turp. = Surirella Auct.

224.

Surirella Turpin 224.

- angusta $\mathrm{Kg} .226$.

- biseriata (Bréb.) VII, 59. 226.

- craticula Ehrbg. 226.

- ovata Kg. VII, 58. 225.

- spiralis Kg. VII, 60. 226.

- splendida Kg. 226.

- tenera Greg. 226.

Surirellinae 223 .

Surirelloideae 223.

Symploca Kg. 66.

- dubia Gom. 66.

- muralis. Kg. II, 8. 66.

- muscorum Gom. 66.

- parietina 66.

Symplocastrum Kirchn. 66.

- friesi Kirchn. II, 1 o. 66.

Synchaeta Ehrbg. (422. 423) 449.

- oblonga Ehrbg. 449.

- pectinata Ehrbg. XIV, 23. 449.

- tremula Ehrbg. XIV, 24. 449.

Synchaetadae 449.

Syncrypta Ehrbg. 340.

- volvox Ehrbg. XI, 70. 340.

Synechococcus Naeg. 52 .

- aeruginosus Naeg. I, 27. 52.

Synedra Ehrbg. 193.

- capitata (Ehrbg.) VII, 19. I94.

- lunaris Ehrbg. 193.

- oxyrhynchus $\mathrm{Kg}$. I94.

- radians $\mathrm{Kg}$.'194.

— ulna Ehrbg. VII, I8. I93.

Synura Ehrbg. 339.

- uvella Ehrbg. XI, 69. 340. 
Tabellaria Ehrbg. I 88.

- fenestrata Kg. VII, IO. 188.

- flocculosa Kg. VII, 9. I 88.

Tabellariinae 187 .

Taphrocampa Gosse 452.

- annulosa Gosse XV, 5. 452.

- selenura. Gosse $45^{2}$.

Testacea 258 .

Tetmemorus Ralfs 156.

- brebissoni Ralfs VI, I7. I56.

- granulatus Ralfs I56.

- laevis Ralfs 156.

Tetrachastrum Hansg. 166.

Tetracoccus West 90 .

- nimbatus De Wildm. 90.

Tetracyclus Ralfs I 88 .

— brauni Grun. VII, I I. I 88 .

- lacustris Ralfs I89.

Tetramitina 307 .

Tetramitus Py. 307.

- descissus Py. XI, I I. 307.

- pyriformis Kl. 308.

- rostratus Py. 307.

- sulcatus St. 308.

Tetrapedia Reinsch 56.

- emarginata B. Sch. I, 43. 57.

- gothica Reinsch I, 42. 56 .

Tetraspora Linck Ioo.

- explanata Ag. IOI.

- gelatinosa Desv. III, 35. 100.

- lubrica Ag. 100.

Tetrasporaceae 97 .

Thaumatonema Lautb. 305 (329).

- setiferum Ltb. XI, 8. 305.

Thincapsa roseo-persicina Win. 34 .

Thiocystis rufa Win. 34 .

- violacea Win. 34 .

Thiodictyon Win. 37.

- bacillosum (Win.) 37.

- elegans Win. I, 8. 37.

Thiopedia rosea Win. I, 4. 35 .

Thiopolycoccus ruber Win. I, 6. 36 .

Thiosarcina rosea Win. 36 .

Thiothece gelatinosa Win. 34 .

Thiothrix Win. 45.

- nivea Win. I, 20. 45 .

- tenuis Win. 45 .

- tenuissima Win. 45 .
Thorea Bory 240.

- ramosissima Bory VIII, I 8. 240.

Tierische Organismen 248.

Tintinnidium S. K. 382 .

- fluviatile (St.) XIII, 3. 382.

Tintinnoina 382 .

Tokophrya Btschli. 4 I 4.

- astaci (St.) 415 .

- carchesii (Cl. u. L.) 416.

- cothurnata(C.u.L.)XIII, 46. 4 I5.

- cyclopum (Cl. u. L.) 4 I 6.

- elongata (Cl. u. L.) 4 I 5 .

- ferrum equinum (Cl. u. L.) 415.

- lichtensteini (Cl. u. L.) 415 .

- pyrum (Cl. u. L.) $4 \mathrm{I} 6$.

- quadripartita (Cl. u. L.) XIII, 47 . 4 I 6.

- steini (Cl. u. L.) 415 .

Tolypothrix $\mathrm{Kg} .75$.

- byssoidea Kirchn. 76 .

- distorta $\mathrm{Kg} .76$.

- lanata Wartmann II, 28. 76.

-- penicillata Thur. 76 .

- tenuis $\mathrm{Kg} \cdot 76$.

Trachelina 356 .

Trachelius Cl. u. L. 3.58.

- ovum Ehrbg. XII, I6. 359.

Trachelomonas Ehrbg. 318.

- armata St. 3 I 9.

- caudata St. XI, 26. 3 I9.

- hispida St. 319.

- lagenella St. 318.

- volvocina Ehrbg. XI, 25. 318.

Trachelophyllum apiculatum P. 354 .

- pusillum C.l. u. L. 354 .

Trentepohlia Mart. I 3 I (243).

- aurea Mart. I 3 I.

- iolithus Wittr. 13I.

- umbrina Born. I3 1 .

Trepomonas Duj. 310.

— agilis Duj. XI, I6. 311.

- rotans K!. XI, I5. 311.

- steini Kl. 3 I I.

Triarthra Fhrbg. 450.

- longiseta Ehrbg. 450.

- mystacina Ehrbg. XV, 2. 45I.

Triarthradae 450 .

Trichoda Ehrbg. 366. 
Trichoda pura Ehrbg. 366 .

Trichodina St. 397.

- mitra v. Sieb. 398.

— pediculus Ehrbg. XIII, 2 I. 397.

- steini Cl. u. L. 398.

Trichodinopsis paradoxa Cl.u.L. 398 .

Trichophoreae 60.

Trichophrya Cl. u. L. 417.

- epistylidis Cl.u.L. XIII, 5.O. 4 I 7 .

Trichormus Born. et Fl. 7 I.

Trichostomata 363 .

Trigonomonas Kl. 309 .

- compressa Kl. XI, I 2. 309.

Trilobus gracilis Io.

Trimastigina 306.

Trinema Duj. 268.

- enchelys (Ehrbg.) IX, I 5. 268.

Triphylus Ehrbg. $45^{2}$.

- lacustris Ehrbg. 452.

Trochilia St. 362 .

- palustris St. XII, 23., 362 .

Tropidoscyphus St. 328.

- octocostatus St. XI, 45. 328.

Tryblionella angustata W. Sm. 221 .

- hantzschiana Grun. VII, 53. 22 I.

Tubicolaria Lamrk. 435.

- najas Ehrbg. 435.

Tubuligerae IValz I 40 .

Ulotrichaceae I 22.

Ulothrix Kg. (92) I 22.

- flaccida Kg. 93.

- mirabilis Hansg. I 23.

-- subtilis (Kg.) 123.

- zonata $\mathrm{Kg} . \mathrm{V}, 5 . \mathrm{I} 23$.

Ulvaceae 120.

Urceolarina 397 .

Urceolopsis sabulosa Stokes 325.

Urceolus Neresch. 325 .

- alenizini Meresch. 325 .

- cyclostomus Meresch. XI, 38 . 325 .

- ovatus Möbius 325 .

Urnula Cl. u. L. 4 I 2.

- epistylidis Cl. u. L. XIII, 40. 4 I 3.

Urocentrina 372.

Uroçentrum Nitzsch 372.

— turbo Ehrbg. XII, 42
Urococcus Kg. 9 I.

- hookerianus (B. et H.) III, 8. 92.

- insignis Kg. 92.

Uroglena Ehrbg. 340.

- volvox Ehrbg. XI, 7 I. 340.

Uroleptus St. 386.

- agilis Engelm. 387 .

- mobilis Eglm. XIII, 9. 387 .

- musculus Ehrbg. 387.

- piscis (Ehrbg.) XIII, 8. 387.

- rattulus St. 387 .

- violaceus St. 387 .

Uronema Lagerh. 124.

- confervicolum Lgh. V, 6. I 24.

Uronema Duj..369.

- griseolum (Mps.) XII, 34. 369.

- marinum Duj. XII, 34. 369.

Urophagus KI. 3 IO.

- rostratus KI. XI, I4. 310.

Urostyla Ehrbg. 384.

- flavicans Wrzesn. 385 .

- grandis Ehrbg. (17) 385 .

- viridis St. 385 .

- weissei St. XIII, 4. 385 .

Urostylinae 384.

Urotricha Cl. u. L. $35 \mathrm{I}$.

- farcta Cl. u. L. $35 \mathrm{I}$.

- globosa Schew. XII, 2. 3.5 I.

Urozona Schewiak. 369.

- bütschlii Schew. XII, 35. 369 .

Ursinella Turp. $=$ Cosmarium p. p. I 60.

Urtiere $2+9$.

Vacuolaria Cienk. 330.

- virescens Cienk. XI, 49. 331.

Vaginicola Ehrbg. 409.

- decumbens Ehrbg. 409.

- longicollis S. K. XIII, 37. 409.

Vampyrella Cienk. (272) 274.

- lateritia Leidy IX, 23. 274.

- spirogyrae Cienk. IX, 23. 274.

Vanheurckia Bréb. 208.

- viridula Bréb. 209 .

- vulgaris H. v. H. VII, 35. 209.

Vaucheria DC. I39.

- de baryana Wor. V, 39. I4I.

- dichotoma Ag. I40. 
Vaucheria geminata DC. I 4 I .

- ornithocephala Ag. I 40.

- racemosa DC. $14 \mathrm{I}$.

- repens Hass. V, 37. 140.

- sessilis DC. V, 38 . I $4 \mathrm{I}$.

- terrestris Lyngb. I41.

Vaucheriaceae I39.

Veilchenstein $13 \mathbf{I}$.

Volvocaceae I 09 .

Volvoceae I I6.

Volvox (I IO) I I 8.

- aureus Ehrbg. IV, 3 I. I I 8 .

- globator L. IV, 30. I 18.

Vorticella Ehrbg. 40I.

- campanula Ebg. XIII, 26 b. 402.

- convallaria Ehrbg. XIII, $26 \mathrm{c}$. 402.

- microstoma Ehrbg. XIII, 26 a. (I 2. 2 I. 346) 40 I.

- monilata Tat. XIII, 26 e. 402.

- nebulifera Ehrbg. XIII, 25. 402.

- patellina Ebg. XIII, 26 d. 401.

Vorticellidina 398.

Vorticellina 397 .
Wimperinfusorien 342 .

Wimperlinge 342 .

Wurzelfüssler $25 \mathrm{I}$.

Xenococcus Thur. 58 .

- kerneri Hansg. 1, 45. 58.

Zachariasia Lemmerm. 53 (242).

- endophytica Lem. I, 32. 53.

Zickzackbandalge I 88 .

Zoogloea I, 25. 20. 26 .

Zoothamnium St. 403 .

- affine St. 404 .

- arbuscula Ehrbg. XIII, 29. 403.

- parasiticum St. 403 .

Zygnema Kg. 177 .

- cruciatum Ag. 177.

- pectinatum Ag. VI, 42. 177.

- stellinum Ag. 177.

Zygnemaceae I I I.

Zygnemeae 172.

Zygomyceten 246 .

Zygogonium De By. I77.

- ericetorum Kirchn. V1, 43. 177.

Zygoselmis nebulosa Duj. XI, 40. 326. 


\section{Erläuterungen}

$\mathrm{zu}$

\section{Tafel I-XVI}

[Die eingeklammerte Zahl mit dem $\rtimes$-Zeichen bedeutet die etwaige Vergrösserung; die Zahl am Ende jeder Figurenerklärung verweist auf die Seite im Texte.] 


\section{Tafel I}

\section{Bacteriaceae (Bakterien)}

Fig. I Ascococcus billrothi Cohn; Kolonie; nach F. Cohn $(35 \nsucc$ ) S. 34

, 2 Streptococcus roseus (Win.); nach Winogradsky $(400>$ ) S. 34

" 3 Strept. erysipelatos Fehleisen; nach Migula (500><) S. 34

" 4 Lampropedia rosea (Win.); nach Winogr. $(400 \succ)$ S. 35

" 5 Sarcina spec.; nach Eyferth $(300 \times)$ S. 35

" 6 Micrococcus ruber Mig.; nach Winogr. $(400 \times)$ S. 36

" 7 Lamprocystis roseo-persicina Schroet.; a) junge Kolonie; b) etwas ältere, im opt. Durchschnitte; c) unregelmässiges Stück einer älteren, zerrissenen Kolonie; Orig. $(200<)$ S. 36

Thiodictyon elegans Win.; Stückchen eines Netzes; nach WV inogr. $(400>)$ S. 37

Chromatium okeni Py.; ein Individuum davon in Teilung begriffen; Orig. $(450 \times)$ S. $3^{8}$

Rhabdochromatium roseum Win.; nach Winogr. (450 \) S. 39

Bacillus subtilis Cohn; a) auskeimende Spore (800 $\chi)$; b) Schwärmer mit Cilien; nach einem gefärbten Präparate $(800 \rtimes)$; c) desgl., mehrere zusammenhängend $(800 \times)$; d) sog. Kahmhaut, aus ruhenden, zu Fäden ausgewachsenen Schwärmern bestehend (I5O $<$ ); e) Fadenstücke mit Sporen; $(800<$ ) nach A. Fischer; S. 39

Myconostoc gregarium Cohn; ein Faden in seiner Gallerthülle; nach F. Cohn $(600>)$ S. 40

Microspira comma Schroeter; nach A. F is cher (I000 $\succ$ ) S. 4I

Spirillum sanguineum Cohn; wie es ohne Färbung erscheint; Orig. (250×) S. 4 I

Sp. rugula Winter; gefärbt; nach einer Photogr. v. Günther (I000 $\Varangle$ ) S. 42

Spirochaete plicatilis Ehrbg.; nach Macé (400>) S. 42

Sphaerotilus natans $\mathrm{Kg}$; a) Fäden an einem Pflanzenstengel befestigt; nach C. Mez (nat. Gr.); b) einzelne Fäden; nach Eyferth $(400 \chi)$ S. 44

Cladothrix dichotoma Cohn; a) ein Räschen mit einigen Fäden; nach Migula $(40>)$; b) Fadenenden, z. T. spiralig gewunden; nach Eyferth $(250 \times)$; c) Schwärmerbildung: bei einigen Zellen sind schon die seitlich inserierten Geisseln ausgebildet; nach einem gefärbten Präparate; von A. Fischer $(500>)$ S. 44

Glaucothrix putealis Kirchn.; nach Kirchner $(500 x)$ S. 45

Thiothrix nivea Win.; a) Fadenende mit Stäbchen-Konidienabschnürung; b) junger Faden, an einem Ende festgeftet; nach W in o gr. $(400>) \mathrm{S} .45$

Leptothrix parasitica $\mathrm{Kg}$; zwei Fäden, auf einer Alge festsitzend; Orig. $(400>)$ S. 46

Gallionella ferruginea Ehrbg.; a) gewöhnliches Aussehen bei schwacher Vergr. $(325>)$; b) einzelner Faden; nach Migul a $(650>)$ S. 46

Crenothrix polyspora Cohn; a) festsitzendes Räschen; an einzelnen $f$ äden sind die Tochterkonidien wieder ausgekeimt $(45 \times) ; \mathrm{b}, \mathrm{c}, \mathrm{d})$ Fadenenden mit Bildung von Mikro- und Makrokonidien; nach Migula (500) S. 47

Beggiatoa alba Trev.; a) Stückchen eines Fadens mit Schwefellkörnchen; Orig. $(450>)$ : b) Faden, dessen Schwefel durch Schwefelhunger entfernt ist; Querwände sichtbar; nach Migula $(450>$ ) S. 48

Zoogloea-Form eines Süsswasserbaktcriums, sog. Zoogloea ramigera der Autoren; nach Cienkowski $(90 \rtimes)$ S. 26

\section{Schizophyceae (Blaualgen)}

\section{Chroococcaceae}

Chroococcus turgidus Naeg.; nach Kützing $(300 \times)$ S. 52

Synechococcus aeruginosus Naeg.; nach $\mathrm{Na}$ eg eli $(200 \times) \mathrm{S} .52$ 
Fig. 28 Chroothece richteriana Hansg.; einzelne Zelle mit ausgeschiedenem Gallertfusse; nach $\mathrm{Hansgirg}(250>)$ S. 53

" 29 Dactylococcopsis rhaphidioides Hansg.; nach Hansgirg (stark) S. 53

Gloeocapsa polydermatica Kg.; Orig. $(300 \times)$ S. 53

Gloeothece linearis Naeg.; nach Na e geli (stark) S. 53

Zachariasia endophytica Lemmerm.; nach Lemmermann aus Kirchner $(400 \times)$ S. 53

" 33 Aphanocapsa pulchra Rabh.; nach Naegeli (stark) S. 54

" 34 Aphanothece stagnina A. Br.; a) u. b) grössere Lager der Alge (6/1); c) ein kleineres Lager; nach $\mathrm{H}$ ansgirg $(450 \times)$ S. 54

" 35 Aph. microscopica Naeg.; nach Naegeli (125 ×) S. 54

Microcystis flos aquae Kirchn.; nach Kirchner $(300 \times)$ S. 55

Clathrocystis aeruginosa Henfr.; a) eine jüngere Kolonie im Gallerthofe; nach C. Schröter $(175 \times)$; b) u. c) ältere zerrissene Lappen $(30 \times)$; d) einzelne Zellen $(300 \times)$; nach Kirchner; S. 55

Gomphosphaera aponina $\mathrm{Kg}$; ; a) Lager, etwas breit gedrückt $(300 \times)$; b) einzelne Zellen des Randes (stärker vergr.); nach Kützing; S. 55

" 39 .Coelosphaerium kuetzingianum Naeg.; a) kleinere Kolonie; nach $\mathrm{H}$ ansgirg $(200 \times)$; b) grössere Kolonie; nach Kirchner $(250 \times)$ S. 55

Merismopedia glauca Naeg.; nach Naeg eli (stark) S. 56

Holopedium irregulare Lagerh.; a) von oben, b) von der Seite gesehen; nach Lagerheim aus Kirchner $(250 \times)$ S. 56

Tetrapedia gothica Reinsch; nach Kirchner $(700 \times)$ S. 56

T. emarginata B. Schröd.; a) kleine, b) grössere Kolonie; c) Zelle im Durchschnitt; nach B. Schröder $(700 \times)$ S. 57

Oncobyrsa rivularis Menegh.; a) Blättchen einer Aneura pinnatifida (eines Lebermooses) mit Polstern der Alge; nach Moebius ans Hansgirg $(14 \times)$; b) ein Lager von oben gesehen $(125 \times)$; c) einzelne Zellen eines Lagers in ihren Gallerthüllen; nach Hansgirg $(325 \times)$ S. 57

\section{Chamaesiphoneae}

Fig. 45 Xenococcus kerneri Hansg.; auf einer anderen Blaualge; nach Hansgirg (stark) S. $5^{8}$

" 46 Pleurocapsa cuprea Hansg.; nach Hansgirg $(250 \times)$ S. 58

" 47 Clastidium setigerum Kirchn.; a) jüngeres, b) älteres Stadium; , letzteres mit Zerfall in Konidien; nach Kirchner $(290 ×) \mathrm{S} .5^{8}$

" 48 Chamaesiphon confervicola A. Br.; z. T. mit Konidienbildung; nach Borzì aus Kirchner $(330>)$ S. 59

" 49 Godlewskia aggregata Jancz.; auf Zellen von Batrachospermum; nach Janczewski $(310>)$ S. 59 


\section{Tafel II}

\section{Hormogoneae}

\section{Oscillatoriaceae}

$\mathrm{GZ}=$ Grenzzelle; $\mathrm{Sp}=$ Spore

Fig. I Oscillatoria limosa Ag.; nach Gomont $(300 \times)$ S. 62

12 Osc. splendida Grev.; nach Gom. $(300 \times)$ S. 63

$" 3$ Osc. tenuis Ag.; nach Gom. $(300 \times)$ S. 62

$" 4$ Arthrospira jenneri Stizenb.; nach Gom. (300 ×) S. 63

" 5 Spirulina maior Kg.; nach Gom. $(400 \times)$ S. 63

" 6 Phormidium subfuscum $\mathrm{Kg}$; ; nach Kirchner $(290 \times) \mathrm{S} .65$

" 7 Hopheothrix luteritia $\mathrm{Kg} \cdot$. $)$ eine Anzahl Fäden in ihren $\mathrm{Sc}$

$" 7 \quad$ b) ein einzelner Faden; nach Gom. $(560>)$ S. 65

" 8 Symploca muralis Kg.; nach Gom. $(300 \times)$ S. 66.

" 9 Hydrocoleum homoeotrichum Kg.; nach Gom. (190×) S. 66

" 10 Symplocastrum friesi Kirchn.; nach Gom. $(300>)$ S. 66

" II Inactis fasciculata Grun.; a) ein Fadenbüschel $(300 \times)$;

"II Faden; nach Gom. $(560 \times)$ S. 67

Schizothrix muelleri Naeg.; a) einige Fäden mit ihren Scheiden $(50 \times)$;

b) Ende eines einzelnen Fadens; nach Gom. (I Io $×$ ) S. 67

Microcoleus paludosus Gom.; nach Gom. (300 $\Varangle)$ S. 68

Micr. vaginatus Gom.; nach Gom. (300>) S. 68

\section{Nostocaceae.}

Fig. 15 Isocystis infusionum Borzi; nach Hansgirg $(300 \times)$ S. 69

" 16 Nostoc paludosum $\mathrm{Kg}$; a) älterer Zellfaden mit Sporen; b) junger, eben aus einer Spore ausgekeimter Faden; nach Janczewski aus Kirchner; $(250 \times)$ S. 70

Nodularia maior Kirchn.; nach Kützing (175 $>$ ) S. 7 r

Anabaena flos aquae Bréb.; a) freischwimmende Gallertkugel mit gewundenen Anab.-Fäden; nach C. Schröter $(150 \times)$; b) Fadenstück mit Grenzzelle und c) Spore $(412 \times)$; bei b) sind in den Zellen die Gasvakuolen sichtbar; nach Klebahn; S. 7I

An. oscillarioïles Bory; nach Hansgirg $(200 \times)$ S. 72

Aphanizomenon flos aquae Ralfs; a) ein freischwimmendes Faden-Bündel; nach C. Schröter $(60 \times)$; b) ein Fadenstück mit Spore, Grenzzelle und Gasvakuolen-haltigen vegetativen Zellen; nach Klebahn (412 $メ)$ S. 72

Cylindrospermum maitus $\mathrm{Kg}$; mit Spore und Grenzzelle; nach Hansgirg $(50 \times)$ S. 73

Microchaete goeppertiana Kirchn.; nach Kirchner $(300>)$ S. 73

Desmonema wrangeli Born. et FI.; a) ein Faden-Büschel; nach Hansgirg (nat. Gr.); b) einzelne Fäden; nach Borzì aus Kirchner (135 $>$ ) S. 73

\section{Scytonemaceae}

Fig. 25 Plectonema tommasinionum Bornet; a) ein Stückchen eines Wassermooses mit einem Algenbüschel (nat. Gr.); b) einige isolierte Fäden; nach Kützing (150×) S. 74

"26 Scytonema crispum Bornet; nach Kützing ( $150 ×$ ) S. 75 
Fig. 27 Petalonema alatum Berk.; nach Kützing (150 >) S. 75

" 28 Tolypothrix lanata Wartm.; Art der Zweigbildung gut sichtbar; nach Hansgirg $(210>)$ S. 76

"29 Hydrocoryne spongiosa Schwabe; nach Hansgirg (I $75>$ S. 76

\section{Stigonemataceae}

Fig. 30 Mastigocladus laminosus Cohn; nach Cohn aus Kirchner (250>) S. 77 Hapalosiphon pumilus Kirchn.; nach Hansgirg (150 × ) S. 77

Stigonema ocellatum Thuret; nach Kützing $(50 \times)$ S. 78

Capsosira brebissoni $\mathrm{Kg}$; a) Pflanzenstengel mit einer Ansiedelung der Alge $(2 \times)$; b) ein verzweigtes Fadenstück $(75 \times)$; an dem inneren der beiden hochstehenden $\mathrm{Z}$ weige ist etwa in der Höhe von GZ die Grenzzelle zu sehen; nach Borzì aus Kirchner $(75 \times)$ S. 78

Nostochopsis lobata Wood; a) ein Wassermoos mit den gallertigen Kolonien der Alge $(3 / 4 \times)$; b) Teil eines Lagers mit den verzweigten Fäden; nach Bornet aus Kirchner $(165><)$ S. 78

\section{Rivulariaceae}

Fig. 35 Leptochaete nidulans Hansg.; mit Vermehrungszellen am Grunde; nach Hansgirg $(440>)$ S. 79

", 36 Amphithrix ianthina Born. et Fl.; nach Kirchner $(290>)$ S. 79

" 37 Homoeothrix juliana Kirchn.; ein polsterförmiges Lager an einem Wassermoose; nach Kützing (nat. Gr.) S. 80

" 38 Calothrix fusca Born. et Fl.; nach Hansgirg (110 $>$ ) S. 80

Dichothrix gypsophila Born. et Fl.; nach Kirchner $(290 \times)$ S. 81

40 Rivularia echinulata Engl. Bot.; a) eine freischwimmende, kugelformige Kolonie $(30 \rtimes)$; b) Basalenden einiger Zellfäden mit Sporen und Grenzzellen; nach P. Richter aus C. Schröter $(175 \succ)$ S. 81

Riv. minutula Born. et Fl.; nach Kützing ( $150><$ ) S. 82 


\section{Tafel III}

\section{Chlorophyceae}

\section{Pleurococcaceae}

Fig. I Dactylothece brauni Lagerh.; nach Hansgirg $(250 \times)$ S. 90

" 2 Palmodictyon viride $\mathrm{Kg}$; ; a) grösseres Stück einer Kolonie $(50 \times)$; b) einzelne Zellen nach $\mathrm{K}$ ützing $(150 \times)$; S. 90

$" 3$ Schizochlamys gelatinosa A. Br.; nach de Wildeman $(225 \times)$ S. 9 I

$" 4$ Kirchneriella lunata Schmidle; nach Schmidle $(200 \times)$ S. 91

" 5 Geminella interrupta Lagerh.; a) vier vegetative Zellen in Gallerthülle; b) zwei Dauerzellen; nach Hansg. $(225>)$ S. 9 I

" 6 Staurogenia lauterborni Schmidle; nach einem gefärbten Präparate von B. Schröder $(315 \rtimes)$ S. 91

Dimorphococcus lunatus A. Br.; eine kleine Kolonie; nach Rabenhorst $\left(45^{\circ} \times\right)$ S. 9 I

8 Urococcus hookerianus Berk. et Hass.; nach Rabenh. (250×) S. 92

9 Acanthococcus hirtus Reinsch; nach Reinsch (160 $>$ ) S. 92

Io Eremosphaera viridis De By.; nach De Bary $(150 \times)$ S. 92

I I Pleurococcus vulgaris Menegh.; einzelne in Teilung begriffene Zellen; nach Wille $(325 \times)$ S. 92

I2 Stichococcus bacillaris Naeg.; a) in Fadenform wachsend $(340 \times)$; b) in
Kokkenform $(590 \times)$; nach John af Klercker; S. 92 Kokkenform $(590 \times)$; nach John af Klercker; S. 92
ephrocytium agardhianum Naeg.; a) eine Kolonie von vier Zellen;

"I 3 Nephrocytium agardhianum Naeg; a) eine Ko
b) einzelne Zelle (150 $>$ ) nach Naegeli; S. 93

Oocystis solitaria Wittr.; vierzellige Familie a) vor b) nach der Zerreissung der Muttermembran; nach Hansg. (300 X) S. 93

Polyedrium enorme De By.; nach Ralfs $(300<)$ S 93

I6 Pol. trigonum Naeg.; nach Hansg. $(300><)$ S. 94

Schroederia setigera Lemmerm.; nach B. Schroeder $(315 \rtimes)$ S. 94

Rhaphidium polymorphum Fres.; Orig. (210 ×) S. 94

Selenastrum bibraianum Reinsch; a) junge Kolonie; b) dass., etwas älter; c) einzelne Zelle, vor Beginn der Teilung; d) dass., kurz vor Zerfall in die einzelnen Tochterzellen; Orig. (210>) S. 94

Cohniella staurogeniaeformis B. Schröd.; a) eine vierzellige Familie; b) dass. im Profil; nach B. Schröder $(375 \times)$ S. 94

Scenedesmus quadricauda Bréb.; eine vierzellige Familie; nach Senn $(400 \times)$ S. 95

Sc. obliquus Kg.; eine vierzellige Familie; nach Senn $(500 \rtimes)$ S. 95

Crucigènia rectangularis Naeg.; eine aus sechzehn Zellen besteliende Kolonie; nach Hansg. $(300>)$ S. 95

Coelastrum sphaericum Naeg.; a) ausgewachsene Kolonie (175 $>$ ); b) junge, achtzellige Kolonie $(300 \times)$; Orig.; S. 95

Sorastrum spinulosum Naeg.; eine ältere Kolonie; nach Naegeli; $(225 \times)$ S. 96

Actinastrum hantzschi Lagerh.; a) eine mittelgrosse Kolonie (3I5 $>$ ); b) eine Zelle, stärker vergrössert, um die Art der Verbindung mit der Nachbarzelle zu zeigen; nach B. Schröder; S. 96

Chodatella longiseta Lemmerm.; nach Lemmermann $(375>)$ S. 96

Richteriella botryoïdes Lemmerm. var. fenestrata; ein sechszehnzelliges Coenobium; nach B. Schröder $(315 \succ)$ S. 97

\section{Tetrasporaceae}

Fig. 29 Dactylococcus infusionum Naeg.; Orig. (250×) S. 99

"30 Kentrosphaera facciolae Borzl; nach Hansg. $(225>$ ) S. 99

"3I Lagerheimia wratislaviense B. Schroeder; nach B. Schröder $(325 \times)$ S. 99 
Fig. 32 Golenkinia radiata Chodat; nach Lemmermann (300 $>$ S. 99 Gloeocystis gigas Lagerh.; a) Gallertkolonie (1/2 natürl. Gr.); b) zwei
Zellfamilien $(175<<)$; nach Kützing; S. I00 Inoderma maius Hansg.; a) Teil eines gallertigen Lagers $(75 \times)$; b) einzelne
Zelle $(250 \times)$; nach Hansg.; S. 100

" 35

Tetraspora gelatinosa Desv.; a) Teil eines zerschlitzten Lagers $(50 \times)$; b) ein kleineres Stückchen davon mit den sich teilenden Zellen $(250>)$; c) ein Schwärmer $(250 \times)$; Orig.; S. 100

" 36 Chlorosphaera angulosa Klebs; zwei Zell-Lager; nach Kützing (150 × S. IOI

n 37

Botryococcus brauni $\mathrm{Kg}$.; rechts eine kugelige Zellfamilie $(75 \nsucc)$; links ein Stück davon, etwas gequetscht $(225>)$; Orig.; S. 102

" 38 Palmodactylon varium Naeg.; ein Haufen schlauchförmiger Kolonien; nach $\mathrm{Naegeli}(50 \rtimes)$ S. 102

" 39 Apiocystis brauniana Naeg.; a) eine grössere Blase mit sich teilenden Zellen $(50>)$; b) eine Schwärmspore $(300 \times)$; nach $\mathrm{Naegeli} ; \mathrm{S}$. 102

" 40 Hormotila mucigena Borzi; a) eine verzweigte Kolonie $(325 \times)$; b) einzelne Zelle, ihre Schwärmsporen entlassend $(660 \times)$; nach Borzi aus Wille; S. 102

"4I Mïschococcus confervicola Naeg.; a) verzweigte Kolonie mit Zellen an den Zweigenden; b) ein Schwärmer; nach Borzi (300 <) S. 103

" 42

Dictyosphaerium pulchellum Wood; eine vielzellige Kolonie; um je vier Tochterzellen eine besondere Gallerthülle, die die darunterliegenden Zellen.z. T. verdeckt, wodurch diese etwas gescheckt erscheinen; nach einem gefärbten Präparate von Senn abgeändert $(375>$ S. I03. 


\section{Tafel IV}

\section{Chlorophyceae}

\section{Protococcaceae}

Fig. I Dicranochaete reniformis Hieron.; a) eine einzelne Zelle mit den verzweigten Gallertborsten $(500 \times)$; b) ein Stückchen eines SphagnumBlattes mit mehreren Zellen der Alge besetzt [die bei dieser Vergr. kaum sichtbaren Borsten sind weggelassen] $(50 \times)$; nach $\mathrm{H}$ i e ronymus; S. 105

$\because 2$ Protosiphon botryoïdes Klebs; eine Zelle mit dem wurzelförmigen Schlauche; nach Klebs $(50 \times)$ S. 105

" 3 Peroniella hyalothecae Gobi; eine einzelne gestielte Zelle, auf einem Faden von Hyalotheca festsitzend; daneben ein Schwärmer; nach Gobi aus Wille $(185 \times)$ S. 105

" 4 Characium naegelii A. Br.; der Inhalt der Zelle ist schon in Schwärmsporen zerfallen; nach Hansgirg $(300 \times)$ S..106

Ophiocytium arbuscula Lemmerm.; a) eine bäumchenförmige Kolonie; nach de Wildeman; b) eine einzelne Zelle mit den wandständigen Chromatophoren; nach Francé; c) eine Zelle mit austretenden Schwärmern; nach A. Braun (alles $300 \times$ ) S. 107

$\begin{array}{rr}" & 6 \\ " & 7 \\ " & 8 \\ " & 9 \\ " & 10\end{array}$

Oph. maius Naeg.; nach Lemmermann $(225 \times)$ S. 107

Oph capitatum-Wolle; nach Lemmermann $(305 \times)$ S. 107

Pediastrum simplex Meyen; nach de Wildeman $(250>)$ S. 108

Ped. duplex Meyen; Orig. $(210 \times)$ S. 108

Hydrodictyon utriculatum Lagerh.; a) Stück eines Netzes mit mehreren vielkernigen Zellen $(60>)$ nach $\mathrm{Klebs}$; b) Teil eines aus zahlreichen langen Zellen bestehenden Netzes bei schwacher Vergr.; nach de Wildeman; c) eine einzelne Zelle, deren im Innern gebildete, geschlechtslose Schwärmer sich zu einem neuen Netze zusammenlegen (100 $\backslash)$; d) ein einzelner Schwärmer; nach Hansgirg; S. 107

\section{Volvocaceae}

Es bedeuten: $\mathrm{cv}=$ kontraktile Vakuole; $\mathrm{N}=\mathrm{Kern}$; $\mathrm{Oc}=$ Augenfleck; Py $=$ Pyrenoid

Fig. II Pyramidomonas tetrarhynchus Schmarda; nach Dill (200×) S. I12

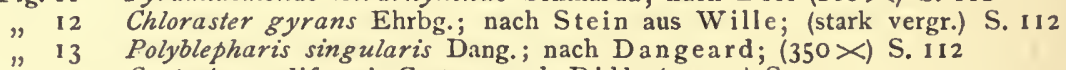

"14 Carteria cordiformis Carter; nach Dill; $(200 \times)$ S. II 3

"I 5 Cylindromonas fontinalis Hansg.; $\mathrm{Chr}=$ Chromatophor; nach $\mathrm{Hansgirg}$ $(250 \times)$ S. II 3

" 16 Chlamydomonas brauni Gorosch.; a) im freischwimmenden Zustande; b) in Teil .ng begriffen, innerhalb einer Gallerthülle; nach G or o sc hank in;

$(375 \times)$ S. I14
Chl. steini Gorosch.; nach Gorośchankin; $(37 j \times)$ S. 114

"17 Chl. steini Gorosch.; nach Goroschankin; $(375 \times)$

" 18 Chlorangium stentorinum Stein; a) in Koloniebildung begriffen (160 $>$ ) nach Cienkowski; b) einzelnes, freischwimmendes Exemplar $(325 \times)$; c) dass., nach der.Festheftung, in Teilung begriffen $(325 \times)$; b) und c) n'co Stein, alles aus Wille; S. II5

"20 Chlorogonium euchlorum Ehrbg.; nach Klebs (200×) S. 115

" 2 I Polytoma uvella Ehrbg.; a) einzelnes Exemplar; Orig.; b) freischwimmendes

Exemplar mit entwickelten Tochterindividuen im Innern; nach Dangeard (210×) S. 115 
Fig. 22 Phacotus angulosus Stein; a) von der Breitseite; b) von der Schmalseite gesehen; nach I) angeard $(290 \times)$ S. I16

" 23 Coccomonas orbicularis Stein; nach Stein $(325 \times)$ S. 116

" 24 Pteromonas alata Seligo; a) von der Breitseite; b) von der Schmalseite gesehen; nach Seligo; (stark vergr.); S. 116

, 25 Spondylomorum quaternarium Ehrbg.; nach Stein (325 ×) S. 117

" 26 Gonium pectorale O. F. Müll.; die Verbindungen zwischen den Zellen nur schwach angedeutet; Gall = Gallerthülle; Orig. $(210 \times)$ S. 117

Stephanosphaera pluvialis Cohn; nach Hieron ymus $(425 \succ)$ S. 117

Pandorina morum Bory; eine kugelförmige Kolonie; Orig. $(250 \times)$ S. I i 8

Eudorina elegans Ehrbg.; eine kugelförmige Kolonie mit den von einander abstehenden Zellen; nach Hansgirg (125 ×) S. 118

Volvox globator L.; a) grosse geschlechtliche Kolonie: a) männliche Geschlechtszellen mit Spermatozoiden-Bündeln und zwar a: von oben, $a^{\prime}$ : von der Seite gesehen, a": das Bündel hat sich aufgelöst, und die Spermatozoiden beginnen auszutreten und sich in der ganzen Kugel zu verteilen; einige umkreisen schon die Eier (b); $a^{\prime \prime \prime}$ : die männliche Zelle hat sich schon fast zurückgebildet; $\mathrm{b}=$ weibliche Geschlechtszellen: Eier; $(125 \times)$ nach F. Cohn; b) Stückchen der Kugeloberfäche mit einigen vegetativen Zellen; vgl. die Art der Plasma-Verbindung; nach Kle in (stärker vergr.) S. 118

„3IVolv. aureus Ehrbg.; Stückchen der Oberfäche einer Kolonie mit einigen Zellen, die Art der Plasmaverbindung zeigend; Orig. $(210 \times)$ S. 118 


\section{Tafel V}

\section{Chlorophyceae}

\section{Ulvaceae}

Fig. I Monostroma bullosum Thuret; a) Stückchen eines Lagers $(340 \times)$; b) Gameten $(480 \times)$; nach Reinke; S. I2t

2 Prasiola crispa $\mathrm{Kg}$; ; a) Thallusfläche bei ganz schwacher Vergrösserung $(2 \times)$; b) Stückchen einer Zellfläche $(75 \times)$; c) ein Stückchen davon: die Faden- (Hormidium-) Form geht in die doppelreihige (Schizogonium-) Form über $(75 \times)$; nach I m häuser; S. I 2 I

, 3 Protoderma viride $\mathrm{Kg}$; ; ein wenigzelliger Thallus; nach Borzi (150×) S. $12 \mathrm{I}$

$" 4$ Enteromorpha intestinalis Linck; a) Habitusbild nach $\mathrm{R}$ abenhorst ( $1 / 2$ nat. Gr.); b) Flächenbild; c) Querschnitt durch den Thallus (b u. c 210X) Orig.; S. 122

\section{Ulotrichaceae}

Fig. 5 Ulothrix zonata $\mathrm{Kg}$; ; a) u. b) zwei vegetative Zellfäden; c) (Geschlechtliche) Gameten; d) Zoosporen; alles stark vergr.; nach Dodel; S. 123

, b) Schwärmspore (stärk. als a vergr.); nach La ge r he im aus Will e; S. I 24 Bumilleria sicula Borzi; a) vegetativer Faden: bei $\mathrm{x}$ sind die H-förmig zerrissenen alten Zellhäute gut sichtbar $(250 \times)$; b) Zoospore $(500 \times)$; nach Klebs; S. 124

Conferva bombycina Wille; vegetativer Faden; nach $\mathrm{H}$ an sgirg (230 <) S. 124 Microspora amoena Rabh.; zwei Stückchen eines Fadens vor und während der Teilung; nach Wille $(240>)$ S. I 24

Binuclearia tatrana Wittr.; a) Faden in schneller Teilung begriffen: an den Enden der Zellen die sog. „Kerne" — wohl nur Gerinnungserscheinungen - zu erkennen; nach Wittrock; b) Faden mit auskeimenden Dauerzellen; nach Wille; (beide 160 ×) S. I25

\section{Chaetophoraceae}

Draparnaldia plumosa Ag.; nach Hansgirg (150 <) S. 127

Chaetophora elegans Ag.; nach Hansgirg (150>) S. 128

Chaet. endiviaefolia Ag.; ein gelapptes Lager (1/2 nat. Gr.) nach $\mathrm{Raben-}$ horst; S. 128

Gloeoplax weberi Schmidle; a) junge, noch tädige Kolonie; b) ältere Kolonie mit schon abgerundeten Zellen; nach Schmidle $(300 \nsucc)$ S. 128

Stigeoclonium tenue $\mathrm{Kg}$; bei einseitiger Beleuchtung gewaclisen; nach $\mathrm{Klebs}(500 \times)$

Chaetonema irregulare Now.; nach Kirchner (130 $\nsim$ ) S. 129

Aphanochaete repens A. Br.; a) Stückchen einer Pflanze $(250 \times)$; nach Klebs; b) junges, einzelliges Pflänzchen $(4 I 2 \succ)$ nach Klebahn; S. I 30

Chaetosphaeridium pringsheimi Kleb.; [die Fäden sind bei dieser wie der folgenden Figur in der Natur bedeutend länger als sie gezeichnet sind] nach Klebahn $(412 \ngtr)$ S. 130

Conochaete klebahni Schmidle; [cf. Fig. 18] eine wenigzellige Kolonie auf einer andern Alge festsitzend; nach Sch midle (sehr stark vergr.) S. I 30

Chlorotylium cataractarum $\mathrm{Kg}$; nach $\mathrm{Rabenhorst} \mathrm{(150<)} \mathrm{S.} 130$

Microthamnion kuetzingianum Naeg.; ein junges Exemplar; Orig. $(225 \times)$ S. 131

Micr. strictissimum Rabh.; ein Stückchen einer Pflanze; nach $\mathbf{R}$ aben horst (stark vergr.) S. I3I

Gongrosira debaryana Rabh.; Stück eines Thallus mit einem Zoosporangium; frei nach Wille $(200 \times)$ S. 131

Phaeothamnion confervicolum Lagerh.; a) ganze Pflanze mit zwei entleerten Zoosporangien $(250 \times)$; b) Ende eines Zweiges $(450 \times)$; nach. Lagerheim aus Wille; S. I3I 


\section{Mycoideae}

Fig. 25 Chaetopeltis orbicularis Berth.; etwas schematisiert und verändert nach Berthold $(125 \times)$ S. 132

\section{Cylindrocapsaceae u. Oedogoniaceae}

Fig. 26 Cylindrocapsa involuta Reinsch; a) ein Stückchen Faden mit vegetativen Zellen; nach Reinsch; b) ein Fadenstückchen mit Oogonium: darin ein $\mathrm{Ei}$ (o) und einige eingedrungene Spermatozoiden (sp); nach Cienkowski aus Wille $(380 \times)$ S. 132

Oedogonium pringsheimi Cram.; a) weiblicher Faden mit zwei Oogonien, von denen eins durch einen Querspalt geöffnet ist; b) männlicher Fadell mit mehreren geöffneten Antheridien; nach $\mathrm{Hansgirg}(150 \times) \mathrm{S} .133$

Oedogonium spec.; a) eine freischwimmende Zoospore mit dem vorderen Cilienkranze; b) gekeimte Zoospore, bald nach dem Festsetzen; Orig.; $(85 \times)$ S. 133

Bulbochaete rectangularis Wittr.; Stückchen eines Fadens mit Geschlechtsorganen : $\mathrm{a}=$ unbefruchtetes $\mathrm{Ei} ; \mathrm{b}=$ Oospore, entleert: ihre skulpturierte Aussenhaut deutlich sichtbar; $c=Z$ wergmännchen mit mehreren entleerten Antheridien; nach Hansgirg (150 メ) S. 135

\section{Coleochaetaceae}

Fig. 30 Coleochaete pulvinata A. Br.; Stückchen eines Thallus mit Geschlechtsorganen; a u. a" Oogonien, deren Hals schon geöffnet ist: a noch unberindet, $a$ " mit beginnender Berindung; $b$ : Antheridien mit und ohne Inhalt; c) Borste mit der scheidigen Basis; nach Pringsheim $(140 \times)$ S. 135

Col. scutata Bréb.; die'Hälfte eines ungeschlechtlichen Thallus mit nur vegetativen Zellen; die Borsten sind in der Natur verhältnismässig länger; nach Pringsheim (125 × S. 136

\section{Cladophoraceae}

Fig. 32 Chaetomorpha herbipolensis Lagerh.; Alter Faden mit nur einer vegetativen Zelle: die andern waren Zoosporangien, die ihren Inhalt schon durch die seitlichen Oeffnungen entlassen haben; nach Lagerheim aus Will e (stark vergr.) S. 136

Rhizoclonium fontinale $\mathrm{Kg}$; ein vegetativer Faden; nach $\mathrm{Hansgirg}$ $(150 \times)$ S. 137

" 34 Cladophora glomerata Kg.: Stückchen eines verzweigten Fadens; nur der rechte Ast ist ausgeführt: hier sind am Ende zwei Zoosporangien ausgebildet, die sich basipetal entleeren: das äusserste entlässt gerade die zahlreichen zweiciligen Zoosporen aus der seitlichen Oeffnung: nach Hansgirg $(35 \times)$ S. 137

\section{Sphaeropleaceae}

Fig. 35 Sphaeroplea annulina Ag.: a) vegetativer Faden mit den ringförmigen Chromatophoren ( $\mathrm{N}=$ Kern; Py = Pyrenoid); nach Heinricher; b) derselbe Faden im Beginne der Eizellen-Bildung; c) reife Oospore; b u. c nach Cohn: alles aus Wille; $(100 \times)$ S. 138

\section{Siphoneae}

Fig. 36 Botrydium granulatum Grev.; ein aus dem Schlamme herauspräpariertes Exemplar mit einem Teile der "Wurzeln"; nach Hansgirg (ganz schwach vergr.) S. 139

" 37 Vaucheria repens Hass.; Ende eines Fadens, das sich in ein Zoosporangium umgebildet hatte: die Zoospore im Augenblicke des Austretens; etwas modifiziert nach $\mathrm{Klebs}(60 \times) \mathrm{S}$. 140

" 38 Vauch. sessilis DC.: ein Stückchen Zellfaden mit einem entleerten Antheridium und zwei befruchteten Oogonien; nach Göt $z(150 \times)$ S. 141

Vauch. de baryana Wor.; ein Stückchen Zellfaden mit einem entleerten Antheridium und zwei befruchteten Oogonien; nach G ötz ( I I $0>$ ) S. 141 


\section{Tafel VI}

\section{Conjugatae}

\section{Desmidiaceae}

Fig. I Gonatozygon brebissoni De By.; zwei zusammenhängende Zellen; nach

De Bary (195 $\times$ ) S. I 45
Genicularia spirotaenia De By.; nach De Bary $(195 \times)$ S. 146

$\begin{array}{ll}" 2 & \text { Genicularia spirotaenia De By.; nach De Bary }(195 \times) \text { S. I46 } \\ " & 3 \text { Hyalotheca mucosa Ehrbg.; leere Schalen; nach Ralfs }(200 \times) \text { S. } 146\end{array}$

" $4 \quad H$. dissiliens Bréb.; eine Reihe von Zellen in der Schleimhülle; darunter der Querschnitt einer Zelle; nach Delponte aus Wille (200x) S. 146 Gymnozyga brebissoni Nordst.; nach De Bary $(375 \times)$ S. 146

$" \quad 5 \quad$ Gpondylosium depressim Arch.; Orig.; $(450 \times)$ S. 147

" 7 Didymoprium grevillei Kg.; in der Längsansicht und im Querschnitt; nach Delponte aus Wille $(200 \times)$ S. 147

Sphaerozosma vertebratum Ralfs; a) einige sich teilende Zellen in Flächenlage; b) die Zellen von der schmalen Seite gesehen; nach De Bary $(195 \times)$ S. 147

Sph. excavatum Ralfs; Flächenansicht; nach Ralfs $(200 \times)$ S. 148

Desmidium swartzi Ag.; a) Flächenansicht; b) Querschnitt; nach Delponte aus Wille $(200>-1)$ S. 148

Mesotaenium brauni De By.; in a sieht man das Chromatophor in Flächenansicht, in b im Profil; nach De Bary $(200 \times)$ S. 149

Spirotaenia condensata Bréb.; nach De Bary $(200 \times)$ S. 149

, 13

Closterium moniliferum Ehrbg.; a) von der Seite gesehen; nach Ralfs; b) Querschnitt, um den Bau des Chromatophoren zu zeigen; nach Naegeli $(125 \times)$ S. 154

Cl. kuetzingi Bréb.; Orig.; $(90 \times)$ S. 154

"I5 Penium interruptum Bréb.; a) von der Seite gesehen; b) schemat. Querschnitt; nach De Bary $(195 \times)$ S. 155

" 16 Cylindrocystis brebissoni Menegh.; a) Vegetative Zelle von der Seite gesehen; b) Zygospore, noch von den leeren Schalen der Zygoten umgeben; Orig.; $(150<)$ S. 155

Tetmemorus brebissoni Ralfs; a) von der Breitseite; b) von der Schmalseite gesehen; nach $\mathrm{R}$ alfs $(200 \times)$ S. 156

" I8 Pleurotaenium trabecula Naeg.; a) ganze Zelle (100 $>$ ); b) ihr Ende (etwas stärker vergr.); c) Stück aus der Mitte $(300 \times)$; nach N a e geli; S. 156

Docidium baculum (Bréb.); nach Delponte aus Wille $(150 \times)$ S. 157

" 20 Holacanthum cristatum Lund.; a) von der Seite gesehen; nach Ralfs; b) von oben gesehen; nach Delponte aus Wille $(200 \times)$ S. 158

Schizacanthum armatum Lund.; nach Ralfs $(200 \times)$ S. 158

Pleurotaeniopsis cucumis Lund.; nach Ralfs $(200 \times)$ S. 159

Arthrodesmus convergens Ehrbg.; von der Breit- und Schmalseite; nach Naegeli $(150 \times)$ S. 159

Arthr. incus Hass.; Zygospore mit den zwei leeren Zellhäuten; nach Ralfs $(150 \times)$ S. 159

Oocardium stratum Naeg.; a) die Kalkröhren mit ihren Zellen von oben gesehen $(300 \times)$; b) dieselben von der Seite gesehen $(200 \times)$; nach

Senn; S. I60
Cosmarium botrytis Menegh.; zwei in Teilung begriffene Zellen; a) die beiden Zellhälften haben sich soeben getrennt, und der Zellinhalt beginnt herauszutreten; in $\mathrm{b}$ treten $\left(\mathrm{I}^{1} !_{2}\right.$ Stunden später) auch die Chromatophoren schon hervor; um jede Zellhälfte $\mathrm{zu}$ einer neuen ganzen Zelle zu ergänzen, muss der Inhalt sich noch etwas mehr hervorwölben; nach De Bary $(195 \times)$ S. 163

Cosmarium ornatum Ralfs; eine ausgebildete Zygospore mit den leeren Zellhäuten; nach Ralfs $(200 \times)$ S. 163 
Fig. 28 Cosmocladium saxonicum De By.; eine Kolonie; nach De Bary aus Wille $(175>)$ S. 163

"29 Euastrum didelta Ralfs; a) von der Breitseite; b) von der Schmalseite gesehen; Orig. $(210><)$ S. 165

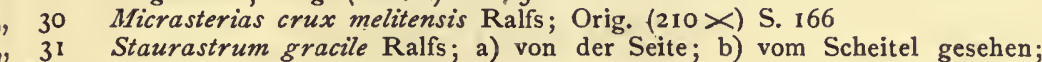
nach Ralfs $(200 \times)$ S. 170

St. cuspidatum Bréb.; vou der Seite gesehen; nach Ralfs $(200 \times)$ S. 170

St. dejectum Bréb.; a) etwas von der Seite gesehen; b) Scheitelanșicht; Orig.; $(210 \times)$ S. 170

Pleurenterium sexcostatum Lund.; a) von der Seite gesehen; b) Scheitelansicht der leeren Schale; nach Ralfs $(200 \times)$ S. 171

\section{Zygnemaceae}

Fig. 35 Spirogyra porticalis Cleve; drei nebeneinander liegende Zellfäden in Konjugation begriffen: einige Zellen haben noch ihre Chlorophyllbänder, die andern sind in Zygosporen-Bildung begriffen; Orig.; $(210 \times)$ S. 173

" $36 \mathrm{Sp}$. weberi Kg.; a) zwei Zellfäden in Konjugation: die eine Zelle links ist dabei übergangen; hier leiterförmige Konjugation; b) Verbindungen zweier Zellen desselben Fadens durch einen seitlichen Konjugationskanal; $(210 \times)$; c) eine "gefaltete“ Querwand, (stärker vergr.); Orig.; S. 175

$S p$. stictica Wittr.; zwei Zellfäden, die eine knieförmige Konjugation eingehen wollen; nach De Bary $(95>)$ S. 175

" 38 Mougeotia spec.; zwei Zellfäden, in denen das plattenförmige Chromatophor in Flächenansicht (a) und in Profilstellung (b) zu sehen ist; Orig.; $(210 \times)$ S. 175

„39 Moug. viridis Wittr.; Zygospore mit den noch ansitzenden konjugierenden Zellfäden; nach De Bary $(210 x)$ S. 176

$" 40$ Debarya glyptosperma Wittr.; zwei Zellfäden mit zwei in den Verbindungskanälen entstandenen Zygosporen; nach De Bary aus Wille (200×) S. 176

Mougeotiopsis calospora E. Palla; a) u. b) zwei vegetative Fäden mit den plattenförmigen Chromatophoren in verschiedenen Lagen: in beiden sind reichlich Oeltröpfchen sichtbar $(330 \times)$; c) zwei Zygosporen in den Konjugationskanälen zwischen zwei Zellıäden $\left(45^{\circ} \times\right)$; nach E. Palla; S. 176

Zygnema pectinatum Ag.; zwei Zellfäden mit einer Zygospore und einigen vegetativen Zellen mit den sternförmigen Chromatophoren; nach D e Bary $(95 \times)$ S. 177

Zygogonium ericetorum Kirchn.; Stück eines vegetativen Zellfadens; nach De Bary $(100 \times)$ S. 177 


\section{Tafel VII}

\section{Bacillariaceae. (Diatomeae)}

Mit Ausnahme der Figuren 1, 4, 32 und 52, wo der Inhalt mitgezeichnet ist, sind nur die verkieselten Schalen dargestellt. G-S = Gürtelseite; Sch-S = Schalenseite; wenn $a$ und $b$ vorhanden, dann bedeutet $a=G-S$ und $b=S c h-S$; die Abbildungen entstammen, wenn nichts angegeben, der Smith'schen Synopsis.

Fig. I Melosira varians Ag.; a': G-S; a" ebenso, mit Auxosporen (bei $\mathrm{x}$ ist solche schon mit Kieselmembran versehen); b: Sch-S; nach Pfitzer comb. $(250 \times)$ S. 183

Mel. arenaria Moore; G-S. (roo $メ)$ S. 184

" 3 Cyclotella kuetzingiana Thw.; a u. b $(250 \times)$ S. 185

" 4 Stephanodiscus hantzschianus Grun. (Herbstform); G-S; nach B.Schröder $(315 \times)$ S. 185

Attheya zachariasi J. Brun; (mit Dauerspore); G-S; nach B. Schröder $(315 \times)$ S. 187

Rhizosolenia longiseta Zach. (mit Dauerspore); G-S; nach B. Schröder $(315 \times)$ S. 186

Cylindrotheca gracilis Grun.; G-S; nach van Heurck aus Schütt $(235 \times)$ S. 186

\section{Diatomella balfouriana Grev.; a u. b; $(250 \times)$ S. I 87}

. Tabellaria flocculosa Kg.; a u. b $(200 \times)$ S. 188

Tab. fenestrata $\mathrm{Kg}$. (var. asterionelloïdes Grun.); a u. b (b etwas stärker vergr.); nach C. Schröter $(100>)$ S. 188

Tetracyclus brauni Grun.; a u. b; Orig. (400 $\Varangle)$ S. 188

Denticula elegans $\mathrm{Kg}$; Sch-S; nach van Heurck aus Schütt $(300 \times)$ S. 189

Meridion circulare Ag.; a u. b $(225>)$ S. 189

Diatoma vulgare Bory; a u. b $(200 \times)$ S. 190

Fragilaria mutabilis Grun. in drei verschiedenen Grössen; a u. b $(250 \times)$ S. 192

Frag. capucina Desmar; a u. b $(200 \nsim)$ S. 192

Frag. virescens Ralfs; a u. b $(180 \times)$ S. 192

Synedra ulna Ehrbg.; a u. b (200×) S. 193

Syn. capitata (Ehrbg.); Ende der Sch-S $(200 \times)$ S. 194

Asterionella formosa Hassall; $\mathrm{a}$ u. b; nach Heiberg aus C. Schröter $(230 \times)$ S. 194

Ast. gracillima Heiberg; a u. b; nach Heiberg aus C. Schröter $(325 \times)$ S. 194

Eun. diodon Ehrbg.; a u. b $(225 \times)$ S. 197

Achnanthes exilis Kg.; a) Kolonie in G-S auf Stiel; b') konkave, b") konvexe Sch-S $(400 \times)$ S. 198 Durchschnitt $(225 \times)$ S. 199

Navicula maior (W.Sm.); Sch-S $(200 \times)$ S. 205

Nav. mesolepta (W. Sm.); Sch-S (200×) S. 204

Nav. brebissoni Kg.; Sch-S (200×) S. 204

Nav. affinis v. amphirhynchus Grun.; a u. b; ohne Schalenzeichnung, aber mit Chromatophoren, die gerade die Teilung einleiten, dargestellt; nach Pfitzer $(375 \succ)$ S. 207 
Fig. 35 Vanheurckia vulgaris H. v. Heurck; Sch.S $(200 \times)$ S. 209

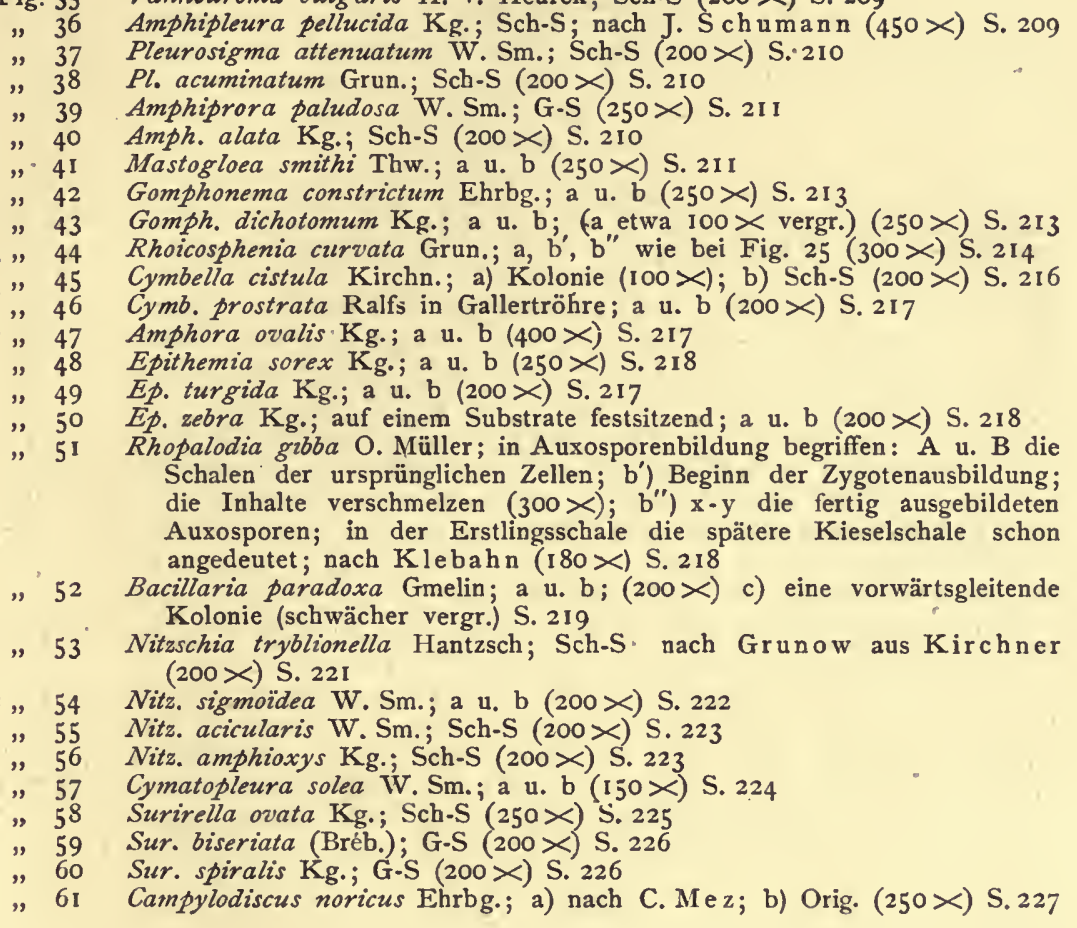




\section{Tafel VIII}

\section{Peridiniaceae}

Bezeichnungen der Panzerplatten: $r=$ Rautenplatte; $b=$ Bauchplatte; $\mathrm{f}=$ seitliche, $\mathrm{d}=$ dorsale Scheitel- (A pikal-) Platten; $\mathrm{v}=$ vordere, $\mathrm{h}=$ hintere Rand(Basal-) Platten; e = End-Platte. Bei 2 und 7 sind die Quergeisseln nicht gezeichnet.

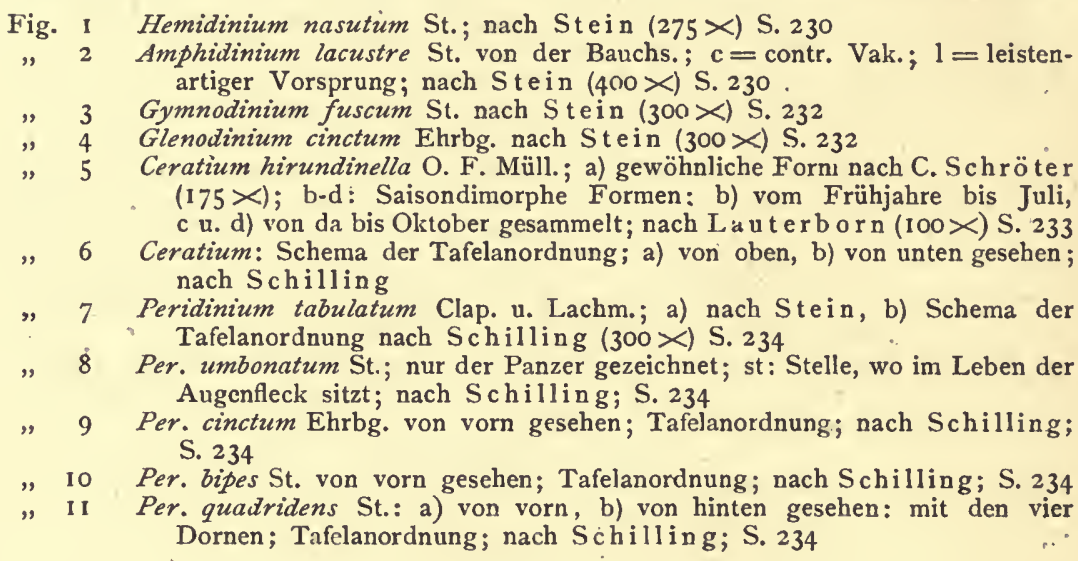

\section{Phaeophyceae}

Fig. I2 Naegeliella fagellifera Correns; a) Habitusbild $(50 \times)$, b) ein Teil des Gallertpolsters mit den Zellen; nach Correns (I $75 \times)$; c) einzelne Zelle mit Chromatophor; nach Correns $(400 \times)$ S. 236

" I3 Lithoderma fontanum Flah.; a) Teil einer Kruste von oben gesehen $(140 \times)$; b) Qu.-Schn. durch einen Sporangientragenden Thallusteil; nach Flahault aus Engler-Prantl; S. 237

"I4 Phaeodermatium rivulare Hansg.; a) Stück eines Flachschnittes (300 $\times)$; b) Stück eines Qu.-Schn.; nach Hansgirg (150×) S. 237

"I5 Pleurocladia lacustris A. Br.; $\mathrm{g}=$ Gametangien; $\mathrm{sp}=$ Sporangien; nach Rabenhorst (100 $\times$ ) S. 237

" I6 Chlamydomyxa labyrinthulödes Arch.; a) einige Zellen eines SphagnumBlattes mit Cysten der "Alge"; b) die Amoebenform frei umherkriechend; nach Hieronymus $(310 \times)$ S. 237

\section{Rhodophyceae}

Fig. I 7 Hildenbrandia rivularis Bréb.; Blick auf den krustenförmigen Thallus; nach Carter (stark) S. 239

"I 8 Thorea ramosissima Bory; a) Habitusbild nach Rabenhorst (2/1); b) Sporangientragende Zweige; nach Schmitz $(150 \times) \mathrm{S} .240$

Lemanea torulosa Sirodot; a) Habitusbild; nach Sirodot aus Schmitz (3/1); b) Längsschnitt durch den Thallus (stark); bei tr Carpogon mit hervorragendem Trichogyn; bei sp ebenso, doch mit zwei ansitzenden Spermatien; die befruchtete Eizelle beginnt, zu den Gonimoblasten (g) auszuwachsen; S. 240 
Fig. 20 Chantransia chalybea Fries; a) ein Polster, an einer andern Alge festsitzend (natürl. Gr.); b) Ende eines Thallus mit (Mono-) Sporangien; $(100 \times)$; nach $\mathrm{R}$ abenhorst S. $24 \mathrm{I}$

Batrachospermum moniliforme Roth; a) Habitusbild nach de Wildeman $(2 \times)$; b) ein Quirl mit Seitenästen; mit Fruchtkörper und Trichogyn, woran zwei Spermatien sitzen; nach $\mathbf{R}$ abenhorst, Trichogyn nach Kirchner eingezeichnet $(150 ×)$ S. 242

\section{Bangiaceae, Varia}

Fig. 22 Bangia atropurpurea C. Ag.; Thallusstückchen; nach Kirchner (175 $メ$ ) S. 242

Allogonium wolleanum Hansg.; a) Kolonie, deren Zellen wandständige Chromatophoren besitzen $(100 \times)$; b) ältere Zellen; Kern strahlenförmig von blaugrünem Protoplasma umgeben; nach Hansgirg $(300 \times)$ S. 243

Gloeochaete wittrockiana Lagerh.; eine vierzellige Familie; nach $\mathrm{Hans}$ girg $(300 \times)$ S. 243

Glaucocystis nostochinearum.Itzigs.; a) eine Kolonie von vier Zellen; Chromatophoren spinnenbeinförmig gestaltet $(360 \times)$; b) einzelne Zelle mit stäbchenförmigen Chromatophoren; nach Hieronymus $(360 \times)$ S. 244

\section{Fungi}

Fig. 27 Chytridium olla A. Br.; mehrere Dauersporen sitzen in dem getöteten Ei eines Oogoniums von Oedogonium. Zwei haben schon Schläuche und Sporangien gebildet, von denen eines schon entleert ist, während die einwimperigen Schwärmer das andre gerade verlassen; nach De Bary aus A. Fischer $(150 \times)$ S. 246

Polyphagus euglenae Now.; der Pilz saugt durch wurzelartige Aeste Io Euglenen (e) aus; (stark); nach Nowak owski aus A. Fischer S. 246

Apodya lactea Cornu; a) einige Thallusäste; nach C. Mez $(\mathbf{I} 75 \times)$;

b) Thallusfaden; in der Nähe der Einschnürungen liegen drei Cellulinkörner; nach Pringsheim aus A. Fischer $(265>)$. S. 247 


\section{Tafel IX}

\section{Sarcodina}

\section{Rhizopoda}

Fig. I Protamoeba primitiva Haeckel; nach Haeckel $(400 \times)$ S. 255

"2 Gloidium quadrifidum Sorok.; in Teilung begriffen; nach Sorokin $(250 \times)$ S. 255

Amoeba proteus Leidy; ein grosses Exemplar mit verschiedenen Nahrungskörpern im Plasma: auf der rechten Seite ist soeben ein Urocentrum durch Umfliessen gefangen; ein anderes Individuum derselben Art schon ganz eingeschlossen im Innern; darunter die kontraktile 'Vakuole; nach Leidy $(300 \times)$ S. 256

Am. verrucosa Ehrbg.; einzelne Nahrungskörper und die Vakuole zu sehen; nach Leidy $(100 \times)$ S. 256

" 5 Hyalodiscus guttula (Duj.); Kern und kontr. Vakuole sichtbar; Orig. $(400 \times)$ S. 257

" 6 Plakopus ruber F. E. Schulze; nach F. E. Schulze $(250 ×)$ S. 257

" 7 Dactylosphaera radiosa Hertw. und Less.; mit fünf relativ starıen und einem amoebenartig vorgewölbten Pseudopodium; Orig. $(300 \times)$ S. 258

" 8 Pelomyxa palustris Greeff; nach Eyferth (300×) S. 258

" 9 Cochliopodium pilosum Hertw. u. Less.; nach L eidy $(250 \times)$ S. 259

", I0 Arcella vulgaris Ehrbg.; a) von oben gesehen: mit mehreren gefressenen Diatomeen im Innern und zwei vorgestreckten Pseudopodien; Orig. $(150 \times)$; b) von der Seite gesehen; nach Leidy $(250 \times)$ S. 259

Difflugia lobostoma Leidy; nach E y ferth (150 X) S. 263

Euglypha alveolata Duj.; nach Leid y $(150 \times)$ S. 266

" I5 Trinema enchelys (Ehrbg.); nach Leidy $(250 \times)$ S. 268
" 16 Cyphoderia ampulla I.eidy; nach Leidy $($ I $75 \times<$ S. 268

$\begin{array}{ll}\text { " I5 Trinema enchelys (Ehrbg.); nach Leidy }(250 \times) & \text { S. } 268 \\ \text { " } 16 \text { Cyphoderia ampulla I.eidy; nach Leidy (I75 } \times \text { ) S. } 268\end{array}$

Lieberkuehnia paludosa (Cienk.); frei nach Cienkowski (40×) S. 269 Microgromia socialis Hertw. u. Less.; a) eine Kolonie im gehäuften (sog. Cystophrys-) Zustande; b) eine ausgebreitete Kolonie; nach Hertwig u. Lesser $(400 \times)$ S. 270

" 19 Pamphagus hyalinus Leidy; nach Leidy (250×) S. 270

" 20 Pseudodifflugia gracilis Schlumb.: nach Leidy $(150 \times)$ S. 27 I

\section{Heliozoa}

Fig. 21 Actinophrys sol Ehrbg.; links eine Nahrungs-, rechts eine pulsierende Vakuole; nach Grenacher $(225 \times)$ S. 274

Actinosphaerium eichhorni (Ehrbg.); Entoplasma mit mehreren gefressenen Diatomeen; Ektoplasma mit sich füllender Vakuole (oben links); eine andre (rechts unten) hat sich vor kurzem entleert; links davon eine Nahrungsvakuole mit einem soeben gefangenen Rädertiere; nach Leidy $(175 \times)$ S. 274

" 23 Vampyrella spirogyrae Cienk.; a) Stückchen eines in Amoebenform kriechenden Exemplares; nach Hertwig u. Lesser $\left(45^{\circ} \times<\right)$; b) ein fest- 
sitzendes Exemplar (Heliozoen-Form), die Zelle eines Spirogyra-Fadens aussaugend; nach Cienkowski aus Bütschli (IO0メ) S. 274

Fig. 24 Nuclearia delicatula Cienk.; nach F. E. Schulze $(200 \times)$ S. 274

" 25 Heterophrys spinifera Arch.; nach Hertwig u. Lesser (stark vergr.) S. 275

„, 26 Sphaerastrum fockei (Arch.); eine Kolonie; nach Greeff (40×) S. 275

" 27 Elaeorhanis cincta Greeff; nach Greeff (I50 $メ$ ) S. 275

" 28 Lithocolla globosa F. E. Schulze; nach F. E. Schulze $(300 \times)$ S. 276 


\section{Tafel $\mathbf{X}$}

Es bedeutet: $\mathrm{cv}=$ kontraktile Vakuole; $\mathrm{N}=$ Nahrungskörper; $\mathrm{n}=$ Nukleus, Kern $;$ oc $=$ Augenfleck; $\mathrm{p}=$ Paramylum; $\mathrm{s}=$ Staborgan.

\section{Sarcodina}

\section{Heliozoa (Fortsetzung)}

Fig. I Hyalolampe fenestrata Greeff; mit eingezogenen Pseudopodien; nach Leidy $(250 \times)$ S. 276

" 2 Pinaciophora fluviatilis Greeff; nach Greeff $(200 \times)$ S. 276

$" 3$ Diplocystis gracilis Pen.; nach Penard (stark vergr.) S. 276

" 4 Rhaphidiophrys elegans Hertw. u. Less.; eine dreizellige Familie; nach Leidy $(250 \times)$ S. 277

" 5 Acanthocystis turfacea Cart.; Stückchen eines Individuums; nach Leidy $(375 \times)$ S. 278

" 6 Clathrulina elegans Cienk.; a) ein auf einem Stiele sitzendes Individuum mit seiner Kieselschale; nach Leidy; b) ein Schwärmer; nach Hertwig $(375 \times)$ S. 279

\section{Mastigophora (Flagellatae)} Natur sind.

Die Geisseln sind in den Zeichnungen teilweise kürzer ausgefallen als sie in

\section{Protomastigina}

Fig. 7 Mastigamoeba invertens Kl.; a) im freischwimmenden Zustande; b) als Amoebe kriechend; die Pfeile deuten die Richtung der Bewegung an; nach Klebs $(700 \times)$ S. 285

" 8 Dimastigamoeba longicauda Blochm.; im Amoebenzustande; nach Klebs $(500 \times)$ S. 286

" 9 Dim. radiata $\mathrm{Kl}$.; im freischwimmenden Zustande; nach $\mathrm{Klebs}(700 \times)$ S. 286

" 10 Dimorpha mutans Grub.; a) im Amoebenzustande; b) freischwimmend; $\mathbf{N}=$ als Nahrung aufgenommene Chlamydomonaden; nach $\mathrm{F}$. Bloch. $\operatorname{mann}(900 \times)$ S. 286

"11 Cercomonas crassicauda Duj.; nach Ste in $(300 \times)$ S. 287

" 12 Oikomonas mutabilis S. K.; zwei verschieden gestaltete, festsitzende Individuen; nach Sav. Kent $(400 \times)$ S. 288

" 13 Phyllomonas contorta Kl.;' zwei Individuen von verschiedenen Seiten; nach Klebs $(750 \times)$ S. 288

"I4 Codonoeca inclinata S. K.; nach Sav. Kent $(400 \succ)$ S. 288

" 15 Monas vivipara Ehrbg.; a) freischwimmend; Ml= sog. Mundleiste; b) mit dem Hinterende festsitzend; nach Sav. Kent $(300 \succ)$ S. 289

" 16 Mon. minima H. Meyer; nach H. Meyer (1500 >) S. 289

" 17 Cephalothamnium caespitosum S. K.; eine Kolonie; nach Sav. Kent $(600 \times)$ S. 290

" 18 Dendromonas laxa Blochm.; eine Kolonie; nach Sav. Kent ( $1500 \times$ ) S. 290

" 18 Anthophysa vegetans Btschli.; a) Kolonien auf verzweigten Stielen $(50 \times)$; b) eine köpfchenförmige Kolonie $(300 \times)$; c) eine einzelne Monade $(500 \times)$; d) Stückchen eines alten Stieles; $(300 \times)$; Órig. S. 29 I 
Fig. 20

Bicosoeca lacustris J.-Cl.; nach Stein $(325 \succ)$ S. $29 \mathrm{I}$

Poteriodendron petiolatum St.; nach Ste in $(200 \times)$ S. 292

Phalansterium digitatum St.; a) Teil einer Kolonie mit einigen Flagellaten $(300 \times)$; nach Stein; b) isoliertes Einzeltier $(600 \times)$; nach Sav. Kent; S. 293

Monosiga ovata S. K.; nach Francé $(300 \times)$ S. 295

Codosiga botrytis Ehrbg.; nach Francé $(300 \times)$ S. 295

Codonocladium umbellatum St.; nach Francé $(300 \times)$ S. 295

Asterosiga radiata Zach.; nach Francé $(440 \succ)$ S. 296

Sphaeroeca volvox Lauterb.; a) Stückchen einer kugeligen Kolonie $(300 \times)$;

b) Einzeltiere, isoliert $(600 \times)$; nach La u terborn; S. 296

Protospongia hacckeli S. K.; eine kleinere Kolonie; nach Francé $(375><)$ S. 296

Codonodesmus phalanx St.; nach Ste in $(350>)$ S. 296

Diplosiga frequentissima Zach.; nach Francé (350>) S. 297

Salpingoeca amphoridium J.-C.; nach Francé $(350 \succ)$ S. 298

Salp. napiformis S. K.; nach Francé $(350 \times)$ S. 298

Lagenoeca globulosa Francé; nach Francé $(325 \times)$ S 298

Diplosigopsis entzi Francé; a u. b stellen zwei verschiedene Formen vor; nach Francé $(300 \times)$ S. 299

Spongomonas intestinum St.; a) eine schlauchförmige Kolonie in natürl. Grösse; nach Sav. Kent; b) Ende der Gallertröhre mit den darinsitzenden Monaden $(300 \times)$; c) isoliertes Individuum aus der Kolonie $(500 \times)$; b u. c nach Stein; S. 300

Spong. sacculus S. K.; eine herabhängende sackförmige Kolonie in natürl. Grösse; nach Sav. Kent; S. 300

Cladomonas fruticulosa St.; eine verzweigte Kolonie mit einem isolierten, etwas vergrössert dargestellten Schwärmer; nach Stein $(325 x)$ S. 300

Rhipidodendron splendidum St.; eine stattliche Kolonie mit $\mathrm{z}$. Teil ausschwärmenden Monaden $(300 \times)$; b) eine junge Kolonie (etw. stärker vergrössert); nach Stein; S. 300

39 Amphimonas globosa S. K.; zwei festsitzende Exemplare; nach Sav. Kent $(300 \times)$ S. 301

Deltomonas cyclopum S. K.; nach Sav. Kent $(300 \times)$ S. 30 I

Streptomonas cordata Kl.; nach $\mathrm{Klebs}(300 \times)$ S. 302

Diplomita socialis S. K. ; nach Sav. Kent $(300>) \mathrm{S} .302$ 


\section{Tafel XI}

\section{Mastigophora}

Inbetreff der Bezeichnungen siehe Tafel $\mathrm{X}$

I Fig. I Bodo globosus St.; nach Klebs $(750 \times)$ S. 304

" 2 B. edax Kl.; eine Monas (Na) aussaugend; nach Kle bs $\left(75^{\circ} \times\right)$ S. 204

" 3 B. caudatus St.; im Begriffe, ein Bakterium (Na) als Nahrung aufzunehmen; nach Klebs $(750>)$ S. 304

" 4 Pleuromonas jaculans Py.; zwei festsitzende Formen, die eine mit Nahrungsvakuole (v) auf dem Rücken; nach Fisch (etwa $300 \times$ ) S. 304

" 5 Rhynchomonas nasuta Kl.; nach Klebs (1000 $>$ ) S. 305

" 6 Phyllomitus amylophagus Kl.; mit Stärkekörnern (st) im Innern; nach. Klebs $(600 \times)$ S. 305

" 7 Colponema loxodes St.; nach Klebs $(500 \times)$ S. 305

" 8 Thaumatonema setiferum Lauterb.; nach Lauterborn $(400 \times)$ S. 305

II " 9 Costia necatrix Leclercq; a) freischwimmendes Exemplar; b) an der Haut von Forellen befestigtes Individuum; nach $\mathrm{Henneguy} \mathrm{(stark)} \mathrm{S.} 306$

Dallingeria drysdalei S. K. n nach Dallinger n. Drysdale aus Sav. Kent $(100 \times)$ S. 307

, 1 I Tetramitus descissus Py.; nach Kle bs $(650>)$ S. 307

" I2 Trigonomonas compressa Kl.; ein Bakterium (Na) fressend; nach $\mathrm{Klebs}$ $(400 \times)$ S. 309

" I3 Hexamitus inflatus Duj.; nach Kle bs $(650 \times)$ S. 309

"I4 Urophagus rostratus $\mathrm{Kl}$.; nach $\mathrm{Kle} \mathrm{bs}(700 \times) \mathrm{S} .310$

" I5 Trepomonas rotans $\mathrm{Kl}$.; nach $\mathrm{Klebs}(800>>) \mathrm{S}$. $3 \mathrm{II}$

, 16

Trep. agilis Duj.; a) Individuum von der Seite, b) von vorn gesehen; nach Büt schli (stark vergr.) S. 3 I I

\section{Spironema multiciliatım Kl.; nach Klebs (1000 ×) S. 312}

Euglena viridis Ehrbg.; a) freischwimmendes Exemplar; b) in starker Metabolie, bei Verlust der Geissel oder bei entgegenstehenden Hindernissen; c) zur Kugel abgernndet; Orig. $(250 \times)$ S. 315

Eugl. gracilis Kl.; nach Z umstein $(250 \times)$ S. 315

Eugl. oxyuris Schmarda; Orig. $(200 \times)$ S. 316

Eugl. deses Ehrbg.; nach Stein $(200 \times)$ S. 316

Colacium calvum St.; 2 festsitzende Individnen; nach St e in $(250 \times)$ S. 317

Col. vesiculosum Ehrbg.: freischwimmendes Individunm, im Begriffe, sich festzusetzen, doch noch mit Geisseln und noch ohne ausgeschiedene Hülle; nach Stein $(325>)$ S. 317

Ascoglena vaginicola St.; nach Stein $(325>)$ S. 3 I 8

Trachelomonas volvocina Ehrbg.; Orig. $(300 \times)$ S. 318

Trach. caudata St.; nach Ste in $(275>)$ S. 319

Phacus ovum Kl.; a) Exemplar, bei dem an den Seiten die breiten Paramylonringe $(p)$ im optischen Durchschnitte zu sehen sind; b) ein halb von der Seite gesehenes, geisselloses Individuum: e in Paramylonring noch viel schmäler als bei a - ist deutlich zu erkennen; $(300 \succ)$ S. 319 Ph. pleuronectes Nitzsch; Orig. $(200 \times)$ S. 320

Eutreptia viridis $\mathrm{Py} . ; \mathrm{nach} \mathrm{Klebs}(200 \times)$ S. 320

Astasia margaritifera Schmarda; nach Kle bs $(200 \times)$ S. 32I

Distigma proteus Ehrbg.; zwei, in verschiedenen Stadien der Metabolie befindl. Exemplare, das eine ohne Geissel; nach Ste in $(250 x)$ S. 322 Menoidium pellucidum Py.; nach Ste in $(250 \times)$ S. 322

Sphenomonas quadrangularis St.; a) Individuum von der Seite, b) von oben gesehen; Sch = Schleimkugel; nach Stein $(300 \times)$ S. 323

Euglenopsis vorax Kl.; mit Stärke (st); nach Klebs $(650 ×)$ S. 324

Peranema trichophorum St.; nach Bütschli $(250 \times)$ S. 324

Urceolus cyclostomus Mereschk.; nach Klebs $(500>)$ S. 325

Heteronema acus $\mathrm{St}_{\text {. }}$ st $=$ Stärke; nach $\mathrm{Klebs}(600 \times) \mathrm{S} .326$

Het. nebulosa Kl.; a) freischwimmende, gewöhnliche Form $(400 \times)$ nach 
Klebs; b) durch aufgenommene Nahrungskörper (Diatomeen etc.) verzerrte Form $(300 \times)$ nach Stein; S. 326

Fig. 4I Dinema griseolum Py.; nach Klebs $(300 \times)$ S. 326

$" 42$ Scytomonas pusilla St.; ein Bakterium (Na) aussaugend; nach Klebs (sehr stark vergr.) S. 327

\section{3 \\ Petalomonas abscissa St.; nach Ste in $(200 \times)$ S. 327}

Pet. sexlobata Kl.; nach Klebs $(400 \times)$ S. 328

Tropidoscyphus octocostatus St.; nach Stein $(325 \times)$ S. 328

Anisonema striatum $\mathrm{Kl}$.; nach $\mathrm{K}$ lebs $(600 \times)$ S. 329

An. acinus Duj.; nach Klebs $(450 \times)$ S. 329

Entosiphon sulcatum St.; nach Kle bs $(600 \times)$, S. 329

Vacuolaria virescens Cienk.; Orig. $(250 \times)$ S. $33 \mathrm{I}$

Chloramoeba heteromorpha Bohlin; zwei amoeboïde Individuen; nach

Bohlin (stark vergr.) S. $33 \mathrm{I}$
Chlorosaccus fuidus A. Luther; im Profil gesehen $(350 \times)$;

A. Luther; S. 33 I
Rhaphidomonas semen St.; nach Stein $(325 \times)$ S. 33 I

a) Gallertlager, konserviert und gefärbt, b) schwärmende Zellen $(4 \mathrm{I} 5 \rtimes)$; nach

Niulticilia lacustris Lauterb.; nach La u terborn (stark vergr.) S. 332

1 bedeutet bei den folg. Formen immer Leukosin.

Chrysamoeba radians $\mathrm{Kl}$.; a) im freischwimmenden Zustande; b) als Amoebe kriechend; nach Klebs $(450 \times)$ S. 333

Chromulina favicans Btschli.; a u. b zwei verschiedene Formen; b mit einer gefressenen Diatomee; nach Kle bs $(600 \times)$ S. 334

$n 5^{6}$

Chrom. rosanoffi Btschli.; a) zahlreiche Flagellaten in einem Schleime als Staubantug auf dem Wasser; b) ein Schwärmer; c) Durchtritt der Schwärmer durch die Oberflächenhaut des Wassers an die Luft: $\alpha$ ) Beginn des Durchtritts, $\beta$ ) schon ausserhalb des Wassers, mit diesem nur durch eine kleine Röhre verbunden; nach Woronin $(260 x)$ S. 334

Ochromonas mutabilis $\mathrm{Kl}$; ; nach Kle bs $(450 \times) \mathrm{S} .335$

Och. chromata H. Meyer; nach H. Meyer (stark vergr.) S. 336

Chrysococcus rufescens $\mathrm{Kl}$; ; a) Individuum in seiner Schale; b) in Teilung begriffen; die eine Tochterzelle verlässt soeben die Mutterschale; nach Klebs $(600 \times)$ S. 336

Stylochrysalis parasitica St.; eine Anzahl von Individuen auf einer Kolonie von Eudorina elegans; nach Stein $(325 \times)$ S. 336

Dinobryon sertularia Ehrbg.; eine Kolonie; nach Stein $(325>)$ S. 337

62 Din. undulatum Kl.; nach Kle bs $(650<)$ S. 337

Din. ramosum Lauterb.; a) Teil einer Kolonie $(450 \times)$; b) Einzeltier am

Eingange seines Gehäuses (sehr stark vergr.); nach Lauterborn; S. 338
Chrysopyxis bipes St.; a) u. b) an einem Algenfaden festsitzende Individuen: a) im Profil, b) von oben gesehen; c) freischwimmend; a u. c nach Stein, b Orig. $\left(35^{\circ} \times\right)$ S. 338

65 Hymenomonas roseola St.; nach Klebs $(500 \rtimes)$ S. 339

66 Chrysosphaerella longispina Lauterb.; nach Lauterborn $(400 \times)$ S. 339

67 Microglena punctifera Ehrbg.; nach Klebs (stark vergr.) S. 339

68 Mallomonas ploessii Py.; nach Kleb s $(500 \times)$ S. 339

69 Synura uvella Ehrbg.; a) eine Kolonie; bei oc dic zahlreichen Augenpunkte;

b) Einzeltier; nach Stein $(325 \times)$ S. 340

70 Syncrypta volvox Ehrbg.; nach Stein (325 ×) S. 340 (stärker vergr.); nach Stein; S. 340

" 72 Cyathomonas truncata (St.); nach Bütschli (stark vergr.) S. 341

" 73 Chilomonas paramaecium Ehrbg.; nach Bütschli, etwas verändert (stark vergr.) S. 34 I

" 74 Cryptomonas ovata Ehrbg.; nach Stein $(300 \times)$ S. $34 \mathrm{I}$

" 75 Hydrurus foetidus Kirchn.; a) eine algenähnliche Kolonie in natürl. Grösse ; nach R ostafinsky; b) Ende eines A stes davon mit den eingeschlossenen Zellen $(450 \times)$; c) eine schwärmende Zelle $(750 \rtimes)$ b u. c nach Klebs; S: 342 


\section{Tafel XII}

Es bedeutet: $\mathrm{a}=$ Zellafter; $\mathrm{cv}=$ kontraktile Vakuole; $\mathrm{Md}=$ Mund; $\mathrm{N}=$ Nahrungskörper; $\mathbf{n}=$ Nukleus, Kern; $\mathbf{M a}=$ Makronukleus und daranliegend der in der Zeichnung meist deutlich hervortretende Mikronukleus (Mi); oe = Oesophagus (Schlund); $\operatorname{Tr}=$ Trichocysten; die betreffenden Bezeichnungen sind den Organen wegen ihrer leichten Erkennbarkeit nur bei einigen Figuren beigesetzt.

\section{Ciliata}

\section{A. Gymnostomata}

Fig. I Holophrya discolor Ehrbg.; pe $=$ Porus excretorius tür die kontr. Vakuole; nach Schewiak off $(150>)$ S. 351

$\begin{array}{ll}\text { " } & 2 \text { Urotricha globosa Schew.; nach J. Roux }(750 \rtimes) \text { S. } 35 \text { I } \\ \text { ", } 3 \text { Enchelys arcuata Cl. u. L.; nach Claparede u. Lachmann }(150 ×)\end{array}$ S. 352

19 Spathidium spathula (O. F. Müll.); nach Lieberkühn aus Bütschli $(75 \times)$ S. 352

Prorodon teres Ehrbg.; nach Schewiak off (150>) S. 353

Dinophrya lieberkuehni Btschli.; nach Schewiak off (150×) S. 353

Lacrymaria olor Ehrbg.; a) ganzes Tier $(185 \times)$; b) Vorderende (stärker vergr.); nach $\mathrm{Claparède} \mathrm{u.} \mathrm{Lachmann;} \mathrm{S.} 354$

Actinobolus radians St.; nach v. Erlanger (stark vergr.) S. 355

Coleps hirtus Ehrbg.; nach Ma upas $(225 \times)$ S. 355

Didinium balbianii Btschli.; nach Schewiak off $(150>)$ S. 356

Mesodinium acarus St.; nach Entz (stark vergr.) S. 356

Askenasia elegans Blochm.; a) von der Seite gesehen [nur die seitlichen Borsten und Cilien sind dargestellt]; b) von oben gesehen; nach Blochmann $(185 \times)$ S. 356

Amphileptus carchesii St.; nach J. Roux $(200 \times)$ S. 357

Lionotus vesiculosus Stokes; nach J. Roux $(70 \times)$ S. $35^{8}$

Loxophyllum fasciola Cl. u. L.; nach Schewiak off $(400 \times)$ S. 358

Trachelius ovum Ehrbg.; $\mathrm{Cy}=$ Cyste; nach Lieberkühn aus Büts chli; $(80 \times)$ S. 359

" 17 Dileptus gigas Wrzesn.; von der rechten Seite betrachtet; nach Schewia k off $(100 \times)$ S. 359

"I8 Loxodes rostrum Ehrbg.; $\mathrm{Na}=$ verschluckte Euglenen; nach J. Roux $(75 \times)$ S. 359

Nassula elegans Ehrbg.; pi = Pigmentfleck; nach Schewiak off $(250 \times)$ S. $36 \mathrm{I}$

Chilodon cucullulus Ehrbg. [besser Ch. steini Blochm.]; nach Wrzesn iow ski (115 X) S. 362

" 21 Opisthodon niemeccensis St.; nach Stein $(200 \times)$ S. 362

,2 22

Phascolodon vorticella St.; a u. b) von verschiedenen Seiten gesehen; nacl St ei n (a etwa $300 \times$, b etwas schwächer vergr.) S. 362

" 23 Trochilia palustris St.; nach J. Roux $(600 \times)$ S. 362

$" 24$ Ervilia fluviatilis (St.); nach Stein $(350 \times)$ S. 363

" 25 Dysteropsis minuta Roux; nach J. Roux (750×) S. 363

\section{B. Trichostomata}

\section{Aspirotricha}

Fig. 26 Leucophrys patula Ehrbg.; u $\mathrm{M}=$ undulierende Membran; nach Maupas $(210 \times)$ S. 365

„ 27 Leucophryïdium putrinum Roux; nach J. Roux $(700 \times)$ S. 366 
Fig. 28

" 29

, 30

, 31

" 32

, 33

, 34

" 35

" 36

" 37

, 38

" 39

" 40

, 41

, 42

, 43

Glaucoma scintillans Ehrbg.; nach Schewiakoff $(175>)$ S. 366

Frontonia leucas Cl. u. L.; a) Infusor $(125 \times)$; b) Isolierte Zoochlorellen (,Zoochlorella conductrix ${ }^{r 6} \mathrm{~K}$. Brandt): $\beta$ in Teilung begriffen $(930 \times)$; nach Schewiak off S. 367

Ophryoglena flavicans Lieberk.; nach J. Roux (150 \) S. 367

Colpidium colpoda St.; nach Schewiak off (200 <) S. 367

Colpoda cucullus Ehrbg.; nach Maupas (250×) S. 368

Chasmatostoma reniforme Engelm.; nach Engelmann (350 \) S. 368

Uronema griseolum (Mps.); Vorderansicht; nach Schewiakoff $(330 \times)$ S. 369

Urozona buetschlii Schew.; es sind nur die seitlichen Wimpern dargestellt; nach Schewiak off $(535 \times)$ S. 369

Loxocephalus granulosus S. K.; nach Lieberkühn aus Büt schli $(300 \times)$ S. 369

Cinetochilum margaritaceum Py.; Ventralseite; nach Schewiakoff $(400 \times)$ S. 370

Microthorax sulcatus Engelm.; nach Engelmann $(175>)$ S. 370

Epalxis mirabilis Roux; nach J. Roux (750 ×) S. 370

Paramaecium caudatum Ehrbg.; nach Schewiak off aus Bütschli (150 $>$ ) S. 371

Par. bursaria Focke; ein getötetes Exemplar; die grossen, unregelmässig abstehenden Fäden sind die ausgeschleuderten Trichocysten; nach Bütschli $(150>$ ) S. 37 I

Urocentrum turbo Ehrbg.; Ventrale Ansicht; pe $=$ Porus excretorius [Ausführungskanal der kontr. Vakuole (cv)]; nach Schewiak off $(250 \nsim)$ S. 372

Lembadion bullinum Py.; Ventrale Ansicht; Der Porus excretorius (pe) ist der längere, schief nach unten ziehende, feine Kanal; nach Schewiak off $(350 \times)$ S. 373

Pleuronema chrysalis St.; Rechtsseitige Ansicht; nach Schewiakoff $(250 \times)$ S. 373

Cristigera pleuronemoïles Roux; nach J. Roux $(250 \times)$ S. 374

Cyclidium glaucoma Ehrbg.; nach Schewiak of f (535) S. 374

\section{Spirotricha}

\section{A. Heterotricha}

Fig. 47 Blepharisma lateritia St.; nach Stein (300 $>$ ) S. 375

" 48 Metopus sigmoïdes Cl. u. L.; nach $\mathrm{Stein}(150 \Varangle)$ S. 376

" 49 Plagiopyla nasuta St.; nach Quennerstedt aus Sav. Kent $(150 \times)$

S. 376

Spirostomum ambiguum Ehrbg.; nach Stein (50 $>$ ) S. 377

" 50

" 51

Stentor roeseli Ehrbg.; nach Stein $(100 \times)$ S. 380

St. igneus Ehrbg.: Orig. $(50 \times)$ S. 380

Gyrocoris oxyura St.; etwas von der Seite und unten gesehen; nach Blochmann $(125 \times)$ S. 381 


\section{Tafel XIII}

Inbetreff der Bezeichnungen siehe Tafel XII.

\section{Ciliata}

\section{Spirotricha}

B. Oligotricha

Fig. I Strombidium viride St.; nach J. Roux $(350 \times)$ S. 382

$" 2$ Halteria grandinella (O. F. Muell.); nach Schewiakoff aus Bütschli $(200 \times)$ S. 382

" 3 Tintinnidium fuviatile (St.) in seinem Gallertgehäuse; nach Entz aus Bütschli $(120 \times)$ S. 382

\section{Hypotricha}

Fig. 4 Urostyla weissei St.; nach Ste in $(200 \times)$ S. 385

" 5 Kerona polyporum Ehrbg.; nach S te in (200×) S. 385

" 6 Stichotricha secunda Py.; nach Ste in (150×) S. 386

" 7 St. socialis Gruber; verzweigtes Gallertgehäuse, das vom Wasserspiegel herabhängt, und dessen Enden je ein Individuum beherbergen; nach Gruber aus Bütschli ( $15 \times$ ) S. 386

Uroleptus piscis (Ehrbg.); nach Kowalewsky aus Bütschli $(75 \rtimes)$ S. 387 Ur. mobilis Engelm.; nach Engelmann (150 <) S. 387

Onychodromus grandis St.; nach Stein $(75 \times)$ S. 388

Pleurotricha grandis St.; nach Stein $(125 \times)$ S. 389

Gastrostyla steini Engelm.; nach Engelmann (100×) S. 390

Gonostomum affine (St.); nach Stein (175 $>$ ) S. 390

Oxytricha pellionella Ehrbg.; nach Ste in (150×) S. $39 \mathrm{I}$

Stylonychia mytilus Ehrbg.; aus dem Zellafter (a) wird gerade eine leere

Diatomeenschale ausgestossen; nach Stein $(100 \times)$ S. 393

Balladina elongata Roux; nach J. Roux $(400 \times)$ S. 394

Dipleurostyla acuminata Roux; nach J. R oux $(250 \times)$ S. 393

Euplotes patella Ehrbg.; nach Ste in $(125 \times)$ S. 394

Aspidisca lynceus Ehrbg.; (oben in der ersten Reihe!) nach S tein (150×)

\section{Peritricha}

Fig. 20 Spirochona gemmipara St.; nach R. Hertwig aus Bütschli (225×) S. 397

" 21 Trichodina pediculus Ehrbg.; nach James Clark aus Bütschli (215 $<$ ) S. 397

Scyphidia physarum Lachm.; nach Quennerstedt aus Bütschli (150 S. 400

Gerda glans I.achm.; Mund in der Zeichnung oben; neben dem Kerne

(n) der lange Zuführungskanal zur kontr. Vak. (cv); nach Cla parède

u. Lachmann $(110 \times)$ S. 400

Vorticella nebulifera Ehrbg.; Makronukleus (Ma) hufeisenförmig; nach Bütschli $(200 \times)$ S. 402

Vort. a) microstoma Ehrbg.; S. 401

b) campanula Ehrbg.; S. 402

c) convallaria Ehrbg.; S. 402

d) patellina Ehrbg.; S. 401

e) monilata Tatem; S. 402

Alle diese Formen sind schematisch - bei willkürlicher Stiellänge und bei schwacher Vergrösserung (25) - gezeichnet, um eine Vorstellung von den morphologischen Unterschieden zu geben; frei nach S. Kent Carchesium polypinum Ehrbg.; a) eine Kolonie im ausgestreckten Zustande $(40 \times)$; b) eine zusammengeschnellte Kolonie $(50 \times)$; nach Ehrenberg aus Bütschli; S. 403 $(175 \times)$ S. 403 
Fig. 30 Glossatella tintinnabulum S. K.; $\mathbf{v}=$ eine Vakuole fraglicher Funktion; nach Sav. Kent aus Bütschli (300X) S. 404

" 31 Epistylis plicatilis Ehrbg.; nach Bütschli $(150 \times)$ S. 406

" 32 Ep. umbellaria Lachm.; Teil einer verzweigten Kolonie mit mehreren Rosetten von "Mikrogonidien" (mi); nach Greeff aus Bütschli (schwach vergr.) S. 405

" 33 Opercularia articulata Ehrbg.; nach Bütschli (100 $>$ S. 407

" 34 Ophrydium versatile Ehrbg.; senkrechter Schnitt durch eine Kolonie mit mehreren Individuen; nach Wrzesn i owski aus Büt s chli $(25 \times)$ S. 408

" 35 Ophr. eichhorni Ehrbg.; rs=Reservoir für die kontr. Vakuole (cv), $\mathbf{M d}=$ der sich an den Mund anschliessende Schlund; nach Wrzesniowski aus Bütschli $(225 \times)$ S. 408

" 36 Cothurnia crystallina Ehrbg.; zwei ausgestreckte Individuen in einem Becher; Orig. $(125><$ S. 409

" 37 Vaginicola longicollis S. K.; ein ausgestrecktes Individuum an einer Alge festsitzend; nach Fromentel aus Bütschli $(125 \times)$ S. 409

" 38 Lagenophrys ampulla St.; (in der Mitte rechts!) an den Kiemen von Gammarus und Asellus, mit noch zwei "Mikrogonidien" (mi) im Gehäuse; nach Stein aus Bütschli $(160><)$ S. 4 IO

\section{Suctoria}

Fig. 39 Rhyncheta cyclopum Zenker; nach Zenker aus Bütschli (90×) S. 4I2 " 40 Urnula epistylidis $\mathrm{Cl}$. u. L. auf dem Stiele von Epistylis; nach Claparède u. Láchmann aus Bütschli (I25 × S. 4I3

" 4I Metacineta mystacina (Ehrbg.); a) Individuum, das durch schiefe Teilung einen Schwärmer (rechts!) gebildet hat, wobei aber die Makronuklei noch zusammenhängen; b) kurzgestieltes, umgeknicktes Individuum, dessen Vorderseite mit den sechs Oeffnungen für die sechs Tentakelbüschel dem Beschauer zurückgekehrt ist; nach Bütschli ( $150 \rtimes)$ S. 413

Sphaerophrya magna Mps.; das dargestellte Individuum saugt gerade einige Exemplare von Cyclidium glaucoma aus; nach Maupas ( $150 \times)$ S. 4 I3

Sphaerophrya-Schwärmer; nach Engelmann (I $75>$ ) S. 413

a) drei Endosphaera-Individuen, z. T. als Schwärmer in Epistylis plicatilis; bei x Austrittsöffnung für die Schwärmer (?); nach Claparède und Lachmann aus Bütschli (stark vergr.); b) Schwärmer einer Endo-

sphaera nach Engelmann $(300 \times)$ S. 414
Podophrya libera $\mathrm{Py}$; ; a) gewöhnliches Individuum, oben links ein gereizter Tentakel, der sich zusammenzuziehen beginnt; b) ein Schwärmer; c) Cyste; nach Maupas aus Bütschli (a u. b: $125>$, c: $160>$ ) S. 414

$" 46$

Tokophrya cothurnata (Cl. u. L.); ein festsitzendes Exemplar, das durch die "Geburtsöffnung " einen Schwärmer entlässt; nach Stein aus Bütschli $(125 \times)$ S. 415

Tok. quadripartita (Cl. u. L.); nach Bütschli ( $150 \times)$ S. 416

" 48 Acineta linguifera CI. u. L.; a) gestieltes Individuum von der Breitseite; b) leere Schale von der Seite; c) ein. Schwärmer; nach Sav. Kent $(75 \times)$ S. 416

Solenophrya crassa Cl. u. L.; nach Claparède u. Lachmann $(75 \times)$ S. 416

" 50 Trichophrya epistylidis Cl. u. L.; nach Bütschli $(75 \times)$ S. 417

" 51 Dendrosoma radians Ehrbg.; Stück einer verzweigten Kolonie; nach Claparède u. Lachmann $(25 \times)$ S. 417

" 52 Dendrocometes paradoxus St.; ein zweiarmiges Exemplar auf einem Kiemenblatte von Gammarus pulex; nach Bütschli (150×) S. 417

" 53 Stylocometes digitatus Cl. u. L.; auf der Kante eines Kiemenblattes von Asellus aquaticus; bei $\mathrm{x}$ schimmert die Haftscheibe durch; nach Plate aus Bütschli $(150 \times)$ S. 417 


\section{Tafel XIV}

\section{Rotatoria}

Es bedeutet: VA $=$ Ventralansicht; $\mathrm{DA}=$ Dorsalansicht $; \mathrm{LA}=$ Lateralansicht; $\delta=$ Männchen; $O=$ Weibchen; die Tiere sind meist im ausgestreckten Zustande dargestellt; die schwarzen Punkte in der Nähe des Gehirns sind Augenflecke; die Abbildungen, bei denen nichts bemerkt ist, entstammen Webers klassischer Arbeit über die Rädertierfauna des Genfersees.

\section{Rhizota}

Fig. I Floscularia cornuta Dobie; O, VA; $(80 \times)$ S. 432.

" 2 Stephanoceros eichhorni Ehrbg.; , DA; $(25 \times)$ S. 433

" 3 Melicerta ringens Schrank; a) , DA; nach Eyferth $(25 \rtimes)$; b) Kauapparat; nach $\mathrm{Hud}$ son (stark vergr.) S. 434

" 4 Limnias ceratophylli Schrank; . VA; nach Ey ferth $(25 \rtimes)$ S. 435

" 5 Cephalosiphon limnias Ehrbg.; +, LA u. I)A; $(60 \times)$ S. 435

" 6 Oecistes socialis Weber; mit ansitzendem Ei; o, LA u. DA; $(80 \times)$ S. 436

" 7 Megalotrocha semibullata Thorpe; 9 , VA; $(45>)$ S. 436

" 8 Lacinularia socialis Ehrbg.; ein einzelnes $O$ Individuum einer kugeligen Familie, am Grunde festgeheftet und in einer gallertigen Substanz eingebettet; VA; nach $\mathrm{Huds}$ on (stark vergr.) S. 437.

" 9 Dasselbe, doch ein ठ̋; LA bei gleicher Vergrösserung; nach $\mathrm{H} u \mathrm{ds}$ on; S. 437

" 10 Conochilus unicornis Rousselet; eine kugelige Familie; + ; (40×) S. 437

\section{Bdelloida}

Fig. II Philodina megalotrocha Ehrbg.; ㅇ, DA; (175 ×) S. 439

" 12 Rotifer macroceros Gosse; $q$; a) DA (100×); b) LA (etwas stärker vergr.) S. $44 \mathrm{I}$

"I3 Rot. actinurus Ehrbg.; ㅇ, LA; $(35>)$ S. 44I

"I4 Callidina symbiotica Zelinka; O, Kauapparat; $(290 \times)$ S. 442

"15 Call. elegans Ehrbg.; + , DA; nach Eyferth $(75 \times)$ S. 442

" I6 Adineta vaga Davis var. maior; + , DA; $\left(\mathrm{r}_{5} \times\right)$ S. 443

\section{Plö̈ma}

Fig. 17 Microcodon clavus Ehrbg.; a) 앙 VA (135 ×); b) Kauapparat (stärker vergr.) S. 445

" 18 Microcodides chloena Gosse; 9, LA; (150×) S. 445

" 19 Asplanchna priodonta Gosse; a) o Individuum; nach Eyferth $(50 \times)$; b) Kauapparat; (125×) S. 447

" 20 Asplanchnopus myrmeleo Ehrbg.; + , VA; nach Plate $(500 \rtimes)$ S. 448

" 21 Ascomorpha helvetica Py.;, DA; mit zwei anhängenden Eiern; $(60 \times)$ S. 449

" 22 Dasselbe, doch ठ̋; bei etwa gleicher Vergrösserung; nach $\mathrm{Hudson}$ und Gosse; S. 449

" 23 Synchaeta pectinata Ehrbg.; , Kauapparat; nach Hudson aus Weber (stark vergr.) S. 449

" 24 Synch. tremula Ehrbg.; + ; a) DA; nach $\mathrm{Huds}$ on und Gosse $(75 \times)$;

b) Kauapparat $(100 \times)$ S. 449 


\section{Tafel XV}

\section{Rotatoria}

III. Ploïma (Fortsetzung)

Inbetreff der Abkürzung etc. siehe die Kopfbemerkungen zu Tafel XIV.

Fig. I Polyarthra platyptera Ehrbg.; , DA; $(70 \times)$ S. 450

" 2 Triarthra, mystacina Ehrbg.; + , LA; mit anhängenden Eiern; (105×) S. $45 \mathrm{I}$

" 3 Hydatina senta Ehrbg. (rechts auf der Tafel!); 우, ViA; Es bedeutet: $\mathrm{Bl}=$ Blase; $\mathrm{ds}=$ Dotterstock; $\mathrm{Fd}=$ Fuss- (Kleb-) Drüse; $\mathrm{Kp}=\mathrm{Kau}$ apparat $; \mathrm{Ks}=$ Keimstock $; \mathrm{lt}=$ Lateraltaster $; \mathrm{md}=$ Magendrüse $; \mathrm{mg}$ = Magen: $\mathrm{v}=$ Wassergefäss; nach Plate $(50 \times)$ S. $45 \mathrm{I}$

" 4 Notops brachionus Ehrbg.; $q$, VA; $(40 \times)$ S. 452

" 5 Taphrocampa annulosa Gosse; O, LA; (i20 $>$ ) S. 453

", 6 Notommata tripus Ehrbg.; ;, DA; (I10 $\times$ ) S. 453

" 7 Distemma collinsi Gosse; 'O, LA; nach Hudson u. Gosse (stark vergr.) S. 454

, 8 Copeus labiatus Gosse; ㅇ, DA; nach Eyferth (50×) S. 454

" 9 Proales tigridia Gosse; 9 ; a) LA $(120 \times)$; b) Kauapparat $(185 \rtimes)$ S. 456

" I0 Furcularia forficula Ehrbg.; 9 , DA; (I15 X) S. 457

"II Eosphora najas Ehrbg.; +, DA; $(60 \times)$ S. 458

" 12 Diglena catellina Ehrbg.; + , LA; $(65 \times)$ S. 459

", I3 Digl. uncinata Milne; + , LA; $(120 \times)$ S. 459

"I 4 Mastigocerca carinata; , LA; $(100 \times)$ S. 463

"I5 Coelopus tenuior Gosse; O, LA; $(110 x)$ S. 464

" I6 Rattulus helminthodes Gosse; +, LA; nach Hudson u. Gosse (stark vergr.) S. 465

" 17 Dinocharis pocillum Ehrbg.; 9 ; a) DA (I $35 \times$ ); b) Kauapparat (250×) S. 466

" I8 Scaridium longicaudum Ehrbg.; , , LA; (100×) S. 466

" I9 Dasselbe, doch ठँ; bei gleicher Vergrösserung, LA; S. 466

" 20 Stephanops lamellaris Ehrbg.; ㅇ; a) VA; b) LA (140×) S. 467

"2 2 Diaschiza lacinulata O. F. Müller; $O$; a) DA ( $50 \times)$; b) Kauapparat $(250 \times)$ S. 469

" 22 Salpina mucronata Ehrbg.; ; ; a) LA (1 10 $\times$ ); "b) Kauapparat (etwas stärker vergr.) S. 470

" 23 Diploïs daviesae Gosse; 9 , DA; S. 470

" 24 Euchlanis dilatata Ebrbg.; 9 ; a) DA (65 $メ)$; b) VA des Kopfteiles $($ I $10 \times$ ); c) Kauapparat $(100>$ ) S. 472 


\section{Tafel XVI}

\section{Rotatoria}

\section{Plö̈ma (Fortsetzung)}

Inbetreff der Abkürzungen u. s. w. siehe die Kopfbemerkungen zu Tafel XIV.

Fig. I Cathypna luna Ehrbg.; 옹 DA; (110×) S. 473

" 2 Distyla ludwigi Eckstein; 9 , DA; bei tieferer Einstellung, um die innern Organe zu zeigen; Rückenpanzerfelderung nicht sichtbar; $(120 \times)$ S. 474

", 3 Monostyla lunaris Ehrbg.; $q$. VA; (140>) S. 475

" 4 Colurus bicuspidatus Ehrbg.; +, LA; (150×) S. 477

$" 5$ Dasselbe, doch $\delta$; (bei gleicher Vergrösserung) LA; S. 477

" 6 Monura dulcis Ehrbg.;, , LA; nach Ehrenberg (stark vergr.) S. 477

" 7 Metopidia oxysternum Gosse; + , LA; $(100 \times)$ S. 478

" 8 Met. triptera Ehrbg.; 9 , DA; $(150 \times)$ S. 478

" 9 Squamella bractea Ehrbg.; , DA; nach Ehrenberg (stark vergr.) S. 479

" Io Pterodina patina Ehrbg.;,$+ \mathrm{VA}$; der aus der Panzeröffnung hervortretende Fuss deutlich zu erkennen ( 1 IO $\times$ ) S. 480

"II Pompholyx complanata Gosse; + , DA; nach Hudson u. Gosse (stark vergr.) S. $48 \mathrm{I}$

, 12 Brachionus urceolaris Ehrbg.; mit zwei anhängenden Eiern ; $q$, DA ; $(45 \times)$ S. 483

, 13 Noteus quadricornis Ehrbg.; ㅇ, DA; die innern Organe schimmern durch den Panzer durch; (110 $>$ ) S. 482

"14 Anuraea cochlearis Gosse; 0 , DA; (110 $>$ ) S. 486

"15, Notholca striata Ehrbg.; + , VA; $(100 \times)$ S. 487

"I6" Noth. longispina Kellicott; +, DA; $(80 \times)$ S. 487

"I 7 Ploesoma truncatum Leander; $0, \mathrm{DA}$; es ist fast nur der Bau der Schale zu sehen; $(10 \times)$ S. 488

" 18 Gastropus stylifer Imhof; ㅇ, LA; (120×) S. 489

" 19 Anapus ovalis Bergendal; +, DA; $(95 \times)$ S. 489

\section{Scirtopoda}

Fig. 20 Pedalion mirum Hudson; $ᄋ$, VA; $(45 \times)$ S. 490

" 2 I Dasselbe, doch $\delta$ (stark vergr.); nach Hudson u. Gosse; S. 490

\section{Gastrotricha}

Fig. 22 : Ichthydium podura O. F. Müller; VA; nach Zelinka $(400 \times)$ S. 493

" 23 Lepidoderma squamatum Duj.; DA; nach Zelinka $(200 \times)$ S. 493

" 24 Chaetonotus maximus Ehrbg.; a) DA $(200 \times)$; b) Rumpfstachel (1200 $>$ );

c) Ei im optischen Durchschnitte $(210 \times)$; a u. b nach Zelinka, c Orig.; S. 494

" 25 Chaet. persetosus Zelinka; LA; nach Z elink a (200 $\rtimes)$ S. 495

" 26 Chaetura capricornia Metsch.; DA; nach Metschnikoff (stark vergr.) S. 495

" 27 Dasydytes longisetosum Metschn.; DA; nach M ets chnik off (stark vergr.) S. 496

\#28 Gossea antennigera (Gosse); DA; nach Gosse (200 $\succ$ ) S. 496 


\section{Inhalt.}

Einleitung . . . . . . . . . . . . . . . . . 1

Geschichtlicher Rückblick . . . . . . . . . . . . . . . 4

Einführung . . . . . . . . . . . . . . . . . . . . . . . 9

Schlüssel . . . . . . . . . . . . . . . . . . . 22

Pflanzliche Organismen . . . . . . . . . . . . . . 24

I. Schizophytae. . . . . . . . . . . . . . . 25

I. Bacteriaceae . . . . . . . . . . . . 25

II. Schizophyceae . . . . . . . . . . . . 48

I. Coccogoneae . . . . . . . . . . 50

II. Hormogoneae . . . . . . . . . . . 59

II. Euphyceae . . . . . . . . . . . . . . . 83

I. Chlorophyceae . . . . . . . . . . . . . 86

I. Protococcoideae . . . . . . . . . . . 87

II. Confervoideae . . . . . . . . . . . . . II9

III. Siphoneae . . . . . . . . . . . . . 138

II. Conjugatae . . . . . . . . . . . . . . . . I4I

I. Desmidiaceae . . . . . . . . . . . . 142

I. Eudesmidieae . . . . . . . . . . I 45

II. Didymoideae . . . . . . . . . . . 148

II. Zygnemaceae . . . . . . . . . . . . . . . I71

III. Bacillariaceae (Diatomeae) . . . . . . . . . . . 178

A. Centricae . . . . . . . . . . . . . 182

I. Discoideae . . . . . . . . . . 183

II. Solenoideae . . . . . . . . . . 186

III. Biddulphioideae . . . . . . . . . . . 186

B. 'Pennatae . . . . . . . . . . . 187

IV. Fragilarioideae . . . . . . . . . 187

V. Achnanthoideae . . . . . . . . . 197

VI. Naviculoideae . . . . . . . . . . 199

VII. Surirelloideae . . . . . . . . . 223

IV. Peridiniaceae . . . . . . . . . . . . . . 227

V. Characeae . . . . . . . . . . . . . . . 235

VI. Phaeophyceae . . . . . . . . . . . . . 235

VII. Rhodophyceae . . . . . . . . . . . . . 238

I. Florideae .. . . . . . . . . . . . . . . . 239

II. Bangiaceae etc. . . . . . . . . . . . . 242

III. Fungi . . . . . . . . . . . . . . . . . 245 
Tierische Organismen ............... . . . . . . 248

I. Protozoa . . . . . . . . . . . . . . . . . . 249

I. Sarcodina . . . . . . . . . . . . . . . . . . 249

I. Rhizopoda . . . . . . . . . . . . 25I

II. Heliozoa . . . . . . . . . . . . . . 271

II. Mastigophora . . . . . . . . . . . . . . 279

I. Protomastigina . . . . . . . . . . . . 283

II. Polymastigina . . . . . . . . . . . . 306

III. Euglenoidina . . . . . . . . . . . . 312

I. Euglenida . . . . . . . . . . . 312

II. Astasiida . . . . . . . . . . . . . . 321

III. Peranemida . . . . . . . . . . . 323

IV. Chloromonadina . . . . . . . . . . . . 330

V. Holomastigina . . . . . . . . . . . . . 331

VI. Chromomonadina . . . . . . . . . . . 332

Anhang: Hydrurina . . . . . . . . 34

III. Ciliata . . . . . . . . . . . . . . . . 342

A. Gymnostomata . . . . . . . . . . . 349

B. Trichostomata . . . . . . . . . . 363

I. Aspirotricha . . . . . . . . . . 363

II. Spirotricha . . . . . . . . . . 374

A. Heterotricha . . . . . . . . . 374

B. Oligotricha . . . . . . . 381

C. Hypotricha . . . . . . . . 383

D. Peritricha . . . . . . 396

IV. Suctoria . . . . . . . . . . . . . . 410

II. Rotatoria . . . . . . . . . . . . . . . . 418

I. Rotifera . . . . . . . . . . . . . 430

I. Rhizota . . . . . . . . . . . . . . . 430

II. Bdelloida . . . . . . . . . . . . . . . . 437

III. Ploïma . . . . . . . . . . . . . . . . . 443

A. Illoricata . . . . . . . . . . . . . 443

B. Loricata . . . . . . . . . . . . 459

IV. Scirtopoda . . . . . . . . . . . . 490

II. Gastrotricha . . . . . . . . . . . . . . 49I

Register . . . . . . . . . . . . . . . . . 497

Tafelerklärung . . . . . . . . . . . . . . . . 525 
Tafel I u. II 




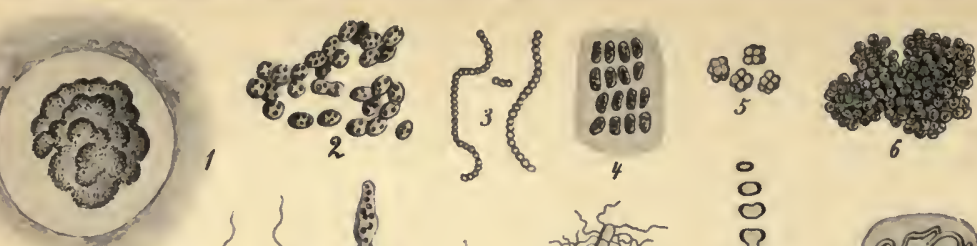

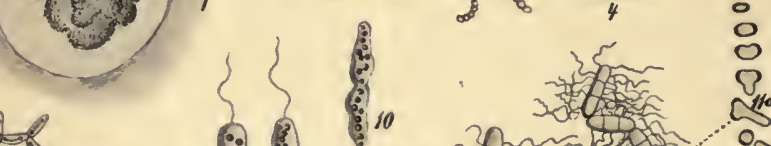

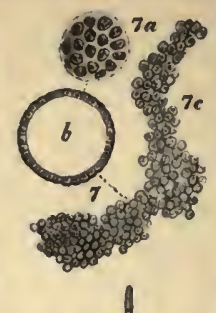

1.0.

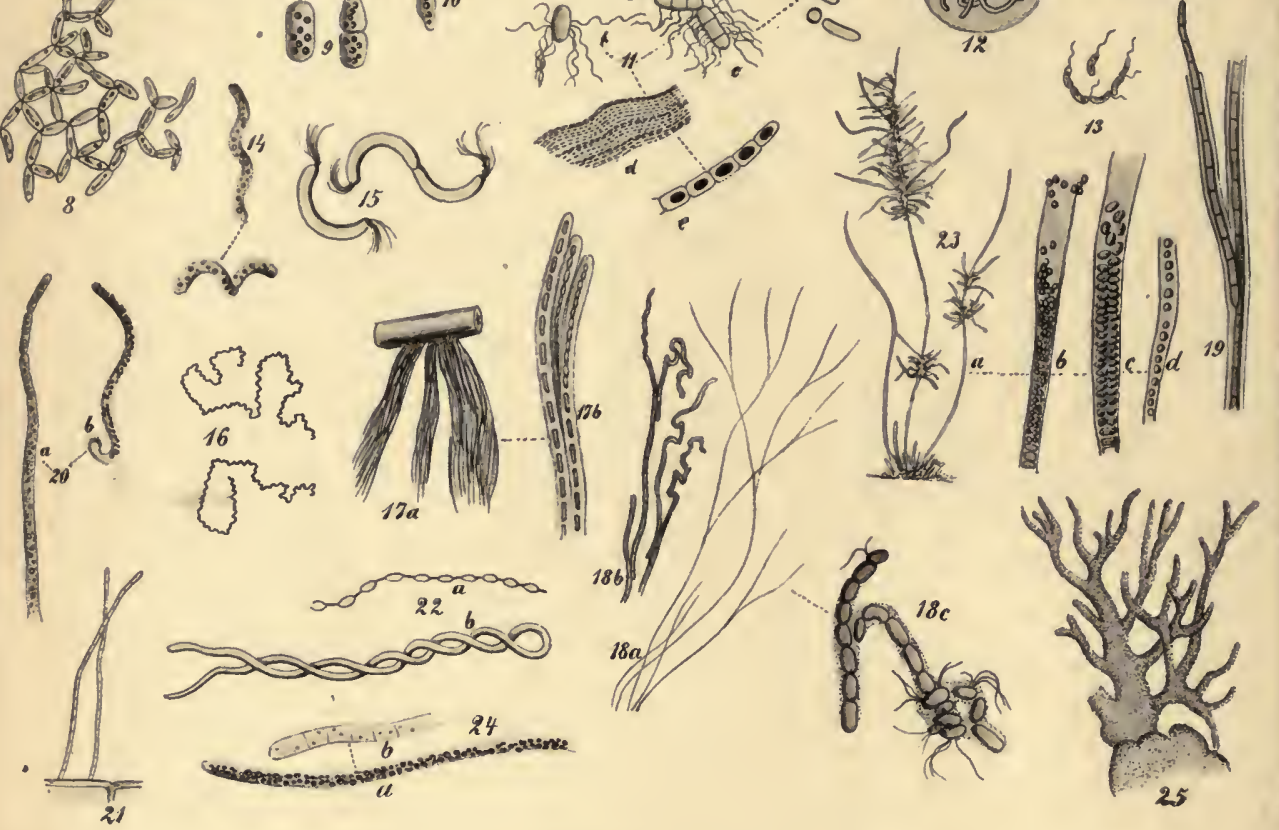

$8: 00$

(3)

20

it $C_{31}^{i}$

$\therefore$

(9)

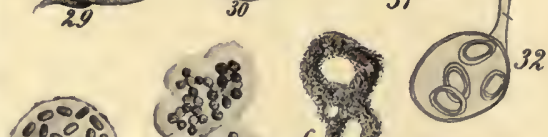

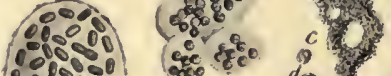

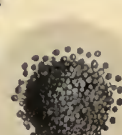

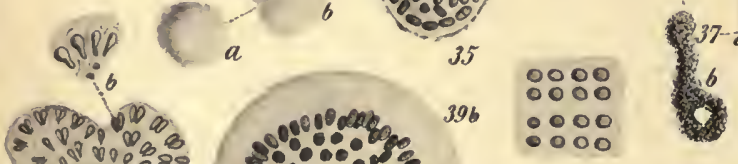
$34=\begin{aligned} & 180800 \\ & 80800 \\ & 88000 \\ & 8080 \%\end{aligned}$
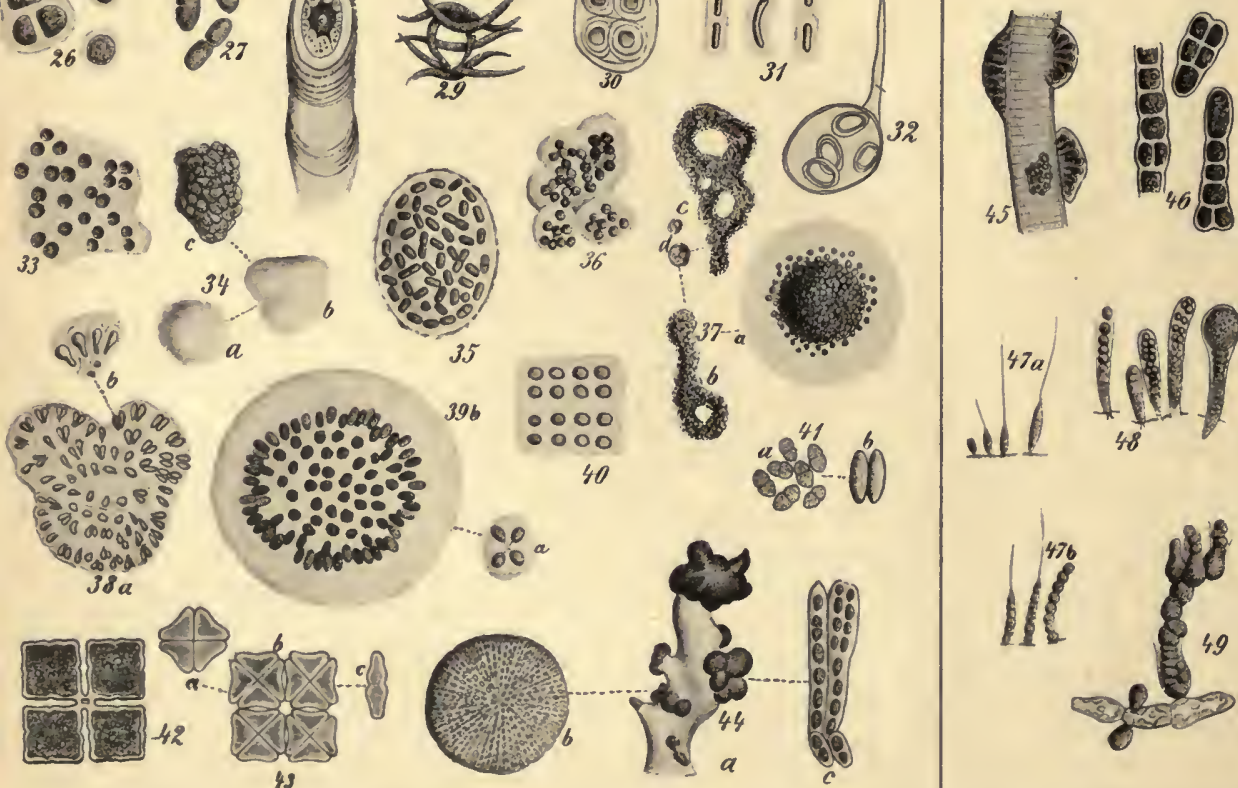

$111+48$

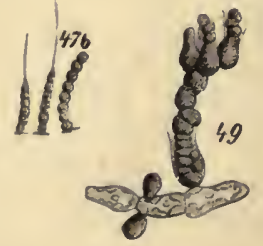




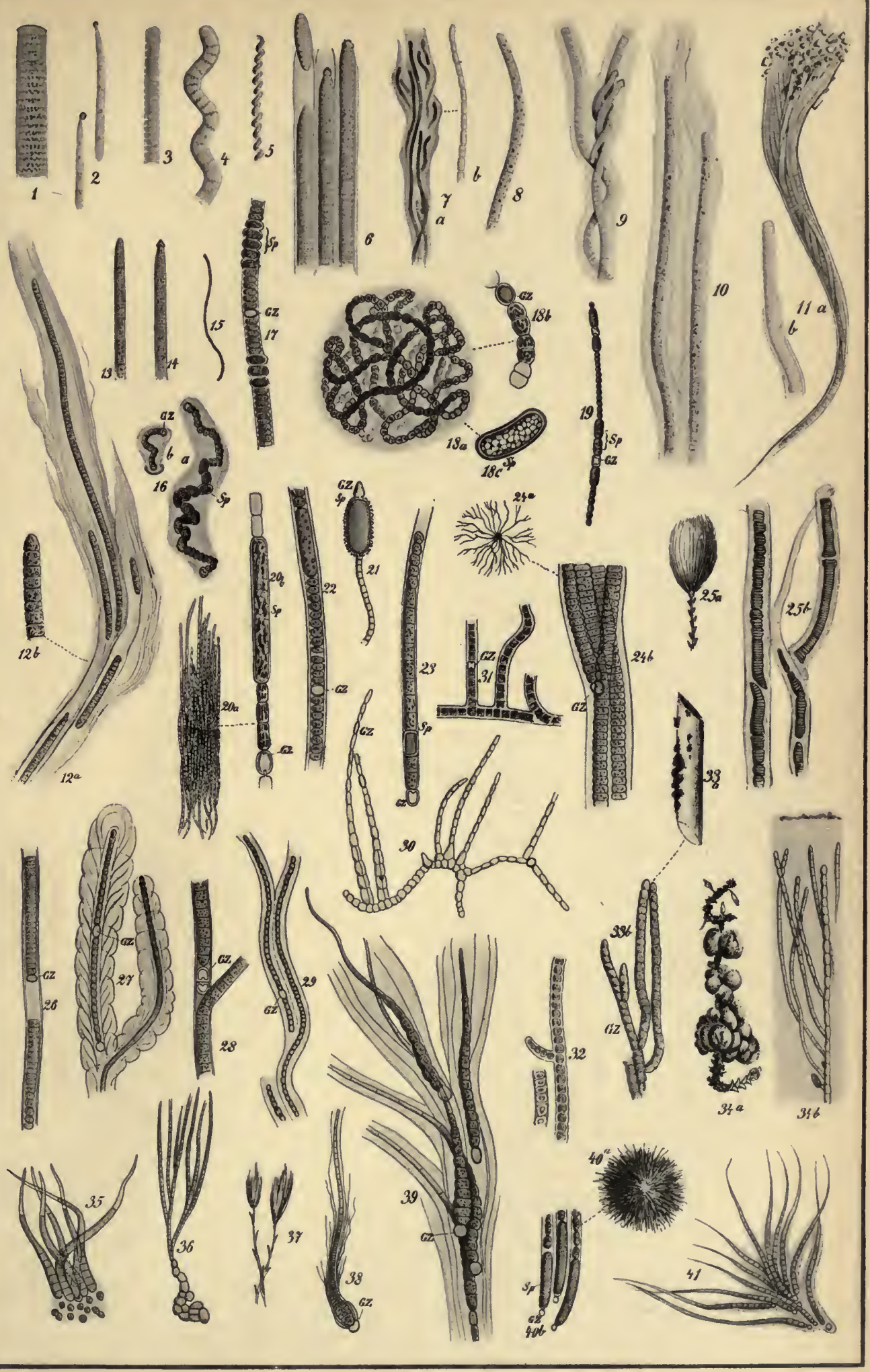



Tafel III u. IV 


$1-6$

(fi) $2 a$. $400^{\circ} 0^{\circ}: 50$

$a^{4} 0^{6} 0^{6}$

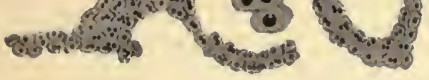

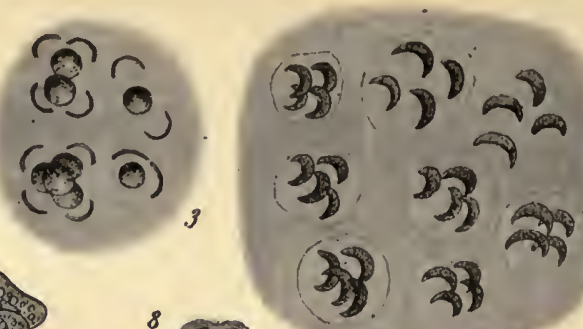

18

4

2), 5,

(3)
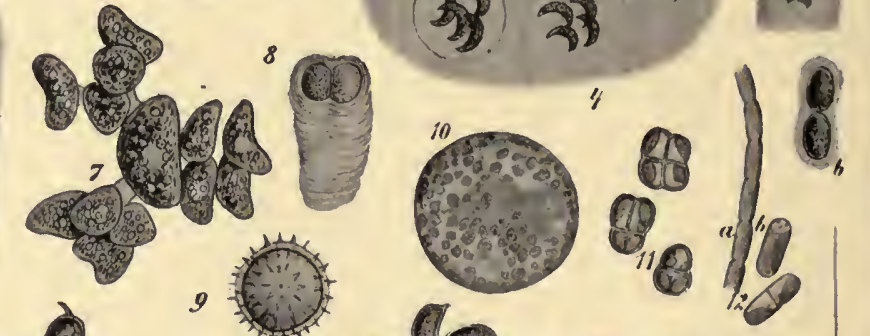
(a)

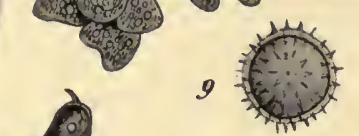

ack

201
401

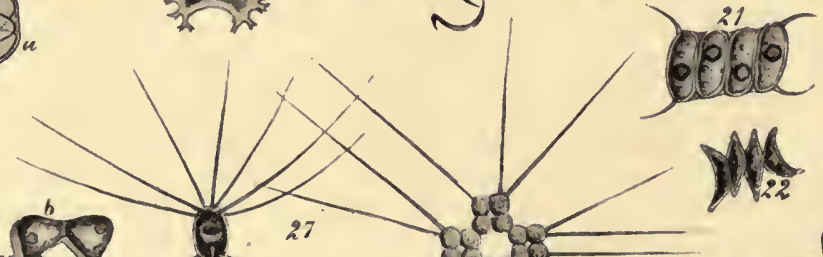

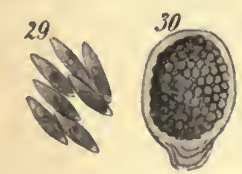
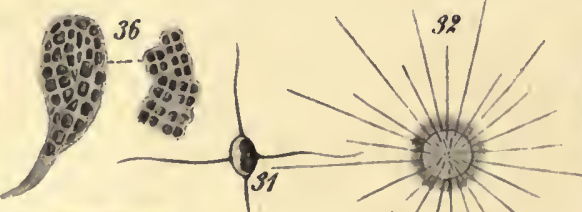

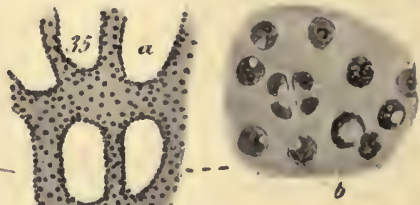

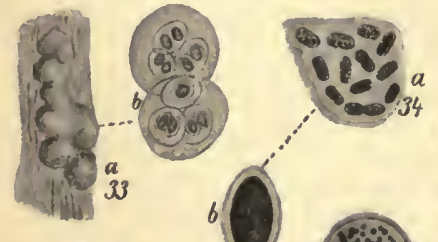

38 연?

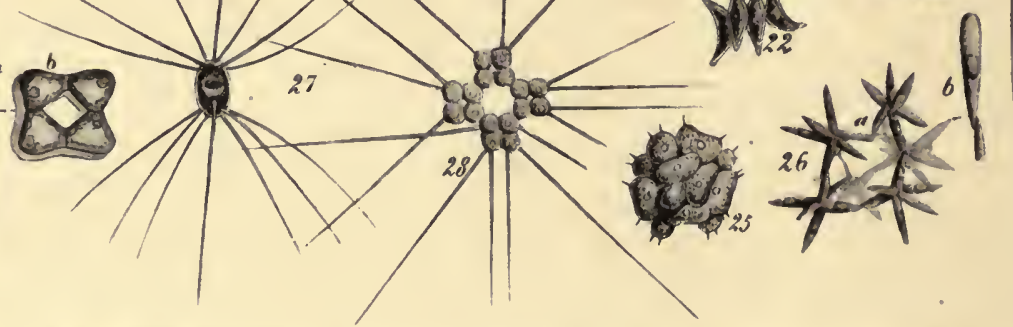

-

2.
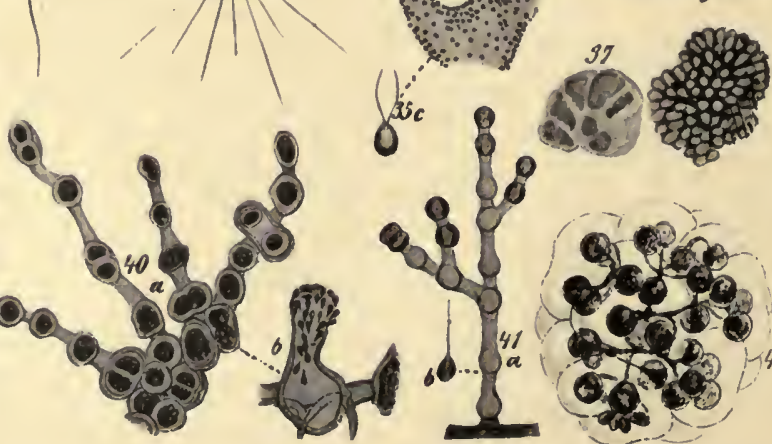

$0^{1 / 2}$

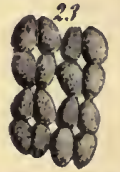




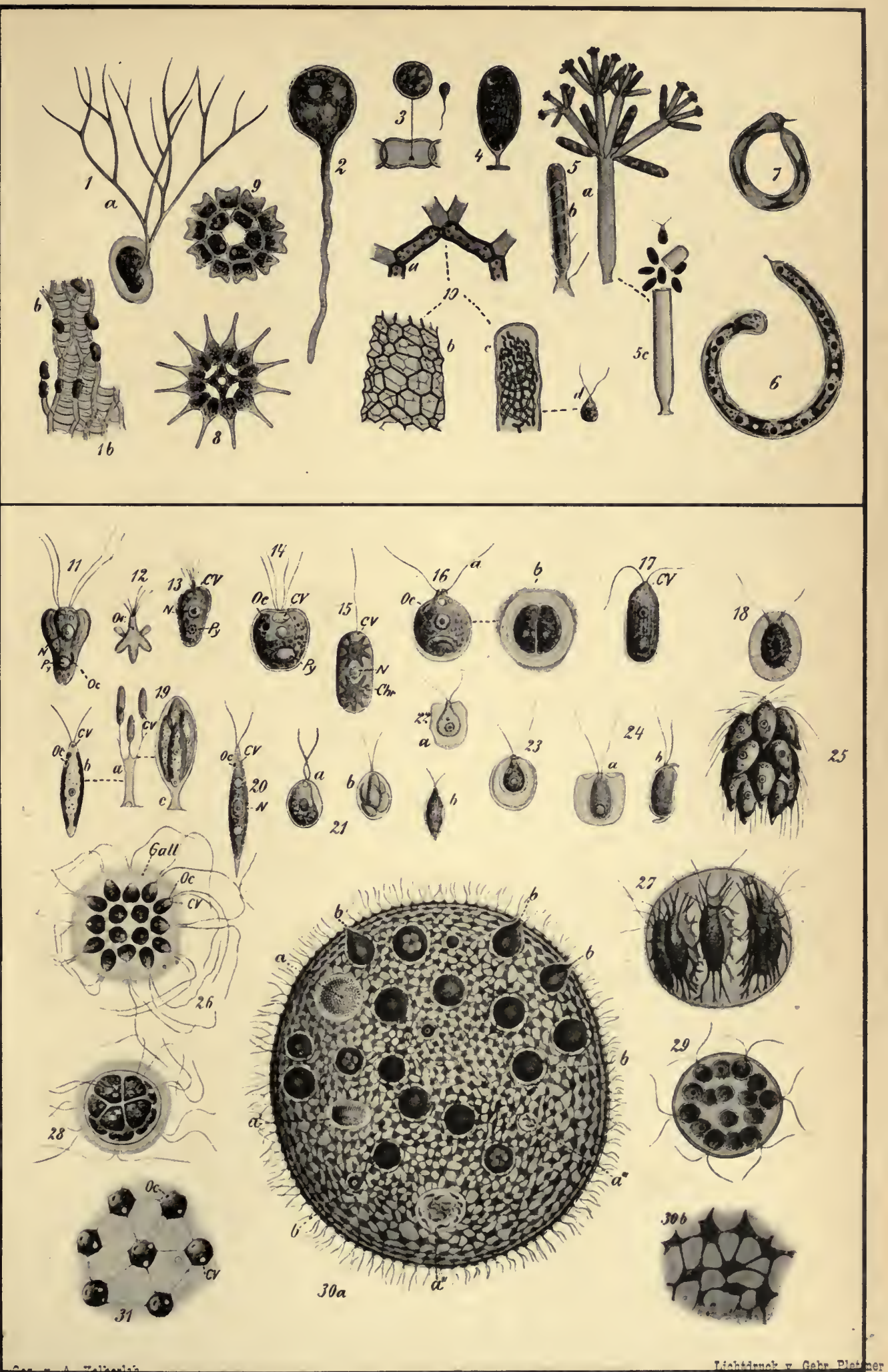



Tafel $\mathrm{V}$ u. VI 




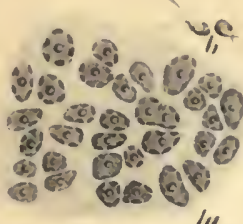
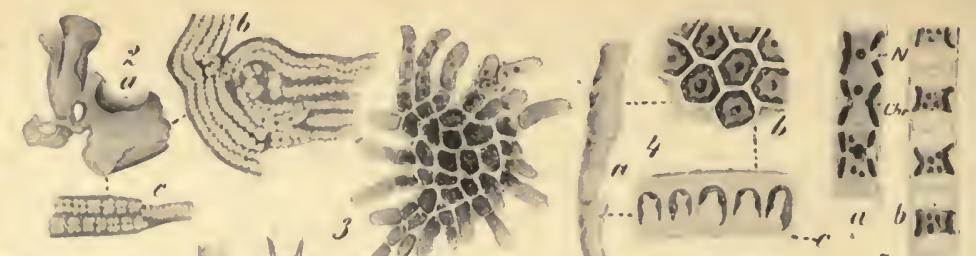

a.

(1)

fiin
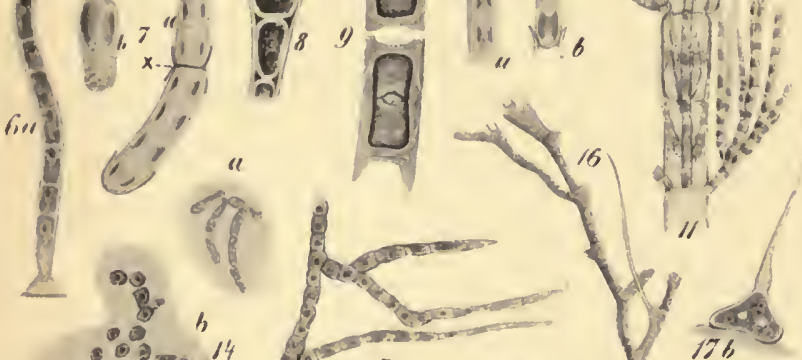

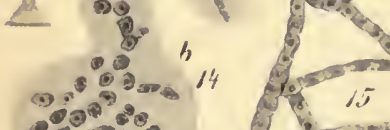

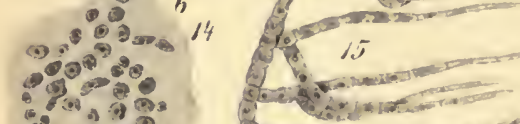

- 8 a

1: :

(1)

(临)
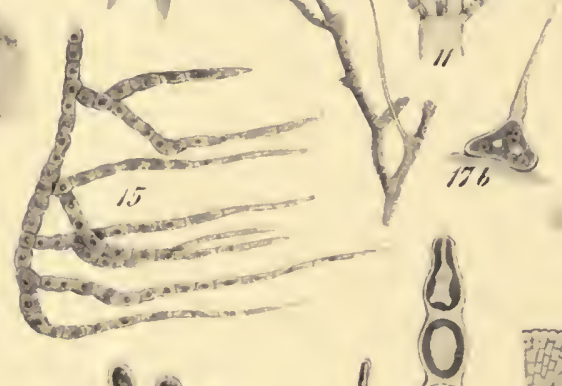

$18(20)$
$(4)$
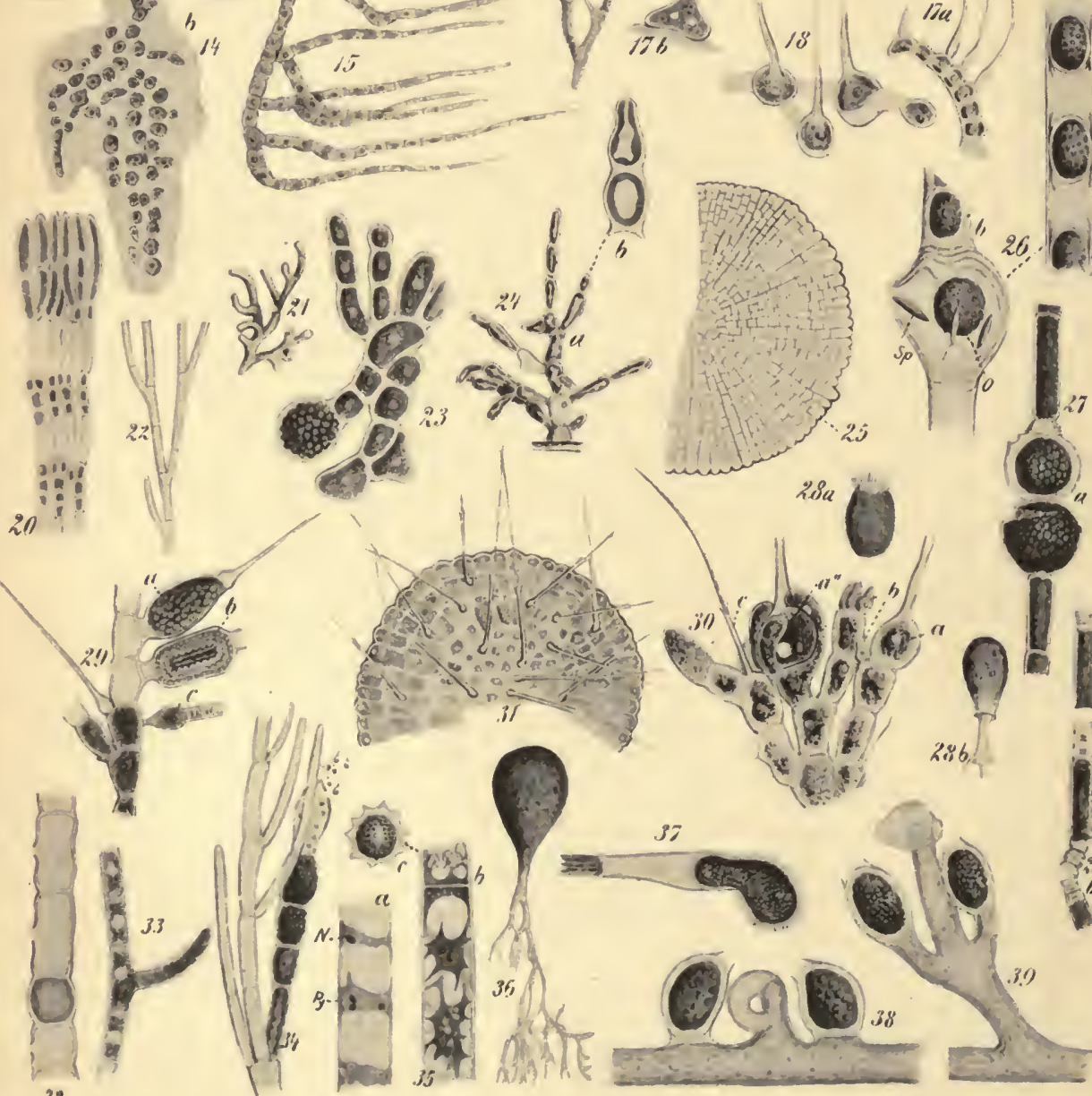

sise 13

- manth

c.

(is)

19

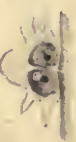




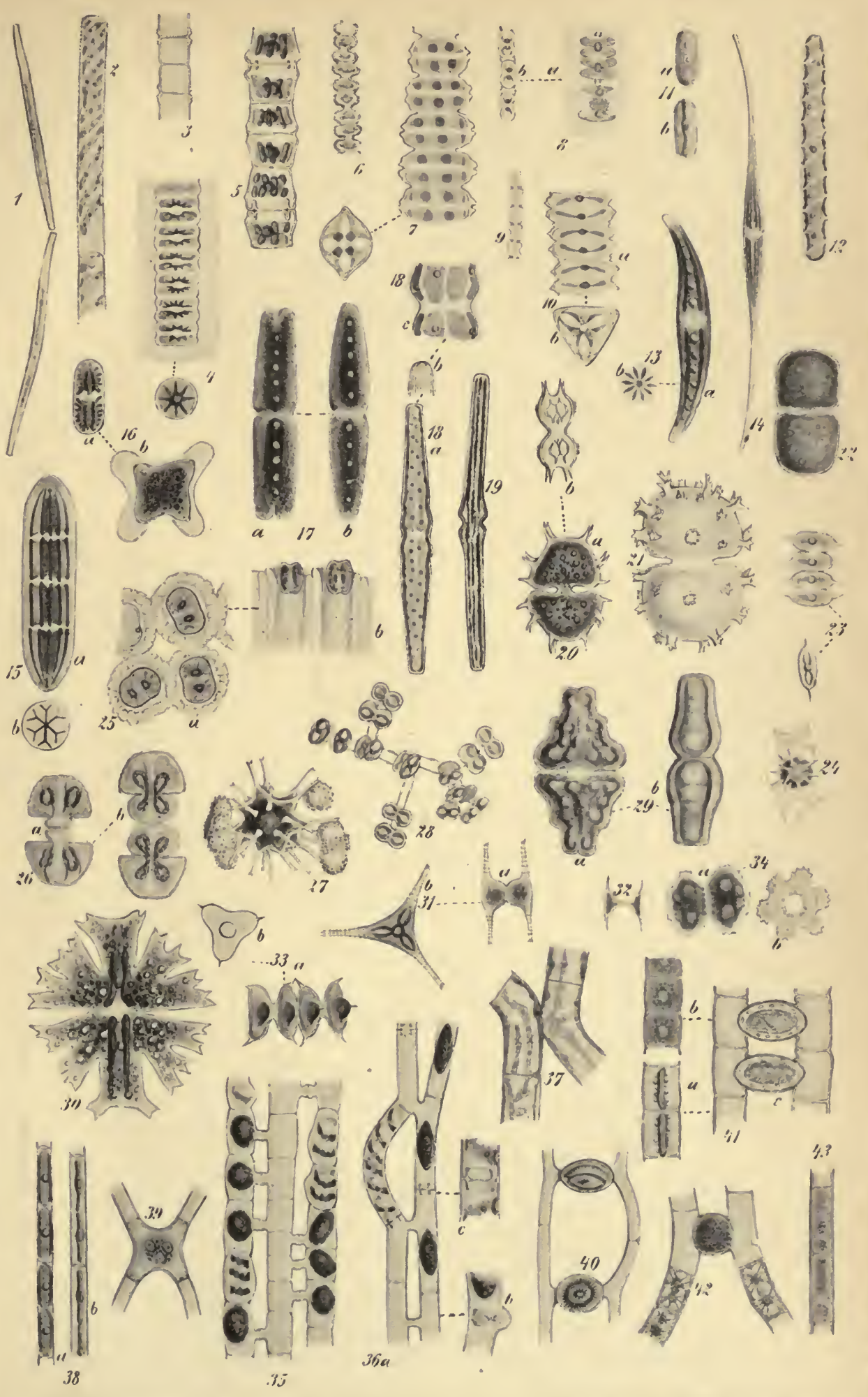





\section{Tafel VII u. VIII}






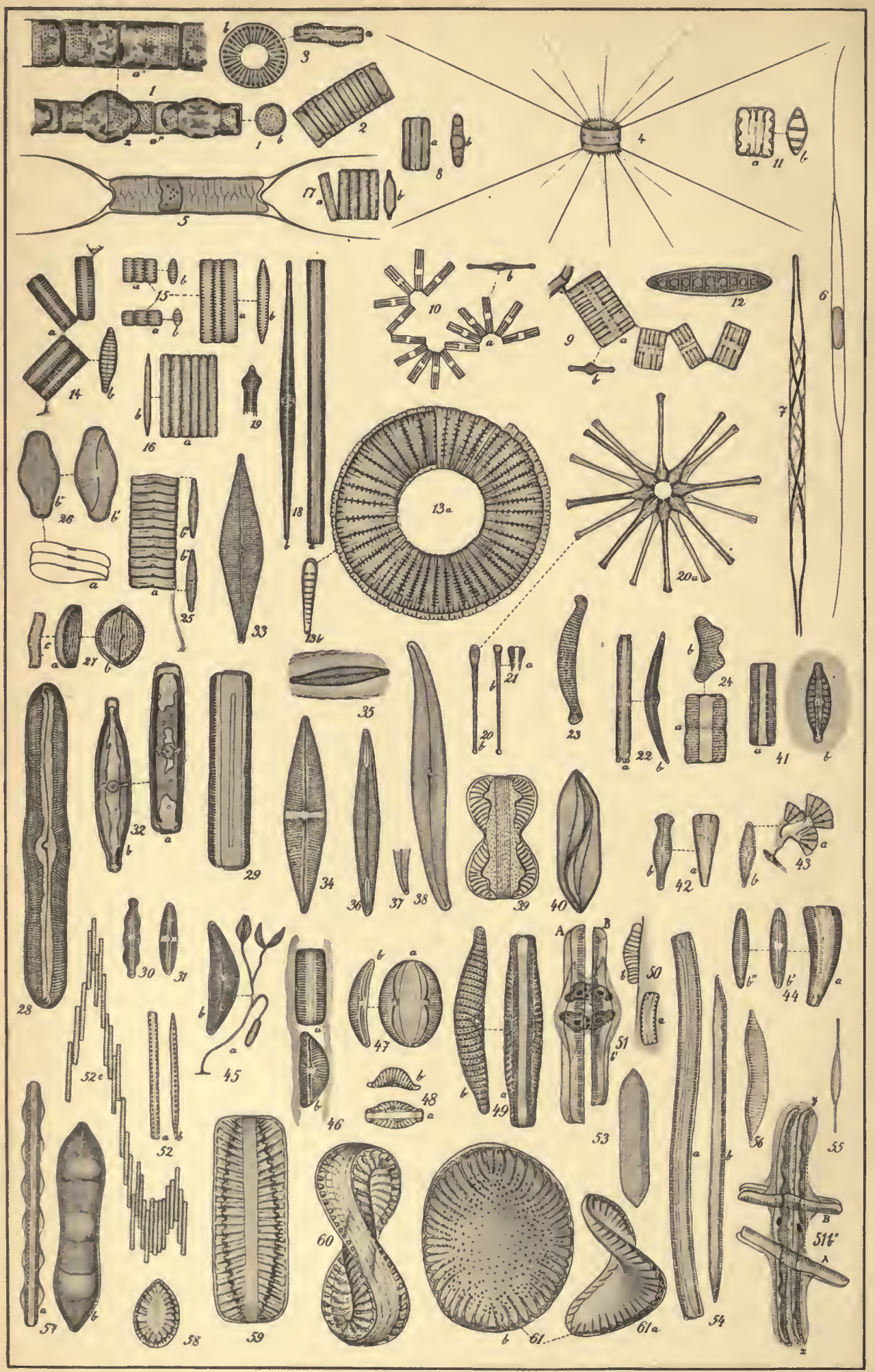




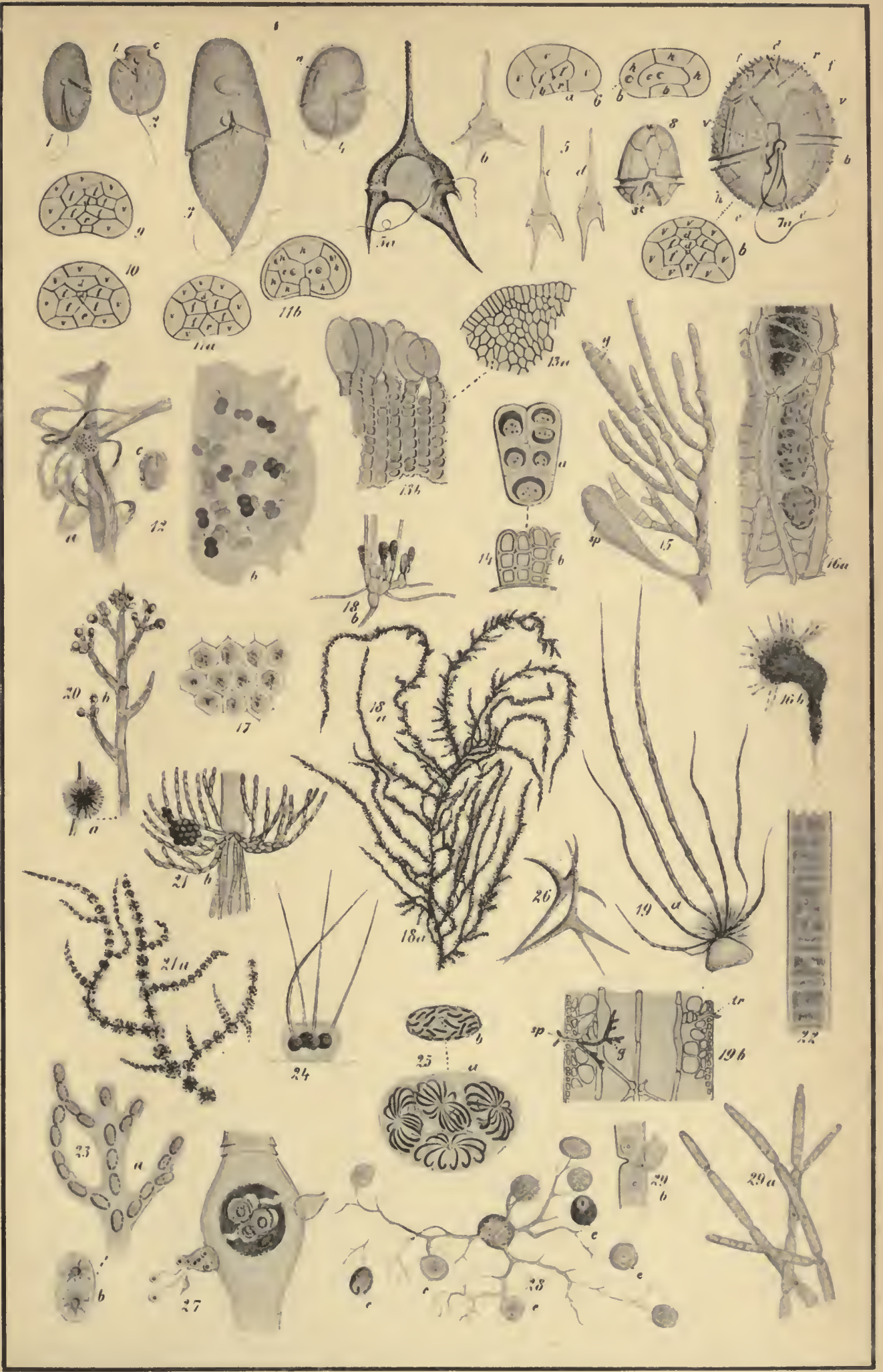



Tafel IX u. X 




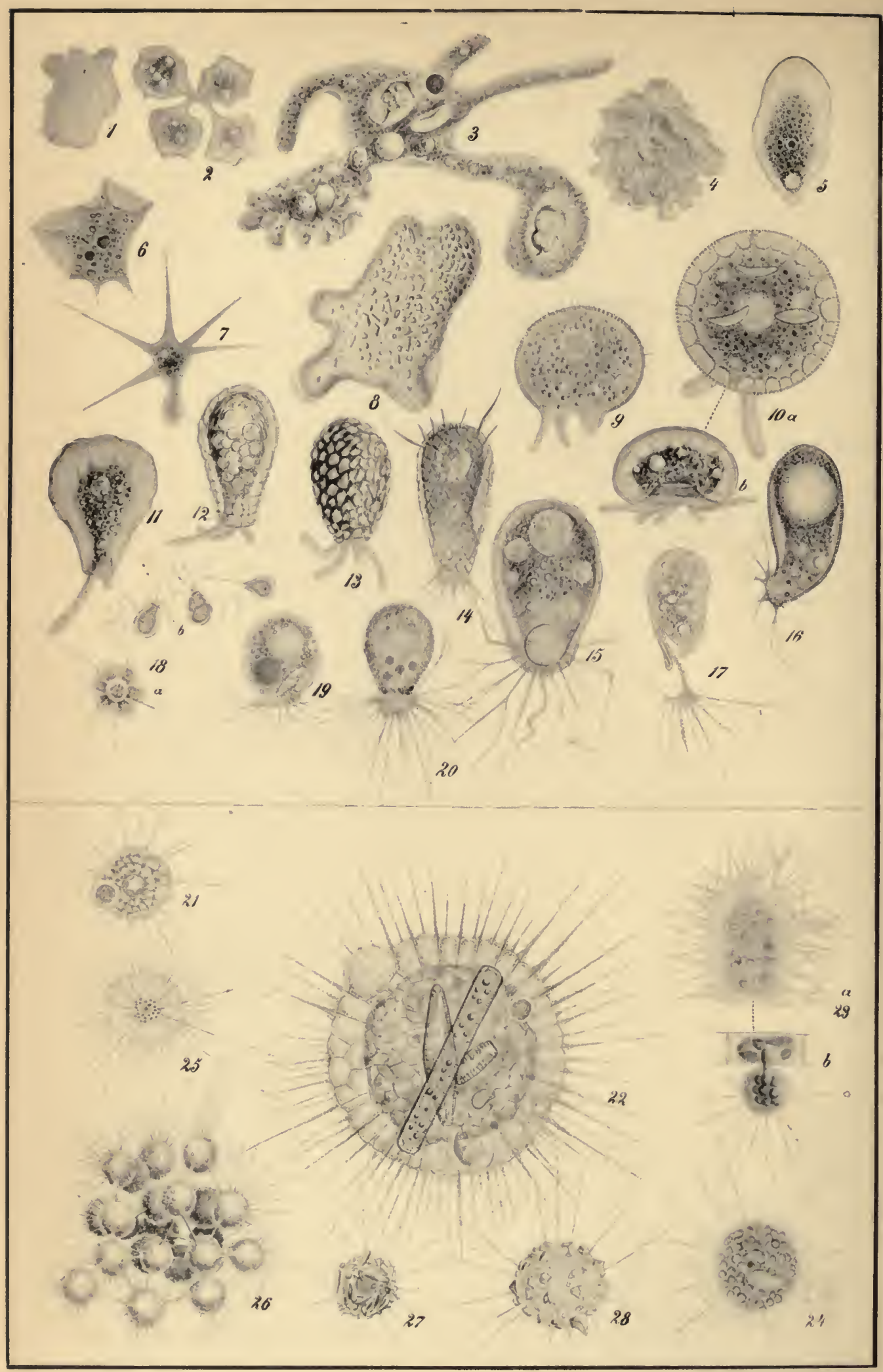




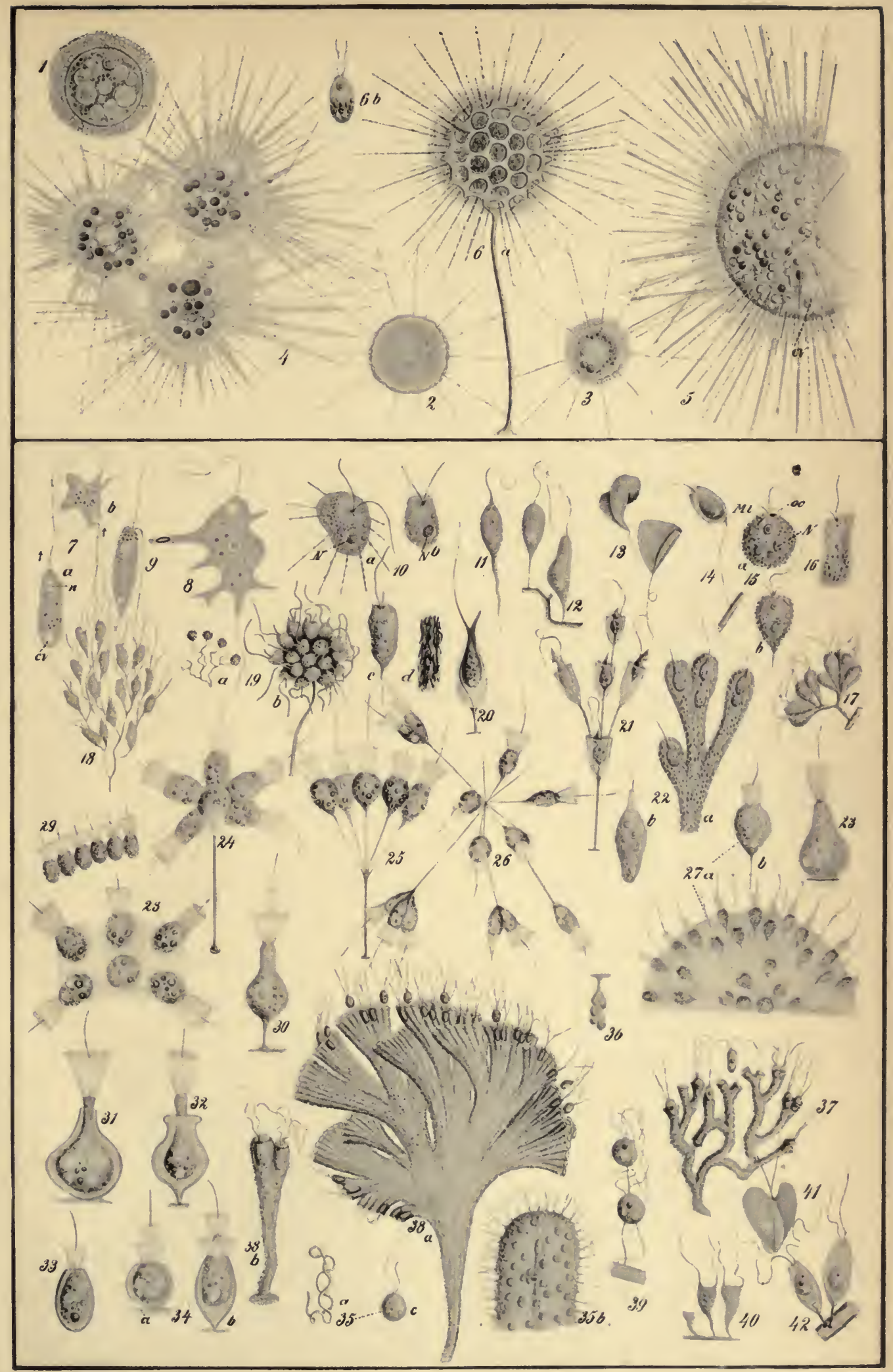



Tafel XI u. XII 




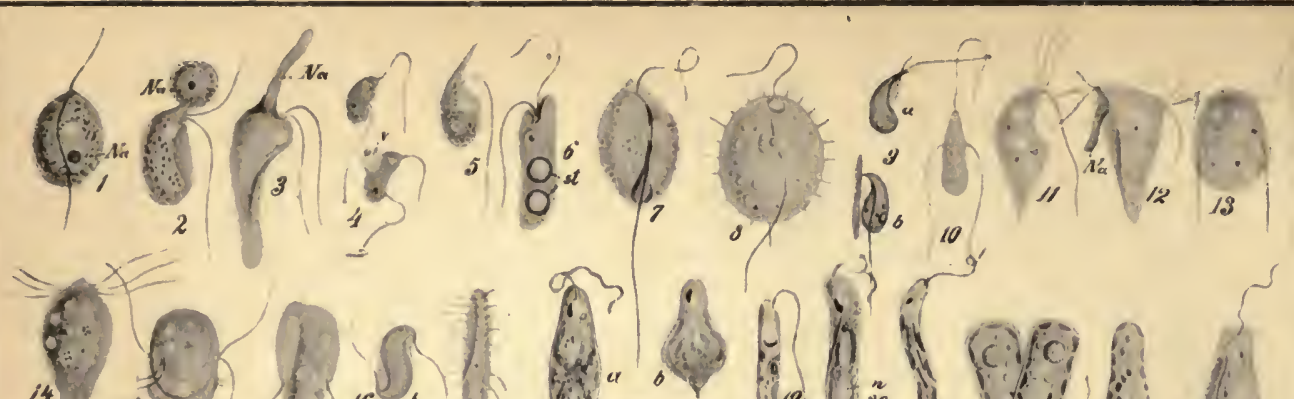

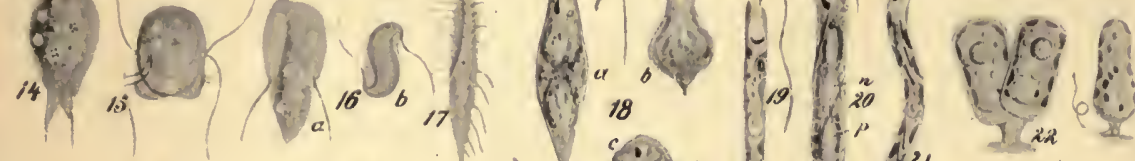

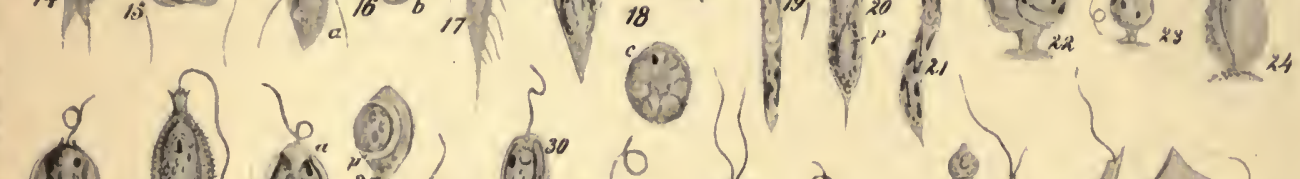

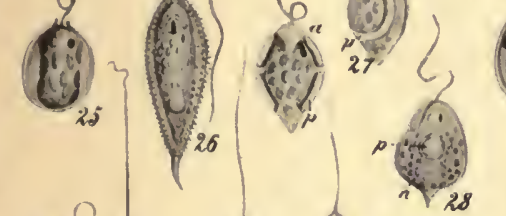

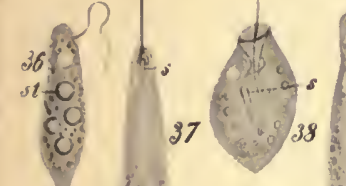

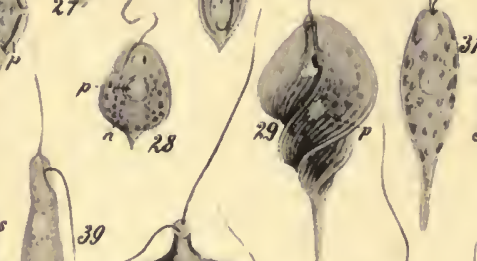

i) 1020

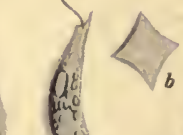

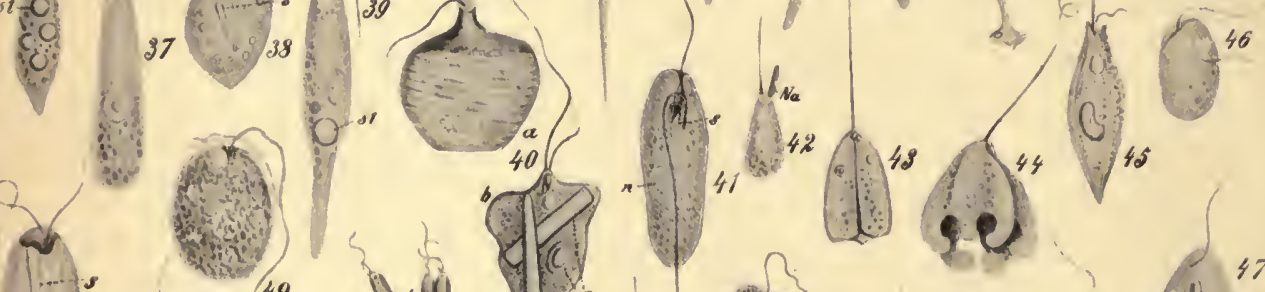

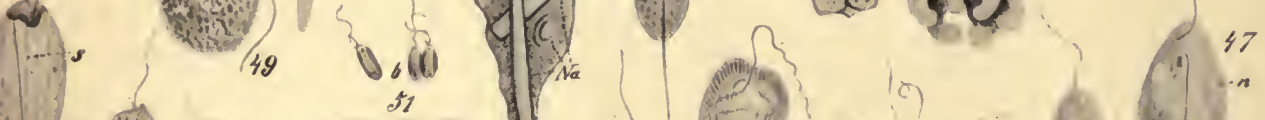

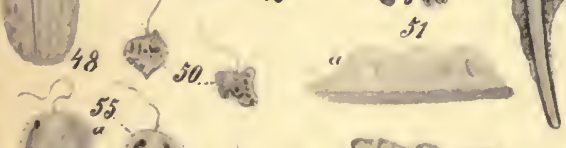

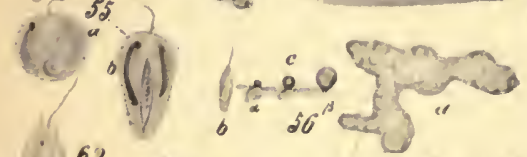

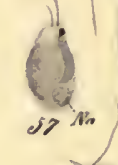

st

(1)

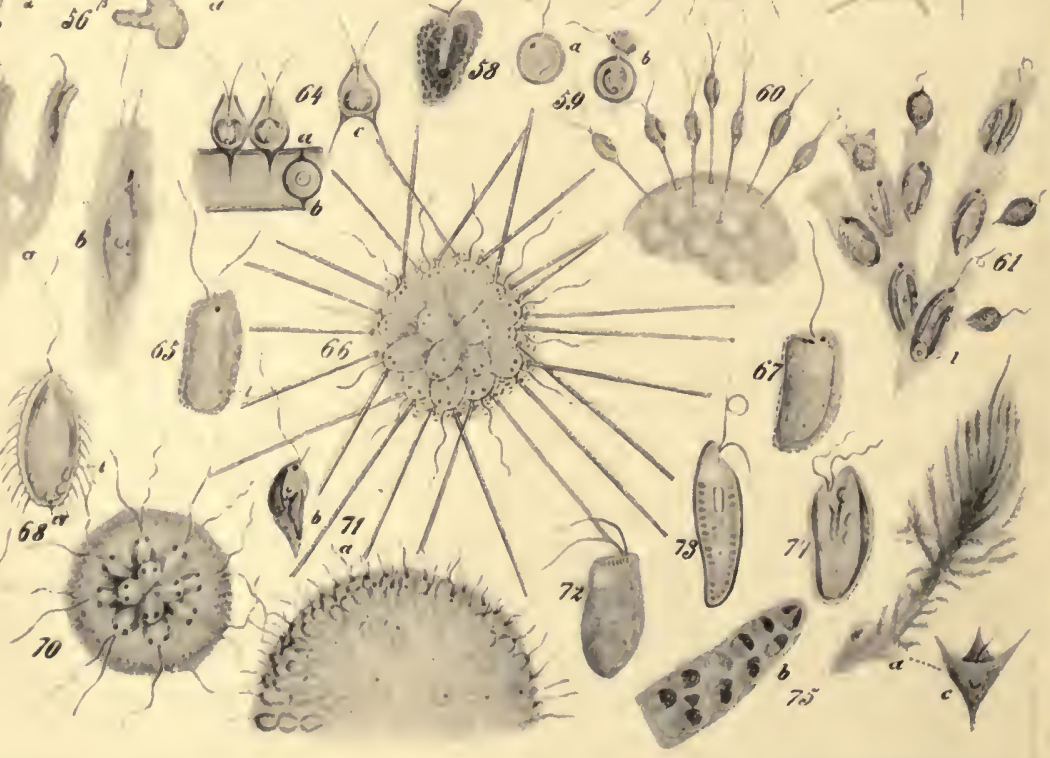

(1)

(1)

20.

( 

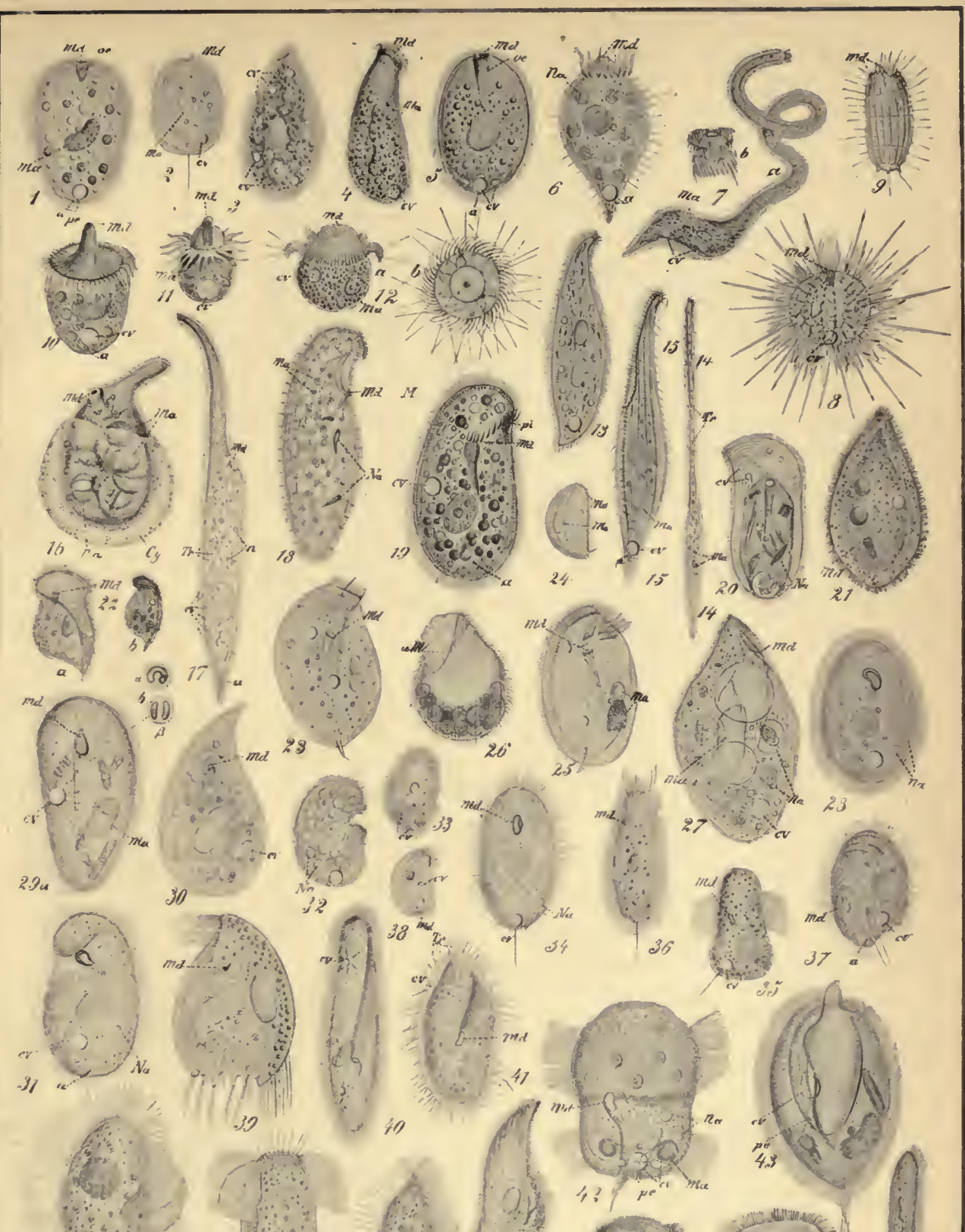

$d$

(n)
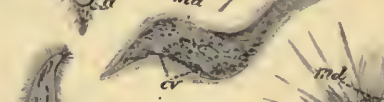

4
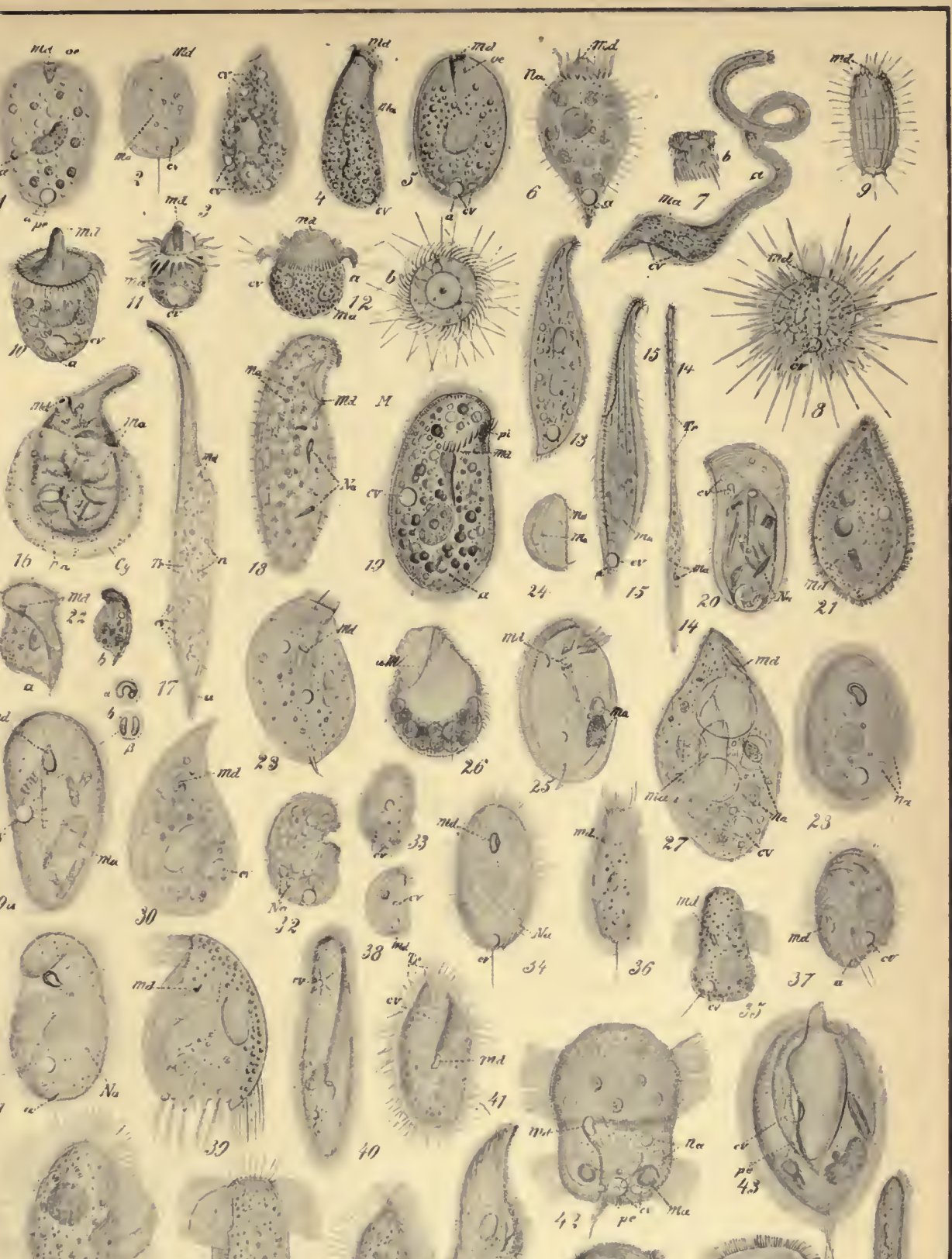

(1)

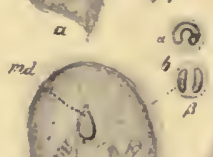
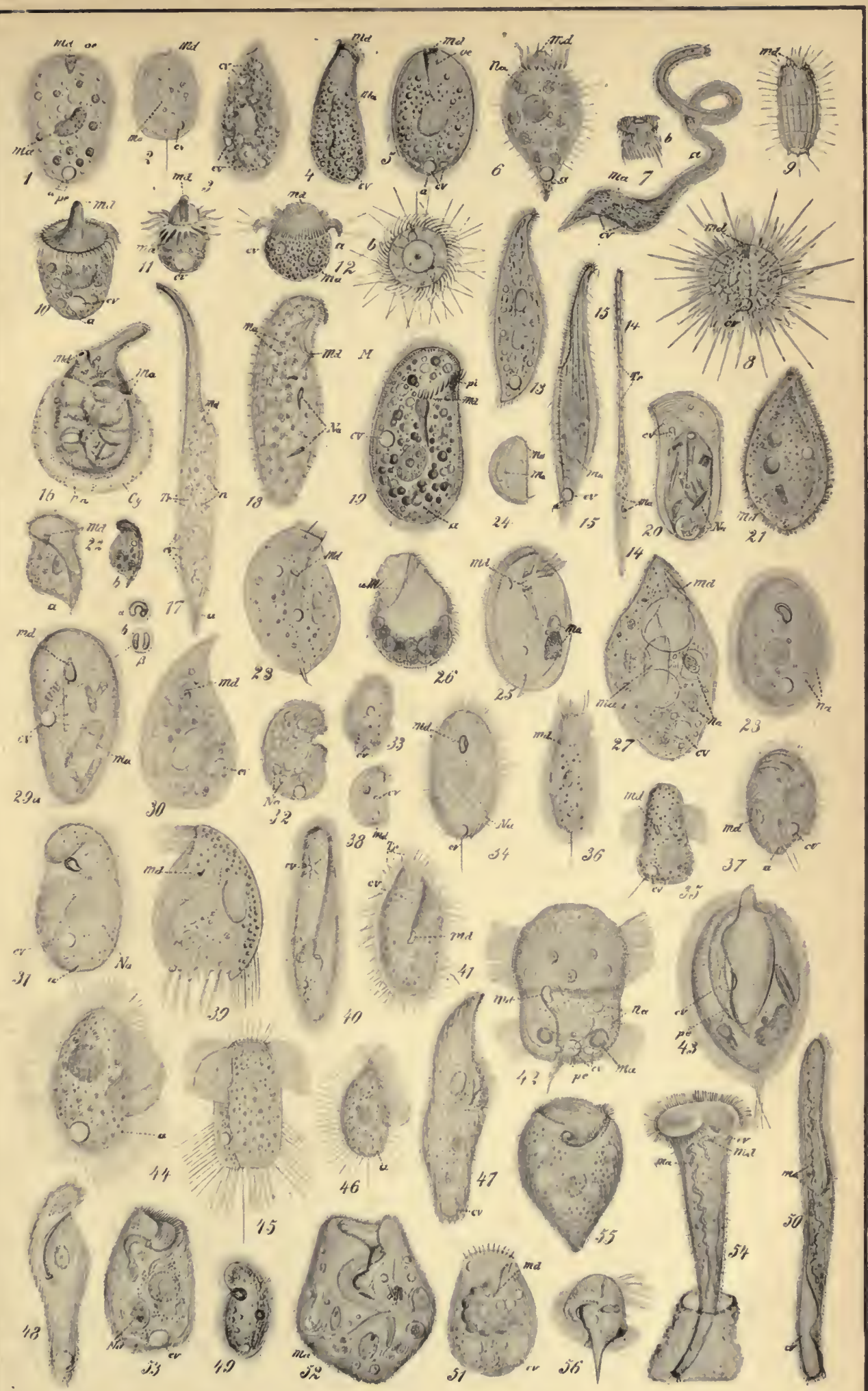

- $n_{x}$
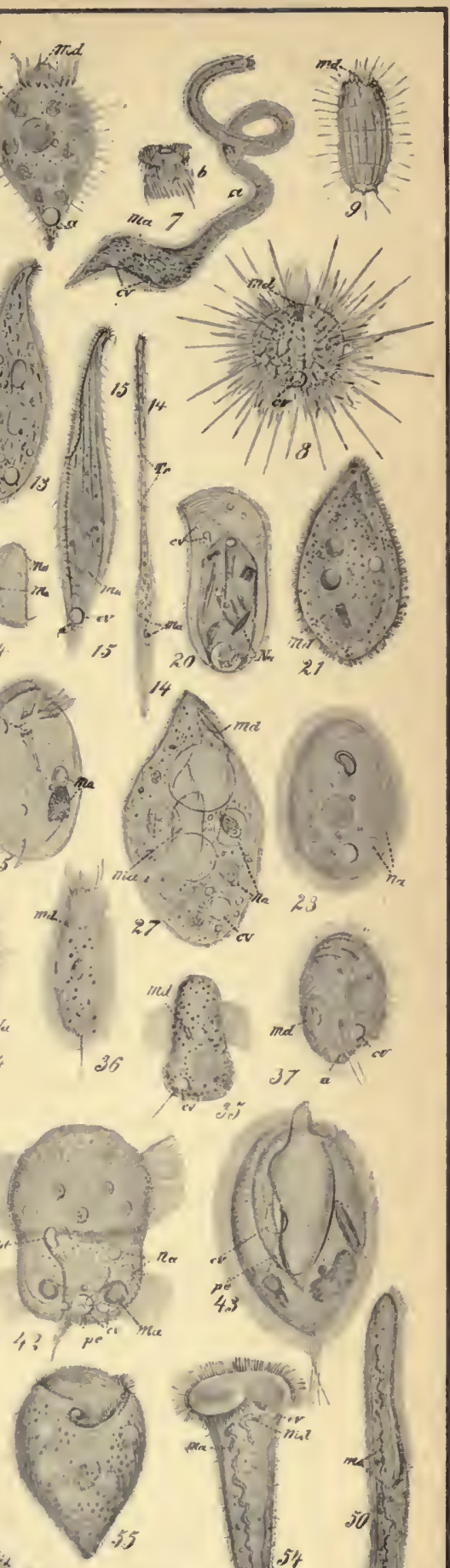

Tafel XIII u. XIV 



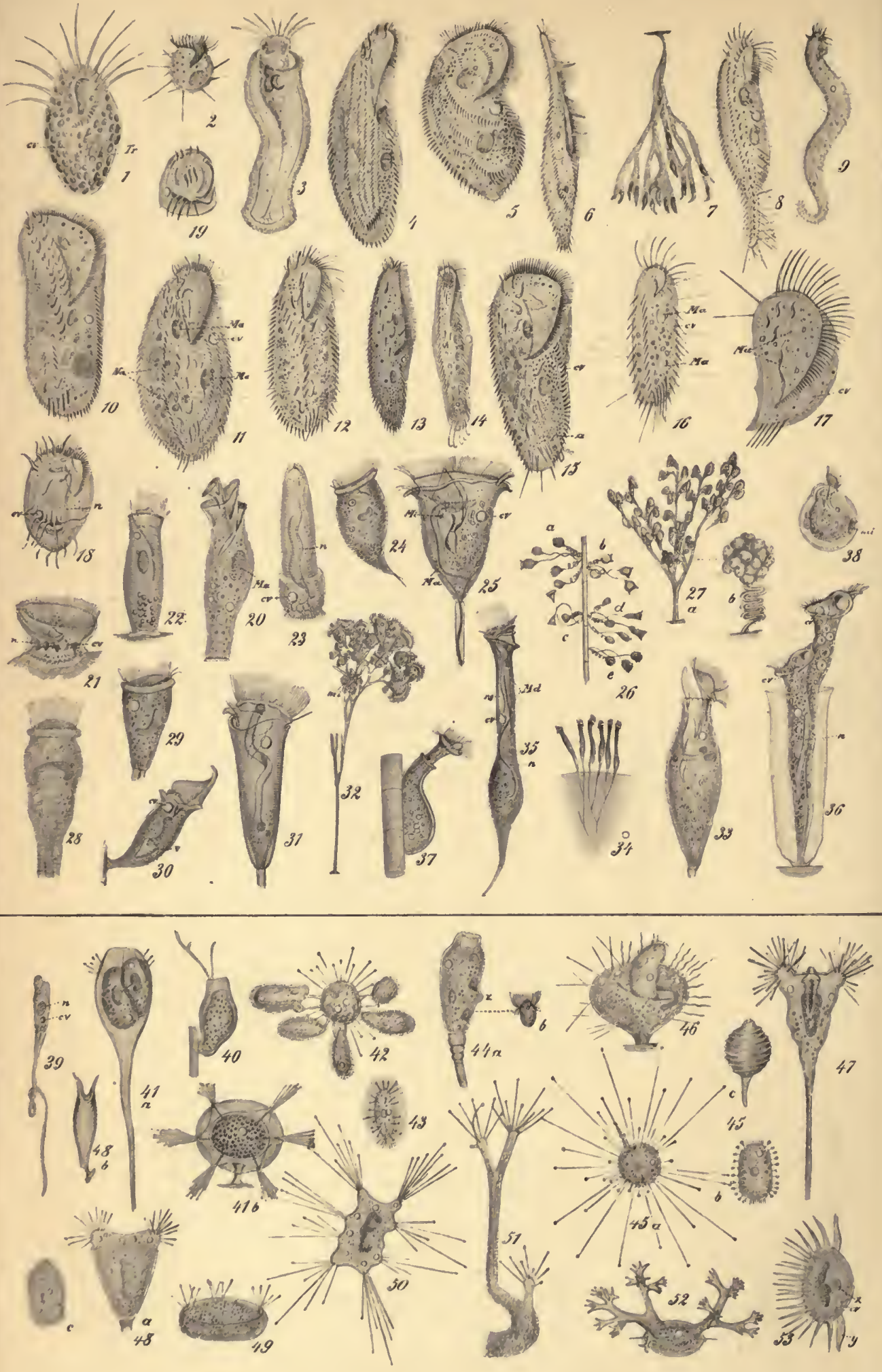


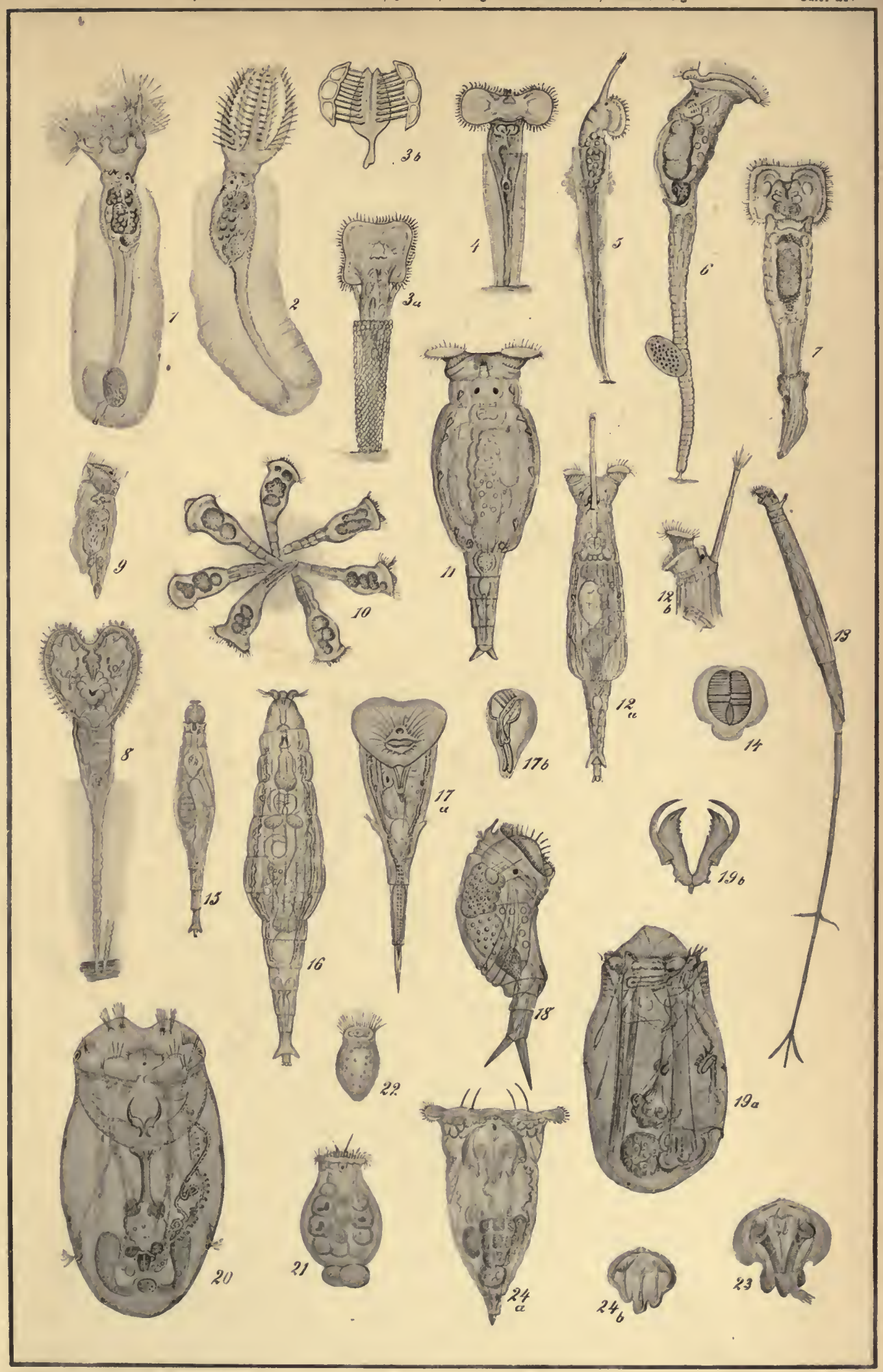



Tafel XV u. XVI 




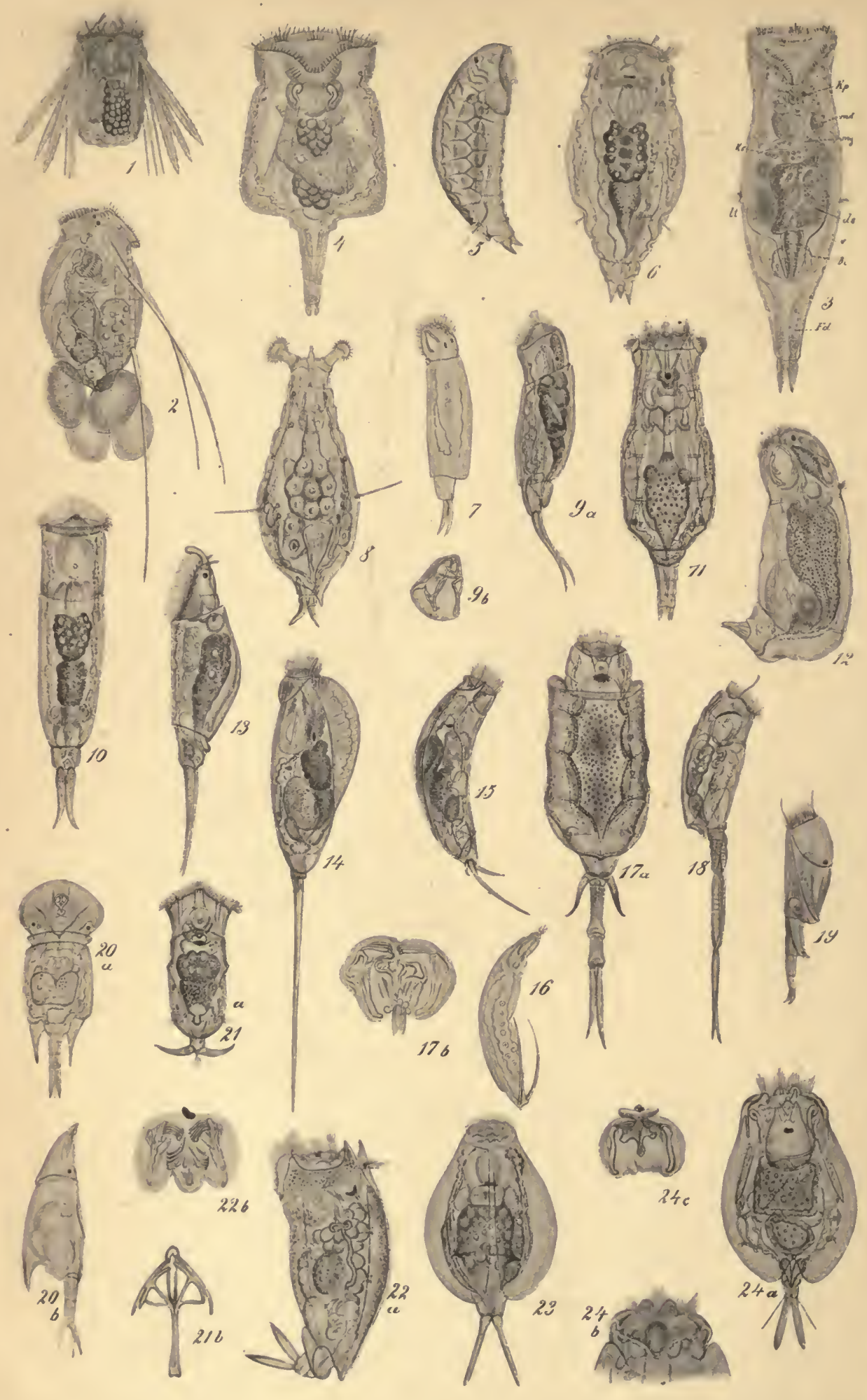




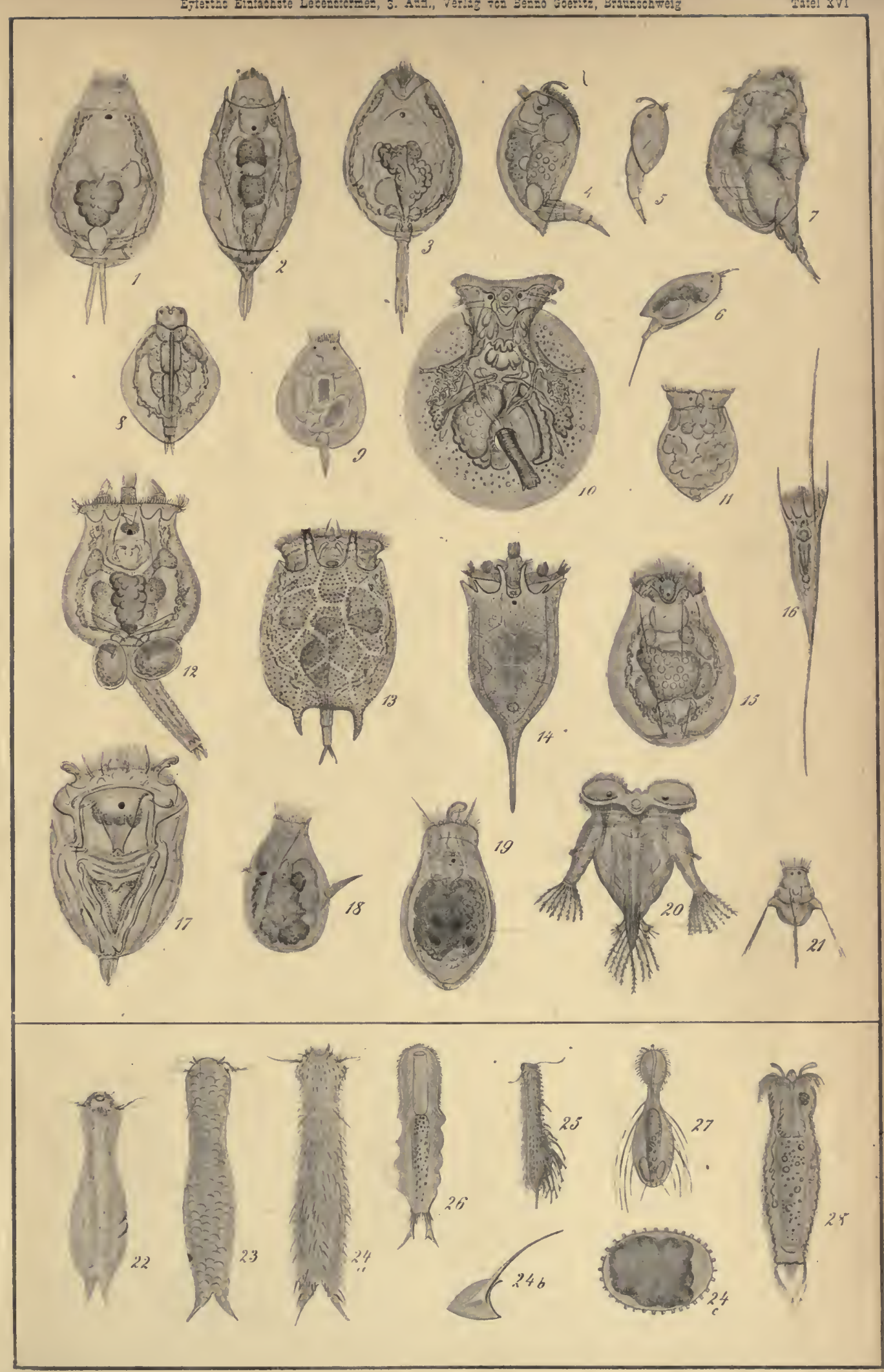






